$$
\begin{array}{cc}
\text { Francisco } & \text { José } \\
\text { Campos } & \text { Rúas } \\
\text { Freire } & \text { Arañjo } \\
\text { (Eds.) } &
\end{array}
$$

\title{
Las redes sociales digitales en el ecosistema mediático
}

Cuadernos Artesanos de Comunicación / 92

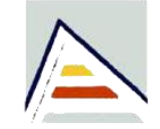

Universitat d'Alacant Universidad de Alicante
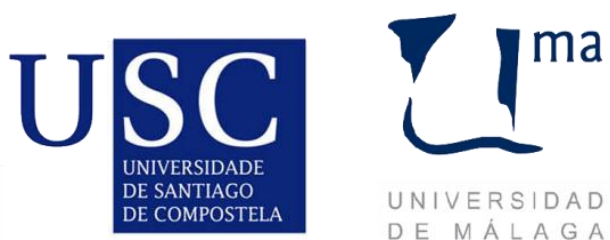

UNIVERSIDAD $D E M A L A G A$

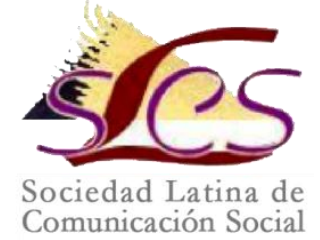




\section{Cuadernos Artesanos de Comunicación}

Coordinador editorial: José Manuel de Pablos

Comité Científico

Presidencia: José Luis Piñuel Raigada (UCM)

Secretaría: Concha Mateos (URJC)

- Bernardo Díaz Nosty (Universidad de Málaga, UMA)

- Carlos Elías (Universidad Carlos III de Madrid, UC3M)

- Javier Marzal (Universidad Jaume I, UJI)

- José Luis González Esteban (Universitas Miguel Hernández de Elche, UMH)

- José Luis Terrón (Universidad Autónoma de Barcelona, UAB)

- José Miguel Túñez (Universidad de Santiago, USC)

- Juan José Igartua (Universidad de Salamanca, USAL)

- Marisa Humanes (Universidad Rey Juan Carlos, URJC)

- Miguel Vicente (Universidad de Valladolid, UVA)

- Miquel Rodrigo Alsina (Universidad Pompeu Fabra, UPF)

- Núria Almiron (Universidad Pompeu Fabra, UPF)

- Ramón Reig (Universidad de Sevilla, US)

- Ramón Zallo (Universidad del País Vasco, UPV-EHU)

- Francisco Javier Martínez Garza (Tecnológico de Monterrey)

- Sarelly Martínez Mendoza (Universidad Autónoma de Chiapas)

- José Antonio Meyer (Benemérita Universidad Autónoma de Puebla, México)

- José Cisneros (Benemérita Universidad Autónoma de Puebla, México)

- Victoria Tur (Universidad de Alicante, UA)

* Queda expresamente autorizada la reproducción total o parcial de los textos publicados en este libro, en cualquier formato o soporte imaginables, salvo por explícita voluntad en contra del autor o autora o en caso de ediciones con ánimo de lucro. Las publicaciones donde se incluyan textos de esta publicación serán ediciones no comerciales y han de estar igualmente acogidas a Creative Commons. Harán constar esta licencia y el carácter no venal de la publicación.

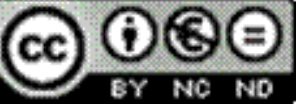

Este libro y cada uno de los capítulos que contiene, así como las imágenes incluidas, si no se indica lo contrario, se encuentran bajo una Licencia Creative Commons Atribución-No Comercial-Sin Derivadas 3.0 Unported. Puede ver una copia de esta licencia en http://creativecommons.org/licenses/by-nc-nd/3.0/ Esto significa que Ud. es libre de reproducir y distribuir esta obra, siempre que cite la autoría, que no se use con fines comerciales o lucrativos y que no haga ninguna obra derivada. Si quiere hacer alguna de las cosas que aparecen como no permitidas, contacte con los coordinadores del libro o con el autor del capítulo correspondiente.

* La responsabilidad de cada texto es de su autor o autora. 
Francisco Campos Freire

José Rúas Araújo

(Eds.)

\section{Las redes sociales \\ digitales en el ecosistema mediático}

Cuadernos Artesanos de Comunicación / 92

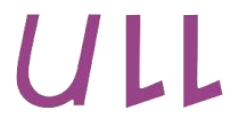

Universidad de La Laguna
Universitat d'Alacant Universidad de Alicante
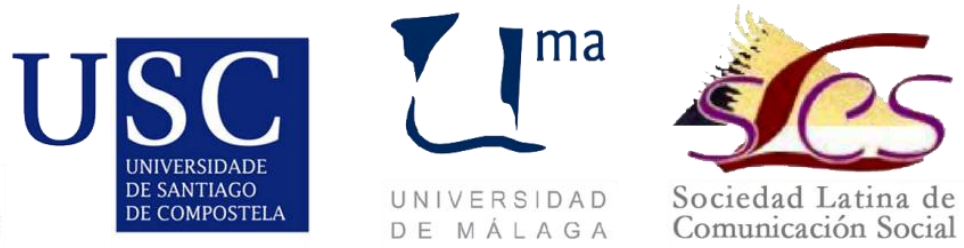


\section{$92^{\circ}$ - Las redes sociales digitales en el ecosistema mediático}

Francisco Campos Freire y José Rúas Araújo | Precio social: 14,10€ | Precio en librería. $18,35 € \mid$

Recopilación y revisión editorial: Iván Puentes Rivera y Alba Silva Rodríguez

Diseño: F. Drago

Ilustración de portada: Fragmento del cuadro Árboles y viento, de Juan Davó (sin fecha).

Imprime y distribuye: F. Drago. Andocopias S. L.

c/ La Hornera, 41. La Laguna. Tenerife.

Teléfono: 922250554 | fotocopiasdrago@telefonica.net

Edita: Sociedad Latina de Comunicación Social - edición no venal

- La Laguna (Tenerife), 2015 - Creative Commons

http://www.revistalatinacs.org/14SLCS/portada2014.html

Descargar en pdf:

http://www.cuadernosartesanos.org/\#92

Protocolo de envío de manuscritos

http://www.cuadernosartesanos.org/protocolo.html

ISBN - 13: 978-84-16458-23-3

DL: TF-848-2015

DOI: $\underline{10.4185 / \operatorname{cac} 92}$ 
Este libro forma parte de los trabajos impulsados por la Red Internacional de Investigación de Gestión de la Comunicación (R2014/026 XESCOM), proyecto financiado en régimen de concurrencia competitiva por la Consellería de Cultura, Educación e Ordenación Universitaria de la Xunta de Galicia.

La Red XESCOM está coordinada por el grupo Novos Medios de la Facultad de Ciencias de Comunicación de la Universidad de Santiago de Compostela y cuenta con la participación de los grupos iMARKA de la Universidad de A Coruña y NECOM y MILE de la Universidad de Vigo, así como de investigadores de las Universidades Fernando Pessoa, Universidade dos Açores (Departamento de Linguas e Literaturas Modernas) y Centro de Estudos de Comunicação e Sociedade da Universidade do Minho en Portugal; del Grupo Medios y Sociedad de la Universidad Autónoma de Tamaulipas en México y de las Escuelas de Comunicación de las Universidades Técnica Particular de Loja y Pontificia Católica Sede Ibarra en Ecuador.

Con estas dos últimas Universidades (PUCESI y UTPL) de Ecuador la Red XESCOM participa además, a través del investigador Francisco Campos Freire, en el Programa Prometeo de SENESCYT.

Los trabajos de este libro fueron desarrollados a partir de las presentaciones y debates celebrados (y ahora ampliadas) en la Mesa 628 sobre "La gestión de las redes sociales en los medios y en la comunicación científica" del VI Congreso Internacional Latina de Comunicación Social, celebrado del 2 al 5 de diciembre de 2014 en la Universidad de La Laguna (Tenerife), coordinada por Diana Rivera Rogel (de la Universidad Técnica Particular de Loja, en Ecuador), por Nancy Ulloa Erazo (de la Pontificia Universidad Católica de Ibarra, igualmente en Ecuador) y por Francisco Campos Freire (de la Universidad de Santiago), y fueron previamemnte sometidos a un sistema de revisión de doble ciego por pares. 


\title{
Las redes sociales digitales en el ecosistema mediático
}

\begin{abstract}
Este libro ofrece un punto de partida para la reflexión sobre el papel, presente y futuro, de las redes sociales y las herramientas digitales, como fenómeno de comunicación emergente e influyente en el establecimiento de nuevos modelos de negocio y el rediseño de las estrategias de comunicación, a partir de la consideración del ecosistema mediático, bajo una perspectiva de análisis científico, en el estudio y observación de la evolución y adaptación de las distintas especies de medios al panorama nacional e internacional.

Una veintena larga de investigadores procedentes de España y Latinoamérica muestran, a lo largo de estas páginas, el uso, impacto y resultados de las redes sociales generalistas y temáticas en los medios tradicionales y los nuevos medios en los terrenos del periodismo, el sector audiovisual, la comunicación corporativa e institucional, la neurocomunicación, la publicidad, el marketing y el turismo, a partir de las presentaciones y debates celebrados en torno a la Mesa sobre "La gestión de las redes sociales y los medios y en la comunicación científica", del VI Congreso Internacional Latina de Comunicación Social, celebrado del 2 al 5 de diciembre de 2014 en la Universidad de la Laguna (Tenerife).
\end{abstract}

\section{Keywords}

Redes sociales, ecosistema mediático, metamedios, multimedia

\section{Forma de citar este libro}

Autor/ra del capítulo (2015): “Título del capítulo", en Las redes sociales digitales en el ecosistema mediático (Francisco Campos Freire, José Rúas Araújo, Eds.). Cuadernos Artesanos de Comunicación, 92. La Laguna (Tenerife): Latina. 


\section{ÍNDICE}

Prólogo. Los sitios de redes sociales como paradigma del ecosistema digital.

Francisco Campos Freire........................................... 13

Metamedios y redes sociales

Los sitios de redes sociales

Investigación sobre los sitios de redes

Modelos de negocio

Paradigma del ecosistema

1. Las herramientas digitales sociales en línea para la inserción laboral. Xosé

Pereira Fariña y Natalia Alonso Ramos............................... 37

Introducción

Metodología

Resultados

Conclusiones

2. Neuropolítica, emoción y sentimiento en las redes sociales. José Rúas-

Araújo, Iván Puentes-Rivera y Borja Dapena-González.

Introducción

De las neurociencias a las ciencias sociales y la comunicación

El papel de la información en el proceso evolutivo

Neurolingüística y lingüística computacional

Política, emoción y sentimiento en las redes sociales

Políticos en Twitter y Facebook en España: perspectiva para el análisis

3. Hacia una epistemología de la economía de la participación: la importancia de compartir noticias. José Manuel Noguera Vivo.........................72

Introducción

Compartir noticias en un nuevo ecosistema de medios

Del paradigma del User-Generated Content al del User-Distributed

Content

Hacia una industria periodística de flujos

investigación sobre contenido distribuido por las audiencias

Conclusiones

\section{PERIODISMO Y REDES SOCIALES}

4. Periodismo total: móvil y enredado. Xosé López García y Ana Isabel

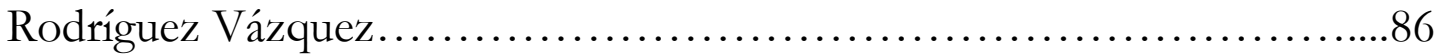

Introducción

La estrategia periodística

Utilización masiva por parte de los periodistas 
Estrategias en clave móvil

A modo de conclusión

5. Redes sociales, periodismo de datos y democracia monitorizada.

Andreu Casero-Ripollés y Amparo López-Meri. ...

Introducción

Plataformas digitales de periodismo de datos para la monitorización cívica

del poder

mySociety (Reino Unido)

Sunlight Foundation (Estados Unidos)

Ciudadano inteligente (Chile)

Fundación Civio (España)

Conclusiones

6. El periodismo en tiempos de las redes sociales: retos y desafíos para viejos y nuevos profesionales de la información que se subieron a Twitter. Xosé Lopez García, Carlos Toural Bran y Alba Silva Rodríguez..................114

Introducción

El nuevo entorno

El papel del periodista

Los datos de algunos periodistas españoles en Twitter

A modo de conclusión

\section{COMUNICACIÓN CORPORATIVA Y REDES SOCIALES}

7. Redes y comunicación organizacional. Aproximación al discurso científico y a los retos más próximos. Berta García Orosa........................127

Introducción

Redes sociales: conversación y seguimiento del usuario

Funciones de las redes sociales en la comunicación organizacional

Retos próximos

8. La gestión de la comunicación corporativa de las empresas mediáticas en

Facebook y Twitter. Ana María López Cepeda..........................142

Introducción

Objetivo y métodos de investigación

Internet y el auge de las redes sociales

Gestión de la comunicación corporativa en las empresas mediáticas

Gestión de la comunicación corporativa a través de las redes sociales

Facebook

Twitter

Conclusiones

9. Presencia y estrategias de comunicación de los hospitales andaluces en las redes sociales. Dolores Rando Cueto... 
Introducción

Metodología

Resultados

Conclusiones

10. El impacto de las TICs en la gestión de las agencias de viajes. Clide

Rodríguez Vázquez, Oscar Juanatey Boga y Jaime Álvarez de la Torre.....174

Introducción

Las agencias de viajes en España. Situación actual

El consumidor turístico y su comportamiento: agencias tradicionales /vs/

las agencias online

Objetivos de la investigación y metodología

Resultados de la investigación cualitativa

Conclusiones

11. Medios sociales y turismo. Eva Sánchez-Amboage, María-Magdalena Rodríguez-Fernández y Valentín Alejandro-Martínez......................195

Introducción

Turismo de salud y turismo termal

Los medios sociales y el turismo termal

Objetivos y metodología

Análisis del turismo termal de la región Norte de Portugal en Facebook

Conclusiones

12. El impacto de las redes sociales en el sector publicitario español. Emma Torres Romay..................................................... 217

Presentación, objeto de estudio, hipótesis y metodología

La situación del sector publicitario español

Los sujetos publicitarios y las redes sociales

Los anunciantes

Agencias y mensajes

Medios

Públicos

$¿$ ¿Nuevas estrategias para las redes sociales?

Conclusiones

\section{MEDIOS AUDIOVISUALES Y REDES SOCIALES}

13. Las televisiones españolas y ecuatorianas usan las redes sociales para reforzar sus canales tradicionales. Lara Lozano Aguiar, Nancy Graciela Ulloa Erazo y Francisco Campos Freire.........................................238

Cómo la aparición de la web 2.0 cambió el concepto de distribución de contenidos periodísticos y uso de las herramientas digitales 
Las redes sociales, plataformas idóneas para reforzar los canales tradicionales y propiciar la participación y fidelización de los ciudadanos El community manager como gestor de las plataformas digitales Análisis y comparativa de la presencia en redes sociales de los principales canales de televisión de España y Ecuador

Conclusiones y propuestas de mejora

14. La gestión de las redes sociales en los servicios de radiodifusión públicos europeos. Tania Fernández Lombao y Andrea Valencia Bermúdez.......254

Introducción

Radiotelevisión pública y redes sociales

Los nuevos servicios de las radiotelevisiones públicas

Redes sociales

Facebook

Twitter

Youtube

Google+

Conclusiones

15. Uso de Facebook como forma de interacción con el público. El caso de los telediarios de Monterrey. Claudia Alicia Lerma Noriega e Ilián Alejandra Cruz Zapata.....................................................273

Introducción

Panorama general

Metodología

Resultados

Hallazgos y conclusiones

16. Un programa transmedia de sketches de humor revoluciona la televisión y las redes sociales en Ecuador. Carlos Ortiz, Miguel Granda y Abel

Suing.........................................................295

Introducción

Inicios de Enchufetv

Lanzamiento del canal en YouTube Enchufe'Tv

El primer año de Enchufe'Tv y el lanzamiento de nuevos segmentos

De la WEB a la televisión tradicional

EnchufeTv consigue rentabilidad económica a través de su propuesta

Un programa con polémica

Premios y reconocimientos

Enchufe'Tv en redes sociales

Metodología

Análisis de resultados

Conclusiones 
17. Campaña "Un Diego para la torre": la estrategia comunicacional de Radio Ahijuna como experiencia de crowdfunding. Martín Iglesias, Carlos Leavi y Juan Pedro Legarreta................................................319 Introducción Ahijúna, la radio comunitaria del sur del Gran Buenos Aires Anecdotario: una primera idea en contexto de crisis o cuando "la crisis se transforma en oportunidad"

Nociones y metodología

Matriz de análisis

Descripción

Objetivo

Público meta

Propósito

Actividades

Recursos

Productos

Comunicados

Bono autoadhesivo, spots audiovisuales y piezas de radio

Remeras y mates

Palabras finales: la vuelta al aire, el valor de la solidaridad colectiva, el papel de las redes sociales y los nuevos desafíos

\section{LOS INVESTIGADORES DE COMUNICACIÓN EN LAS REDES SOCIALES}

18. La comunicación científica a través de las redes sociales digitales. Gabriela Coronel Salas y Francisco Campos Freire

Introducción

Comunicación en vivo de recuperación arqueológica

Promoción del congreso de narrativas audiovisuales

Metodologías empleadas

La comunicación científica

Las redes generalistas y la ciencia

Las redes sociales científicas

Resultados de dos experiencias

Conclusiones

19. La participación e interacción de los investigadores de comunicación de países iberoamericanos en las redes sociales digitales científicas. Maria Isabel Punín Larrea Sabela Direito Rebollal y Daniela Calva Cabrera...

Introducción

Metodología

Las principales redes sociales digitales

La penetración y uso de las redes científicas en el área iberoamericana 
La interacción en las redes digitales científicas

El impacto de los investigadores en ResearchGate y Google

Académico

Conclusiones

\section{OPERADORES MÓVILES Y REDES SOCIALES}

20. La intersección entre las empresas de contenidos, tecnología e Internet y el nuevo papel de Telefónica como TV Company. José Vicente García Santamaría y María José Pérez-Serrano......................................373

Introducción

Estado de la cuestión y propuesta analítica

Discusión y análisis de caso

Los procesos de integración de redes y contenidos

Telefónica y la lucha en España por los contenidos de pago

La pugna por los derechos de emisión y el futuro inmediato

Conclusiones

21. La influencia de las redes sociales en las versiones móviles de los medios digitales. Nancy Graciela Ulloa Erazo y Alba Silva Rodríguez...............386

Introducción

La situación en América Latina

Metodología

Análisis

Análisis del consumo de medios en Ecuador

Interactividad Participativa: Redes sociales y comentarios

Conclusiones 


\section{A}

Prólogo

\section{Los sitios de redes sociales como paradigma del ecosistema digital}

Francisco Campos Freire ${ }^{1}$ Universidad de Santiago de Compostela (USC, España), francisco.campos@usc.es

DOI: $\underline{10.4185 / \operatorname{cac} 92 \mathrm{FCF} 2015}$

T OS sitios, plataformas o ecosistemas de redes sociales digitales se Whan convertido en un nuevo modelo y en el centro del sistema actual de medios de comunicación. Son un fenómeno de comunicación emergente y popular que ha adquirido su madurez antes de alcanzar su mayoría de edad. Tanto así que sigue en el alero hasta el alcance analítico y científico de su propia denominación. Para entender y explicar el conjunto así como la complejidad del sistema actual de comunicación, que se articula a través de grandes redes de interacción y relación social, se recurre al concepto de ecosistema para

\footnotetext{
${ }^{1}$ Francisco Campos Freire es profesor de la Facultad de Ciencias de la Comunicación de la Universidad de Santiago de Compostela e investigador Prometeo del SENECYT de Ecuador en las Universidades UTPL de Loja y PUCESI de Ibarra. Es miembro del Grupo de Investigación de Novos Medios de la Universidad de Santiago de Compostela y coordinador de la Red Internacional de Investigación de Gestión de la Comunicación (R2014/026 XESCOM), apoyada por la Consellería de Cultura, Educación e Ordenación Universitaria de la Xunta de Galicia.
} 
observar el impacto sobre la evolución y sostenibilidad de las distintas especies de medios. También se analizará aquí la denominación de red social digital, sus investigaciones y modelos de negocio.

Estas y las siguientes líneas son una introducción a la recopilación de las investigaciones que fueron presentadas (y ahora ampliadas) en la Mesa 628 sobre "La gestión de las redes sociales en los medios y en la comunicación científica" del VI Congreso Internacional Latina de Comunicación Social, celebrado del 2 al 5 de diciembre de 2014 en la Universidad de La Laguna (Tenerife), coordinada por Diana Rivera Rogel (de la Universidad Técnica Particular de Loja, en Ecuador), por Nancy Ulloa Erazo (de la Pontificia Universidad Católica de Ibarra, igualmente en Ecuador) y por el que suscribe (de la Universidad de Santiago de Compostela).

En dicho panel temático del congreso fueron presentadas docena y media de comunicaciones de España, Ecuador, Portugal, México y Argentina. A las autoras y autores de las mismas se les propuso ampliar sus investigaciones y recogerlas con más pausa de reflexión en un nuevo volumen, cuyo resultado es el que se ofrece a través de las páginas posteriores. El objetivo era abrir un espacio de encuentro interdisciplinar a las investigaciones realizadas y en curso sobre el uso, impacto y resultados de la gestión de las redes sociales generalistas y temáticas en los medios tradicionales y nuevos así como en las organizaciones e instituciones de comunicación. También se han incorporado algunas aportaciones más sobre la temática.

Las redes digitales, a través de Internet y del teléfono, se están convirtiendo en herramientas o plataformas multimedia hegemónicas de la mediación, relación e interacción social que han obligado a los medios tradicionales (prensa, radio y televisión) y a las organizaciones corporativas a buscar alternativas de convergencia que les permitan interconectarse con los usuarios en el nuevo ecosistema de la comunicación. Su gestión e investigación representan un nuevo campo que se está configurando desde mediados de la primera década de este siglo con importantes retos científicos que merecen enriquecer el contraste y conocimiento.

Los sitios de redes digitales generalistas y especializados, de carácter profesional o científico, no sólo es importante e interesante contemplarlos como plataformas de comunicación, que es sobre lo que más han desarrollado sus estrategias las empresas y 
organizaciones, sino también como ecosistemas y laboratorios de producción, acción, mediación, observación y experimentación de las interacciones sociales. A través de ellos se articula y desarrolla una nueva economía y sociabilidad en red. Es este último aspecto el de mayor importancia para la valoración del capital social que, juntamente con el capital humano y el intelectual (conocimiento), contribuye a consolidar el valioso pero complejo balance de los llamados activos intangibles de una organización y de la sociedad, en general. La llamada economía de las interacciones ya domina la agenda de las principales empresas y organizaciones.

Los sitios de redes digitales, que emergen en los últimos años del pasado siglo XX y principios del actual, son una evolución, remediación (Bolter y Grusin, 1999) e hibridación de las comunidades en línea con los medios sociales de autocomunicación (Web 1.0, Web 2.0 y blogging), donde los usuarios se convierten no solo en receptores sino también productores, protagonistas y centros de un proceso de comunicación que se multiplica de muchos a muchos convirtiendo las redes sociales personales de los usuarios en el paradigma del sistema de distribución e interacción. Esa articulación de un nuevo modelo de autodifusión en red es la que trastorna y trastoca (Campos, 2008) los sistemas de distribución (así como sus modelos de negocio) de los medios tradicionales de comunicación, que paulatinamente se tendrán que ir adaptando y acoplando a esas nuevas plataformas reticulares de circulación de la cultura e información digital.

El proceso de comunicación característico del siglo XX de los medios de masas tradicionales se ha transformado en masas de medios digitales. La revolución de Internet, de la web y de la convergencia digital no sólo afecta al paisaje de los medios sino también a la cultura y a las propias identidades. Esta era de la conectividad impone un nuevo paradigma de la transmedialidad para comprender las nuevas identidades porque "la línea entre la vida y la vida en línea o fuera de línea se ha vuelto borrosa, como una equivalencia existencial entre lo analógico y lo digital" (Sage Elwell, 2014).

La revolución de la última década del siglo XX fue la de la web hipermedia (1990-93), que permitió la navegación e interconexión a través de Internet. La de los primeros diez años del nuevo siglo XXI fue la de la autocomunicación de masas (la web social 2.0 y las redes digitales) que permiten la autocreación y difusión global de mensajes 
(Castells, 2009: 88). La de la segunda década del siglo XXI es la del Internet de las cosas (Web 3.0, automatización de datos y comunicaciones con los objetos) y la del tercer decenio va ser la de la interpretación semántica, robotización, biotecnología e inteligencia artificial (la Web 4.0 para liberar más atención humana de las tareas y procesos rutinarios).

Como citábamos al principio, para describir la complejidad del sistema mediático se recurre a la metáfora del ecosistema, un espacio en el que conviven distintas especies de organizaciones que tienen rasgos diferentes y comunes, a la vez, y que se relacionan o pueden relacionarse en el mismo ambiente. El ecosistema mediático actual está formado por cinco tipos de organizaciones de comunicación: medios tradicionales de masas (prensa, radio y televisión), medios de autocomunicación social (páginas web y blogs personales o de entidades corporativas e institucionales), medios interpersonales de interacción (SMS, email, telefonía), sitios de redes sociales digitales y plataformas de búsqueda o agregación de contenidos (infomediarios). Cada una de ellas tiene su propio origen y evolución histórica así como sus particulares características, pero todas compiten por captar la atención de sus usuarios y audiencias.

Un ecosistema digital es una nueva arquitectura de autoorganización y autogestión de comunicación en red y en un ambiente colaborativo. Es una comunidad abierta, sin control centralizado o distribuido a través del comportamiento individual de los agentes u organizaciones que intervienen en ella (Boley y Chang, 2007). Según estos autores, en un ecosistema destacan dos tipos de elementos (múltiples especies en un entorno que necesitan interactuar y equilibrarse entre sí, aunque existen liderazgos y tensiones) y cuatro aspectos: interacción, compromiso, equilibrio y autoorganización agrupada. La semántica, que es un proceso de interpretación para la comunicación entre especies, se vuelve más compleja cuando un agente o actante del sistema. Ssegún Latour (1999), forma parte de múltiples ecosistemas que se suporponen. Es lo que se produce en la articulación de las redes digitales.

Si recurrimos a la genealogía biológica, un ecosistema es una unidad de biología funcional de los organismos de un espacio (biocenosis) y del medio ambiente físico (biotopo) del mismo. El término fue propuesto por el ecólogo inglés Arthur George Tansley, 
que también estudió psicología en Viena con Sigmund Freud, y que acabó como profesor de botánica en Oxford. En síntesis, el ecosistema es el conjunto de los elementos bióticos (organismos vivos) y abióticos (sustancias inorgánicas, proteinas, clima, ect) de una región. Los elementos bióticos pueden ser autrofos (capaces de generar su propia nutrición) y heterotrofos (que se nutren de las sustancias elaboradas por otros seres vivos).

Si trasladamos, de nuevo, la metáfora al sistema de medios de comunicación, coincidiremos en que el equilibrio y la sostenibilidad también son factores cruciales de este ecosistema. La esencia de ese contraste ecológico está relacionada con el origen, evolución y disrupción creativa provocada por las formas de acceso e innovación de las tecnologías, procesos y sistemas de los medios de comunicación (Campos, 2015). La innovación disruptiva es la que imponen los nuevos competidores que van entrando a lo largo de la historia en la industria de la comunicación -algunos de ellos heterotrofos tambiénprovocando cambios - proporcionales a la importancia de la nueva especie- en los equilibrios existentes (Canavilhas, 2015).

Los medios sociales digitales son los últimos allegados pero pronto se han convertido en los organizadores y dominadores del ecosistema, como reflejan las estrategias de los cinco grandes GAMAF (Google, Apple, Microsoft, Amazon y Facebook) del mundo conectado de Internet (Tung y Wu, 2013), que involucra tanto a los viejos como a las nuevos medios (Hanna, Rohm y Crittenden, 2011). El principio de equilibrio y sostenibilidad de la metáfora de los ecosistemas queda en evidencia más pronto que tarde dando paso a la teoría de la remediación.

La representación evolutiva de los medios la describen las hipótesis de Riepl, de la remediación y las aportaciones de los macluhianos. El periodista alemán Wolfgang Rielp, editor de la Gazeta de Nuremberg, publicó en un ensayo en 1913 la primera hipótesis de la convergencia mediática al señalar que los nuevos medios (la radio frente a la prensa, luego también la televisión) no reemplazaban a los anteriores ni en su forma ni uso, aunque se producía una readaptación entre ellos (Rielp, 2013).

Marshall McLuhan señala al inicio de Comprender los medios de comunicación (1996) que los viejos medios se convierten en contenido de los nuevos y que ese producto es siempre, a su vez, otro medio 
remediado distinto (Islas, 2007; Jenkins, 2008). Para Bolter y Grusin (1999) los medios digitales remedian a sus predecesores, intentando absorberlos totalmente, "de modo que las discontinuidades entre ambos se minimicen (....) empero el mismo acto de remediación asegura que el viejo medio no se borrará completamente; el nuevo medio sigue dependiendo del antiguo en formas reconocidas y no reconocidas".

\section{Metamedios y redes sociales}

La teoría macluhiana inspira también el concepto remediado de metamedio, que es la denominación y el carácter que Manovich le atribuye a los nuevos medios digitales. Según Lev Manovich (2005 y 2008) -que toma el concepto enunciado por McLuhan (1964) y luego desarrollado por Kay y Goldberg (1977) - un metamedio es un medio con nuevas propiedades, mediante combinación de técnicas informáticas para la generación, edición y acceso (navegación, búsqueda, lectura, escucha, visualización e interacción) a nuevos contenidos (formatos y software). Los nuevos medios son postmedia o metamedia porque utilizan la materia prima de los medios tradicionales y la evolución de las técnicas informáticas "existentes o aún no inventadas" para reinventarse continuamente.

Esa evolución metamedia la categoriza Manovich (2008: 288) a través de cuatro etapas: a) 1960-70, de experimentación e innovación; b) 1980-90, de comercialización y aplicación masiva; c) 1990-2003, de convergencia e hibridación; y d) 2004-15, de medios sociales. La primera oleada de metamedios digitales es la que surge de la Web 1.0 y luego llega el fenómeno de los blogs. Los sitios de redes digitales surgen de la remediación de los blogs y otras herramientas de la Web 2.0 de finales del siglo XX (Boyd y Ellison, 2007). Estos nuevos sitios web son metamedios que adaptan la gestión de la comunicación al modelo de estructura de relaciones establecido por las redes sociales de personas y organizaciones, proyectándolo y multiplicándolo exponencialmente a través del espacio digital.

La denominación de redes sociales digitales se ha impuesto en la cultura popular y en la literatura divulgativa digital aunque los científicos que han estudiado estos nuevos medios no están muy de acuerdo con esa denominación, lo que exige un gran esfuerzo para su definición y caracterización, tan difícil como compleja por su propia 
naturaleza y por la rapidez con que evolucionan y mutan, lo que es característico en casi toda la cultura digital (Beer, 2008). Además de la conceptualización de metamedio de Manovich, otros las han incluido en el paquete de herramientas técnicas de generación de contenidos por los usuarios y en la Web 2.0.

La primera aproximación y definición específica (Boyd y Ellison, 2007) las ha conceptualizado como sitios de redes sociales (Social Network Sites) aunque luego han ido apareciendo también otras denominaciones como plataformas y ecosistemas de redes digitales. David Beer (2008) analiza, discute y matiza esa primera definición de Danah Boyd y Nicolle Ellison, pero sin ir mucho más allá de la categoría general de aplicaciones en red de la Web 2.0. Pero hay dos aspectos intrínsecos en estos artefactos tecnoculturales que no se pueden obviar: a) sus características de medio o metamedio de autocomunicación; b) y su arquitectura sistémica capaz de integrar en línea múltiples redes físicas que se articulan o pueden rearticular en nuevas redes. Esta última característica es la que prevalece en la aceptación y denominación popular de las redes sociales digitales.

Las redes son parte de la estructura de las relaciones sociales y unen a las personas u organización en el mundo real. Una red es la representación (mediante líneas, vínculos o lazos) de un conjunto de relaciones entre una serie definida de elementos (nodos) de una estructura social (Molina, 2004). Emmanuel Lazega (1998) define la red social como un conjunto de relaciones específicas entre determinados actores que comparten una cultura. El antropólogo británico John Barnes (1954) es el primero al que se le atribuye la utilización del concepto de red social, sus orígenes científicos en la sociología, en los sistemas de relaciones, interacciones y estructuras sociales son muy anteriores y se remontan al tránsito de los siglos XIX al XX con Saint Simon, Comte, Durkheim, Spencer, Cooley o Simmel (Requena, 2003; Mattelart, 2007; Freeman, 2012).

Varias ciencias (sociología, antropología, sociometría, psicología social, matemática e informática) abordan desde distintas perspectivas teóricas el estudio de las redes sociales durante todo el siglo XX, especialmente en sus últimos 25 años, centrándose en la observación de las interconexiones, patrones de interacción, vinculaciones parentales, lazos de los individuos y de las organizaciones sociales así como sus respectivas representaciones. Según Linton C. Freeman (2012: 2008), 
el sincretismo del paradigma de las redes se nutre de las concepciones estructural, relacional, del intercambio, de la separación de los seis grados (Stanley Milgran y Duncan Watts, 2011), de la noción de los vínculos débiles (Granowetter, 1974) y del valor del capital social (Bordieu 1993; Coleman, 1990; Putnam 1993; Burt, 1992; Lin, 2001).

\section{Los sitios de redes sociales}

Las redes son tan antiguas como la humanidad y las relaciones sociales pero adquieren una nueva dimensión organizativa social, cultural y política en el ambiente tecnosocial de la era digital (Rheingold, 2004). Para Castells (2009: 45-47), una red es un conjunto de nodos interconectados que se articulan formando la espina dorsal de las sociedades. Las redes informativas son "inherentemente instituciones sociales" porque vinculan a personas, organizaciones y conocimiento (Wellman, 2001). Pueden ser de carácter generalista y temáticas o especializadas. Entre estas últimas podemos citar las redes científicas, de investigadores y académicas, así como las de negocios o de otras actividades específicas.

La conceptualización de estos nuevos sitios digitales, cuya primera definición publican Danah M. Boyd y Nicole B. Ellison en 2007, prioriza la perspectiva comunicacional sobre la reticular basándose en que dichos metamedios surgen, se organizan y difunden a partir de las relaciones preexistentes (conocimiento y amistad) de las personas u organizaciones, que las redes visibilizan, multiplican y proyectan exponencialmente. Son definidos como servicios basados en la web que permiten a los individuos (1) construir un perfil público o semipúblico dentro de un sistema acotado; (2) articular una lista de usuarios con los que compartir conexión; (3) y ver sus contenidos agregados o enlazar con sus listas de conexiones.

Las primeras tesis sobre este nuevo fenómeno de la comunicación digital no enfatizan el concepto de red social -por eso Boyd y Ellison usan "social network sites"- porque sostienen que la conexión se inicia a partir de lazos latentes (Haythornthwaite, 2005) de conocidos, que ya forman parte de redes personales, y estos van sumando escaladamente a sus respectivas relaciones, como agegación y rearticulación de redes preexistentes. No niegan que el sistema impida la posibilidad de establecer networking o redes propias entre extraños, pero afirman que no es la práctica más común, lo que no les 
diferencia tanto de otras formas de comunicación mediada por ordenador, según los primeros trabajos de Boyd y Ellison (2007).

En la réplica a la publicación de esta investigación de Boyd y Ellison (2007), el profesor de medios de comunicación de la York St John University, David Beer (2008), destaca el mérito prionero de la conceptualización pero cuestiona el valor analítico de esa primera definición de los sitios de redes sociales, debatiendo no sólo la denominación sino también los aspectos relacionados con las características sobre la sociabilidad offline y online (amistad, confianza) y la ausencia de referencias a las implicaciones de la economía política (control de infraestructura y algoritmos, códigos, privacidad, uso de perfiles), así como sobre la retórica o falta de rigor sobre los conceptos de colaboración, inteligencia colectiva y culturas participativas.

El concepto de amistad que operan e instrumentalizan las redes y la cultura digital es objeto de análisis tanto por parte de Boyd y Ellison como de Beer, así como de otros investigadores que ya se fijaron en ella con anterioridad (Lash, 2002, 2007; y Pahl, 2002). La amistad ("Friends") en línea de las redes digitales no es como en la vida real, es más etérea, virtual e imprecisa. Esa remediación de la amistad (Graham, 2004), cuando a la vida le damos sentido a través de los artefactores tecnológicos, se vuelve mucho más general y sus valores pueden ser alterados, lo que significa que hay que verla e intepretarla en ese mismo contexto de conectividad (Pahl, 2002).

La amistad es un eslabón para la conexión y también para la confianza, que son la base de las redes de relación y del capital social. En las redes sociales se manifiesta a través de lazos fuertes, latentes y débiles. Los primeros son evidentes en las redes físicas y los últimos en las digitales, como ha demostrado Granovetter (1973) aplicándolos al networking de la selección laboral. Las redes físicas difícilmente cuentan con más de 124 contactos inmediatos (Hill y Dumbar, 2003) mientras que las digitales pueden alcanzar miles. Esa distinción entre la intensidad y la levedad de los lazos de los contactos caracteriza el grosor o la longitud de la "larga cola" (Enders, Hungenberg, Denker y Mauch, 2008) de las redes, que ilustra más adelante el detalle de sus modelos de negocio.

De la denominación de "sitios web" se pasa a la de "plataformas de comunicación" y la interrelación entre personas se 
extiende también tanto a las organizaciones como a los propios datos sistémicos, incorporando concepciones de la economía política y de la llamada teoría del actor-red o de la ontología del actante-rizoma de Bruno Latour para dar sentido a las distintas capas de estos artefactos tecno socioculturales (Van Dijck, 2013).

Thomas Stenger (2009) y más tarde Danah Boyd junto a Nicole Ellison (2013) fueron ampliando la concepción de los sitios de redes sociales (Social Network Sites) a la de plataformas de autocomunicación en línea. Pero la evolución de las tecnologías de la comunicación no sólo es acelerada sino también mutante e intensiva. Esas plataformas de redes digitales no sólo despliegan innovaciones de herramientas de la Web 2.0 sino también sistemas de autoorganización avanzada y conocimiento de la web semántica y la inteligencia artificial. Por eso su caracterización actual es más acorde con la de ecosistemas de metamedios de redes sociales digitales en los que los participantes (actantes: personas, organizaciones y subsistemas) pueden:

1) Disponer de perfiles públicos o semipúblicos asociados a una identificación única que son creados por una combinación de contenidos producidos por utilizadores, conocidos y datos sistémicos;

2) Exponer públicamente las relaciones susceptibles de ser visualizadas y consultadas por otros a través de una lista de enlaces dentro del sistema;

3) Acceder a flujos de contenidos (combinaciones de textos, fotos, vídeos, datos y nuevos enlaces) generados por los usuarios, sus contactos y otros proveedores de contenidos a través de internet;

4) Recomendar y convertirse en prescriptores de productos y marcas;

5) Formar parte de nuevos modelos de negocio;

6) Interconectarse con distintas constelaciones de aplicaciones y dispositivos comunicacionales;

7) Intercambiar mensajes, servicios colaborativos y publicidad gestionada por el operador principal;

8) Desarrollar conversaciones y transacciones;

9) Aplicar dispositivos de inteligencia artificial semántica;

y 10) Conformar redes de comunicación, relación y metaservicios digitales que se valorizan en forma de capital social. 


\section{Investigación sobre los sitios de redes}

A pesar de ser un campo nuevo y relativamente reciente, son muchos los autores que han investigado y/o escrito sobre los sitios de redes sociales digitales. La mayoría de ellos sobre la concepción instrumental y mediática de sus funcionalidades (tecnologías de la información y la comunicación, Internet, email y ahora también los teléfonos inteligentes), las plataformas de intercomunicación (sitios web), la capacidad de navegación, conectividad, afiliación y establecimiento de perfiles dentro del sistema. La profundización en las características, potencialidades y aplicaciones de la interacción social de las redes es menos frecuente $\mathrm{o}$, en todo caso, forma parte de una segunda generación de investigaciones que empiezan a conocerse a partir de 2010.

Además de la descripción y reflexión teórica, dos grandes campos metodológicos han aportado técnicas y herramientas para su análisis. Por una parte la metodología cuantitativa de la informática social y del Cultural Big Data (Manovich, 2015), que permite procesar y analizar grandes masas de datos de la cultura popular y profesional digital actual, y por otra las técnicas cualitativas de observación de la etnografía virtual (Hine, 2004) para el estudio de las interacciones digitales que se producen dentro del ecosistema polymedia (Madianou, Miller, 2012).

Para apreciar el volumen y la progresión de las investigaciones sobre las redes sociales y los sitios de redes digitales reproducimos a continuación algunos datos cuantitativos obtenidos a partir de una búsqueda efectuada a finales de septiembre de 2015 en tres indexadores (Wef of Science, Scopus y Google Académico) sobre diez metadatos relacionados con el tema. Lo que se puede observar es que la mayoría de los artículos, recursos y referencias científicas de los sitios de redes sociales, redes digitales, redes de investigadores y científicas se generan a partir del año 2000. Estamos, por lo tanto, ante un campo científico joven pero crecientemente productivo, como es coherente con la prolífíca actividad y conectividad de estos metamedios sociales. 
Tabla 1: La investigación de redes sociales

\begin{tabular}{|l|l|l|l|l|l|l|l|l|l|}
\hline & \multicolumn{3}{|c|}{ WOK } & \multicolumn{3}{c|}{ SCOPUS } & \multicolumn{3}{c|}{ GOOGLE SCHOLAR } \\
\cline { 2 - 10 } & $\mathbf{1 9 0 0 / 2 0 1 5}$ & $\mathbf{2 0 0 0 / 1 5}$ & $\mathbf{2 0 0 5 / 1 5}$ & Todos & $\mathbf{2 0 0 0 / 1 5}$ & $\mathbf{2 0 0 5 / 1 5}$ & Todos & $\mathbf{2 0 0 0 / 1 5}$ & $\mathbf{2 0 0 5 / 1 5}$ \\
\hline $\begin{array}{l}\text { Social network } \\
\text { sites }\end{array}$ & 5.296 & 5.160 & 4.941 & 77.060 & 6.819 & 6.500 & 2.310 .000 & 1.830 .000 & 836.000 \\
\hline $\begin{array}{l}\text { Social networks } \\
\text { analysis }\end{array}$ & 22.718 & 21.333 & 19.706 & 39.248 & 36.946 & 34.333 & 4.130 .000 & 3.460 .000 & 1.350 .000 \\
\hline $\begin{array}{l}\text { Online social } \\
\text { networks }\end{array}$ & 7.174 & 7.174 & 7.086 & 25.063 & 24.936 & 24.603 & 2.640 .000 & 2.590 .000 & 17.600 \\
\hline $\begin{array}{l}\text { Digital social } \\
\text { networks } \\
\text { communication }\end{array}$ & 759 & 750 & 715 & 1.532 & 1.410 & 1.311 & 1.800 .000 & 1.600 .000 & 27.600 \\
\hline $\begin{array}{l}\text { Ecosystem of } \\
\text { social media }\end{array}$ & 193 & 182 & 176 & 174 & 1.158 & 1.131 & 396.000 & 295.000 & 299.000 \\
\hline $\begin{array}{l}\text { Academic } \\
\text { digital social } \\
\text { networks }\end{array}$ & 162 & 161 & 155 & 212 & 206 & 196 & 1.120 .000 & 958.000 & 187.000 \\
\hline $\begin{array}{l}\text { Scientific } \\
\text { digital social } \\
\text { networks }\end{array}$ & 95 & 94 & 92 & 208 & 203 & 198 & 969.000 & 760.000 & 46.100 \\
\hline $\begin{array}{l}\text { Academic } \\
\text { social networks }\end{array}$ & 2.440 & 2.293 & 2.105 & 3.711 & 3.417 & 3.119 & 3.260 .000 & 2910.000 & 17.600 \\
\hline $\begin{array}{l}\text { Scientific social } \\
\text { networks }\end{array}$ & 2.380 & 2.258 & 2.076 & 4.263 & 4.018 & 3.776 & 3.810 .000 & 3.020 .000 & 17.600 \\
\hline
\end{tabular}

Fuente: Elaboración propia, a 29 de septiembre de 2015, con datos de

Web of Science (WOK), Scopus y Google Académico

Las investigaciones y escritos sobre las redes sociales digitales se pueden agrupar en unas cuantas categorías temáticas: a) sobre estudios aplicados a la comunicación corporativa, institucional y política; b) como nuevos medios y sobre sus relaciones e interacciones con los medios de comunicación tradicional; c) sobre las principales redes o plataformas generalistas y temáticas; d) sobre modelos de negocio, comercialización y marketing; e) sobre cuestiones de análisis crítico de sus infraestructuras, operadores, relaciones e impactos en la sociedad; f) y de teoría general de las redes en el contexto de la cultura digital actual.

Acercándanos a algunos de esos estudios podemos observar en ellos la comprensión genérica de las redes sociales digitales. Alain Degenne (2011: 39) concibe las redes digitales como herramientas de mediación, de relación e interacción, a través de Internet y el teléfono, entre personas y organizaciones. Para Duncan J. Watts (2011: 15), "la ciencia de las redes es la del mundo real que permite entender la era de la conectividad... (a través de) representaciones extremadamente sencillas de fenómenos extremadamente complejos. (...) Mas bien, las partes interactúan unas con otras, y al interactuar, incluso cuando se trata de componentes relativamente sencillos, pueden generar un comportamiento desconcertante". 
Christakis y Fowler (2010: 310, 321) señalan que “el estudio de las redes sociales es de hecho parte de un proyecto de integración en la ciencia mucho más amplio... El gran proyecto del siglo XXI es comprender cómo la humanidad puede ser mayor que la suma de las partes". Para Rheingold (2004), "nos hallamos ante un nuevo medio de organización social, cultural y política en ciernes". Según Castells (2009:20), "una sociedad red es aquella cuya estructura social está compuesta de redes activadas por tecnologías digitales de la comunicación y la información basadas en la microelectrónica".

Para Pierre-Jean Benghozzi (2011: 32), las redes son un laboratorio de diversas formas de organización, de nueva economía híbrida, de una arquitectura innovadora de relaciones, de modelos de negocio diferentes, en varios casos también disruptivos para las industrias tradicionales. Y el antropólogo Antonio A. Casilli (2010) se pregunta si esas liasons digitales son una nueva sociabilidad, atajando tres mitos: 1) la imposibilidad de sustitución de un espacio físico por un imperio inmaterial de bytes; 2) la conexión a la web no nos elude de la vida real "transfigurándonos en ángeles electrónicos renacidos del abandono de la carne débil"; 3) pero tampoco por sí mismas las tecnologías son desocializantes.

Otro de los aspectos más investigados de las redes sociales presenciales y digitales es el del capital social y relacional. Es la representación de la dimensión relacional de la sociabilidad, que se desarrolla tanto en las relaciones presenciales como en las interacciones digitales. Ha sido ampliamente estudiado por Bordieu (1986, 1993), Coleman (1990), Putnam (1993), Burt (1992), Granowetter (1974), Lin (2001), Benghozzi (2011) y otros. Granowetter introdujo la idea de las relaciones débiles como fuente del capital social y Burt el paradigma de los agujeros estructurales o contactos no redundantes que confieren más poder e influencia a los nodos necesarios para establecer conexiones en red.

El análisis de redes permite estudios macro y micro, lo que Erving Gofman hizo desde la microsociología para adentrarse en el backstage de personas y grupos. Ambos enfoques deberían combinarse, según Alain Degenne (2011), para adentrarse en las redes sociodigitales, para estudiar su capital social, los vínculos fiables, lazos fuertes y débiles, redundancias, topología de los enlaces, dinámicas de 
conectividad, nuevas prácticas, redes complejas y de ego-network, nuevas formas de sociabilidad y estructura de los ecosistemas.

El capital social, el potencial del ecosistema de conexiones a distancia y la utilidad de los lazos débiles también son destacados por Piscitelli al estimar, como valor agregado de la red, la mitad de las conversaciones de utilidad que se producen a través de Twitter, frente a un $40 \%$ de temas intrascendentes, $6 \%$ de autopromoción y 4\% spam (Orihuela, 2011: 19-20). Debido a la compleja articulación de las prácticas de comunicación y a las dificultades para su medición, el capital intelectual basado en las redes aún no se contabiliza adecuadamente (Vatamanescu, Andrei y Leovaridis, 2015).

Para la medición del capital relacional es preciso introducir la noción y dimensión del ecosistema "porque no sólo se trata de lo que sabes sino también del contexto y de con quién te relacionas" (Still, Huhtamaki \& Russel, 2014). La nueva gestión de las organizaciones tiene que integrar en esa dimensión el ecosistema del Big Data (Davenport, Barth \& Bean, 2012) y de las redes de valor, que son conjuntos de roles e interacciones que se establecen a través de la arquitectura sistémica de las nuevas tecnologías (Allee; Schawabe, 2011).

La explosión de las redes introduce un cambio de paradigma en las interacciones humanas y del ecosistema virtual, generando una sobredemanda de atención, que requiere una reflexión sobre la ecología digital y la capacidad de gestión para atraer y mantener un recurso tan limitado de los usuarios (Kleineberg; Boguna, 2015). El impacto de la comunicación y las interacciones se ha multiplicado en la sociedad actual (Mangold; Faulds, 2009). En una investigación de finales de los años 90 se estimaba ya que las interacciones representaban en Estados Unidos el 51\% de la actividad laboral y un tercio de su PIB (Butler, Hall, Hanna et alt., 1997). El uso de las tecnologías de la información y de las redes de comunicación incrementó mucho más ese potencial.

\section{Modelos de negocio}

Los sitios de redes digitales se desarrollan a partir de las economías de la atención, afiliación, participación, colaboración y transación, requiriendo el perfil de los usuarios como columna vertebral del sistema de organización reticular y de los respectivos modelos de 
negocio para la gestión de la publicidad, suscripción, comercio electrónico y comercialización de datos de las identidades y huellas digitales. Sus modelos de negocio, la mayor parte de ellos comunes a los de las herramientas y nuevos medios de la Web 2.0, se articulan a partir de la "economía de la larga cola" descrita por Crihs Anderson (2009), que es la suma de numerosas pequeñas ventas de muchos mercados que facilitan Internet y la logística de la globalización. Las redes y los usuarios con muchos contactos, aunque sean débiles, tienen la cola más larga mientras que aquellos que tienen menos, pero próximos o latentes (de confianza), la tienen más gruesa. Por lo tanto, escala y grosor son dos conductores de valor.

Los cuatro principales modelos de negocio de las redes digitales (Enders, Hungenberg, Denker, y Mauch, 2008) son los de publicidad, pago por productos y servicios, suscripción y transacciones aunque, como los metamedios sociales en general, la tendencia general es que sus características y fuentes de ingresos sean de componente muy híbrido. La clave de la cuestión radica en cómo crean o pueden crear valor las redes digitales para sus usuarios y como ese valor no sólo se transforma en capital social sino también como se captura, monetiza y convierte en fuente de ingresos sostenible. Otros tres aspectos centrales para completar esa ecuación son el número de usuarios de la plataforma, su disposición a pagar por los servicios y el nivel de confianza del consumidor.

El modelo de publicidad necesita escala, cola larga y altas tasas de tráfico, con capacidad de especialización y diferenciación para maximizar los ingresos (Laudon y Traver, 2007), partiendo de la base de que los usuarios no están dispuestos a pagar y aceptan los mensajes publicitarios como un precio por el acceso libre (Cancer, 2006). El modelo de pago se base en la disposición a pagar y en la confianza, cola gruesa en primer lugar y también escala o longitud para conseguir la masa crítica necesaria para la obtención de los ingresos. Como variedad del anterior o modelo nuevo, el de suscripción se fundamenta en altos niveles de valor para el usuario; por eso se articula con tipos como el "freemium", en el que se paga solo por el acceso a la parte de más interés exclusivo: más contenidos, más funcionalidades e incentivos y distintos paquetes de membresía con diferentes esquemas de precios. 
El modelo de transacción y comercio electrónico requiere masa crítica, disposición a pagar por encima de la media y, sobre todo, una fuerte cultura de la confianza, teniendo en cuenta que es la palanca para hacer negocio en línea, sin contacto físico, con personas y organizaciones desconocidas. "La confianza es un constructo que tiene un impacto significativo en el comportamiento de los usuarios en línea" (Ratnasingham, 1993; Lim et alt., 2006). La colaboración, la interacción, la confianza y la lealtad son valores necesarios para los modelos de negocio de las redes digitales.

El profesor de la Universidad Carolina del Norte, Michael Rappa (2010), identifica y clasifica nueve modelos de negocio en el entorno digital: brokerage (intermediación a comisión de B2B, B2C y C2C); publicidad (de portal, clasificados, de afiliación o huella de conexión, emplazamiento, contextual, intromercials y ultramercials); infomediarios (intermediaros de información y comunicación de otros proveedores para los usuarios); comercio electrónico (propio o intermediado); venta directa virtual de los fabricantes (productos y servicios informáticos); de afiliación (comisión por la gestión de la intermediación); de comunidad (basados en la comunidad, membresía y colaboración); suscripción; y de pago por uso a la carta.

Tomando como referencia la descripción de Javier Celaya (2014) de los modelos digitales, en las redes también podemos hallar las siguientes tipologías: a) de pago por servicio, por descarga, suscripción, alquiler, micropagos; paquete (bundle); freemium-premium, pago mediado y membresía o club; b) de publicidad por acceso abierto o libre, tipo banner y afiliación, patrocinio, bartering, merchandising y product placement, c) y de otras formas híbridas y filantrópicas tales como colaboración, P2P, MOOCs, mecenazgo, crowfunding, crowsourcing o gamificación.

Las tendencias de evolución de los modelos de negocio de estos metamedios sociales apuntan a la especialización y tematización -el crecimiento y penetración de las redes académicas (González-Díaz, Iglesias-García y Codina, 2015) es un ejemplo más-; a la innovación en aplicaciones (Periscope, 360 grados, Hyperlapse, realidad aumentada y virtual); desintermediación y P2P; reconocimiento de imágenes; despliegue de metaversos; aumento de la publicidad nativa; algoritmos de análisis cognitivo y predictivo; y optimización de las herramientas de aplicación en la telefonía móvil. Por delante tienen los retos de la 
monetización del Big Data, proteger la seguridad de los datos, garantía de la privacidad, control de la publicidad engañosa y verificación del retorno de las inversiones (ROI).

\section{Paradigma del ecosistema}

Casi la mitad de los norteamericanos que utilizan Internet (Pew Research 2014) aceden a las noticias de política y del gobierno a través de Facebook, la red digital con la cola más larga. ¿Por qué lo hacen? Por autoeficiencia de accesibilidad, incentivo de sociabilidad, interacción y por saber para poder contar lo que pasa en su comunidad (Kwon, Halavias y Havener, 2015). Estudios sobre las dinámicas de heterogeneidad -sobre una base de 386 millones de mensajes- de la difusión de las noticias a través de las redes digitales revelan que estas son más influyentes en política y cultura frente a los medios tradicionales, que conservan su prevalencia en economía y artes (Kim, Netwth y Christen, 2013).

Sea equilibrado y sostenible o no, lo cierto es que los datos cuantitativos confirman que estos modelos de metamedios de redes sociales digitales se han convertido en el paradigma central del ecosistema mediático en línea. Las estadísticas de uso de las redes digitales así lo reflejan. Según datos de Statshot Digital, a finales de 2014 había 2.000 millones de cuentas activas en redes sociales, un 28\% de la población del planeta, 1.600 millones de ellas conectadas a través de dispositivos móviles. En cabeza, Facebook con 900 millones de visitas mensuales, Twitter 310 millones, Linkedin 255 millones, Pinterest 250 millones, Google +120 millones, Tumblr 110 millones, Instagram 100 millones, VK 80 millones, Flickr 65 millones y Vine 42 millones. Datos significativos pero, en todo caso, cambiantes y expandibles como la propia fisonomía del ecosistema.

En las páginas siguientes a esta introducción podrán hallar más datos, interpretaciones, análisis y visiones. El tema, en modo alguno, está agotado, ni mucho menos, porque se podría decir que aún está en la flor de su pubertad. Se necesita más tiempo, más madurez, más investigación y reproducción para profundizar en este campo actual de la cultura y la sociabilidad digital. A todo ello animamos a proseguir. 


\section{Referencias bibliográficas}

Allee, Verna; Schwabe, Oliver (2011). Value networks and the true nature of collaboration. ValuetNet Works, ed.

http://www.valuenetworksandcollaboration.com

Anderson, Crihs (2009): La economía Long Tail. Del mercado de masas al triunfo de lo minoritario. Empresa Activa, Barcelona

Barnes, John (1954): "Class and comittees in a Norwegian Island parish”. En Human Relations, 7, pp. 39-58.

Baudry, Bernard (2005): L economie des relations interentreprises. París, La Découverte.

Beer, David (2008): "Social network(ing) sites.revisiting the story so far: A response to danah boyd \& Nicole Ellison". En Journal of Computer-Mediated Communication, 13, pp. 516-529, International Communication Association

Benghozi, Pierre-Jean (2006): "Communaute virtuelle: structuration sociale ou outil de gestion?”. En Entreprises et Histoires, núm. 43, pp. 67-81.

Benghozi, Pierre-Jean (2011): "Économie numérique et industries de contenu: un nouveau paradigme pour les résaux". En Hermès, 59. París, CNRS.

Boley, H.; Chang, E. (2007): "Digital Ecosystems: Principles and Semantics", Inaugural IEEE International Conference on Digital Ecosystems and Tecnnologies, Australia. http://nparc.cisti-icist.nrc cnrc.gc.ca/npsi/ctrl?action=rtdoc\&an=8914187\&lang=en.

Bolter, Jay David, y Grusin, Richard (1999): Remediation. Understanding New Media. Cambridge, MIT Press. Publicación en español del capítulo "Inmediatez, hipermediación y remediación" en el volumen 16 (2011) de la revista CIC (Cuadernos de Información y Comunicación de la Universidad Complutense de Madrid), en traducción de la profesora Eva Aladro.

Bordieu, Pierre (1993): Sociology in Question. Londres, Sage

Bourdieu, Pierre (1986): "The Forms of Capital”, en Richards J.G. (ed): Handbook o Theory and Research for the Sociology of Education. Nueva York, Greenwood Press, pp. 241-258

Burt, Ronal S. (1992): Structural Holes: The Social Structure of Competition. Cambridge, MA, Harvard University Press 
Butller, Patrick; Hall, Ted W.; Hanna, Alistair M.; Mendonca, Lenny; Auguste, Byron; Manyika, James; Sahay, Anupam (1997): “A revolution in interaction". En The McKinsey Quartely, 1.

Butts, Carter T. y Cross, B. Remy (2009). "Change and External Events in Computer-Mediated Citation Networks: English Language Weblogs and the 2004 US Electoral Cycle". En Journal of Social Structure (JOSS), vol. 10, 3.

Calmard, Pierre (2015): L'homme à venir. Comment le numérique va nous transformer. París: Editions Telemaque.

Campos Freire, Francisco (2008): "Las redes sociales trastocan los modelos de medios de comunicación tradicionales". En la Revista Latina de Comunicación Social, 63, páginas 287 a 293, La Laguna (Tenerife), Universidad de la Laguna. Recuperado el 29-9_2015: http://www.ull.es/publicaciones/latina/2008/23 34 Santiago/Fran cisco Campos.html

Campos Freire, Francisco (2011): El nuevo escenario mediático. Zamora-Salamanca: Comunicación Social.

Campos-Freire, Francisco (2015): “Adaptación de los medios tradicionales a la innovación de los metamedios". El Profesional de la Información, v. 24, n. 4, pp. 441-450.

Canavilhas, João (2015): "Nuevos medios, nuevo ecosistema". El Profesional de la Información, v. 24, n. 4, pp. 357-362.

Cancer, B. (2006): E-business: Strategic Thinking and Practice. Houghton Mifflin Company, Boston.

Casilli, Antonio A. (2010): Les liaisons numériques. Vers une nouvelle sociabilité? París: Seuil

Castells, Manuel (2009): Comunicación y poder. Madrid, Alianza Editorial.

Celaya, Javier et al (2014): "Nuevos modelos de negocio en la era digital". Un estudio elaborado por Dosdoce.com para CEDRO con motivo del lanzamiento de la plataforma Conlicencia.com. Disponible en: http://www.dosdoce.com

Christakis, Nicholas A., y Fowler, James H. (2010): Conectados. El sorprendente poder de las redes sociales y cómo nos afectan. Madrid, Taurus.

Coleman, James S. (1990): "Social Capital in the Creation of Human Capital". En American Journal of Sociology, 94, pp. 95-120.

Davenport, Thomas H. y Beck, John C. (2002): La economia de la atención: el nuevo valor de los negocios. Barcelona: Paidós. 
Degenne, Alain (2011): "Retour à l' analyse des réseaux sociaux (entretien)". En Hermès, 59, pp. 39-40. París, CNRS.

Doueihi, Milad (2011): La grande conversion numérique. Suive de Rêveries d'un promeneur numérique. París, Seuil.

Ellison, Nicole B. (2011): "Réseaux Sociaux, numérique et capital social (entretien)". Realizada por Thomas Stenger y Alexandre Coutant. En Hermès, 59, pp. 21-24

Ellison, Nicole B., Steinfield, Charles, y Lampe, Clif (2011): "Connection strategies: Social capital implications of Facebookenabled communication practices". En New Media\& Society, vol. 13, 6, Sage Pub.

Ellison, Nicole y Boyd, Danah (2013): "Sociality through Social Network Sites." En The Oxford Handbook of Internet Studies (ed. William H. Dutton). Oxford: Oxford University Press.

Enders, Albrecht; Hungenberg, Harald; Denker, Hans-Peter; Mauch, Sebastian (2008): “The long tail of social networking. Revenue models of social networking sites". En European Management Journal, 26, pp. 199-211.

Flichy, Patrice (2010): Le sacre de l'amateur. Sociologie des passions ordinaires à l'ère numérique. París, Seuil.

Freeman, Linton C. (2012): El desarrollo del análisis de redes sociales. Un estudio de sociología de la ciencia. Bloomington, Palibro.

Fuchs, Christian; Boersma, Kees; Albrechtslund, Anders; Sandoval, Marisol, eds. (2011): Internet and Surveillance: The Challenges of Web 2.0 and Social Media. N. York, Routledge.

González-Díaz, Cristina; Iglesias-García, Mar; Codina, Lluís (2015): "Presencia de las universidades españolas en las redes sociales digitales científicas: caso de los estudios de comunicación”. En El Profesional de la Información, v. 24, n. 5, pp. 640-647.

Graham, S. (2004): "From dreams of transcendence to the remediation of urban life". In S. Graham (ed.): The Cybercities Reader, pp. 1-30. Londres, Routledge.

Granovetter, M. S. (1973): “The strength of weak ties". En American Journal of Sociology 6, pp. 1360-1380.

Granovetter, Mark S. (1974): Getting a Job: a study of contacts and careers. Cambridge, Harvard University Press.

Grenstein, Shane (2013): "Collective Intelligence and Neutral Point of View: The Case of Wikipedia". Kellogg School of 
Management, Northwestern University, Boston.

Hanna, Richard; Rohm, Andrew; Crittenden, Victoria L. (2015): "We're all connected: The power of the social media ecosystem". En Business Horizons, vol. 54, 3, pp. 265-273.

Haythornthwaite, C. (2005): "Social networks and Internet connectivity effects". En Information, Communication \& Society, 8, 2, pp. 125-147.

Hill, R. A.; Dunbar, R. I. M. (2003): "Social network size in humans". En Human Nature 14, pp. 53-72.

Hine, Christine (2004): Etnografía virtual. Barcelona, UOC.

Islas, Octavio (2007): "Internet y la obligada remediación de la televisión”. En Razón y Palabra, 12 (59), México

Jenkins, Henry (2008): Convergence culture: La cultura de la convergencia de los medios de comunicación. Barcelona, Paidós

Jenkins, Henry (2009): Fans, blogueros y videojuegos: la cultura de la colaboración. Barcelona, Paidós.

Jenkins, Henry (2010): Piratas de textos: fans, cultura participativa y televisión. Barcelona, Paidós.

Kaplan, Andreas M., Haenlein, Michael (2010): "Users of the world, Unite! The challenges and opportunities of Social Media". En Business Horizons, 53, 1, pp. 54-68

Kay, Alan y Goldberg, Adele (1977): "Personal Dynamic Media". Journal Computer, 10(3).

Kim, Minkyoung; Netwth, David; Christen, Peter (2013): "Modeling Dynamics of Diffusion Across Heterogeneous Social Networks: News Diffusion in Social Media". En Entropy, 15, 10, pp. 4215-4242.

Kirkpatrick, David (2011): El efecto Facebook. La verdadera bistoria de la empresa que está conectando el mundo. Barcelona, Planeta editorial.

Kleineberg, Kaj-Kolja; Boguna, Marian (2015): “Digital Ecology: Coexistence and Domination among Interacting Networks". En Scientific Reports, vol. 5, núm. 10268.

Knight, Megan; Cook, Clare (2013): Social Media for Journalists. Principles and Practice. Londres, Sage.

Kwon, K. Hazel; Halavias, Alexander; Havener, Shanon (2015): "Tweeting Badges: User Motivations for Displaying Achievement in Publicy Networked Environments". En Cyberpsychology Behavior and Social Networking, 18, 2, pp. 93-100. 
Lash, S. (2002): Critique of Information. Londres, Sage.

Lash, S. (2007): "Power after Hegemony: Cultural Studies in Mutation". Theory, Culture \& Society, 24(3), pp. 55-78.

Latour, Bruno (1999): Pandora's Hope. Essays on the Reality of Science Studies. Harvard University Press.

Laudon, K. C.; Traver, C. G. (2007): E-Commerce: Business, Technology, Society. Pearson Prentice Hall, N. Jersey.

Lazega, Emmanuel (1998): Réseaux sociaux et structures relationnelles. París, PUF.

Lim, K. H., Ling, S. C., Lee, M. K. O. and Benbasat, I. (2006): "Do I trust you online, and if so, will I buy?". En Journal of Management Information Systems, 23, pp. 233-266.

Lin, Nan (2001): Social Capital: a theory of social structure and action. Cambridge, University Press.

Lusher, Dean y Ackland, Robert (2011): “A Relational Hyperlink Analysis of an Online Social Movement". En Journal of Social Structure (JOSS), vol. 12,5.

Madianou, Mirca, y Miller, Daniel (2012): "Polymedia: Towards a new theory of digital media in interpersonal communication". En International Journal Cultural Studies, 16, 2.

Mangold, W. Glynn; Faulds, David J. (2009): "Social media: The new hybrid element of the promotion mix". En Business Horizons, vol. 52 , 4, pp. 357-365.

Manovich (2015): “The Science of Culture? Social Computing, Digital Humanities and Cultural Analytics Studying Big Cultural Data: Social Computing and Digital Humanities". Consultado 30-9-2015 en: http://manovich.net/index.php/projects/cultural-analytics-socialcomputing

Manovich, Lev (2005): El lenguaje de los nuevos medios de comunicación: la imagen en la era digital. Barcelona, Paidós.

Manovich, Lev (2008): Software takes command. New York:

Georgetown University. Disponible en: http://faculty.georgetown. edu/irvinem/theory/Manovich-Software-Takes-Command- ebook2008-excerpt.pdf.

Mattelart, Armand (2007): Historia de la sociedad de la información. Barcelona, Paidós

Mcluhan, Marshall (1964): Understanding media: the extensions of man. New York, McGraw-Hill. 
McLuhan, Marshall (1996): Comprender los medios de comunicación: las extensiones del ser bumano. Barcelona, Paidós.

Molina, José Luis (2004): "La ciencia de las redes". En Apuntes de Ciencia y Tecnología, número 11. Accesible en: http:// revistaredes.rediris.es/recerca/jlm/ars/ciencia.pdf.

Orihuela, José Luis (2011). Mundo Twitter. Barcelona: Alienta.

Pahl, R. (2002): "Towards a more significant sociology of friendship". En European Journal of Sociology, 43(3), pp. 410-423.

Pew Research Center (2015): "State of the News Media 2014". Accesible en: http://www.journalism.org/packages/state-of-thenews-media-2014/

Poncier, Anthony (2011): Les réseaux sociaux d'entreprise. París, Diateino.

Putnam, Robert (1993): "The prosperous community: social capital and public life". En The American Prospect, 13.

Rappa, Michael (2010): “Business models on the web”. En Managing The Digital Enterprise. Accesible en: http://digitalenterprise.org/models/models.html

Ratnasingham, P. (1998): "The importance of trust in electronic commerce." En Internet Research: Electronic Networking Applications and Policy, 8, pp. 313-321.

Requena Santos, Félix (2003, 2012): Análisis de redes sociales. Origenes, teorias y aplicaciones. Madrid, CIS.

Requena Santos, Félix (2011): Las redes de apoyo social. Madrid, Thomson Reuters.

Rheingold, H. (1993, 2000): The virtual community: Homesteading on the electronic frontier. Reading, MA, Addison-Wesley.

Rheingold, Howard (2004): Multitudes inteligentes. Las redes sociales y las posibilidades de las tecnologias de cooperación. Barcelona, Gedisa.

Riepl, Wolfgang (1913): Das Nachrichtenwesen des Altertums mit besonderer Rücksicht auf die Römer. Leipzig, Teubner

Sage Elwell (2014): "The transmediated self: Life betwen the digital and the analog". En Convergence: The International Journal of Research into New Media Technologies, vol. 20, 2, pp. 233-249.

Statshot Digital (2014): "We Are Social's Statshot Digital 002". Accesible en: http://es.slideshare.net/wearesocialsg/we-are-socialsdigital-statshot-002

Stenger, Thomas (2009): "Social Network Sites (SNS): do they 
match? Definitions and methods for social sciences and marketing research”. En XXIX Conferencia INSNA en San Diego (EE.UU.). Accesible también en línea en:

http://www.academia.edu/2521387/Social_Network_Sites_SNS_do_ they_mat

ch_Definitions_and_methods_for_social_sciences_and_marketing_re search.

Stenger, Thomas, y Coutant, Alexandre (2011): "Introduction.

Ces réseaux numériques dits sociaux". En Hermès, 59, pp. 9-20.

Still, Kaisa; Huhtamaki, Jukka; Russel, Martha (2014): “New Insights for Relational Capital". En Proceedings of the $11^{\text {th }}$ International Conference on Intellectual Capital, Knowledge Management and Organizational Learning (ICIKKM), editado por Rooney, J; Murthy, V. $11^{\text {th }}$ International Conference on Intellectual Capital, Knowledge Management and Organizational Learning, Sydney Business Universtiy, Australia.

Tapscott, Don y Williams, Anthony D. (2007): Wikinomics. La nueva economía de las multitudes inteligentes. Barcelona, Paidós.

Thrift, N. (2005): Knowing capitalism. Londres, Sage.

Tung, Chien-Ming; Wu, Hsuan-Yi (2013): “An InternetConnected World: Google's Platform Strategies to Network Industry". Editado en Workshop Proceedings of The 9Th International Conference on Intelligent Environments, coordinado por Botia, JA; Charitos, $\mathrm{D}$, Taylor \& Francis Gr. De $9^{\text {th }}$ Iternational Conference on Intelligent Environments, Atenas.

Van Dick, Jose (2013): "Facebook and the engineering of connectivity: A multi-layered approach to social media platforms". En Convergence. The International Journal of Research into New Media Technologies, vol. 19, núm. 2, pp. 141-155.

Watts, Duncan J. (2006). Seis grados de separación. La ciencia de las redes en la era del acceso. Barcelona, Paidós

Web, Amy (2015): “Tech Trends for Journalist". En $8^{\text {th }}$ Annual Online News Association Presentación en: http://es.slideshare.net/webbmedia/ona2015-full 


\section{Las herramientas digitales sociales en línea para la inserción laboral}

Xosé Pereira Fariña. Universidad de Santiago de Compostela (USC, España),xose.pereira@usc.es

Natalia Alonso Ramos. Universidad de Santiago de Compostela (USC, España),natalonso@gmail.com

\section{Resumen}

La metamorfosis que han experimentado las Tecnologías de la Información y la Comunicación (TIC) a lo largo de los últimos años y, sobre todo, la eclosión de la web 2.0 ha modificado, sustancialmente, las pautas a seguir de cara a la búsqueda y consecución de un puesto de trabajo, tanto desde la perspectiva del empleador, como desde la óptica del potencial empleado. En la actualidad, la búsqueda de trabajo ya no se corresponde con un proceso presencial, sino que los usuarios de Internet echan mano de las numerosas herramientas digitales en línea disponibles - portales de empleo, redes sociales, blogs, entre otros- para promocionar su perfil profesional vía telemática y acceder a las ofertas que mejor se ajusten a su perfil.

Metodología: El presente artículo constituye una revisión de las principales y más recientes aportaciones científicas en lo concerniente al uso de este tipo de recursos destinados a implementar la progresión profesional de sus usuarios y usuarias. Resultados: El primordial propósito de este trabajo consiste en exponer los diferentes instrumentales metodológicos desde los que ha sido abordado nuestro objeto de estudio -las herramientas digitales en línea para la autopromoción laboral-, así como sus conclusiones, a fin de construir su Estado de la Cuestión. 
Palabras clave: portales de empleo, redes sociales, blogs, metodología, estado de la cuestión.

\section{Introducción}

Z S un hecho: la imparable evolución de las Tecnologías de la 1 Información y de la Comunicación (TIC), el acceso a Internet y la eclosión de las denominadas Redes Sociales han modificado nuestro modo de habitar los contextos sociales en los que nos hayamos insertos, así como la forma en la que ciframos nuestra realidad o proyectamos -a través de múltiples y convergentes máscaras significantes- la imagen que de nosotros aspiramos a construir, difundir y perpetuar. Según el Informe Sociedad de la Información en España 2013, elaborado por la Fundación Telefónica, 25 millones de españoles acceden a Internet (700.000 más que el año anterior) y 19 millones lo hacen a diario. La población que hace un uso intensivo de la Red supone el 53,8\% del total de los españoles. En la franja de 16 a 24 años, el porcentaje de usuarios intensivos es del 86\%. La consolidación de la vida digital en España también se muestra por el incremento en el uso de las redes sociales: el 64,1\% de los usuarios de Internet en los últimos tres meses participa en redes sociales de carácter general (Facebook, Twitter o Tuenti). Este porcentaje aumenta hasta el 94,5\% entre los jóvenes de 16 a 24 años. Además según el Estudio General de Medios (EGM) relativo al periodo comprendido entre octubre de 2013 y mayo de 2014, Internet es el único medio cuya penetración en la sociedad mantiene, desde el año 1997, una tendencia siempre al alza, llegando a 58,5\% de la población. Por su parte, la Encuesta sobre Equipamiento y Uso de Tecnologías de Información y Comunicación en los Hogares, correspondiente al año 2014, evidencia que por primera vez en España hay más usuarios de Internet (76,2\%) que de ordenador (73,3\%). El 77,1\% de los internautas accedieron a Internet mediante el teléfono móvil y más de la mitad de la población $(51,1 \%)$ participa en redes sociales.

A la luz de estos datos, no resulta extraño, por tanto, que procesos cotidianos como la búsqueda de un puesto de trabajo ya no se corresponda, exclusivamente, con un acto tangible o presencial, sino que los usuarios de la Red echan mano de las numerosas herramientas digitales en línea disponibles -portales de empleo, redes 
sociales, blogs, entre otros- para promocionar su perfil profesional vía telemática y acceder a las ofertas que mejor se ajusten a su perfil. Según el III Estudio Adecco Profesional de Intermediación Laboral, en el que se entrevistó a 574 empresas con una notable dispersión sectorial y geográfica, además de realizar una encuesta online dirigida a 8.777 candidatos, se constató que 48,7\% de las empresas emplea las Redes Sociales como mecanismo para reclutar candidatos. Asimismo, Internet sigue siendo el medio predilecto para captar mandos, técnicos y empleados $(68,8 \%)$. Sin embargo, para la selección de directivos se mantiene el uso de las empresas de selección (89\%). El sector de las infocomunicaciones es donde Internet ha alcanzado mayor penetración como medio de difusión, superando el $90 \%$ de las empresas encuestadas. En un segundo lugar, y a gran distancia, se encuentra la industria $(69,11 \%)$, la construcción $(68,73 \%)$ y el sector servicios $(67,06 \%)$. Los contactos personales se muestran como la principal fuente de búsqueda de trabajo por parte de los candidatos $(97,2 \%)$, seguido de la búsqueda en portales de empleo $(76,42 \%)$ y la consulta en las web de las empresas $(73,15 \%)$. Finalmente, para la búsqueda de empleo en el extranjero, son los portales de empleo nacionales $(43,2 \%)$, los buscadores de Internet (38\%), los portales de empleo extranjeros $(36,1 \%)$ y las páginas web corporativas $(32 \%)$, los más usados por los candidatos.

El claro protagonismo de las herramientas sociales en línea de cara a postularse como candidato, o desde la óptica del reclutador laboral por parte de las empresas, también se ha visto claramente fortalecido por la situación de crisis económica global que ha sacudido con especial crudeza a los países del sur de Europa disparando sus cifras de desempleo. Sin ir más lejos, la Encuesta de Población Activa, correspondiente al tercer trimestre de 2014, en España, revela que la tasa de paro se sitúa en el 23,67\%, o lo que es lo mismo, que cerca de una cuarta parte de la población española carece de un puesto de trabajo. De hecho, de acuerdo con datos extraídos del $V$ Estudio Anual de Redes Sociales, correspondiente a abril de 2014 y elaborado por el Interactive Advertising Bureau, una red social profesional, LinkedIn, es la sexta más empleada en España, siendo utilizada por el $22 \%$ de los encuestados (figura 1). 
Tabla 1: Redes Sociales más empleadas en España (abril, 2014)

\begin{tabular}{cc}
\hline Red Social & Porcentaje de Usuarios \\
\hline Facebook & $94 \%$ \\
\hline YouTube & $68 \%$ \\
Twitter & $49 \%$ \\
Google+ & $41 \%$ \\
Tuenti & $22 \%$ \\
\hline LinkedIn & $22 \%$ \\
\hline
\end{tabular}

Fuente: V Estudio Anual de Redes Sociales. Interactive Advertising Bureau.

Además, según el II Informe Infoempleo y Adecco sobre Redes Sociales y Mercado de Trabajo en España, correspondiente al año 2013, el 64\% de los profesionales de Recursos Humanos considera que un candidato activo en Redes Sociales tiene más oportunidades laborales. Asimismo, los propios usuarios valoran LinkedIn como la red social más idónea para buscar trabajo, seguida de Facebook y Twitter. Finalmente, a la hora de buscar empleo, los portales de empleo online se erigen en fuente de información preferente (figura 2).

Tabla 2: Medios que siempre se consultan para buscar empleo (2013).

\begin{tabular}{cc}
\hline Tipo de Medio & Porcentaje de Usuarios \\
\hline Portales de empleo & $78 \%$ \\
Contactos & $24 \%$ \\
\hline Empresas de selección & $25 \%$ \\
Redes Sociales & $19 \%$ \\
Anuncios en prensa & $18 \%$ \\
\hline Otros & $9 \%$ \\
\hline
\end{tabular}

Fuente: II Informe Infoempleo y Adecco sobre Redes Sociales y Mercado de Trabajo en España

En un contexto en el que resulta obvia la pujanza de los medios sociales en línea de cara a la autopromoción laboral y la consecución de empleo, resulta preciso definir de qué modo y desde qué perspectivas se está abordando la eclosión de un fenómeno que invierte las pautas que, hasta hace poco más de una década, definían la gestión de los Recursos Humanos en España y en el mundo. La presente investigación constituye una revisión de las principales y más 
recientes aportaciones científicas en lo concerniente al uso de este tipo de recursos destinados a implementar la progresión profesional de sus usuarios y usuarias. El primordial propósito de este trabajo consiste en exponer los diferentes instrumentales metodológicos desde los que ha sido abordado nuestro objeto de estudio - las herramientas digitales en línea para la autopromoción laboral-, así como sus conclusiones, a fin de construir un actualizado Estado de la Cuestión. Para ello, comenzaremos abordando el concepto y evolución interdisciplinar de la noción Red Social para, a acto seguido, centrarnos en los que se ha dado en denominar como e-recruitment, esto es, la utilización de las herramientas sociales en línea de cara al reclutamiento de nuevos empleados y empleadas.

\section{Metodología}

En su artículo titulado "Social networks on the Internet", Musiał y Kazienko (2013: 31-72) apuntan a J. A. Barnes (1954) como primer acuñador del concepto Social Network, no obstante, el responsable del paradigma moderno de Red Social es Stanley Milgram (1967 y 1969), cuya línea de investigación se centró en describir los problemas de un pequeño universo mediante relaciones o vínculos indirectos. Incluso si dos personas $\mathrm{X}$ e $\mathrm{Y}$ no se conocen directamente, ambos pueden compartir nexos comunes, tales como una tercera persona que los conozca a ambos. Milgram llevó a cabo dos experimentos -Kansas Study y Nebraska Study- en los que solicitó a varias personas de una ciudad que preparasen un envío destinado a otros habitantes de otra ciudad distante, de los cuales solo conocían su nombre de pila, ocupación y localización aproximada. Asimismo, se les indicó que realizasen dicho envío a la persona de su entorno que ellos considerasen que podría tener más posibilidades de conocer al destinatario que les había tocado en suerte. Este conocido debería hacer lo mismo y así, sucesivamente, hasta conseguir que el envío llegase al destinatario final. Tras analizar las misivas, Milgram concluyó que la gente que reside en Estados Unidos constituye una red social, encontrándose todos y cada uno de ellos conectados mediante "six degrees of separation" ya que cada envío solo necesitó un promedio de entre cinco y siete intermediarios. A partir de Milgram, el concepto de Social Network fue adoptado y abordado desde diversas disciplinas. 
De hecho, muchos han sido los autores que se han aproximado a esta noción y propuesto sus propias definiciones (figura 3).

Tabla 3: Definiciones de Social Network.

Autor

Definición

Wasserman and Faust The finite set or sets of actors and one or more relations defined on them. Friendship among children in a classroom; all nations in the world and the formal diplomatic connections between them.

Hanneman and Riddle A set of actors that may have relationships with one another.

Family; co-workers in a company; the network of neighbors; friendship among students in a classroom

A set of social entities connected

Garton, Haythorntwaite, by a set of social relationships. y Wellman

Friendship among people; coworkers in a company; people who communicate with one another via computer.

Hatala

A set of actors with some patterns of interaction or "ties" between them; represented by graphs or diagrams illustrating the dynamics of the various connections and relationships within the group. Co-workers 
within a company.

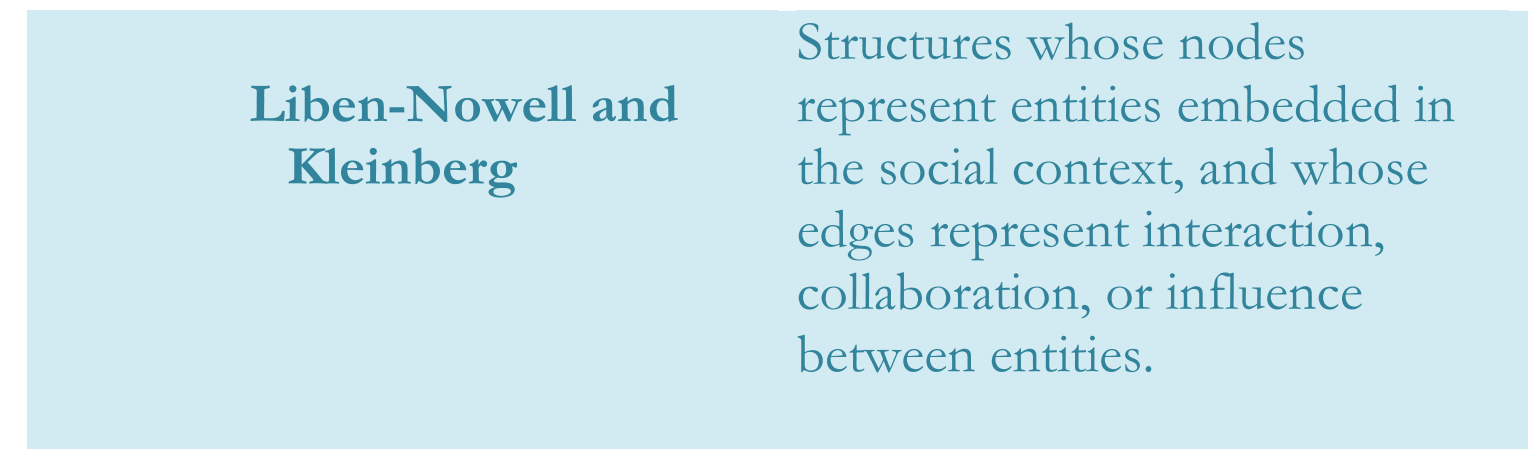

\section{Yang, Dia, Cheng, and Lin}

An undirected, unweighted graph. Co-authors of the scientific papers in a particular discipline; project groups in a large company; business leaders who have served together on a corporate board of directors

Fuente: Musiał y Kazienko (2013: 34)

Linton C. Freeman (2012) establece diversas etapas en torno al estudio de las redes sociales. Por un lado, la prehistoria de este tipo de estudios se vincula a la teoría de la interconexión social y de la observación sistemática. En una segunda etapa, se sitúan los estudios del psiquiatra Jacob Levy Moreno, que junto a su esposa Ellen Jennings, desarrolla un nuevo enfoque que denomina, primero, 'geografía psicológica' (1933) y luego 'sociometría', plasmada en su clásica obra Who Shall Survive? (1934) y fundamentada en la terapia grupal. A finales de la década de 1930, siguiendo la historiografía de la investigación de redes de Freeman (2012), la Escuela de Postgrado de la Universidad de Harvard reúne a William Lloy Warner, George Elton Mayo, Fritz Roethlinsberger, North Whitehead y Lawrence J. Henderson para estudiar la importancia e impacto de las estructuras sociales. Además, el judío alemán Kurt Lewin llega a Estados Unidos y, después de su paso por las Universidades de Cornell e Iowa, funda en la década de los años 40, en el MIT, el Centro de Investigación de Dinámica de Grupos. En la Universidad de Columbia, Paul Lazarsfeld, 
incorpora a su equipo de investigadores de la comunicación de masas a Robert King Merton para la realización de un trabajo sobre los efectos de un programa de radio. En 1977, desde Toronto, Barry Welman propone la creación de la Red Internacional de Análisis de Redes Sociales (INSNA, International Network for Social Network Analysis). Freeman y Welman ponen en marcha también en 1977 un Sistema Electrónico de Intercambio de Información (EIES), el primer ensayo de una comunidad virtual y de una red digital científica. La INSNA organiza en 1981, en Tampa, Florida, la primera conferencia internacional de redes sociales, a la que asiste como invitado John Barnes, el antropólogo al que se le atribuye el primer uso del concepto de red social. Junto a la organización de las conferencias internacionales en distintas partes del mundo, la INSNA anima también la edición de varias revistas científicas: Connections, Journal of Social Structure, Social Networks y Redes, esta última publicada en España.

Con la eclosión de Internet, el concepto de red social adquiere nuevos matices. Para Castells (2009: 45-47), una red es un conjunto de nodos interconectados que se articulan formando la espina dorsal de las sociedades. Son conjuntos de actores sociales enlazados entre sí mediante relaciones sociales, que se pueden representar - a partir de la teoría matemática de los grafos- a través de puntos o nodos, que son los actores, y líneas que reflejan los vínculos que los conectan. Las principales diferencias entre la red social tradicional y la red social en la era de Internet son:

1. Lack of physical, in person contact - only by distance, sometimes very large distances.

2. Usually the lack of unambiguous and reliable correlation between member's identity in the virtual community - internet identity and their identity in the real world.

3. The possibility of multimodal communication, simultaneously with many members; also the possibility of easy switches between different communication channels, espe- cially online and offline, e.g. online VoIP and offline text communication.

4. The simplicity of a break up and suspension of contacts or relationships.

5. The relatively high ease of gathering data about communication or common activities and its further processing. 
6. Potential lower reliability of the data about users available on the Internet. Users of internet services relatively frequently provide fake personal data due to privacy concerns" (Musiał y Kazienko, 2013: $35)$.

Al escritor e internauta norteamericano Jorn Barger se le cita como el primer creador de una página personal que denomina web-blog (Robot Wisdom) en diciembre de 1997 y a Dave Winer por ser el pionero de la sindicación de contenidos (Nafría, 2007: 235). En 1999 nace la primera versión de MySpace, que supervive hasta 2001 como sistema de intercambio de archivos, para ser recuperada como red social por Tim Anderson y Chris DeWolfe en 2003. En esos años de tránsito de los siglos XX a XXI hincha y estalla la burbuja financiera de las punto.com en la bolsa electrónica de Nueva York (Nasdaq, marzo 2000), pero no se detiene el emprendimiento ni la innovación tecnológica y económica porque surgen nuevas herramientas y modelos de negocio (Benkler, 2006). Tal y como detalla Caldevilla Domínguez (2010: 48), como consecuencia de la crisis informática vivida en el año 2003 y el cierre de numerosas compañías, tres norteamericanos crean "sendas empresas destinadas a que los internautas puedan hablar entre ellos y conocerse mejor": se trata de Marc Pincus, Reid Hoffman y Jonathan Abrams que ponen en marcha respectivamente Tribe.net, LinkendIn y Friendster, las tres primeras redes sociales de Internet. En España fueron tres catalanes, Toni Salvatella, Albert Armengol y Horaci Cuevas, los que cogieron el testigo creando eConozco en diciembre de 2003, la primera red social hispana, utilizando para ello recursos excedentes de su empresa, Galenicom.

Boyd y Ellison (2007) describen los sitios de redes sociales (Social Network Sites) como servicios web que permiten a los utilizadores (1) construir un perfil público o semipúblico en el seno del sistema informático, (2) generar una lista de utilizadores con los que se comparte un enlace, (3) ver y navegar a través de la lista de enlaces propios así como de los establecidos por los otros en el seno del sistema. Cuando nos referimos al concepto Social Media nos referimos a una forma "of electronic communication that allows user-generated interaction between the media's creator and the user" (Hudson y Roberts 2012: 769). De acuerdo con Smith (2012: 1), Social Media "is a term used to describe social interactions using technology (such as the 
Internet and cell phones) with any combination of words, pictures, video, or audio". No nos encontramos, por tanto, ante un tipo de comunicación pasiva ya que "visitors can communicate and socialize, sharing emails, documents, pictures, video, audio files, and do each in a number of different ways" (Smith, 2012: 1). Venezia (2012: 24) define Social Media como "any online service or site that focuses on building social networks or relations among people who share interests. Generally, these sites consist of a representation of each user (usually a profile), his/her links, and a variety of additional services depending upon the individual site. Most of these services are webbased and provide means to interact over the Internet, like Facebook does. Social media sites allow users to share ideas, activities, events, photos, videos, and many other things to whoever may be interested." Gelms (2012: 265) añade que "social media allows users to connect with previously established friends and also build new relationships based on common interests, thereby providing an alternative technological platform for standard social communication and interaction." De acuerdo con Campos Freire (2014), entre 2007 y 2013, se publicaron 73 trabajos sobre redes sociales digitales en las diez revistas de comunicación de mayor impacto en 2011 de Journal Citation Reports (JCR) del Institute of Scientific Information (ISI), correspondientes a autores de 20 países y 50 Universidades. Siguiendo el mismo criterio, en las 20 principales revistas españolas de comunicación se publicaron en el mismo periodo de 2007-13 un total de 153 artículos sobre redes sociales digitales, de 118 autores de Universidades españolas y 22 de otros países. Los ejes temáticos, objetivos, tratamiento y metodologías empleadas confirman que la orientación de la mayoría de aquéllas y estas investigaciones aborda el estudio de las redes sociales digitales, principalmente, más como un nuevo medio de comunicación y/o cibercomunicación que como un sistema tecnosocial a través del que se articulan y desarrollan importantes tipos de relaciones.

\section{Resultados}

Ghazzawi y Accoumeh (2014: 164) actualizan en su artículo "Critical Success Factors of the E-Recruitment System" el concepto de eRecruitment: "E-recruitment is a part of electronic Human Resource Management (e-HRM). It is known as one of the most popular e- 
HRM applications used by organizations. E-recruitment could be defined as the use of the internet to attract potential employees to an organization and hire them". Por su parte Sills (2014: 12), afirma que el "E-recruitment can only be described as the process of any personnel advertising or attracting, selection and application processing via the Internet, for external candidates, or Intranet, for internal candidates". La tesis de Maureen Sills, defendida en la Helsinki Metropolia University of Applied Sciences bajo el título Erecruitment: A comparison with traditional recruitment and the influences of social media. A qualitative and quantitative review, constituye una de las obras más actualizadas en torno al concepto de e-Recruitment y su Estado de la Cuestión. A la hora de abordar, los diversos análisis que se han venido realizando en los últimos años en torno al proceso de reclutamiento online, o dicho de otro modo, la capacidad telemática para postularse como candidato o seleccionar desde la perspectiva del empleador a nuevos candidatos, resulta crucial detenernos en la tarea desempeñada por el Centre of Human Resources Information Systems (CHRIS), que desde el año 2002, y en colaboración con el portal privado de búsqueda de empleo Monster.de, ha ido publicando informes anuales en torno a los patrones de empleabilidad de las 1000 empresas más importantes de Alemania. En el informe publicado en 2014 y con datos correspondientes al ejercicio 2013, se concluye que el $64,8 \%$ de los encuestados valoran como positivo el empleo de los medios sociales como vía para obtener empleo, de hecho, esta tendencia se manifiesta al alza ya que, en 2012, solo el 50\% realizaban esta valoración positiva. Facebook se erige en la red social predilecta, seguida de Xing. Un 63\% de los encuestados afirma tener perfil en alguna red social profesional. Asimismo, el estudio evidencia que más de la mitad de las empresas alemanas prefieren que los candidatos se postulen mediante formularios en línea, en un segundo lugar se sitúan los envíos por correo electrónico y un porcentaje muy residual se decanta por las candidaturas en formato papel. En una línea semejante y aún dentro del país germánico, deben destacarse las investigaciones llevadas a cabo por Sonja Salmen y Bernd Rath, autores de la obra Recruiting im Social Web (2012), en virtud de la cual se puede acceder a una detallada definición y evolución de los procesos vinculados al $e$ recruitment. 
Dinamarca también se erige en un foco basilar en lo concerniente a la investigación de los procesos de reclutamiento telemáticos, destacándose, por encima de todo, un nombre: el de la investigadora Anna Holm de la Aarhus University, autora de la obra E-recruitment: Towards an Ubiquitous Recruitment Process and Candidate Relationship Management (2012). Pero sin duda, ciñéndonos al ámbito anglosajón, la entidad especializada en el estudio del e-recruitment es Jobvite, con sede en California. Nos encontramos ante una aplicación que implica a todo el personal de la empresa en las tareas de reclutamiento de la misma, invitándoles a publicar o comentar las ofertas de trabajo en sus redes sociales y entre sus conocidos, de manera que son los propios empleados los que recomiendan a los candidatos, ahorrando costes de reclutamiento. En el informe más reciente que han publicado, Job seeker nation study: an authoritative survey of the social, mobile job seeker (2014), concluyen que el 76\% de los Social Job Seekers han accedido a un puesto de trabajo a través de la red social Facebook, si bien dicho estudio afirma que los contactos personales siguen siendo la primera vía de empleabilidad, seguida, en un segundo lugar, por las redes sociales. Además, cerca de la mitad de los buscadores de empleo a través de herramientas sociales en línea han modificado su privacidad en las redes que frecuentan porque son conscientes de que los reclutadores están pendientes de ellos como potenciales candidatos para sus empresas.

De acuerdo con Galindo Huertas (2013: 14), cuando nos referimos al e-recruitment, estamos apuntando hacia la automatización de los procesos de reclutamiento, hecho que supone ahorro de costes y de tiempo, así como a una optimización substancial en el tratamiento de los datos ya que el e-recruitment favorece la emisión de una ingente cantidad de información cuyo traslado era imposible con anterioridad. En este sentido, el autor discierne entre las dos vigas que sustentan los procesos telemáticos de empleabilidad: por un lado los jobsites o portales de búsqueda de empleo y, por el otro, las redes sociales propiamente dichas. Los Jobsites son webs que albergan ofertas de empleo como parte de su contenido aunque también contienen noticias, información sobre empresas, enlaces de interés, prestación de asesoramiento $\mathrm{y}$, en definitiva, todo lo que la política del site o creatividad del webmaster estime oportuno. Su principal objetivo es poner en contacto a empleadores y candidatos. Pueden ser generalistas 
-esto es, no especializados en ningún sector profesional en concreto-, o especializados -centrados, por tanto, en un ámbito laboral específico-. Las redes sociales, por su parte, son "espacio de interacción en tiempo real de una persona con su entorno virtual, formado a su vez por otras personas que interactúan entre ellos y con terceros a través del mismo medio, compartiendo contenidos. Se trata pues de un sistema virtual abierto y en permanente evolución" (Galindo Huertas, 2013: 21). De acuerdo con la taxonomía propuesta por este autor y según giren o no en torno a un eje temático específico, las redes sociales pueden ser horizontales (Facebook y Twitter) o verticales, situándose en este último apartado, las redes sociales verticales profesionales, tales como LinkedIn, Viadeo o Xing.

La eclosión de las redes sociales y muy especialmente la incidencia de éstas en los procesos de reclutamiento y autopromoción profesional genera la emergencia de todo tipo de nuevas investigaciones desde perspectivas interdisciplinares e innovadoras. Barzilay y Urquhart (2014: 1613-1628), en su artículo "Understanding reuse of software examples: A case study of prejudice in a community of practice", realizan un análisis cualitativo de las percepciones vertidas por los desarrolladores de software a través de la red social LinkedIn. Por su parte, Middleton, Bragin y Parker (2014: 291-302) ofrecen una comparación del proceso de reclutamiento en medios tradicionales, Social Media y la invitación directa en "Finding people who will tell you their thoughts on genomics-recruitment strategies for social sciences research". Kim, Kim y Nam (2014: 2605-2614), en "How does industry use social networking sites? An analysis of corporate dialogic uses of Facebook, Twitter, YouTube, and LinkedIn by industry type", abordan los usos de diálogo corporativo con el público en esas cuatro redes sociales por parte de la industria. Ben Ahmed, Nabli y Gargouri (2014: 29-47) en "Group extraction from professional social network using a new semi-supervised hierarchical clustering", acometen los grupos de extracción de la red social profesional y enriquecen la representación del perfil del usuario y sus grupos afines, mediante la construcción de una red social de almacenamiento. El análisis de las redes sociales también se traslada a sectores profesionales muy específicos -tal es el caso de Loeb, Bayne, Frey et al. (2004: 993-998) en "Use of social media in urology: data from the American Urological Association (AUA)" o "The impact of 
social media on a major international emergency medicine conference" (Neill, Cronin, Brannigan et al., 2014: 401-404)- o espacios geográficos concretos -véase a este respecto la investigación realizada en Grecia por Nikolaou (2014: 179-189), bajo el título "Social Networking Web Sites in Job Search and Employee Recruitment"-.

\section{Conclusiones}

En un contexto en el que el consumo de medios sociales en línea se encuentra en pleno apogeo -en el caso español, por ejemplo, Internet se erige en el único medio de comunicación cuya penetración mantiene una dinámica ascendente ya que más de la mitad de los ciudadanos realiza un uso intensivo de la Red, mientras que casi la mitad de las empresas echan mano de las Redes Sociales para reclutar potenciales candidatos-, la investigación sobre este ámbito comunicativo gira en torno a tres pilares básicos:

1. Estudios teóricos genéricos que se dedican a reconstruir el concepto histórico del e-Recruitment, así como a inferir posibles taxonomías dentro de los medios sociales en línea para fomentar la autopromoción profesional.

2. Estudios sectoriales en los que se aborda el influjo del Social Media en ámbitos laborales muy concretos.

3. Estudios geográficos en los que se aborda el influjo del Social Media en el marco de unas determinadas fronteras $y$, en consecuencia, dentro de un sedimento cultural específico.

Dentro de estas tres parcelas, se combinan el análisis de contenido cualitativo y/o cualitativo, con los estudios de recepción que abordan las pautas de consumo de los usuarios en términos tales como redes sociales predilectas o tipo de uso que se hace de las mismas. En todo caso, el concepto de e-recruitment se encuentra en plena génesis, así como las cuestiones que surgen en torno a su naturaleza.

\section{Referencias bibliográficas}

Barzilay, O. y Urquhart, C. (2014): "Understanding reuse of software examples: A case study of prejudice in a community of 
practice", en Information and Software Technology, Vol. 56, N. 12, páginas 1613 a 1628.

Ben Ahmed, E., Nabli, A. y Gargouri, F. (2014): “Group extraction from professional social network using a new semisupervised hierarchical clustering", en Knowledge and information systems, Vol. 40, N. 1, páginas 29 a 47.

Benkler, J. (2006): The wealth of networks: how social production transforms workets and freedom. New Haven: Yale University Press.

Boyd, D. M. y Ellison, N. B. (2007): "Social Network Sites: Definition, History, and Scholarship", en Journal of Computer-Mediated Communicaton, Vol. 13, 1, páginas 210 a 230.

Campos Freire, F. (2014): "La investigación y gestión de las redes sociales digitales”, en Panóptico 01, páginas 7 a 51. La Laguna (Tenerife): Latina.

Capdevilla Domínguez, D. (2010): "Las Redes Sociales. Tipología, uso y consumo de las redes 2.0 en la sociedad digital actual", en Documentación de las Ciencias de la Información, Vol. 33, páginas 45 a 68.

Castells, M. (2009): Comunicación y poder. Madrid: Alianza Editorial.

Freeman, L. C. (2012): El desarrollo del análisis de redes sociales. Un estudio de sociología de la ciencia. Bloomington: Palibro.

Galindo Huertas, J.C. (2013): La estrategia de selección de recursos humanos y las nuevas tecnologías. Valladolid: Universidad de Valladolid.

Gelms, J. (2012): “High-Tech Harassment: Employer Liability Under Title VII for Employee Social Media Misconduct", en Washington Law Review, vol. 87, páginas 249 a 280.

Ghazzawi, K. y Accoumeh, A. (2014): "Critical Success Factors of the E-Recruitment System”, en Journal of Human Resources Management and Labor Studies, June 2014, Vol. 2, N. 2, páginas 159 a 170.

Holm, A. B. (2012): E-recruitment: Towards an Ubiquitous Recruitment Process and Canadidate Relationship Management. Aarhus V: Rainer Hampp Verlag.

Hudson, S.C. y Roberts, K. (2012): "Drafting and Implementing an Effective Social Media Policy", en Texas Wesleyan Law Review, Vol. 18, páginas 767 a 794 . 
Kim, D., Kim, J. y Nam, Y. (2014). "How does industry use social networking sites? An analysis of corporate dialogic uses of Facebook, Twitter, YouTube, and LinkedIn by industry type", en QUALITY \& QUANTITY, Vol. 48, N. 5, páginas 2605 a 2614.

Loeb, S., Bayne, C.E., Frey, C. et al (2014): "Use of social media in urology: data from the American Urological Association (AUA)", en BJU INTERNATIONAL, Vol. 113, N. 6, páginas 993 a 998.

Middleton, A., Bragin, E. y Parker, M. (2014): "Finding people who will tell you their thoughts on genomics-recruitment strategies for social sciences research", en Journal of community genetics, Vol. 5, N. 4, páginas 291 a 302.

Musiał, K. y Kazienko, P. (2013): "Social networks on the Internet", en World Wide Web, N.16, páginas 31 a 72.

Nafría, I. (2007): Web 2.0. El usuario, el nuevo rey de Internet. Barcelona: Gestión 2000.

Neill, A., Cronin, J.J., Brannigan, D. et ál (2014): “The impact of social media on a major international emergency medicine conference, en Emergency Medicine Journal, Vol. 31, N. 5, páginas 401 a 404.

Nikolaou, I. (2014): "Social Networking Web Sites in Job Search and Employee Recruitment". En International Journal Of Selection And Assessment, Vol. 22, N. 2, páginas 179-189.

Salmen, S. (2012): Einleitung - Die Suche von Top-Mitarbeitern im War for Talent! In B. Rath, \& S. Salmen, Recruiting im Social Web. Götingen: BusinessVillage GmbH.

Salmen, S. (2012): What's Next - Die nächsten Trends. In B. H. Rath, \& S. Salmen, Recruiting im Social Web (p. 284). Göttingen:

BusinessVillage GmbH.

Sills, M. (2014): E-recruitment: A comparison with traditional recruitment and the influences of social media. A qualitative and quantitative review. Helsinki: Helsinki Metropolia University of Applied Sciences Bachelor of Business Administration.

Smith, M.C. (2012): "Social Media Update", en The Advocate, Vol. 58, páginas 1 a 12 .

Venezia, S.J. (2012): “The Interaction of Social Media and the Law and How to Survive the Social Media Revolution" en New Hampshire Bar Journal, Vol. 52, páginas 24 a 39. 


\section{Neuropolítica, emoción y sentimiento en las redes sociales}

José Rúas-Araújo, Universidad de Vigo (UVIGO, España), joseruas@uvigo.es

Iván Puentes-Rivera, Universidad de Vigo (UVIGO, España), ivanpuentes@uvigo.es

Borja Dapena-González, Universidad de Vigo (UVIGO, España), borjadapenagonzalez@gmail.com

\section{Resumen}

El estudio de mente y cuerpo, a través de las distintas disciplinas que integran las denominadas neurociencias, abre nuevas vías de investigación y aplicación en las ciencias sociales y la comunicación.

En este trabajo se describe cómo se ha producido la evolución de las neurociencias y la traslación (con el apoyo de la tecnología, de sus métodos y herramientas), al lenguaje, la política y la comunicación. La progresiva adaptación del prefijo "neuro" al reino de las ideas, para el análisis de palabras, textos e imágenes. Una evolución sobre la consideración del "bit", el átomo y los genes, como elementos básicos para la unificación entre la biología y la teoría de la información, constituyendo un nuevo modo de pensar y relacionarse en la sociedad en red.

Igualmente, se muestran diversos ejemplos de utilización de programas de computación lingüística para el análisis de la carga emocional de los textos publicados por los parlamentarios, así como los intentos de aplicación de las neurociencias al análisis de las cuentas 
en Twitter y Facebook de candidatos y partidos, para finalizar con el estudio de su evolución en España.

Palabras clave: neurociencias, neuropolítica, parlamento, redes sociales, Twitter, Facebook.

\section{Introducción}

\subsection{De las neurociencias a las ciencias sociales y la comunicación}

$\mathrm{D}$ URANTE las últimas décadas, la investigación del cerebro se convirtió en un tema estrella: el gobierno USA declaró la década de los noventa como la "Década del Cerebro", asumió el reconocimiento de la primera década del siglo XXI como la "Década de la Mente" y el prefijo "neuro" se generalizó como sustantivo en múltiples actividades científicas hasta llegar a las ciencias sociales, con la celebración, en abril de 2001, del primer congreso en "neurociencia social" (Ochsner, Kevin y Matthew, 2001: 717).

A partir de entonces los investigadores comenzaron a preocuparse no sólo del cerebro físico, sino también del social (Gazzániga, 1993) y emocional (Damasio, 1999), una vez que la psicología cognitiva cogió el relevo del conductismo y comenzaron a estudiarse "abordajes alternativos" desde la sociología (Matthes, 2006), bajo la perspectiva de la agenda-setting, distinguiendo entre asuntos de relevancia personal, relevancia social y relevancia emocional, esta última, a través de medidores emocionales (Miller, 2007).

$\mathrm{Y}$ a todas estas perspectivas también hay que añadir, por supuesto, la neurocomunicación, dirigida a comprender la acción y reacción del sujeto en el proceso de comunicación y su incidencia en la estrategia publicitaria (Serrano y De Balanzo, 2011). La explicación de ese "reino de las ideas" expresado a través de una "inteligencia conectiva o a escamas" - en expresión de Derrick De Kerckhove- que constituye la vía dominante en los desarrollos teóricos de las ciencias de la comunicación, además de un nuevo modo pensar y de relacionarse en la nueva sociedad en red (Timoteo, 2013:15).

Toda esta explosión ha tenido, naturalmente, sus críticos, que acusan la utilización "abusiva y sin límite" del prefijo "neuro" al estudio "de cualquier actividad o manifestación humana", señalando 
que la contribución de las neurociencias al desarrollo de otras disciplinas, específicamente en el ámbito de las ciencias sociales y humanas, no aporta nada significativo (García-Albea, 2011: 577).

Sin embargo, la aplicación de los métodos y técnicas de las neurociencias a las ciencias sociales en general y, en particular, al análisis de los procesos cognitivos, de la atención y la percepción y el análisis del comportamiento de los individuos, está ofreciendo nuevas vías para la investigación y medición de la eficacia publicitaria. Igualmente, las neurociencias se están abriendo camino en la investigación de las audiencias y la opinión pública, tanto en el ámbito social, como comercial y político (Gómez, M. y Bandrés, E., 2014).

\subsection{El papel de la información en el proceso evolutivo}

La información (como bit, como gen, como unidad básica computable, como factor empático, como inteligencia emocional, como orden de la vida) es el principio de todo (Gleick, J, 2012). El entendimiento de que la vida es, básicamente, información, y de que la evolución no se ha detenido en el proceso fisiológico, sino que ha continuado con el desarrollo de sistemas y procesos necesarios en la aparición de la inteligencia.

En ese proceso se incluye el "sistema" de "memes", el término acuñado por Richard Dawkins (2000: 21), para designar las ideas que circulan por la sociedad, señalando que si los genes son las unidades mínimas de transmisión de la herencia biológica, los "memes" constituyen unidades mínimas de transmisión de la herencia cultural y del conocimiento colectivo.

Así, al igual que los genes se propagan de un cuerpo a otro mediante los espermatozoides, los "memes" también se desplazan de un cerebro a otro, por imitación. "Memes" que, en forma de imágenes, ideas, frases o eslóganes, crean corrientes (de opinión) muy similares a las producidas por la colonización del espacio por las plagas de insectos, epidemias o la invasión de los cuerpos por células, siguiendo los patrones de agrupamiento descritos por el experto en modelos computacionales biomédicos y sociales, Joshua M. Epstein (2007). 


\section{Neurolingüística y lingüística computacional}

Desde la consideración del lenguaje político como "jerga" (Lázaro Carreter, 1963) o, al menos, como un "lenguaje especial" y "sectorial" (Núñez Cabezas y Guerrero Salazar, 2002) equiparable como tal al lenguaje periodístico (Diezhandino Nieto, 1994: 150), hemos llegado, con la implantación de la denominada Comunicación Mediada por Ordenador (CMO), la Web 2.0 y las redes sociales, a un estilo híbrido, entre lo público formal y lo privado coloquial.

Algo que autores como Fairclough (1995) clasificaron bajo el término "conversacional", una forma de definir la tendencia de este lenguaje a la "coloquialización" como "un reflejo de la necesidad del acercamiento de los políticos, tanto a las prácticas comunicativas de la conversación cotidiana" (Blas Arroyo, 2011: 23), como a las redes sociales, conscientes de la extensión y popularización de las mismas.

Otros autores consideran que todo el lenguaje es político, desde el momento en que cualquier hablante, ya sea un profesional de la política o un ciudadano de la calle, adopta distintas estrategias lingüísticas y comunicativas con el objeto de influir en los demás (Lakoff, 1990; Alvar López, 1995, López Eire y de Santiago Guervós, 2000).

Pero al margen de las distintas interpretaciones, lo cierto es que los textos tradicionales iniciaron su camino hacia modos de representación de la realidad, incorporando la aplicación y uso de las nuevas tecnologías, los lenguajes y metalenguajes de la denominada sociedad en red y la hipertextualidad, en su adaptación y evolución hacia el cerebro digital, que significa, en palabras de Small y Vorgan (2009), un desarrollo del mismo en función de las tecnologías de la comunicación e información.

En concreto, se experimentaron avances revolucionarios en análisis lingüístico por ordenador (Jurafsky y Martin, 2008), estructura lingüística (Biber, 1988), procesamiento del discurso (Graesser, Gernsbacher y Goldman, 2003) y representación estadística del mundo del conocimiento y el significado (Landauer, McNamara, Dennis y Kintsch, 2008).

En el caso de España, Sánchez García (2012: 15) identifica una corriente de estudio del lenguaje político español centrada en la lexicometría o estadística léxica, es decir, el tratamiento informatizado de corpus textuales - metodología escogida por autores como Anglada 
(1980), Cabré (1978) y Coloma Lleal (1973) - y la lexicología social, con autores como Fernández Lagunilla (1985), Rebollo Torío (1976) y de Santiago Guervós (1992). A ellos se añaden otros autores que, basándose en la teoría de la enunciación, sostienen que no podemos analizar los textos políticos sin tener en cuenta el contexto en el que se producen, además un grupo de estudiosos sobre la retórica en el discurso político español, como López Eire y de Santiago Guervós (2000), Díaz Rojo (1994) y Moreno Lara (2004).

Todo ello sin olvidarnos de Chomsky (1971), como uno de los máximos exponentes de la lingüística cognitiva, que concibe el lenguaje como un fenómeno integrado dentro de las capacidades cognitivas humanas (Croft y Cruse, 2008: 17).

La ciencia cognitiva, en su combinación con la lingüística y la neurobiología y en la búsqueda de una explicación sobre el funcionamiento de la inteligencia humana, partió de la concepción del lenguaje como "una clase de instinto" (no un auténtico instinto, ya que toda lengua debe aprenderse, pero sí en cuanto a la tendencia instintiva a hablar que posee toda persona), en palabras de Darwin (1874), supuesto sobre el que, en parte, también se asienta Pinker (2012).

De igual modo, el estudio de las metáforas políticas a partir de la lingüística cognitiva ha sido desarrollado por George Lakoff (2007), quien, entre otras cuestiones, propuso una categorización de los votantes demócratas y republicanos y su forma de ver y entender el mundo, de acuerdo con series de metáforas y marcos conceptuales.

\section{Política, emoción y sentimiento en las redes sociales}

Una situación similar se vive en el estudio de los comportamientos predictivos en política. A partir de la hipótesis bastante generalizada de que las decisiones de voto se mueven más por emociones que en convencer mediante razones, se abren horizontes inexplorados de relación entre neurociencias y comunicación política.

Una línea de trabajo tiene que ver con el supuesto de que, como en buena parte de los comportamientos animales, la política y su representación tienen una fuerte base bioquímica y de que pueden registrarse diferentes niveles de testosterona en los votantes de un candidato sobre otro e, incluso, buscando en otra hormona, la dopamina, la explicación de la personalidad de algunos líderes, o 
encontrado en los genes las cualidades de quienes son más proclives a la actividad política (Arroyo, 2012: 35).

Pudiera suceder que, igual que las instituciones políticas constriñen la conducta de los grupos, los genes son las instituciones del cuerpo humano que constriñen la conducta individual, tal y como indican Fowler y Dawes (2008: 588). Y si los genes son los diseñadores de la política primaria, los cerebros son sus ejecutivos. En consecuencia, se investiga sobre la posible influencia de la transmisión genética en la orientación política y en el proceso de socialización de las personas (Alford, Funk y Hibbing, 2005: 153).

De hecho, se han estudiado también grandes muestras de genoma encontrando zonas cromosómicas en las que se apreciaban diferencias significativas entre conservadores y progresistas (Hatemi y Gillespie, 2011), observando las predisposiciones ante la suposición de la existencia de distintos fenotipos condicionantes de nuestras posiciones ideológicas y actitudes políticas ante distintos temas. $\mathrm{O}$ el estudio de la tensión (disonancia cognitiva) entre razón y emoción que se muestra ante la presentación de mensajes y que resolvemos y simplificamos a través de atajos cognitivos (Rúas, 2011).

Por lo que respecta al análisis de textos y discursos políticos en los medios digitales, se clasifican tres tipos básicos de corrientes teóricas: las que buscan monitorizar los discursos, las que analizan sentimientos y reacciones frente a los comportamientos de los políticos $y$, finalmente, las que intentan predecir resultados electorales a partir de lo publicado en las redes sociales.

La aplicación de las denominadas tecnologías de minería para valorar el caudal de los tweets generados por los usuarios, provocó una corriente de investigación favorable sobre su capacidad de predicción de resultados electorales (Tumasjan et. al, 2010; Asur y Huberman, 2010; O'Connor et. al, 2010; Tjong y Bos, 2012) y otra crítica (Goldstein y Rainey, 2010; Panagiotis, 2011; Gayo-Avello et al., 2011 y Jungherr et al., 2012).

Sobre el análisis de emociones en Twitter, destaca el trabajo de Bollen et al. (2009), que emplean la herramienta "POMS" (Profile of Mood States), para obtener series temporales sobre la evolución de seis atributos emocionales diferentes: tensión, depresión, ira, vigor, fatiga y confusión. Se trata de un instrumento psicométrico que 
proporciona una lista de adjetivos y donde cada adjetivo se relaciona con un estado de ánimo.

La aplicación de las denominadas tecnologías de minería para valorar el caudal de información generada en Twitter está abriendo nuevas vías de investigación, también en España.

Congosto y Aragón (2012), trataron de medir la participación ciudadana en las últimas elecciones generales, celebradas en noviembre del 2011, y de analizar el nivel de emotividad de los políticos en los mensajes, utilizando para ello el corpus SPANEW (Redondo et. al., 2007), la adaptación al español del programa ANEW (Affective Norms for English Words).

El programa mide los siguientes factores emocionales: valencia (valores altos que se corresponden a sentimientos de felicidad, satisfacción y esperanza o, por el contrario, valores bajos a tristeza, descontento y desesperación), excitación (capta la asociación de palabras con sentimientos de entusiasmo, ira o frenesí y sus opuestos) y dominancia (sentimientos de dominación frente a sumisión o terror).

Otros programas de análisis computerizado de textos y minería de datos son VPro, TextPack, TextQuest, WordStat y SAS (Neuendorf, 2002), como también se registraron programas de indexación y búsqueda de lenguaje natural, a través del rastreo de equivalencias semánticas y categorías de palabras (Tropes Semantic Knowledge), nubes de palabras (Tagxedo, Wordle, Word It Out) o el análisis positivo, negativo o neutro de opiniones (Sentiwordnet)(Esuli y Sebastiani, 2006), utilizados, por ejemplo, para el análisis de debates presidenciales (Lema y Abascal-Lema, 2014).

Uno de los programas utilizados para la evaluación cognitiva y emocional de textos es el software Linguistic Inquiry and Word Count (LIWC).

El programa está avalado en la literatura científica por autores como Tausczik y Pennebaker (2009) y en su empleo para medir, por ejemplo, los niveles de sentimiento en los discursos del senado norteamericano ( $\mathrm{Yu}$, Kaufmann y Diermeier, 2008). Otros ejemplos de su aplicación se encuentran en el análisis del lenguaje utilizado por Rudolph Giuliani, alcalde de Nueva York, a lo largo de su mandato (Pennebaker y Lay, 2002), observando que varía según se va enfrentando a crisis tanto políticas como personales, además de la comparación, en otro trabajo (Slatcher, Chung, Pennebaker, y Stone, 
2007), de los estilos lingüísticos de los candidatos a la presidencia de los USA (George Bush y John Kerry) y la vicepresidencia (Dick Cheney y John Edwards), en la campaña electoral correspondiente al año 2004.

El programa "Linguistic Inquiry and Word Count" (LIWC) es un software desarrollado para la evaluación cognitiva y emocional de textos a través de una serie de categorías psicológicas y estructurales. Este programa analiza textos, palabra por palabra, en una clasificación de 70 variables lingüísticas, que incluyen categorías de lenguaje estándar (artículos, preposiciones, pronombres, etc.), procesos psicológicos (categorías de emociones positivas y negativas, variables cognitivas), palabras relacionadas con la relatividad espacio-temporal, los tiempos verbales y dimensiones tradicionales de contenido, organizadas de forma jerárquica.

La utilización del programa LIWC, diseñado en 2001 por James W. Pennebaker, profesor de psicología en la Universidad de Austin (Texas), Roger J. Booth y Martha E. Francis, cuenta con una validación para su aplicación en idioma español (Ramírez-Esparza, N; Pennebaker, J.W.; García, F.A. y Suria, R., 2007).

En el caso de España, se utilizó el programa LIWC para el análisis de rasgos suicidas en la actriz Marilyn Monroe partiendo de sus textos personales, publicados en "Fragmentos" (2010) (FernándezCabana y cols., 2012).

También se aplicó la herramienta LIWC al análisis de los mítines de los candidatos a las elecciones al Parlamento de Galicia, celebradas en 2012 (Rúas, Fernández y Puentes, 2013) así como al estudio de los tweets publicados por durante esa misma campaña electoral por partidos (Míguez, Fernández y Alves, 2013) y candidatos (Pérez, Puentes-Rivera y García, 2013). Previamente a la celebración de estos comicios, otro grupo de investigadores (Carrera, Guardia y Peró, 2013), aplicaron el programa LIWC al análisis del estilo lingüístico de los candidatos del PP y el PSOE a la presidencia del Gobierno de España, comparando, entre otros aspectos, sus intervenciones en los debates televisados celebrados en las campañas de las elecciones generales de 2011 y 2008.

Pero la aplicación de las técnicas y herramientas de las neurociencias al neuromarketing y la comunicación, también está encontrando nuevas vías para el análisis a través del Eye-Tracking, en 
el estudio del movimiento ocular, presente desde hace más de una década en el ámbito científico internacional (Van Essen, Anderson y Felleman, 1992; Paulson y Goodman, 1999) y que se ha demostrado muy eficaz en los procesos de observación de la denominada atención visual (Rossini y Galera, 2006), para analizar el recorrido ocular ante la exposición a estímulos impresos y audiovisuales, tales como los carteles, spots y, por supuesto, las páginas web.

$\mathrm{Y}$ el auge de algunas redes sociales como Facebook, abre también nuevas vías para la exploración y el análisis de la carga emocional de las imágenes, como uno de los recursos cada vez más utilizados en esta herramienta por parte de los políticos y que los usuarios acreditan tanto través del cómputo de sus apoyos (el marcador "me gusta"), como de sus comentarios y opiniones.

\section{Políticos en Twitter y Facebook en España: perspectiva para el análisis}

El último de los estudios sobre el empleo de Internet y las redes sociales publicado por Asociación para la Investigación de Medios de Comunicación (AIMC) en marzo de 2015, con datos correspondientes al último trimestre del $2014^{2}$, muestra un perfil de usuarios cada vez más adulto, más conectado y durante más tiempo. En concreto, se indica que el $71 \%$ de los usuarios utilizaron Internet durante el último mes y, de ellos, el 90\% varias veces al día. Además, casi la cuarta parte de los encuestados se conectó a través del teléfono móvil y 1/3 de ellos durante más de una hora al día. $\mathrm{Y}$ al mismo tiempo que se incrementa la lectura de la prensa electrónica frente al papel (3/4 partes de los usuarios admiten que utilizan los diarios electrónicos para informarse y la consulta de periódicos online supera por primera vez a la combinada papel/online), también crece el número de usuarios que utilizan las redes sociales para informarse de la actualidad, pasando del 45,8\% registrado en 2013 al 50,6\% del 2014.

El uso diario de redes sociales supera las $3 / 4$ partes de los entrevistados, distribuyéndose del siguiente modo: Facebook (89\%), Twitter (47\%), Linkedin $(30 \%, 5$ puntos más con respecto al año anterior) e Instagram (26,5\%, 6 puntos más sobre el año anterior).

${ }^{2}$ http://www.aimc.es/-Navegantes-en-la-Red-.html (Fecha de consulta: 03/04/2015) 
Los datos correspondientes a la VI Ola del Observatorio de Redes Sociales, una encuesta online realizada a 1.200 internautas elaborada por "The Cocktail Analysis", muestra que un 90\% de los usuarios disponen de cuenta en alguna de las redes sociales, con 2,3 cuentas de media disponibles por persona, y que Facebook y WhatsApp se confirman como líderes de penetración, con un 83\% y $87 \%$, respectivamente, seguidos de Twitter, con un $47 \%$.

Sin embargo, este incremento sostenido en la utilización de Internet y las redes sociales por parte de los ciudadanos no parece corresponderse con la lenta incorporación de la clase política española a las nuevas tecnologías.

De hecho, son los jóvenes quienes más toman la iniciativa y participan de forma activa a través de las redes sociales, pues no sólo generan respuestas, sino también preguntas, propuestas y llamadas a la acción, destacando por su grado de compromiso (García, Hoyo y Fernández, 2014), por contraste con los políticos, que rara vez utilizan la red para la conversación y el debate político y siguen sin aprovechar el potencial que ofrecen como formas participativas no jerárquicas, entendiéndolas únicamente como un dispositivo de propaganda a corto plazo (Zamora y Zurutuza, 2014).

Con motivo de las elecciones generales celebradas en el año 2011, Borondo, Morales, Losada y Benito (2012) observaron que el $40 \%$ de dichos mensajes eran re-tweets, lo que les llevó a concluir la falta de discusión y debate sobre dicha campaña en Twitter, además de sugerir que la atención colectiva estaba dirigida por un porcentaje muy pequeño de usuarios.

En el año 2011, Túñez y Sixto mostraban que sólo uno de cada cuatro parlamentarios $(25,14 \%)$ del Congreso de los Diputados disponía de perfil o página en Facebook. Ese mismo año, la Asociación para la Investigación de Medios de Comunicación (AIMC) afirmaba, en su estudio sobre Ciudadanos en la red, que el 89,8\% de los usuarios utilizaba la red social Facebook.

También en el año 2011, Rúas y Dapena, analizaron la presencia en Facebook de los diputados del Parlamento gallego, que fue de 46 de los 75 parlamentarios (61,3\%), una proporción menor a los presentes en Twitter, con 34 de los 75 diputados gallegos registrados

\footnotetext{
${ }^{3}$ http://tcanalysis.com/blog/posts/the-cocktail-analysis-y-arena-publican-la-viola-del-observatorio-de-redes-sociales (Fecha de consulta: 03/04/2015).
} 
en esta red social, tal y como comprobaron, años más tarde, Otero y Rolán (2013).

Asimismo, Almansa y Castillo (2014), en su estudio sobre la presencia de los parlamentarios del Congreso de los Diputados en Twitter, observaron que tan sólo 176 de los 350 representantes políticos están presentes en esta red social y que el total de los presentes en Facebook es de 86, con una actualización media, en este último caso, de entre dos y tres días y quince días, concluyendo, en consecuencia, que la mayoría de los políticos que están en esta red es de forma puramente testimonial.

Ortega y Azagra (2014), hicieron un seguimiento de las cuentas de Twitter de los candidatos a la presidencia del Gobierno, Mariano Rajoy y Alfredo Pérez Rubalcaba, concluyendo que, más allá de contribuir a enriquecer el debate, el 68\% de los mensajes analizados se correspondían con menciones de usuarios, de los cuales un 14\% iban dirigidas a políticos de la misma formación y un 4,1\% de la oposición.

En el congreso Ibercom 2013, celebrado en Santiago de Compostela (Galicia), que reunió a investigadores procedentes en su mayoría de Brasil, Portugal y España, se presentaron los primeros resultados de un trabajo de investigación que tiene por objeto analizar la utilización de Twitter por parte de partidos políticos y candidatos en distintos procesos electorales. Así, el estudio presentado por Míguez, Fernández y Alves (2013) ofrece conclusiones relativas al modo de utilización de Twitter por parte de los principales partidos políticos que concurrieron a las elecciones autonómicas gallegas del año 2012, mientras que el trabajo de Pérez, Puentes-Rivera y García (2013) realiza lo propio con las cuentas de Twitter de los principales candidatos en ese mismo proceso electoral.

Partiendo de la idea de que las comunidades no sólo son de tipo territorial, sino que también pueden interrelacionarse de forma temática, las redes sociales pueden constituir un nexo de unión para salvar grandes distancias.

En consecuencia, un estudio sobre eurodiputados españoles en la red era imprescindible para conocer cómo influye la distancia a la hora de analizar la presencia y el uso de Facebook para comunicarse con el ciudadano. En este sentido, en el estudio realizado sobre la presencia de los eurodiputados españoles en Facebook, se constató que 24 de los 50 europarlamentarios disponían de Facebook (48\%) y, 
de ellos, tan sólo el 24\% actualizaban el Facebook al menos una vez cada dos días (Rúas y Dapena, 2013).

Con motivo del VI Congreso Internacional Latina de Comunicación Social (VI CILCS) y continuando con esta línea de investigación, se intentó dar un paso más, con el propósito de analizar la intensidad de la utilización por partidos políticos y candidatos de la red social Twitter, además de determinar si se percibían patrones lingüísticos y estratégicos comunes en el uso de esta herramienta de microblogging.

Igualmente, con respecto a Facebook, además de analizar la presencia e intensidad de los políticos, se hizo un análisis de las fotografías publicadas por los mismos, con la intención de determinar su peso y evolución, frente al empleo del texto.

Finalmente, el último de los propósitos era comprobar si se podía establecer una relación entre el número de seguidores de Twitter y Facebook y los resultados obtenidos por cada una de las formaciones políticas.

Entre las conclusiones observadas con motivo del citado congreso $^{4}$, se destaca el peso que las siglas siguen teniendo sobre los candidatos en cuanto a actividad en las redes sociales, así como el notable incremento de la utilización de las fotografías e imágenes de los candidatos en Facebook con respecto a comicios anteriores (77\% de las actualizaciones son imágenes frente al 23\% de texto).

Otra de las conclusiones a destacar de este trabajo es que no sólo no se observa una relación directa entre la actividad de las formaciones políticas en Twitter y Facebook y los resultados electorales obtenidos en las urnas, sino que esta relación es, incluso, inversamente proporcional, pues los partidos más votados fueron los de menor actividad en las redes sociales.

Diversos estudios sobre la presencia en las redes sociales por parte de los candidatos a alcaldes en las elecciones sociales van sucediéndose también y arrojando algunos detalles significativos, por

\footnotetext{
${ }^{4}$ Cfr. Rúas, J., Puentes, I. y Dapena, B. (2014): "Neurocomunicación, Facebook y Twitter: r-evolución en la observación y medición de los parlamentarios en las redes sociales", en Actas del VI Congreso Internacional Latina de Comunicación Social, La Laguna (Tenerife): Universidad de La Laguna. Disponible en: http://www.revistalatinacs.org/14SLCS/2014_actas/044_Ruas.pdf (Fecha de consulta: 06/04/2015).
} 
ejemplo, sobre la presencia en Twitter de los candidatos de las 52 principales ciudades españolas. En concreto, se muestran datos que indican que el $75 \%$ de los candidatos a alcalde estaban presentes en Twitter, si bien el 20\% no actualizaba sus cuentas (Vázquez, 2013); sobre el incremento, del 25,11\%, en el porcentaje de los seguidores de los candidatos (Criado, Martínez y Silván, 2013) y la observación, incluso, de que los candidatos de las ciudades situadas en el centronorte del país son más activos que los del sur (López, 2014).

Las elecciones celebradas en Andalucía el 22 de marzo del 2015 y las municipales celebradas en mayo del mismo año abrieron un nuevo debate sobre el uso de WhatsApp con fines políticos por parte de los candidatos.

Más allá de la discusión sobre la legalidad del empleo de esta herramienta en cuanto a garantías de protección de datos y cumplimiento de las condiciones del servicio (que algunos entienden que podrían vulnerarse, al entender que no se está utilizando para un uso personal), lo cierto es que este modo de mensajería instantánea está siendo incorporado por los principales candidatos y partidos de las citas electorales que están en proceso.

Así, además de aportar inmediatez y cercanía, el uso de WhatssApp no sólo está muy extendido entre los jóvenes, sino también entre los usuarios más adultos, logrando por ello alcanzar a un público objetivo más amplio y diverso, convirtiéndose en una herramienta muy popular que diluye las fronteras entre lo público y lo personal, con todas las ventajas e inconvenientes derivados de esta circunstancia.

Y si Facebook y Twitter lograron imponerse, poco a poco, a las webs y blogs de contenido político, está por ver en qué medida WhatssApp contribuirá, igualmente, a desplazar a las primeras en su utilización con fines políticos.

\section{Referencias bibliográficas}

Alford, J. R., Funk, C. L. y Hibbing, J. R. (2005): “Are political orientations genetically transmitted?", en American Political Science Review, 99, 2, páginas 153 a 167.

Almansa, A. y Castillo, A. (2014): “Comunicación institucional en España. Estudio del uso que los diputados españoles hacen de las 
TIC en sus relaciones con la ciudadanía”, en Chasqui, Revista Latinoamericana de Comunicación, Ecuador, página 126.

Anglada Arboix, E. (1980): "Estadística léxica: una aplicación al vocabulario político", en Anuario de Filología, 6, páginas 367 a 378.

Arroyo, L. (2012): El poder político en escena. Historia, estrategias y liturgias de la comunicación política. Barcelona: RBA.

Asur, S., y Huberman, B. A. (2010): Predicting the future with social media. CoRRabs/1003.5699.

Biber, D. (1988): Variation across speech and writing. Cambridge: Cambridge University Press.

Bollen, J., Pepe, A., y Mao, H. (2009): "Modeling Public Mood and Emotion: Twitter Sentiment and Socio-Economic Phenomena". Cfr.: http://arxiv.org/pdf/0911.1583.pdf .

Borondo, J., Morales, A.J., Losada, J.C. y Benito, R.M. (2012): "Characterizing and modelling an electoral campaign in the context of Twitter: 2011 Spanish Presidential Election as a case study", en Chaos, 22.

Cabré Castell, Ví, M. T. (1978): "La lexicometría como método de localización de rasgos ideológicos”, en Revista Española de Lingüística, 8, 2, páginas 335 a 344.

Carrera-Fernández, M. J., Guardia-Olmos, J. y Peró-Cebollero, M. (2013): "Psicología y lenguaje en política: los candidatos a la Presidencia del Gobierno y su estilo lingüístico", en Anuario de Psicología, 43 (1), páginas 39 a 52.

Chomsky, N. (1971): Sobre politica y lingüistica. Barcelona: Anagrama.

Coloma Lleal, J. M. (1973): Léxico de política. Barcelona: Laia.

Congosto, M. y Aragón, P. (2012): "Twitter, del sondeo a la sonda: nuevos canales de opinión, nuevos métodos de análisis”, en Redes Sociales y Gobernanza. Más Poder Local, n 12, septiembre, páginas 50 a 56.

Criado, J.I., Martínez, G. Y Silván, A. (2013): “Twitter en campaña: las elecciones municipales españolas de 2011”, en RIPS: Revista de Investigaciones Políticas y Sociológicas, 12, páginas 93 a 113.

Croft, W. y Cruse, D. (2008): Lingüistica cognitiva. Madrid: Akal.

Damasio, A. (1999): El error de Descartes: la razón de las emociones. Madrid: Andrés Bello.

Darwin, C. (1873): The expression of emotions in animals and man. 
New York: Appleton. Traducción al castellano en Madrid: Alianza, 1984.

Dawkins, R. (2000): El gen egoísta: las bases biológicas de nuestra conducta. Barcelona: Salvat.

Epstein, J. M. (2007): Generative Social Science: Studies in Agent-Based Computational Modeling. Princeton University.

Esuli, A. y Sebastiani, F. (2006): SENTIWORDNET: A Publicly Available Lexical Resource for Opinion Niming", en Proceedings of the $5^{\text {th }}$ Conference on Language Resources and Evaluation, Genova, páginas 417a 422.

Fernández-Cabana, M., García-Caballero, A., Alves-Pérez, M. T., García, M. J. y Mateos, R. (2013): "Suicidal Traits in MarilynMonroe's Fragments An LIWC Analysis", en Crisis. 34(2), páginas 124 a 130. DOI: $10.1027 / 0227-5910 / \mathrm{a} 000183$.

Fernández Lagunilla, M. (1985): Aportación al estudio semántico del léxico político: el vocabulario de los republicanos. Hamburgo: Verlag.

Fowler, J. H. y Dawes, C. T. (2008): “Two genes predict voter turnout", en The Journal of Politics, 70, 3, páginas 579 a 594.

García-Albea, J. E. (2011): “Usos y abusos de lo neuro”, en Revista Neurol., 52, 10, páginas 577 a 580.

García, M.C., Del Hoyo, M. y Fernández, C. (2014): “Jóvenes comprometidos en la Red: el papel de las redes sociales en la participación activa”, en Comunicar, 43, páginas 35 a 43.

Gayo Avello, D., Metaxas y Mustafaraj (2011): "Limits of Electoral Predictions Using Twitter. Association for the Advancement of Artificial Intelligence", en Proceedings of the Fifth International AAAI Conference on Weblogs and Social Media.

Gazzániga, M. (1993): El cerebro social. Madrid : Alianza Editorial.

Goldstein, P., and Rainey, J. (2010): “The 2010 elections: Twitter isn't a very reliable prediction tool", en Los Ángeles Times, 3 de noviembre.

Gómez, M. y Bandrés, E. (2014): “El neuromarketing: Una nueva disciplina para la investigación de audiencias y de la opinión pública", en Icono 14, vol.12, páginas 395 a 415.

Graesser. A. C., Gernsbacher, M. A., \& Goldman, S. (Eds.) (2003): Handbook of discourse processes. Mahwah, NJ: Lawrence Erlbaum Associates. 
Gunsch, M. A.; Brownlow, S.; Haynes, S. E.; y Mabe, Z. (2000). Differential linguistic content of various forms of political advertising. Journal of Broadcasting \& Electronic Media, 44, 27-42.

Hatemi, P. K. et al. (2011): "A genome-wide analysis of liberal and conservative political attitudes”, en Journal of Politics, 73, 1, páginas 1 a 15.

Jungherr, A. Jürgens, P. y Schoen, H. (2012): "Why the Pirate Party Won the German Election of 2009 or The Trouble With Predictions: A Response to Tumasjan, A., Sprenger, T.O., Sander, P.G. \& Welpe, I.M. "Predicting Elections With Twitter: What 140 Characters Reveal About Political Sentiment", en Social Science Computer Review. 30(2), páginas 229 a 234.

Jurafsky, D, y Martin, J. (2008): Speech and language processing. Englewood, NJ: Prentice Hall.

Lakoff, G. (2007): No pienses en un elefante. Lenguaje y debate politico. Madrid: Editorial Complutense.

Landauer, T., McNamara, D. S., Dennis, S. y Kintsch, W. (Eds.). (2008): Handbook of Latent Semantic Analysis. Mahwah, NJ: Lawrence Erlbaum Associates.

Lema, R. y Abascal-Mena, R. (2015): “Tuit, tuit, tuit, chabacanerías y @MLOVERS: Debate presidencial”, en Razón y Palabra, 88, páginas 1 a 64.

López Eire, J. y Guervós, J. (2000): Retórica y Comunicación Política. Madrid: Cátedra.

López Pumar, P.A. (2014): "Uso de Twitter por los alcaldes de las capitales de provincia españolas entre marzo y mayo de 2012", en Ámbitos, 26.

Mancera, A. y Pano, A. (2013): El discurso politico en Twitter. Madrid: Anthropos.

Míguez, M. I., Fernández, M. y Alves, M. T. (2013): “La actividad en Twitter de los partidos políticos en las elecciones gallegas", en Ledo, M.; Vasallo de Lopes, M. (eds.) Comunicación, cultura e esferas de poder. Santiago de Compostela: AssIBERCOM/ AGACOM, páginas 3.505 a 3.521.

Miller, J. M. (2007): "Examining the mediators of agenda setting: A new experimental paradigm reveals the role of emotions", en Political Psychology, 28, páginas 689 a 717.

Neuendorf, K.A. (2002): The content analysis guidebook. Thousand 
Oaaks (CA): Sage.

O'Connor, B.; Balasubramanyan, R.; Routledge, B. R., y Smith, N. A. (2010): "From tweets to polls: Linking text sentiment to public opinion time series", en Proc. of 4th International AAAI Conference on Weblogs and Social Media (ICWSM, 122-129).

Ochsner, Kevin N., \& Matthew D. Lieberman (2001): “The Emergence of Social Cognitive Neuroscience", en American Psychologist, 56, páginas 717 a 728. (DOI: http://dx.doi.org/10.1037\%2F0003066X.56.9.717).

Ortega, C.G. y Azagra R.Z. (2014): “a campaña virtual en Twitter: análisis de las cuentas de Rajoy y Rubalcaba en las elecciones generales de 2011”, en Historia y Comunicación Social, 19, páginas 299 a 311.

Otero, T.P. y Rolán, X.M. (2013): "Presencia, uso e influencia de los diputados del Parlamento de Galicia en Twitter", en Revista de Comunicación de la SEECI, 32, páginas 106 a 126.

Panagiotis et al. (2011): "How (not) to Predict Elections", en Privacy, Security, Risk and Trust. IEEE Third International conference on Social Computing.

Paulson, E. J. y Goodman, K. S. (1992). "Influential Studies in Eye-Movement Research". Disponible en: http:/ /www.readingonline.org/research/eyemove.html

Pennebaker, J.W. y Lay, T.C. (2002): "Language use and personality during crises: Analyses of Mayor Rudolph Giuliani's press conferences", en Journal of Research in Personality, 36, páginas 271 a 282.

Pérez, J.; Puentes-Rivera, I. y García, A. (2013): "Los candidatos en las elecciones gallegas en Twitter", en Ledo, M.; Vasallo de Lopes, M. (eds.): Comunicación, cultura e esferas de poder. Santiago de Compostela: AssIBERCOM/AGACOM, páginas 3.572 a 3.590.

Pinker, S. (2012): El instinto del lenguaje. Madrid: Alianza Editorial.

Ramírez Esparza, N. et al. (2007). La psicología del uso de las palabras: Un programa de computadora que analiza textos en Español (The psychology of Word use: A computer program that analyzes texts in Spanish). Revista Mexicana de Psicología, 24, 85-99.

Rebollo Torío, M. A. (1976): Estudios sobre el vocabulario político español. Cáceres: Universidad de Extremadura. 
Redondo et al. (2007): "The Spanish asdaptation of ANEW (affective norms for English words)", en Behavior Research Methods, 39 (3), páginas 600 a 605.

Rossini, J. C. y Galera, C. (2006): “Atención visual: estudios comportamentales de la selección basada en el espacio y en el objeto", en Estudios de Psicologia. vol.11, n.1, páginas 79 a 86.

Rúas Araújo, J. y Dapena González, B. (2013): “Los europarlamentarios españoles en la red”. En Rúas Araújo, J. y Alejandro Martínez, V.: Comunicación, política y redes en Europa. Oporto (Portugal): Mediaxxi Formalpress.

Rúas Araújo, J. y Dapena González, B. (2011): “Los Diputados del Parlamento Gallego en Facebook", en REDMARKA, Revista Digital de Marketing Aplicado, Año IV, Número 7, páginas 77 a 106. Rúas, J. (2011): Manual del candidato electoral. Madrid: Los Libros de la Catarata.

Sánchez García, F. J. (2012): Retórica parlamentaria española. Madrid: Editorial Síntesis.

Sexton, J. B. y Helmreich, R. L. (2000): “Analyzing cockpit communications: The links between language, performance, and workload", en Human Performance in Extreme Environments, 5, 63-68.

Slatcher, R. B., Chung, C. K., Pennebaker, J. W. y Stone, L. D. (2007): "Winning words: Individual differences in linguistic style among U.S. presidential and vice presidential candidates", en Journal of Research in Personality, 41, páginas 63-75.

Small, G. y Vorgan, G. (2009): El cerebro digital. Cómo las nuevas tecnologías están cambiando nuestra mente. Barcelona: Urano.

Santiago Guervós, J. de (1992): El léxico político de la Transición Española. Salamanca: Servicio de Publicaciones de la Universidad de Salamanca.

Serrano, N. y Balanzo, C. (2011): "Neurociencias y estrategia publicitaria: redefiniendo el rol del inconsciente", en Tripodos, 28, páginas 35 a 50.

Tausczik, Y. R. y Pennebaker, J. W. (2010). The Psychological Meaning of Words: LIWC and Computerized Text Analysis Methods, en Journal of Language and Social Psychology, 29, 1, 24-54.

Timoteo Álvarez, J. (2013): "Neurocomunicación: el factor 'Olla de Inducción' en los procesos de inteligencia conectiva”. En Neurocomunicación: Gestión de la Comunicación Social basada en las 
Neurociencias. Proyecto de Investigación CSO2011-28099. Plan

Nacional de I+D. Ministerio de Economía y Competitividad. Madrid: Fragua.

Tjong, E. y Bos, J. (2012): "Predicting The 2011 Dutchd Senate Election Results With Twitter", en Association for Computational Linguistics. Proceedings of the 13tj Conference of the European Chapter of the Association for Computational Linguistics, páginas 53 a 60.

Tumasjan, A; Sprenger, T; Sandner, Ph., Welpe, I. (2010):

"Predicting Elections with Twitter: What 140 Characters Reveal about Political Sentiment", en Association for the Advancement of Artificial Intelligence $(A A A I)$.

Van Essen, D. C., Anderson, C. H., y Felleman, D. J. (1992): "Information processing in the primate visual system: an integrated systems perspective", en Science, 255, páginas 419 a 423.

Vázquez Sande, P. (2013): "Alcaldes españoles en Twitter: ¿diálogo o monólogo?”, en Fonseca Journal of Communication, 7, páginas 44 a 71.

Yu, B., Kaufmann, S. y Diermeier, D. (2008). "Exploring the characteristics of opinion expressions for political opinion classification". Proceedings of the 2008 International Conference on Digital Government Research. Montreal, 82-91.

Zamora Medina, R. y Zurutuza Muñoz, C. (2014): “Campaigning on Twitter: Towards the Personal Style Campaign to Activate the Political Engagement During the 2011 Spanish General Elections”, en Comunication \& Society, 27(1), páginas 83 a 106.

- Nota: Este trabajo forma parte de las investigaciones desarrolladas por la Red Internacional de Investigación de Gestión de la Comunicación (R2014/026 XESCOM), proyecto financiado en régimen de concurrencia competitiva por la Consellería de Cultura, Educación e Ordenación Universitaria de la Xunta de Galicia, con la participación de los grupos Novos Medios de la Universidad de Santiago de Compostela, iMARKA de la Universidad de A Coruña y NECOM y MILE de la Universidad de Vigo. 


\section{Hacia una epistemología de la economía de la participación: la importancia de compartir noticias}

José Manuel Noguera, Universidad Católica de Murcia (UCAM, España),jmnoguera@ucam.edu

\section{Resumen}

La forma en la que consumimos las noticias y usamos los medios ha cambiado radicalmente en los últimos años. Procesos como la recomendación social de contenidos, el consumo multipantalla -sin tener ya muy claro cuál es realmente la primera pantalla- o la creciente variedad de formas de participación de los usuarios con los cibermedios hacen necesario un nuevo paradigma científico para las ciencias de la comunicación en general y el periodismo en particular. Con este capítulo, se propone el marco conceptual de la economía de la participación como uno de los más idóneos para abordar de forma sistemática y rigurosa el estudio de la participación de la audiencia. Se recogen las investigaciones y tendencias más significativas para defender este nuevo paradigma científico del periodismo: por qué y cómo compartimos las noticias.

Palabras clave: economía de la participación, cibermedios, audiencias, periodismo.

\section{Introducción}

A NTE el escenario actual de medios y sobre todo, ante el que nos 1 viene, cada vez se hace más necesaria la investigación científica sobre los procesos por los que la audiencia comparte contenidos 
mediáticos. Mostrar esa necesidad y revisarla bajo un nuevo contexto es el objetivo principal de este capítulo. El fenómeno de compartir contenidos en la Web no es en absoluto novedoso, pero los últimos años han mostrado un creciente interés por introducir estas dinámicas dentro de los procesos de generación de valor de los medios de comunicación. Si bien a priori se podría pensar que compartir una noticia (o un vídeo, una foto o un informe) forma parte de la esfera de lo lúdico o el mero entretenimiento (me gusta compartir, para mi eso es Internet, podría ser una afirmación que resumiese ese enfoque), estudios como The Psichology of Sharing (The New York Times, 2011) se han encargado de recordarnos que compartir un texto está más asociado al propio consumo y comprensión de la noticia que a cualquier otro proceso mental. De hecho, en esa investigación, realizada sobre 2500 personas, hasta un $73 \%$ de los sujetos analizados contestó que pensaban sobre un contenido de una forma más "profunda", más "a fondo", cuando lo compartían. Además, hasta un $85 \%$ señaló que leer las respuestas y comentarios de otras personas les ayudaba a comprender mejor un contenido informativo.

Los datos señalados son de especial relevancia para el objetivo de este capítulo, que pretende enfocar el hecho de compartir contenidos informativos no desde el ámbito de lo privado, el entretenimiento o la gestión de comunidades online, sino como una parte esencial y propia del consumo de noticias. Es una perspectiva que se ha trabajado para diversos sectores desde la llamada "economía de la participación" (Noguera et al., 2014) y que sin embargo sigue siendo novedosa en lo periodístico, donde los estudios son escasos. Desde este enfoque se podría afirmar, en otras palabras, que si bien compartir una noticia no siempre es consumirla, cada vez más sí deberíamos considerar que consumir una noticia implica, inevitablemente, compartirla de algún modo. Este capítulo explora los primeros acercamientos científicos a este fenómeno desde la óptica de las ciencias de la comunicación y por tanto subraya, con especial énfasis, la importancia de reclamar un lugar para la investigación científica sobre cómo y por qué son más compartidos determinados contenidos periodísticos por la audiencia frente a otros. En ese sentido, este capítulo pretende ser un pequeño avance crítico de la literatura más significativa que se está empezando a generar sobre este 
fenómeno, junto con algunas reflexiones personales a modo de conclusiones y pistas para futuros estudios.

El carácter líquido del actual ecosistema de medios no ha pasado desapercibido para grandes autores en los últimos años. Cabe reseñar como punto de inflexión significativo las aportaciones de Jenkins, Ford y Green (2013), acuñando los spreadable media como el paradigma de los medios digitales contemporáneos, donde la capacidad de compartir contenidos es una de las más palpables. Si bien estos autores no ponían el foco en el periodismo, ya esbozaban los numerosos desafíos y oportunidades que afrontaban áreas afines de la comunicación -como marketing, publicidad o industrias culturales-, tanto empresas como ciudadanos, ante la posibilidad de influir en la jerarquía, visibilidad o credibilidad de los contenidos con sus acciones en red. Sin apenas darnos cuenta, el foco mediático sobre los contenidos generados por el usuario (User-Generated Content) estaba migrando hacia otro tipo de acciones, los contenidos distribuidos por el usuario (User-Distributed Content).

Apenas encontramos referencias explícitas al user-distributed content en la literatura especializada de ciencias de la comunicación, salvo unas pequeñas excepciones (Napoli, 2009) que son, en todo caso, un mero acompañamiento al verdadero concepto protagonista hace apenas cinco años, el contenido generado por usuario, más comúnmente sintetizado de forma arriesgada como periodismo ciudadano.

Una de las primeras pistas que nos alerta sobre la necesidad de investigar más y mejor sobre cómo se comparten los contenidos es el hecho de que, por ejemplo, las vías de entrada a los medios de comunicación pueden ser muy diversas. Por tanto, conceptos que proceden de medios y consumos tradicionales están perdiendo parte de vigencia y lógica. El valor de la portada (bomepage) en los medios digitales cada vez es menor. Por ejemplo, sólo un tercio de los lectores de www.nytimes.com la ha visitado alguna vez (The New York Times, 2014). Esto no debería interpretarse de forma obligada como malas noticias para el periodismo, más bien, se trata de un cambio drástico en las pautas de consumo de noticias en la Web. La información cada vez es más periférica tanto en su difusión como en su acceso (buscadores, agregadores, redes sociales, páginas personales...), a la vez que la recomendación social ejerce con fuerza como criterio que define qué leemos y cuándo lo leemos. La marca del medio del que 
proceden las noticias se enfrenta a otras de renovado auge, como son la marca personal del periodista y la de los prescriptores de cada comunidad de seguidores, a su vez diferentes en cada plataforma social y que con sus acciones no dejan de influir sobre el consumo informativo que hacemos a diario.

\section{Compartir noticias en un nuevo ecosistema de medios}

Desde la llegada del periodismo a Internet, los medios han intentado pensar nuevas prácticas narrativas que fueran nativas del entorno digital (por ejemplo durante marzo de 2015 The New York. Times abrió una cuenta principal en Instagram buscando, según su nota de prensa el 9 de marzo, experimentar con la narrativa propia de esta red social). Los medios también han proporcionado numerosos espacios para recibir y gestionar contenido creado por sus audiencias, pero hasta ahora no existía una gran preocupación acerca de cómo se estaba produciendo el consumo de los contenidos propios y sobre todo, cómo se estaba compartiendo. El último informe interno de innovación en The New York Times, encargado por Jill Abramson a Arthur G. Sulzberger y filtrado a mediados de mayo de 2014, alertaba desde sus primeras páginas de la necesidad de crear una cultura periodística para no ser sólo los mejores creando contenido (un objetivo que se entiende como obvio en cualquier redacción), sino también compartiendo contenido y fomentando ese fenómeno. Las palabras del equipo de Sulzberger, que había estado trabajando durante seis meses para elaborar una nueva estrategia de innovación digital en el medio, estaban claramente enfocadas a dejar claro que compartir el contenido y promocionarlo es una tarea más periodística que de marketing:
"en Times, el descubrimiento [de contenido], la promoción y la participación se han dejado a un margen, normalmente para los compañeros del área de negocio o en manos de pequeños equipos de la Redacción. Negocios tiene un rol importante que desempeñar, pero la Redacción tiene que reclamar su lugar en este asunto, porque cómo presentar, promocionar y compartir nuestro periodismo es algo que necesita una supervisión editorial" (The New York Times, 2014: 23-25). ${ }^{5}$

\footnotetext{
${ }^{5}$ Traducción propia, texto original: “... at The Times, discovery, promotion and engagement have been pushed to the margins, typically left to our business-side
} 
El consultor y director de Nieman Journalism Lab, Joshua Benton, interpreta estas palabras con un diagnóstico tajante: "En el Times se debe hacer un mejor trabajo fomentando el intercambio de contenidos" (2014). Además, añade que esta tarea está muy ligada a saber re-empaquetar viejos contenidos en nuevos formatos. Por ejemplo, Times hizo el experimento con unos reportajes sobre tráfico sexual que databan de 1996. Tras la adaptación, estos artículos superaron las 450.000 páginas vistas en sólo seis días y los usuarios permanecieron en ellos una media de 2 minutos y 35 segundos. Para Benton, este gran éxito se debió a que los lectores se habían animado a compartir esas historias en los medios sociales (2014).

Como ilustra el anterior ejemplo, en un escenario de incertidumbre ante los futuros modelos de negocio que necesita el periodismo, hay motivos para ocuparse de las claves por las que un usuario se decide a compartir lo que ha leído entre sus contactos. La recomendación social en la Web es un fenómeno que siempre ha estado a la sombra del impacto mediático de los contenidos creados por los ciudadanos. Dar a éstos la responsabilidad de crear contenidos para los medios puede derivar en productos puntualmente valiosos pero que no dejan de representar algo residual dentro de la rutina de un medio profesional. Sería la derivación periodística de la regla del 90-9-1 en la Web, donde para un sitio web en concreto el 1\% de su comunidad crea contenido, el 10\% lo edita de algún modo y el $90 \%$ no hace nada (Nielsen, 2006).

En cambio, el fenómeno de cómo la audiencia comparte los contenidos que le atraen afecta directamente al periodismo tal y como lo conocemos hoy, ya que influye tanto en la creación de las historias como en su forma de difusión y por tanto, también en su alcance e impacto final. El periodismo y los periodistas necesitan comprender mejor cómo sus contenidos pueden llegar más lejos gracias a las acciones de su audiencia. Una de las consecuencias de este proceso sería asumir un entorno periodístico donde las noticias son un producto premeditadamente inacabado, en constante edición,

colleagues or handed to small teams in the newsroom. The business side still has a major role to play, but the newsroom needs to claim its seat at the table because packaging, promoting and sharing our journalism requires editorial oversight". 
desembocando en formas más abiertas y colaborativas de periodismo, de lo que podría denominarse un "end-user journalism" (Noguera, 2013).

\section{Del paradigma del User-Generated Content al del User- Distributed Content}

Entre los diferentes roles que la audiencia ha ido adoptando dentro del proceso periodístico, es sin duda la capacidad para producir contenidos la que mayor interés mediático ha despertado. En consecuencia, se multiplicaron las investigaciones sobre las audiencias prosumidoras, adjetivo creado desde el ámbito anglosajón por Alvin Toffler en la década de los setenta y popularizado más tarde, aprovechando las posibilidades de la Web 2.0, por diversos autores (Bruns, 2009; Ritzer, 2010). Al margen del prosumer y en paralelo, la etiqueta que más ha calado para contextualizar el papel activo de las audiencias en la generación de contenido periodístico ha sido sin duda la tan aceptada y mediática etiqueta de "periodismo ciudadano".

Este término -acuñado curiosamente desde los propios periodistas y no tanto desde la ciudadanía- ha sido abordado desde puntos de vista informativos, filosóficos, tecnológicos, empresariales, deontológicos o incluso, legales. La investigación sobre el periodismo ciudadano tiene un marco de referencia mayor desde el concepto de contenido generado por el usuario (user-generated content), cuya investigación ha sido intensiva y extensiva a lo largo de los últimos años, en la mayoría de las ocasiones conectada a ese periodismo ciudadano (Outing, 2005; Papandrea, 2006; Allan, 2007; Carpenter, 2008; Goode, 2009; Lewis et al., 2010; Khamis y Vaughn, 2011). Conviene destacar, para una certera aproximación al fenómeno de la generación de contenidos ciudadanos para los medios, el estado de la cuestión realizado por García de Torres (2010).

Sin embargo, cada vez son más habituales y crecientes las menciones a un escenario más rentable y menos explorado desde el punto de vista de los medios: los flujos de la comunicación periodística cuando es la propia audiencia la que se encarga de difundir la información. En otras palabras, el contenido distribuido por el usuario (user-distributed content). El paradigma de la producción por parte de las audiencias mantiene su vigencia y sigue depurando su investigación en busca de aquellas fórmulas más novedosas para motivar y coordinar los contenidos de la audiencia, pero el fenómeno 
de la distribución de esos contenidos, en un escenario mediático cada vez más ubicuo, móvil y multiplataforma, cuando menos parece tener la misma importancia estratégica para los medios -si no más-.

Los usuarios suficientemente motivados para ser productores de contenido acaban siendo una parte residual del total, pero son muchos más aquellos que se deciden a ampliar su difusión ya que lógicamente, marcar un Me gusta o un RT supone menos esfuerzo. Existe literatura científica de referencia que se ha preocupado de abordar los perfiles de los usuarios más activos en la Web a la hora de compartir contenido (Hargittai y Walejko, 2008), pero hasta ahora no son muchas las referencias que lo han sistematizado como un flujo permanente de contenido distribuido por los usuarios -lo que implicaría un énfasis en destacar que no se trata de un contenido producido por esos mismos usuarios-.

Las primeras referencias explícitas al contenido distribuido por el usuario aparecen vinculadas a la publicidad y a la necesidad de encontrar nuevos modelos de negocio para los medios digitales (Bhattacharya et al., 2006). A partir de ahí sigue mencionándose el concepto, todavía subordinado al fenómeno de la generación de contenidos ciudadanos (Jensen, 2007), aunque ya aparecen algunas voces que subrayan como verdadera disrupción no los nuevos modelos de producción de contenidos, sino cómo son distribuidos por los propios usuarios: "la verdadera novedad radica en la distribución y la estructuración del contenido por los usuarios, por eso preferimos el término user-distributed content para subrayar lo novedoso" (Mabillot, 2007: 43). ${ }^{6}$

Este alegato para profundizar en el estudio de la difusión ciudadana no recobra vitalidad hasta un par de años más tarde cuando Napoli (2009), al igual que hizo Mabillot (2007), pone el poder de distribución de los usuarios individuales por encima de su capacidad de producción. Posteriormente, se publican investigaciones donde se nombra el concepto para recordar su importancia estratégica en los ámbitos de la ciberdemocracia (Carpenter, 2010) y la distribución de música por Internet (Schaedel y Clement, 2010). En un ámbito más divulgativo y reciente, el profesor Alfred Hermida recupera el punto

\footnotetext{
${ }^{6}$ Traducción propia, texto original: "the real originality lies in the distribution and structuring of the content via the users, so that we should prefer the term "user distributed content" to underline the real novelty".
} 
de vista periodístico poniendo el foco sobre el fenómeno de la compartición de contenidos en las redes sociales (2014), mientras la periodista Delia Rodríguez lo hace desde la perspectiva de la viralidad y los memes (2013). Jenkins, Ford y Green (2013) plantean de forma muy ilustrativa el cambio de paradigma ya que, si en los inicios de la Web el gran valor de los medios era demostrar su capacidad de adherencia (que los visitantes no abandonaran la página), en una era interconectada y multiplataforma el desafío se ha desplazado al otro extremo: ser lo más expandible posible (spreadable).

Buena parte de esa capacidad para expandir los contenidos depende del tipo de comunidad que rodea a cada medio y es en este punto donde cobra importancia entender los mecanismos que activan la participación de los usuarios. Entender cómo y por qué se comparten ciertas noticias más que otras es algo que formará parte, más pronto que tarde, de las habilidades básicas que deberá tener cualquier periodista digital o, directamente, cualquier periodista. Dicha capacidad repercute directamente en las fases de producción, edición y distribución, es transversal a todas las figuras de la redacción y supone un contacto directo con la audiencia, con sus reacciones sobre cada tipo de contenido. En este sentido, el fundador de la productora de contenidos web El Cañonazo Transmedia, Roger Casas-Alatriste, nos explicó su visión acerca de las motivaciones por las que los usuarios comparten contenido en las redes sociales y por tanto, qué tipo de contenidos se producen en su empresa: ${ }^{7}$

"¿Qué compartimos en las redes sociales? Cosas que nos hagan mejor personas. Puede parecer una cosa muy seca y radical pero si hacemos un pequeño análisis, nuestra vida es maravillosa en las redes sociales (...) hacemos cosas en las redes sociales que nos hacen parecer más graciosos, más interesantes, más gourmet, o más comprometidos políticamente. Y es la misma moneda social de los conocimientos que compartimos por ejemplo en un bar. Por lo tanto, en nuestro caso, creamos contenidos que la gente tiene impulso de ir a consumir, y luego, la segunda vuelta de tuerca "OK, he ido, lo he consumido, y me representa. Y como me representa voy a ponerlo en mi muro de Facebook, porque me hace parecer una persona más interesante, más divertida, más comprometida, más gourmet".

\footnotetext{
${ }^{7}$ Entrevista personal realizada el 13 de junio de 2014.
} 
El análisis de Casas-Alatriste, genérico para cualquier tipo de industria cultural, bien podría valer para repensar por qué se comparten determinados contenidos periodísticos más que otros. En primer lugar, es necesario destacar que la industria de medios al menos ya parece haberse dado cuenta de la importancia del fenómeno. ¿Por qué se comparten mis contenidos? ¿Por qué no? ¿Qué podría hacer para facilitar la compartición de mis contenidos? Diversas iniciativas de los medios en los últimos años demuestran la plena conciencia sobre estas cuestiones.

\section{Hacia una industria periodística de flujos}

A principios de 2014 y en el marco del XV Congreso de Periodismo Digital de Huesca, el periodista francés Jean Fraçois Fogel pronunció una conferencia dirigida a profesores universitarios de periodismo y periodistas principalmente, se titulaba "El flujo y el stock" y con ella ofreció una destacada reflexión para advertir de la coexistencia de dos tipos de industrias de contenidos: las que producen un stock (los medios) y las que producen flujos (las redes sociales).

La industria de flujos explicada por Fogel (2014) permite una breve reflexión acerca de los modelos de empresas ligadas a la comunicación y que han triunfando en la Web. Por señalar solo las más evidentes, si nos detenemos en qué es lo que tienen en común gigantes como Google, Facebook o Twitter, podríamos decir que son modelos donde lo importante no es generar contenido, ya que es la propia audiencia quien lo genera directa o indirectamente, por lo que la clave radica en ser un buen filtro de contenido de terceros y propiciar las mejores condiciones para que sea visible y permanezca en circulación.

Cabe en este punto un matiz entre difusión y circulación. El primer concepto podría ubicarse de forma natural en el ámbito de los medios de comunicación tradicionales, donde la producción informativa tiene un origen y cada medio lo hace llegar hasta donde le es posible. Tiene, por tanto, un componente de linealidad que implica un inicio y un fin. No es el mismo caso cuando hablamos de circulación de contenidos. Con esta expresión hacemos referencia no a una linealidad, sino a procesos en constante retroalimentación donde, por ejemplo, contenidos viejos son renovados por una parte de la audiencia y a partir de esa actualización, compartidos en masas con pequeñas ediciones en 
algunos casos. La circulación es el paradigma de las industrias de flujos, de cómo se consume la información en las redes sociales. Y además, sería la evolución de esa difusión en la Web que resulta insuficiente frente a aquellos contenidos de medios que, gracias a sus comunidades activas, sí son compartidos y representan una fuente de consumo contemporáneo de noticias: la recomendación social. Aunque corremos el riesgo de consumir un diario personalizado más sesgado que nunca en la medida en que podamos confundir nuestro timeline o muro con la realidad, también es cierto que por la vía de esa recomendación social nos acercamos a contenidos de cabeceras informativas que nunca consumimos.

Por los motivos citados, en ese paradigma de consumo social marcado por contenidos recomendados por nuestros contactos, los medios necesitan convertirse un poco en una industria de flujos, tal y como explicaba Fogel. No se trata de que cada medio esté obligado a ser una red social, sino de implicar a su comunidad de usuarios más activos dentro de la experiencia social ligada a esas contenidos, una experiencia que permitirá que esos contenidos empiecen a circular de forma natural en el ingente cauce de los numerosos contenidos que compartimos a diario en la Web.

Podría pensarse, por último, que este escenario idílico de noticias compartidas solo sería posible para los denominados contenidos blandos (soft news), siendo muy improbables para los duros (bard news). Pero si se entiende que en Internet, al igual que proponen las narrativas transmedia, los contenidos tienen diversas puertas de entrada (una galería de imágenes, una infografía, un breve vídeo, una fotografía...), entonces parece más asumible que los contenidos aparentemente más duros también entren dentro de esa denominada industria de flujos de contenidos compartidos. Otra visión, menos idílica, subrayaría cómo muchas redacciones apenas disponen de recursos humanos para cubrir noticias de un modo convencional y mucho menos, por tanto, para experimentar con nuevas puertas para su consumo. La otra cara de la moneda serían los numerosos medios creados desde el periodo 2007-2008 y que, apostando por la especialización, sí están logrando arroparse rápidamente por comunidades activas de usuarios. 


\section{La investigación sobre contenido distribuido por las audiencias}

Las mencionadas comunidades activas de usuarios que se forman alrededor de los medios digitales (especialmente de aquellos nativos de la Web), están protagonizando procesos de consumo informativo que afectan directamente a la difusión de los contenidos. La investigación sobre cómo y por qué se comparte contenido en la web no es tan numerosa como en otros ámbitos periodísticos, pero sí disponemos ya de algunos puntos desde los que plantear un desarrollo sólido de lo que podríamos entender como la epistemología de una economía de la participación, que en el ámbito periodístico tiene el hecho de compartir una de sus variables clave.

La idea de que para los medios de comunicación es más rentable implicar a su audiencia en la circulación del contenido y no tanto en su producción podría parecer nueva a la luz del auge mediático que tuvo el denominado periodismo ciudadano (donde se apelaba justo a lo contrario), pero lo cierto es que ya tiene cierto recorrido (Singer et al., 2011; Villi, 2012). La expresión user-distributed content o contenido distribuido por usuario, ya hacía mención a este planteamiento (Napoli, 2009).

Más allá de la popularidad de plataformas específicas y de su protagonismo a la hora de compartir contenido en la Web, a lo que estamos asistiendo es a un cambio en las pautas de consumo, donde se está añadiendo una experiencia social concreta. En otras palabras, compartir contenido para muchos usuarios ya es una parte inherente a su consumo. Facebook, YouTube, Twitter, WhatsApp y Google+ son las redes preferidas para compartir noticias en muchos países (Newman y Levy, 2014). Más allá de escenarios puntuales, un hecho característico común de todas estas plataformas puede ser, desde el punto de vista periodístico, cómo todas ellas suponen hábitos de consumo diferentes, basados en la interconexión entre los usuarios y el consumo fragmentado.

Existe un creciente interés por el estudio de las dinámicas de consumo en un escenario multiplataforma y cómo las acciones de los usuarios modifican la escala de valores y prioridades para los medios de comunicación (Bechmann, 2012; Noguera et al., 2013), pero aún no se puede decir que exista una literatura científica lo suficientemente 
amplía y a la vez acotada al fenómeno como para constituir un marco conceptual de relevancia.

Entender el consumo de medios como una experiencia social compartida (Hermida et al., 2012: 5; Villi, 2012: 627) es un paradigma muy válido para entender estas nuevas rutinas de consumo que están en gran parte determinadas por cómo se comparten los contenidos en la Web. Hay por otro lado quien ya ha sabido señalar qué medios están entendiendo las reglas tácitas de estos flujos de información, para denominarlos como spreadable media (Jenkins, Ford y Green, 2013). Frente a estos medios nativos de la Web también se encontrarían aquellos para los que la circulación de contenidos no es una oportunidad sino un problema, como sería el caso de aquellos modelos de negocio que buscan premiar al suscriptor del medio de papel (Villi y Hayashi, 2014).

Los contenidos compartidos abren además un nuevo ámbito de analítica web que puede ofrecer rendimientos aún inexplorados para el periodismo. El denominado friendcasting (Lee y Cho, 2011) supone mucho más que un renovado Two-Step Flow informativo, es la prueba palpable de que nuevos escenarios mediáticos plantean consumos diferentes. El "friendcasting de las noticias" supone la agenda de muchos ciudadanos en la actualidad y paradójicamente, aún no tenemos un marco conceptual de referencia con el que estudiarlo.

\section{Conclusiones}

Como ha pretendido reflejar este capítulo, la investigación sobre el impacto en el periodismo de las formas de compartir contenido apenas se encuentra en un estado incipiente. El friendcasting no es más que una aplicación de la denominada economía de la participación en el ámbito de las coberturas informativas. Pero sin un marco teórico sólido, la investigación relevante está por hacer y el presente capítulo es una invitación para futuros estudios en torno a este fenómeno.

Tras lo reseñado anteriormente, parece oportuno concluir con ciertas recomendaciones que pueden ser útiles para alcanzar un verdadero conocimiento de los fundamentos y métodos útiles para estudiar la economía de la participación en un ecosistema de medios. Dichas pistas, resumidas en cinco enunciados, son las siguientes: 
1. Hay que estudiar el proceso de compartir noticias de forma sistémica, no como acciones aisladas en el consumo de medios del individuo.

2. Es necesario identificar variables basadas en la comprensión del producto informativo, no en el mero carácter lúdico de compartir (entretenimiento) o en su componente identitario (prestigio).

3. La investigación en torno a las dinámicas por las que se consumen y comparten contenidos, aunque debe ser sistémica y entender el consumo informativo de forma holística en su realidad multiplataforma, necesita acercarse a este fenómeno desde diferentes niveles tales como las motivaciones, los contenidos o el estudio de redes de influencia originadas a partir de estos procesos.

4. La relación con los medios tradicionales debe ser vista desde una perspectiva de complementariedad y no de sustitución. En muchos casos, un titular compartido fugazmente en Twitter o Facebook sigue con un consumo más pausado de un reportaje en prensa escrita o un programa de televisión.

5. Como en tantos otros ámbitos, la investigación centrada en este fenómeno debe ir más allá de hipótesis cuantitativas y de meros datos, para ahondar en las motivaciones, las causas y las características de aquellos contenidos de medios que son compartidos por la audiencia, así como entender dicho proceso como parte inherente del consumo.

Para el periodismo y dentro de una verdadera economía de la participación, la actividad clave del periodista y el medio no acaba al publicar en la Web, sino que empieza precisamente en el momento de la publicación.

\section{Referencias bibliográficas}

Bechmann (2012): “Towards Cross-Platform Value Creation”, en Information, Communication \& Society, 15(6), páginas 888 a 908.

Fogel, J. F. (2014): “El flujo y el stock”. Conferencia en el XV Congreso de Periodismo Digital de Huesca. Marzo de 2014.

Hermida, A.; Fletcher, F.; Korrell, D. y Logan, D. (2012): "Share, Like, Recommend: Decoding the social media news consumer", en Journalism Studies, 13(5), páginas 815 a 824. 
Jenkins, H.; Ford, S. y Green, J. (2013): Spreadable Media. Creating value and meaning in a networked culture. Nueva York: New York University Press.

Lee, S. y Cho, M. (2011): "Social Media Use in a Mobile Broadband Environment. Examination of Determinants of Twitter and Facebook Use", en International Journal of Mobile Marketing, 6(2), páginas 71 a 87.

Napoli, P. M. (2009): "Navigating producer-consumer convergence: Media policy priorities in the era of user-generated and user-distributed content", en Communications and Convergence Review, 1(1), páginas 32 a 43.

Newman, N. y Levy, D. (2014): Reuters Institute Digital News Report 2013: Tracking the Future of News. Reuters Institute for the Study of Journalism, University of Oxford.

Noguera, J. M.; Villi, M.; Nyiro, N.; De Blasio, E. y Bourdaa, M. (2013): "The role of the media industry when participation is a product". En Carpentier, N., Schroder, K. y Hallett, L. Audience Transformations. Shifting Audience Positions in Late Modernity. Routledge Studies in European Communication Research and Education, páginas 172 a 187.

Noguera, J. M.; Martínez, J.; Nicolás, M. A.; Pérez, M.; Gómez, A.; Grandío, M.; Hernández, F. y Del Henar, P. (2014): Economía de la Participación. Madrid: Fundación EOI.

Rodríguez, D. (2013): Memecracia. Barcelona: Gestión 2000.

Scolari, C. (2013): Narrativas transmedia. Cuando todos los medios cuentan. Deusto.

Singer, J.; Domingo, D.; Hermida, A.; Heinonen, A.; Paulussen, S., Quandt, T., Reich, Z. y Vujnovic, M. (2011): Participatory Journalism: Guardian Open Gates at Online Newspapers. Chichester, Reino Unido: WileyBlackwell.

The New York Times (2011): The Psichology of Sharing. Why Do People Share Online?. Nueva York: Customer Insight Group.

Villi, M. (2012): "Social Curation in Audience Communities: UDC (User-distributed Content) in the Networked Media Ecosystem", en Participations: The International Journal of Audience and Reception Studies, 9(2), páginas 614 a 632.

Villi, M. y Hayashi, K. (2014): "The Mission is to Keep this Industry Intact: Digital Transition in the Japanese Newspaper Industry", en 64 Congreso Anual de ICA, Seattle, Washington, 22-26 mayo de 2014. 


\section{$\Upsilon 4$ \\ Periodismo total: móvil y enredado}

Xosé López García, Universidad de Santiago de Compostela (USC, España),xose.lopez.garcia@usc.es

Ana Isabel Rodríguez Vázquez, Universidad de Santiago de Compostela (USC, España), anaisabel.rodriguez.vazquez@usc.es

\section{Resumen}

Las redes sociales reinan en la constelación comunicativa del tercer milenio. Todo apunta a que les queda larga vida en la comunicación mediada tecnológicamente. Quizá por ello la industria de los medios tradicionales de comunicación ha pasado de mirar de reojo a las redes sociales generalistas, en el momento de su aparición y en la primera fase de su popularización, a darles prioridad en el diseño de sus estrategias de actuación, tanto para la difusión como para el trabajo informativo. El motivo ha sido el creciente incremento de las visitas de usuarios a los cibermedios desde las redes sociales y el convencimiento de que estas plataformas comunicativas han venido para quedarse. Estas calles virtuales que enredan el ciberespacio se han revelado como un escenario central no solo en el funcionamiento del ecosistema comunicativo actual sino en buena parte de las estrategias de los actores económicos, sociales y políticos, lo que contribuye a construir una nueva cultura marcada por el eco de los enredados ${ }^{8}$. Su

\footnotetext{
${ }^{8}$ Este artículo forma parte de la divulgación de los resultados del proyecto de investigación del Ministerio de Economía y Competitividad titulado "Innovación y desarrollo de los cibermedios en España. Arquitectura de la interactividad
} 
sombra acompaña buena parte de las iniciativas en el ecosistema comunicativo?

Palabras clave: periodismo, ciberperiodismo, periodismo móvil, redes sociales.

\section{Introducción}

W $\mathrm{L}$ presente de los procesos comunicativos mediados ecosistema comunicativo ha encontrado en ellas un elemento más que rodea el núcleo central del entramado que alimenta los flujos de mensajes de la sociedad en red. No cabe duda de que las redes sociales transformaron la forma de comunicarse de muchos ciudadanos en la sociedad que gira alrededor de Internet. A medida que pasan los años de la segunda década del tercer milenio, cobran más fuerza como eje de difusión y gestión de todo tipo de mensajes de comunicación, al tiempo que incrementan su importancia en el panorama periodístico. Los medios informativos online están en las redes y sus periodistas las incorporaron a sus rutinas de trabajo diarias.

El éxito de la comunicación desde los dispositivos móviles inyecta actividad a las redes sociales. Los datos del Informe de la Sociedad de la Información en España que elabora la Fundación Telefónica indican que más de la mitad de los españoles utiliza Internet a diario, que el 77 por ciento de los jóvenes no sale de casa sin el móvil y que el 45 por ciento de los usuarios de smartphones de nuestro país se conecta diariamente a las redes sociales y que un 25 por ciento utiliza este dispositivo para realizar compras (2014: V-7-6668). Es la confirmación del éxito de la movilidad, que gana enteros a medida que pasa el tiempo y que se muestra como un complemento de los dispositivos fijos.

periodística en dispositivos múltiples: formatos de información, conversación y servicios". Referencia: CSO2012-38467-C03-03.

${ }^{9}$ Este texto está basado en un artículo elaborado por los autores con el título "Estrategias de los diarios online de proximidad para las redes sociales: el caso de La Voz de Galicia” y en los resultados de la observación no participante para el proyecto de investigación con la referencia CSO2012-38467-C03-03. 
A los usuarios, en muchos momentos de su vida diaria, les resulta más fácil intervenir de la mano de los nuevos dispositivos móviles. De ahí que el progresivo incremento de estos artilugios esté alimentado nuevos usos y consumos comunicativos en los que las redes sociales generalistas y las especializadas están no solo presentes, sino que sus escaparates de mensajes se han convertido en un importante almacén por el que, a modo de punto de encuentro, pasan muchos usuarios con el fin de encontrar las piezas más insospechadas, hacer un pequeño viaje comunicativo y entablar una conversación multidireccional. Es una tendencia que avanza con fuerza.

El potencial de crecimiento de los dispositivos móviles, según el mencionado informe de la Fundación Telefónica, permite suponer que en los próximos años incrementarán su protagonismo. En Europa, en diciembre de 2012, los datos ya indicaban que el 75 por ciento de los móviles que se vendían eran smarphones. Las previsiones apuntan que en el presente año 2015 la venta de tablets en el ámbito mundial supere al de ordenadores personales en su conjunto y que en el año 2017 serán un 20 por ciento más elevadas (2014: 7). Su protagonismo como terminal de acceso y producción parece evidente, lo que permite suponer que incidirá en el acceso e intervención en el funcionamiento de las redes sociales.

El potencial del uso de estas plataformas como canal de difusión de los mensajes periodísticos, como espacio de búsqueda de temas y de fuentes informativas, y como interacción para una renovada relación con los usuarios ha animado a los responsables de los medios a diseñar estrategias para estos nuevos espacios de la comunicación mediada tecnológicamente en una fase en la que las cabeceras tradicionales atraviesan por una importante crisis y el tránsito a la sociedad en red se ha convertido en una turbina de mudanzas que exige constante innovación para no perder el tren del futuro. La delicada situación de los medios, que inicialmente se desentendieron de las redes sociales, aparece como uno de los principales motivos del cambio de tendencia en la actuación de la industria, que ha contemplado como la consolidación de la sociedad enredada constituye una característica de la evolución de una sociedad que ha abrazado a Internet como paradigma de la comunicación total y mundial. 
A medida que las redes han ido formando parte del centro neurálgico de las sociedades actuales, los medios han dado pasos para aprovechar estas plataformas de comunicación que han desarrollado un nuevo modelo de negocio basado en la interacción y el intercambio social que se ha unido a la economía de la atención y la publicidad procedente de los medios tradicionales (Campos, 2013: 359). El potencial informativo y comunicativo que han demostrado estas redes en las conocidas como "revueltas árabes" que comenzaron en la primavera de 2011, confirmándolas como una alternativa a la censura oficial, (Soengas, 2013: 1-10), les ha catapultado al primer plano de los debates públicos sobre alternativas a los modelos de control informativo ejercidos por los gobiernos de muchos países. Fue el espaldarazo definitivo para este nuevo entramado comunicativo al que muchos acuden para hacer visibles sus iniciativas.

\section{La estrategia periodística}

Las redes sociales siguen conquistando espacios. Aunque no nacieron con fines periodísticos y a pesar de que muchos profesionales de la información las minusvaloraron en sus inicios, pronto mostraron sus ventajas comunicativas para un modelo de sociedad enredada y para un mayor eco del trabajo periodístico. Su capacidad para hacer más visibles hechos relevantes ha sido un factor determinante para que muchos periodistas y medios abrazasen las redes sociales como compañeras de viaje en la búsqueda de renovadas informativas y económicas que permitan vencer los desafíos colocados por el escenario de crisis actual. Los profesionales más jóvenes pronto mostraron vías para sacarles partido en la labor de recogida, producción, difusión y gestión de los mensajes periodísticos.

La evolución de los usos y consumos informativos parecen darle la razón a estos profesionales más jóvenes que apostaron desde el primer momento por las redes sociales. El motivo parece evidente. Como ha quedado legitimado socialmente durante más de un siglo, el papel del periodista en las sociedades actuales, al igual que la era industrial, consiste, básicamente, en contar lo que pasa en la sociedad, es decir, tiene que explicar los hechos mediante unas técnicas sedimentadas y asumidas profesionalmente y socialmente como las más adecuadas para garantizar la indagación de aquello que hay detrás de los hechos puntuales y su contextualización a fin de que los 
ciudadanos puedan entender las complejidad de esos acontecimientos y formar su criterio. Y este trabajo lo hace en la sociedad de la conectividad, con la ubicuidad de la comunicación en muy diferentes lugares de fácil acceso y con unos usuarios que no solo reciben, sino que también producen información. El profesional del periodismo del tercer milenio precisa convertirse "en un narrador mucho más habilidoso, en alguien que pueda no solo entretejer los datos de un acontecimiento o de un proceso, sino también conectarlos en un conjunto mucho más amplio de hechos y circunstancias contextualizados" (Pavlik, 2005: 336-337). Y en esa tarea de entretejer las redes facilitan el trabajo.

Este cometido relacional del trabajo periodístico se hace ahora de la mano de los usuarios activos que, mediante su participación en los procesos, cambian las dinámicas y pueden resultar muy relevantes tanto para la confección de la pieza periodística, para su seguimiento y evolución, y para su recomendación a otros usuarios (la multiplicación de la difusión). Las propias dinámicas de trabajo de las redacciones de muchos medios fueron llevando a los periodistas a este nuevo escenario de las redes sociales, por donde han tenido que caminar para la realización de su cometido profesional. Fue así como pronto quedaron atrapados, con mayor o menor intensidad, en la dinámica de las redes sociales.

Esta rápida apuesta periodística de algunos sectores profesionales por las redes sociales ha reavivado el viejo debate sobre cómo debe actuar el profesional de la información en los conocidos genéricamente como nuevos medios. La respuesta, desde el ámbito académico y desde el ámbito profesional, ha sido mayoritaria alrededor del planteamiento que sostiene, como explica Alejandro Rost, "que el periodista tiene que usar en estos espacios los mismos parámetros que a la hora de elaborar cualquier información, ser prudente con el uso de la ironía, ser consciente de que sus seguidores pueden ser público muy diverso (en cuanto a países, por ejemplo), cuidar a sus fuentes, construir y proteger su propio prestigio como periodista, y no perder de vista que trabaja en el contexto de una organización" (2012: 11).

Mientras persisten debates profesionales sobre el uso de las redes sociales, algunos medios regularon la forma en que deben emplearlas sus periodistas y determinadas asociaciones introdujeron decálogos de autorregulación. Se trata de un desafío que afrontan 
mientras asumen que hay que contar con estas plataformas de comunicación para realizar el trabajo periodístico en las sociedades actuales. Pero no existe unanimidad sobre cómo utilizar las redes sociales por parte de los periodistas.

\section{Utilización masiva por parte de los periodistas}

La cultura periodística actual ha asumido, con diferentes consideraciones, las redes sociales como un elemento del contexto comunicativo que incide en la práctica del ejercicio profesional. De hecho, figura como uno de los principales cambios en las rutinas profesionales de los periodistas del siglo XXI. En el año 2013, el 40 por ciento de los periodistas norteamericanos ya indicaba que las redes sociales eran muy importantes para su trabajo y más de un tercio ya reconocía que dedicaba entre treinta y sesenta minutos cada día a las redes sociales (Willnat/Weaver, 2014: 22).

Los principales medios online promovidos por una industria que ha nacido y se ha desarrollado de la mano del papel, tras entender que las redes sociales son algo más que una moda cultivada por las generaciones más jóvenes, han dado pasos para que sus periodistas conozcan las nuevas herramientas y se adentren en los canales alternativos que han surgido en la última década. El impulso, en la mayor parte de los casos, ha nacido, como hemos señalado, de los profesionales de menor edad, porque muchos las empleaban para su comunicación personal, y de los sectores más emprendedores de esas empresas. En España, no solo los medios con más difusión y considerados referentes (El País o El Mundo) han fomentado entre sus periodistas una cultura 2.0 basada en la integración de las redes sociales en sus trabajos (Herrero, 2013: 264), sino también los medios regionales y locales.

El índice de utilización de las redes sociales por parte de los periodistas españoles es relevante en la actualidad y las redes más utilizadas son Twitter y Facebook en las rutinas de la producción diaria. El intenso uso se sitúa por encima del 80 por ciento de los profesionales (Cerviño, 2013: 79). Otras investigaciones recientes muestran como los periodistas españoles están en la red y la usan de alguna forma, indicando porcentajes en la misma dirección. Una tesis doctoral defendida recientemente en la Universidad Carlos III de Madrid señala que el 95 por cien de los periodistas españoles entran en 
la red para publicar información y el 82 por cien para buscar noticias (Herrero, 2013: 243). Y los periodistas emplean estas redes sociales para completar la investigación periodística y no para reemplazar sus principios básicos (Cerviño, 2013: 79).

\section{Estrategias en clave móvil}

Tanto el índice de utilización por parte de los periodistas como la introducción de las redes en los productos periodísticos ha llevado a los principales grupos de comunicación a elaborar estrategias para las redes sociales. Uno de los diarios de referencia, The New York Times/NYT.com, ha puesto en marcha varias estrategias en las redes sociales para mejorar su relación con la audiencia (Herrero, 2013: 14). Esta tendencia ha sido seguida por los principales medios, incluidos los de proximidad, aunque su objetivo ha sido la mejora de las relaciones con los usuarios sin entrar en muchos otros aspectos que han abierto las redes sociales tanto en lo relativo a la producción como en la gestión para las diferentes plataformas. La evolución de las audiencias ha sido casi siempre el objetivo preferente.

El primer paso adelante para ampliar el campo de actuación en estas estrategias de difusión ha sido para diferenciar las características de los mensajes según la red (en especial, diferenciar las de Twitter y los de Facebook) y para prestar más atención a la personalización. El denominador común ha estado caracterizado por convertir la marca en fiable en las redes y, por tanto, introducir un elemento que asegure la fidelización de usuarios necesitados de vencer la desconfianza mediante el contacto con productos solventes, que no le defrauden. Sin embargo, esto apenas ha implicado cambios en la estrategia de producción.

A medida que se analiza el efecto de las estrategias, en lo relativo a la producción han surgido debates acerca de la conveniencia de mejorar la combinación de trabajos individuales y trabajos en equipo, así como prestar más atención a las nuevas narrativas. En el fondo se analiza la conveniencia de superar modelos del pasado y prestar más atención a las narrativas transmedia, con las redes sociales como centro de la gestión, difusión y promoción de muchas de estas iniciativas. Los periodistas de los medios actuales buscan como afrontar el desafío de la secuencia transmedia mediante más trabajos 
en equipos bien estructurados para las nuevas necesidades de producción para diferentes soportes y dispositivos.

Las redes sociales, como plataformas de comunicación de la sociedad conectada, ofrecen potencialidades para una gestión de las estrategias transmedia, que comienzan a cobrar fuerza en el último año. La necesidad de buscar canales centrales de promoción y gestión de las estrategias sitúa a las redes sociales en buena posición para llevar adelante un papel relevante en las nuevas dinámicas narrativas que se popularizan en el ecosistema comunicativo del tercer milenio.

El periodismo total, entendiendo por tal el que aplica todas las técnicas útiles para una buena información de calidad -las afianzadas a lo largo de la historia periodística y las de última generación, que nacen de la mano de tecnologías y herramientas actuales-, orienta sus estrategias teniendo en cuenta el creciente protagonismo de los dispositivos móviles, los nuevos usos y consumos comunicativos que alimentan las redes sociales, las nuevas narrativas que nacen de la mano de los múltiples dispositivos y canales sobre los que se construye la sociedad enredada, las aportaciones de los usuarios como "prosumidores", y los consumos emergentes, tanto los mayoritarios como los de "nicho". Es su respuesta a un desafío total que plantean las nuevas plataformas de comunicación mundial.

\section{A modo de conclusión}

Las redes sociales generalistas no solo transformaron la forma de comunicarse de los ciudadanos en la Sociedad de la Información y el Conocimiento sino que están transformando las rutinas profesionales de los periodistas, que las emplean para la búsqueda, elaboración, difusión y gestión de sus piezas informativas. El uso de estos espacios implica la aplicación de los principios periodísticos para la elaboración de información, es decir, de sus códigos deontológicos y la preceptiva, pero en un nuevo contexto y en un escenario donde debe trabajar en contacto directo con los usuarios activos, que plantean renovadas demandas a las piezas periodísticas.

En el momento actual, la mayoría de los periodistas reconocen que han introducido en sus rutinas profesionales las redes sociales y que resultan útiles para cumplir con sus cometidos, aunque les plantean nuevos desafíos y algunas dudas sobre la forma de emplearlas en determinados casos. Las nuevas dinámicas comunicativas han 
obligado a los medios informativos online a diseñar estrategias tanto para la mejora de la relación con los usuarios como para conseguir la mayor eficacia a la hora de aprovechar sus potencialidades por parte de los centros de producción de contenidos. La producción periodística se ha convertido en una secuencia continua y encadenada, con múltiples ramificaciones.

A pesar de los avances, se presume que las redes sociales pueden desempeñar papeles todavía más relevantes para la promoción y gestión de las estrategias, en especial en el campo por el que transitan las narrativas transmedia y todas las iniciativas enredadas que marcan la secuencia de piezas periodísticas que tratan de aportar valor a la cadena comunicativa en diferentes ámbitos. La necesidad de establecer relaciones entre campos muy diversos de actuación en el escenario comunicativo, entre canales y dispositivos de todo tipo, orienta muchas miradas hacia las redes sociales, que, de momento, se han revelado como plataformas de comunicación que han ampliado y mejorado el funcionamiento del ecosistema comunicativo del siglo XXI, al tiempo que han introducido renovados riesgos y desafíos para el periodismo y para la comunicación mediada tecnológicamente.

\section{Referencias bibliográficas}

Campos, F. (2013): "La gestión de los medios tradicionales en las redes sociales". En VV.AA., Recopilatorio de artículos científicos sobre redes sociales (Coord., F. Campos, Francisco). La Laguna (Tenerife): Latina.

Cerviño, B. (2013): El uso de las redes sociales como fuente de información para periodistas. Barcelona: Universidad Autónoma. Trabajo de fin de Máster. Accesible en:

http://www.recercat.net/bitstream/handle/2072/216886/Versión digital del trabajo.pdf? sequence $=1$. Consulta para este trabajo: 24 de enero de 2015.

Herrero, E. (2013): Periodistas y redes sociales en España. Del $11 \mathrm{M}$ al 15M (2004-2011). Getafe: Universidad Carlos III. Tesis doctoral. Accesible en: http://e-archivo.uc3m.es/handle/10016/17648. Consulta para este trabajo: 24 de enero de 2015.

Pavlik, J. V. (2005): El periodismo y los nuevos medios de comunicación. Barcelona: Paidós Comunicación. 
Rost, A. (2012): "Modelos de uso y gestión de redes sociales en el Periodismo". IV Congreso Internacional de ciberiodismo y web 2.0. Accesible en:

https://www.academia.edu/2762807/Modelos de uso y gesti ón de redes sociales en el periodismo. Consulta para este trabajo: 23 de enero de 2015.

Soengas, X. (2013): "El papel de Internet y las redes sociales en las revueltas árabes: una alternativa a la censura de la prensa oficial", en Revista Comunicar, número 41, Volumen 21. Accesible en: http://www.revistacomunicar.com/indice/articulo.php?numero=412013-14. Consulta para este trabajo: 23 de enero de 2015.

VV.AA. (2014): La Sociedad de la Información en España 2013. Madrid: Fundación Telefónica/Ariel Comunicación. Accesible en: http://www.fundaciontelefonica.com/arte cultura/publicaciones-

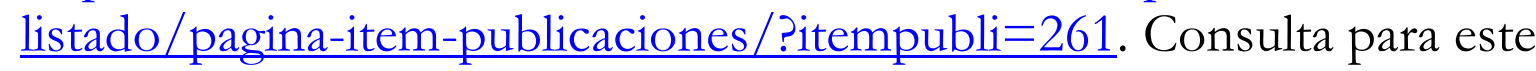
trabajo: 26 de enero de 2015.

Willnat, L. y Weaver, D. H. (2014): The American Journalist in the Digital Age. Indiana: School of Journalism. Indiana University. Accesible en: http://news.indiana.edu/releases/iu/2014/05/2013american-journalist-key-findings.pdf. Consulta para este trabajo: 24 de enero de 2015. 


\section{Redes sociales, periodismo de datos y democracia monitorizada}

Andreu Casero-Ripollés, Universitat Jaume I de Castellón (UJI, España),casero@uji.es

Amparo López-Meri, Universitat Jaume I de Castellón (UJI, España), meri@uji.es

\section{Resumen}

Las redes sociales están provocando cambios en el periodismo que van más allá de la producción, la distribución y el consumo de información y que tienen impacto sobre la democracia. En este sentido, destaca la aparición de nuevos actores informativos, vinculados a la sociedad civil, que, desde Internet y las redes sociales, practican el periodismo de datos y, con ello, generan una fiscalización y un escrutinio permanente de los centros de poder. El objetivo de este capítulo es analizar las características, actividad e incidencia de estas plataformas digitales. La metodología aplicada se basa en el estudio de cuatro casos: mySociety, Sunlight Foundation, Ciudadano Inteligente y Fundación Civio. Los resultados sugieren que estas iniciativas contribuyen a la renovación del periodismo de investigación y a la extensión de la democracia monitorizada. ${ }^{10} 11$

\footnotetext{
${ }^{10}$ Este trabajo forma parte del proyecto de investigación «Medios sociales y activismo político en Internet: hacia una redefinición de los vínculos entre la comunicación y la democracia en la era digital» beneficiario de la «I Convocatoria de Ayudas Fundación BBVA a Investigadores, Innovadores y Creadores Culturales» concedida en 2014. La Fundación BBVA no se responsabiliza de las opiniones, comentarios y
} 
Palabras clave: periodismo, redes sociales, democracia, monitorización, periodismo de datos y comunicación política.

\section{Introdución}

T AS redes sociales y el entorno 2.0 están introduciendo numerosas Ltransformaciones en el campo del periodismo. Una de ellas es especialmente significativa por su conexión con los cambios informativos y democráticos. Se trata de la aparición de nuevos actores informativos, procedentes de la sociedad civil, que practican el periodismo de datos y que, con ello, generan una fiscalización y un escrutinio permanente de los centros de poder. Se trata de platafomas que aúnan dos de las potencialidades más relevantes de la web 2.0: la capacidad de producir y difundir información de manera autónoma (Castells, 2009) y la competencia de empoderar a la ciudadanía (Jenkins, 2006), otorgándole un contrapoder para incidir sobre el sistema político, condicionando su comportamiento, sus acciones e, incluso, sus decisiones (Casero-Ripollés, 2010). Con ello, su actividad afecta tanto a la renovación del periodismo de investigación como a la extensión de la democracia monitorizada.

La aparición de estos nuevos actores informativos, vinculados a la sociedad civil, está conectada al fenómeno del big data (MayerSchönberger y Cukier, 2013). El desarrollo de Internet, en general, y de las redes sociales, en particular, ha propiciado un doble proceso en este sentido. Por un lado, ha generado un gran volumen de datos disponibles que no dejan de crecer cada día. Éstos incluyen bases de datos, repositorios o plataformas de información pública. Estas últimas están vinculadas a la creciente introducción de mayor transparencia en los procesos políticos y en las administraciones públicas, mediante leyes específicas, y al avance del gobierno abierto (open government). Con ello, se han liberado y se han puesto en línea, a disposición de cualquier ciudadano, numerosos datos sobre la

contenidos incluidos en este capítulo ni de los resultados derivados del mismo, los cuales son total y absoluta responsabilidad de los autores.

${ }^{11}$ Este trabajo forma parte del proyecto de I+D CSO201452283-C2-1-P, financiado por el Ministerio de Economía y Competetividad (MINECO) del Gobierno de España. 
actividad de las instituciones políticas. Junto a esta información, la expansión de Internet y las redes sociales también ha generado un amplísimo volumen de datos sobre el comportamiento digital de los usuarios que incluye aspectos tan variados como sus consultas en buscadores, sus visitas a páginas web, su consumo de música o vídeo en portales especializados, sus interacciones con contactos y amistades o sus mensajes difundidos a través de perfiles o blogs. Toda esta actividad genera grandes cantidades de información cuyo uso puede ser tanto comercial, para ser vendido a los anunciantes para crear publicidad segmentada (Fuchs, 2014), como político, para identificar a los públicos y lanzarles mensajes personalizados, o periodístico, para producir nuevos tipos de reportajes y noticias.

El elevado volumen de información disponible, y su potencial explotación, ha generalizado la aparición de instrumentos para analizar esa gran cantidad de datos. Se trata de aplicaciones y programas, asociados a la analítica web y a las métricas de las redes sociales, que permiten procesar los datos y también ofrecer una visualización atractiva de los resultados mediante gráficos interactivos (SánchezBonheví y Ribera, 2014).

Ambos factores están en la base de la aparición del periodismo de datos que aplica nuevas técnicas para la creación de informaciones a partir del procesamiento, la comparación y el análisis de grandes cantidades de datos disponibles en Internet. Eso exige la combinación de competencias específicas de búsqueda de datos, de manejo de herramientas estadísticas para tratarlos y de uso de interfaces y programas de visualización de la información (Flores Vivar y Salinas Aguilar, 2013).

El periodismo de datos abre la posibilidad de elaborar nuevos productos informativos cuyo objetivo es descubrir tendencias, patrones y comportamientos atípicos recopilando y tratando datos (Chaparro Domínguez, 2014). Por ello, está estrechamente vinculado al periodismo de investigación puesto que aspira a descubrir cosas a través de los datos. La capacidad para acceder a grandes cantidades de información en bruto y para procesarla y analizarla mediante herramientas informáticas permite renovar y reforzar el periodismo de investigación que, en los últimos tiempos, había experimentado un retroceso debido a la reducción de costes de producción en las 
empresas mediáticas, motivado por la crisis del sector, y a su escaso interés de enfrentarse a los poderes políticos y económicos.

Pero también a través del tratamiento periodístico de los datos disponibles en Internet y las redes sociales se puede realizar una tarea de contrapoder para revitalizar la democracia (Sampedro, 2014). Específicamente, este tipo de periodismo facilita el escrutinio de las actividades de los actores políticos, económicos e, incluso de los propios medios de comunicación. Esto conecta su práctica a la rendición de cuentas puesto que, a través de los datos, se pueden crear productos o plataformas que ofrezcan información a los ciudadanos sobre la tarea de los parlamentarios, las actividades de los lobbies o grupos de presión, las partidas y cuestiones en las que se invierten los recursos públicos o la financiación de los partidos políticos y sus campañas electorales mediante donaciones, entre otros aspectos. De esta forma, a través de los datos y su tratamiento periodístico, se defiende el interés público provocando una extensión de la función de perro guardián tradicionalmente atribuida a los medios de comunicación (Feenstra y Casero-Ripollés, 2014).

Con ello, se potencia la democracia monitorizada, que consiste en la fiscalización de los centros de poder político y económico por parte de la sociedad civil gracias a las herramientas tecnológicas y a la abundancia de información derivadas del entorno digital (Keane, 2009). Supone la emergencia de mecanismos examinadores del poder vinculados a los ciudadanos, que van más allá de las fórmulas establecidas institucionalmente y que conectan con formas de participación política extrarrepresentativas (Schudson, 1998). Así, la ciudadanía adquiere la capacidad de actuar como un contrapoder capaz de denunciar las malas prácticas y los abusos de poder, exigiendo, así, responsabilidades. Los efectos de sus acciones monitorizadoras pueden generar cambios en las decisiones políticas, rectificaciones, dimisiones o la incorporación de nuevos temas de debate a la agenda pública, entre otras consecuencias (Feenstra, 2012). Por lo tanto, la monitorización lleva aparejada un fuerte componente de regeneración democrática.

El objetivo de este capítulo es analizar las características, actividad e incidencia de las plataformas digitales vinculadas a la sociedad civil, que desde Internet y las redes sociales practican el periodismo de datos desde una óptica monitorizadora. La metodología 
aplicada se basa en el estudio de casos. Concretamente se analizan cuatro iniciativas: mySociety, Sunlight Foundation, Ciudadano Inteligente y Fundación Civio. Su elección se basa en un doble criterio: por un lado, el territorial, ya que se recogen las principales plataformas en Estados Unidos, Reino Unido, Latinoamérica (Chile) y España, y por otro, la relevancia, que motiva la selección de casos caracterizados por una elevada intensidad en la elaboración de productos informativos basados en el periodismo de datos y, a la vez, dotados de una orientación monitorizadora. Los aspectos estudiados en cada uno de los casos son, por un lado, los objetivos, las fuentes de financiación y las principales iniciativas desarrolladas por estas plataformas. Asimismo, por otro, se analiza el tipo de productos informativos que difunden y los efectos de su actividad monitorizadora sobre la democracia.

\section{Plataformas digitales de periodismo de datos para la monitorización cívica del poder \\ 2.1. mySociety (Reino Unido)}

El embrión de mySociety se remonta a 1996, cuando un pequeño grupo de desarrolladores interesados en explorar el potencial democrático de internet funda el colectivo UKCOD (UK Citizens Online Democracy, Democracia en Línea de Ciudadanos del Reino Unido), con el objetivo de investigar cómo la gente puede utilizar Internet para intervenir directamente en la política y participar en la discusión de las cuestiones que le afectan, según se describe en su sitio web (https://www.mysociety.org/). Tres años después, en 1999, UKCOD paraliza su actividad, y resurge en 2003, auspiciada por un nuevo grupo de voluntarios que lanza el proyecto mySociety.

UK Citizens Online Democracy (UKCOD) es una sociedad limitada registrada como asociación sin ánimo de lucro en Inglaterra y Gales. Su finalidad es realizar y promover investigaciones sobre el uso y los efectos de las tecnologías digitales en cualquier contexto donde exista un electorado, y difundir los resultados en beneficio de los ciudadanos. Su principal actividad es la gestión de mySociety, un proyecto que cuenta con 25 empleados y 10 voluntarios, dedicados al desarrollo de sitios web para la monitorización de la actividad de las autoridades públicas, y también para facilitar información y formación 
a los ciudadanos en el manejo de la web 2.0 como herramienta de fiscalización del poder político.

Las investigaciones y portales de mySociety se financian con las donaciones de fundaciones, instituciones públicas, entidades comerciales y ciudadanos. Normalmente, cada proyecto cuenta con uno o varios patrocinadores. En la actualidad, colaboran Omydyar Network, Google.org, The Indigo Trust, Open Society Foundations, The Joseph Rowntree Reform Trust, The William y Flora Hewlett Foundation, Making All Voices Count, Google Ad Grants y Bytemark. En el pasado, mySociety también ha contado con la financiación de GovEval, The Young Foundation, The Esmée Fairbairn Foundation, GeoVation, The Technology Strategy Board, Hivos y John S. and James L. Knight Foundation, así como del Ministerio de Justicia y el Departamento de Transporte del Gobierno británico. Además, cualquier particular puede realizar donaciones puntuales o periódicas desde la página web, vía PayPal o mediante el pago con tarjeta, cheque, transferencia o domicilición bancaria. Las cuentas de mySociety son públicas y pueden consultarse en el sitio web de la Comisión de Caridad del Gobierno británico. En 2014, los ingresos ascendieron a 1,57 millones de libras, procedentes de donaciones en su totalidad. Respecto a los gastos, se invirtieron 1,42 millones de libras en actividades no lucrativas y 20.000 libras en materia de gobernanza.

Aunque mySociety se circunscribe al ámbito geográfico del Reino Unido, ha desarrollado herramientas y software de código libre para que sus iniciativas puedan aplicarse en otros paíes. De este modo, como iniciativa pionera en su campo, mySociety ha contribuido e impulsado el desarrollo de un movimiento internacional que confía en el empoderamiento del ciudadano y el uso de las nuevas tecnologías digitales para controlar a los gobiernos. En esta dirección, cuenta con los proyectos WhatDoTheyKnow (QueSaben), TheyWorkForYou (TrabajanParaTi), WriteToThem (Escríbeles) y FixMyStreet (ReparaMiCalle), destinados a facilitar la transparencia y el acceso libre a la información, y a monitorizar la actividad de los parlamentarios británicos y promover la participación ciudadana en la vida pública. La mayor parte de sus proyectos han sido reconocidos en diferentes ediciones de los premios New Statesman New Media Awards, por su innovación y contribución a la sociedad civil del Reino Unido. 
Respecto a la libertad de información, destaca el proyecto WhatDoTheyKnow (https://www.whatdotheyknow.com), inspirado en la Ley de Libertad de Información del Reino Unido, que garantiza desde el año 2000 el derecho de cualquier ciudadano a solicitar información del Gobierno. Se trata de un portal web que ayuda a los ciudadanos a encontrar información privilegiada sobre el Gobierno británico, los ayuntamientos y los organismos públicos del Reino Unido, como el Parlamento, el Servicio Nacional de Salud, las Fuerzas Armadas o las escuelas y universidades públicas. También puede usarse para obtener la información que el Gobierno maneja sobre empresas y otras organizaciones. Los ciudadanos dejan sus solicitudes en esta página web, que las envía a las autoridades competentes y publica las respuestas, disponibles para cualquier lector. Existen versiones similares a WhatDoTheyKnow a saber en Hungría (http:// kimittud.atlatszo.hu), Nueva Zelanda (https://fyi.org.nz), Israel (http://www.askdata.org.il) o España (http://www.tuderechoasa ber.es), en este último caso de la mano de la Fundación Civio, como se analizará más adelante. Con los mismos parámetros, también es posible dirigirse a las instituciones de la Unión Europea (http:// www.asktheeu.org).

WhatDoTheyKnow cuenta con 30.000 usuarios registrados. Según sus gestores, entre el 15\% y el $20 \%$ de las peticiones de información al Gobierno se realizan a través de este sitio web, que anima a los ciudadanos a controlar lo que el Gobierno hace con su dinero, porque "cuanto más sepamos del funcionamiento del Gobierno, más capaces seremos de realizar sugerencias para mejorar lo que hacen mal, y celebrar lo que hacen bien". Hasta abril de 2015, se han efectuado más de 263.000 requerimientos de información a más de 16.000 autoridades. El mayor volumen de consultas afecta a los departamentos de Trabajo y Pensiones (5.798), Defensa (2.329) y Sanidad (1.739). También la British Broadcasting Corporation (BBC) recibe un número significativo de peticiones de información (2.065). Gracias a este portal se han conocido hechos que han derivado en la exigencia de responsabilidades políticas, incluso en dimisiones. Se descubrió, por ejemplo, que los miembros de la Comisión Electoral gastaron miles de libras de dinero público, entre otros, en chicas de compañía o chocolate, porque pagaron estos servicios y productos con las tarjetas 
de crédito del Gobierno. También salió a la luz que la $B B C$ gastó 10 millones en el alquiler de coches para su personal.

En cuanto a la fiscalización del poder, mySociety cuenta con el sitio web TheyWorkForYou (http://www.theyworkforyou.com), para la monitorización de los parlamentarios británicos. En este portal se informa de la actividad parlamentaria de una manera clara y sencilla, para todos los públicos, con el objetivo de que cualquier ciudadano, sin ser experto en la materia, pueda entender las medidas aprobadas, acceder a los documentos originales y vídeos de los debates, y compartir y enlazar estos datos fácilmente. Los usuarios también pueden comentar las declaraciones de los políticos y recibir alertas por email, cada vez que interviene un parlamentario específico o se menciona un asunto concreto. Además, destaca el valor histórico del portal, que permite remontarse hasta la década de 1930 para consultar debates anteriores. En la misma línea, WriteToThem (https://www. writetothem.com) facilita el envío de correos electrónicos entre los ciudadanos y sus representantes locales en el Parlamento. Según mySociety, muchos políticos han mejorado su manera de responder después de obtener puntuaciones bajas en el ranking de WriteToThem. Asimismo, con FixMyStreet (https://www.fixmystreet.com) los ciudadanos pueden denunciar los desperfectos o incidentes detectados en sus calles y barrios. Los gestores de la web se encargan de hacer llegar la información a la autoridad competente en cada caso.

\subsection{Sunlight Foundation (Estados Unidos)}

Sunlight Foundation es una organización estadounidense no partidista y sin ánimo de lucro, fundada en abril de 2006 por dos abogados, Michael Klein y Ellen Miller, para conectar a los votantes con una amplia oferta de información sobre los candidatos al Congreso a través de internet. El nombre de la fundación deriva de una cita del juez del Tribunal Supremo de los Estados Unidos, Louis Brandeis, que afirmó que "la luz del sol (sunlight) es el mejor de los desinfectantes." De eso se trata, de desinfectar y desenmascarar los "despilfarros" del Congreso, para dar a los ciudadanos "el poder de acabar con la corrupción”, explica la propia organización en su ideario. Según detalla su página web (http://sunlightfoundation.com), aspira a lograr cambios legislativos para exigir la transparencia en línea de toda la información relacionada con el Gobierno, prestando especial atención 
a los flujos de dinero, para controlar cómo éstos tratan de influir en el Gobierno y cómo responde éste, tanto en el ámbito local, como estatal y federal. Para lograr este fin, según afirma, recurre a las herramientas de la tecnología cívica, los datos abiertos (open data) y el periodismo de datos, en beneficio de la información a los ciudadanos, para promover una participación democrática más equitativa y eficaz.

La plataforma Sunlight Foundation, que actualmente tiene 40 trabajadores, nace con un capital inicial de 3,5 millones de dólares, aportados por uno de sus co-fundadores. En su sitio web desglosan las donaciones que reciben anualmente para financiar sus proyectos. En 2014 recibieron un total de 6,5 millones de dólares, la mayoría procedentes de fundaciones y particulares. Algunos de sus patrocinadores coinciden con los de mySociety, como Omidyar Network, Open Society Foundations o John S. and James L. Knight Foundation. También cuentan con las aportaciones de Rockefeller Family Fund, Rockefeller Brothers Fund, Global Integrity, Ford Foundation, Transparency International, Investigative News Network, Microsoft y el Banco Mundial, entre otros.

Respecto a sus acciones, pueden enmarcarse en dos grandes ámbitos, la lucha por la transparencia y la creación de bases de datos abiertas para facilitar el acceso a la información. En el ámbito de la transparencia, investigan la financiación de las campañas electorales y monitorizan la actividad legislativa, a través de la presentación de alegaciones a los proyectos de ley sobre la materia. Por ejemplo, a través del proyecto de ley para acabar con el secreto de las donaciones y obligar a la rendición de cuentas de los partidos, concido en EE.UU. como Ley SUPERPAC (Stop Undisclosed Payments in Elections from Ruining Public Accountability), Sunlight Foundation ha logrado incorporar algunas de sus reivindicaciones. Así, desde 2012, se ha de detallar el origen de las contribuciones a los partidos y justificar públicamente todos los gastos de campaña. Las organizaciones, empresas y sindicatos que realicen donaciones han de presentar también informes de transparencia. Todos estos informes deben estar disponibles en línea y en formatos de faciliten su consulta por los contribuyentes. También en 2012, en consonancia con las demandas de Sunlight Foundation, la Comisión Federal de Comunicaciones del Gobierno estadounidense aprobó la creación de una base de datos centralizada, de acceso público, con toda la información sobre la 
contratación de anuncios políticos para televisión. Las cadenas deben facilitar el accceso en línea a estos archivos.

Esta fundación también proporciona herramientas e investigaciones en línea, basadas en el periodismo de datos, para seguir los estrechos vínculos que se establecen entre el sector financiero y los legisladores. Es el caso de la herramienta Lobbying Tracker, un registro para monitorizar en tiempo real las reuniones con los lobbies o grupos de presión (http://lobbying.influenceexplorer.com/lobbying/registra tions). También ofrecen información del dinero recibido en diferentes campañas electorales, aunque para conseguir datos más actualizados, delegan en la organización Follow The Money (Sigue el dinero) y recomiendan visitar su página web (http://followthemoney.org). Medios de referencia como The New York Times, The Washington Post o Reuters han publicado noticias y reportajes a partir de las investigaciones de Sunlight Foundation. En 2011, por ejemplo, The Washington Post, a partir de los registros de esta plataforma, informó que Standard and Poor's gastó más de 11 millones de dólares durante 15 años en el cabildeo o ejercicio de influencia sobre congresistas y senadores y que, al menos un millón, estaba vinculado a legislación aprobada que afectaba directamente a temáticas vinculadas a los intereses de esta compañía.

En el ámbito de creación de bases de datos, interpretan y organizan información que ya es pública pero resulta difícil de obtener e interpretar por parte de los ciudadanos. En su web pueden consultarse, por ejemplo, los archivos correspondientes a las donaciones de la campaña electoral de 2012 y de las últimas convenciones nacionales de los partidos demócrata y republicano. Además, a través del programa OpenGov Grants, se han ofrecido becas para proyectos destinados a recopilar y publicar información que haga más transparente la acción del Gobierno. Sunlight Foundation también colabora con gobiernos locales, apoya la labor de ONGs como OpeningParliament.org (http://www.openingparliament.org), y desarrolla aplicaciones informáticas para propiciar la configuración de bases de datos. Además, se moviliza para exigir al Gobierno el acceso a información relevante hasta ahora oculta. Es el caso de la actual campaña para que el Servicio de Investigación del Congreso (Congressional Research Service), que cuenta con 100 millones de presupuesto, explique públicamente cómo se invierte este dinero. 
Entre los logros, en su página web se felicitan porque el Gobierno federal, a instancias de esta fundación, acordó iniciar el proceso de liberación de todos los datos en poder de los organismos federales.

\subsection{Ciudadano inteligente (Chile)}

La Fundación Ciudadano Inteligente (http://ciudadanointeligente.org) se define como una organización laica, no partidista, sin ánimo de lucro, respetuosa y defensora de la diversidad política, cultural, social, religiosa y sexual. Nace a finales de 2009, con sede en Santiago de Chile, con la misión de fortalecer la democracia y reducir la desigualdad en América Latina, mediante la promoción de la transparencia y la participación ciudadana a través de las tecnologías digitales. Trabaja para establecer la cultura del acceso a la información pública y la reutilización de los datos abiertos, impulsar la rendición de cuentas de los distintos poderes y fortalecer la participación ciudadana para conseguir mejorar los mecanismos representativos de la democracia. Para lograr sus propósitos, informar e involucrar a los ciudadanos en la esfera pública, desarrollan aplicaciones web y recurren a las redes sociales. En septiembre del 2011, Ciudadano Inteligente recibió el premio internacional Prix Ars Electronica a las comunidades digitales, un galardón también obtenido, entre otros, por Wikipedia, Creative Commons y los estudios de cine Pixar.

Para asegurar su independencia, Ciudadano Inteligente no recibe financiación del Gobierno, ni de los partidos o de organizaciones con intereses políticos. Se financia a través de las donaciones. En 2014, contó con un presupuesto total de 777.195 dólares, aportados por fundaciones y organizaciones sin ánimo de lucro, como Avina, Omidyar Network, Hivos, mySociety o Unicef. Se trata de una cifra más reducida si se compara con los ingresos de mySociety o Sunlight Foundation. En años anteriores, también recibió dinero de Open Society Foundations, el Banco Mundial y Google.

Respecto a los proyectos que Ciudadano Inteligente tiene en activo, destacan las acciones en defensa de la transparencia. Sigue el ejemplo de mySociety y Sunlight Foundation para motivar cambios en la legislación, con campañas como ¿Quién te financia? (http:// quientefinancia.cl), que recoge firmas para pedir a los candidatos de Chile que informen de la procedencia de las donaciones que reciben. También destaca el portal web ¿Hay acuerdo? (http://haya 
cuerdo.ciudadanointeligente.org), donde expone sus alegaciones a los proyectos de ley presentados por el Gobierno. En estos momentos, por ejemplo, mientras se tramita en el Congreso chileno la Ley de Financiamiento de la Política, para que los partidos informen públicamente sobre sus fuentes de financiación, Ciudadano Inteligente usa el sitio ¿Hay acuerdo? para comparar sus propuestas con las medidas del Gobierno. Además, integra de un modo muy activo el uso de redes sociales como Twitter, para fomentar la participación ciudadana en el debate sobre estas cuestiones. El proyecto ¿Quién te financia? también incluye el perfil de Twitter y el correo electrónico de los políticos que tramitan la Ley de Financiación de Políticos en Chile. Se busca que la población pueda contactar con ellos directamente y pedir explicaciones, desde una lógica de la rendición de cuentas y del fortalecimiento de los mecanismos representativos.

Ciudadano Inteligente también ha intervenido en la regulación de la Ley del Lobby, que obliga al registro de los lobbistas o gestores de intereses particulares de Chile y al control de sus actividades (http://www.infolobby.cl). En concreto, para mejorar esta regulación, Ciudadano Inteligente ha reunido a más de 30 organizaciones que, de manera colaborativa, han elaborado un Reglamento para la aplicación de la Ley del Lobby impulsada por el Gobierno. Fruto de este esfuerzo, en agosto de 2014 se publicó dicho Reglamento en el Diario Oficial de Chile. Esta organización no sólo promueve cambios legislativos. También protagoniza acciones para exigir responsabilidades políticas. En esta línea, en el marco de la investigación judicial por el caso Penta-SQM, en marzo de 2015, ha presentado una querella por cohecho contra varios senadores, diputados y ex altos cargos del Gobierno de Sebastián Piñera. Los acusa de haber recibido financiación ilegal durante la campaña electoral.

En esta misma línea, Ciudadano Inteligente se emplea a fondo en monitorizar a los congresistas, con el proyecto Congreso abierto (http://congresoabierto.cl), y al Gobierno, con Del dicho al hecho (http://deldichoalhecho.cl). El primer caso sigue la estela de TheyWorkForYou de mySociety. Los usuarios pueden seguir la tramitación de los proyectos de ley en el Congreso chileno, establecer alertas sobre materias de su interés y comunicarse directamente con sus congresistas. En cuanto a la campaña Del dicho al hecho, desde la perspectiva del periodismo de datos, evalúa el grado de cumplimiento 
de los programas electorales. Así, respecto al mandato de Sebastián Piñera, entre 2010 y 2014, Ciudadano Inteligente sitúa en un 61\% este grado de cumplimiento. Estas iniciativas se complemetan con los portales Votainteligente (http://votainteligente.cl) y Candideit.org (http://candideit.org), espacios que abren nuevos canales de comunicación para la ciudadanía, tanto para plantear dudas sobre las elecciones, manifestar preferencias y realizar simulaciones, como para dirigirse directamente a los candidatos y dialogar con ellos.

La Fundación Ciudadano Inteligente se integra en la Red Latinoamericana de Transparencia Legislativa, que aglutina a 22 organizaciones de la sociedad civil de 11 países latinoamericanos. Todos estos países se han sumado a la Declaración sobre Transparencia Parlamentaria auspiciada en 2012 por OpeningParliament.org. Ciudadano Inteligente promueve y participa en encuentros internacionales para la colaboración y empoderamiento de la sociedad civil, como Populusaurio (http://www.populusaurio.cl), y la defensa de los datos abiertos, como Abrelatam (http:// 2015.abrelatam.org). Igualmente, como mySociety o Sunlight Foundation, impulsa el desarrollo de aplicaciones tecnológicas innovadoras con fines cívicos, a través de las plataformas Desarrollando América Latina (DAL) (http://desarrollandoamerica.org) y Poplus (http:// poplus.org).

\subsection{Fundación Civio (España)}

Fundación Civio es una organización sin ánimo de lucro que nació en diciembre de 2011 con los propósitos de ayudar a mejorar la transparencia, exigir rendición de cuentas a las administraciones y promover el libre acceso a los datos públicos. Sus dos fundadores, Jacobo Elosua y David Cabo, apuestan por combinar tecnología y periodismo para lograr estos objetivos. No parece casual que esta iniciativa surja pocos meses después de las movilizaciones ciudadanas del 15M, en mayo de 2011. De hecho, Fundación Civio enaltece a la ciudadanía como motor del cambio. "Creemos en una sociedad construida por una ciudadanía activa y participativa con una fuerte responsabilidad democrática", indican en su sitio web (http:// www.civio.es). Mediante el desarrollo de herramientas y aplicaciones "para dar luz al valor cívico de los datos", investigan y generan información sobre la gestión pública, "para mejorar el 
empoderamiento ciudadano y la rendición de cuentas de las instituciones". Como se aprecia, siguen la estela y la influencia de mySociety, Sunlight Foundation y Ciudadano Inteligente. Tampoco es casual que en la página principal de su web destaquen la afirmación del juez Louis Brandeis, "la luz del sol es el mejor desinfectante", cita que, como se ha comentado, también inspira el nombre de Sunlight Foundation.

Fundación Civio también reivindica el valor de la libertad para justificar sus propósitos, recordando las ideas de Walter Lippmann (2003), que argumentó que no puede haber libertad para una comunidad que carece de los medios para detectar mentiras. Precisamente, por combatir la mentira y la ocultación de datos, Fundación Civio ha logrado diversos reconocimientos, como el Premio a la Mejor iniciativa no pública de transparencia de 2014, concedido por Open Knowledge Foundation Spain (http://okfn.es), y el Premio a la Mejor iniciativa de empoderamiento de 2013, otorgado por la Fundación Cibervoluntarios (http://www.cibervoluntarios.org), por poner la innovación al servicio del ciudadano. Además, recientemente, Fundación Civio ha ganado la Global Impact Competition 2015 en España (http://global.singularityu.org/gic), que selecciona a emprendedores con proyectos innovadores basados en la tecnología. Este premio consiste en un beca para cursar un programa de postgrado en Silicon Valley (EE.UU.).

Respecto a su financiación, se sustenta con la aportación de donaciones de particulares y de instituciones. También recibe ingresos por la prestación de servicios de asesoría y formación. Publica sus cuentas anuales en su página web. En 2014, ingresó un total de 99.211 euros, 19.064 euros vía donaciones directas y campañas de crowdfunding, 42.837 euros por la prestación de servicios y 37.310 euros en becas y apoyos institucionales. Respecto a las donaciones, Fundación Civio cuenta con 117 colaboradores que aportan pequeñas cantidades mensualmente, normalmente entre 5 y 10 euros. Otros 200 ciudadanos y entidades han realizado donaciones puntuales desde 2012, cuando la organización se inscribió en el registro de fundaciones. El equipo de Fundación Civio, dirigido por David Cabo, está formado por 14 personas, entre trabajadores, colaboradores y miembros del patronato.

En cuanto a las acciones que Fundación Civio desarrolla, destaca el proyecto $\mathrm{Tu}$ derecho a saber (http://www.tuderechoasaber.es), 
portal que permite a los ciudadanos pedir información a las instituciones públicas españolas. Está inspirado en WhatDoTheyKnow y se ha desarrollado gracias a la tecnología de Alaveteli (http:// alaveteli.org), una herramienta creada por mySociety desde Reino Unido para ayudar a otros países en el acceso libre a los datos públicos. En este ámbito, según Fundación Civio, todavía impera el silencio administrativo. En 2014, los ciudadanos plantearon 314 peticiones de información a través de Tu derecho a saber, y sólo el $42,7 \%$ obtuvo respuesta. No obstante, el dato muestra una ligera mejoría, pues la opacidad superaba el 57\% en 2013.

En sintonía con la monitorización de políticos y lobbies que efectúa el resto de organizaciones analizadas, Fundación Civio también ha puesto en marcha ¿Quién manda? (http://quienmanda.es), un mapa que dibuja los vínculos que se esconden detrás de gobernanes y cargos públicos, sus relaciones con el mundo empresarial y financiero, para que el ciudadano entienda los intereses y motivaciones que trascienden a las decisiones del poder. Este proyecto, que cuenta con el soporte de Global Integrity y Sunlight Foundation, responde a la esencia del periodismo de investigación y aporta información relevante para la ciudadanía y para los medios de comunicación. Las consecuencias de su labor son visibles. Como se destaca en la propia web, ya hay cuatro partidos políticos que publican las agendas completas de todos sus diputados (UPyD, ICV, EUiA y Compromís). El PSOE publica información sobre 40 diputados, pero oculta las reuniones que sus interlocutores prefieren mantener en secreto.

En la misma línea, para fiscalizar a los políticos, Fundación Civio colabora con la iniciativa ¿Qué hacen los diputados? (http:// quehacenlosdiputados.net), gestionada por otra organización, y cuenta con proyectos propios como ¿Dónde van mis impuestos? (http:// dondevanmisimpuestos.es), que desglosa y explica los presupuestos del Estado y de las Comunidades Autónomas, El BOE nuestro de cada día (http://elboenuestrodecadadia.com), para que no pase desapercibido ningún nombramiento o subvención aprobados por las administraciones, y Digo Diego (http://digodiego.es), para que los ciudadanos puedan acceder a los tuits que los políticos publican y después borran. También despierta mucho interés El Indultómetro, la primera web que registra los más de 10.000 indultos concedidos en 
España desde 1996 (http://www.elindultometro.es/index.html). Gracias a este recurso, se ha sabido, por ejemplo, que el ex ministro de Justicia Alberto Ruiz-Gallardón (Partido Popular) concedió indultos relacionados con casos de corrupción.

Fundación Civio también ha trabajado activamente para mejorar la Ley de Transperencia en España. En febrero de 2013, junto con Acces Info Europe, realizó con éxito una campaña de recogida de firmas, vía el sitio de petición Change.org, para que la ley obligara a todos los partidos políticos, no únicamente al Gobierno. En defensa de esta transparencia, Fundación Civio también ha logrado que el Gobierno abra al público la base de datos nacional sobre incendios forestales, a la que recurren periodistas y ciudadanos. El equipo de esta plataforma analiza estos datos en la web España en llamas (http: L/www.espanaenllamas.es). Además, publica con frecuencia noticias y reportajes con los resultados de sus investigaciones y proyectos. Por eso, encabeza el Ranking de Innovación Periodística 2014, elaborado por el Grupo de Investigación de la Comunicación (GICOV) de la Universidad Miguel Hernández (UMH) de Elche.

\section{Conclusiones}

$\mathrm{Al}$ amparo del potencial de la web 2.0, que propicia el libre acceso y difusión de la información, y aprovechando la gran cantidad de datos disponibles en Internet están proliferando nuevas plataformas digitales, vinculadas a la sociedad civil, que empoderan al ciudadano (Castells, 2009; Jenkins, 2006), al que dan voz para exigir responsabilidades a sus gobernantes. Todas ellas articulan sus proyectos y demandas en torno a tres premisas: mejorar la transparencia, facilitar el acceso a la información relativa a gobiernos e instituciones, por considerarla pública, y aplicar las tecnologías digitales para lograrlo. Estos tres motivos responden a un objetivo común, el de renovar los mecanismos representativos de la democracia involucrando más activamente a los ciudadanos en la participación y la vida políticas a través de la fiscalización. En este sentido, mySociety, Sunlight Foundation, Ciudadano Inteligente y Fundación Civio sitúan la monitorización del poder en el centro su actividad. Ésta se orienta, a través del periodismo de datos, al escrutinio público de los centros de poder políticos (Keane, 2009, Feenstra, 2012) y también de los poderes económicos, como los lobbies, que son también uno de sus objetivos 
preferentes. Un punto común de las cuatro plataformas analizadas es la activación de mecanismos para que la ciudadanía pueda interpelar directamente, a través, de herramientas digitales, a los representantes democráticos. Esto no sólo supone la práctica del ejercicio de rendición de cuentas a través de una extensión y reformulación de la función de perro guardián o watchdog (Feenstra y Casero Ripollés, 2014), sino que también puede contribuir, potencialmente, a reducir la distancia entre gobernantes y gobernados, activando las estructuras de representación y renovando su vigencia. Algo que puede favorecer la reducción de la desafección de la política que, actualmente, se sitúa en niveles muy elevados.

Complementan esta labor de supervisión con el descifrado de informaciones opacas, por ejemplo, cuando aclaran y desglosan el complicado léxico legal que dificulta a los ciudadanos entender los presupuestos del Estado o la Ley de Transparencia. En este terreno, aplican estrategias y técnicas propias del periodismo de datos, publicando sus propios informes y reportajes. Con ello, ponen en circulación productos informativos que suponen una actualización y una modernización del periodismo de investigación, especialmente aquel que afecta a los centros neurálgicos del poder en nuestras sociedades. A través de los datos buscan desvelar, haciendo saber y dando cuenta, aspectos de la realidad social desconocidos hasta ese momento. Así, los datos masivos disponibles en Internet pasan a jugar un papel clave como materia prima de un nuevo desarrollo del periodismo de investigación adaptado al entorno digital.

Las acciones de estas plataformas digitales, vinculadas a la sociedad civil, tienen, por lo tanto, un doble efecto. Por un lado, generan consecuencias democráticas, desde el momento en que los ciudadanos recurren a esta vía para exigir que los políticos rindan cuentas de sus acciones y sus errores (Feenstra, 2012). Por otro lado, su actividad informativa, basada en el periodismo de datos, renueva el concepto y la práctica del periodismo de investigación que asume un rol remozado y un nuevo impulso en el escenario digital de la mano de los datos.

\section{Referencias bibliográficas}

Casero-Ripollés, A. (2010): “¿El despertar del público?: comunicación política, ciudadanía y web 2.0”. En VV.AA., Meios de 
comunicaçao e cidadania (Eds., M. Martin Vicente y D. Rothberg). Sao Paulo: Cultura Académica.

Castells, M. (2009): Communication power. Oxford: Oxford University Press.

Chaparro Domínguez, M. Á. (2014): "Nuevas formas informativas: el periodismo de datos y su enseñanza en el contexto universitario", en Historia y Comunicación Social, 19, páginas 43 a 54.

Feenstra, R. (2012): Democracia monitorizada en la era de la nueva galaxia mediática. Barcelona: Icaria.

Feenstra, R. A., y Casero-Ripollés, A. (2014): "Democracy in the digital communication environment: A typology proposal of political monitoring processes", en International Journal of Communication, 8, páginas 2448 a 2468.

Flores Vivar, J. M. y Salinas Aguilar, C. (2013): "El periodismo de datos como especialización de las organizaciones de noticias en Internet", en Correspondencias y Análisis, 3, páginas 15 a 34.

Fuchs, C. (2014): Social Media: a critical introduction. London: Sage.

Jenkins, H. (2006): Convergence culture: Where old and new media collide. New York: NYU Press.

Keane, J. (2009): The life and death of democracy. London: Simon and Schuster.

Lippmann, W. (2003): La opinión pública. Madrid: Langre.

Mayer-Schönberger, V. y Cukier, K. (2013): Big data: la revolución de los datos masivos. Madrid: Turner.

Sampedro, V. (2014): El cuarto poder en red. Barcelona: Icaria.

Sánchez-Bonheví, C., y Ribera, M. (2014): "Visualización de la información en la democratización de los datos", en El Profesional de la Información, 23 (3), páginas 311 a 318.

Schudson, M. (1998): The good citizen: A history of American civic life. New York: Martin Kessler Books. 


\section{El periodismo en tiempos de las redes sociales: retos y desafíos para viejos y nuevos profesionales de la información que se subieron a Twitter}

Xosé López García, Universidad de Santiago de Compostela (USC, España), xose.lopez.garcia@usc.es

Carlos Toural, Universidad de Santiago de Compostela (USC, España),carlostoural@gmail.com

Alba Silva Rodríguez, Universidad de Santiago de Compostela (USC, España), albasilvarodriguez@gmail.com

\section{Resumen}

Los profesionales de la información han comprobado directamente que la irrupción de las redes sociales en los últimos años ha variado la forma en que la sociedad participa de la vida pública y, por tanto, su acceso a la información como periodistas. Además, su participación en los nuevos escenarios comunicativos de tipo social ha afectado, de manera importante, a su labor profesional diaria.

El periodismo como ámbito en continua reconfiguración, con actores que afrontan la redefinición de su rol y papel estratégico como son los periodistas y el nuevo escenario de las redes sociales, son los tres ejes en los que este texto se centra.

En este trabajo abordamos los cambios que este nuevo contexto ha producido en el ámbito periodístico a través de la redefinición del papel del profesional de la información. Analizamos, además, la presencia de diez conocidos periodistas españoles (directores y ex 
directores de importantes medios, y un relevante reportero de internacional) en Twitter.

Palabras clave: periodistas, redes sociales, Twitter.

\section{Introducción}

L

AS redes sociales se han convertido en estos últimos años, tras su popularización y seguimiento masivo por importantes sectores de la población en los países de nuestro entorno, en un ámbito presente en la agenda de los profesionales de la información. Las fuentes que circulan y visitan por estas "calles virtuales" son útiles a los periodistas, que precisan de las redes para la difusión de sus trabajos y para establecer relaciones con las audiencias más activas. Una década después $^{12}$, el periodismo difícilmente pude cumplir con sus cometidos en la sociedad sin contar con lo que aportan las redes sociales y con los riesgos y peligros derivados de su mal uso.

Las redes sociales, que están revolucionando la forma de relacionarse de muchas personas, de comunicarse y de difundir información, están cada vez más presentes en las actividades profesionales de los periodistas. La mayoría de los profesionales de la información han incorporado las redes sociales a sus rutinas de trabajo. Aunque muchos las contemplan con ciertos reparos sobre su utilidad y sus aportaciones a las labores informativas, algunos de los últimos estudios revelan un progresivo incremento de su uso por parte de los profesionales de los medios de comunicación.

Un reciente estudio de la Universidad de Indiana, en Estados Unidos, señala que para el 40 por ciento de los periodistas norteamericanos las redes sociales forman parte de su trabajo y una tercera parte declara que les dedica entre treinta y sesenta minutos diarios $^{13}$. El citado estudio indica que la plataforma de microblogging Twitter es, con diferencia, la más utilizada. Más de la mitad de los

${ }^{12}$ Nos referimos a los diez años transcurridos desde el nacimiento de Facebook, la red social generalista con más usuarios. Su creador, Mark Zuckerberg, realizó el proyecto primigenio, Thefacebook, en el año 2004.

${ }^{13}$ El estudio, titulado "The American Journalist in the Digital Age: Key Findings", del que son autores Lars Willnat y David Weaver, puede consultarse en la red en: http://news.indiana.edu/releases/iu/2014/05/2013-americanjournalist-key-findings.pdf. Consulta para este trabajo: 14 de octubre de 2014. 
periodistas norteamericanos declaran que utilizan este tipo de servicios habitualmente para obtener información.

La mayoría de los periodistas españoles también están en una red social y Facebook y Twiter son las más utilizadas, aunque es esta última la que consideran más útil para su trabajo (Herrero Curiel, 2013: 244). Los periodistas reconocen que utilizan las redes para contactar con usuarios para buscar temas propios o para el seguimiento de temas que surgieron en las redes sociales, así como para promoción de la marca personal, la búsqueda de empleo y la mejora de su agenda de contactos ${ }^{14}$.

Los periodistas españoles veteranos ${ }^{15}$, cuando se les pregunta acerca de su entrada en las redes sociales y su proceso de adaptación, sostienen que les han permitido mejorar su documentación de algunos trabajos que han elaborado, que les han posibilitado la difusión de sus piezas informativas y de sus juicios de valor, y que les han reportado puntos de vista de usuarios acerca de sus trabajos. Aunque algunos están en varias redes, es Twitter la que les reporta más información generada en el lugar de los hechos y donde son más activos ${ }^{16}$. Este punto de vista aparece destacado en las respuestas que ofrecen los periodistas norteamericanos en el citado estudio de Willnat y Weaver.

\section{E1 nuevo entorno}

La convergencia tecnológica, la web social y las innovaciones tecnológicas han supuesto una verdadera revolución en la sociedad del siglo XXI, y los medios de comunicación también se han visto

\footnotetext{
${ }^{14}$ Los datos proceden de las encuestas realizadas por Eva Curiel Herrero para su tesis doctoral entre los profesionales.

${ }^{15}$ Entendemos por periodistas españoles veteranos aquellos que tienen en la actualidad entre 50 y 75 años y que han ocupado puestos relevantes, tanto en la gestión y dirección como en trabajos de corresponsalías y reporterismo internacional. La totalidad de estos periodistas tenían cincuenta o más años cuando se popularizaron las redes sociales.

${ }^{16}$ Para este texto hemos analizados la actividad en Twitter durante una semana del mes de octubre del año 2014 de diez periodistas españoles. Los elegidos, en una muestra aleatoria pero ponderada con la incorporación de alguno de los directores de los principales medios impresos de Madrid, han sido: Pedro J. Ramírez, Fernando Jauregui, Arsenio Escolar, Casimiro García-Abadillo, Jesús Maraña, Bieito Rubido, Ramón Lobo, Agustín Valladolid, Jesús Rivasés y Antonio Caño.
} 
afectados tanto a nivel estructural como de contenidos. No solamente se han alterado los antiguos modelos de producción de noticias (Paterson y Domingo, 2008), sino que también se han abierto de par en par las "puertas" del medio a contenidos generados por el usuario, permitiendo y fomentando la inclusión de comentarios, fotos, vídeos, blogs e incluso artículos elaborados por los lectores (para ejemplos e implicaciones de este hecho, véase Hermida y Thurman, 2008; Thurman, 2008).

Con la llegada de las nuevas tecnologías, las noticias se han convertido en una materia prima con la que es posible elaborar productos de mayor complejidad, con un valor añadido, gracias a la convergencia entre medios y tecnología. Ya en 1995 Nicholas Negroponte predijo que en el futuro las noticias en línea darían a los lectores la habilidad de escoger solo los temas y las fuentes que les interesan. $\mathrm{Y}$ parece que ese futuro ha llegado ya. Los lectores no solamente condicionan la agenda noticiosa, sino que incluso dirigen $\mathrm{u}$ orientan la práctica informativa. En el libro The Elements of Journalism, Bill Kovach y Tim Rosenstiel (2007) explican que cada vez más la noticia es producida y condicionada por los lectores-usuarios. No en vano, el periodismo interactivo es aquel que hace posible la participación activa de los actores sociales que intervienen en todo el procesamiento de la información de interés público. Por lo tanto, sus características esenciales se relacionan con la formación de la opinión pública mediante la creación de públicos deliberantes y la promoción de la participación ciudadana.

La democratización de la producción online de los medios merece el escrutinio de científicos y académicos para entender sus efectos en el diálogo y en la participación en la esfera pública (Haas, 2005). El trabajo teórico y empírico, en los últimos años, ha demostrado que la deliberación pública puede promover una ciudadanía informada, puesto que posibilita que los ciudadanos se sientan atraídos por los temas, comparte la información y sopesa alternativas, todas ellas necesarias para construir una opinión pública formada que afecta al ejercicio de la política pública (Gastil, 2008).

Estos cambios en el sector de la comunicación y el nuevo papel de la deliberación pública han obligado a los periodistas a adentrarse en el nuevo escenario para seguir informando de la sociedad actual y a la sociedad actual. Aunque han sido los más jóvenes los que, en la 
mayoría de los casos, antes han apostado por las redes sociales, muchos periodistas veteranos abrieron sus cuentas y comenzaron, con más o menos acierto según los casos, a familiarizarse con las redes sociales en los últimos cinco años.

\section{El papel del periodista}

Después de que Internet modificase la relación tradicional entre fuente/emisor, periodista y receptor, la web social estableció nuevos marcos referenciales, con un mayor protagonismo de los usuarios, y animó a muchos ciudadanos a estar presentes en las redes sociales. Fue una evolución lógica, pero auspiciada por los principales actores del nuevo ecosistema mediático del siglo XXI. La incorporación de la tecnología digital y la evolución de la sociedad en red han puesto de manifiesto el inicio de una nueva etapa no solo para el ecosistema mediático, sino para los mediadores profesionales, los periodistas.

La ruptura de paradigmas y el impacto de las transformaciones no deben impedirnos observar lo que pervive del periodismo heredado del pasado siglo. Si analizamos la preceptiva periodística que preside la práctica profesional y los códigos deontológicos, constatamos que los principales valores éticos del periodismo y que defendieron los periodistas durante el pasado siglo permanecen en la actualidad $^{17}$. Lo que ocurre es que los periodistas muestran su desconcierto ante los cambios en las rutinas periodísticas, que han dejado sin efecto muchos de los antiguos sistemas de autorregulación ética de los profesionales de la comunicación, y apuntan a la necesidad de nuevas formas de control que resulten eficaces.

Aunque internet permite un funcionamiento en red, muchos procesos de trabajo permanecen estructuralmente iguales. El día a día de los periodistas sigue marcado por muchas rutinas de la producción

\footnotetext{
${ }^{17}$ Distintos estudios realizados sobre los principios que definen al periodismo y las características de las prácticas profesionales demuestran esta afirmación. A la hora de citar algunos trabajos concretos, podemos referirnos al libro The Elements of Journalism, de Bill Kovach y Tom Rosentiel (Three Rivers Press, New York, 2001, y publicado en castellano con el título "Los elementos del periodismo"). Los sucesivos informes elaborados por el "Proyect for Excellence in Journalism" dieron continuidad al citado trabajo (se puden consultar en: www.journalism.org), así como varios informes elaborados por observatorios de los medios (en especial, el de prensa brasileño -www.observatoriodaimpren sa.com.br- y el francés de los medios).
} 
noticiosa, pero se está modificando su papel como gatekeeper por los nuevos intermediarios que aconsejan y recomiendan, hay nuevas dinámicas en el campo periodístico, sin que éstas alteren las principales bases de actuación. Es cierto que en los últimos cinco años, de la mano de las herramientas de la web social, hubo alteraciones estructurales en las rutinas productivas de los periodistas, pero no hubo grandes cambios en la propia cultura de Newsroom y en la integración de los profesionales en la redefinición de estrategias para el futuro.

La búsqueda de una nueva cultura para las redacciones se produce en una sociedad de matriz digital, bajo la alargada sombra de las herramientas actuales, y en un escenario marcado por los debates periodísticos apuntados. Aunque muchos de los desafíos afectan a los medios tradicionales y a los nuevos medios, lo cierto es que cada grupo busca sus propias recetas a la hora de redefinir las estrategias para el cambio que haga posible afrontar la cultura del periodismo para la sociedad en red. Mientras, desde distintos sectores ciudadanos se destaca el papel de piedra angular -central, por lo tanto- en las sociedades democráticas actuales.

El proceso de reconfiguración de los medios de comunicación en España está marcado por la convergencia digital, tanto en el ámbito tecnológico (multiplataforma) como en el empresarial (concentración), en el profesional (polivalencia) y de contenidos (multimedialidad) ${ }^{18}$. Las tendencias de la evolución en los últimos diez años (2000-2010) indican que, además de la nueva organización logística, con la consiguiente reorganización de las redacciones, y del incremento de plataformas de distribución, también se ha producido un impulso en las coberturas informativas coordinadas entre distintos medios, una adaptación de los profesionales al nuevo marco tecnológico.

La reorganización de las redacciones, la aplicación de las herramientas de la web social, la búsqueda de nuevas vías para conectar con los usuarios y propuestas de nuevas técnicas y formatos para hacer el mejor periodismo constituyen el eje central de lo que dicen los principales diarios españoles en papel y sus correspondientes cibermedios españoles que están haciendo para afrontar ahora, en el

\footnotetext{
${ }^{18}$ Los resultados de las tendencias de la reconfiguración de los medios de comunicación en España entre los años 2006 y 2009 pueden consultarse en el libro Convergencia digital. Reconfiguración de los Medios de Comunicación en España, coordinado desde el grupo Novos Medios por Xosé López y Xosé Pereira.
} 
cambio de década, los nuevos desafíos ${ }^{19}$. Y es en esas nuevas vías de conectar con los usuarios y promocionar los trabajos de los periodistas donde hay que enmarcar el papel de algunos conocidos periodistas españoles que han dirigido medios en papel y que actualmente dirigen medios digitales o tienen una importante presencia en las redes sociales después de una brillante trayectoria como reporteros o como responsables de importantes cabeceras.

\section{Los datos de algunos periodistas españoles en Twitter}

Aunque la industria de los medios de comunicación tradicionales ha entrado en las redes sociales diferenciando sus capacidades como herramienta de comunicación y sus cualidades como instrumentos de estructuración (Campos, 2013: 333), lo cierto es que algunos de los periodistas españoles que han estado al frente de esos medios se muestran muy activos en la actualidad, en el año 2014, y parecen caminar hacia una renovada visión del papel de las redes sociales. El uso de las redes sociales desde la difusión, la recepción y la interacción les conduce a una práctica que les muestra que esas dos dimensiones (comunicación y estructuración) caminan de la mano.

El análisis de la presencia en Twitter de directores y ex directores de medios tradicionales como Casimiro Garcia-Abadillo, Fernando Jauregui, Pedro J. Ramírez, Antonio Caño, Jesús Rivasés, Agustín Valladolid, Jesús Maraña, Arsenio Escolar o Bieito Rubido muestra que han quedado atrapados por las redes sociales y que cultivan su presencia en estos canales de comunicación de la sociedad en red. Lo mismo ocurre con el veterano reportero de especialista en temática internacional Ramón Lobo, conocido bloguero y actual colaborador en varios medios de, tanto tradicionales como nativos digitales.

A continuación recogemos capturas del perfil oficial de los periodistas mencionados en Twitter así como los datos más relevantes de su actividad en dicha red social ${ }^{20}$ :

\footnotetext{
${ }^{19}$ Los datos están recogidos del seguimiento de las secciones de comunicación de los nueve principales diarios españoles de información general, en sus versiones en papel y on line, durante los seis primeros meses de 2010.

${ }^{20}$ La muestra para el seguimiento de las cuentas que se recoge en este trabajo se hizo el día 17 de octubre del año 2014.
} 
Imagen 1: Perfil y datos de los periodistas mencionados en Twitter

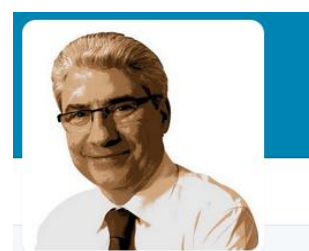

c. garcia-abadillo

Periodista. Director de EL MUNDO

$\checkmark$ Madrid

() Joined February 2011

$$
\begin{aligned}
& \text { FOLLOWERS } \\
& 64 \mathrm{~K}
\end{aligned}
$$

$\begin{array}{cc}\text { FAVORITES } & \text { LISTS } \\ 7 & 1\end{array}$

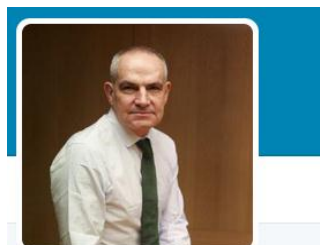

Antonio Caño

Director de El Pais Editor-in-chief

P SPAIN

8 elpais.com

(ㄷ) Joined April 2009

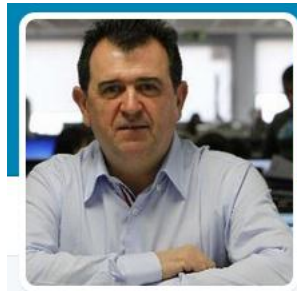

Arsenio Escolar

Periodista. Director de 20

minutos/20minutos.es. Antes, en muchos

otros medios

$\checkmark$ Madrid

(3) blogs.20minutos.es/arsenioescolar

() Joined April 2011
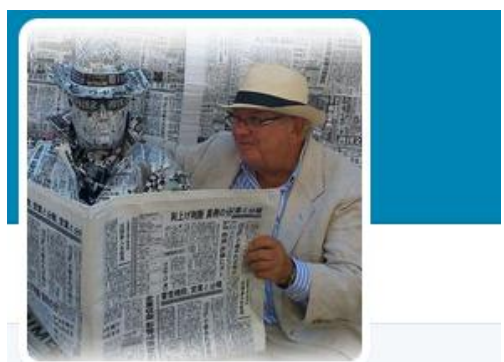

Fernando Jáuregui

@Fjaureguic

Editor del Grupo Diariocritico

@diariocritico

(2) diariocritico.com/blogs/politica/

() Joined February 2010
TWEETS FOLLOWING FOLLOWERS FAVORITES LISTS

$14.2 \mathrm{~K}$

$25.1 \mathrm{~K}$

\section{TWEETS \\ FOLLOWING \\ FOLLOWERS \\ $15.9 \mathrm{~K}$ \\ 28 \\ 7,701}

15.96




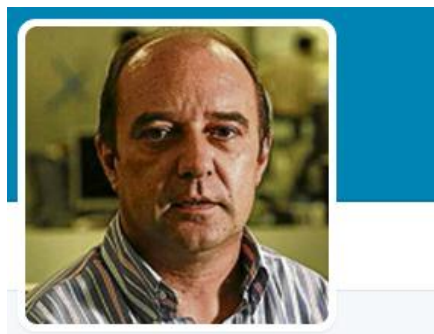

roliowing

FOLLOWERS

FAVORITES

\section{Jesús Maraña}

@jesusmarana

Periodista. Director editorial de

@ infolibre. Antes, 'Público' y unas

cuantas aventuras más. Me equivoco,

pero no miento.

$\checkmark$ Madrid

(S) infolibre.es

(ㄷ) Joined March 2011

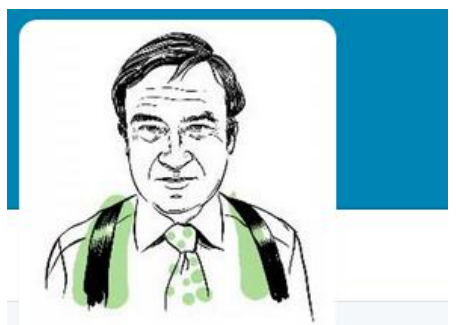

Pedro J. Ramirez

@pedroj_ramirez

Fundador, 25 años Director y ahora

Columnista de EL MUNDO

$\mathcal{Q}$ elmundo.es

() Joined March 2011

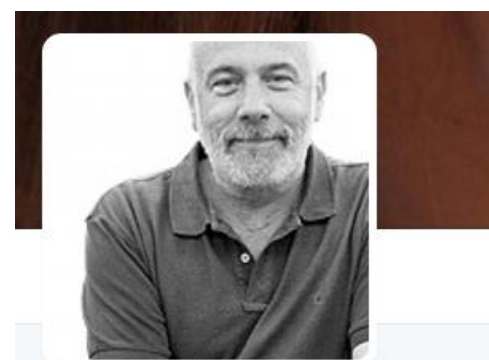

Ramón Lobo

@ramonlobo

Spanish war correspondant for 20 years in Balkans, Chechenia, Africa, Irak and Afghanistan. I would like to write stories in Latin America. Writer and blogger

P Spain

(3) ramonloboweb.com

(). Joined January 2009

\section{TWEETS FOLLOWING FOLLOWERS FAVORITES} 441 $69.2 \mathrm{~K}$ 375 


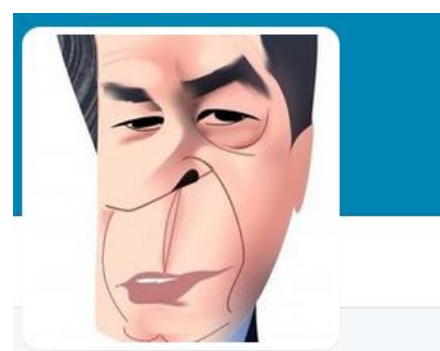

jesusrivases

@jesus_rivases

Director de la revista TIEMPO, periodista, escritor

S

tiempodehoy.com/COMUNIDAD/blog...

(ㄷ) Joined April 2011

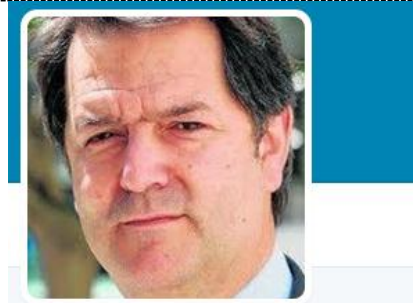

Bieito Rubido

@bieitorubido

Toda mi vida he querido ser periodista

No recuerdo otra vocación. Es un

privilegio dirigir $A B C$, innovador en su

nacimiento y que aspira a seguir

siéndolo.

$\mathcal{S}$ abc.es

() Joined April 2011

\section{TWEETS}

6,080

FOLLOWING 446

FOLLOWERS

4,589

FAVORITES

$\begin{array}{cccc}\text { TWEETS } & \text { FOLLOWING } & \text { FOLLOWERS } & \text { FAVORITES } \\ 6,397 & 457 & 14.1 \mathrm{~K} & 2\end{array}$

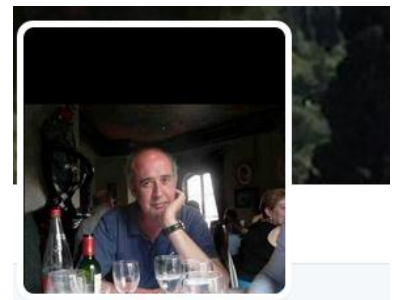

$\begin{array}{ccccc}\text { TWEETS } & \text { FOLLOWING } & \text { FOLLOWERS } & \text { FAVORITES } & \text { LIS } \\ 4,915 & 907 & 1,538 & 130 & :\end{array}$

Agustín Valladolid

Periodista. Director de Zoom News. Ex

director de Tiempo e Interviú. Escribo

todas las semanas en Zoom News y en

Tiempo.

España

8 zoomnews.es

() Joined July 2011

Fuente: Elaboración propia a partir de capturas de pantalla de Twitter

Los datos del análisis de su presencia en Twitter indican que son muy activos y constantes en su participación en la red social de microbologging. Así, vemos que los más veteranos en estas lides son 
Ramón Lobo y Antonio Caño, que tienen perfil en Twitter desde enero y abril del año 2009, respectivamente. La mayoría llegó a esta red social en el año 2011, en un momento en el que su uso profesional ya estaba más o menos consolidado.

Unos son más prolíficos que otros en sus manifestaciones en forma de tuits, ya que Agustín Valladolid, director de Zoom News, cuenta con casi 5.000 mensajes lanzados a la red social del pájaro mientras que Pedro J. Ramírez es un auténtico adicto a Twitter, tal y como demuestran sus más de 60.000 tuits. Además, hay que tener en cuenta que Pedro J. llegó a Twitter en 2011, por lo que el cálculo sale a unos 20.000 tuits al año.

La mayoría ha ido intensificando su relación con Twitter y los tuiteros a partir de 2011, donde se concentran la mayor parte de los tuits e interacciones provocadas y recibidas por nuestro elenco de periodistas.

Esta participación desigual en Twitter también ha configurado, tal y como se puede comprobar en las capturas aportadas, diferentes comunidades dependiendo de la actividad de los periodistas, de su fomento de la interacción y, en definitiva, del grado de participación que han mostrado con sus comunidades en el tiempo que llevan tuiteando. Pedro J. Ramírez es la referencia en cuanto a número de seguidores ya que destaca con más de 275.000. Jesús Maraña es el siguiente en el escalafón de los periodistas analizados con la comunidad más grande con más de 100.000 seguidores y ya a la zaga aparecen Ramón Lobo y Arsenio Escolar con más de 69.000 y García Abadillo con 64.000 o Antonio Caño con 25.000.

\section{A modo de conclusión}

El periodismo afronta nuevos desafíos por el proceso de reconfiguración que vive el ecosistema mediático y por el impacto de las redes sociales, que ha llevado a muchos periodistas a tener presencia en estos canales de comunicación tanto para difundir sus trabajos como para entablar relación con los usuarios. La reorganización de las redacciones, que algunos de los veteranos periodistas de medios promovieron, y la aplicación de las herramientas de la web social les han colocado ante nuevos retos profesionales, que asumen como una experiencia en la que muestran destrezas, si nos atenemos al número de seguidores y al número de tuits emitidos. 
Las redes sociales, que mantienen altos índices de usuarios habituales en nuestro país y los países de nuestro entorno, están cada vez más presentes en las actividades profesionales de los periodistas. Un número considerable de los profesionales de la información españoles han incorporado las redes sociales a sus rutinas de trabajo. Aunque muchos llegaron a ellas con muchos recelos, algunos de los últimos estudios revelan un progresivo incremento de su uso por parte de los profesionales de los medios de comunicación españoles. La práctica totalidad de los cibermedios españoles gestiona su presencia en redes sociales, con más o menos intensidad, y conocidos periodistas se han convertido en relevantes "tuiteros".

El seguimiento de las cuentas de twitter de diez conocidos periodistas españoles, que han ocupado u ocupan puestos relevantes en medios de comunicación, señala que la mayoría no lleva más de tres años participando en Twitter y los que crearon su perfil antes no han empezado a mostrar una actividad elevada hasta después de ese año 2011. La gran mayoría son activos o muy activos y cuentan con comunidades de seguidores de un tamaño proporcional a su actividad, nivel de interacción e implicación en la conversación tuitera.

En líneas generales, se observa cómo los periodistas, en un primer momento más reacios a tener presencia en Twitter o a tener una actividad reseñable en esta red social, ya están acostumbrados al uso de los 140 caracteres, conocen los mecanismos de interacción, los fomentan y cuidan a sus comunidades en forma de respuestas, interacción efectiva y participación constante.

\section{Referencias bibliográficas}

Gastil, J. (2008): Political Communication and Deliberation. Thousand Oaks/London: Sage.

Haas, T. (2005): “From 'public journalism' to the 'public's journalism'? Rhetoric and reality in the discourse on weblogs", en Journalism Studies, 6 (3), páginas 387 a 396.

Hermida, A. y Thurman, N. (2008): "A clash of cultures: The integration of user-generated content in the discourse on weblogs", en Journalism Studies, 6 (3), páginas 387 a 396.

Herrero Curiel, E. (2013): Periodistas y redes sociales en España. Del 11 M al 15 M. (2004-2011). Madrid: Universidad Carlos III. Tesis doctoral.

Kovach, B. y Rosenstiel, T. (2007): The Elements of Journalism: 
What Newspeople Should Know and the Public Should Expect. New York: Three River Press

López, X. y Pereira, X. (coordinadores)(2010): Convergencia digital. Reconfiguración de los Medios de Comunicación en España. Santiago de Compostela: Universidad de Santiago.

Negroponte, N. (1995): El mundo digital. Barcelona: Ediciones B. Puede consultarse en la red en:

http://users.dcc.uchile.cl/ cgutierr/cursos/INV/serDigital.pdf. Consulta para este trabajo: 14 de octubre de 2014.

Patterson, C. y Domingo, D. (2008): Making online news: The etnography of new media production. New York: Peter Lang.

Thurman, N. (2008): "Forums for citizen journalists? Adoption of user generated content initiatives by online news media", en New Media \& Society, 10 (1), páginas 139 a 157.

* Este texto se basa en los datos recogidos y analizados en el estudio sobre periodistas españoles relevantes de más de cincuenta años con presencia en Twitter elaborado en el marco del proyecto de investigación del Ministerio de Economía y Competitividad "Innovación y desarrollo de los cibermedios en España. Arquitectura de la interactividad periodística en dispositivos múltiples: formatos de información, conversación y servicios" [Referencia: CSO2012-38467C03-03]. 


\section{Redes y comunicación organizacional. Aproximación al discurso científico y a los retos más próximos}

Berta García Orosa, Universidad de Santiago de Compostela (USC, España),bertago@gmail.com

\section{Resumen}

Las redes sociales, entendidas como un instrumento más de la comunicación organizacional, han alcanzado en los últimos años un lugar importante en la estrategia de los departamentos de comunicación. Sin embargo, las potencialidades de la red parecen todavía aletargadas en algunos elementos nucleares. El artículo realiza una aproximación al panorama de su conceptualización y uso en la práctica de los departamentos de comunicación a través del discurso creado por la academia en las revistas científicas. Finalmente, analiza los retos próximos y las posibilidades de cambio de modelo comunicativo en comunicación organizacional.

Palabras clave: redes sociales, gabinetes de comunicación, comunicación organizacional, web 2.0, internet, dircom.

\section{Introducción}

— L origen y la evolución de los gabinetes de comunicación en los 1 diferentes países europeos desarrollan historias distintas (Rodríguez Salcedo, 2012: 334) pero caracterizadas, en cualquier caso, por una gran influencia en la opinión pública. Cada vez más 
vinculados a las direcciones de las entidades y en más sectores y organizaciones -incluso con la creación frecuente de gabinetes encargados de la comunicación de una única persona-, fueron asumiendo responsabilidades, retos y exigiendo nuevos perfiles profesionales.

En España en las últimas décadas del siglo pasado, destacamos dos momentos de gran desarrollo: el cambio de régimen político y la década de los 80 . Pero, sin duda, desde la última década del siglo XX, la irrupción de un nuevo instrumento -internet- permite comenzar a reflexionar sobre un nuevo modo de comunicación organizacional. No obstante, el diseño de estrategias específicas para la red fue muy paulatino y diferente en cada entidad. El cambio de modelo comunicativo implementado a través de este instrumento lo denominamos gabinete 2.0 o gabinete transparente o colaborativo que, en su fase más avanzada, conllevaría la creación de una comunidad colaborativa que participaría en la elaboración de mensajes con el departamento de comunicación. Se trataría del inicio de un nuevo modelo comunicativo en el que se crearían estructuras participativas para obtener ventajas mutuas en las que el gabinete obtendría una mayor presencia en internet y un buen retorno de su posición en la red social (García Orosa, 2009). Esta comunidad virtual permitiría al departamento de comunicación aprovechar todos los recursos de la red, entre ellos, el feed-back recibido a través de diferentes medios de los receptores. Así, el departamento de comunicación es un actor más que, aunque provee información, ya no es el emisor único (pero sí privilegiado) de las anteriores fases, sino que participa en el proceso.

No obstante, esta presencia y la incitación a la interacción no siempre implican una conversación real con el ciudadano y algunos investigadores advierten en algunos casos sobre la continuidad de un $<$ modelo de la normalización, o ajuste de los nuevos medios a las pretensiones tradicionales de impacto persuasivo y propaganda> (Dader, Cheng, Campos, Quintana, Vizcaíno-Laorga, 2014: 116). En este sentido, Sánchez Duarte y Rodríguez Esperanza (2013) señalan cómo los partidos políticos y sus candidatos despliegan sus páginas digitales para consolidar por otra vía sus afanes de persuasión y propaganda dominantes en campañas tradicionales con el fin de $<$ permanecer, estar en la red $>$. 
Dentro de estas potencialidades de cambio de modelo, las redes sociales son unas de las herramientas más útiles ya que en su esencia está escrita la relación con el ciudadano y, por lo tanto, la aproximación a una comunicación 2.0. No realizaremos una revisión de la conceptualización de redes sociales, remitimos a la extensa y completa revisión de la investigación sobre el tema elaborada por Francisco Campos (2013) y, para este artículo, entendemos las redes sociales como un instrumento más dentro de la estrategia de comunicación organizacional.

Los informes sobre el desarrollo de la Sociedad de la Información y los específicos sobre periodismo coinciden en el incremento del uso de redes sociales (Cerviño, 2013; Herrero, 2013). Los directores de comunicación no son ajenos a esta evolución de uno de sus públicos objetivos y las redes sociales se conviertan en parte fundamentales de la evolución de los departamentos de comunicación de las últimas décadas (Noguera, A.; Peláez Sánchez, I., 2013; Soler, 2013).

La producción científica en este sentido ha sido prolija y no pretendemos con las limitaciones espaciales del capítulo hacer una exhibición exhaustiva ni siquiera un resumen de las mismas. Antes bien, las próximas líneas pretenden marcar las tendencias de un fenómeno contemporáneo a las mismas a través del discurso elaborado por los académicos en las revistas científicas españolas ya que, por las características del tema abordado, son éstas las más capacitadas para ofrecernos una panorámica completa y actual.

\section{Redes sociales: conversación y seguimiento del usuario}

Los directores de comunicación introdujeron en sus estrategias las redes sociales concretas que sus públicos iban incorporando a sus hábitos de relación en línea. Este nuevo instrumento podía haber sido un impulso para transformar el modelo tradicional de los gabinetes de comunicación, unidireccional y asimétrico, hacia el que denominamos CCAA y que incluye las siguientes funciones: crear contenido, conocer e investigar, conversar y actualizar. Las redes sociales aportan valor para todos los brazos de dicho modelo comunicativo pero proponen avances, sobre todo, en el ámbito de la investigación y de la conversación con los diversos públicos. Si bien en el primero de ellos la transformación fue destacable, en el segundo de ellos, los pasos son 
paulatinos y muy diferentes en cada una de las entidades. En muchas ocasiones, los dircom utilizaron las redes sociales más como una estrategia de marketing y promoción o como un instrumento de difusión y distribución en el mundo on line del mensaje construido, empaquetado y difundido por su propio departamento, que como verdaderas herramientas con vocación de intercambio comunicativo real con los ciudadanos.

La búsqueda de una estrategia coherente integrada dentro del plan de comunicación, que entienda a las redes sociales como un instrumento más con potencialidades interesantes para la modificación no sólo de mensajes sino también del propio modelo comunicativo, se dibuja en el horizonte y en algunas de las experiencias de los últimos años (García Orosa, 2013; Pérez Dasilva, Genaut Arratibel, Meso Aierdi, Mendiguren Galdospín, Marauri Castillo, Iturregui Mardaras, Rodríguez González, Rivero Santamarina, 2013; Capriotti, 2013).

Los gabinetes de comunicación integraron desde un primer momento a las redes sociales normalmente en un lugar privilegiado de la página web de la entidad e incluso con omnipresencia en todas las páginas a las que el receptor pudiera acceder. Se constatan diferencias importantes en el empleo en cada una de las experiencias seguidas por los investigadores pero la utilización de las redes como instrumento de investigación de hábitos y usos de los propios receptores, así como altavoces importantes que difunden y multiplican el alcance de los mensajes diseñados y lanzados desde los propios gabinetes de comunicación, son una clara apuesta por la visibilidad en la red.

No obstante, pese a la carencia de una estrategia común en la utilización de las redes sociales (Segado-Boj, Díaz-Campo, LlovesSobrado, 2015) algunas investigaciones desvelan tendencias concretas en ámbitos determinados: "However, it was also demonstrated that the use made of the different social networks and the communication strategies required by the different companies are distinguishable and identifiable" (Pérez, Genaut, Meso, Mendiguren, Marauri, Iturregui, Rodríguez, Rivero, 2013).

Se trata, de todos modos, de estudios de caso que nos ofrecen una fotografía o panorámica general de un aspecto concreto de la realidad analizada. Dos de los ámbitos que más interesaron a los investigadores en los últimos años son la universidad y la comunicación política entendida, sobre todo, como mensajes 
transmitidos desde las instituciones públicas y los partidos políticos, aunque cada vez más se extienden a otros ámbitos como los museos, las ONG o las empresas en general.

En el primero de los ámbitos de estudio, la comunicación política, los investigadores se centran en las campañas electorales ya que es el período en el que políticos y partidos utilizan casi exclusivamente -salvo excepciones- las redes (Cabezuelo Lorenzo; Ruiz Carreras, 2010) y, sobre todo en el ámbito municipal, más proclive, en principio, al diálogo con la ciudadanía. En la misma dirección que lo apuntado anteriormente, el uso de las redes en campaña electoral todavía no aprovecha todas las potencialidades que las redes sociales ofrecen como han señalados algunos autores: < Still, the opportunity Twitter presented for greater specificity, proximity, empathy, and humanization was overlooked, and these goals remained forgotten aspects in the traditional mediated campaigns $>$ (Zamora, Zurutuza, 2014). Los mensajes, similares en muchas ocasiones a los trasladados a través de los medios tradicionales y deudores de los lemas breves, concisos y repetitivos adoptados por los partidos políticos, no responden a las necesidades de los usuarios de las redes sociales ávidos de nuevas informaciones ni a las de la propia tecnología que, dadas las características de formato y transmisión, exigen nuevas narrativas. Tampoco cubren las estrategias políticas las posibilidades de conversación y diálogo bidireccional con el ciudadano ya que, si bien, ofrecen los logos de las redes sociales (con un incremento importante de su número) no implican una respuesta en casi ningún caso por parte de los promotores políticos (Sampedro, 2008; Dader, Campos, 2005), antes bien funcionan como elementos de propaganda y difusión de información.

Los resultados son relativamente optimistas en los estudios de corte cuantitativo ya que el uso de las redes sociales presentes desde el inicio en una parte importante de los actores analizados, registra un incremento relevante. Como ejemplo de este punto, el análisis de Buendía (2014) sobre el PSC-PSOE en el que sostiene que ha habido una evolución en relación con la manera de implicar a los grassroots e incrementar la participación ciudadana atendiendo a que "el número de retweets y de mensajes de respuestas aumentó, de 2010 a 2012, multiplicándose por 3,5”. Pero el optimismo se relativiza cuando los investigadores optan por analizar las opciones reales de conversación y 
participación de los ciudadanos. En el caso de los ayuntamientos, por ejemplo, se asegura que "no tienen como finalidad prioritaria entablar una relación comunicacional con el ciudadano, ni tampoco ésta se incrementa en función del nivel poblacional” (García Jiménez, 2013). De igual modo ocurre cuando las redes sociales las utilizan los alcaldes. En estudios de casos propuestos por Vázquez Sande (2013) y López Pumar (2014), entre otros, se insiste en que la utilización por parte de los alcaldes de twitter es entendida como un instrumento más de un modelo de comunicación unidireccional y asimétrico.

Fuera del ámbito de la campaña electoral, en el Congreso de los Diputados Túñez y Sixto (2011) indican el bajo nivel de uso de las redes sociales y señalan que todavía se no se detecta una confianza real en su uso como "forma de contacto directo, como plataforma de visibilidad de la persona y de su gestión, como herramienta de ciberactividad, como alerta de posibles conflictos o como foro de debate". Del mismo modo acontece en casos de crisis analizados como el "Bárcenas" (Polo Serrano, Cárdenas Rica, 2014) en el que las redes tuvieron un uso puramente propagandístico.

Sin embargo, las potencialidades de la red permanecen intactas e incluso en algún estudio se propone su uso desde el punto de vista de la investigación como predictores. En este sentido, un estudio realizado durante las elecciones autonómicas andaluzas de 2012 dibuja un modelo de predicción de resultados electorales a través de twitter. "Todas las encuestas tradicionales que se realizaron durante la campaña electoral se equivocaron en sus predicciones con un error del 8,69 al 13,30 puntos porcentuales entre los dos grandes partidos, sin embargo utilizando nuestro modelo basado en Twitter el error es de 3,01 puntos porcentuales" (Deltell, Claes, Osteso, 2013).

En el caso de las universidades la tendencia parece apuntar hacia un empleo más heterogéneo en el momento actual (Rodríguez y Santamaría, 2012), pero con falta de planificación (Reina, Fernández, Noguer, 2012). La práctica totalidad de las universidades españolas tienen presencia en redes sociales (Paniagua Rojano, Gómez Calderón, Fernández Sande, 2012; Alonso, Alonso, 2014; Reina, Fernández, Noguer, 2012 y Simón, 2014; Bustos, 2013), aunque el camino hacia la interacción con el usuario y la participación es lento (Gómez Calderón y Paniagua Rojano, 2014; Rodríguez y Santamaría, 2012). 


\section{Funciones de las redes sociales en la comunicación organizacional}

Dentro del modelo comunicativo indicado anteriormente, las redes sociales pueden ejecutar diferentes funciones y roles en función del plan de comunicación establecido por la entidad. En el siguiente gráfico pretendemos resumir esos roles, puntualizadas a continuación por las particularidades de algunas entidades o ámbitos analizados por investigadores españoles:

Imagen 1: Redes sociales y comunicación organizacional. Modelo comunicativo

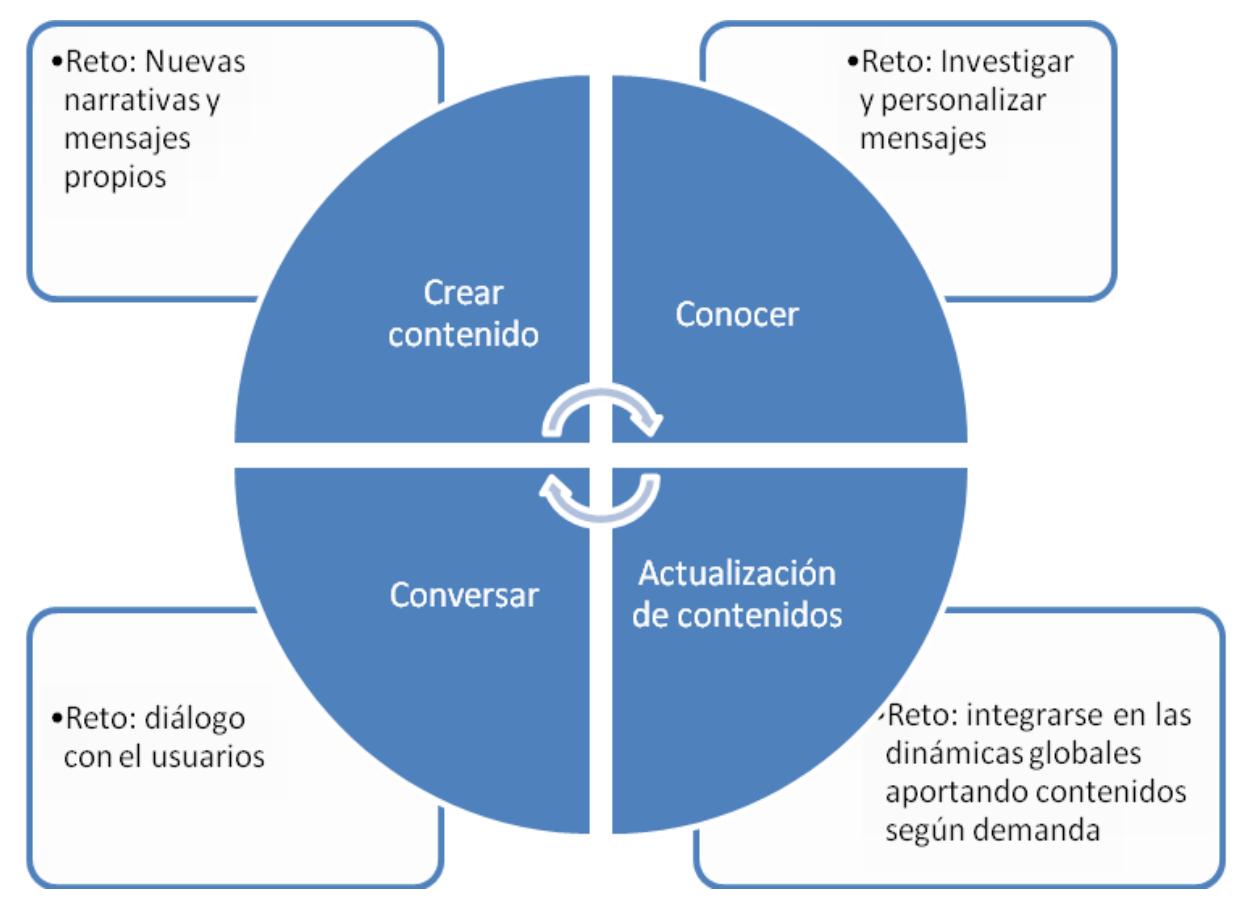

Fuente: Elaboración propia

Como se puede observar en la imagen, uno de los principales roles que están desempeñando las redes sociales es la difusión y distribución de contenido diseñado por el gabinete de comunicación, normalmente de carácter informativo o persuasivo. Sirva como ejemplo, un estudio de caso sobre el Servei Catalá de Trànsit (SCT) en el que se concluye que twitter se utiliza básicamente como complemento a los contenidos distribuidos a través de la web sin casi opciones de diálogo con los periodistas (González-Molina, 2013).

Sin embargo, las redes sociales, igual que todas las herramientas de la red permiten y exigen mensajes y formatos específicos que 
permitan aprovechar todas sus potencialidades. Así, se estipula como reto la utilización de nuevas narrativas y mensajes específicos para las redes, que podría incluir, entre otros, la convergencia de soportes.

La actualización de contenido inmediata y la capacidad para conocer e investigar los hábitos y usos de cada una de las personas que consumen información o participan en las redes es una de las peculiaridades compartidas con otros elementos de la red y, en algunos casos, de las más desarrolladas con el fin de elaborar mensajes personalizados para el usuario. Otra de las funciones destacadas de las redes sociales es, además de la de informar y difundir información, la de fidelizar a un público determinado aunque sea a través de temas diferentes a los suyos. Así lo explican Ruiz Iniesta en el caso del uso de redes sociales por parte de los bancos para aproximarse a sus públicos con temas ajenos a la empresa como la Fórmula 1: $<$ Se ha comprobado que la respuesta del público aumenta considerablemente cuanto más se alejan las publicaciones de los temas empresariales, es decir, las publicaciones que tratan temas corporativos tienen una respuesta mucho menor que aquellas que tratan temas como la Fórmula 1, Fernando Alonso, sorteos, etc.> (Ruiz Iniesta, 2012: 70). De modo similar ocurre en el ámbito del fútbol (Olabe-Sánchez, 2015: 97) y en las compañías de telecomunicaciones mexicanas que utilizan Facebook primordialmente para sus relaciones públicas, publicidad y promoción, mientras que sus usuarios las utilizan primordialmente para reportar incidentes y problemas, formular quejas y solucionar dudas (Valerio, Herrera, Herrera, Martínez, 2015).

Pero, sin duda, la característica más destacada de los investigadores y Dircom de las redes sociales es la posibilidad de conversación, interacción o incluso debate con el usuario. Su aplicación correcta podría implicar grandes beneficios para el gabinete de comunicación pero, al mismo tiempo, también comporta determinados riesgos de imagen con una planificación e implementación incorrectas. Autores como Óscar Rodríguez (2012: 157) insisten en que lo más importante de las redes es crear diálogo con los usuarios y que éste sea bidireccional (Simón, 2014). Sin embargo, los estudios realizados por el momento dibujan una tendencia lejana a la bidireccionalidad y las posibilidades de conversación. 
Las redes sociales también se convirtieron en fundamentales en las situaciones de crisis ante las que no debemos obviar las redes como origen, seguimiento o herramienta de apoyo para la salida de la misma. Para su aplicación seguiremos las pautas clásicas propuestas para la gestión de comunicación de crisis (Martínez Rolán, 2012: 613): llevar la iniciativa, establecerse como autoridad, hablar con frecuencia, utilización del off-the record, dar la posición y repetirla, mostrar calma y no adoptar actitudes defensivas, poner al público en actitudes defensivas, no mentir, no especular y colaborar y no disputar con los medios de comunicación.

\section{Retos próximos}

Comentábamos, hace un lustro que <el dircom no sólo es un responsable de transmitir información; es responsable de ubicar y posicionar correctamente a la organización en un entorno global> (García Orosa, 2009). Hace dos años, Smolak-Lozano (2013: 470) argumentaba que las estrategias 2.0 predominan actualmente en las actividades de comunicación organizacional debido a su bajo coste de implementación, enfoque en el público y -posibilidad de medición-, lo que concuerda con los últimos paradigmas de comunicación online interactiva (Sheldrake, 2011). Sin embargo, indica el autor, "se despierta bastante incertidumbre en cuanto a la evaluación de su eficacia y efectividad entre los profesionales, los negocios que las desarrollan y los científicos".

Las nuevas herramientas tecnológicas y las aplicaciones en algunos casos de éxito superaron las previsiones. Los cambios de rutinas (Dircom), los nuevos perfiles profesionales y nuevas formas de narrar (transmedia, crossmedia...) conviven con, en algunos casos, una escasa adaptación a todos los soportes. Las oportunidades de las redes son variadas y la evolución irregular en los diferentes sectores.

En general, las características de la planificación e implementación de las redes sociales en los gabinetes coinciden con las normas generales de creación de un departamento online. Conviene destacar tres de ellas:

a. Internet de canal de transmisión a valor añadido. La entidad asume que la red ya no es sólo un mero canal de transmisión como en su 
día fueron el fax y el teléfono, sino que incluye un valor añadido al mensaje transmitido.

b. Plan de comunicación. Es fundamental que el uso de redes sociales en la estrategia de comunicación de la entidad esté imbricado en el plan de comunicación general de la misma. La implementación sin tener en cuenta este punto o su empleo contrario a la estrategia y filosofía básica de comunicación podría resultar negativo para la imagen y, por lo tanto, para la comunicación de la misma.

c. Conocimientos, recursos y competencias necesarias. La planificación, implementación y evaluación de las salas de prensa online fueron, desde el inicio, una espada de Damocles. La llegada de las redes sociales aceleró esta situación porque multiplicaron las posibilidades de participación de los usuarios y, sobre todo, la velocidad de respuesta a través de la accesibilidad de las herramientas y los dispositivos móviles. Para un empleo correcto y satisfactorio, los dircom no deberían olvidar en ningún caso que su aplicación debe conllevar las tres fases -planificación, implementación y evaluación-, todas ellas imprescindibles y que en todas ellas se debe contar con el personal, las competencias y habilidades técnicas y de comunicación correctas. Uno de los errores posibles, sería incluir redes sociales como una cuestión de imagen, pero sin un uso real. En su momento ocurrió con los foros que no se moderaban o no se dinamizaban, correos electrónicos que se consultaban cada cuatro días y, en el caso de las redes sociales, entradas en las redes sociales de moda como una apuesta superficial pero sin una participación activa y un seguimiento de la imagen de la entidad dentro de la misma.

\section{Referencias bibliográficas}

Buendía, D. F. (2014): “De lectores a creadores de discurso político. Participación ciudadana en Twitter en las campañas electorales del PSC-PSOE (2010-2012)"en Ámbitos, 26.

Bustos, L. (2013): "Nuevas tecnologías en los gabinetes de comunicación de las universidades españolas" en Revista Internacional de Relaciones Públicas, Vol. III (6), 137-154. Disponible en:

http://revistarelacionespublicas.uma.es/index.php/revrrpp/article/vi ew/195 [última consulta el 15 de marzo de 2015]. 
Cabezuelo Lorenzo, F. y Ruiz Carreras, M. (2010): "Comunicación digital y política en Aragón. Una fórmula para la bidireccionalidad en la interacción entre políticos y ciudadanos", en Revista Latina de Comunicación Social, 65, páginas 340 a 353, Disponible en:

http://www.revistalatinacs.org/10/art2/904 Aragon/26 Cabezuelo.h tml [última consulta el 15 de marzo de 2015].

DOI: $10.4185 /$ RLCS-65-2010-904-340-353

Campos Freire, F. (coord.) (2013): “Antologia de artículos científicos sobre redes sociales y la gestión de los medios tradicionales en las redes sociales digitales". La Laguna: Revista Latina de Comunicación Social. Disponible en:

http://www.researchgate.net/profile/Francisco Freire/publications [última consulta el 15 de marzo de 2015].

Capriotti, P. (2013): "Maniging Strategic Communication in Museums. The case of Catalan museums" en Communication \& Society / Comunicación y Sociedad, vol. 26 (3), páginas 98 a 116.

Casals Carro, M. J. (2005): Periodismo y sentido de la realidad. Teoría y análisis de la narrativa periodística. Madrid: Fragua.

Cerviño, B. (2013): El uso de las redes sociales como fuente de información para periodistas. Barcelona: Universidad Autónoma. Trabajo de fin de Máster. Disponible en:

http://www.recercat.net/bitstream/handle/2072/216886/Versión digital del trabajo.pdf? sequence $=1$ [última consulta el 15 de marzo de 2015.].

Dader, J. L., Cheng, L., Campos, E., Quintana, N., y VizcaínoLaorga, R. (2014): "Las webs de los partidos españoles en campaña electoral. Continuismo entre 2008 y 2011”, en Trípodos, 1 (34), páginas 115 a 152.

Dader, J. L y Campos, E. (2006): "Internet parlamentario en España (1999-2005): los recursos para el contacto ciudadano y su uso, con una comparación europea", en Zer. Revista de Estudios de Comunicación 11 (20), páginas 135 a 162.

Deltell, L., Osteso, J. M., y Claes, F. (2013): "Predicción de tendencia política por Twitter: Elecciones andaluzas 2012”, en Ámbitos, Revista Internacional de Comunicación, 22. 
García Orosa, B. (2009): Gabinetes de Comunicación online. Claves para generar información corporativa en la Red. Zamora: Comunicación Social ediciones y publicaciones.

García, B. C. y Jiménez, A. G. (2013): "Herramientas interactivas y participación ciudadana en los ayuntamientos españoles" en Ambitos: Revista internacional de comunicación, (22), páginas 181 a 190.

González-Molina, S. (2013): "El uso de Twitter en el entorno del Periodismo Institucional 2.0: estrategias cross-media y diálogo informativo", en Icono 14, volumen 11 (2), páginas 141 a 162. Doi: 10.7195/ri14. v11i2.582

Herrero, E. (2013): Periodistas y redes sociales en España. Del 11M al 15M (2004-2011). Getafe: Universidad Carlos III. Tesis doctoral.

Disponible en: http:// fcic.periodistes.org/wpcontent/uploads/2013/11/Estudi-Periodistas-y-redes-sociales-enEspaña.pdf [última consulta el 15 de marzo de 2015].

Lobo, M. D. O. y Pérez, L. M. L. (2013): “La divulgación de la Ciencia española en la Web 2.0: El caso del Consejo Superior de Investigaciones Científicas en Andalucía y Cataluña”, en Revista Mediterránea de Comunicación: Mediterranean Journal of Communication, 4(1), páginas 169 a 191.

López Pumar, P. A. (2014): "Uso de Twitter por los alcaldes de las capitales de provincia españolas entre marzo y mayo de 2012", en Ambitos, 26.

Martínez Rolán, X (2012): "La irrupción del Social Media en la comunicación de crisis", en Estudios sobre el mensaje periodístico, vol 18 (n. especial), páginas 607 a 615.

Moreno Sardà, A; Molina Rodríguez-Navas, P y Corcoy Rius, M (2013): "La información de las administraciones públicas locales. Las webs de los ayuntamientos de Cataluña", en Revista Latina de Comunicación Social, 68, páginas 502 a 528. Disponible en: http://www.revistalatinacs.org/068/paper/987 Bellaterra/21 Moren o.html. [Última consulta el 15 de marzo de 2015]. DOI: 10.4185/RLCS-2013-987/CrossRef link

Noguera Vivo, J. M. (2010): "Redes sociales como paradigma periodístico. Medios españoles en Facebook", en Revista Latina de Comunicación Social, 65, páginas 176 a 186. Disponible en: http://www.revistalatinacs.org/10/art/891 UCAM/13 JM Noguera. 
html. [última consulta el 15 de marzo de 2015]. DOI: 10.4185/RLCS65-2010-891-176-186.

Olabe-Sánchez, F. (2015): "El gabinete de Comunicación como impulsor de la gestión comunicativa de los clubes de fútbol", en Revista Mediterránea de Comunicación: Mediterranean Journal of Communication, 6(1), páginas 83 a 104.

Paniagua Rojano, F. J.; Gómez Calderón, B. J. y Fernández Sande, M. (2012): "La incorporación de los departamentos de comunicación de las universidades españolas al entorno digital. Un análisis cuantitativo", en Estudios sobre el Mensaje Periodístico, 18, páginas 691 a 701.

Pérez Dasilva, J. Á., Genaut Arratibel; Meso Aierdi, A. K.; Mendiguren Galdospín, T.; Marauri Castillo, I.; Iturregui Mardaras, L.; Rodríguez González, M. M. y Rivero Santamarina, D. (2013): "Companies on Facebook and Twitter. Current situation and communication strategies", en Revista Latina de Comunicación Social, 68, páginas 676 a 695. DOI: 10.4185/RLCS-2013-996en.

Polo Serrano, D y Cárdenas Rica, M. L. (2014): “Infoxicación y tweets: Análisis del caso Bárcenas a través del twitter de Mariano Rajoy", en Ámbitos. Revista Internacional de Comunicación, n.26 (tercer trimestre).

Reina Estévez, J., Fernández, I. y Noguer, A. (2012): “El uso de las redes sociales en las universidades andaluzas: el caso de facebook y Twitter", en Revista Internacional de Relaciones Públicas, Vol. II (4), páginas 123 a 144. Disponible en:

http://revistarelacionespublicas.uma.es/index.php/revrr $\mathrm{pp} /$ article/view/128. [última consulta el 15 de marzo de 2015]

Rodríguez Ruibal, A. y Santamaría Cristino, P. (2012): “Análisis del uso de las redes sociales en internet: Facebook y Twitter en las Universidades españolas", en Revista Iconpo14. Revista científica de Comunicación y Tecnologías emergentes, 10(2), páginas 228 a 246, doi: 10.7195/ri14.v10i2.198.

Rodríguez Ruibal, A y Santamaría Cristino, P. (2012): “Análisis del uso de las redes sociales en Internet: Facebook y Twitter en las Universidades españolas", en Revista Icono14. Revista científica de Comunicación y Tecnologías emergentes, 10(2), páginas 228 a 246. 
Rodríguez Salcedo, N. (2012): "Mapping public relations in Europe: writing national histories against the US paradigm", en Comunicación y Sociedad, vol. XXV (2), páginas 331 a 373.

Paniagua Riojano, F. J., Calderón, B. J. G., y Sande, M. F. (2012): "La incorporación de los departamentos de comunicación de las universidades españolas al entorno digital. Un análisis cuantitativo", en Estudios sobre el Mensaje Periodístico, 18, páginas 691 a 701.

Ruiz Iniesta, C. (2012): “El uso de las herramientas digitales por parte de los bancos. El caso de la imagen en Internet de Banco Santander y BBVA en época de crisis", en Revista Internacional de Relaciones Públicas, 4 (II), páginas 51 a 72.

Sampedro, Víctor (Ed.) (2008): Medios y elecciones 2004. La campaña electoraly "las otras campañas. Madrid: Editorial Universitaria Ramón Areces.

Sánchez Duarte, J. M. y Rodríguez Esperanza, S. (2013): “La extrema-derecha en Facebook. España 2000 y Democracia Nacional durante la campaña electoral de 2011", en Revista Mediterránea de Comunicación, vol. 4 (1), páginas 221 a 258. Disponible en: http://mediterranea-comunicacion.org. [última consulta el 15 de marzo de 2015].

Sande Vázquez, P. (2013): “Alcaldes españoles en Twitter: ¿diálogo o monólogo?”, en Fonseca, Journal of Communication, 7, páginas 44 a 71 .

Segado-Boj, F.; Díaz-Campo, J. y Lloves-Sobrado, B. (2015): "Líderes latinoamericanos en Twitter. Viejas costumbres para nuevos medios en tiempos de crisis políticas", en Revista Latina de Comunicación Social, 70, páginas 156 a 173. Disponible en:

http://www.revistalatinacs.org/070/paper/1040uni/10es.html. [última consulta el 15 de marzo de 2015]. DOI: 10.4185/RLCS-20151040

Baamonde Silva, X. M. (2010): "Ferias + web 2.0: medio definitivo de comunicación profesional”, en Revista Mediterránea de Comunicación/Mediterranean Journal of Communication, 1(1), páginas 98 a 112.

Simón Onieva, J. E. (2014): "El uso de las Redes Sociales en el ámbito de la comunicación universitaria andaluza/Using Social Networks in the field of Andalusian university communication", en Revista Internacional de Relaciones Públicas, 4(8), páginas 139 a 160. 
Smolak-Lozano, E. (2013): “Conceptos teóricos de la evaluación de las estrategias de comunicación en social media", en Estudios sobre el Mensaje Periodístico 19 (Núm. especial marzo), páginas 469 a 479.

Soler Humanes, A. (2013): "La Gestión de la Comunicación Externa Online con los Visitantes en los Museos y Centros de Arte Malagueños", en Revista Internacional de Relaciones Públicas, Vol. III (6), 197-216. Disponible en:

http://revistarelacionespublicas.uma.es/index.php/ revrrpp/article/view/234. [última consulta el 15 de marzo de 2015]

Túñez, M., y Sixto, J. (2011): "Redes sociales, política y Compromiso 2.0: La comunicación de los diputados españoles en Facebook", en Revista Latina de comunicación social, (66), páginas 1 a 25.

Valera Ordaz, L. (2013): “¿Deliberación 2.0 o radicalización de la retórica partidista? Un análisis de las discusiones políticas en los muros de Facebook de candidatos políticos españoles", en Text \& Visual Media, (5), páginas 311 a 340.

Valerio Ureña, G.; Herrera Murillo, D.; Herrera Murillo, N. y Martínez Garza, F. J. (2015): "Propósitos de la comunicación entre empresas y sus seguidores en Facebook", en Revista Latina de Comunicación Social, 70, páginas 110 a 121.

Disponible en:

http://www.revistalatinacs.org/070/paper/1037mx/07es.html.[última consulta el 15 de marzo de 2015].

DOI: $10.4185 /$ RLCS-2015-1037

Viñarás Abad, M. y Cabezuelo Lorenzo, F. (2012): “Claves para la participación y generación de contenido en redes sociales: estudio de caso del Museo del Prado en Facebook", en adComunica. Revista Cientifica de Estrategias, Tendencias e Innovación en Comunicación, 3, páginas 87 a 103. DOI: http://dx.doi.org/10.6035/2174- 0992.2012.3.6

VV.AA. (2013): El Dircom del futuro y el futuro del Dircom. Madrid: Burson-Marsteller.

Zamora Medina, R. y Zurutuza Muñoz, C. (2014): “Campaigning on Twitter: Towards the 'Personal Style' Campaign to Activate the Political Engagement During the 2011 Spanish General Elections", en Communication \& Society / Comunicación y Sociedad, Vol. 27 (1), páginas 83 a 106. 


\section{La gestión de la comunicación corporativa de las empresas mediáticas en Facebook y Twitter}

Ana María López Cepeda, Universidad de Castilla-La Mancha (UCLM, España), ana.lopezcepeda@uclm.es

\section{Resumen}

En un contexto de apertura y nitidez de la comunicación corporativa de las empresas a través de la web 2.0 y de las redes sociales, el objetivo de este artículo es presentar los resultados del análisis de la transparencia y gestión de la comunicación corporativa de los principales grupos de comunicación en España a través de las redes sociales. Para ello, se parte del análisis en profundidad de la información corporativa aportada por los grupos mediáticos a través de Facebook y Twitter.

Un avance de los resultados evidencia que si bien la mayoría de los principales grupos de comunicación españoles disponen de perfil en redes sociales, también es cierto que no lo utilizan de una forma completamente adecuada, conforme a los estándares teóricos de transparencia corporativa y buen gobierno.

Palabras clave: Facebook, Twiiter, grupos de comunicación, información corporativa. 


\section{Introducción}

T A web 2.0 ha revolucionado la forma de entender la red, Ldefiniéndose como un sistema de comunicación interactivo que permite multiplicar la relación y circulación de los mensajes mediante el uso de las nuevas herramientas informáticas y su distribución a través de Internet a miles de destinatarios. Este nuevo modelo de comunicación supone un cambio importante en el sistema de mediación social porque permite convertir en medios de autocomunicación masiva a las personas, administración pública e instituciones y empresas privadas a través de sus propias webs, blogs y enlaces o grupos respectivos en las diferentes redes sociales (López Cepeda, 2013: 3309).

A esta revolución tecnológica se une una importante crisis financiera y política que en los últimos años está asolando con fuerza a países como el nuestro. La propia recesión económica junto con casos flagrantes de corrupción política y empresarial han originado el incremento de demandas sociales en pro de una información más transparente y responsable de los gobiernos y administraciones públicas, pero también de las empresas privadas. Y todo ello apoyándose en el uso de las nuevas tecnologías comunicativas que ofrece internet. En palabras de Manuel Castells (2008):

"El surgimiento de la autocomunicación de masa proporciona un extraordinario medio para que los movimientos sociales y los individuos rebeldes construyan su autonomía y hagan frente a las instituciones de la sociedad en sus propios términos y en torno a sus propios proyectos".

El sector empresarial es consciente de la importancia que para la sociedad está teniendo la transparencia y el buen gobierno, por lo que la evolución de su comunicación a través de las redes sociales está siendo bastante positiva. La importancia de la nitidez en las organizaciones es cada vez más evidente reflejándose a través de la apertura social a una mayor información corporativa, social, política y económica pasando por un incremento de la accesibilidad y certeza. 
Los medios de comunicación social han contribuido a la expansión de este concepto de transparencia. Sin embargo, estas empresas no deben olvidar su condición de compañía que ofrece un producto y/o servicio a la sociedad, por lo que ellas también están obligadas a cumplir los similares criterios de gestión, organización y rendición que el resto de las empresas. A mayores, la actividad que desarrollan, en especial delicada dado el impacto político y sociocultural que generan en los ciudadanos, acentúa su responsabilidad con la ciudadanía (López Cepeda y Manfredi, 2013: 46).

En el ámbito académico, el buen gobierno corporativo o la transparencia de los medios no han sido temas preferentes (Arrese, 2006), si bien ya hay estudios que apuntan a un déficit de éstos (Almirón, 2005).

En este contexto de apertura y nitidez a través de la web 2.0 y de las redes sociales, el objetivo de este artículo es presentar los resultados del análisis comparativo del uso de las redes sociales por parte de los principales grupos de comunicación en España en relación a las empresas del IBEX-35, que han incrementado el uso de los medios de autocomunicación masiva en los últimos años. También se analizará en qué medida estos conglomerados mediáticos utilizan correctamente los perfiles corporativos en las redes sociales.

Un avance de los resultados evidencia que si bien la mayoría de los principales grupos de comunicación españoles disponen de perfil en redes sociales, también es cierto que no lo utilizan de una forma completamente adecuada, conforme a los estándares teóricos de transparencia corporativa y buen gobierno.

\section{Objetivo y métodos de investigación}

El objetivo de este artículo es conocer si los principales grupos de comunicación españoles utilizan correctamente las redes sociales a través de internet para ofrecer información corporativa de forma transparente y responsable en aras de mejorar su gobernabilidad y credibilidad en la sociedad.

Los principales medios de masas tienen redes sociales en las que se comunican con sus usuarios para informar y entretener. Sin embargo, el objeto de estudio de la presente investigación no es este tipo de comunicación, sino la relativa a cuestiones corporativas 
(órganos, accionistas, memorias, información socio-laboral, responsabilidad social...) que los conglomerados mediáticos publican a través de los medios de autocomunicación de masa.

Se eligieron los principales grupos de comunicación en España (y no los medios que los conforman) siguiendo la clasificación de Ramón Reig (2011), actualizada en el momento de la investigación (2014): Grupo Prisa, Unidad Editorial, Vocento, Grupo Planeta, Telefónica, Grupo Zeta, Grupo Godó, Editorial Prensa Ibérica, Grupo Mediapro, Grupo RTVE, Grupo Voz, Grupo Joly, Grupo Atresmedia, Grupo Promecal y Grupo Intereconomía. Se decidió analizar también el Grupo Mediaset (a través de Mediaset España Comunicación) dado que a pesar de tener origen italiano es una de las sociedades dominantes en el duopolio televisivo existente en España junto con Atresmedia (García Santamaría, 2013; García Santamaría, Pérez Serrano y Alcolea Díaz, 2014).

Se estudió la presencia de estos grupos en Facebook, Twitter, Linkedin, Instagram, Pinterest, YouTube, Flickr, Apple Store, Google + , Slideshare y Wikipedia siguiendo la clasificación de redes sociales publicada por Berceruelo en el año 2013.

El análisis se dividió en dos partes: la primera de ellas consistió en una comparativa entre la presencia en las redes sociales de los conglomerados de comunicación objeto de estudio y las empresas del IBEX-35.

Una vez constatada ésta se analizó en profundidad la información corporativa aportada durante el mes de octubre de 2014 por los grupos mediáticos a través de las redes sociales con más usuarios en España: Facebook y Twitter (AIMC, 2014) en función de los siguientes esquemas:

a. Facebook: 1) Número de publicaciones. 2) Número de publicaciones sobre noticias de actualidad: se entiende por este tipo de información aquella referida a hechos noticiosos no relacionados con la información corporativa del grupo. 3) Número de veces que han sido compartidas las noticias de actualidad. 4) Número de "Me gusta" de las noticias de actualidad. 5) Número de comentarios de las noticias de actualidad. 6) Número de publicaciones sobre entretenimiento: se entiende por este tipo de publicaciones aquellas que hacen referencia a cuestiones relacionadas con el ocio o la ficción sin contener información corporativa del grupo. 7) Número de veces que han sido 
compartidas las publicaciones sobre entretenimiento. 8) Número de "Me gusta" de las publicaciones sobre entretenimiento. 9) Número de comentarios de las publicaciones sobre entretenimiento. 10) Número de publicaciones sobre información corporativa: se entiende por información corporativa aquella que aporta datos sobre la gestión, administración, capital, estructura, responsabilidad social, premios, audiencias, etc. del grupo de comunicación en cuestión. 11) Número de veces que han sido compartidas las publicaciones sobre información corporativa. 12) Número de "Me gusta" de las publicaciones sobre información corporativa.13) Número de comentarios de las publicaciones sobre información corporativa.

b. Twitter: 1) Número de tweets.2) Número de tweets sobre información de actualidad: para clasificar la información de actualidad se aplicaron los mismos criterios que en el caso de Facebook. 3) Número de retweets de la información de actualidad. 4) Número de favoritos de la información de actualidad. 5) Número de tweets sobre entretenimiento / ficción: para clasificar el entretenimiento / ficción se aplicaron los mismos criterios que en el caso de Facebook. 6) Número de retweets sobre entretenimiento / ficción. 7) Número de favoritos sobre entretenimiento / ficción. 8) Número de tweets sobre información corporativa: para clasificar la información como corporativa se aplicaron los mismos criterios que en el caso de Facebook. 9) Número de retweets sobre información corporativa. 10) Número de favoritos sobre información corporativa.

\section{Internet y el auge de las redes sociales}

El uso de Internet es un fenómeno en constante crecimiento a lo largo de todo el mundo. En diciembre de 2013, la población mundial ascendía a 7.181.858.619 y se contabilizaron 2.802.478.934 de usuarios de internet.

Los datos evidencian que es en América del Norte en donde hay una mayor penetración de la red (84,9\%), seguida de Europa $(68,6 \%)$ y de Oceanía y Australia (67,5\%). América Latina y el Caribe (49,3\%), Medio Oriente (44,9\%), Asia (31,7\%) y África (21,3\%) presentan una penetración menor al 50\% pero el crecimiento es constante año a año en todos los continentes. En España con una población en 2013 de 47.737.941 habitantes se contabilizaron más de 35 millones de usuarios de internet (Internet World Stats, 2013) 
En este contexto, las redes sociales adquieren una gran importancia. Estas nuevas plataformas se definen como sistemas de comunicación masivos encuadrados en el marco de la web 2.0 y que permiten la multiplicación de mensajes, relaciones e impactos a partir del desarrollo de las herramientas de comunicación (López Cepeda, 2013: 3311).

Esta situación ha generado que la sociedad actual esté "más segmentada, personalizada, instantánea, diluida, convergente, transparente, flexible, liviana, conversacional, interconectada y abocada a la colaboración, participación y trivialización" (Campos Freire, 2008).

\section{Gestión de la comunicación corporativa en las empresas mediáticas}

La industria de la comunicación está en proceso de cambio, pero a pesar de ello pervive la idea de que los medios tienen una función primordial de guardianes en las sociedades democráticas. Esta función es la que origina que éstos tengan una enorme responsabilidad social, a través de una información libre y transparente que supervise las actividades del Estado y denuncie los abusos de los poderes públicos (Curran, 2005: 217).

Pero "si los grandes medios actúan como vigilantes de las instituciones sociales influyentes, inevitablemente también ellos deben ser transparentes para la sociedad" (López y Manfredi, 2013: 51).

En este contexto, la Unión Europea se ha preocupado de la transparencia en los medios de comunicación social y desde hace varios años ha orientado varias de sus políticas de comunicación a regular este aspecto. Son varias las directivas, reglamentos y recomendaciones de la UE a este respecto pero destacan la Comunicación de la Comisión sobre la aplicación de las normas en materia de ayudas estatales a los servicios públicos de radiodifusión (2001), revisada en 2009 y la Directiva de Servicios de Medios Audiovisuales (DSMA), aprobada en 2007 y modificada en 2010.

Algunas empresas audiovisuales públicas en Europa como las de Reino Unido y Alemania ya están adoptando estándares más transparentes (Fernández Lombao, 2013). En España, se ha producido un acercamiento a estas políticas con la aprobación de la Ley 7/2010, de 31 de marzo, General de la Comunicación Audiovisual que regula 
en el artículo 6 la transparencia de los medios de comunicación audiovisuales, señalando el "derecho a conocer la identidad del prestador del servicio de comunicación audiovisual, así como las empresas que forman parte de su grupo y su accionariado".

La necesidad de nitidez en los medios de comunicación públicos también está prevista en la Ley 2/2011, de 4 de marzo, de Economía Sostenible y en la reciente Ley 19/2013, de 9 de diciembre, de transparencia, acceso a la información pública y buen gobierno. En la primera de ellas se introduce la necesidad de mejorar la gobernanza en las empresas públicas; la segunda, tras su entrada en vigor reclamará la obligación de los entes públicos de dar a conocer información corporativa relevante a la sociedad.

Esta normativa, sin embargo, se concibe como insuficiente al regular la transparencia solo en los medios de comunicación audiovisuales y en los públicos, dejando al resto de los soportes la autorregulación, tantas veces objeto de fracaso en nuestro país. A esto habría que añadir que los requisitos impuestos legalmente a los operadores audiovisuales no se cumplen siempre en su total plenitud (López Cepeda y Manfredi, 2013).

\section{Gestión de la comunicación corporativa a través de las redes sociales}

El auge del concepto de transparencia y de responsabilidad social corporativa ha originado la tendencia a que las grandes empresas publiquen información corporativa a través de sus páginas web. Los valores de transparencia, responsabilidad, ética y rendición de cuentas están adquiriendo una gran importancia en la economía moderna (Campos, 2013: 33) y las empresas de comunicación deben adoptarlo desde una doble perspectiva: a) para informar a la sociedad de una forma veraz, transparente y responsable; b) pero también como compañías que son.

El contexto que ofrecen las redes sociales es idóneo para ser nítidas y responsables en la información corporativa. Las empresas del IBEX-35 ofrecen una evolución lenta pero positiva al analizar su presencia en las redes sociales. La nitideza de estas empresas pasa a ser uno de sus objetivos desde la publicación de la Ley 26/2003 de Transparencia de Sociedades Anónimas Cotizadas. 
En el año 2013, la investigación de Berceruelo (2013) señalaba que las redes sociales en las que había una mayor presencia de estas empresas eran Wikipedia, Linkedin, Youtube y Twitter, con una tendencia al incremento de su acceso a otros medios de autocomunicación masivos.

$\mathrm{Al}$ investigar la existencia de los principales grupos de comunicación en estas redes sociales se observa que tienen una mayor presencia en Facebook y Twitter que las empresas del IBEX-35. Igualmente hay un dominio de Linkedin, Wikipedia y Youtube en el sector mediático. Los principales hándicaps los encontramos en que son escasos los grupos de comunicación con un canal propio en Instagram o Pinterest. También se podría reclamar una mayor presencia de estos grupos en Apple Store, aunque la tendencia es positiva. Igualmente es destacable que el acceso a estas redes sociales desde la propia página web de las organizaciones objeto de estudio es en la mayoría de las ocasiones imposible o muy tedioso.

Tabla 1: Los principales grupos de comunicación españoles ${ }^{21}$ en las redes

\begin{tabular}{|c|c|c|c|c|c|c|c|c|c|c|c|}
\hline & Facebook & Twitter & Linkedin & Instagram & Pinterest & Youtube & Flickr & $\begin{array}{l}\text { Apple } \\
\text { Store }\end{array}$ & $\begin{array}{l}\text { Google } \\
+\end{array}$ & Slideshare & Wikipedia \\
\hline Grupo Prisa & $\bar{y}$ & $\bar{y}$ & $\bar{y}$ & $\bar{y}$ & $\bar{y}$ & $\bar{y}$ & $\bar{y}$ & $y$ & $y$ & $\bar{y}$ & $\bar{\gamma}$ \\
\hline $\begin{array}{l}\text { Unidad } \\
\text { Editorial }\end{array}$ & $\bar{y}$ & $\bar{y}$ & $\bar{y}$ & $\mathrm{X}$ & $\mathrm{x}$ & $\bar{y}$ & $\bar{\gamma}$ & $\mathrm{x}$ & $\bar{\gamma}$ & $\bar{y}$ & $\bar{\gamma}$ \\
\hline Vocento & $\bar{y}$ & $\bar{y}$ & $\bar{y}$ & $\bar{y}$ & $\bar{y}$ & $\bar{\gamma}$ & $\mathrm{x}$ & $\mathrm{x}$ & $\bar{y}$ & $\bar{y}$ & $\bar{\gamma}$ \\
\hline $\begin{array}{l}\text { Grupo } \\
\text { Planeta }\end{array}$ & $\bar{y}$ & $\bar{\gamma}$ & $\bar{y}$ & $\mathrm{X}$ & $\bar{\gamma}$ & $\bar{y}$ & $\bar{y}$ & $\bar{y}$ & $\mathrm{x}$ & $\bar{y}$ & $\bar{\gamma}$ \\
\hline Telefónica & $y$ & $\bar{y}$ & $y$ & $\mathrm{X}$ & $\mathrm{x}$ & $y$ & $\bar{y}$ & $\bar{y}$ & $\mathrm{x}$ & $\bar{y}$ & $\bar{y}$ \\
\hline Grupo Zeta & $\bar{y}$ & $\bar{y}$ & $\bar{y}$ & $\mathrm{X}$ & $\mathrm{x}$ & $\mathrm{x}$ & $\mathrm{x}$ & $\bar{y}$ & $\mathrm{x}$ & $\bar{y}$ & $\bar{y}$ \\
\hline Grupo Godó & $\mathrm{x}$ & $\mathrm{X}$ & $y$ & $\mathrm{X}$ & $\mathrm{x}$ & $\mathrm{x}$ & $\mathrm{x}$ & $\mathrm{x}$ & $\mathrm{x}$ & $\bar{y}$ & $\bar{y}$ \\
\hline Prensa Ibérica & $\bar{y}$ & $\bar{y}$ & $\mathrm{x}$ & $\mathrm{X}$ & $\mathrm{x}$ & $\bar{y}$ & & $\mathrm{x}$ & $\mathrm{x}$ & $\mathrm{x}$ & $y$ \\
\hline $\begin{array}{l}\text { Grupo } \\
\text { Mediapro }\end{array}$ & $y$ & $y$ & $\bar{y}$ & $\mathrm{X}$ & $\mathrm{x}$ & $\bar{\gamma}$ & $y$ & $\mathrm{x}$ & $y$ & V & $y$ \\
\hline Grupo RTVE & $\bar{y}$ & $\bar{y}$ & $\bar{\gamma}$ & $\mathrm{X}$ & $y$ & $\bar{y}$ & $\gamma$ & $\bar{y}$ & $\mathrm{x}$ & $\bar{y}$ & $y$ \\
\hline Grupo Voz & $y$ & $\mathrm{X}$ & $\bar{y}$ & $\mathrm{X}$ & $y$ & $y$ & $\bar{y}$ & $\bar{y}$ & $\mathrm{x}$ & $\bar{y}$ & 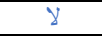 \\
\hline Grupo Joly & $y$ & $\bar{y}$ & $\bar{y}$ & $\mathrm{X}$ & $\mathrm{x}$ & $\bar{y}$ & $\bar{y}$ & $\mathrm{x}$ & $\mathrm{x}$ & $y$ & $y$ \\
\hline $\begin{array}{ll}\text { Grupo } & \text { A3 } \\
\text { Media } & \\
\end{array}$ & $\bar{y}$ & $\bar{y}$ & $\bar{y}$ & $\bar{y}$ & & $\bar{y}$ & $\bar{y}$ & $\bar{y}$ & $\bar{y}$ & $\bar{y}$ & $\bar{y}$ \\
\hline $\begin{array}{l}\text { Grupo } \\
\text { Mediaset }\end{array}$ & $y$ & $\bar{y}$ & $\bar{y}$ & $\bar{y}$ & $y$ & $\bar{y}$ & $\mathrm{y}$ & $\mathrm{y}$ & $\bar{y}$ & $\bar{y}$ & $\bar{y}$ \\
\hline $\begin{array}{l}\text { Grupo } \\
\text { Promecal }\end{array}$ & $\bar{\gamma}$ & $\bar{y}$ & $\mathrm{x}$ & $\mathrm{x}$ & $\mathrm{x}$ & $\mathrm{x}$ & $\mathrm{x}$ & $\mathrm{x}$ & $\mathrm{x}$ & $\mathrm{x}$ & $\mathrm{x}$ \\
\hline $\begin{array}{l}\text { Grupo } \\
\text { Intereconomía }\end{array}$ & V & $\bar{y}$ & y & y & $\mathrm{x}$ & V & $\mathrm{x}$ & V & $\mathrm{x}$ & $y$ & $\bar{y}$ \\
\hline
\end{tabular}

Fuente: Elaboración propia, octubre de 2014 a partir de la metodología de Berceruelo (2013)

${ }^{21}$ Se analizó solo la existencia de perfiles corporativos de los grupos de comunicación y no de cada uno de los medios que los componen. 


\subsection{Facebook}

A pesar de que prácticamente todos los grupos mediáticos analizados tienen Facebook corporativo, lo cierto es que los resultados evidencian que su uso en la mayoría de las ocasiones no es el correcto. Los grupos Prisa y Atresmedia son las únicas empresas analizadas que utilizan esta red social solo para publicar información corporativa. En el caso de Prisa, el 28,6\% versa sobre acciones de Responsabilidad Social Corporativa y el $71,4 \%$ sobre la estructura mediática de la empresa. El 100\% de la información publicada por Atresmedia en Facebook está relacionada con las audiencias alcanzadas por el grupo.

Mediaset también publica información corporativa, en la mayoría de las ocasiones relacionada con las audiencias de las diferentes cadenas y programas. Destaca en este caso que domina el entretenimiento y ficción sobre el resto de los contenidos.

Finalmente, RTVE, Vocento e Intereconomía utilizan la red social para aportar información de actualidad y de entretenimiento. Se considera que esto no es negativo para la imagen del conglomerado pero debería hacerse a través de la red social de cada uno de los medios del grupo y no a través del Facebook corporativo. Se observa que la tendencia de los usuarios es a compartir la información de actualidad y fundamentalmente de entretenimiento que en general produce una mayor participación. El resto de los grupos analizados no ofrece información actualizada a través de su Facebook corporativo.

Tabla 2: Publicaciones en el perfil corporativo de Facebook de las principales empresas mediáticas españolas

\begin{tabular}{|c|c|c|c|c|c|c|c|c|c|c|c|c|c|}
\hline \multirow[b]{2}{*}{ Medios } & \multirow{2}{*}{$\begin{array}{l}\text { Número de } \\
\text { publicaciones }\end{array}$} & \multicolumn{4}{|c|}{ Noticias de actualidad } & \multicolumn{4}{|c|}{ Entretenimiento / Ficción } & \multicolumn{4}{|c|}{ Información corporativa } \\
\hline & & $\mathbf{N}^{\circ}$ & Comp & $\begin{array}{l}\text { Me } \\
\text { gusta }\end{array}$ & Coment & $\mathbf{N}^{\circ}$ & Comp & $\begin{array}{l}\text { Me } \\
\text { gusta } \\
\end{array}$ & Coment & $\mathbf{N}^{\circ}$ & Comp & $\begin{array}{l}\text { Me } \\
\text { gusta } \\
\end{array}$ & Coment \\
\hline Grupo Prisa & 7 & 0 & 0 & 0 & 0 & 0 & 0 & 0 & 0 & 7 & 5 & 26 & 1 \\
\hline $\begin{array}{l}\text { Unidad } \\
\text { Editorial }\end{array}$ & 0 & 0 & 0 & 0 & 0 & 0 & 0 & 0 & 0 & 0 & 0 & 0 & 0 \\
\hline Vocento & 15 & 15 & 0 & 3 & 0 & 0 & 0 & 0 & 0 & 0 & 0 & 0 & 0 \\
\hline Grup. Planeta & 0 & 0 & 0 & 0 & 0 & 0 & 0 & 0 & 0 & 0 & 0 & 0 & 0 \\
\hline Telefónica & 0 & 0 & 0 & 0 & 0 & 0 & 0 & 0 & 0 & 0 & 0 & 0 & 0 \\
\hline Grupo Zeta & 0 & 0 & 0 & 0 & 0 & 0 & 0 & 0 & 0 & 0 & 0 & 0 & 0 \\
\hline Grupo Godó & 0 & 0 & 0 & 0 & 0 & 0 & 0 & 0 & 0 & 0 & 0 & 0 & 0 \\
\hline Prensa Ibérica & 0 & 0 & 0 & 0 & 0 & 0 & 0 & 0 & 0 & 0 & 0 & 0 & 0 \\
\hline $\begin{array}{l}\text { Grupo } \\
\text { Mediapro }\end{array}$ & 0 & 0 & 0 & 0 & 0 & 0 & 0 & 0 & 0 & 0 & 0 & 0 & 0 \\
\hline Grupo RTVE & 25 & 19 & 1509 & 6697 & 675 & 6 & 818 & 4054 & 122 & 0 & 0 & 0 & 0 \\
\hline Grupo Voz & 0 & 0 & 0 & 0 & 0 & 0 & 0 & 0 & 0 & 0 & 0 & 0 & 0 \\
\hline Grupo Joly & 0 & 0 & 0 & 0 & 0 & 0 & 0 & 0 & 0 & 0 & 0 & 0 & 0 \\
\hline Atres media & 2 & 0 & 0 & 0 & 0 & 0 & 0 & 0 & 0 & 2 & 2 & 12 & 3 \\
\hline Mediaset & 52 & 5 & 4 & 187 & 8 & 33 & 4.864 & 7.676 & 125 & 14 & 64 & 1272 & 23 \\
\hline $\begin{array}{l}\text { Grupo } \\
\text { Promecal }\end{array}$ & 0 & 0 & 0 & 0 & 0 & 0 & 0 & 0 & 0 & 0 & 0 & 0 & 0 \\
\hline Intereconomía & 8 & 7 & 3 & 110 & 30 & 1 & 6311 & 731 & 83 & 0 & 0 & 0 & 0 \\
\hline
\end{tabular}

Fuente: Elaboración propia, octubre de 2014 


\subsection{Twitter}

Frente a lo que ocurría con Facebook parece que en general las empresas de comunicación sí utilizan Twitter con una finalidad propiamente corporativa, si bien hay excepciones. El análisis evidencia que al menos siete de los grupos analizados publican datos empresariales en esta red social. Además se evidencia que hay una amplia participación de los usuarios que comparten este tipo de información.

Las excepciones vienen marcadas fundamentalmente por los grupos RTVE e Intereconomía que publican en esencia noticias de actualidad en esta red. Esto explicaría que contabilicen una gran cantidad de tweets.

Mediaset si bien incrementa la información corporativa (en esencia referida a audiencias) si lo comparamos con Facebook, sigue utilizando el perfil corporativo de Twitter en un gran número de ocasiones para ofrecer información de entretenimiento.

Tabla 3: Publicaciones en el perfil corporativo de Twitter por parte de las principales empresas mediáticas españolas

\begin{tabular}{|c|c|c|c|c|c|c|c|c|c|c|}
\hline \multirow[b]{2}{*}{ Medios } & \multirow{2}{*}{$\begin{array}{l}\text { Número } \\
\text { de } \\
\text { tweets }\end{array}$} & \multicolumn{3}{|c|}{ Información de actualidad } & \multicolumn{3}{|c|}{ Entretenimiento / Ficción } & \multicolumn{3}{|c|}{ Información corporativa } \\
\hline & & Tweets & Retweet & Favoritos & Tweets & Retweet & Favoritos & Tweets & Retweet & Favoritos \\
\hline Grupo Prisa & 3 & 0 & 0 & 0 & 0 & 0 & 0 & 3 & 82 & 59 \\
\hline $\begin{array}{l}\text { Unidad } \\
\text { Editorial }\end{array}$ & 85 & 56 & 17 & 15 & 0 & 0 & 0 & 29 & 323 & 273 \\
\hline Vocento & 263 & 245 & 12 & 9 & 7 & 7 & 1 & 11 & 10 & 9 \\
\hline Grupo Planeta & 0 & 0 & 0 & 0 & 0 & 0 & 0 & 0 & 0 & 0 \\
\hline Telefónica & 80 & 17 & 44 & 40 & 2 & 1 & 1 & 61 & 246 & 95 \\
\hline Grupo Zeta & 0 & 0 & 0 & 0 & 0 & 0 & 0 & 0 & 0 & 0 \\
\hline Grupo Godó & 0 & 0 & 0 & 0 & 0 & 0 & 0 & 0 & 0 & 0 \\
\hline Prensa Ibérica & 0 & 0 & 0 & 0 & 0 & 0 & 0 & 0 & 0 & 0 \\
\hline $\begin{array}{l}\text { Grupo } \\
\text { Mediapro }\end{array}$ & 13 & 0 & 0 & 0 & 0 & 0 & 0 & 13 & 0 & 0 \\
\hline Grupo RTVE & +500 & +500 & +1000 & +1000 & 0 & 0 & 0 & 0 & 0 & 0 \\
\hline Grupo Voz & 0 & 0 & 0 & 0 & 0 & 0 & 0 & 0 & 0 & 0 \\
\hline Grupo Joly & 135 & 0 & 0 & 0 & 0 & 0 & 0 & 135 & 36 & 9 \\
\hline A3Media & 0 & 0 & 0 & 0 & 0 & 0 & 0 & 0 & 0 & 0 \\
\hline Mediaset & +-300 & +-5 & 0 & 0 & +-75 & +-1200 & +-1000 & +-100 & +-1200 & +-1000 \\
\hline $\begin{array}{l}\text { Grupo } \\
\text { Promecal }\end{array}$ & 0 & 0 & 0 & 0 & 0 & 0 & 0 & 0 & 0 & 0 \\
\hline $\begin{array}{l}\text { Grupo } \\
\text { Intereconomía }\end{array}$ & +500 & +500 & +1000 & +1000 & 0 & 0 & 0 & 0 & 0 & 0 \\
\hline
\end{tabular}

Fuente: Elaboración propia, octubre de 2014

\section{Conclusiones}

El auge de la transparencia y buen gobierno se ha extendido al sector privado que en aras de recuperar su credibilidad y confianza ciudadana se ve en la necesidad de aplicar los mecanismos de responsabilidad 
social y transparencia. En este escenario, aparece la web 2.0 que ha supuesto un cambio en la manera de entender la comunicación y la relación del poder económico con la sociedad.

En la actualidad la ciudadanía solicita instituciones más transparentes, modificándose los escenarios donde se debaten las necesidades sociales y solicitando el uso de las nuevas tecnologías.

En este escenario los medios de comunicación han contribuido a expandir los conceptos de transparencia y buen gobierno pero ellos mismos se presentan como sociedades y grupos de comunicación que ofrecen un servicio $\mathrm{y} / \mathrm{o}$ producto que genera una importante influencia en la ciudadanía. En España no hay una legislación que obligue a todas las empresas de comunicación a ser transparentes, si bien sí se localiza ésta en el ámbito audiovisual y en el sector público (Ley 7/2010 de 31 de marzo, General de la Comunicación Audiovisual y Ley 19/2013, de 9 de diciembre, de transparencia, acceso a la información pública y buen gobierno).

A pesar de esta deficiencia normativa, prácticamente todos los grandes grupos de comunicación españoles disponen de un perfil en las redes sociales dominantes. La tendencia es similar a la de las empresas del IBEX 35 si bien se evidencian diferencias notables en las preferencias de unas redes por otras.

El uso, sin embargo, que hacen de ellas los grupos mediáticos no siempre es el adecuado. Esta investigación demuestra que los sujetos analizados utilizan el perfil de Facebook corporativo en la mayoría de las ocasiones para ofrecer entretenimiento o noticias de actualidad y no información corporativa como cabría esperar.

El resultado del análisis de Twitter evidencia que en este caso se utilizan de forma más correcta los perfiles corporativos con un incremento de la información empresarial.

Sería conveniente que hubiera una evolución hacia la transparencia corporativa a través de las ventajas que ofrece internet y las redes sociales. La web 2.0 abre posibilidades que deberían ser aprovechadas por los grupos mediáticos de cara a ofrecer una información de gestión y administración, responsabilidad y buen gobierno con la sociedad, y no solo utilizar estos mecanismos como meros canales de entretenimiento o de información de actualidad.

En un contexto en donde la crisis económica y de credibilidad ha afectado a los medios de comunicación, sería necesario potenciar 
políticas a favor de una mayor transparencia y responsabilidad social. El reto en la actualidad pasa por dar el salto cualitativo desde la transparencia y gestión 1.0 a la 2.0. En este escenario, sin embargo, parece que los grandes grupos de comunicación se están quedando atrás. El número de noticias sobre transparencia y responsabilidad social en sus agendas settings se ha incrementado pero, sin embargo, los propios medios no quieren hacerse eco de su propia situación como conglomerados con una importante influencia en la sociedad.

\section{Referencias bibliográficas}

AIMC (2014): “Navegantes en la red". Recuperado el 29 de octubre de 2014, de http://www.aimc.es/-Navegantes-en-la-Redhtml

Almirón, N. (2005): "Banca y medios de comunicación en la sociedad de la información: el caso de los paraísos fiscales en El País", en Zer, 18, páginas 123 a 142.

Arrese, A. (2006): "Reflexiones sobre el buen gobierno corporativo en las empresas periodísticas", en Doxa Comunicación, 4, páginas 59 a 82 .

Berceruelo, B. (2013): "No hablar por hablar", Presencia de las empresas del IBEX-35 en la web 2.0, Recuperado el 29 de octubre de 2014, de http://www.estudiodecomunicacion.com/extranet/wpcontent/uploads/2013/09/ESTUDIO IBEX 35 EN LA WEB 2.0.pdf

Campos, F. (2008). "Las redes sociales trastocan los modelos de los medios de comunicación tradicionales", en Revista Latina de Comunicación Social, 63, páginas 287 a 293. Recuperado el 29 de octubre de 2014, de

http://www.ull.es/publicaciones/latina/ 2008/23 34 Santiago/Fran cisco Campos.html

Campos, F. (2013): "Las empresas de comunicación adaptan los estándares de gestión de la Responsabilidad Social Corporativa", en Revista de Comunicación, $\mathrm{n}^{\circ}$ 12, páginas 32 a 58.

Castells, M. (2008): "Comunicación, poder y contrapoder en la sociedad red (I). Los medios y la política", en Telos: Cuadernos de comunicación e innovación, 74, 2008, páginas 13 a 24.

Curran, J. (2005): Medios de comunicación y poder en una sociedad democrática. Barcelona: Hacer. 
Fernández Lombao, T. (2013): "Las corporaciones de radiotelevisión pública de la Unión Europea y el incipiente uso de la web 2.0 para comunicar RSC", en Fonseca Journal of Communication, $\mathrm{n}^{\circ}$ 6, páginas 86 a 110.

García Santamaría, J. V. (2013): “Televisión y concentración en España: el duopolio de Mediaset y Atresmedia”, en Palabra clave, 16 (2), páginas 366 a 397.

García Santamaría, J. V.; Pérez Serrano, M. J. y Alcolea Díaz, G. (2014): "Las nuevas plataformas televisivas en España y su influencia en el mercado", en Revista Latina de Comunicación Social, 69, páginas 390 a 417. Recuperado el 29 de octubre de 2014, de http://www.revistalatinacs.org/069/paper/1017 UC3/20jes.html Internet World States (2013): "Estadísticas mundiales de internet". Recuperado el 29 de octubre de 2014, de http://www.internetworldstats.com/

López Cepeda, A. (2013): "Reputación online y política 2.0 a través de las redes sociales y personales". En VV.AA., Comunicación, Cultura e Esferas de Poder. Libro de actas de XIII Congreso Internacional IBERCOM (Eds., Ledo Andión y Vassallo de Lopez), páginas 3309 a 3316. Santiago de Compostela: Assibercom, Ibercom.

López Cepeda, A. y Manfredi, J. L. (2013): “Análisis de la transparencia de las páginas web de los principales medios de comunicación audiovisuales en España”, en Trípodos, 32, pp. 45 a 61.

Reig, R. (2011): Los dueños del periodismo: Claves de la estructura mediática y mundial y de España. Barcelona: Gedisa.

* Esta investigación forma parte del proyecto Comunicación pública, transparencia, rendición de cuentas y participación en los gobiernos locales (CSO2013-46997-R) Convocatoria 2013. Programa estatal de investigación, desarrollo e innovación orientada a los Retos de la Sociedad. 


\section{Presencia y estrategias de comunicación de los hospitales andaluces en las redes sociales}

Dolores Rando Cueto, Universidad de Málaga (UMA, España), lrandocueto@gmail.com

\section{Resumen}

En la investigación se analiza la eficacia de la comunicación de los hospitales andaluces en redes sociales, exponiendo como estudio de caso la actividad comunicativa en social media de los centros hospitalarios malagueños. Se pretende comprobar la coherencia entre los intereses que la institución sanitaria persigue con el uso de las referidas herramientas de comunicación y las metas alcanzadas. Como resultados, destacan, una exigua presencia de los hospitales andaluces en redes sociales, el $34^{\prime} 02^{\%} \%$ y una escasa participación de los ciudadanos en las mismas. No obstante, se califica como beneficiosa la actividad de los centros hospitalarios en social media por parte de aquellas entidades sanitarias que han apostado por comunicarse en red. Tras la investigación realizada se considera que existe una notable brecha entre los fines que persiguen los hospitales con su incursión en redes y la consecución de los mismos.

Palabras clave: redes sociales, comunicación corporativa, hospitales, salud, bienestar ciudadano, periodismo especializado, atención sanitaria. 


\section{Introducción}

T A actividad investigadora en el campo de la salud es cada vez más Lintensa y diversa (Lázaro y Echegaray, 2014: 6). A su vez, existe una variada literatura sobre redes sociales institucionales en diferentes ámbitos profesionales (Paniagua y Sánchez, 2013; Gómez y Paniagua, 2014; Huertas y Mariné, 2014; Palomo, 2014).

También son profusas las publicaciones digitales de asociaciones de pacientes y familiares. (Troncoso, 1995; Fernández, 2005; Celedón y Noé, 2000; Campos, 2008; Aruguete, 2001; Merchant, 2011).

No obstante, cuando se trata de instituciones y su actividad comunicativa a través de las redes sociales, las publicaciones científicas son escasas. Torrente, Martí y Escarrabill (2010) soportan esta idea al mismo tiempo que abogan por una mayor calidad en la información que se ofrece a través de las redes sociales sanitarias.

El presente estudio se centra en Andalucía, región caracterizada por la heterogeneidad de sus centros hospitalarios. La elección de Málaga, como provincia-caso de investigación se debe a que es esta área geográfica es la provincia andaluza más participativa en redes sociales hospitalarias, por el número de hospitales que cuentan con estos canales de comunicación y por la actividad mantenida en los mismos.

Los objetivos que se plantean con el desarrollo de la investigación son: analizar el empleo que hospitales andaluces hacen de las redes sociales y examinar el grado de cumplimiento de los objetivos que centros hospitalarios malagueños persiguen con su participación en redes sociales.

Desde que se publicaran las primeras teorías sobre la comunicación organizacional, corporativa, institucional o de firma (Villafañe, 2000: 264) en el seno de la empresa, a principios del siglo $\mathrm{XX}$, hasta nuestros días, los estudios relacionados con este tema han evolucionado enormemente, pero desde la década de los 40 hasta hoy, la mayoría de las publicaciones sobre este asunto cuentan con el denominador común de la necesidad que surge en la entidad jurídica por comunicar (Martín, 2010).

La comunicación de, en o hacia la empresa no es una tendencia reciente, sino que se trata de "una respuesta, en términos de 
management, a la creciente complejidad de la propia empresa". (Villafañe, 2000: 237).

Ya en la década de los 2000, la comunicación organizacional se encuentra "profundamente mediatizada por los avances tecnológicos" (Martín, 2010: 34) y entre sus características destaca la "vinculación personalizada de usuarios múltiples", a través de las redes sociales, donde las empresas: "encuentran las personas y conocimientos necesarios; son conectores rápidos, recíprocos, cercanos e íntimos; elaboran listado de personas a invitar y a quien ayudar (...)". (Martín, 2010: 281-284).

De esta forma, la comunicación adquiere un rol más social, se diluyen las jerarquías. Como preconizaba Timoteo "la comunicación social es hoy el factor decisivo en el éxito de las actuales sociedades" (Álvarez, 1997: 11).

Sobre las nuevas oportunidades de comunicación que se ofrecen a través de las redes sociales, Cervera (2008, 211-215) indica tres conceptos sobre lo que internet ha incidido: "interactividad, personalización y globalización”. La comunicación interactiva, como una de las posibilidades que ofrece la red, "debe descansar sobre cuatro pilares: flujo, funcionalidad, feedback y fidelización (...). Las características de inmediatez y la interactividad propias de la comunicación on-line hacen imprescindible cuidar el flujo de información".

La moda de estar comunicados a través de las redes sociales se extiende a todos los niveles -tanto profesionales, como particulares-. El estudio realizado por el centro de investigaciones Pew Research Center, determina que en 2013 el 73\% de los adultos usan algún tipo de red social.

Con este panorama, son numerosos los textos que hacen referencia a la eclosión de las redes sociales (Terrón, 2014; Santamaría, 2014; García Orosa, 2014). La gran mayoría coincide en los efectos positivos de su utilización, su irremediable uso en la sociedad actual y, en muy menor medida, los efectos que puede tener el eludirlas, especialmente, por parte de una entidad pública o privada.

García Orosa (2014) y Álvarez (2014: 28) analizan la evolución 1.0 y 2.0. Álvarez alude a las redes sociales como favorecedoras de un entorno conversacional y más libre, en el que se favorece la 
socialización y una mayor difusión y permanencia en el tiempo de los mensajes.

En esta transformación, García Orosa (2014) se refiere a los directores de comunicación como figuras en la empresa cada vez más vinculadas a la dirección.

Más de 2.500 directores de comunicación de 42 países europeos han sido consultados en 2014 sobre el uso de redes sociales corporativas, para la ejecución del estudio European Communication Monitor. Estos profesionales preconizan un incremento del uso de las redes sociales por las organizaciones de forma que de usarlas en la actualidad un 63'2\%, en el año 2017 este porcentaje sería de 89'1\%.

En el estudio llevado a cabo por la consultoría Kreab Gavin Anderson en 2013 sobre el uso que de las redes sociales realizan directores de comunicación se apunta que el 92\% de estos utiliza los social media en el desempeño de su trabajo. Pero, en el mismo trabajo se indica que más de la mitad no dispone de los instrumentos necesarios para monitorizar o realizar un seguimiento de la interacción online.

En paralelo a la propagación del uso de las redes sociales corporativas, expertos recomiendan prudencia y abogan por un examen de las consecuencias de lo que estar en redes sociales supone (Celaya y Herrera, 2007), así como, una evaluación previa (Huertas, 2014).

Nicolás y Grandío (2012: 70-72) consideran la "fragmentación de los públicos" como una de las premisas en la elaboración de los mensajes, a pesar de las dificultades que ello implica.

En el seno de una corporación hospitalaria, por lo que respecta a los hospitales públicos del Servicio Andaluz de Salud, las acciones de comunicación que se llevan a cabo se rigen por las directrices que marca el IV Plan Andaluz de Salud (2013-2020). Especial hincapié se hace en la necesidad de que la administración se acerque a los ciudadanos de manera transparente en aras a una mejor atención sanitaria y difusión del conocimiento, escuchando y atendiendo a las necesidades de la sociedad.

En la misma línea se expresa el Plan de Calidad del Sistema Sanitario Público de Andalucía (2010-2014), en el cual una de las acciones impulsadas es la de "identificar y potenciar la diversificación de canales que promuevan el acceso proactivo con la ciudadanía”, con 
objeto de "reforzar el papel de cada usuario para ejercer su autonomía y participación sobre su propia salud".

Atendiendo al binomio redes sociales-sector sanitario, la ex consejera de Salud y Bienestar Social de la Junta de Andalucía, María Jesús Montero, reconoce en el prólogo de la Guía de usos y estilo en las redes sociales del Sistema Sanitario Público de Andalucía (2013: 1), acerca del uso de las redes sociales, que este hecho "supone abrirnos a la red de forma mucho más transparente y proactiva, en una manera en la que no estamos acostumbrados, pero que ya no es optativo".

Esta obligatoriedad asumida por las instituciones se hace patente en la política de comunicación sobre redes sociales impulsada desde la Consejería de Igualdad, Salud y Políticas sociales a través de la plataforma RedSaludAndalucía y la edución la referida guía, a partir de 2012.

En el Libro Blanco Sobre el Sistema Sanitario Español (2011) se reconoce cómo la profusión de actuaciones llevadas a cabo a través de internet está repercutiendo en un cambio sobre las actitudes de usuarios y condicionando la percepción que estos puedan tener sobre sus necesidades y mecanismos de autoayuda. $\mathrm{Y}$ en publicaciones como 'El e-paciente y las redes sociales' (Traver y Fernández-Luque, 2011), se deja patente la imposibilidad "en la sociedad de la información de desconectarnos de las redes en donde nos manejamos profesional y personalmente".

Oviedo Valenzuela (2013) incide en el incremento exponencial del uso de las nuevas tecnologías en las empresas, aunque reconoce que aún hay entidades que deciden eludir los social media o se adentran en este territorio a tientas.

Ya sea por la ingente cantidad de información que han de controlar, las múltiples herramientas de las que han de conocer su manejo, la mayor demanda de información a la que han de responder..., lo cierto es que como Villafañe (2008: 11) apunta, "la función de comunicación e imagen en las empresas (...), exige la formalización precisa de instrumentos y técnicas de gestión cada vez más sofisticados. Disponer de esas herramientas y utilizarlas habitualmente es lo que diferencia (...) la gestión profesional de la imagen de las empresas de las rutinas, más o menos eficaces, de las direcciones de comunicación tradicionales". 
La clave se encontraría en la adaptación a los cambios por la rápida invasión de las redes sociales, para lo que, en opinión de Flores (2009), se han de asumir riesgos e incorporar dentro de las estrategias empresariales nuevos códigos de comunicación. Riesgos, que se ponen en entredicho en los estudios Sachin (2009), quien renuncia a cualquier recelo que puedan tener gestores de las instituciones sanitarias ante las redes sociales por miedo a violar la vulnerabilidad de la intimidad, la confidencialidad o la privacidad de los pacientes en sus relaciones con los profesionales sanitarios a través de las redes sociales.

Sobre riesgos habla también Martínez (2014: 38), quien alienta a los responsables de comunicación de las corporaciones a asumirlos, evitando "poner en peligro nuestras partes sensibles o las de la organización para la que trabajamos (...)".

Algunas claves para hacer más efectivos los mensajes en redes sociales por parte de las organizaciones las da Wen-Ying (2009), quien habla en sus artículos de segmentación, a través del estudio de la heterogenidad de los destinatarios.

\section{Metodología}

El universo del que partió el estudio fueron los 97 hospitales de Andalucía en el año 2013. Las principales fuentes de información para la elaboración de una clasificación propia fueron el Observatorio para las TICs en salud y la Consejería de Igualdad, Salud y Políticas Sociales de la Junta de Andalucía, a través de su plataforma de redes sociales RedSaludAndalucía.

Se clasificaron los hospitales según su actividad en lo que a social media se refiere, a través de un ejercicio de observación no participante de las diferentes web y redes sociales empleadas por los centros hospitalarios, así como de la información telefónica u online ofrecida por los responsables de los centros sanitarios.

Se desarrolló un análisis de contenido, cuantitativo y cualitativo (Bardin, 1986; Cea, 1996; Enrique, 1995; Igargúa, 2006; Krippendorff, 1985, 1990 y 2008; Navarro y Díaz, 1995; Neuendorf, 2002; Piñuel, 2002; Riffe, Lacy y Fico, 2005; Roger y Joseph, 1996) y se llevaron a cabo encuestas semiestructuradas con respuestas cerradas y abiertas realizadas a los responsables de la gestión y control de las redes sociales de cada uno de los hospitales analizados, entre los meses de mayo y agosto de 2013. 
De la totalidad encuestas emitidas, se obtuvieron 38 respuestas, un 39'18\% del total. Este porcentaje se consideró óptimo por ser superior al porcentaje de los hospitales que participan en redes sociales.

A su vez, se utilizaron las herramientas Fanpage karma y Simply Measured para el análisis de características como la visibilidad de centros hospitalarios, interactividad en redes sociales hospitalarias y la participación en las mismas de los ciudadanos.

Como complemento a estos instrumentos de análisis y con objeto de describir características cualitativas de las redes sociales de los hospitales malagueños se siguió una ficha de análisis, basada en una de las fichas utilizadas por los docentes Paniagua y Gómez (2014) que se aplicó a cuentas de twitter -red social presente en la totalidad de los centros de Málaga-.

Y completando los procedimientos metodológicos referidos, se llevaron a cabo entrevistas en profundidad: a Isabel Atencia, responsable de la gestión de redes sociales de la Consejería de Igualdad, Salud y Políticas Sociales de la Junta de Andalucía y a José Antonio Trujillo, médico especialista experto en la gestión de redes sociales en el ámbito sanitario.

\section{Resultados}

Como resultados obtenidos destaca una escasa participación de los hospitales andaluces en las redes sociales, siendo en 2013, 33 de un total de 97 los centros hospitalarios que disponen de red social. No obstante, existen significativas diferencias por provincias.

Uno de los ejemplos del heterogéneo panorama encontrado de las redes sociales en los centros andaluces es que, frente a hospitales como el público Infanta Margarita de Córdoba, referente nacional por su implantación en redes sociales, encontramos una quincena de hospitales que no cuentan ni siquiera con web corporativa propia.

Por lo que respecta al caso de Málaga, esta provincia cuenta con siete hospitales públicos y trece centros hospitalarios privados. Del total de los hospitales públicos, la mitad participa en redes sociales (el $50 \%$, se encuentra más de cuatro puntos por encima de la media andaluza $-45,83 \%-)$.

La diferencia entre públicos y privados es notable, ya que si de los siete hospitales públicos, tan solo tres se comunican a través de 
redes sociales, de los trece hospitales privados, siete utilizan estas herramientas en su actividad comunicativa.

Además, los hospitales públicos malagueños que cuentan con redes sociales tienen operativas, como máximo, tres cuentas, mientras que en el caso de los hospitales privados, hay centros que operan hasta en ocho.

En cuanto a contenidos, destaca la difusión de información sanitaria; la emisión de aspectos relacionados con prevención sanitaria y promoción de la salud; seguimiento de actos en directo; intercambio de opiniones; acceso a documentación sanitaria; entre otros.

Para llevar a cabo el análisis cualitativo referido se tuvieron presente las respuestas de responsables de la gestión de la comunicación hospitalaria en redes sociales. En total, se recibieron respuesta de todos los centros hospitalarios públicos existentes, independientemente de si participaban o no en redes sociales y de siete centros hospitalarios privados: dos de ellos, Hospiten Estepona y Parque San Antonio -Grupo Vithas-, rechazando su participación.

Las cinco encuestas de hospitales privados contestadas corresponden a centros que están presentes en redes sociales. Los demás centros hospitalarios que no respondieron no cuentan con redes sociales, excepto en el caso del Complejo Hospitalario Integral (CHIP) y Clínica del Doctor Gálvez, presentes en dos y una red social, respectivamente.

Se clasificaron las respuestas en cinco apartados subdivididos en categorías:

a) ¿Cómo surge la iniciativa? Los encuestados coincidieron en seis aspectos por los que un hospital está representado en redes sociales: por obligación y necesidad de adaptarse al cambio; por mejorar la difusión de información; por interactuar con los profesionales; por favorecer la interacción con la población; por crear imagen corporativa; por decisión de un equipo directivo.

b) ¿Por qué el hospital se encuentra representado en determinadas redes sociales y no en otras? Cinco fueron las respuestas más repetidas sobre la elección de las redes sociales: por ser las que mejor se adaptan a los destinatarios; por ser las más conocidas, las de mayor impacto y con mayor número de seguidores; por ser las idóneas para informar e interactuar; por la rapidez para emitir información; por la sencillez para interactuar y crear comunidad. 
c) ¿Quién gestiona la comunicación en redes sociales? ¿Se forma a los profesionales para ello? Sobre la gestión de la comunicación, el 58 '33 \% de los hospitales consultados respondió que es personal de los departamentos o unidades de comunicación y de la dirección de Sistemas de Información quien se responsabiliza de los contenidos de las redes sociales y en el $25 \%$ de los casos son profesionales sanitarios, no de Comunicación, quienes asumen esa tarea.

En menos de la mitad de los centros hospitalarios se reconoce que cuentan con formación específica para llevar a cabo las acciones comunicativas oportunas en redes sociales.

d) ¿Qué objetivos persigue el hospital al estar presente en redes sociales? Cinco fueron los objetivos subrayados: promover una comunicación eficaz con la sociedad; impulsar la proyección social del hospital; difundir información; favorecer el acercamiento con los profesionales; mejorar la calidad asistencial.

e) ¿Qué beneficios aportan las redes sociales? Las personas encuestadas consideran las redes sociales beneficiosas para la institución sanitaria, sus profesionales o la ciudadanía, en general. Esta aseveración subjetiva se sostiene en la experiencia personal de cada entrevistado, no en datos objetivos que la refrenden.

De una u otra forma, las respuestas relacionadas con la pregunta que encabeza este apartado se dividen en seis categorías: mayor interacción con profesionales y ciudadanos y capacidad de escucha; potenciar hábitos y estilos de vida saludables; inmediatez en la transmisión de información; dotar al hospital de otro canal de información; lograr mayor visibilidad y notoriedad; captar más clientes.

f) ¿Existen dificultades en la implantación y el mantenimiento de redes sociales hospitalarias? En este apartado la respuesta fue prácticamente unánime por parte de los profesionales, quienes no encontraron dificultad en el inicio de la actividad en social media a través de la apertura de una o varias cuentas.

En lo que sí encuentran problemas, en el 60\% de los casos, es en el trabajo posterior que requiere este tipo de comunicación, la actualización de contenidos.

En cinco aspectos se resumen los problemas planteados desde los diferentes departamentos o unidades de comunicación:

- Falta de formación para la gestión de las redes sociales. 
- Mantener actualizado el contenido de redes sociales, a través del trabajo coordinado y la participación de unidades y servicios hospitalarios.

- Falta de recursos humanos e implicación de la plantilla.

- Falta de presupuesto para ofrecer contenidos atractivos.

- Falta de tiempo.

Los conceptos de participación ciudadana o interacción y visibilidad se repitieron en la mayoría de las respuestas recogidas en las referidas encuestas. Es por ello, por lo que se añadió al trabajo el análisis de las cuentas de Facebook y Twitter de los centros hospitalarios.

Los conceptos de interactividad y visibilidad se entendieron al igual que se definen en el trabajo de Huertas y Mariné (2014: 117-134) sobre el empleo de redes sociales en turismo. De esta forma, por interactividad se consideró la relación

"con los gestores de comunicación y entre los propios usuarios, la frecuencia, el nivel de apertura del social media -si permitían colgar comentarios a los usuarios, sólo hacer comentarios, valoraciones, o solo decir si les gustaba, si permitían los comentarios negativos y cómo se tratan, si los respondían o también si respondían preguntas o consultas".

A su vez, la visibilidad se entendió como "el número de fans o seguidores, los me gusta, comentarios y comparticiones que generaban, etc.

Del análisis cuantitativo obtenido a través de la herramienta Fanpage Karma, algunos de los resultados obtenidos de las cuentas de Facebook de los hospitales malagueños, entre el 20 de julio y el 16 de agosto de 2014 fueron: por lo general, escasa actividad en redes sociales en lo que a emisión de mensajes se refiere; prácticamente nula comunicación o diálogo entre institución y ciudadanos; poca variabilidad en los recursos utilizados. No se corresponde el número de seguidores o fans con el nivel de interactividad de los centros.

De acuerdo a los porcentajes obtenidos, estos indican buenos resultados si lo que se pretende es darse a conocer, por el número de fans o followers, pero muy bajos en cuanto a interactividad $y$ participación ciudadana. 
Los datos obtenidos a través de Simply Measured corresponden al período comprendido entre el 10 y el 25 de agosto de 2014. Sobre resultados obtenidos, independientemente del número de menciones recibidas, ninguno de los centros hospitalarios emite ningún tipo de respuesta en la semana analizada.

La ficha de análisis sobre contenido en twitter se añade a las herramientas precedentes. En este caso, la ficha se aplicó a las cuentas twitter, donde la totalidad de los centros hospitalarios malagueños que se comunican en social media cuentan con esta red.

En el análisis, sorprende la variabilidad de datos obtenidos en lo que a número y origen de mensajes, seguidores, meses con más actividad y tipología de contenido publicado se refiere en los 455 tweets analizados durante julio. Los resultados más significativos fueron:

La media de tweets al día difiere desde los más de cinco mensajes del hospital HC Marbella a menos de un tweet diario, de los hospitales CHIP, Regional Universitario de Málaga, Universitario Virgen de la Victoria y Antequera.

Más del 90\% de los tweets de los hospitales Xanit Internacional, Clínicas Dr. Gálvez y Hospital Universitario Virgen de la Victoria fueron tweets propios. A este porcentaje, le siguen el Hospital HC High Care, el Complejo Hospitalario Integral Privado, Hospital Regional de Málaga y Hospitales Quirón.

Estas cantidades no son proporcionales al índice de respuestas que reciben; un mayor número de tweets no se corresponde con un mayor número de interactividad o participación ciudadana. En casi todos los casos, tanto el número de retweets como el número de mensajes marcados como favoritos es menor al número de tweets propios publicados.

Por lo que se refiere a respuestas ofrecidas por el hospital a raíz de un comentario o consulta, como índice de interactividad, éstas solo se producen en diez ocasiones. En los casos en que la respuesta es a un comentario negativo el problema planteado no se resuelve de manera pública.

No existen retweets entre hospitales de financiación pública y privada, ni entre centros privados tampoco. En cambio, sí destacan dos tweets de crítica a la sanidad pública. 
Estos resultados difieren en gran medida de los 20 consejos que la consultora de Marketing Off y Online, Adrea Pallares ofrece en su blog sobre cómo gestionar un twitter corporativo, quien aboga por no "utilizar twitter solamente para promocionar nuestra marca, debemos ofrecer contenidos útiles que puedan interesar a nuestro público objetivo y lo más importante, crear conversación”.

Completando el análisis cualitativo, se analizaron las respuestas ofrecidas por Isabel Atencia y José Antonio Trujillo.

Uno de los argumentos repetidos por Atencia fue el referente a la importancia de "establecer un flujo bidireccional de comunicación". Los beneficios que reportan las redes sociales, tanto a nivel institucional como ciudadano, la ausencia de riesgo por el uso de las mismas y la demanda social existente por el uso de los social media, "que no podríamos considerarla presión", son motivos que apoyan el empleo de dichas herramientas de comunicación.

Una vez más se subraya la idea de la potencialidad de las redes sociales como "forma directa de comunicación" con la ciudadanía y de la posibilidad de "interacción" con periodistas y sociedad, en general. Se habla de potencialidad, pero, como se comprueba en esta investigación, la iniciativa ciudadana a la hora de mostrarse activa en el diálogo en redes sociales con los hospitales es bastante limitada.

Además de difundir información a través de "notas de prensa, contenidos de interés puntual de la web, retweets a otros organismos de la Junta...", entre los objetivos que la administración persigue con la comunicación en red social destacan, "conocer la opinión de la ciudadanía" y "crear buena imagen".

De los objetivos expuestos, el primero sí depende directamente de los gestores de las redes sociales, si bien, para conocer los mensajes que generan más interés en la sociedad, o para evaluar conceptos como imagen o visibilidad, la Consejería utiliza herramientas como Hootsuite o SocialBro. No obstante, la evaluación no se hace de forma individualizada, dejando esta actividad a manos de cada centro hospitalario.

Trujillo destacó la necesidad de utilizar adecuadamente las redes sociales en comunicación sanitaria, con objeto de construir "el nuevo discurso social de colaboración" y "contribuir al debate y desarrollo de la sociedad donde trabajan", ya que "su protagonismo está relacionado 
con la entidad de la labor que realizan y su forma en cómo la comunican".

Este experto habla de obligatoriedad al referirse a la presencia de las instituciones sanitarias en las redes sociales, puntualizando que estas "no pueden permanecer en silencio", para conseguir las metas referidas, pero alerta, de la escasa formación y el poco tiempo de los profesionales a los que se les encomienda la tarea de comunicar a través de estas medios.

Para Trujillo, la apuesta de la administración pública por las redes sociales ha sido tardía y miedosa de los posibles riesgos que puedan conllevar las mismas, no sabiendo gestionar períodos de crisis con estas herramientas.

Soluciones de Trujillo para una mala gestión de las redes sociales sanitarias sería la contratación de profesionales especializados en nuevas fórmulas de comunicación, con objeto de otorgar "visibilidad", "confianza, credibilidad y prestigio" a la entidad sanitaria.

\section{Conclusiones}

La potencialidad de los social media se considera inmensurable, entre otras cuestiones, por la falta de conocimiento que en muchas áreas se tiene sobre estos. Esta situación se refleja en el campo de la sanidad, donde los ciudadanos expresan un interés cada vez mayor por ser protagonistas de su salud, pero donde la comunicación en red social orientada desde las instituciones o empresas es aún hoy un camino por recorrer.

Guías, normas de estilo y planes estratégicos de las administraciones sanitarias sobre cómo, de qué forma o cuándo comunicar a través de las redes sociales no se corresponden con la aplicación de las mismas en las rutinas profesionales de los responsables de la gestión de la comunicación en los centros sanitarios. Los compromisos publicados sobre transparencia y escucha no se materializan en las redes sociales.

De acuerdo a los resultados del estudio, en los social media hospitalarios se ofrece información y, en contados casos, una comunicación bidireccional, pero no escenarios virtuales comunes en los que compartir conocimiento, experiencias o consultas.

No existe un propósito de mejora asistencial y no existe una voluntad de acercamiento a la sociedad y a los profesionales sanitarios 
a través de la comunicación en redes sociales, cuando uno de los contenidos que menos se repiten en las redes sociales es la difusión de servicios hospitalarios o información de relevancia para la salud de los pacientes, con respuestas ágiles y públicas.

Existe, finalmente, una gran distancia entre los objetivos que la institución sanitaria plantea como bandera de social media y sus acciones para alcanzar los mismos. Las redes sociales hospitalarias continúan funcionando como una estructura jerarquizada en el que la institución emite mensajes y su voz puede ser recogida o no. Si de lo que las instituciones sanitarias tratan es de provocar interacción en redes sociales, este propósito no se ha conseguido.

No obstante, las corporaciones sanitarias se exponen en las redes sociales. Han magnificado su uso, a pesar de que infravaloran aspectos de suma importancia como la planificación de comunicación en redes sociales y formación profesional que deberían llevar aparejadas.

Son algunos de los profesionales responsables de la gestión de la comunicación en centros hospitalarios, en su mayoría periodistas especializados en salud, quienes aprovecharon el estudio para reclamar más formación especializada en social media para su ejercicio en redes sociales. Más de la mitad considera la falta de formación la mayor dificultad de su labor y menos de la mitad ha recibido algún tipo de adiestramiento en la materia.

Junto la barrera de la formación, otras dificultades encontradas para la actualización permanente de contenidos en social media son la falta de recursos humanos e implicación de la plantilla de trabajadores para nutrir de contenido o responder a la demanda social en redes sociales; la falta de presupuesto para ofrecer un valor añadido a los mensajes que se emiten por parte de la institución sanitaria; y la falta de tiempo para dedicarle a las nuevas herramientas de comunicación.

La necesaria planificación de todo tipo de comunicación también alcanza a los social media, para los que parece que no queda tiempo, no merece la pena o no existe necesidad por su volatilidad, al menospreciar su principal característica: su capacidad para llegar a una ingente cantidad de usuarios, clientes o competencia.

\section{Referencias bibliográficas}

Aruguete, G. (2001): "Redes sociales. Una propuesta organizacional alternativa". En Jornadas sobre Gestión de las Organizaciones de la Sociedad 
Civil, Buenos Aires, noviembre:

http://www.gestionsocial.org/archivos/00000303/Aruguete, Gustav o.pdf.

Bardin, L. (1986): Análisis de contenido. Madrid: AKAL.

E. Blanco Castilla y F. Paniagua Rojano (2007): "Periodismo, salud y calidad de vida", en FISEC - Estrategias, 8. Zamora: Facultad de Ciencias Sociales de la Universidad Nacional de Lomas (Argentina), páginas 03 a 24; recuperado el 19 de julio de 2015, de http://www.cienciared.com.ar/ra/doc.php?n=766.

Campos-Freire, F. (2008): "Las redes sociales trastocan los modelos de los medios de comunicación tradicionales", en Revista Latina de Comunicación Social, 63. La Laguna (Tenerife): Universidad de La Laguna, páginas 287 a 293; recuperado el 19 de julio de 2015, de http://www.ull.es/publicaciones/latina/2008/23 34 Santiago/Fran cisco Campos.html.

Cea D’ancona, M. A. (1996): Metodología cuantitativa. Estrategias y técnicas de investigación social. Madrid: Síntesis Sociología.

Celaya, J. y Herrera, P. (2007): Comunicación empresarial 2.0. Madrid: Grupo BPMO.

Celedón, C. y Noé, M. (2000): "Reformas del sector de la salud y participación social" en Revista Panamericana de Salud, 8 (1/2). Chile, páginas 099 a 104; recuperado el 19 de julio de 2015, de http://dx.doi.org/10.1590/S1020-49892000000700013.

Cervera, Á. L. (2008): Comunicación total. Madrid: ESIC Editorial.

Consejería de Igualdad, Salud y Políticas Sociales (2013): Guia de usos y estilo en las redes sociales del Sistema Sanitario Público de Andalucía. Sevilla: Consejería de Igualdad, Salud y Políticas Sociales de la Junta de Andalucía.

Criado, J. I. (2001): "E-Administración: ¿Un reto o una nueva moda?", en Revista V asca de Administración Pública, 61. Vitoria, páginas 01 a 21.

Enrique Alonso, L. (1995): "Sujeto y discurso". En VV.AA., Métodos y técnicas cualitativas de investigación en ciencias sociales (Coords., M. Delgado y J. Gutiérrez). Madrid: Síntesis Psicología.

Fernández Peña, R. (2005): "Redes sociales, apoyo social y salud", en revista Periferia, 3. Barcelona: Departamento de Antropología Social y Cultural de La Universidad Autónoma de 
Barcelona; recuperado el 19 de julio de 2015, de http://ddd.uab.cat/pub/periferia/18858996n3/18858996n3a4.pdf.

Flores Vivar, J. M. (2009): "Nuevos modelos de comunicación, perfiles y tendencias en las redes sociales", en Comunicar, 33. Madrid, páginas 73 a 81; recuperado el 19 de julio de 2015, de http://dx.doi.org/10.3916/c33-2009-02-007.

García Orosa, B. (2013): “Los gabinetes de comunicación on line de las empresas del Ibex 35", en Historia y Comunicación Social, 18. Madrid, páginas 295 a 306; recuperado el 19 de julio de 2015, de http://dx.doy.org/10.5209/rev HICS.2013.v18.43967.

Generalidad de Cataluña (2011): Guia de usos y estilo en las redes sociales de la Generalidad de Cataluña. Cataluña: Generalitad de Cataluña.

Gómez, B. J. y Paniagua, F. J. (2014): "Las universidades españolas en Twitter", en Historia y Comunicación Social, 19. Madrid:

Servicios de Publicaciones de la Universidad de Madrid, páginas 681 a 694; recuperado el 19 de julio de 2019, de http://dx.org/10.5209/rev HICS.2014.v19.44994.

Huertas, A. y Mariné, E. (2014): “Uso y utilidades de las herramientas de análisis online para la evaluación de la comunicación de las marcas de destino a través de los social media", en Sphera Publica. Murcia: Universidad Católica de Murcia, páginas 117 a 134. Huertas, A. (2014): "Redes sociales vs diálogo y participación". En VV.AA., La conducta interactiva de los públicos para las relaciones eficaces (Coords., M. C. Carretón y K. Matilla). España: Universidad de San Jorge.

Igartúa, J. J. (2006): Métodos cuantitativos de investigación en comunicación. Barcelona: Bosch.

Kreab Gavin, A. (2013): Redes sociales y gobiernos. Madrid: Kreab \& Gavin Anderson.

Krippendorf, K. (1985): Content Analysis. An introduction to its methodology. London: Sage Publications Beverly Hills.

Krippendorf, K. (1990): Metodología de análisis de contenido. Teoría y práctica. Barcelona: Ediciones Paidós.

Krippendorf, D. y Bock, A. (2008): The Content Analysis Reader. London: Thousand Oaks: Sage.

Martín, F. (2010): Comunicación Empresarial e Institucional. Madrid: Editorial Universitas, S.A. 
Martínez, D. (2014): Comunicación POP. Del periodismo de marca a la marca personal. Barcelona: Editorial UOC.

Merchant, R. (2011): "Integrating Social Media into EmergencyPreparedness Efforts", en New England Journal of Medicine, 365.

Massachusetts, páginas 289 a 291; recuperado el 19 de Julio de 2015, de http://www.nejm.org/doi/full/10.1056/NEJMp1103591

Navarro, P. y Díaz, C. (1995): "Análisis de contenido". En VV.AA., Métodos y técnicas cualitativas de investigación social (Coords., J. M. Delgado y J. Gutiérrez). Madrid: Síntesis Psicología.

Neuendorf, K. A. (2002): The content analysis guidebook. United Kingdom: Thousand Oaks: Sage.

Nicolás, M. A. y Grandío, M. M. (2012): Estrategias de comunicación en redes sociales. Barcelona: Editorial Gedisa.

Oviedo, C. (2013): "El camino sin retorno de la comunicación corporativa", en Telos: Cuadernos de Comunicación e Innovación, 96. Madrid: Fundación Telefónica, páginas 6 a 8.

Palomo, M. B. (2014): "Nuevas narrativas informativas: el caso de Storify", en Hipertext.net, 12; recuperado el 19 de julio de 2015, de http://raco.cat/index.php/Hipertext/article/view/274338/364580.

Palomo, M. B. (2004): El periodista on line: de la revolución a la evolución. Salamanca: Comunicación Social Ediciones y Publicaciones.

Pallarés, A. (2013): "20 Consejos para la gestión del Twitter Corporativo", en Social Media Marketing, enero:

http://www.puromarketing.com/index.php?user=83297\&pag=3; consultado el 12 enero de 2014.

Peñafiel, C. y Echegaray, L. (Coords.) (2014): Estudios de Comunicación y Salud, 63. La Laguna (Tenerife): Sociedad Latina de Comunicación Social.

Piñuel, J. L. (2002): Epistemología, metodología y técnicas del análisis de contenido. Madrid: Universidad Complutense de Madrid.

Riffe, D., Lacy, S. y Fico, F. G. (2005): Analyzing media messages: Using quantitative content analysis in research. New Jersey: Lawrence Erlbaum Associates: Mahwah.

Rubia Vila, F. J. et al. (2011): Libro Blanco sobre el Sistema Sanitario Español. Madrid: Academia Europea de Ciencias y Artes (AECYA).

Sachin, J. (2009): "Practicing Medicine in the Age of Facebook", en New England of Medicine, 361. Boston: Harvard Business School and Departament of Medicine at Brigham and Women's Hospital, páginas 
649 a 651; recuperado el 19 de julio de 2015, de http://www.nejm.org/doi/full/10.1056/NEJMp0901277.

Sánchez-González, M. y Paniagua-Rojano, F. J. (2013):

"Estrategias de comunicación 2.0 en asociaciones profesionales.

Estudio del caso de los Colegios Oficiales de Médicos en España", en Revista Mediterránea de Comunicación, 4. Alicante: Universidad de Alicante, páginas 21 a 51; recuperado el 19 de julio de 2015, de http://dx.doi.org/10.14198/MEDCOM2013.4.1.02.

Santamaría, C. D. y Terrón, J. L. (2014): "Estudios de Comunicación y Salud". En VV.AA., Estudios de Comunicación y Salud (Coords., C. Peñafiel y L. Echegaray). La laguna, Tenerife: Sociedad Latina de Comunicación.

Timoteo Álvarez, J. (1997): Del viejo orden informativo. Madrid: Actas Editorial.

Timoteo Álvarez, J. (2012): Manejo de la comunicación organizacional. Espacios, herramientas y tendencias en la gestión de negocios. Madrid: Díaz de Santos.

Torrente, E., Martí, T. y Escarrabill, J. (2010). "Impacto de las redes sociales de pacientes en la práctica asistencial", en Revista de Innovación Sanitaria y Atención Integrada. 2. Consultado el 12 de enero de 2014 en http://pub.bsalut.net/risai/vol2/iss1/1/

Traver, V. y Fernández-Luque, L. (2011): El e-Paciente y las redes sociales. España: Publidisa y Fundación Vodafone.

Troncoso, M. (1995): "Redes sociales, salud mental y esquizofrenia. Una revisión del tema", en Revista de Psiquiatría, 12. Santiago de Chile, páginas 163-72; recuperado el 19 de julio de 2015, de http://www.worldcat.org/title/redes-sociales-salud-mental-yesquizofrenia-una-revision-del-tema/oclc/69859339

Trujillo, J. A. (2013): La Medicina basada en el Humanismo. Málaga: Fundación Málaga.

Villafañe, J. (2008): La gestión profesional de la imagen corporativa. Madrid: Pirámide.

Villafañe, J. (2000): Imagen positiva: gestión estratégica de la imagen de las empresas. Madrid: Pirámide.

Wen-Ying, S. (2009): "Social Media Use in the United States: Implications for Health Communication", en Journal of Medical Internet Research, 11. United States: US National Library of Medicine; 
recuperado el 19 de julio de 2015, de http://www.ncbi.nlm.nih.gov/pmc/articles/PMC2802563/citedby/ Wimmer, R. y Dominic, J. (1996): La investigación cientifica de los medios de comunicación. Una introducción a sus métodos. Barcelona: Bosch.

Zerfass, A. et al (2014): European Communication Monitor. Bruselas: European Public Relations Education and Research Association, the European Association of Communication Directors and Communication Director Magazine. 


\section{El impacto de las TICs en la gestión de las agencias de viajes}

Clide Rodríguez, Universidad de A Coruña (UDC, España), crodriguezv@udc.es

Oscar Juanatey, Universidad de A Coruña (UDC, España), oscarjb@udc.es

Jaime Álvarez, Universidad de A Coruña (UDC, España), jaime.delatorre@udc.es

\section{Resumen}

El sector de las agencias de viajes en España ha experimentado una profunda transformación propiciada por la llegada de Internet y el desarrollo de las Tecnologías de la Información y de la Comunicación (TICs). Las agencias online, han ganado cuota de mercado y el número de agencias tradicionales se ha reducido.

El objetivo principal de este trabajo se fundamenta en analizar la situación actual del negocio online y offline a través de los cambios propiciados por la aplicación de las TICs.

En virtud de los aspectos inherentes a la investigación, se optó por aplicar una metodología cualitativa mediante entrevistas en profundidad a agentes de viaje y directores de agencias de viajes minoristas y online.

Las conclusiones a las que se ha llegado corroboran que si bien el modo de informarse y acceder a la información del consumidor ha variado a causa de las TICs, provocando situaciones de desintermediación y reintermediación, la convivencia del negocio online 
y offline es posible. Para ello las agencias tradicionales deben agregar valor a la cadena de suministro y escuchar sus necesidades del cliente para competir con garantías.

Palabras clave: agencias de viajes online, agencias de viajes tradicionales, intermediación turística, TICs, Internet.

\section{Introducción}

$\mathrm{E}$ L sector de las agencias de viajes español está sufriendo en los últimos años una importantísima transformación. Internet ha supuesto múltiples desafíos y también nuevas oportunidades, puesto que pone a su disposición, herramientas novedosas que les ayudan a alcanzar un mejor posicionamiento en el mercado, lo que a su vez permite una mayor captación de clientes y su posterior fidelización.

El sector turístico y, en especial la industria de la distribución, ha asimilado esta nueva situación de una forma especialmente intensa, lo que ha provocado que los avances tecnológicos hayan generado en los últimos años una reorganización del sector de las agencias de viajes en España.

De esta forma, autores como De Pablo y Juberías (2004) consideran que la Red es uno de los elementos más determinantes en la revolución en la que el sector está inmerso, introduciendo importantes modificaciones en el ámbito de la comercialización, especialmente en el caso de la distribución (O'Connor y Frew, 2012: 33-45) y venta directa de ciertos bienes y servicios (Christian, 2001: 170-178; Law, et al., 2004: 100-107) permitiendo el logro de importantes ventajas en la forma tradicional de operar, así como en las relaciones que mantienen con otras empresas y sus clientes.

Desde el lado de la oferta, desaparecen las fronteras geográficas y se ve incrementada de forma significativa, al igual que aumentan las operaciones realizadas. Desde el lado de la demanda los actuales sistemas de información y distribución han cambiado las reglas del juego, ya que permiten a los clientes acceder a una oferta muy amplia, acompañada de una gran cantidad de información a un menor coste (Abella, et al., 2002: 603-613).

Como señala Garrido (2010), la llegada de Internet y la instauración de la world wide web, hicieron posible alcanzar 
importantes avances en la aplicación de las nuevas tecnologías al mundo de los negocios, lo que ha de ser observado desde un punto de vista tecnológico, social, económico y organizativo.

Así, en este nuevo panorama, surge el comercio electrónico o como desarrollo de actividades económicas a través de las redes de telecomunicaciones" (Del Águila, 2000) o tal y como lo definió Gariboldi (1999) "toda transacción comercial (producción, publicidad, distribución y venta de bienes y servicios) realizada tanto por personas, empresas o agentes electrónicos a través de medios digitales de comunicación en un mercado virtual que carece de límites geográficos y temporales". Incluso hay autores que van más allá y establecen que se trata de una parcela, importante y extensa del eBusiness (Rufín, 2002).

De este modo, una de las consecuencias inmediatas que tuvo el desarrollo del comercio electrónico en la intermediación tradicional fue la aparición de agencias de viajes que operan sólo en el ámbito online, careciendo de soporte físico. En España se denominan agencias de viajes online o virtuales, aunque también son conocidas como online travel agencies (OTAS), pure players o pure etailers. Para este tipo de agencias, la red es su razón de ser y una amplia fuente de retos y oportunidades (De Nuñez y Lugones, 2001).

En el campo de las agencias de viajes tradicionales también ha tenido enorme influencia este canal puesto que les permite disponer de un medio de ventas adicional y favorecer los procesos de reintermediación. Agencias tradicionales como Viajes El Corte Inglés o Barceló Viajes, implementan sus ventas offline a través de sus páginas web en Internet, lo que les permite tener una mayor visibilidad en el mercado online y favorecer el acceso a sus productos a todos sus clientes de una manera fácil y cómoda.

Sin embargo, y aunque las ventajas del comercio electrónico son múltiples, no todas las agencias tradicionales han entrado todavía en este mercado, restándoles competitividad.

\section{Las agencias de viajes en España. Situación actual}

La industria turística actual tiene sus orígenes en el siglo XIX, siendo considerado el británico Thomas Cook como uno de sus padres al haber sido el creador de la primera agencia de viajes (Vogeler y Hernandez, 1997; Fernandez, 1985). 
En España, Viajes Marsans abrió al público en el año 1910 como la primera agencia de viajes. Desde ese momento se fueron creando otras agencias de viajes que, en conjunto, logran unir esfuerzos dando lugar a comienzos de los años 30 a la Federación de Agencias de Viajes Españolas. La primera agencia de viajes mayorista, Pullmantur, se fundó en el año 1965 obteniendo el título número 1 de las agencias mayoristas españolas (Vila, 1997). Desde sus inicios, las agencias de viajes, han sido consideradas como una de las fuerzas más poderosas en el desarrollo del turismo, actuando como intermediarias en las demandas de los consumidores y las ofertas de los proveedores turísticos (Martín, 2004).

Las agencias de viajes en España están reguladas por el Real Decreto 271/1988 de 25 de Marzo (Boletín Oficial del Estado, número 76, de 29 de marzo de 1988), desarrollado reglamentariamente por la Orden Ministerial de 14 de abril de 1988 (Boletín Oficial del Estado, número 97, de 22 de abril de 1988) por la que se aprueban las normas reguladoras de las agencias de viajes ${ }^{22}$.

En cuanto a su clasificación y, en relación a nuestro ámbito de estudio, debemos indicar en este contexto que, las agencias de viaje online a nivel legal en nuestro país tienen la misma consideración que la agencia de viajes tradicional incluida bajo el epígrafe "agencia de viaje minorista o mayorista-minorista". De este modo y de acuerdo a la legislación española y al artículo tres de la Orden Ministerial del 14 de abril de 1988, las agencias de viajes se clasifican en 3 grupos: Mayoristas, Minoristas y Mayoristas-Minoristas. Así, las agencias mayoristas son las que crean el producto; las minoristas las que lo distribuyen y las mayoristas-minoristas las que simultanean ambas funciones.

${ }^{22}$ El primer Reglamento de Agencias de Viaje se estableció en el Decreto de 19 de febrero de 1942. Otras disposiciones importantes fueron la Orden de 14 de julio de 1951 y la de 28 de marzo de 1955 sobre servicios por Agencias de Viaje, la Orden de 26 de febrero de 1963 que desarrollaba el Decreto 735/1962 y la Orden de 12 de abril de 1966 por la que se regulaba la actividad de mayoristas de Agencias de Viaje. En 1979 se promulgó una nueva normativa basada en el Decreto 1524/1973, de 7 de junio, desarrollado por la Orden de 9 de agosto de 1974. Finalmente, por Orden de 8 de mayo de 1978 de reorganizó la composición de la comisión mixta de vigilancia de las Agencias de Viaje. Todas estas disposiciones han sido expresamente derogadas. 
Algunos autores, como es el caso de Del Alcázar (2002), señalan que los profundos cambios que se están produciendo en el sector turístico y su entorno se podrían resumir en dos pilares fundamentales: por un lado, una marcada tendencia para evitar a las agencias de viajes como intermediarios en el canal de distribución por parte de los prestadores de servicios y por otro, la repercusión tan importante que la tecnología está teniendo en el ámbito de la intermediación turística al propiciar la aparición de nuevos actores en la distribución.

A estos dos puntos se les unen una serie de factores del entorno que obligan a las agencias de viajes a replantearse su estrategia en la industria turística tales como: reducción de las comisiones procedentes de los proveedores; concentraciones empresariales; distribución directa o nuevos modelos de negocio empresarial (Del Alcázar, 2002).

Si a estos elementos le unimos aspectos coyunturales como la crisis económica que hemos sufrido en España desde el año 2008 y hasta la fecha, podremos poner de manifiesto la situación actual de nuestras agencias.

En el año 2007, año previo a la crisis, nuestro país contaba con una planta de más de 12.000 agencias de viaje. En los seis años posteriores, del 2008 al 2013, se produjeron 5.000 cierres, lo que provocó que en diciembre de 2013 se contara con una planta de 7.000 agencias de viajes. Esto significa que el tamaño del sector se habría reducido un $40 \%$, afectando particularmente a las agencias de viajes minoristas tradicionales y a las mayoristas; viéndose muy poco castigadas las agencias de viaje online que al saber adecuarse mejor a estas circunstancias económicas tan adversas. Los cuadros que se muestran a continuación pretenden ser ejemplo de esa situación:

Cuadro 1: Evolución cierre de agencias

\begin{tabular}{|l|l|}
\hline Año* & Número de cierres ** \\
\hline 2008 & 800 \\
\hline 2009 & 1.500 \\
2010 & 1.500 \\
\hline 2011 & 500 \\
2012 & 200 \\
2013 & 500 \\
\hline Total cierres & 5.000 \\
\hline
\end{tabular}

Fuente: Adaptado de Hosteltur (2014) 
* Los años de la tabla siempre toma como muestra el mes de diciembre

** Centrales más sucursales. Estimaciones de Hosteltur a partir de las cifras de las bases de datos de los principales proveedores de las agencias.

Ante el escenario descrito, las agencias online que operan en España consiguieron afianzarse adaptando su fórmula de negocio para poder ganar mayor cuota de mercado y, aunque en los últimos años su ritmo de crecimiento ha frenado, su porcentaje de ventas ha aumentado y sus cifra de negocio ha llegado, en algunos casos, a ser superiores a los obtenidos por las agencias presenciales tradicionales.

\section{Cuadro 2: Ranking Hosteltur de agencias online}

\begin{tabular}{|c|c|c|c|}
\hline Agencia & Fact. 2012 & Fact. 2011 & Dif\% 11-12 \\
\hline 1 eDreams* & 1.230 & 1.125 & $10 \%$ \\
\hline 2 Rumbo* & 450 & 495 & $-9 \%$ \\
\hline 3 Logitravel & 294 & 275 & $6 \%$ \\
\hline \multirow{2}{*}{\multicolumn{4}{|c|}{$\begin{array}{ll}4 & \text { Atrapalo } \\
& \text { Muchoviaje }\end{array}$}} \\
\hline & & & \\
\hline \multicolumn{4}{|l|}{ Lastminute } \\
\hline \multicolumn{4}{|l|}{ Destinia } \\
\hline Total & 2.195 & 2.105 & $5 \%$ \\
\hline
\end{tabular}

Fuente: Hosteltur (2013)

\section{El consumidor turístico y su comportamiento en las agencias tradicionales vs. Online}

Siguiendo a Werthner y Ricci (2004: 101-105) en el siglo XXI nos encontramos ante un nuevo consumidor menos leal. Debido a esta falta de fidelizad del cliente, las empresas turísticas dedican buena parte de sus esfuerzos a tratar de mejorar el grado de satisfacción entre sus clientes así como aumentar su rentabilidad y también su competitividad a través de una optimización de la organización y de las estructuras de la misma (Buhalis, 1998: 112-149).

Tal y como señala Alfaro (2006: 47-59), un alto nivel de satisfacción tiene como consecuencia un elevado nivel de fidelidad, aunque no al contrario. Además, en el entorno virtual, cuanto más satisfechos están los clientes con las páginas web, más disposición tienen a realizar sus reservas a través de este medio y también a recomendar la página que han utilizado para reservar (Davidson, 1998). Lu y Lu (2004: 221-239) no indican que las principales razones de insatisfacción del viajero que realiza una compra online derivan en su mayor parte de la conexión lenta a Internet, de las altas tarifas, de la 
falta de suministro de información y de la falta de mecanismos que permitan la interacción.

De igual forma, en el ámbito de los viajes y de la intermediación turística nos encontramos con un nuevo consumidor (Werthner y Ricci, 2004: 101-105). Este nuevo cliente se caracteriza por que realiza viajes con mayor frecuencia y de menor duración (Buhalis y Jun, 2011). En cuanto a la motivación del viaje Rodríguez et al. (2006) señalan que la tendencia es la de visitar destinos nuevos y menos conocidos.

En el diseño de productos turísticos, tal y como señala Solé (2003) los consumidores y sus nuevos hábitos de consumo desempeñan un papel importante, especialmente desde el ámbito virtual, ya que como pone de manifiesto Buhalis (1998: 112-149), la empresa virtual no es un complejo aislado de instalaciones de producción, sino más bien un módulo en el complejo entramado formado por los proveedores, los clientes, la elaboración de procedimientos y otras funciones de servicio. Kotler y Gertner (2004: 54-62) apuntan que debido a esto, las empresas turísticas se ven en la obligación de investigar cuáles son los valores que como usuarios buscan los turistas (de rendimiento, sociales y emocionales), además de lo que buscan como compradores (conveniencia y personalización) y lo que buscan como pagadores (precio y crédito).

Debido a esto, las empresas turísticas, han de apostar por adaptar su estrategia a esta nueva situación y será necesario que incrementen su eficiencia y reduzcan su costes (Wherthner y Ricci, 2004: 101-105); además, se deberán crear sistemas de recogida y almacenamiento de datos eficientes que les permitan, mediante el correcto tratamiento de los mismos y tal y como señalan Stergiou y Airey (2003: 355-366), desarrollar una completa red de productos y servicios adaptados a las preferencias y opiniones del consumidor a la hora de planificar sus viajes.

Amadeus España y $\mathrm{ACAV}^{23}$ en el año 2010 realizaron un análisis cuantitativo y cualitativo del sector de las agencias de viajes que puso de manifiesto las preferencias y hábitos de consumo del usuario de las agencias de viajes españolas. En relación a ese estudio y en cuanto al uso de las agencias de viajes, podemos afirmar que cerca de un $40 \%$ de los hogares españoles habían utilizado en ese año los servicios de

${ }^{23}$ ACAV: Asociación Catalana de Agencias de Viajes. 
agencias de viajes tanto tradicionales como online; además el número de españoles que utilizó la agencia tradicional duplicó al de quienes visitan la online y alrededor de un 36\% de los clientes emplearon ambos tipos de agencia, aunque prima el uso de la agencia tradicional. Además un $80 \%$ de los clientes que acuden a una agencia de viajes acaban formalizando un viaje, frente al 20\% que sólo contacta para solicitar información. De este dato se desprende que hay un importante margen de captación del cliente. Ambos tipos de agencias consiguen que el cliente perciba un alto nivel de satisfacción.

Sin embargo, las áreas susceptibles de mejora son la agilidad en el servicio y el poder ofrecer mayor información, principalmente sobre el destino consultado, Para dar respuesta a estas demandas la formación, en las agencias presenciales, y la implantación de herramientas y/o procesos que minimicen los tiempos de espera para ambos tipos de agencia serían posibles fórmulas a seguir.

Por otro lado cabe destacar que el cliente percibe de manera muy diferenciada las ventajas que le ofrecen tanto la agencia tradicional como la online y se decanta por una u otra en función del valor que concede a estos beneficios o lo que en cada momento esté buscando.

La tasa de fidelidad del cliente de la agencia presencial es mayor que la del cliente de la agencia online, existiendo una mayor competitividad entre éstas últimas, ya que sus usuarios visitan una media de cinco websites antes de contratar frente a los dos establecimientos a los que acude el cliente de la tradicional.

Los clientes de ambos tipos de agencias son sensibles al precio, siendo más acusado este aspecto en los cliente de las online, claramente orientados a este factor, sin embargo el cliente de la agencia presencial otorga más relevancia a valores como el servicio; por lo que asesoramiento, experiencia y atención personalizada y cualificada son las principales fortalezas de los agentes de viaje.

A la hora de seleccionar una agencia online para contratar un servicio son aspectos determinantes el pago seguro por Internet y la claridad y sencillez de la web. Algo que pone de manifiesto que la seguridad en comercio electrónico aún no es un debate superado entre los usuarios además de demostrar que las TICs siguen ofreciendo grandes oportunidades para guiar al usuario y hacer que su navegación sea más fácil e intuitiva. 
Por último, el cliente de la agencia online realiza viajes con mayor frecuencia y fuera de temporadas típicamente vacacionales con respecto al cliente de la tradicional; en este sentido, la agencia tradicional es más dependiente de la estacionalidad que la online. En cuanto a los productos vendidos, en la agencia tradicional el paquete turístico tiene una alta penetración, mientras que en la online este nivel de penetración es muy bajo.

\section{Objetivos de la investigación y metodología}

El sector de las agencias de viajes en nuestro país está sufriendo en los últimos años una importantísima transformación directamente relacionada con el desarrollo de Internet y las TICs. El número de agencias de viajes tradicionales se ha visto reducido de manera significativa y las agencias de viajes virtuales, nacidas por y para la web, ganan en cuota de mercado.

\subsection{Objetivos}

De este modo, el objetivo principal de esta investigación es analizar la situación actual del negocio online y offline a través de los cambios propiciados por la aplicación de las TICs. A partir del objetivo básico, establecemos otros objetivos secundarios, para que el análisis de los mismos contribuya a justificar en mayor medida el objeto central de estudio:

- Primer Objetivo secundario: tratar de conocer cuáles son los cambios introducidos por las TICs en las agencias de viajes y su repercusión en el futuro de la intermediación turística.

- Segundo Objetivo secundario: conocer los hábitos de consumo turístico de los clientes que acuden a agencias tradicionales y online.

\subsection{Metodología}

Nuestra investigación se basa en la utilización de fuentes secundarias como AMADEUS o ACAV y en publicaciones relacionadas con agencias de viajes como HOSTELTUR; así como en otras fuentes documentales publicadas por determinados organismos públicos relacionados con el turismo como la OMT o el IET, entre otros.

También se han empleado fuentes primarias realizando entrevistas en profundidad, que ha permitido conocer lo que es 
importante y significativo para el entrevistado (Selltiz, Wrightsman y Cook, 1980). Nos hemos decantado por la utilización de técnicas cualitativas, por su carácter exploratorio; y en concreto por la entrevista en profundidad porque ha sido un modelo ampliamente utilizado en ciencias sociales (Benney y Hughes, 1970: 175-181).

Sustentamos además el hecho de aplicar una investigación cualitativa, en que existen diversos estudios relacionados con el ámbito de las agencias de viaje en los que el empleo de entrevistas en profundidad ha sido relevante como aproximación inicial al objeto de estudio.

Nuestra investigación exploratoria ha consistido en el desarrollo de cinco entrevistas en profundidad realizadas en agosto-septiembre de 2013 a través de las cuales, como apuntan Taylor y Bogdan (2000) pudimos "conocer lo que piensa o siente una persona con respecto a un tema en particular". Para ello hemos seleccionado individuos en posesión de conocimientos, status o destrezas comunicativas especiales y disponibilidad a cooperar con el investigador" (Goetz y LeCompte, 1988). En nuestro caso elegimos personas directamente relacionadas con el sector de las agencias de viaje tanto tradicionales (minoristas y minoristas/mayoristas) como online; puesto que de este modo su contribución al desarrollo de esta investigación sería más provechosa.

En el cuadro que figura a continuación reflejamos la ficha técnica de las entrevistas realizadas en este estudio:

\begin{tabular}{|c|c|}
\hline UNIVERSO & $\begin{array}{l}\text { Categorizado por: agencias de viaje } \\
\text { online y tradicionales }\end{array}$ \\
\hline UNIDAD MUESTRAL & $\begin{array}{l}\text { Agentes de viaje y directores de } \\
\text { sucursal }\end{array}$ \\
\hline $\begin{array}{c}\text { COMPOSICIÓN DE LA } \\
\text { MUESTRA }\end{array}$ & $\begin{array}{l}\text { Contacto directo y personal a través de } \\
\text { correo electrónico y cara a cara con } \\
\text { agencias de viaje }\end{array}$ \\
\hline $\begin{array}{c}\text { PROCEDIMIENTO DE } \\
\text { MUESTREO }\end{array}$ & Por conveniencia \\
\hline METODOLOGÍA & $\begin{array}{l}\text { Desarrollo de ocho preguntas, } \\
\text { divididas en dos bloques relacionadas } \\
\text { con los objetivos que perseguimos en } \\
\text { la investigación }\end{array}$ \\
\hline
\end{tabular}

Fuente: Elaboración propia

En las entrevistas se planteaban ocho cuestiones, con secuencia de embudo; comenzando por los aspectos muy generales, frecuentemente 
en formulación abierta, para pasar luego a otras preguntas más específicas, por lo general de manera cerrada, hasta llegar a los aspectos más concretos y precisos (Mayntz, et al., 1993).

En el cuadro 4, se relacionan los participantes en este estudio cualitativo, la empresa en la que desarrollan su actividad, el cargo que ocupan en la actualidad o habían ocupado en el momento de las entrevistas y el tipo de agencia en el que desempeñan sus funciones:

Cuadro 4: Panel de expertos

\begin{tabular}{|c|c|c|c|}
\hline Entrevistado & Empresa & Cargo & Agencia \\
\hline E.1 & $\begin{array}{c}\text { Viajes El } \\
\text { Corte Inglés }\end{array}$ & $\begin{array}{c}\text { Agente de } \\
\text { viaje }\end{array}$ & Minorista / Mayorista \\
\hline E.2 & $\begin{array}{c}\text { Viajes } \\
\text { Halcón }\end{array}$ & Director & Minorista / Mayorista \\
\hline E.3 & Nuba & Director & Minorista \\
\hline E.4 & Destinia & $\begin{array}{c}\text { Agente de } \\
\text { viaje }\end{array}$ & Online \\
\hline E.5 & Logitravel & $\begin{array}{c}\text { Agente de } \\
\text { viaje }\end{array}$ & Online \\
\hline
\end{tabular}

Fuente: elaboración propia

El siguiente paso fue realizar una delimitación más precisa de diferentes conceptos, entre los que subyacen 2 cuestiones que consideramos importantes para nuestro estudio: ¿Cómo es el cambio estructural que están sufriendo las empresas de intermediación? y ¿Cuáles son los hábitos de consumo del cliente turístico en la actualidad?

\section{Resultados de la investigación cualitativa}

Para una mejor interpretación y comprensión de los resultados obtenidos en esta fase cualitativa, hemos estructurado las entrevistas en dos bloques temáticos. A continuación se transcriben las opiniones dadas por los profesionales entrevistados.

Tras el análisis de las respuestas que nos ofrecen los entrevistados, podemos determinar que nuestros expertos son conscientes de los cambios que, propiciados por las TICs, se han ido 
produciendo en la gestión de las agencias de viajes así como en las formas de comunicarse e interactuar con el consumidor.

Cuadro 5: Resultados de las entrevistas en profundidad

\begin{tabular}{|c|c|}
\hline Entrevistado & $\begin{array}{l}\text { Cambio de paradigma de la intermediación } \\
\text { turística y su visión de futuro en este sector }\end{array}$ \\
\hline E.1 & $\begin{array}{l}\text { "Apostaría por la reintermediación. El cliente puede } \\
\text { obtener prácticamente el } 100 \% \text { de la información } \\
\text { necesaria sin desplazarse. La clave pasará por la } \\
\text { especialización". }\end{array}$ \\
\hline E.2 & $\begin{array}{l}\text { "La aplicación de las TICs genera desintermediación } \\
\text { (servicios sencillos) y reintermediación en Viajes } \\
\text { Combinados. Internet ha traído ventajas en cuanto a } \\
\text { agilidad, accesibilidad, venta online...pero también } \\
\text { exigencia por parte del cliente que exige de las agencias } \\
\text { tradicionales asesoramiento" }\end{array}$ \\
\hline E.3 & $\begin{array}{l}\text { "Desintermediación, cada vez son más los proveedores } \\
\text { que venden directamente a un cliente cada vez más } \\
\text { informado. La supervivencia pasa por fidelizar a nuestros } \\
\text { clientes ofreciéndoles especialización y trato } \\
\text { personalizado". }\end{array}$ \\
\hline E.4 & $\begin{array}{l}\text { "Principalmente desintermediación. Hay muchos } \\
\text { servicios a los que el cliente tiene acceso directamente. Al } \\
\text { mismo tiempo hipermediación y reintermediación ya que } \\
\text { las TICs han propiciado la aparición y desarrollo de } \\
\text { nuevos intermediarios. Las agencias de viajes } \\
\text { tradicionales se verán reemplazadas por las online a } \\
\text { menos que den un mayor valor añadido". }\end{array}$ \\
\hline E.5 & $\begin{array}{l}\text { "La aparición de Internet ha provocado un proceso de } \\
\text { hipermediación con la aparición de nuevos modelos de } \\
\text { intermediarios. El cliente tiene acceso a gran cantidad de } \\
\text { información y puede además formalizar sus reservas } \\
\text { online. Las agencias tradicionales que no puedan } \\
\text { adaptarse a los cambios tecnológicos tenderán a } \\
\text { desaparecer". }\end{array}$ \\
\hline
\end{tabular}

Fuente: Elaboración propia 
Tal y como apunta uno de nuestros entrevistados, este período se caracteriza por la gran cantidad de actores en el ámbito de la intermediación provocando hipermediación, que permite la convergencia de medios tales como imagen, vídeo, audio o mapas, entre otros soportes, de tal modo que el resultado obtenido nos da la posibilidad de interactuar con los usuarios.

En cuanto a la desintermediación los entrevistados opinan que existen servicios, como el aéreo y el hotelero, que son más susceptibles de ser reservados directamente por el cliente debido principalmente a su mayor experiencia en el ámbito online y a la buena usabilidad de las web de los proveedores. Nuestros entrevistados también han opinado sobre los procesos de reintermediación, que se producen como consecuencia del hecho de que la información que Internet facilita es demasiado amplia y el tiempo necesario para encontrar lo que el usuario realmente busca limitado.

Por último todos tienen una idea bastante clara sobre el futuro de la intermediación. Todos ellos son conscientes del cambio de paradigma que la intermediación turística ha sufrido con la incorporación de las TICs aunque dependiendo de si desempeñan su función en el ámbito online u offline su visión de futuro tiene matices diferentes.

Para las agencias minoristas tradicionales, su futuro radica en rediseñar su papel como intermediarios en el canal de distribución y determinar si su negocio lo enfocan a los proveedores o a los clientes. Son menos esperanzadores en sus comentarios nuestros expertos representantes del ámbito online; que ven el final de la intermediación clásica a través de las agencias de viajes tradicionales, sin embargo, los más optimistas auguran una larga vida a los intermediarios, como pieza fundamental en la distribución de productos y servicios turísticos, para ello deberán aportar al cliente valor añadido y deberán diferenciarse de los competidores.

Debido a la aplicación de las TICs el cambio en el modelo de comercialización tradicional ha dado un giro hacia un modelo multicanal en el que además de los canales tradicionales se emplean otras vías como metabuscadores, blogs, marketing de afiliación y las Web. 
Cuadro 6: Resultados de las entrevistas en profundidad

\begin{tabular}{|c|c|}
\hline Entrevistado & $\begin{array}{l}\text { Hábitos de consumo y búsqueda de } \\
\text { información de los consumidores de viajes }\end{array}$ \\
\hline E.1 & $\begin{array}{l}\text { "Utilizamos la web, promoción y difusión por } \\
\text { diversos canales: propios puntos de venta, e-mails } \\
\text { o redes sociales para llegar a nuestros clientes, } \\
\text { quienes valoras la accesibilidad, la información y la } \\
\text { posibilidad de compra directa. Cada vez son más } \\
\text { los clientes que actúan como prescriptores". }\end{array}$ \\
\hline E.2 & $\begin{array}{l}\text { "Hoy comercializamos a través de los puntos de } \\
\text { venta, de redes sociales, mensajería instantánea o } \\
\text { malings. Las TICs han influído en los hábitos de } \\
\text { compra y el exceso de información hace que la } \\
\text { venta se cierre con nosotros ya que les damos más } \\
\text { confianza. Son muchos los clientes que actúan } \\
\text { como prescriptores". }\end{array}$ \\
\hline E.3 & $\begin{array}{l}\text { "El principal canal de comercialización es la propia } \\
\text { oficina; además de nuestra web y Facebook. Para } \\
\text { algunos servicios sueltos simples, notamos que el } \\
\text { cliente utiliza cada vez más compras en web; pero } \\
\text { para los productos más especializados como } \\
\text { grandes viajes o reservas internacionales el cliente } \\
\text { sigue confiando en la agencia tradicional." }\end{array}$ \\
\hline E.4 & $\begin{array}{l}\text { "Nuestra propia página web, banners en distintos } \\
\text { blogs, webs y portales tanto especializados como } \\
\text { generalistas y presencia en todas las redes sociales. } \\
\text { Las opiniones de nuestros clientes sobre nuestra } \\
\text { empresa: fiabilidad, productos, precio... son } \\
\text { altamente valoradas por otros posibles clientes a la } \\
\text { hora de confiarnos la gestión de sus viajes". }\end{array}$ \\
\hline E.5 & $\begin{array}{l}\text { "Hoy utilizamos canales online, redes sociales, } \\
\text { newsletters, e-mails, blogs, nuestra web y en otras } \\
\text { mediante enlace. Los clientes se asesoran mucho } \\
\text { más, buscan más información sobre el destino a } \\
\text { través de Internet." }\end{array}$ \\
\hline
\end{tabular}

Fuente: Elaboración propia 
Actualmente la mayor parte de las agencias de viaje emplean al menos un doble canal de comercialización: el canal tradicional presencial y las páginas web. Además de estos dos canales destaca la utilización de redes sociales, en la que la mayor parte de agencias publican ofertas, y otros medios como publicidad en medios generalistas y especializados. Los consumidores se encuentran cada vez más informados a la hora de realizar sus compras. De hecho, Internet ha pasado a ser clave en este proceso y en la toma de decisión final sobre la adquisición de un servicio o producto turístico.

Todos los expertos afirman que las TICs facilitan al consumidor el acceso a la información y la compra del servicio turístico a través de Internet. Las agencias de viaje tradicionales matizan además que para determinados productos turísticos los clientes siguen prefiriendo cerrar la venta bajo el asesoramiento de un profesional, no siendo así para los servicios sueltos simples.

Los tres representantes de agencias de viaje tradicionales coinciden al opinar que el exceso de información, la desconfianza o la complicación de determinados viajes son factores que determinan la compra del servicio a través del canal tradicional en lugar de la compra online.

Todos los expertos entrevistados coinciden al afirmar que el cliente ha variado sus hábitos para obtener información sobre servicios y productos turísticos. Actualmente, y, una vez más debido a Internet, surge una oportunidad para el turismo. Miles de comunidades de consumidores de todo el mundo se reúnen virtualmente, de forma síncrona y asíncrona, para el intercambio de información y experiencias sobre destinos y respecto a sus productos turísticos. Para ello, utilizan tecnología de interactuación social, es decir herramientas como blogs y comunidades de viajeros.

Por último, todos ellos afirman que la figura del prescriptor está alcanzando cotas de credibilidad importantes.

\section{Conclusiones}

La industria de los viajes en España está afrontando un momento histórico, difícil. El sector de la intermediación turística está sufriendo un intenso proceso de adaptación a los nuevos desarrollos tecnológicos aplicados al sector, producidos por la incorporación de 
las TICs, teniendo una mayor relevancia desde la aparición de Internet.

Este cambio de paradigma en el ámbito de la intermediación turística impulsado por las TICs, en un sector que tiene como función estratégica básica la gestión de la información, ha afectado especialmente al rol de las agencias de viaje tradicionales; dando entrada además a nuevos formatos de comercialización y participantes en el proceso de intermediación.

A modo de conclusión, cabe señalar que al analizar las entrevistas se evidencian los siguientes resultados acordes con el marco teórico:

En relación al cambio de paradigma en la intermediación asociado a la implementación de las tecnologías de la información, y ante el panorama descrito, encontramos como factor más influyente en el cambio en la intermediación turística, Internet y el desarrollo tecnológico posterior. Internet que ha dejado el papel del intermediario tradicional en estado crítico y que les ha obligado a aportar valor con su desempeño si no quieren ver mermado, cerrado o digitalizado su negocio.

Podemos decir que la implementación de las TICs plantea nuevos retos y cambios para el sector turístico. Estos cambios que afectan a proveedores, intermediarios y consumidores finales de igual manera, darán como resultado el establecimiento de nuevas estructuras empresariales en un futuro cercano; además de estar siendo especialmente significativos en el canal de distribución, que ha experimentado alteraciones importantes en relación con las estructuras más tradicionales que existían en el sector. Las agencias de viajes tradicionales, están viendo peligrar su supervivencia y deben emprender acciones que les permitan seguir ofreciendo valor añadido en el mercado, especialmente con el objetivo de continuar siendo competitivas.

Como hemos visto en el marco teórico, el acceso a Internet del consumidor y de las agencias de viajes ha cambiado su modo de relacionarse, lo que ocasiona que las estrategias a seguir se adapten a las nuevas circunstancias. Esta nueva realidad está marcada por un cliente con mayor acceso a las tecnologías; por operadores que aumentan sus ventas a través de Internet; por una reducción en las comisiones a los intermediarios turísticos tradicionales; por una mayor 
oferta y por contar con más canales de distribución, lo que ha dado lugar a un "modelo multicanal". En este modelo, además de los mass media, se utilizan: apps, blogs, RSS, geoposicionamiento, metabuscadores o Web 3.0.

Las agencias de viajes tradicionales están siendo conscientes de que la digitalización en la comercialización y distribución de sus productos es cada vez más una necesidad, pero también una oportunidad para adecuar su estrategia competitiva y sacar provecho a esta nueva realidad antes que la competencia. Sin embargo, el contacto directo con el cliente que les permite su venta tradicional sigue siendo considerado como un valor añadido y un elemento de diferenciación con la competencia online.

En lo que respecta a la influencia de las TICs en el hábito de compra del cliente, se ha constatado que el desarrollo de la tecnología facilita al cliente el acceso a la información, a la comparación de ofertas, a la operativa de las reservas y en definitiva a la compra final. Sin embargo, no en todos los casos es igual, ya que esta influencia está condicionada por el tipo de producto del que estemos hablando. Así, si hablamos de un servicio suelto como puede ser la reserva de una plaza de avión, la experiencia previa del cliente y la operativa sencilla de reserva determina el éxito de la compra a través del canal online. Sin embargo, si nos referimos a un viaje combinado el cliente, aunque puede crear su propio producto a través de los paquetes dinámicos, se encuentra infoxicado y con poca experiencia personal en la creación del viaje, por lo que la figura del intermediario se hace necesaria.

Sobre los hábitos de información de los clientes actuales, podemos afirmar que algo ha cambiado en relación a tiempos pasados, ya que, el acceso a Internet ha permitido al consumidor turístico poder escuchar a sus amigos y familiares, además de dejarse seducir por aquellos que han logrado una reputación online favorable (stakeholders) en cualquier etapa de la planificación del viaje. Ello, por supuesto, sin obviar el asesoramiento profesional del agente de viajes. Por lo tanto, se puede determinar que el boca-oreja, sea cual sea el canal, tiene una gran importancia en las decisiones de un viaje. De esta manera, a la hora de informarse nuestro viajero consulta primero a los que tiene más cerca para tomar ideas e información pero, a medida que adopta métodos de reserva online, las críticas de usuarios y los medios sociales son más importantes. 
A este respecto, nuestros entrevistados y, dependiendo del tipo de agencia al que representaran, tenían percepciones diferentes. Así, si los que opinan son las agencias online, los prescriptores para ellos son sus clientes que gozan de cierta credibilidad y que exponen sus experiencias a través de su Web, de foros, blogs o redes sociales y son seguidos sus comentarios por otros usuarios. Si los que hablan pertenecen al ámbito offline, la función de asesorar recae en los propios agentes de viajes como profesionales del sector y buenos conocedores de los productos que venden.

\section{Referencias bibliográficas}

Abella, S., Gorgemans, S., Martínez, Á. y Perez, M. (2002): "Implications of the Internet - an analysis of the Aragonese hospitality industry", en Tourist Management, 25, páginas 603 a 613; recuperado el 11 de noviembre de 2014 de http://www.sciencedirect.com/science/article/pii/S02615177030015 $\underline{23}$

Alfaro, E. (2006): "La satisfacción del turista en España. Un análisis de los estudios Familitur y Frontur", en Estudios Turísticos, 168, páginas 47 a 59; recuperado el 29 de octubre de 2014 de http://www.iet.tourspain.es/img-iet/revistas/ret-168-2006-pag49-59_ 97138.pdf

Amadeus España y ACAV (2010): Primer estudio estratégico de las agencias de viajess españolas. Primera parte: Preferencias y hábitos de consumo del usuario de las agencias de viajes españolas. Amadeus España y ACAV (Asociación Catalana de Agencias de Agencias de viajes).

Benney, M. y Hughes, E. C. (1970): "Of Sociology and the Interview”. En VV.AA., Sociological Methods: A Sourcebook (Ed., N. D.), páginas 175 a 181. Chicago: Aldine; recuperado el 2 de noviembre de 2014 de

http://www.jstor.org/discover/10.2307/2773343?sid=211059633519 73\&uid $=3737952$ \&uid $=4$ \&uid $=2$

Buhalis, D. (1998): "La empresa turística virtual. Conceptos, prácticas y lecciones”, en Papers de Turisme, 23, páginas 112 a 149; recuperado el 11 de noviembre de 2014 de http:/ / dialnet.unirioja.es/servlet/articulo?codigo $=208965$

Buhalis, D. y Jun, S. H. (2011): E-Tourism. Contemporary Tourism Reviews. Oxford: Goodfellow Publishers Limited. 
Christian, R. (2001): "Developing an online access strategy: issues facing small-to medium-sized tourism and hospitality enterprises", en Journal of V acation Marketing, 7, páginas 170 a 178; recuperado el 15 de noviembre de 2014 de

http://jvm.sagepub.com/content/7/2/170.refs

Davidson, R. (1998): Viajes y turismo en Europa. $2^{\mathrm{a}}$ ed. Madrid: Síntesis.

De Nuñez y Lugones, F. A. (2001): Modelos de negocios en Internet: visión postcrisis. Madrid: McGraw-Hill / Interamericana de España, S.A.

De Pablo, R. y Juberías, G. (2004): Impacto de las nuevas tecnologías en el sector turístico. Facultad de Ciencias Económicas y Empresariales España: Universidad Nacional de Educación a Distancia (UNED).

Del Águila, A. R. (2000): Comercio electrónico y estrategia empresarial. Madrid: Ra-Ma.

Del Alcázar, B. (2002): Los canales de distribución en el sector turístico. Madrid: Esic.

Fernandez, L. (1985): Introducción a la Teoría y técnica del turismo. Madrid: Alianza Española.

Gariboldi, G.(1999): Comercio electrónico: conceptos y reflexiones básicas. Buenos Aires: Bid-Intal.

Garrido, P. (2010): Agencias de viajes Online: Situación y perspectivas en el comercio electrónico español. Madrid: Tesis Doctoral. Universidad Complutense de Madrid. Servicio de publicaciones.

Goetz, J. P. y LeCompte, M. D. (1988): Etnografía y Diseño Cualitativo en Investigación Educativa. Madrid: Morata

Hosteltur (2013): "Las grandes agencias del mercado español facturaron 7.500 M €.", en Hosteltur, 228, páginas 28 a 29; recuperado el 10 de octubre de 2014 de http://www.hosteltur.com/155920 grandes-agencias-mercadoespanol-facturaron-7500-m-5-menos.html

Hosteltur (2014): "El turismo vislumbra la luz al final del túnel", en Hosteltur, 234, páginas 16 a 30; recuperado el 10 de octubre de 2014 http://static.hosteltur.com/web/uploads/2014/01/REPORTAJE El turismo vislumbra la luz al final del tuEnel.pdf

Kotler, P. y Gertner, D. (2004): "El país como marca y como producto", en Gestión de Negocios, 5, páginas 54 a 62; recuperado el 15 de noviembre de 2014 de http://www.wobi.com/es/articles/marcapaís-el-país-como-marca-y-como-producto 
Law, R., Leung, K. y Wong, J. (2004): “The Impact of Internet on Travel Agencies", en International Journal of Contemporary Hospitality Management, 16, páginas 100 a 107; recuperado el 10 de noviembre de 2014 de

http://www.emeraldinsight.com/doi/abs/10.1108/095961104105199 $\underline{82}$

Lu, J. y Lu, Z. (2004): "Development, Distribution and Evaluation of Online Tourism Services in China", en Electronic Commerce Research, páginas 221 a 239; recuperado el 15 de octubre de 2014 de http://link.springer.com/article/10.1023\%2FB\%3AELEC.000002798 $1.81945 .2 \mathrm{a}$

Martín, I. (2004): Dirección y gestión de empresas del sector turístico. $3^{\text {a }}$ edición. Madrid: Pirámide.

Mayntz, R., Holm, K. y Hüber, P. (1993): Introducción a los métodos de la sociología empirica. Madrid: Alianza

O'Connor, P. y Frew, A. J. (2012): "The future of hotel electronic distribution: Expert and industry perspectives", en Cornell Hotel and Restaurant Administration Quarterly, páginas 33 a 45; recuperado el 27 de octubre de 2014 de

http://www.sciencedirect.com/science/article/pii/S00108804028001 $\underline{67}$

Rodríguez, M. M., Martínez, V. A. y Rodríguez, M. L. (2006): Las nuevas estrategias de comunicación en el sector turistico, FISEC-Estrategias - Facultad de Ciencias Sociales de la Universidad Nacional de Lomas de Zamora.

Rufín, R. (2002): Las empresas turísticas en la sociedad de la información. Madrid: Editorial Universitaria Ramón Areces.

Selltiz, C., Wrightsman, L. S. y Cook, S. W. (1980): Métodos de investigación en las relaciones sociales. Madrid: Rialp.

Solé, M. L. (2003): Los consumidores del siglo XX. Madrid: ESIC Editiorial.

Stergiou, D. y Airey, D. (2003): "Inquiry Conversion and Tourism Website Effectiveness: Assumptions, Problems and Potential", en Tourism and Hospitality Research, 4, páginas 355 a 366; recuperado el 10 de noviembre de 2014 de http://www.jstor.org/discover/10.2307/23745925?sid=21105963351 973\&uid $=4 \&$ uid $=3737952 \&$ uid $=2$ 
Taylor, S. J. y Bogdan, R. (2000): Introducción a los métodos cualitativos de investigación. $3^{\mathrm{a}} \mathrm{ed}$. Barcelona: Paidós

Vila, J. (1997): La gran aventura del turismo en España. Barcelona: Editur Ediciones Turísiticas S.A.

Vogeler, C. y Hernandez, E. (1997): Estructura y organización del mercado turístico. Madrid: Centro de Estudios Ramón Areces.

Werthner, H. y Ricci, F. (2004): “E-commerce and Tourism", en Communications of the $A C M, 47$, páginas 101 a 105; recuperado el 7 de octubre de 2014 de http://citeseerx.ist.psu.edu/viewdoc/download?doi=10.1.1.395.9661 \&rep $=$ rep $1 \&$ type $=$ pdf 


\section{Medios Sociales y Turismo}

Eva Sánchez-Amboage, Universidad de A Coruña (UDC, España), eva.sanchez.amboage@udc.es

María-Magdalena Rodríguez-Fernández, Universidad de A Coruña (UDC, España),mmrodriguez@udc.es

Valentín-Alejandro Martínez-Fernández, Universidad de A Coruña (UDC, España), valejand@udc.es

\section{Resumen}

Los avances tecnológicos han cambiado nuestra forma de actuar y de percibir el mundo, provocando así una revolución en el ámbito social, económico, cultural y personal donde, tal y como destacan muchos autores, el conocimiento se ha convertido en el activo más importante.

Los elementos fundamentales de este actual y nuevo escenario se pueden resumir en cuatro: Revolución, Tecnología, Información y Relación.

Al igual que el resto de sectores, el turístico ha tenido que adaptarse a esta nueva situación, implantando para ello modelos de marketing capaces de satisfacer las necesidades de un cliente cada vez más exigente e informado. Ante este contexto los Medios Sociales se presentan cada vez más, como una de las herramientas fundamentales en la promoción turística.

Debido a todos estos cambios acaecidos en el entorno, el presente estudio exploratorio analiza la situación y promoción del sector Turístico Termal de la región Norte de Portugal en la Red Social Facebook. Para ello, se ha llevado a cabo un estudio a partir de la observación de las páginas oficinales de Facebook de los balnearios ubicados en dicha zona, con el propósito de descubrir de forma 
individualizada la actividad virtual que desarrolla cada establecimiento y establecer de este modo, las conclusiones conjuntas y pertinentes en relación al termalismo de la región Norte de Portugal.

Palabras clave: medios sociales, Facebook, turismo termal, balnearios, Norte Portugal.

\section{Introducción}

— L sector turístico se caracteriza por su complejidad, no sólo debido a la cantidad de elementos que lo componen, sino también a los distintos sectores económicos que se encuentran involucrados en su desarrollo.

Durante muchos años, la industria turística se ha posicionado como la actividad soberana capaz de generar desarrollo económico, social, cultural y medioambiental en una zona determinada.

Gracias a la globalización y al aumento de ingresos sostenibles, en 2011 el sector turístico generó un 5\% del Producto Interno Bruto (PIB) mundial y entre el $6 \%$ y el $7 \%$ de los puestos de trabajo del planeta (Conferencia de las Naciones Unidas sobre Comercio y Desarrollo, 2013).

Desde un punto de vista más específico, cabe precisar que de los países de la Organización para la Cooperación y Desarrollo Económico (OCDE), Portugal, junto con España, son las dos naciones que más dependen del turismo para su desarrollo económico, especialmente en el momento actual de crisis económica en el cual se encuentran inmersos (Hosteltur, 2012).

Si observarnos en ambos países las diferentes tipologías de turismo, merece la pena hacer especial distinción al Turismo Termal tanto en el caso de Portugal, a la región Norte; como en España, a la

${ }^{24}$ Este trabajo forma parte de las investigaciones desarrolladas por la Red Internacional de Investigación de Gestión de la Comunicación (R2014/026 XESCOM), proyecto financiado en régimen de concurrencia competitiva por la Consellería de Cultura, Educación e Ordenación Universitaria de la Xunta de Galicia, con la participación de los grupos Novos Medios de la Universidad de Santiago de Compostela, iMARKA de la Universidad de A Coruña y NECOM y MILE de la Universidad de Vigo. 
comunidad gallega, cuya importancia se remonta en las dos zonas, a la época romana, quienes concentraban además, el mayor número de "Ciudades Aquae" de toda la Península Ibérica.

Según González (2011) las "Ciudades Aquae" eran aquellas zonas que poseían una mayor riqueza mineromedicinal, tanto en número de manantiales como en la calidad de las aguas.

En este sentido, y siendo conscientes del potencial termal que posee la región Norte de Portugal, la Agenda Regional de Turismo (2009), ha querido impulsar el producto denominado allí, "Turismo de Saúde e Bem-Estar ${ }^{25}$ ", con una serie de estrategias enmarcadas en el horizonte 2015.

En dicho programa se identifica al Turismo Termal de la región Norte de Portugal como un producto turístico prioritario, clave para dinamizar la zona a nivel social, medioambiental y económico.

Además, entre los objetivos del PENT (Plan Estratégico Nacional del Turismo) Horizonte 2013-2015 elaborado por el Ministerio de Economía y Empleo de Portugal (2007) se encuentran: crear y desarrollar productos turísticos que sean capaces de diversificar y potenciar el sector turístico de Portugal.

Entre los productos definidos como prioritarios, se encuentra nuevamente el "Turismo de Saude e Bem-Estar".

De hecho, el documento resalta que el país luso posee una oferta diversificada y un alto potencial de competitividad en las empresas de este sector.

Especifica también que las condiciones naturales y singulares que ofrece el territorio, junto con la variedad y calidad de las aguas termales y marinas y la competitividad de los servicios relacionados con la salud y el bienestar; permiten enriquecer la oferta asociada al Turismo de Salud y al Turismo Termal de Portugal.

Del mismo modo, cabe precisar que entre las líneas de actuación del Plan Estratégico, destaca también la importancia de las Tecnologías de la Información y Comunicación, donde el fenómeno de los Medios Sociales ${ }^{26}$ acapara gran parte de la atención. Se detalla

\footnotetext{
${ }^{25}$ El término "Turismo de Saúde e Bem-Estar" es utilizado en Portugal para referirse a lo que España es conocido, de forma individual, como balnearios, talasos y establecimientos con Spa.

${ }^{26}$ Cavalganti y Sobejano (2011) hablan de Medios Sociales, en lugar Redes Sociales, término más extendido en España. Se intenta establecer una distinción
} 
además, que las aplicaciones móviles, junto con los Medios Sociales, están transformando la actividad turística entre los principales actores: productores de servicios, distribuidores y clientes.

Este hecho genera oportunidades en cuanto a la visibilidad de información que ofrecen las redes digitales para los procesos de negocio de las empresas del sector turístico en general y, en el caso que nos ocupa, puede contribuir a complementar y a mejorar la promoción del Turismo de Saude e Bem-Estar, en particular.

\section{Turismo de salud y turismo termal}

El agua, según Legido, Mourelle, Medina, Gómez y Meijide (2009) ha sido utilizada como fuente de salud y bienestar desde tiempos inmemoriales. Estas prácticas milenarias, resurgen en la actualidad a través de distintos tipos de instalaciones y técnicas, promoviéndose el estudio de las aguas mineromedicinales y sus aplicaciones terapéuticas.

Un factor importante en el resurgir de la actividad balnearia es el incremento de las denominadas "enfermedades de la civilización", fundamentalmente de tipo psico-somático, que promueve la aplicación de la terapéutica termal a un sector cada vez más amplio de la población, descendiendo así la edad de los usuarios de los establecimientos termales y ampliándose la oferta termal de forma generalizada (Legido et al, 2009).

El Turismo de Salud, al igual que otras tipologías turísticas, consiste según el Ministerio de Industria Comercio y Turismo (2013), en el proceso por el cual una persona viaja para recibir servicios de salud en un país diferente a aquel en el que reside. El motivo del viaje es la búsqueda de estos servicios de salud, en un sentido amplio.

Son muchos los autores y organizaciones, entre las que destaca la Organización Mundial de la Salud (OMS), que entienden la palabra "salud" no sólo como la ausencia de enfermedades, sino como la búsqueda de un estado físico y mental saludable, una forma de vida donde prime la relajación y el descanso.

Este tipo de turismo, tal y como afirman Lopes, Henn, Alén y Gonçalves (2011), así como, Fraiz, Branco, Henn y Gonçalves (2011)

entre las Redes Sociales Virtuales (Medios Sociales) que han permitido la interacción entre usuarios de forma virtual y las Redes Sociales Reales (aquellos grupos de personas físicas que se unen por un interés común) (Celaya, 2008). 
concentra dos vertientes: una encaminada al mundo de la medicina, donde el viaje se realiza claramente por salud, y otra más enfocada al ámbito del ocio y del turismo, donde se busca desconectar del día a día y encontrar la relajación tal y como se puede apreciar en la siguiente tabla.

Tabla1: Turismo de Salud

\section{Turismo de Salud}

Industria donde las personas viajan largas distancias para obtener cuidado médico, dental y quirúrgico disfrutando al mismo tiempo de un período de vacaciones. Hoz (2013)

Salud integral. Salud vista desde algo más que la ausencia de enfermedades. Henn, Lopes, Gonçalves y Fraiz (208)

\begin{tabular}{|l|l|}
\hline \multicolumn{1}{|c|}{ Vertiente médica } & \multicolumn{1}{c|}{ Vertiente turística o de ocio } \\
\hline $\begin{array}{l}\text { Oferta de servicios de carácter } \\
\text { médico que buscan poner remedio a a } \\
\text { ciertas dolencias. }\end{array}$ & $\begin{array}{l}\text { Oferta de servicios de carácter } \\
\text { turístico y de ocio que tratan de } \\
\text { proporcionar descanso y desconexión } \\
\text { de la rutina diaria. }\end{array}$ \\
\hline
\end{tabular}

Fuente: Elaboración propia

Cabe que precisemos al respecto, algunas definiciones que giran en torno al Turismo de Salud.

Según Taleghani, Chirani y Saabani (2011) por un lado, el Turismo Médico situado en la vertiente médica, antes mencionada, es definido como el fenómeno donde las personas viajan a destinos internacionales para acceder a cuidado médico (cirugía cosmética, operaciones dentales, cirugías de corazón, etc).

En la vertiente turística, encontraríamos el Turismo de Bienestar o Wellness $^{27}$. En este caso, el turista no tiene ninguna enfermedad física, pero se desplaza para buscar alivio al estrés diario, sin incurrir en intervenciones médicas.

Entre ambas tipologías turísticas, dichos autores, sitúan el Turismo Curativo, definido como aquel donde el viajero hace uso de recursos naturales con propiedades curativas (agua mineral, sal, lodo,

${ }^{27}$ Cabe precisar que dentro de esta tipología también se encuentran los Spas, establecimientos que ofrecen un ambiente y un servicio de descanso y distensión que influyen positivamente en el estado de salud de las personas, aun no contando sus aguas con propiedades de carácter mineromedicinal. 
etc) para el tratamiento de ciertas dolencias con o sin indicaciones terapéuticas.

Dentro de este tipo, se incluirían el Termalismo Terapéutico (relacionado principalmente con la vertiente médica del Turismo de Salud) y el Turismo Termal (más propio del Turismo de Salud de carácter turístico y de ocio).

Según Amor (2014) el Termalismo Terapéutico pone en valor las aguas minerales como hábito saludable para promover el envejecimiento activo y mejorar la calidad de vida de las personas a través de tratamientos respiratorios, digestivos, dermatológicos y del aparato locomotor.

El Turismo Termal, es para Henn, Lopes, Gonçalves y Fraiz (2008) el segmento del Turismo de Salud que utiliza el agua mineromedicinal como materia prima, representado en España por los balnearios $^{28}$.

No obstante, existen otros autores que sitúan el balneario a caballo entre la vertiente turística y la médica. Estos establecimientos se caracterizan por la presencia de minerales y la temperatura de sus aguas, que ayudan en la recuperación y curación de enfermedades, tanto físicas como psíquicas.

Dependiendo del tipo de agua con la que cuenten, o de los tratamientos que oferten, podrán estar indicados para una u otras afecciones.

Llegados a este punto es necesario aclarar que para el presente artículo se ha decidido emplear los términos "balneario" y "establecimiento termal" para referirnos a lo que en Portugal se conoce más como "termas" o "estâncias hidrominerais".

\section{Los medios sociales y el turismo termal}

Prat y Cànoves (2013) a través de Buhalis (2013) destacan que paralelamente a la emergencia de las nuevas motivaciones y necesidades de los turistas, los rápidos avances de las tecnologías nos

\footnotetext{
${ }^{28}$ En relación a los balnearios, es necesario aclarar los distintos términos con los que son reconocidos este tipo de establecimientos: Balnearios en España. "Health resorts", "Geothermal Spas", "Mineral Spa Resorts" o simplemente "Spas" en los países de habla inglesa, "termas o estâncias hidrominerais" en los países de habla portuguesa. (Henn, Lopes, Gonçalves y Fraiz, 2008).
} 
han situado en la "sociedad de la información", donde la generación, el proceso y la transmisión de la información y del conocimiento se han convertido en elementos fundamentales de productividad y poder.

En este sentido, Internet ha sido clave para propiciar el intercambio de información entre personas de diferentes partes del mundo.

Del mismo modo, para entender la importancia y repercusión que cada vez más tienen los Medios Sociales es necesario mencionar el estudio realizado por "Insites Consulting" (2011), cuyo informe destaca que en Europa, 347 millones de personas utilizan Social Media, lo que representa el $73 \%$ de los internautas europeos.

Se instala así un nuevo espacio donde los clientes pueden opinar e intercambiar información sobre un determinado producto o servicio.

Nos referimos a la Web 2.0 como "una plataforma virtual abierta, construida sobre una arquitectura basada en la participación de los usuarios" (Cobo y Pardo, 2007), o lo que lo mismo, "una etapa en la que la Web ha comenzado a utilizarse para lo que fue creada: compartir, colaborar, aportar, editar y sobre todo comunicar personas con personas" (Marín, 2010)

Gomis (2000) destaca al respecto, la importancia que tienen también los Medios Sociales, como canal de publicidad, quien los define como: "medios que, en sus diferentes formatos, facilitan el acceso a segmentos de usuarios que se pueden clasificar en función de sus intereses, inquietudes, sentimientos, ideologías, etc".

Según Hudson y Thal (2013) estos medios han cambiado fundamentalmente el proceso de decisión de compra del consumidor, y en la última década ha surgido una visión más sofisticada acerca de cómo los consumidores se involucran con las marcas.

Para Hudson y Thal (2013) los momentos o fases en las cuales cobran mayor importancia los Medios Sociales, son dos:

- En primer lugar, cuando nos disponemos a evaluar un producto o un servicio para efectuar la compra. En este caso, las opiniones de otros consumidores nos ayudarán a tomar una u otra decisión.

- En segundo lugar, los Medios Sociales vuelven a tener importancia una vez que ya hemos disfrutado del producto o 
servicio y estamos por lo tanto en condiciones de informar a futuros consumidores.

Gráfico 1: La decisión de compra del viajero actual

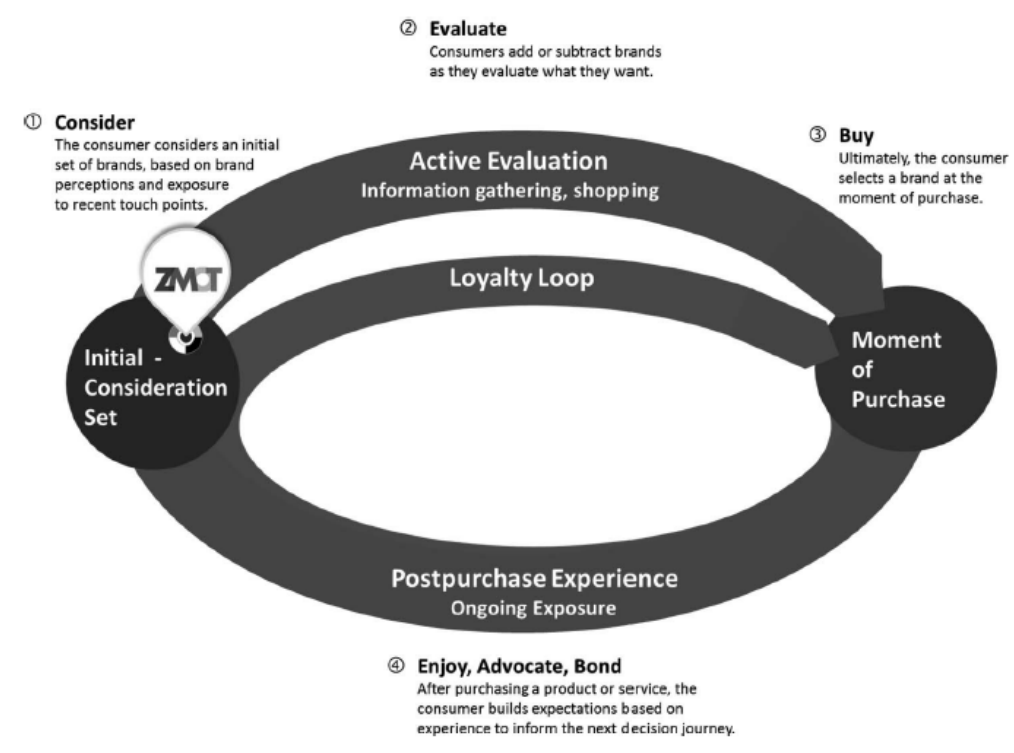

Fuente: Hudson y Thal (2013) a través de Court, Elzinga, Mulder, and Vetvik (2009)

La importancia del Social Media en el sector turístico es también sustentada por Kang y Schuett (2014). Ambos autores afirman que los Medios Sociales juegan un papel importante como plataforma para opiniones personales de viaje donde las historias, advertencias, consejos y recomendaciones influyen en las decisiones de compra de un servicio turístico, llegando incluso a modificar la percepción, sobre un producto o destino, en el caso de los futuros viajeros.

Howison, Finger y Hauschka (2014) hacen mención además a la repercusión que tienen para dar mayor visibilidad a los productos y empresas turísticas, considerándolos de este modo como un complemento fundamental a las páginas web.

Lo cierto es que el interés de las empresas turísticas por los Medios Sociales es cada vez mayor, sin embargo, tal y como apuntan Leung y Bai (2013) en su investigación centrada en las empresas hoteleras, aunque cada vez son más los hoteles que los utilizan, todavía queda por estudiar cómo se puede aprovechar al máximo su potencial como herramientas de marketing. 
Howison, Finger y Hauschka (2014) consideran al respecto que todavía existe un uso insuficiente de dichos medios por parte de una amplia mayoría de empresas turísticas entre los que destacan los operadores de turismo, al recalcar la existencia de falta de comprensión por parte de las organizaciones sobre la utilidad de estas nuevas herramientas.

En los resultados del estudio de Howison, Finger y Hauschka (2014), se muestra que los operadores turísticos seleccionados no estaban utilizando correctamente los Medios Sociales, aún siendo conscientes de la repercusión y la efectividad de los mismos.

Así, revelaron que las tasas de crecimiento de fans en Facebook y seguidores en Twitter demuestran que la participación activa en este tipo de medios conlleva a un mejor conocimiento de la empresa y a una mayor atracción de clientes.

Ante este contexto, en el sector turístico en general, y en el Turismo Termal en particular, los Medios Sociales, se han convertido en herramientas clave para optimizar y mejorar la gestión y comercialización de su actividad, junto con otras técnicas de promoción más tradicionales como pueden ser la comunicación a través de asociaciones, asistencia a ferias, notas de prensa, artículos en revistas, folletos, "boca-oreja”, pagina web, etc.

\section{Objetivos y metodología}

En aras de clarificar el propósito de este artículo, se elabora el siguiente gráfico

Gráfico 2: Breve explicación del estudio. (Elaboración propia)

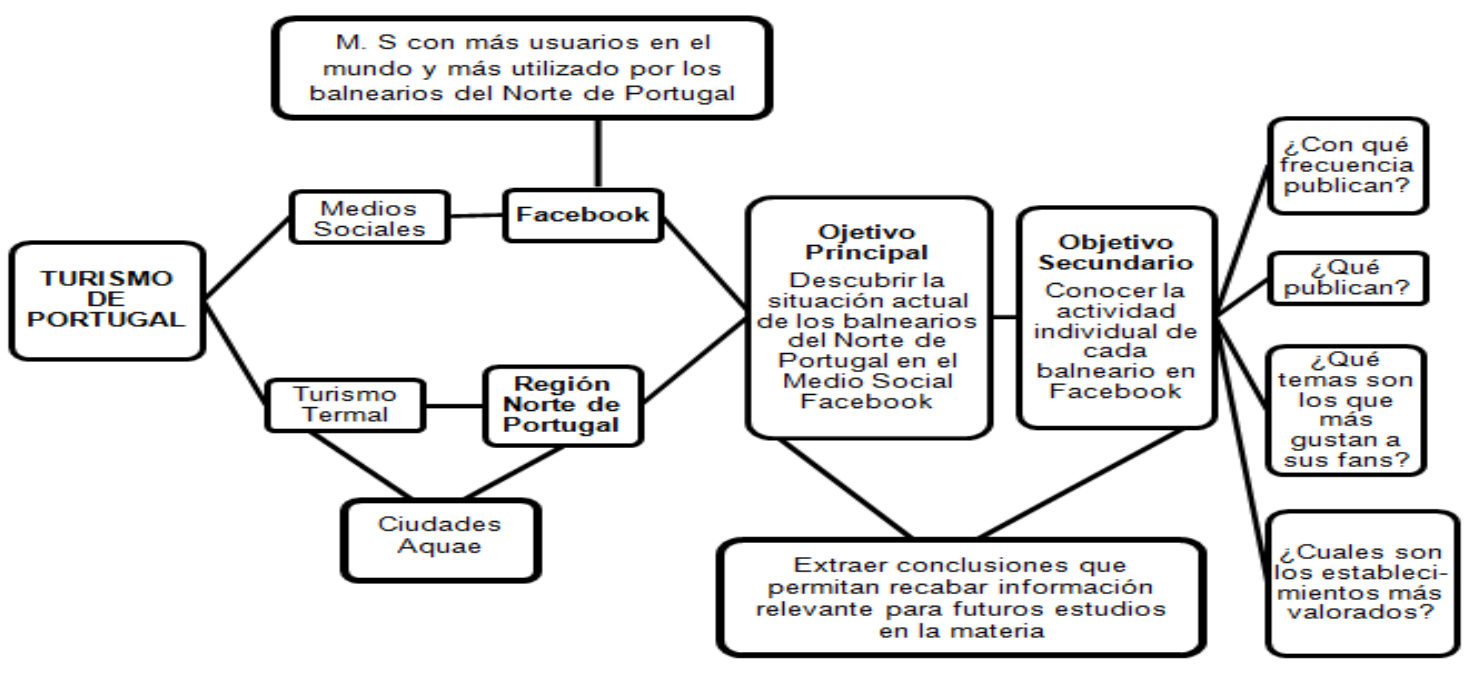


Debido a la importancia que se otorga en el Plan Estratégico Nacional de Turismo de Portugal a los Medios Sociales como nueva herramienta de comunicación para el sector turístico en general y al Turismo Termal como modelo capaz de atraer a futuros turistas; creemos que es importante aunar ambos elementos en un mismo estudio.

El objetivo que se persigue se fundamenta por tanto en analizar la situación actual de los balnearios de la región Norte de Portugal en Facebook $^{29}$ con el propósito de detectar posibles tendencias y rasgos comunes en el sector.

En este sentido, consideramos que sería relevante realizar el estudio individualizado de cada establecimiento termal, de modo que los resultados permitan establecer conclusiones conjuntas.

El método científico utilizado se ha sustentado en la búsqueda y análisis de información a través de fuentes primarias y secundarias.

En relación a las Primarias, es decir, información que el investigador crea expresamente para un estudio concreto permiiéndole un control sobre todo el proceso, los datos son obtenidos directamente para posteriormente ser interpretados y organizados en distintas gráficas, que a su vez, proporcionan el orden necesario para extraer las conclusiones pertinentes (Grande y Abascal, 2011).

La metodología en este caso se ha basado en una investigación cualitativa de carácter exploratorio, donde la observación realizada a lo largo de las distintas páginas oficinales de Facebook de los balnearios de la región Norte de Portugal, ha sido la técnica elegida para la recogida de información.

Según Strauss y Corbin (2002) la investigación cualitativa es: "cualquier tipo de investigación que produce hallazgos a los que no se llega por medio de procedimientos estadísticos $\mathrm{u}$ otros medios de cuantificación". Tal y como destaca Stern (1980), citado por Strauss y Corbin (2002), los métodos que se emplean en la investigación

\footnotetext{
${ }^{29}$ Facebook, comunidad virtual creada por Mark Zuckerberg y fundada junto a Eduardo Saverin, Chris Hughes y Dustin Moskovitz en 2004. Según el último informe publicado por Facebook, este Medio Social posee 1.390 millones de usuarios activos mensualmente Cuenta con más de 1200 millones de usuarios totales y una media de 890 millones de usuarios activos al día http://newsroom.fb.com/company-info/
} 
cualitativa se pueden usar para explorar áreas sustantivas sobre las cuales se sabe poco o mucho, pero se busca obtener un conocimiento nuevo.

En el caso de las Fuentes Secundarias, es decir aquéllas que aportan información ya elaborada o existente (Grande y Abascal, 2011), se han utilizado tres tipos de herramientas: las páginas web y las páginas oficiales de Facebook de los establecimientos termales del Norte de Portugal, así como el estudio Internet República (2012) que ha servido de guía para establecer nuestro análisis.

A continuación, en la Tabla 2, se especifica la muestra de balnearios de la región Norte de Portugal que cuentan con una página en Facebook.

Bien es cierto, que existen establecimientos que tienen también presencia en otros medios como: Twitter, YouTube, Google+, Vimeo, Instagram, Pinterest o Picasa, sin embargo, para este artículo, se ha optado por analizar únicamente Facebook al ser el Medio Social más utilizado por la mayoría de los balnearios considerados en el ámbito de este estudio.

Se enumeran así los distintos establecimientos del Norte de Portugal que se encuentran en activo, con su respectiva situación en Facebook.

Tabla 2: Balnearios de la región Norte de Portugal que se encuentran en activo y su situación en Facebook

\begin{tabular}{|l|l|c|}
\cline { 2 - 3 } \multicolumn{1}{l|}{} & NOMBRE ESTABLECIMIENTO & ACTIVIDAD EN FACEBOOK \\
\hline 1 & Termas de Caldelas & SI \\
\hline 2 & Taipas Termal & SI \\
\hline 3 & Termas da Moimenta & SI \\
\hline 4 & Hotel Bienestar Termas de Vizela & SI \\
\hline 5 & Hotel Vidago Palace & SI \\
\hline 6 & Pedras Salgadas Spa \& Nature Park & SI \\
\hline 7 & Caldas de Carlão & SI \\
\hline 8 & Termas de Melgaço & SI \\
\hline 9 & Termas de Monçao & SI \\
\hline 10 & Palace Hotel\&Spa Termas de & SI \\
& S.Vicente & SI \\
\hline 11 & Caldas da Saúde & SI \\
\hline 12 & Termas Caldas de Aregos & SI \\
\hline 13 & Termas de São Jorge & \\
\hline
\end{tabular}




\begin{tabular}{|c|l|c|}
\hline 14 & Termas do Gerês & Sólo perfil, no existe página \\
\hline 15 & Termas de Carvalhelhos & $\begin{array}{r}\text { Sólo existe página para la fábrica } \\
\text { embotelladora }\end{array}$ \\
\hline 16 & Termas de São Lourenzo & Sin presencia en este medio \\
\hline 17 & Termas da Terronha & Sin presencia en este medio \\
\hline 18 & Termas de Entre-Os-Rios & $\begin{array}{c}\text { Sólo a través de la institución } \\
\text { INATEL }\end{array}$ \\
\hline
\end{tabular}

Fuente: Elaboración propia

Tal y como puede observarse en anterior, existen trece balnearios con actividad dentro de Facebook, en cambio, los últimos cinco establecimientos no han sido analizados debido a las características que arriba se especifican.

En la Tabla 3, se muestra la metodología de análisis que hemos seguido para la recogida de datos.

Tabla 3: Metodología de análisis para las publicaciones en Facebook

\begin{tabular}{|c|c|}
\hline \multicolumn{2}{|r|}{ FACEBOOK } \\
\hline \multicolumn{2}{|r|}{ Se utiliza como modelo, el estudio Internet República (2012) } \\
\hline \multicolumn{2}{|c|}{$\begin{array}{c}\text { Se analizan únicamente las páginas oficiales de los establecimientos termales, } \\
\text { descartando los perfiles por considerarlos menos institucionales. }\end{array}$} \\
\hline \multicolumn{2}{|c|}{$\begin{array}{l}\text { La observación y recogida de datos se efectúa durante el mes de octubre de } \\
\qquad 2014 .\end{array}$} \\
\hline \multicolumn{2}{|c|}{$\begin{array}{l}\text { Se analizan los seis últimos meses de actividad, desde abril hasta septiembre } \\
\qquad 2014 \text { (ambos inclusive) }\end{array}$} \\
\hline Fans & $\mathrm{N}^{\circ}$ total de fans de la página \\
\hline Interacciones & $\mathrm{N}^{\circ}$ de personas que están hablando sobre el establecimiento \\
\hline Aplicaciones & Si cuenta o no con aplicaciones \\
\hline \multirow{5}{*}{$\begin{array}{l}\text { Actualización } \\
\text { del canal }\end{array}$} & Diariamente (6-7 días a la semana) \\
\hline & $\begin{array}{l}\text { Frecuentemente: Media óptima 3-5 a la semana } \\
\text { (según Internet República, 2012) }\end{array}$ \\
\hline & Regularmente (2 veces a la semana) \\
\hline & Poco (1 a la semana) \\
\hline & Muy poco (0 a la semana) \\
\hline \multirow{6}{*}{$\begin{array}{l}\text { Tipo de } \\
\text { contenido }\end{array}$} & Ajeno \\
\hline & Propio \\
\hline & Mixto: Comentario propio y enlace a otra página \\
\hline & Info. Establecimiento \\
\hline & Info. Golf \\
\hline & Info. Restaurante \\
\hline
\end{tabular}




\begin{tabular}{|l|l|}
\hline \multirow{4}{*}{$\begin{array}{c}\text { Clasificación } \\
\text { del }\end{array}$} & Info. Termalismo \\
\cline { 2 - 2 } contenido & Info. General \\
\cline { 2 - 3 } & Info. Zona \\
\cline { 2 - 2 } & Info. Bodas \\
\cline { 2 - 2 } & Ofencurso \\
\hline Tras observar las páginas de Facebook de los balnearios del Norte de Portugal \\
hemos detectado que el contenido de las publicaciones se puede dividir en nueve \\
subgrupos, tal y como aparecen en las cuadrículas anteriores. Cabe precisar que \\
en el caso de "Info. Establecimiento" se incluye toda aquella información que \\
tiene que ver, a nivel general, con el establecimiento tanto del hotel como del \\
balneario. En cuanto al subgrupo "Info. General" se agrupa aquella información \\
que no tiene lugar en el resto de subgrupos ej. iFeliz lunes!, jFeliz día de la \\
madre!, información meteorológica, etc. La "Info. Zona" puede ser tanto del \\
municipio al que pertenece el establecimiento como de la región Norte de \\
Portugal en general. En el caso del subgrupo "Concurso" se incluyen aquellas \\
publicaciones destinadas a sorteos específicos para Facebook. \\
\hline
\end{tabular}

Fuente: Elaboración propia

En total, la muestra de publicaciones analizadas para elaborar el presente estudio exploratorio se especifica en la siguiente tabla:

Tabla 4: Muestra de publicaciones totales empleadas en el estudio

\begin{tabular}{|c|}
\hline $\begin{array}{c}\mathrm{N}^{\mathrm{o}} \text { publicaciones } \\
\text { Facebook }\end{array}$ \\
\hline 652 \\
\hline Fuente: Elaboración propia
\end{tabular}

\section{Análisis del turismo termal de la región Norte de Portugal en Facebook}

A continuación se lleva a cabo un análisis pormenorizado de la situación de los balnearios de la región Norte de Portugal en Facebook.

En primer lugar, y en relación a la repercusión e influencia de dichos establecimientos termales en el Medio Social seleccionado dentro del ámbito de nuestro estudio, se empieza por analizar dos aspectos básicos de las páginas: "Me Gusta" y "Personas que están hablando sobre esto". 
"Me Gusta"30 indica la cantidad de fans que tiene una determinada página.

"Personas que están hablando sobre esto" es una métrica, más reciente que "Me Gusta", su finalidad es ofrecer información sobre la interacción que una página mantiene con sus fans, en los últimos días; es decir, recogen el número de personas que comentan, indican que les gusta o comparten una de las publicaciones o eventos de la página. Es también conocida como (PTAT: People Talking About This).

Cabe precisar que en determinadas ocasiones existe una desviación importante entre el número de "Me Gusta" y las "Personas que están hablando sobre esto", lo que muestra una inadecuada gestión de la página al entender que sus publicaciones no consiguen motivar la participación de sus fans.

Gráfico 3: "Me Gusta" y "PTAT" de los balnearios de la región Norte de Portugal en Facebook

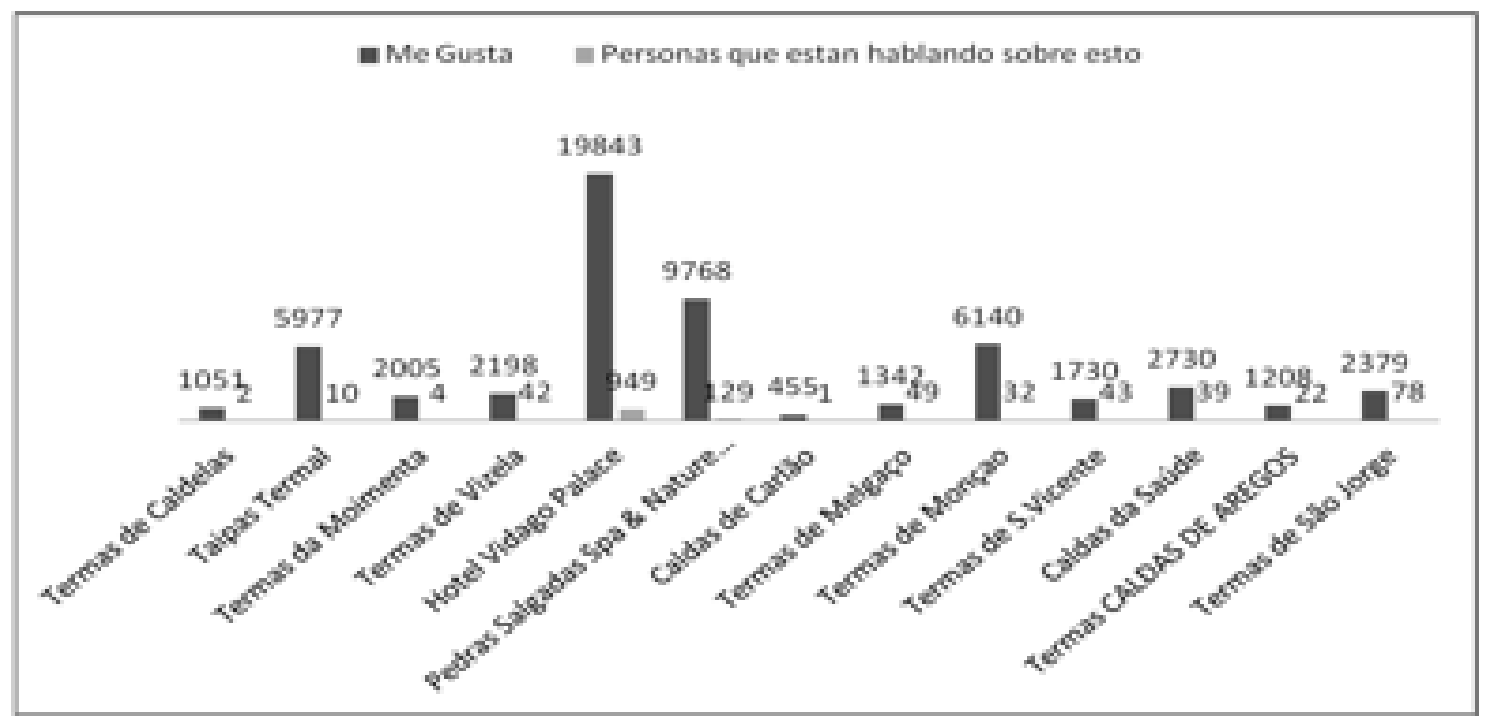

Fuente: Elaboración propia

Si se presta atención al gráfico anterior podemos comprobar que de todos los establecimientos termales de la región que tienen presencia en Facebook, el Hotel Vidago Palace es el que cuenta, con gran diferencia, con el mayor número de fans, al alcanzar los 19.843 "Me Gusta".

\footnotetext{
${ }^{30}$ En este estudio, en algunas ocasiones, se utilizará la palabra "fan" como sinónimo de "Me Gusta".
} 
En segundo lugar, aunque con un número de fans mucho menor, se encuentra el establecimiento Pedras Salgadas Spa \& Nature Park con 9.768 "Me Gusta".

Termas de Monçao y Taipas Termal se posicionan también entre los balnearios más representativos de la región Norte de Portugal en Facebook con 6.140 y 5.977 fans respectivamente.

El resto de establecimientos termales, exceptuando Caldas de Carlão que posee 455 fans, se sitúan en cifras comprendidas entre los 1.000 y los 3.000 fans.

En lo referente a los "PTAT", observamos que los datos, son de momento, muy bajos para todos los establecimientos, lo cual significa, que la interacción de las empresas termales con sus clientes virtuales no se está gestionando de forma óptima.

Gráfico 4: Número de Aplicaciones de las páginas de Facebook de los balnearios de la región Norte de Portugal

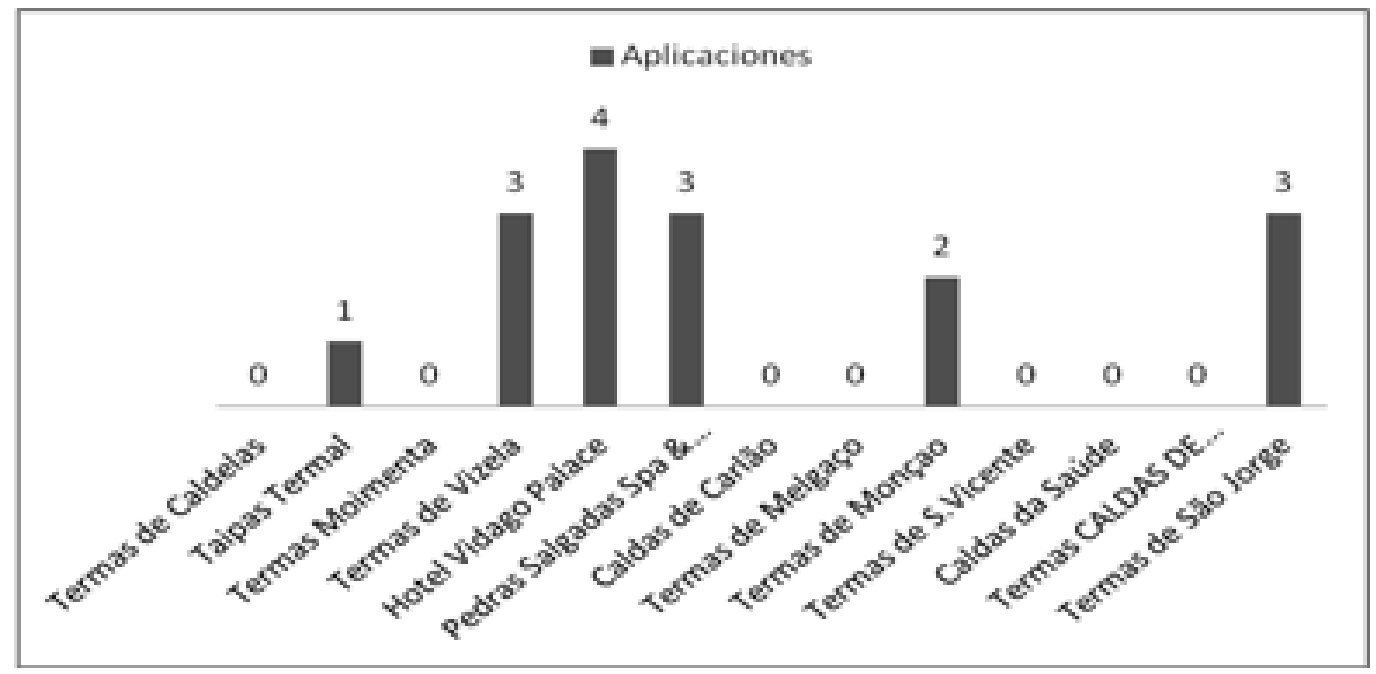

Fuente: Elaboración propia

En el caso del número de aplicaciones que emplean los balnearios analizados, cabe precisar que el Hotel Vidago Palace vuelve a situarse en primer lugar, con 4 aplicaciones, seguido de Pedras Salgadas Spa \& Nature Park, Termas de Vizela y Termas de São Jorge que utilizan un total de 3 aplicaciones cada uno de ellos.

Finalmente con 2 y 1 aplicaciones, respectivamente, estarían los balnearios Termas de Monçao y Taipas Termal.

El resto de establecimientos no emplean ninguna aplicación para su actividad en Facebook. 
En cuanto a la temática, podemos decir que la aplicación Twitter es la más utilizada, seguida de Pinterest, Youtube, Book Now y Tripadvisor.

Gráfico 5: Actualización del Canal de los balnearios de la región Norte de Portugal en Facebook

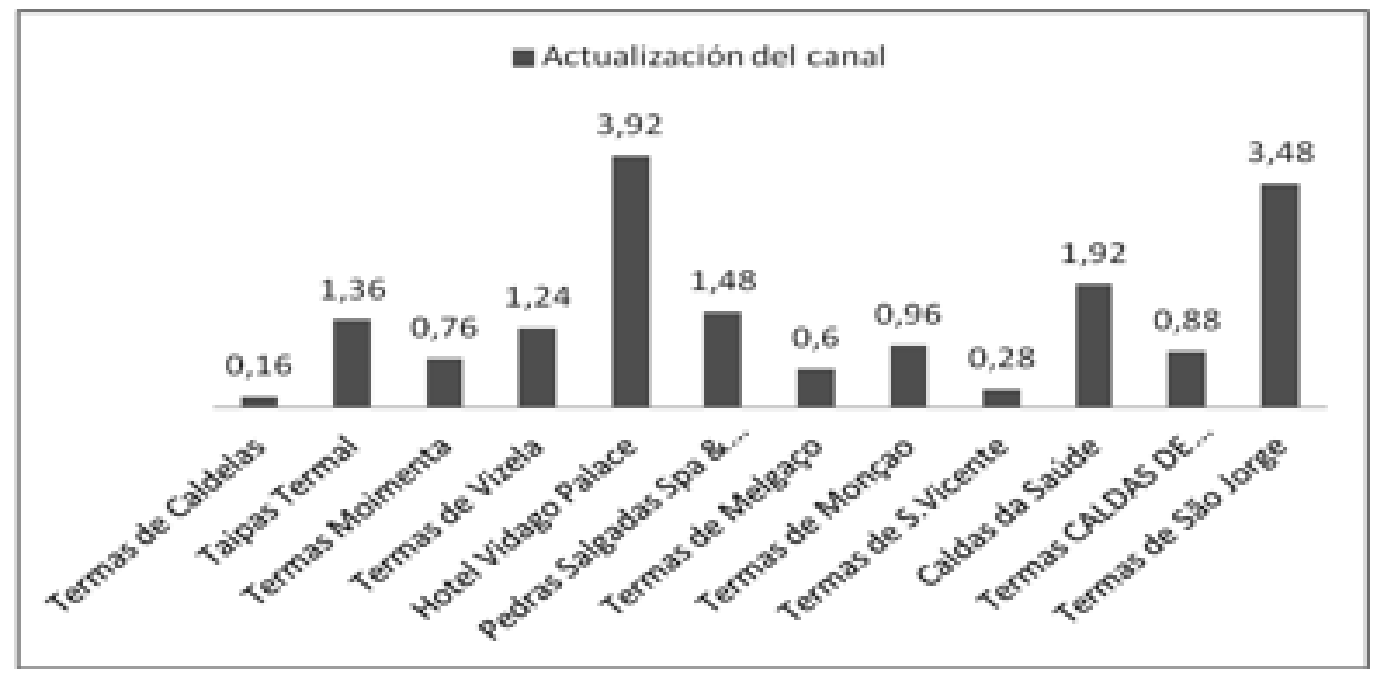

Fuente: Elaboración propia

Antes de interpretar el Gráfico 5 es necesario puntualizar que no se ha podido incluir el establecimiento Caldas de Carlão por haber finalizado su actividad en Facebook en el año 2013, no encontrándose por tanto, entre los meses de abril y septiembre del 2014, meses seleccionados para efectuar la recogida de datos del presente estudio.

Este gráfico informa acerca de varios aspectos. En primer lugar, podemos afirmar que el Hotel Vidago Palace es el establecimiento termal del Norte de Portugal que más actualiza su canal, situándose en una media que roza las 4 publicaciones por semana, es decir, en lo que Internet República (2012) denominaría como una actualización frecuente del canal.

Lo que realmente sorprende es que se encuentren entre los primeros puestos de este gráfico las Termas de São Jorge y Caldas da Saúde con una media de 3,48 y 1,92 publicaciones por semana.

Este dato indica que ambos balnearios, aun no siendo en la actualidad los más representativos de la región Norte de Portugal en Facebook como veíamos en el Gráfico 3, pueden en un futuro aumentar considerablemente el número de fans debido principalmente al elevado número de actualización del canal. 
En esta ocasión vuelve a aparecer de nuevo, aunque con menor representatividad, Pedras Salgadas Spa \& Nature Park, con 1,48 publicaciones por semana.

Taipas Termal y Termas de Vizela actualizan su canal 1,36 y 1,24 veces por semana, respectivamente.

El resto de establecimientos renuevan muy poco su canal, siendo en estos casos, inferior a una vez por semana.

Gráfico 6: Número Publicaciones y Número Total Me Gusta de los balnearios de la región Norte de Portugal en Facebook

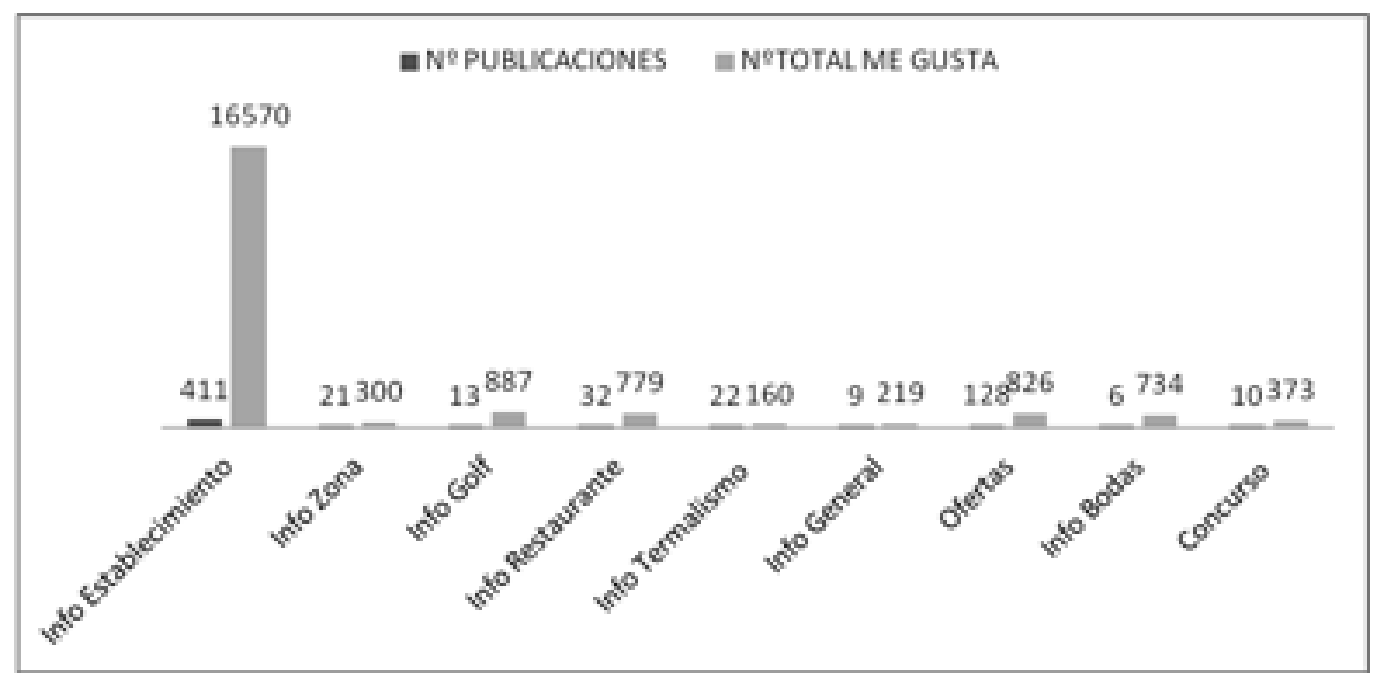

Fuente: Elaboración propia

Finalmente, al observar el Gráfico 6, descubrimos que mayoritariamente, los establecimientos termales del Norte de Portugal actualizan su canal de Facebook con noticias relacionadas con su propio establecimiento, siendo además éstas, las que más gustan a sus fans.

Dichos balnearios recurren en segundo lugar a las ofertas para hacer publicaciones, con un total de 128 y 826 "Me Gusta".

En general, el resto de publicaciones, se concentra entre las restantes temáticas. Destaca así, la información del subgrupo "General" como aquella que posee un menor número de "Me Gusta" y, después la información sobre Bodas, como la menos utilizada para los "posts" 31 " de dichos balnearios.

${ }^{31}$ El vocablo inglés "post" se traduce, en el ámbito de foros, blogs y Medios Sociales como mensaje, artículo o publicación. 
Cabe precisar que de todos los establecimientos, el Hotel Vidago Palace es el que elabora un contenido más diversificado para sus publicaciones, concentrándose en cada uno de los subtipos que se muestran en el Gráfico 6. Además, por sus servicios, es el único balneario que ofrece posts sobre Golf.

Para finalizar, es necesario añadir que en general, todos los establecimientos termales del Norte de Portugal llevan a cabo sus publicaciones con un tipo de contenido mixto, es decir, su propia información es normalmente apoyada con enlaces a videos, noticias, imágenes, etc.

\section{Conclusiones}

A continuación se presentan las principales resultados del estudio.

Primeramente cabe destacar que en general, entre los distintos Medios Sociales Generalistas, los balnearios analizados prefieren Facebook para promocionar su negocio.

Además, en cuanto al número de fans se refiere, los establecimientos: Hotel Vidago Palace y Pedras Salgadas Spa\& Nature Park, son los más representativos en dicho Medio Social.

Es necesario añadir que en general, y para todos los balnearios, la interacción con sus fans, que muestra el gráfico del "PTAT", es insuficiente, considerando que se están desaprovechando las oportunidades que puede ofrecer Facebook, en materia de promoción para la actividad del Turismo Termal.

Asimismo, cabe precisar la importancia que supone el hecho de actualizar el canal. En este sentido, el Hotel Vidago Palace es el que realiza el mayor número de actualizaciones situándose en la media recomendada por Internet República (2012), con un tipo de actualización del canal frecuente, y una media de casi 4 publicaciones por semana.

Sin embargo, exceptuando al Hotel Vidago Palace y Termas de São Jorge, el resto de establecimientos no alcanzan la media recomendada, aspecto que debería ser reconsiderado para lograr optimizar su actividad en Facebook.

También es el Hotel Vidago Palace el que destaca en cuanto al número de aplicaciones utilizadas en su canal, siendo éstas: Youtube, Twitter, Book Now, Pinterest. 
La información sobre el propio establecimiento es la temática más utilizada para las publicaciones de los balnearios del Norte de Portugal en Facebook. Cabe mencionar de nuevo la figura del Hotel Vidago Palace por ser el único en utilizar en sus actualizaciones de canal los 9 subgrupos indicados.

Finalmente, si comparamos las cifras recogidas en el Gráfico 4, donde se analizaban los "Me Gusta" y el "PTAT", con el modelo de negocio de los establecimientos termales de la región con la finalidad de extraer algunas conclusiones que ayuden a entender el porqué del éxito de los dos balnearios más representativos en Facebook: Hotel Vidago Palace y Pedras Salgadas Spa\& Nature Park podemos concluir que:

En primer lugar, el Hotel Vidago Palace y Pedras Salgadas Spa \& Nature Park, comparten una característica común, ambos poseen instalaciones hoteleras que complementan a la actividad balnearia; servicio del cual carecen algunos de los balnearios analizados.

Además, los dos establecimientos comparten una arquitectura singular.

El Hotel Vidago Palace, de principios del S.XX, cuenta con el característico y atractivo estilo señorial inspirado en los grandes balnearios europeos de la época.

Por su parte, Pedras Salgadas Spa \& Nature Park, destaca también por su modelo arquitectónico. La remodelación actual del balneario y la instalación de las "Eco Houses" se han convertido en uno de los principales atractivos del establecimiento.

Asimismo, también cabe mencionar los complementos a la actividad balnearia y hotelera con los que cuentan ambos establecimientos, como es el golf y la importancia natural y paisajística del entorno.

En general y para finalizar, se puede añadir que tanto El Hotel Vidago Palace como Pedras Salgadas Spa \& Nature Park desarrollan su actividad enfocándose más, a la práctica balnearia desde un punto de vista de la vertiente turística y de ocio y no tanto desde la propiamente médica.

\section{Referencias bibliográficas}

Agenda Regional de Turismo. (2009): "Programa de Acção Saúde e Bem-Estar", Portugal, junio: 
http://www.portoenorte.pt/client/skins/categoria.php?cat=197\&top $=15$

Amor, B. (2014): "Sector Termal en Galicia". Presentación para el IGAPE por La Asociación Balnearios de Galicia.

Cobo, C y Pardo, H. (2007): Planeta Web 2.0. Inteligencia colectiva o medios fas food. Barcelona: Grup de Recerca d'Interaccions Digitals.

Conferencia de las Naciones Unidas sobre Comercio y Desarrollo. (2013): "Turismo sostenible: contribución del turismo al crecimiento económico y al desarrollo sostenible", en Reunión de expertos sobre la contribución del turismo al desarrollo sostenible. Ginebra, marzo:http://unctad.org/meetings/es/SessionalDocuments/ciem5d2 sp.pdf

Fraiz, J., Branco, P., Henn, M. y Gonçalves,J. (2011): “La importancia de la cosmética termal para los balnearios y el turismo termal: el caso de la comunidad Autónoma de Galicia-España”, en PASOS. Revista de Turismo y Patrimonio Cultural, $\mathrm{n}^{\circ}$ 9, páginas 25 a 35; recuperado el 20 de febrero de 2015 de http://www.pasosonline.org/articulos/446-la-importancia-de-lacosmetica-termal-para-los-balnearios-y-el-turismo-termal-el-caso-dela-comunidad-autonoma-de-galicia-espa $\%$ C3\%B1a ISSN: 1695-7121

Gomis López, J.M. (2000): "La información turística: del papel a la Red" en Manual de Comunicación Turística. De la información a la persuasión, de la promoción a la emoción, Girona: Editorial Documenta Universitaria.

González, S. (2011): El valor del agua en el mundo antiguo. Sistemas bidráulicos y aguas mineromedicinales en el contexto de la Galicia romana. A Coruña: Fundación Barrié.

Grande, E y Abascal, E. (2011): Fundamentos y técnicas de investigación comercial. Madrid: Esic Editorial.

Henn, M., Lopes, P., Gonçalves, J., y Fraiz, J. (2008): “Turismo Termal: Cambios conceptuales y mercadológicos de los balnearios en España”, en Revista Turismo Visão e Ação - Eletrônica, vol 10, $n^{\circ} 03$. páginas 415 a 434; recuperado el 20 de febrero de 2014 de http://www6.univali.br/seer/index.php/rtva/article/view/773

Hosteltur (2012) “España y Portugal los dos países que más dependen del turismo según la OCDE”.Agosto:http://www.hosteltur.com/199900 espana-portugaldos-paises-ocde-dependen-turismo.html 
Howison, S., Finger, G y Hauschka, C. (2014): "Insights into the Web presence, online marketing, and the use of social media by tourism operators in Dunedin, New Zealand", en revista Anatolia: An International Journal of Tourism and Hospitality Research; recuperado el 20 de febrero de 2015 de http://dx.doi.org/10.1080/13032917.2014.940357 DOI:

10.1080 / 13032917.2014 .940357

Hudson, S y Thal, K. (2013): “The Impact of Social Media on the Consumer Decision Process: Implications for Tourism Marketing", en Journal of Travel \&Tourism Marketing, vol 30, $n^{\circ} 1-2$, páginas 156 a 160; recuperado el 20 de febrero de 2015 de http://www.tandfonline.com/doi/abs/10.1080/10548408.2013.75127 6\#.VGN-1vmG-vQ DOI:

10.1080 / 10548408.2013 .751276

InSites Consulting (2011). Septiembre: http://www.insitesconsulting.com/

Internet República (2012) "La banca a examen en las redes sociales", Madrid, Enero:

http://www.slideshare.net/slideshow/embed code/11256128

Kang, M y Schuett, M. (2013): "Determinants of Sharing Travel Experiences in Social Media", en Journal of Travel \& Tourism Marketing, vol30, n 1-2, páginas 93 a 107; recuperado el 20 de febrero de 2015 de http://dx.doi.org/10.1080/10548408.2013.751237 DOI:

10.1080 / 10548408.2013 .751237

Leung, X y Bai, B. (2013): "How Motivation, Opportunity, and Ability Impact Travelers' Social Media Involvement and Revisit Intention”, en Journal of Travel \&Tourism Marketing, vol 30, n¹-2, páginas 58 a 77; recuperado el 21 de febrero de 2015 de

http://dx.doi.org/10.1080/10548408.2013.751211 DOI:

10.1080 / 10548408.2013 .751211

Lopes, P., Henn, M. , Alén,M. y Gonçalves,J. (2011): “El turismo de salud y el uso terapéutico del agua", en Estudios y Perspectivas en Turismo, 20, páginas 462 a 477; recuperado el 22 de febrero de 2015 de http://www.scielo.org.ar/scielo.php?pid=S1851$17322011000200011 \&$ script $=$ sci arttext

Marín, J. (2010): Web2.0, una descripción muy sencilla de los cambios que estamos viviendo. A Coruña: Netbiblo. 
Ministerio de Economía y Empleo de Portugal (2007): "Plano Estratégico Nacional do Turismo (PENT) Horizonte 2013-2015”, Governo de Portugal, http://www.turismodeportugal.pt/Portugu $\% \mathrm{C} 3 \% \mathrm{AAs} /$ turismodeport ugal/publicacoes/Documents/PENT\%202012.pdf

Ministerio de Industria Comercio y Turismo (2013): “Turismo de Salud en España", Madrid:

http://www.minetur.gob.es/turismo/es-

ES/PNIT/Eje3/Documents/turismo salud espana.pdf

Mourelle, M., Medina, C., Gómez, C., Mejide, R. (2009):

Termalismo: Aspectos generales. Vigo: Servizo de Publicacións da Universidade de Vigo

Prat, J y Cànoves, G. (2013): “La participación en redes sociales y su incidencia sobre el comportamiento y satisfacción de los consumidores de turismo”, en Investigaciones Turísticas, $n^{\circ} 5$, páginas 2959; recuperado el 20 de febrero de 2015 de http://rua.ua.es/dspace/bitstream/10045/29119/1/Investigaciones Turisticas 05 02.pdf ISSN:2174-5609

Strauss, A y Corbin, J. (2002): Bases de la investigación cualitativa. Técnicas y procedimientos para desarrollar la teoría fundamentada. Colombia: Universidad de Antioquia.

Taleghani, M.; Chirani, E. y Shaabani, A. (2011): "Health tourism, tourist satisfaction and motivation", en Interdisciplinary Journal of Contemporary Research in Business, vol 3, n4, páginas 546 a 555; recuperado el 13 de febrero de 2015 de http:// search.proquest.com/docview/899779558?accountid=14542 ISSN2073-7122 


\section{El impacto de las redes sociales en el sector publicitario español}

Emma Torres Romay, Universidad de Vigo (UVIGO, España), emmatr@uvigo.es

\section{Resumen}

Desde que en el año 2004 se puso en marcha Facebook, las denominadas redes sociales al alcanzado ya al $25 \%$ de la población mundial. Nos encontramos, por tanto, ante un fenómeno comunicativo revolucionario que está condicionando las formas de relación social y, en consecuencia, la forma de consumo de los medios de comunicación. Este nuevo escenario ha aumentado la incertidumbre en lo relativo a la gestión publicitaria tanto en lo referido a los contenidos como, por supuesto, a la inversión. Todo ello implica un cambio necesario en los procesos estratégicos que, a día de hoy, aún sigue pendiente. En este trabajo realizamos, por tanto, un análisis pormenorizado de las consecuencias que, a esos niveles, han tenido las redes sociales en la estructura, articulación y funcionamiento del sector publicitario español.

Palabras clave: redes sociales, publicidad, internet, inversión, sector publicitario.

\section{Presentación, objeto de estudio, hipótesis y metodología}

— L indiscutible impacto de las redes sociales en la comunicación puede ser valorado desde múltiples perspectivas más allá de las propias implicaciones sociales (Menéndez, 2003). De esta forma, son numerosos los trabajos que abordan este tema desde el punto de vista 
de la modificación del panorama mediático (Campos-Freire, 2008; Cebrián, 2008), teniendo en cuenta tanto sus consecuencias en las variaciones en la profesión periodística (Noguera, 2010) como en lo relativo al consumo de medios (Caldevilla, 2010). Sin embargo, frente a otras cuestiones como el uso de estas redes en la comunicación política (Caldevilla, 2009) o incluso en educación (Santamaria, 2008; Area, 2008 y Tapia et al. 2010), las implicaciones de las redes sociales en la publicidad no han contado con una atención académica o investigadora semejante; todo ello a pesar del énfasis que durante la primera década del 2000 se ha puesto en la publicidad vinculada a internet (Martínez-Rodrigo y Sánchez, 2012).

Por esta razón nuestro objeto de estudio se centra en realizar un análisis de las consecuencias del crecimiento de las redes sociales en el sector publicitario desde la perspectiva estratégica, es decir, analizando los posibles cambios que su uso ha supuesto en la estructura del sector publicitario y su funcionamiento.

Este objeto de estudio surge del planteamiento de unas hipótesis de partida que guardan relación con los actores del proceso publicitario y con el propio procedimiento de planificación estratégica. La estructura planteada sigue, por tanto los modelos aplicados en trabajos anteriores (Torres-Romay y García-Mirón, 2014):

- La crisis del sector publicitario guarda relación con la desinversión en medios por parte de los anunciantes. En ese punto cabe señalar que existe cierta incertidumbre en lo relativo a los niveles de eficacia de los medios de comunicación convencionales, lo que ha trasladado la inversión a los medios no convencionales (TorresRomay, 2013).

- Los grandes anunciantes han dado el salto a las redes sociales incluyéndolas incluso en la estrategia de marketing, si bien el uso de las mismas resulta confuso y poco concreto. La cuantificación de dicho uso también resulta compleja (Benavides et al, 2010).

- Los medios de comunicación han entendido que las redes sociales (entre otros factores) han modificado el modelo de negocio y deben ser tenidas en cuenta de forma permanente (Farias e Roses, 2009).

- Las agencias de publicidad han incorporado las redes sociales a su oferta de servicios, pero no se han desarrollado estrategias 
específicas para ellas si no que se han incorporado a los planteamientos $360^{\circ}$ de las campañas (Del Río y Kaufmann, 2014).

- Los públicos han realizado un cambio muy profundo en lo relativo al consumo de medios y, en consecuencia, con respecto a la publicidad. Nos enfrentamos a públicos críticos, proactivos y poco receptivos; prosumidores a los que la publicidad en redes sociales les resulta invasiva y poco memorable (García y Valdivia, 2014).

- Las estrategias publicitarias han incorporado las redes sociales de forma mayoritaria, si bien existen sectores y productos donde su funcionamiento parece más justificado. Los casos de éxito (eficacia) son menos, sin embargo, que la situaciones de crisis provocadas por su mal uso (Martínez, Amiguet y Visiedo, 2014).

Para el trabajo sobre estas hipótesis se establece una metodología en tres fases. La primera de ellas consiste en una recogida de datos en fuentes secundarias que permite obtener información cualitativa y cuantitativa sobre el estado de la cuestión.

En la segunda fase tomamos como referencia la base de datos realizada mediante el proyecto de investigación puesto en marcha en la Facultad de Ciencias Sociales y de la Comunicación en el año 2008. Se trata de un observatorio permanente sobre las consecuencias de la crisis en las estrategias publicitarias de los anunciantes en España. Este trabajo ha dado lugar a algunas publicaciones (Torres-Romay, 2010a; 2010b; 2010c; 2011) y a una amplia base de datos que permite realizar análisis completo de los cambios que se están produciendo.

En la tercera fase se realiza un análisis de casos, sustentando tanto en los materiales extraídos de los Premios de Eficacia Publicitaria que otorga la Asociación Española de Anunciantes como por los casos recogidos en las publicaciones del sector.

Toda la información será estructurada en tres bloques de contenido. El primero aborda los datos básicos de la actual situación del sector publicitario español. El segundo analiza lo relativo a los sujetos del proceso publicitario, siempre desde el punto de vista de las consecuencias de las redes sociales en lo relativo a su papel. Finalmente, el tercer bloque, se concentra en los procedimientos estratégicos desarrollados hasta este momento vinculados a las redes sociales. Debe tenerse en cuenta que las metodologías se aplican según las necesidades de cada apartado y no de forma lineal. 


\section{La situación del sector publicitario español}

En el gráfico 1 observamos la evolución de la inversión publicitaria en nuestro país. La crisis ha tenido notables consecuencias en términos económicos en el sector, que arrastra pérdidas desde el año 2008 (Torres-Romay, 2012). Todos los datos apuntan a que aunque se produzca una recuperación económica en términos generales, resulta poco probable volver a los niveles anteriores a la crisis (Legerén y García-Mirón, 2012). La recesión publicitaria se produjo con cierta lentitud y se relaciona directamente con la caída de la inversión de anunciantes especialmente vulnerables a esta coyuntura, como los del sector inmobiliario y los de marcas de automóvil (Infoadex, 2009).

\section{Gráfico 1: Evolución de la inversión publicitaria en España}

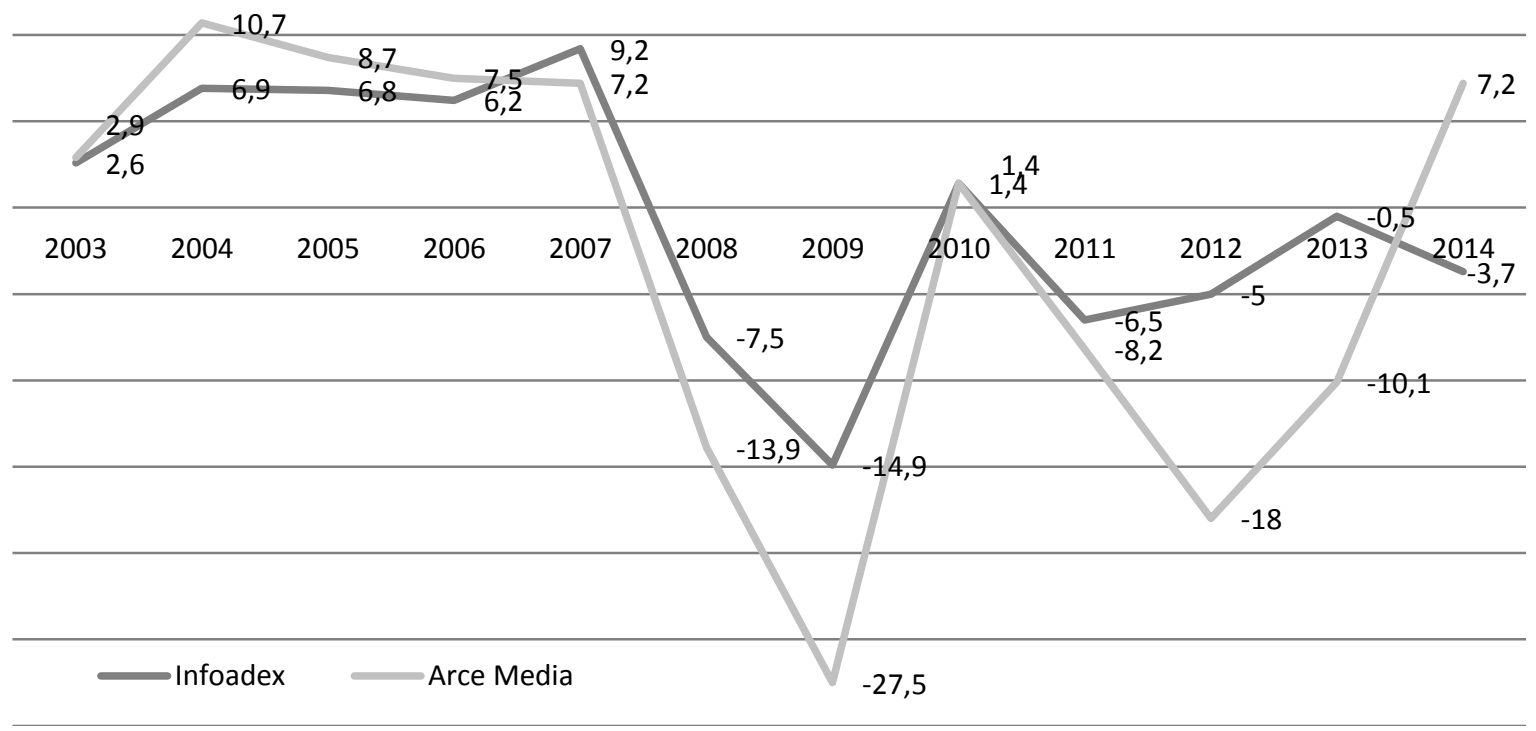

Fuente: Infoadex y Arce Media, 2014

Pero este recorte tiene especial interés desde la perspectiva de la distribución de la inversión. Así, todo apunta a que la crisis económica puede haber acelerado un proceso iniciado tiempo atrás y que guarda relación directa con la pérdida de confianza en los medios de comunicación convencionales, desviando así la inversión hacia los no convencionales. 
Gráfico 2: Evolución de la inversión en medios

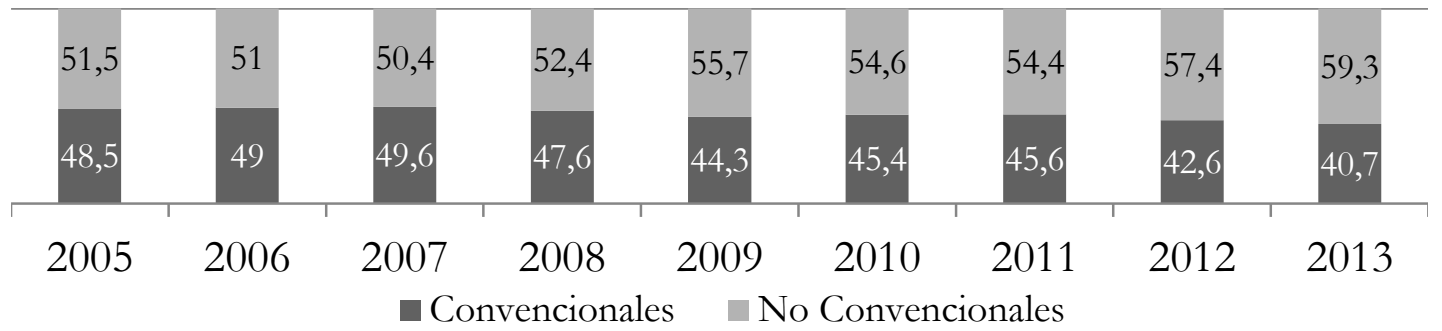

Fuente: Infoadex, 2014.

Este dato tiene, sin embargo, matices, ya que en los medios convencionales se incluye internet, aunque Infoadex sólo cuantifica formatos gráficos (display) o enlaces patrocinados (search), sin que exista referencia expresa a otras fórmulas como las redes sociales. Ese es el mismo criterio que aplica el Interactive Advertising Bureau (IAB) que aporta el siguiente panorama de inversión en medios digitales (Tabla 1):

Tabla 1: Inversión en publicidad digital, 2013

\begin{tabular}{|c|c|c|c|c|c|c|}
\hline & Mill./€ & $\%$ & Mill./€ & $\%$ & Mill. / $€$ & $\%$ \\
\hline Internet & \multicolumn{2}{|c|}{ PC/ Laptop } & \multicolumn{2}{|c|}{ Mobile } & \multicolumn{2}{|c|}{ Digital Signame } \\
\hline Display & 332,2 & 39,9 & 27,8 & 69,7 & \multirow{3}{*}{6,1} & \multirow{3}{*}{0,7} \\
\hline Search & 500,3 & 60,1 & 12,1 & 30,3 & & \\
\hline TOTAL & 832,5 & 94,8 & 39,9 & 4,5 & & \\
\hline
\end{tabular}

Fuente: IAB, 2013

Todo lo anterior nos dibuja un panorama donde la crisis publicitaria está afectando especialmente a los medios convencionales pero, al mismo tiempo, donde resulta muy complejo determinar el papel que pueden jugar las redes sociales. Queda constancia de la importancia de la inversión en internet, pero en unos formatos muy concretos.

Resulta mucho más difícil cuantificar la inversión en redes sociales. Distintas consultoras aportan datos de carácter global. Así, eMarketer indica que el gasto en publicidad en redes sociales aumentará un 33,5\% en 2015 (con respecto al año anterior), alcanzando 23.680 millones de dólares. Por zonas geográficas Europa Occidental se sitúa por debajo de Estados Unidos-Canadá y Asía- 
Pacífico, con una estimación de 4.740 millones de euros lo que supone un $20 \%$ del total mundial y un incremento del 28,9\% (Marketing Directo, 2015). De una forma más concreta, Carat indica que el crecimiento en España será de un 6,8\% en 2015, revisando la previsión publicada en 2014 cuando se calculaba que el mismo sería del 3,3\% (Prmarketing, 2015).

Volviendo a los datos del IAB podemos tomar como referencia su estudio sobre la inversión en comunicación digital, elaborado mediante un tracking cuantitativo de periodicidad anual que en 2013 llegó a la tercera edición. En el mismo se confirma que la página corporativa, la presencia en redes sociales y los formatos display son las áreas de comunicación digital en las que más invierten las empresas españolas aunque no se aportan datos concretos del volumen de esa inversión. De una forma más detallada aportamos lo recogido en el Tabla 2.

Tabla 2: Inversión en comunicación digital. Áreas de inversión

\begin{tabular}{|l|r|c|l|r|c|}
\hline \multicolumn{1}{|c}{ Área } & \multicolumn{1}{c}{ Var. } & \multicolumn{2}{c|}{ Área } & \multicolumn{1}{c|}{ Var } \\
\hline Página corporativa & 98,0 & & Página promocional & 58,4 & $*$ \\
\hline Redes sociales & 88,9 & & Atención al cliente & 52,4 & $*$ \\
\hline Display & 76,5 & & Web adaptada & 50,5 & $*$ \\
\hline E-mails y newsletters & 71,7 & & Apps & 45,7 & \\
\hline SEO & 70,8 & & eCommerce & 32,8 & $*$ \\
\hline Branded content & 66,2 & $*$ & SMS / MMS & 32,4 & \\
\hline Juegos & 64,8 & & Códigos QR & 27,5 & \\
\hline Blogs & 59,9 & & TV Conectada & 7,9 & $*$ \\
\hline
\end{tabular}

Fuente: IAB, 2012 *Nueva categoría en 2011.

Comprobamos como el incremento en la inversión en redes sociales es un hecho, pero no se cuenta con datos concretos sobre el volumen que esto aporta a la totalidad del sector en nuestro país.

\section{Los sujetos publicitarios y las redes sociales}

A continuación debemos valorar, por tanto, cómo afecta ese crecimiento de las redes sociales en el papel de cada uno de los sujetos del proceso publicitario. 


\subsection{Los anunciantes}

El primer elemento que debemos tener en cuenta es si las empresas anunciantes están incluyendo las redes sociales en su estrategia empresarial. El punto de partida de la aplicabilidad de este recurso está en su implementación en las estrategias de marketing. Ya desde años atrás la "nueva cultura empresarial" ha comprendido la importancia de los recursos de la web 2.0 en la mejora del proceso de comercialización a todos los niveles (Celaya y Herrera, 2007) por lo que, con el paso de los años, la propia evolución de la red ha conllevado que las empresas deban adaptarse a toda una nueva oferta de servicios comunicativos.

En lo referido a la estrategia de marketing, en el año 2011 el 60\% de las empresas europeas utilizaba las redes sociales para sus actividades, según datos de eCircle (Marketing Directo, 2011), este porcentaje aumenta año tras año pero siguen existiendo muchas incógnitas sobre cómo se gestiona este elemento.

El primer factor es si las redes sociales están condicionando los productos comercializados. Existen ejemplos puntuales, como el caso de Wispa de Cabdury un snack que fue relanzando al mercado en 2008 tras las peticiones de los consumidores en las redes sociales o la empresa Dunkin'donut permite que los usuarios elijan un elemento del menú. En el análisis de los casos se detecta una cierta confusión con el concepto de "marketing viral".

Las cuestiones relativas al precio resultan aún más complejas. En este punto debemos partir de datos que indican que el 74\% de los consumidores confía en la información que recogen las redes sociales para tomar sus decisiones de compra (Puromarketing, 2014), de esta forma el intercambio de opiniones o valoraciones sobre el producto se convierte en un proceso fundamental en el que el factor precio puede, o no, estar presente.

Más concreta parece la gestión de las redes sociales como mecanismo de distribución en el proceso de marketing. De esta forma, y siempre entendiendo la distribución como el proceso completo de compra, las redes sociales cobran importancia en el proceso de toma de decisión - el 2014 el 11\% de los usuarios de habían realizado alguna compra o reserva gracias a la información conocida a través de ellas- pero también en la ejecución. 
En 2012, PWC estimaba que las compras en redes sociales alcanzarían el 16\% de los usuarios en 2015 convirtiéndose en una de las actividades de mayor importancia en este contexto. En este punto han surgido aplicaciones específicas que simplifican la ejecución de la compra directamente desde la red social (Por ejemplo la creada por Gerencianet para Instagram) y que, posteriormente, permiten realizar un seguimiento de la entrega y el servicio postventa.

Pero el elemento que más nos interesa para este trabajo es el relativo a la comunicación. Desde la perspectiva del marketing tradicional, esto supondría valorar el mix de comunicación que plantean las empresas, sin embargo, la realidad recogida en los factores anteriores (aunque poco concreta) deja claro que debe modificarse el planteamiento tradicional. El marketing operativo que fue sustituido por el marketing estratégico debe evolucionar hacia el Social Media Marketing (SMM) (Tuten y Solomon, 2014).

\section{Gráfico 3: Social Media Marketing}

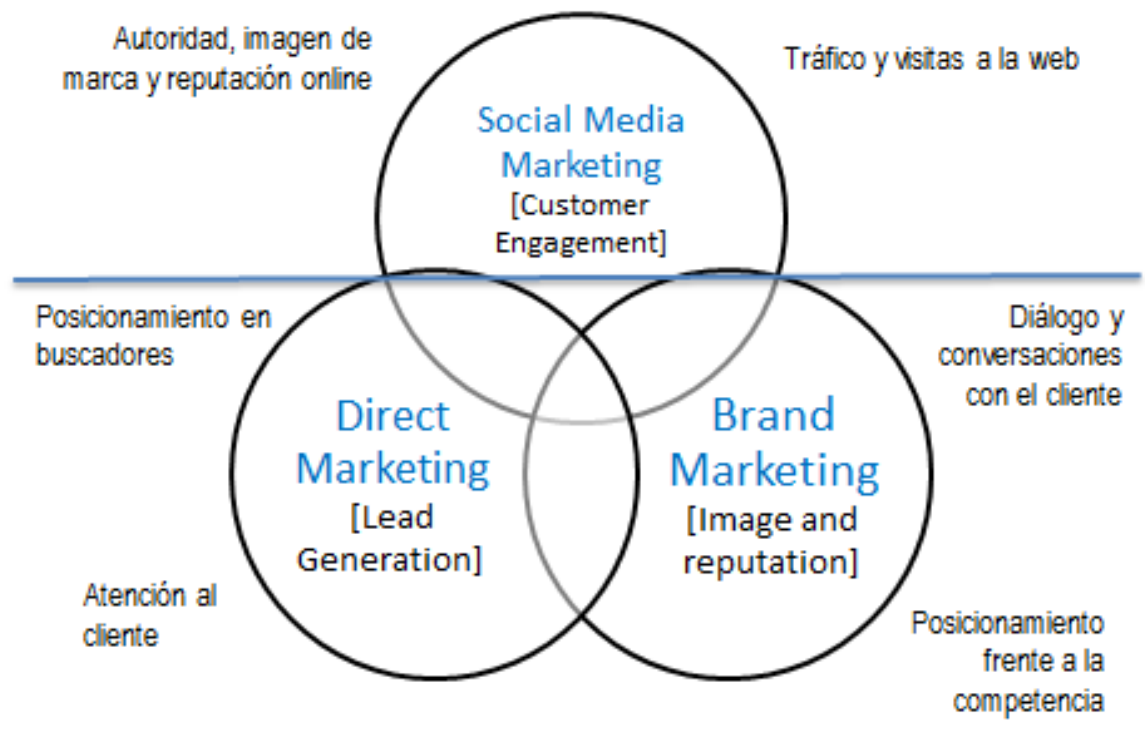

Fuente: Elaboración propia

Se trata de construir la marca y promocionar la empresa incentivando y favoreciendo que sean los propios individuos los que transmitan de forma rápida el mensaje de otros. Este sistema se sustenta en tres elementos, tal y como recogemos en el siguiente esquema, en el que queda claro que lo importante no es el medio si no el tipo de relación establecida con el consumidor. Desde ese punto de vista, debemos 
centrarnos en cómo se gestionan los medios que contribuyen al logro directo de esos fines, pero teniendo en cuenta la existencia de estrategias $360^{\circ}$.

De esta forma, los estudios realizados en lo relativo a las empresa españolas indican que el medio al que se destina la mayor inversión sigue siendo la televisión (58\%), seguido de internet o comunicación online $(16 \%)$, la prensa $(12 \%)$, la radio $(6 \%)$, publicidad exterior $(5 \%)$, revistas $(4 \%)$ y otros $(3 \%)$ (ISDI, 2012). Centrándonos en la inversión en internet o online la distribución es la siguiente:

Gráfico 4: Inversión por canal / campañas de marketing online (\%) 2012
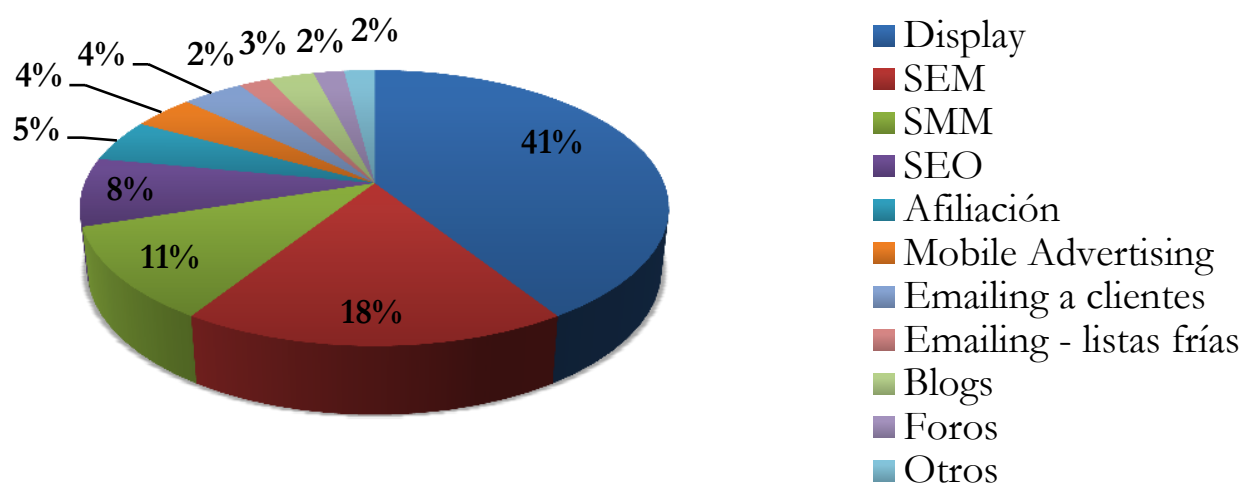

Fuente: ISDI, 2012

Nos encontramos por tanto con que la inversión online está por detrás de la televisión y con que las redes sociales (Social Media Marketing- SMM) son el tercer canal de inversión online.

\subsection{Agencias y mensajes}

En el siguiente nivel debe evaluarse el contenido de esa comunicación en las redes sociales. El punto de partida está en cómo ofrecen esos servicios las agencias de publicidad en nuestro país. En términos globales, el $71 \%$ de las agencias de publicidad declaran que usan los anuncios en medios sociales en paralelo con otra publicidad online. Por otro lado, el $41 \%$ indica que usa este tipo de publicidad sobre otras formas de publicidad offline (Marketing Directo, 2013). En el caso de España, el aumento del trabajo de las agencias en lo referido a lo digital es muy notable: 
Gráfico 5: Incremento del trabajo digital de las agencias (2013) (\%)

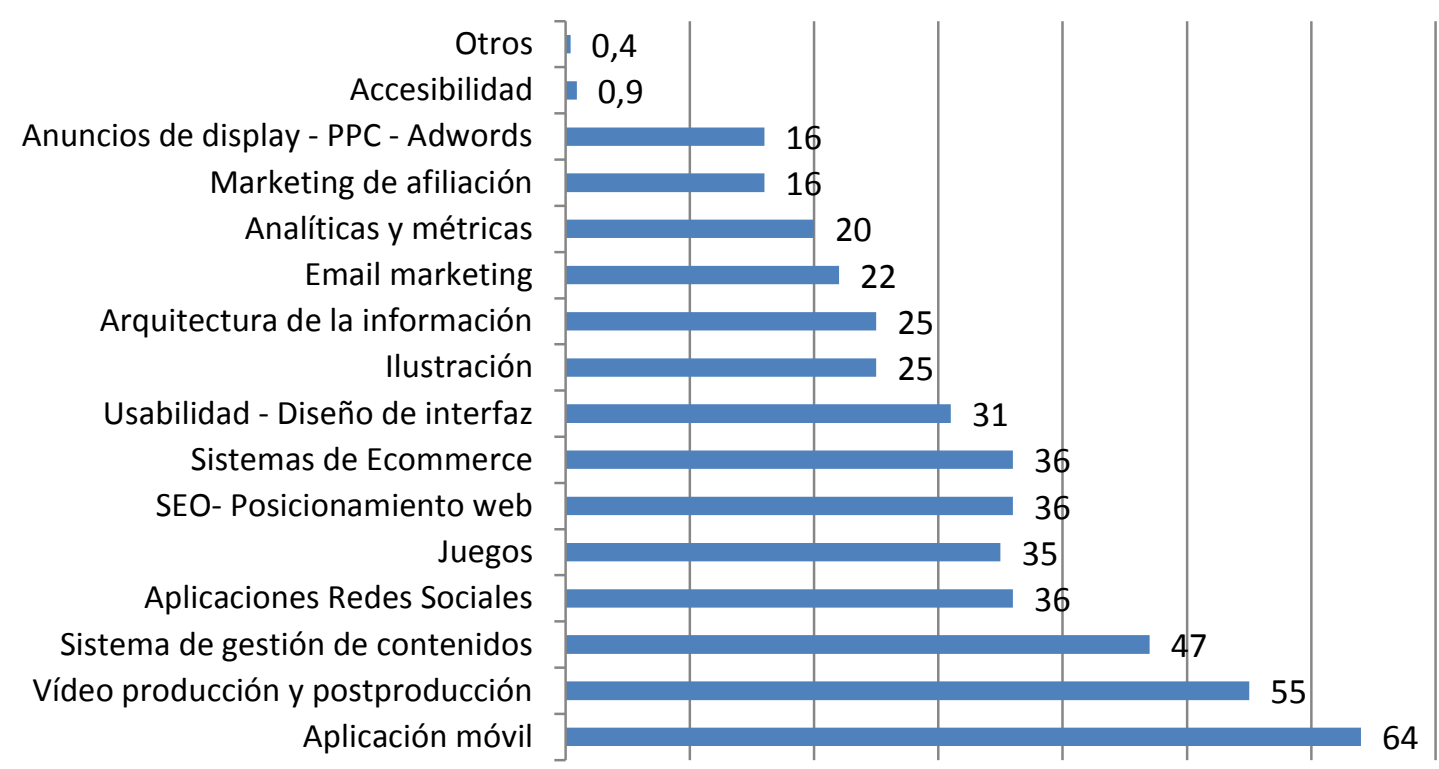

Fuente: AZSeo, 2013

En el gráfico anterior observamos como las redes sociales no son el elemento que más trabajo está generando en las agencias, si bien cuenta con una notable importancia.

Pero aunque este estudio se refiera a la situación de España, la propia estructura actual de las agencias a nivel mundial (centralizadas en grandes corporaciones) permiten que podamos tomar como referencia datos globales como los relativos al top 50 de agencias realizado por Pivostack en el que se otorga una puntuación para valorar su desempeño en redes sociales. En la siguiente tabla recogemos las 10 primeras:

Tabla 3: Puntuación de agencias por uso de Redes Sociales (principales redes y puntuación de Alexa.com)

\begin{tabular}{|l|l|r|r|r|r|r|}
\hline \multicolumn{2}{|c}{ Agency } & \multicolumn{1}{c}{ Puntuación } & \multicolumn{1}{c}{ Facebook } & \multicolumn{1}{c|}{ Twitter } & \multicolumn{1}{c|}{ Linkedin } & \multicolumn{1}{c|}{ Alexa } \\
\hline 1 & Ogilvy \& Mather & 647.474 & 205.900 & 172.064 & 208.870 & 16.507 \\
\hline 2 & IDEO & 379.854 & 86.800 & 165.863 & 101.226 & 38.513 \\
\hline 3 & Wieden+ Kennedy & 241.711 & 27.101 & 123.258 & 81.690 & 103.501 \\
\hline 4 & JW'T & 234.887 & 28.783 & 48.304 & 133.203 & 40.656 \\
\hline 5 & Leo Burnett & 233.756 & 46.724 & 50.925 & 128.772 & 135.415 \\
\hline 6 & Razorfish & 210.622 & 20.137 & 95.319 & 78.292 & 59.264 \\
\hline 7 & BBDO & 207.311 & 42.231 & 74.137 & 86.136 & 208.027 \\
\hline 8 & Edelman & 188.647 & 35.379 & 45.101 & 71.560 & 27.317 \\
\hline 9 & R/GA & 175.729 & 21.142 & 94.014 & 48.574 & 83.337 \\
\hline 10 & TBWA & 165.000 & 41.606 & 86.330 & 32.479 & 218.101 \\
\hline
\end{tabular}

Fuente: Pivostack, 2015 
Más allá de la compleja metodología empleada para calcular estas cifras, del análisis de esta tabla extraemos dos ideas fundamentales: la primera tiene que ver con el hecho de que las agencias de publicidad de mayor tamaño son las que también obtienen buenas puntuaciones a la hora de gestionar redes sociales; la segunda se deriva del hecho de que la correcta gestión de las redes sociales no necesariamente implica más visitas a la web (lo comprobamos al incluir los datos de Alexa).

Sea como fuere, las grandes agencias parecen tener claro que las redes sociales tienen un papel fundamental en el desarrollo estratégico del futuro pero, a día de hoy, no consiguen identificar el modelo de negocio que pueden generar en su actividad publicitaria.

\subsection{Medios}

Según explica Campos-Freire (2008): "Las redes sociales se configuran con un nuevo sistema de entretenimiento y también de información, que toma elementos, recursos y características de los medios tradicionales pero que incorpora tanto un nivel de interacción como un modelo de negocio más magro. Su evolución apunta más hacia el medio audiovisual y virtual que a las características de la prensa escrita".

De esta forma, al realizar un análisis de las consecuencias de las redes sociales en los medios de comunicación debemos tener en cuenta que estas han tenido efecto en el modelo de negocio tanto desde el punto de vista de sus propios contenidos como de la gestión específica de la venta de sus espacios publicitarios.

En lo relativo a los contenidos, siguiendo los criterios de la IAB en el contexto digital debemos diferenciar entre medios de comunicación, soportes (redes sociales, medios de comunicación, portales y foros) y finalmente los medios de comunicación online. De esta forma, la cuestión estaría en cómo los medios convencionales usan las redes sociales o como lo hacen los medios digitales y si existe alguna diferencia entre ellos.

Sin embargo, en el caso que nos ocupa, el interés reside en el segundo aspecto planteado ¿cómo afectan las redes sociales a la venta de los espacios publicitarios de los medios de comunicación?.

Más allá de los datos generales aportados en los epígrafes anteriores, donde hemos incidido en la predisposición de las empresas 
en invertir en publicidad en redes sociales, los medios de comunicación convencionales parecen haber interpretado que el papel de las redes sociales se centra, fundamentalmente, en la generación de tráfico hacia las plataformas donde, de una forma más clara, puede conseguir el correspondiente rendimiento publicitario.

Las redes sociales son, por lo tanto, un medio de difusión y distribución de contenidos, sin beneficio publicitario directo. Se trata de profundizar la convergencia de medios y en la distribución multiplataforma de contenidos.

Así, según el estudio de la consultora GAD3 del año 2012, las cadenas de televisión se han posicionado principalmente en la plataforma de vídeos online Youtube; las cadenas de Radio Fórmula, ostenta el liderazgo de los medios en Facebook; la prensa, está prioritariamente centrada en Twitter.

\subsection{Públicos}

En lo referido a los sujetos del proceso publicitario, el siguiente elemento que debemos tener en cuenta es el relativo a los públicos de la publicidad en Redes Sociales. Como punto de partida, debemos conocer cuáles son las que tienen mayor "audiencia".

Pero además de conocer las redes más consumidas, es importante valorar que actividades realizan los usuarios en las mismas. Desde ese punto de vista entenderemos el interés de anunciantes y agencias en la publicidad a través de redes, donde existen claras potencialidades de conexión con los públicos.

De esta forma nos encontramos con un público que consume redes sociales y que a través de ellas realiza actividades vinculadas con las marcas y, por tanto, con la comunicación publicitaria de las mismas (seguir marcas, hablar de un producto que he comprado, contactar con el servicio al cliente, comprar marcas...). Se trata, por tanto, de un mercado potencial positivo. Sin embargo, existen muchos matices sobre esta cuestión, matices que tienen que ver con el cambio en el modelo de consumo. 


\section{Gráfico 6: Redes utilizadas/visitadas}

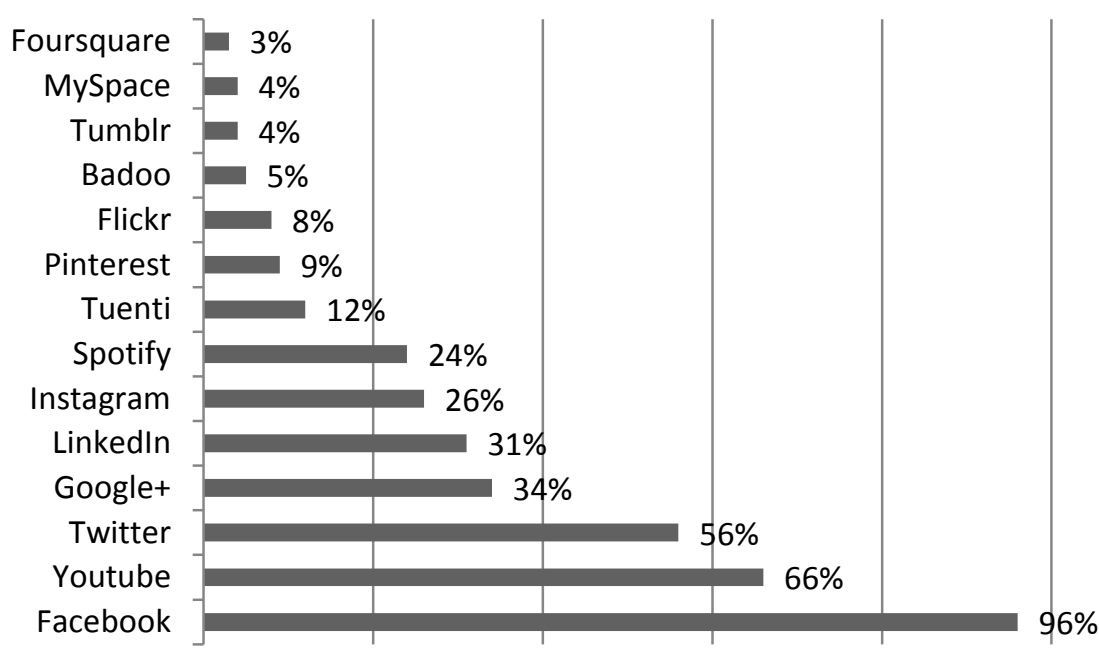

Fuente: IAB Spain, 2013

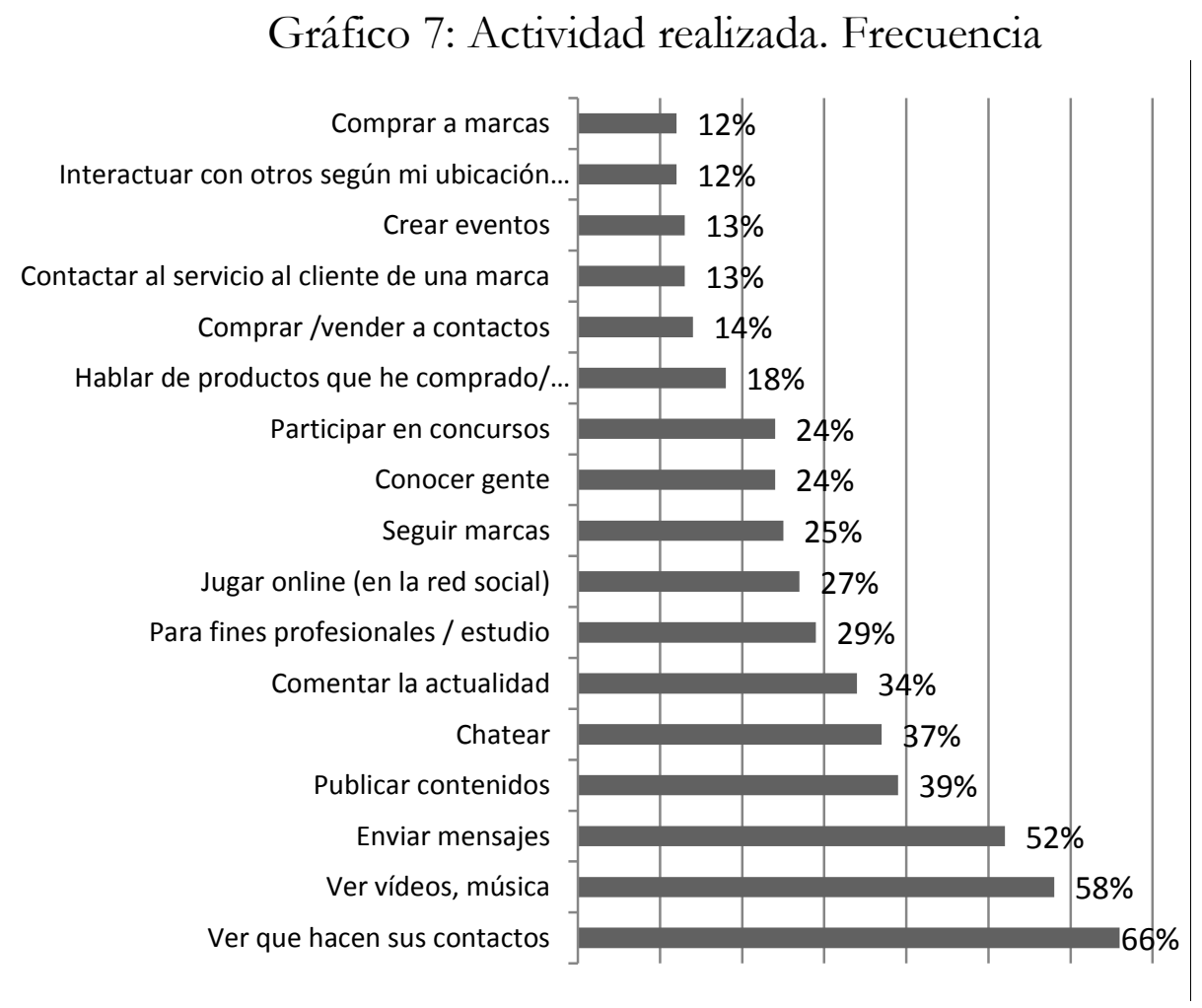

Fuente: IAB Spain, 2014

Debemos hacer una especial referencia a los cambios de comportamiento del consumidor ya que debemos tener en cuenta que existen modificaciones coyunturales derivadas de la crisis y que han provocado una serie de cautelas en su consumo y, sobre todo, en su relación con las marcas. Pero además de "recortes" en gastos los 
nuevos hábitos son, si cabe, más complejos de asumir ya que suponen grandes cambios en la relación de fuerzas del mercado.

Nos encontramos ante el modelo de "prosumidor" que, como hemos visto en el gráfico 7, tiene una especial preferencia por "hablar de los productos que ha comprado". Su capacidad de generación de contenidos implica un mayor dinamismo en las relaciones con las marcas, requiriendo una interacción ("contactar con el servicio al cliente de la marca") y unas motivaciones diferentes para establecer esa relación.

Gráfico 8: Motivaciones de seguimiento de marca

Fuente: IAB Spain, 2014

Las redes sociales reúnen, por tanto una serie de características que entroncan directamente con las demandas de ese nuevo consumidor. De hecho, el $52 \%$ de los usuarios de redes manifiestan que la publicidad en este medio "me parece bien, me da información", un $39 \%$ se muestra indiferente y un $9 \%$ indican que "me parece mal, creo que las redes no son para eso" (IAB, 2014). El nivel de personalización que permiten técnicamente las redes sociales es otro factor relacionado con ese nuevo perfil. 
Gráfico 9: Promociones / publicidad personalizada

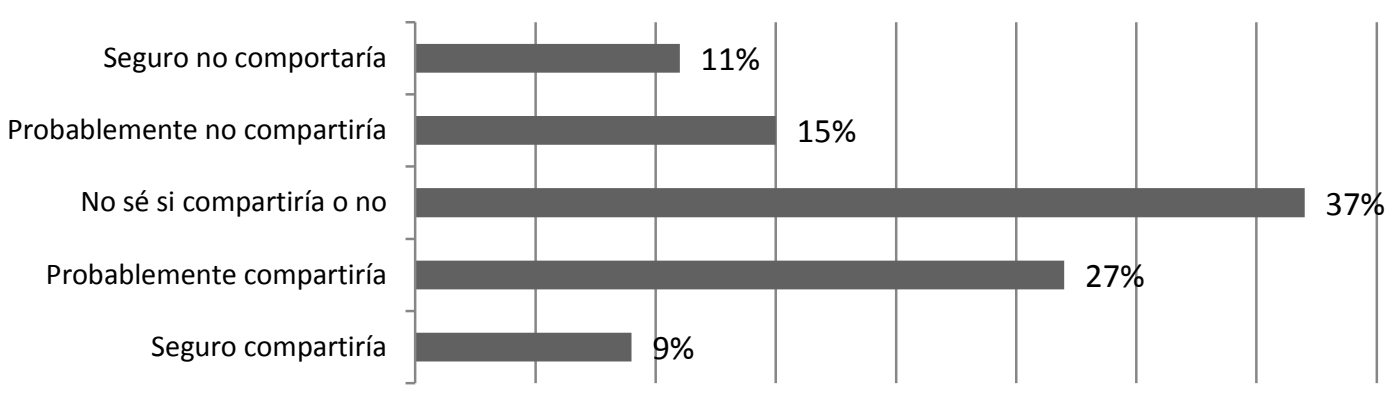

Fuente: IAB Spain, 2014

No parece que sea el factor relativo al consumidor el que ralentice la búsqueda de un modelo de gestión comunicativo de las redes sociales, ya que estas reúnen una serie de características que, teóricamente, deberían funcionar de forma eficaz en la transmisión de contenidos publicitarios.

\section{4. ¿Nuevas estrategias para las redes sociales?}

El breve recorrido por las implicaciones de las redes sociales en los distintos sujetos del proceso publicitario da paso al planteamiento de otras cuestiones relativas a si se están aplicado nuevas estrategias para este fin. Para valorar este elemento hemos tomado como referencia los premios de eficacia de la última edición aplicando de nuevo el análisis de contenido para recoger cuestiones relativas a la estrategia planteada. A esto añadimos un elemento que podemos denominar "táctica" relativa al uso de medios y soportes, intentado identificar el uso de las redes sociales.

Como se puede comprobar, en el tema que nos ocupa, resulta clave la combinación de medios convencionales y no convencionales. De esta forma, aún en 2014, la televisión sigue siendo el medio básico y el punto de partida para todas las acciones no convencionales planteadas en estas campañas.

Los índices de penetración de los medios convencionales son necesarios para conectar a nivel general con los públicos, pero este primer contacto debe ser el punto de partida para el establecimiento de una relación directa con los consumidores, siendo esta mayoritariamente realizada a través de medios digitales. 
Tabla 4: Análisis estratégico de las campañas ganadoras de los premios de eficacia (2014)

\begin{tabular}{|c|c|c|c|c|c|c|}
\hline Anunciante & Marca & Producto & Agencia & Objetivo & Estrategia & Fórmula \\
\hline $\begin{array}{l}\text { Banco } \\
\text { Sabadell }\end{array}$ & $\begin{array}{l}\text { Banco } \\
\text { Sabadell }\end{array}$ & $\begin{array}{l}\text { Planes } \\
\text { personalizados } \\
\text { de futuro }\end{array}$ & *S,C,P,F .. & Comportamiento & $\begin{array}{l}\text { Desarrollo } \\
\text { extensiva }\end{array}$ & $\begin{array}{l}\text { Televisión y } \\
\text { generación } \\
\text { marketing } \\
\text { viral }\end{array}$ \\
\hline $\begin{array}{l}\text { Campofrío } \\
\text { Food } \\
\text { Group }\end{array}$ & Campofrío & $\begin{array}{l}\text { Hazte } \\
\text { extranjero }\end{array}$ & $\begin{array}{l}\text { McCann / } \\
\text { MRM Mc } \\
\text { Cann }\end{array}$ & Actitud & Fidelización & $\begin{array}{l}\text { Televisión y } \\
\text { generación } \\
\text { de tráfico en } \\
\text { redes } \\
\text { sociales }\end{array}$ \\
\hline Coca-Cola & Coca-Cola & $\begin{array}{l}\text { Benditos } \\
\text { Bares }\end{array}$ & $\begin{array}{l}\text { Sra. } \\
\text { Rushmore } \\
\text { / Carat }\end{array}$ & Comportamiento & Fidelización & $\begin{array}{l}\text { Televisión y } \\
\text { generación } \\
\text { de tráfico en } \\
\text { web y redes } \\
\text { sociales }\end{array}$ \\
\hline $\begin{array}{l}\text { Seguros El } \\
\text { Corte Inglés }\end{array}$ & $\begin{array}{l}\text { Seguros El } \\
\text { Corte } \\
\text { Inglés }\end{array}$ & Seguros & $\begin{array}{l}\text { VCCP } \\
\text { Spain }\end{array}$ & Actitud & Posicionamiento & $\begin{array}{l}\text { Televisión, } \\
\text { prensa y } \\
\text { tráfico a } \\
\text { microsite. }\end{array}$ \\
\hline
\end{tabular}

Fuente: elaboración propia

La valoración general de la totalidad de los datos (más allá de la pequeña muestra aquí aportada) deja entrever que las redes sociales tienen una presencia mayoritaria en las estrategias planteadas, si bien son gestionadas como elementos de apoyo y de generación de tráfico. Dichas estrategias se vinculan, además con objetivos relativos a modificación de actitudes y comportamientos, precisamente los ejes más directamente relacionados con los cambios del modelo de consumo.

En este punto los casos corroboran que las redes contribuyen a la eficacia de la campaña, pero existen datos más concretos que indican incluso posibles retornos gracias a su uso.

Tabla 5: Retorno de inversión estimado en redes sociales

\begin{tabular}{|c|c|c|c|c|c|c|c|c|c|c|c|}
\hline & Facebook & Linkedin & Twitter & YouTube & FourSquare & Google+ & Instagram & Tuenti & Pinterest & WhatsApp & Line \\
\hline Rol $>0$ & $32,0 \%$ & $30,0 \%$ & $32,1 \%$ & $28.7 \%$ & $17.9 \%$ & $19.1 \%$ & $26.5 \%$ & $22,9 \%$ & $14.3 \%$ & $51.4 \%$ & $52,4 \%$ \\
\hline Rol - o & $22,9 \%$ & $31,0 \%$ & $27.4 \%$ & $30.4 \%$ & $38.8 \%$ & $35.1 \%$ & $33.3 \%$ & $28.6 \%$ & $36,1 \%$ & $30.0 \%$ & $4.8 \%$ \\
\hline Rol $<0$ & $45.1 \%$ & $39.0 \%$ & $40,5 \%$ & $40,9 \%$ & $43.3 \%$ & $45.8 \%$ & $40,2 \%$ & $48,6 \%$ & $49.7 \%$ & $18,6 \%$ & $42,9 \%$ \\
\hline
\end{tabular}

Fuente: IAB, 2014 


\section{Conclusiones}

En este breve recorrido hemos podido constatar, mediante la revisión de los datos, alguna de las hipótesis planteadas. La principal idea que subyace de este análisis es, precisamente, el elevado nivel de incertidumbre existente en el desarrollo estratégico que plantean los anunciantes con respecto a las redes sociales. No resulta posible, en el año 2015, contar con datos concretos sobre la implantación de esas redes entre los anunciantes españoles si bien hemos intentado aportar distintos elementos que puedan servir de referencia para valorar su impacto.

De esta forma, se constata que las agencias publicitarias tampoco parecen haber encontrado todavía la fórmula adecuada para dar respuesta a las demandas o dudas de los anunciantes con respecto al uso de las redes sociales, siendo especialmente llamativo el hecho de que, una vez más, son las grandes corporaciones de comunicación las que están llegando a mejores rendimientos del uso de las mismas.

La inexistencia de un modelo establecido para la explotación publicitaria de las redes sociales también guarda relación con la lentitud que parecen estar demostrando los medios de comunicación en encontrar una vía de explotación adecuada de este recurso.

Debe tenerse en cuenta que desde el punto de vista de los públicos las redes sociales cumplen una serie de requisitos de interés para poder transmitir mensajes publicitarios. Es, por tanto, necesario seguir avanzando para encontrar la adecuada vía de implementación de las redes sociales en los procesos de planificación estratégica.

\section{Referencias bibliográficas}

Area Moreira, M. (2008): "Las redes sociales en Internet como espacios para la formación del profesorado”, en Razón y palabra, 63, página 4.

Benavides, J. et al. (2010): "Los anunciantes españoles y el nuevo contexto de comunicación: una aproximación cualitativa”, en Revista Latina de Comunicación Social, 65, La Laguna (Tenerife), páginas 159 a 175, recuperado el 21 de marzo de 2014 de http://www.revistalatinacs.org/10/art/890 UCM/12 Benevides et $\underline{\text { al.html }}$ 
Caldevilla Domínguez, D. (2009): “Democracia 2.0: La política se introduce en las redes sociales", en Pensar la publicidad: revista internacional de investigaciones publicitarias, 3, 2, páginas 31 a 48.

Caldevilla Domínguez, D. (2010): "Las Redes Sociales. Tipología, uso y consumo de las redes 2.0 en la sociedad digital actual", en Documentación de las Ciencias de la Información, 33, páginas 45 a 68.

Campos-Freire, F. (2008): "Las redes sociales trastocan los modelos de los medios de comunicación tradicionales", en Revista Latina de Comunicación Social, 63, La Laguna (Tenerife), páginas 287 a 293, recuperado el 21 de marzo de 2015.

Celaya, J. y Herrera, P. (2007): Comunicación empresarial 2.0. La función de las nuevas tecnologías sociales en la estrategia de comunicación empresarial. Madrid: Grupo BPMO ediciones.

Del Río Pérez, J. y Kaugmann Argueta, J. (2014): "Revisión teórica de la agencia publicitaria en la cultura digital", en adComunica, 8. Castellón, Facultat de Ciències Humanes i Socials, páginas 57 a 72.

Farias Batlle, P. y Roses Campos, S. (2009): "La crisis acelera el cambio del negocio informativo", en Estudios sobre el mensaje periodístico, 15. Madrid: Universidad Complutense de Madrid, páginas 15 a 32.

García, M. del C. y Valdivia, N. A. (2014): "Prosumidores mediáticos: Cultura participativa de las audiencias y responsabilidad de los medios", en Comunicar: Revista científica iberoamericana de comunicación y educación, 43. Huelva: Universidad de Huelva, páginas 10 a 13.

Grupo Consultores y Interactive Advertising Bureau (2013): "Inversión publicitaria en medios digitales", en $L A B$, recuperado el 21 de marzo de 2015 de http:/ /www.iabspain.net

Herreros Cebrián, M. (2008): "La Web 2.0 como red social de comunicación e información”, en Estudios sobre el mensaje periodístico, 14. Madrid: Universidad Complutense de Madrid, páginas 345 a 361.

Infoadex (2014): "Estudio Infoadex de la inversión publicitaria en España, 2014", en Infoadex. Madrid, Infoadex; recuperado el 21 de marzo de 2015 de http://www.infoadex.es/resumen estudio 2014.pdf

Legerén Lago, B. y García-Mirón, S. (2012): "Cambios tendencias de la publicidad a nivel mediático. Más con menos”, en Icono 14, 10, 3. Recuperado el 21 de marzo de 2015 de http://dx.doi.org/10.7195/ri14.v10i3.185 
Marketing Directo (2011): "El 60\% de las empresas europeas utiliza las redes sociales para sus actividades de marketing", en Marketing Directo, 21 de noviembre de 2011, recuperado el 21 de marzo de 2015 de

http://www.marketingdirecto.com/actualidad/anunciantes/el-60-delas-empresas-europeas-utiliza-las-redes-sociales-para-sus-actividadesde-marketing/

Marketing Directo (2013): "El gasto en publicidad en redes sociales superará los 8.000 millones de euros en 2017”, en Marketing Directo, 6 de mayo de 2013, recuperado el 21 de abril de 2015 de http://www.marketingdirecto.com/actualidad/agencias/el-gasto-enpublicidad-en-las-redes-sociales-superara-los-8000-millones-de-eurosen-2017/

Marketing Directo (2015): "El gasto global en publicidad en redes sociales ascenderá a los 23.680 millones de dólares en 2015", en Marketing Directo, 15 de abril de 2015, recuperado el 21 de abril de 2015 de http://www.marketingdirecto.com/actualidad/social-mediamarketing/el-gasto-global-en-publicidad-en-redes-sociales-ascenderaa-los-23-680-millones-de-dolares-en-2015/

Martínez Sáez, J.; Amiguet Esteban, J. M. y Visiedo Claverol, R. (2014): "Presencia de las redes sociales en las campañas publicitarias transmedia más premiadas", en Historia y Comunicación Social, vol.19, Madrid: Universidad Complutense de Madrid, páginas 301 a 313.

Martínez-Rodrigo, E. y Sánchez Martín, L. (2012): "Publicidad en Internet: nuevas vinculaciones en las redes sociales", en Revista de Comunicación Vivat Academia, 14. Madrid: Universidad Complutense de Madrid, páginas 469 a 480.

Noguera Vivo, J. M. (2010): "Redes sociales como paradigma periodístico. Medios españoles en Facebook", en Revista latina de comunicación social, 65. La Laguna (Tenerife): Universidad de La Laguna, página 13.

Online Business School (2014): “OBS Social 2015. Análisis de las tendencias de uso y participación en las redes sociales a nivel mundial en España", en Online Business School, recuperado el 21 de marzo de 2015 de http://www.eae.es/new/2014/03/31/la-inversionde-las-empresas-espanolas-en-redes-sociales-crecio-un-24-en-2013

PRNoticias (2015): "La inversión publicitaria crecería un 6,8\% en España durante 2015, según la agencia de medios Carat”, en 
PRMarketing, 20 de abril de 2015, recuperado el 21 de abril de 2015 de http://www.prnoticias.com/index.php/marketing/1103-inversionpublicitaria-prmarketing/20139927-la-inversion-publicitaria-creceriaun-68-en-espana-durante-2015-segun-la-agencia-de-medios-carat

Puro Marketing (2014): "Influencia de las redes sociales en el proceso de compra", en Puro Marketing, s.d. recuperado el 21 de marzo de 2015 de http://www.puromarketing.com/42/19243/aumentainfluencia-redes-sociales-decisiones-compra.html

PWC (2012): "La compra online será el área que más crecerá en las redes sociales en España en los próximos años", en Pricewaterhousecoopers, recuperado el 21 de marzo de 2015 de http://www.pwc.es/es/sala-prensa/notas-prensa/2012/informeenredados-pwc-redes-sociales.jhtml

Santamaría González, F. (2008): "Posibilidades pedagógicas: Redes sociales y comunidades educativas", en Telos: Cuadernos de comunicación e innovación, 76, páginas 99 a 109.

Sanz Menéndez, L. et al. (2003): "Análisis de redes sociales: o cómo representar las estructuras sociales subyacentes", en Apuntes de Ciencias y Tecnología, 7. Madrid, CSIC, páginas 21 a 28; recuperado el 21 de marzo de 2015 de http://digital.csic.es/bitstream/10261/1569/1/dt-0307.pdf

Tapia Frade, A. et al (2010): "Los estudiantes universitarios ante las redes sociales: cuestiones de uso y agrupación en estructuras elitistas o pluralistas", en Vivat Academia, 113. Madrid: Universidad Complutense de Madrid, páginas 1 a 13.

Torres-Romay, E. (2010b): "Publicidad y crisis: estrategias eficaces para el desarrollo de campañas publicitarias en contextos de crisis". En VV.AA., Escenario actual de la investigación en comunicación: objetivos, métodos y desafíos (Coords., M. Perlado y C. Jiménez). Madrid: Edipo, páginas 360 a 378.

Torres-Romay, E. (2011): “Advertcrisis: nuevas estrategias publicitarias para hacer frente a la crisis". En VV.AA., Reflexiones cientificas sobre cine, publicidad y géneros desde la perspectiva audiovisual (Coords., J. Sierra Sánchez y S. Liberal Ormaechea). Madrid: Fragua, páginas 291 a 308.

Torres-Romay, E. (2012): “Tendencias actuales en la producción publicitaria. La evolución de las estrategias publicitarias y su reflejo en 
los procesos de producción”. En VV.AA., Planificación estratégica y creatividad (Coord., U. Cuesta). Madrid: ESIC, páginas 167 a 188.

Torres-Romay, E. (2013): “Estrategias publicitarias eficaces ante el nuevo consumidor. Los cambios en la planificación estratégica como consecuencia de la crisis en España”, en Business Review, 223. páginas 42 a 49.

Torres-Romay, E. y García-Mirón, S. (2014): “La evolución de la estrategia publicitaria. Del brand management a la marca adaptada y el nuevo papel del consumidor", en Revista Mediterránea de Comunicación, 5, 2. Alicante, Grupo de Investigación Comunicación y Públicos Específicos (COMPUBES), recuperado el 21 de marzo de 2015 de http://www.mediterranea-

comunicacion.org/Mediterranea/article/view/150

Torres-Romay, E. (2010): "La crisis del sector publicitario en España”. En VV.AA., El cambio mediático (Coord., F. Campos Freire). Sevilla: Editorial Comunicación Social.

Torres-Romay, Emma (2010a): "La influencia de la crisis en las estrategias comunicativas de las empresas españolas", en Fisec_Estrategias. Buenos Aires: Universidad Nacional de Lomas de Zamora, páginas 3 a 30.

Tuten, Tracy L. y Solomon, Michael R. (2014): Social media marketing. Nueva York: SAGE. 


\section{Las televisiones españolas y ecuatorianas usan las redes sociales para reforzar sus canales tradicionales}

Lara Lozano Aguiar, Universidad de Santiago de Compostela (USC, España), laralozanoaguiar@gmail.com

Nancy Graciela Ulloa Erazo, Pontificia Universidad Católica del Ecuador Sede Ibarra (PUCESI, Ecuador), nulloa@pucesi.edu.ec

Francisco Campos Freire, Universidad de Santiago de Compostela (USC, España), francisco.campos.freire@gmail.com

\section{Resumen}

Esta comunicación realiza una investigación, a partir de técnicas metodológicas mixtas de observación cuantitativa y etnografía digital, sobre el uso que las televisiones realizan de las redes sociales virtuales, tomando como referencia de contraste las ocho cadenas nacionales de Ecuador (Ecuavisa, Teleamazonas, TC TV, Gama TV, RTS, RTU, Telerama y Ecuador TV) y los veintinueve canales también de ámbito estatal de España.

El trabajo forma parte de la primera parte del Proyecto de Investigación Prometeo, aprobado por la Secretaría Nacional de Educación Superior, Ciencia, Tecnología e Innovación (SENESCYT) sobre 'El uso, impacto y resultados de la gestión de las redes sociales en los medios, organizaciones e instituciones de comunicación de Ecuador así como en las redes científicas y la promoción de las buenas prácticas de calidad y RSC'. Se toman las 
redes sociales digitales como objeto de estudio en tanto y cuanto se están convirtiendo en paradigma del cambio y transición de los medios tradicionales analógicos a los nuevos medios digitales, apuntando a mutaciones significativas tanto en los sistemas y formas de gestión o distribución de contenidos como en las propias narrativas audiovisuales. Por el momento, las televisiones tradicionales gestionan las redes sociales digitales como herramientas de apoyo, refuerzo y potenciación de sus canales tradicionales, aunque se detectan tendencias convergentes dirigidas a públicos jóvenes, ensayos de nuevas narrativas y de difusión multipantallas.

Palabras clave: redes sociales digitales, ecosistemas digitales, interacción, nuevas narrativas audiovisuales y TV conectada a Internet.

\section{Como la aparición de la web 2.0 cambió el concepto de distribución de contenidos periodísticos y uso de las herramientas digitales}

$\mathrm{L}$

A aparición de la World Wide Web y su evolución en los últimos años ha sentado las bases de la comunicación que actualmente se materializa en variedad de herramientas virtuales. «Internet se convirtió en un medio de comunicación que permitía, por primera vez, la comunicación de muchos a muchos en un tiempo escogido y a una escala global»(Castells, 2001). Así la red de comunicaciones apareció como un medio para dar voz a cualquiera persona, situación que ha provocado que la línea divisoria entre productos y consumidores de información se difumine (Gillmor, 2005).

La sociedad en red muestra nuevas formas de organización y comunicación, que hacen posibles nuevas vías de participación y de diálogo además de variedad de posibilidades narrativas. Por todo esto, hoy en día es necesario dialogar, fomentar la participación en los procesos de construcción de los mensajes y sobre todo escuchar a los consumidores a lo largo de todo el proceso comunicativo, antes de elaborar los contenidos como en la fase posterior de su circulación, momento en el que comienza otra fase del proceso productivo. $\mathrm{Y}$ teniendo esta premisa como punto de partida, los medios de comunicación deben reconocer que la información es para el 
ciudadano. Este hecho les hará preocuparse por los intereses del usuario para así poder considerar estrategias en la forma de gestionar su presencia y participación en la denominada web 2.0.

La idea de la web 2.0 se basaba en la de una realidad que suponía la continuación de la denominada web 1.0, una web estática programada en lenguaje HTML y caracterizada por ser unidireccional, donde los contenidos eran esencialmente textuales y carecían de actualización. La interacción no era característica de este estado de la World Wide Web, por lo que el usuario estaba limitado a consumir información. El período de esta primera era de la web comprende desde la aparición de esta hasta, proximadamente, el año 2004.

La web 2.0 era una nueva forma de considerar la web como una plataforma o herramienta. Esto significaba que el usuario podía emplear los sitios web como si fueran aplicaciones o programas. Era, por tanto, una nueva forma de pensar la web que ofrecía la posibilidad de participar a través de wikis y blogs y que permite la sindicación de contenidos, optimización de las búsquedas (Search Engine Optimization, SEO), la evolución desde los directorios (característicos de la primera era) a las etiquetas (folksonomy), conceptos tales como podcasts, mashups y widgets, tecnologías AJAX y social networks, entre otras posibilidades.

Con respecto a la participación, característica de esta fase web, debe entenderse como apuesta a favor de la transparencia y la pluralidad. Así, la mayoría de los principales cibermedios de referencia están abriendo vías a los contenidos generados por el usuario, unos como estrategia para conseguir mayor audiencia y sintonizar mejor con su público y otros convencidos de la necesidad de asegurar la participación para elaborar una buena información y para cumplir con la finalidad de atender sus necesidades informativas.

Es necesario escucharlos y hacerlos partícipes y esto se puede conseguir centrando los esfuerzos en la gestión de una de las herramientas/plataformas que más influencia está teniendo en el mundo de la comunicación en general y las cuales vinculan en una sola base todas las necesidades del usuario (información, entretenimiento, comunicación y conocimiento): las redes sociales. 
En este contexto, mientras era necesario reconfigurar el modelo de negocio de los cibermedios puestos en marcha a partir de medios tradicionales o de medios nativos digitales, algunas iniciativas de la red generaban importantes ingresos y ganaban cada día mayor protagonismo. Era el caso de Google, YouTube o las redes sociales. Los hábitos de consumo de muchos ciudadanos estaban cambiando y la respuesta de los cibermedios era lenta, por lo que ahora más que nunca los medios tenían que buscar maneras y estrategias para adaptarse.

La principal preocupación en este momento era la migración de los lectores, oyentes y televidentes a las plataformas online. No sólo era necesario atender a los contenidos en cibermedios sino conseguir distribuir información y contenidos con el único fin de interactuar y abrir nuevas vías de aproximación al lector. Los nuevos hábitos de consumo de información marcarían así las estrategias de los principales medios que, bajo la premisa de convergencia de contenidos, intentarían aproximarse a la idea de multimedialidad. Y recordando a Castells (2009) había que hacer realidad una sociedad en red -aquella cuya estructura social está compuesta de redes activadas por tecnologías digitales de la comunicación y la información basadas en la microelectrónica a nivel digital-.

\section{Las redes sociales, plataformas idóneas para reforzar los canales tradicionales y propiciar la participación y fidelización de los ciudadanos}

Antes de comenzar a hablar de la vinculación y presencia de los principales canales de comunicación en las redes sociales, vamos a ofrecer una aproximación al concepto de red social.

Las redes sociales se entienden como plataformas web mediante las cuales los usuarios, al crear perfiles, engendran una red de interacción cuya actividad principal es el intercambio de información. El concepto de red social fue acuñado por J.A. Barnes en el año 1954 para definir una estructura social de carácter físico que representaba las relaciones entre personas, grupos y organizaciones. Pese a todo, las redes sociales se fundamentan en la Teoría de los Seis Grados de Separación propuesta por Frigyes Karinthy en 1929 en la que afirmaba que toda la población del planeta está conectada a través de no más de seis personas. 
La investigación y definición más citada desde 2007 es la de Danah Boyd y Nicole Ellison. La primera es investigadora principal en Microsoft Research, doctorada en informática y que realizó estudios con Henry Jenkis, actualmente profesora asistente de investigación en Medios, Cultura y Comunicación en la Universidad de Nueva York y miembro del Berkman Center de Harvard. Nicole Ellison, que se doctoró en la Escuela de Comunicación de Annenberg de California, es profesora asociada del Departamento de Telecomunicaciones, Ciencias de la Información y Medios de Comunicación de la Universidad de Michigan Ambas colaboran en investigaciones conjuntas desde hace años.

Esa primera definición de Boy y Ellison (2007) describe los sitios de redes sociales (Social Network Sites) como servicios web que permiten a los utilizadores (1) construir un perfil público o semipúblico en el seno del sistema informático, (2) generar una lista de utilizadores con los que se comparte un enlace, (3) ver y navegar a través de la lista de enlaces propios así como de los establecidos por los otros en el seno del sistema. Posteriormente amplían y contextualizan más esa definición.

Según las investigadoras anteriores (Ellison y Boyd, 2013), un sitio de red social es una plataforma de comunicación en red en la que los participantes (1) disponen de perfiles asociados a una identificación única que son creados por una combinación de contenidos producidos por el utilizador, por amigos y datos sistémicos; (2) pueden exponer públicamente las relaciones susceptibles de ser visualizadas y consultadas por otros; (3) y pueden acceder a los flujos de contenidos (combinaciones de textos, fotos, vídeos, datos y nuevos enlaces) generados por los utilizadores y sus contactos a través de los sitios de Internet. Conviene observar que en ambas definiciones matizan el concepto de red y emplean el término de 'sitios de servicios web' o plataformas de comunicación.

Y gracias a las características que definen estas plataformas los medios de comunicación intentaron estar presentes en las redes sociales desde un principio como apoyo para dirigir el tráfico a las páginas web propias. Con todo, y a pesar de que las cuentas en redes sociales refuerzan los medios tradicionales, la función utópica de medios de comunicación en las redes sociales es la de, a través de un tipo de marketing continuo, fidelizar al usuario. Dejando de lado 
los modelos de negocio en el terreno comunicativo, que deben ser redefinidos, los contenidos informativos llegan a estos lugares digitales que son «el cuarto de estar de muchos ciudadanos», tal y como afirma el communnity manager del periódico La Voz de Galicia, Ignacio de la Fuente.

No se trata solo de estar presente y subir contenido, aquí lo importante y provechoso es mejorar el engagement-compromiso- con los lectores. Participar, interactuar y fidelizar son las acciones que ayudarían a crear una aura fructífera de relaciones porque al fin y al cabo los usuarios que deseen acceder a los contenidos no tienen que ir específicamente a una red social para ello.

En este sentido, la BBC es un ejemplo de medio que recoge en su guía de uso de las redes sociales, esta situación idónea. Establece así, "nuestra meta en Facebook y en Twitter es construir engagement, y al hacerlo, atraer a los lectores y profundar su relación con nuestras emisoras y canales de radio, televisión y servicios online" expone la guía. Añade además la siguiente aclaración: "Incrementar nuestro número de fans en Facebook o seguidores en Twitter no significa, en si mismo, que estemos incrementando nuestro nivel de engagement con la audiencia. Ese es un paso en la dirección correcta" (BBC, 2012).

\section{El community manager como gestor de las plataformas digitales}

El usuario/consumidor cambió la forma de compartir sus opiniones al pasar del círculo reducido al global que permiten las herramientas 2.0. Este hecho debe considerarse en los medios de comunicación que deben buscar los lugares mediante los cuales los consumidores de información y entretenimiento intercambian contenidos. Las experiencias ahora no solo se comparten face to face, el boca a boca pasa a ser digital (e-wonm, electronic worth of mouth). Además el usuario interviene en las redes hecho que lo convierte en productor de contenidos. El periodista debe actuar marcando los límites entre el trabajo profesional de los comunicadores y el aficionado de los actuales internautas.

La función hasta el día de hoy olvidada del periodista, la de participar y crear conversación con las audiencias y públicos, renace con fuerza en el gestor de las cuentas oficiales de los medios de 
comunicación en las plataformas digitales, el denominado community manager.

La Asociación Española de Responsables de Comunidad y Profesionales Social Media (AERCO) lo define como «aquella persona encargada/responsable de sostener, acrecentar y, en cierta forma, defender las relaciones de la empresa con sus clientes en el ámbito digital, gracias al conocimiento de las necesidades y las formulaciones estratégicas de la organización y los intereses de los clientes. Conoce los objetivos y actúa en consecuencia para conseguirlos. Muy genéricamente podría decirse que un gestor de comunidades es aquella persona que preserva la identidad digital de la compañía». El responsable de comunidades es más que un moderador porque además debe marcar los límites con respecto al periodismo amateur.

El concepto de community manager surge en el terreno del marketing. Conviene deslindar el papel del responsable de comunidades, relacionador del marketing de la empresa periodística, con el del gestor de las relaciones de la redacción con sus audiencias. En el primer caso su función se acerca mucho más al marketing y en el segundo a la del ombudsman o defensor de los lectores. En las redacciones actuales, se busca un periodista capacitado para gestionar las redes sociales al mismo tiempo que se avista una tendencia a la especialización.

Así, las principales funciones de un community manager son (Aced, 2010):

-Definir los objetivos y la estrategia de presencia en línea de la empresa, en línea con la estrategia general de la compañía.

-Monitorizar y escuchar. Detectar donde están los usuarios que conversan sobre la empresa, en que blogs y redes sociales, además de seguir las conversaciones que tienen lugar en la red relacionadas con la empresa y el sector.

-Participar en las conversaciones pertinentes iniciadas por los usuarios y responder a las dudas y comentarios que estos hagan con la mayor brevedad temporal posibles.

-Crear y compartir. Generar y distribuir -tanto en plataformas creadas por la empresa como generalistas- contenidos propios sobre 
temas relacionados con la empresa, pero sin caer en el discurso corporativo. Iniciar nuevas conversaciones si lo considera oportuno.

-Relacionarse y conectar. Ponerse en contacto con bloggers y usuarios que tratan habitualmente temas relacionados con la empresa en la red, de manera transparente y solicitando permiso. Establecer una relación directa y honesta con estos líderes de opinión.

-Moderar y dinamizar. Incentivar la conversación cuando la participación de los usuarios disminuya. Moderar el parloteo si fuera necesario.

-Posicionarse. Representar a la empresa, y dejar clara su posición en la red, sin llegar a ser un portavoz corporativo, sino un embajador próximo.

\section{Análisis y comparativa de la presencia en redes sociales de los principales canales de televisión de España y Ecuador}

La televisión avanza en un paradigma híbrido e convergente de servicios audiovisuales en los que Internet se convierte en el ecosistema central al ofrecer nuevos modelos tecnológicos como la televisión conectada, o Streaming TV o la Smart TV.

Observando el panorama actual de consumo de contenidos audiovisuales y con el objetivo principal de saber como están gestionando su presencia los principales canales de televisión tanto de España como de Ecuador mostraremos un estudio basado en las cifras obtenidas directamente de las cuentas oficiales de los canales en las siguientes redes sociales: Twitter, Facebook, Google+, Tuenti y Youtube. Además analizamos la primera noticia de cada medio en las web oficiales para comprobar a través de que plataformas permiten compartir dicho contenido.

Para continuar con la presentación de los datos, debemos señalar que actualmente no están activos algunos de los canales españoles que forman parte de la investigación. De este modo, entre los meses de abril y mayo de 2014 y tras la aplicación de una sentencia del Tribunal Supremo de España, en virtud de una orden del Ministerio de Industria del gobierno español, nueve cadenas de la TDT (Televisión Digital Terrestre) fueron obligadas a cerrar.

Así, Atresmedia tuvo que dejar de emitir contenidos en los canales Xplora, Nitro y LaSexta3, Mediaset cesó las emisiones de La Siete y Nueve y Veo prescindió de AXN -a partir de ahora en 
plataformas de pago- y de Marca TV. De Net TV, en febrero de 2014 desapareció MTV y también Intereconomía -actualmente en soportes de pago y en dos cadenas locales de Madrid e Valencia-. Todos estos canales fueron adjudicados en 2010 sin que se convocara concurso público.

Con todo, desde principios de 2014 y tras la compra del 25\% de multiplex de Net TV, de Intereconomía, Real Madrid TV intentaron emitir contenidos en abierto a través de TDT.

Sumado a esto cabe señalar que los datos correspondientes a los canales de televisión de España fueron analizados en diciembre de 2013, mientras los obtenidos de las cuentas oficiales en redes sociales de los canales de Ecuador son de septiembre del año 2014 por lo que hay que tener en cuenta que a día de hoy las cifras son mayores, sobre todo en el primer caso. No obstante, consideramos que todo eso no desvirtúa el fondo de la investigación.

Tras esta aclaración exponemos los resultados del estudio sabiendo que en la actualidad el consumo audiovisual no lineal es una tendencia evidente desde hace más de un lustro y así se incrementa cada día más la circulación y descarga de vídeos a través das redes también.

A la hora de hablar de seguidores en Twitter, las cadenas españolas que encabezan la lista son: MTV con 2.725.564 seguidores, el grupo RTVE con 614.956, Antena 3 con 581.233, Telecinco con 366.741 y La Sexta con 302.681. El canal que más personas sigue es Telecinco con 1.287 mientras el grupo que mayor número de listas tiene es RTVE con 21 y Telecinco que ocupa el segundo lugar con 13.

En esta misma red social, pero con respecto a los canales ecuatorianos, debemos resaltar la cadena Ecuavisa, que lidera la lista de seguidores con un total de 948.726 seguidores, una cifra importante ya que MTV, al ser reconocido en un contorno geográfico mayor que España y ser originariamente estadounidense, puede contar con seguidores no potenciales, es decir, que no participen activamente en la red y que además no hagan referencia a temas propios de España. A todo esto se suma la temática musical de la cadena televisiva MTV. 
Tabla 1: Datos de las cuentas oficiales en las principales redes sociales correspondientes a las cadenas de televisión españolas

\begin{tabular}{|c|c|c|c|c|c|c|c|c|c|c|c|c|c|c|}
\hline & \multirow[b]{2}{*}{ Cadenas } & \multicolumn{5}{|c|}{ Twitter (Datos cuenta principal) } & \multicolumn{3}{|c|}{ Facebook } & \multicolumn{2}{|c|}{ Google +} & \multirow[b]{2}{*}{$\begin{array}{l}\text { Tuenti } \\
\begin{array}{c}\text { Seguid } \\
\text { ores }\end{array}\end{array}$} & \multirow[b]{2}{*}{$\begin{array}{l}\text { Youtube } \\
\begin{array}{c}\text { Reproducci } \\
\text { ones }\end{array}\end{array}$} & \multirow[b]{2}{*}{$\begin{array}{c}\text { Permite } \\
\text { compartir } \\
\text { contenidos a } \\
\text { través de otras } \\
\text { redes como... }\end{array}$} \\
\hline & & $\begin{array}{l}\text { Seguid } \\
\text { ores }\end{array}$ & $\begin{array}{l}\text { Siguie } \\
\text { ndo }\end{array}$ & $\begin{array}{l}\text { List } \\
\text { as }\end{array}$ & $\begin{array}{l}\text { Twe } \\
\text { ets }\end{array}$ & $\begin{array}{l}\text { Cuen } \\
\text { tas }\end{array}$ & $\begin{array}{c}\text { Página/p } \\
\text { erfil }\end{array}$ & $\begin{array}{l}\text { Seguid } \\
\text { ores }\end{array}$ & $\begin{array}{c}\text { Edad } \\
+ \\
\text { frecue } \\
\text { nte }\end{array}$ & $\begin{array}{l}\text { Seguid } \\
\text { ores }\end{array}$ & $\begin{array}{l}\text { Perso } \\
\text { nas a } \\
\text { las } \\
\text { que } \\
\text { tienen } \\
\text { en } \\
\text { Círcul } \\
\text { os }\end{array}$ & & & \\
\hline 1. & RTVE & 614956 & 186 & 21 & $\begin{array}{c}4871 \\
8 \\
\end{array}$ & 1 & PÁG & 284883 & $25-44$ & 508066 & $\begin{array}{c}45352 \\
9 \\
\end{array}$ & $72802 *$ & 246880222 & $\begin{array}{l}\text { MENÉAME, } \\
\text { DELICIOUS }\end{array}$ \\
\hline 2. & LA 1 & 134583 & 47 & 2 & 7252 & 1 & $\mathrm{TM}$ & 17425 & - & - & - & - & - & $\begin{array}{l}\text { MENÉAME, } \\
\text { DELICIOUS, } \\
\text { TUENTI, G+ }\end{array}$ \\
\hline 3. & LA 2 & 107292 & 92 & 3 & $\begin{array}{c}1256 \\
6\end{array}$ & 1 & PÁG & 18603 & $25-44$ & - & - & - & - & $\begin{array}{l}\text { MENÉAME, } \\
\text { DELICIOUS, } \\
\text { TUENTI, G+ }\end{array}$ \\
\hline 4. & CANAL $24 \mathrm{H}$ & 272640 & 44 & 3 & $\begin{array}{c}3563 \\
5\end{array}$ & 1 & $\mathrm{TM}$ & 11594 & - & - & - & - & - & $\begin{array}{l}\text { MENÉAME, } \\
\text { DELICIOUS, } \\
\text { TUENTI, G+ }\end{array}$ \\
\hline 5. & $\begin{array}{l}\text { TELEDEPOR } \\
\text { TE }\end{array}$ & 119606 & 165 & 11 & $\begin{array}{c}1146 \\
2\end{array}$ & 1 & - & - & - & - & - & - & - & $\begin{array}{l}\text { MENÉAME, } \\
\text { DELICIOUS, } \\
\text { TUENTI, G+ }\end{array}$ \\
\hline 6. & CLAN & 14920 & 12 & 1 & 1317 & 1 & TM & 27831 & - & - & - & - & - & - \\
\hline 7. & A3 MEDIA & - & - & - & - & - & - & - & - & - & - & - & - & - \\
\hline 8. & ANTENA 3 & 581233 & 192 & 3 & $\begin{array}{c}1838 \\
0\end{array}$ & 1 & PÁG & 809539 & $18-24$ & 38649 & 31676 & $19967^{*}$ & 682547012 & MENÉAME \\
\hline 9. & LA SEXTA & 302681 & 382 & 6 & $\begin{array}{c}2134 \\
4 \\
\end{array}$ & 1 & PÁG & 162488 & $18-24$ & 3853 & 598 & $2763^{*}$ & 153445137 & MENÉAME \\
\hline $\begin{array}{l}1 \\
0 .\end{array}$ & LA SEXTA 3 & 109711 & 312 & 0 & 8880 & 1 & PÁG & 22910 & $25-34$ & - & - & - & - & $\begin{array}{l}\text { MENÉAME, } \\
\text { TUENTI, G+ }\end{array}$ \\
\hline $\begin{array}{l}1 \\
1 .\end{array}$ & XPLORA & 16126 & 14 & 0 & 1106 & 1 & PÁG & 20508 & $25-34$ & - & - & - & - & $\begin{array}{l}\text { MENÉAME, } \\
\text { TUENTI, G+ }\end{array}$ \\
\hline $\begin{array}{l}1 \\
2 .\end{array}$ & NEOX & 161105 & 83 & 0 & 1404 & 1 & PÁG & 73458 & $18-24$ & - & - & - & - & $\begin{array}{l}\text { MENÉAME, } \\
\text { TUENTI,G+ }\end{array}$ \\
\hline $\begin{array}{l}1 \\
3 . \\
\end{array}$ & NOVA & 5428 & 191 & 4 & $\begin{array}{c}1052 \\
0 \\
\end{array}$ & 1 & PÁG & 1064 & $18-24$ & - & - & - & - & $\begin{array}{l}\text { MENÉAME, } \\
\text { TUENTI,G+ }\end{array}$ \\
\hline $\begin{array}{l}1 \\
4 .\end{array}$ & NITRO & 15226 & 74 & 0 & 441 & 1 & PÁG & 15746 & $25-44$ & - & - & - & - & $\begin{array}{l}\text { MENÉAME, } \\
\text { TUENTI,G+, }\end{array}$ \\
\hline $\begin{array}{l}1 \\
5 .\end{array}$ & MEDIASET & 12386 & 418 & 2 & 2892 & 1 & PÁG & 2176 & $25-34$ & 614 & 563 & 53 & - & $\begin{array}{l}\text { MENÉAME, } \\
\text { DELICIOUS }\end{array}$ \\
\hline $\begin{array}{l}1 \\
6 .\end{array}$ & TELECINCO & 366741 & 1287 & 13 & $\begin{array}{c}2500 \\
3 \\
\end{array}$ & 1 & PÁG & 517774 & $18-24$ & 271988 & $\begin{array}{c}26170 \\
7\end{array}$ & $36621^{*}$ & 1770 & $\begin{array}{l}\text { MENÉAME, } \\
\text { DELICIOUS }\end{array}$ \\
\hline $\begin{array}{l}1 \\
7 . \\
\end{array}$ & CUATRO & 189928 & 522 & 9 & $\begin{array}{c}1625 \\
6 \\
\end{array}$ & 1 & PÁG & 383197 & $18-24$ & 3273 & 2424 & $35413 *$ & - & $\begin{array}{l}\text { MENÉAME, } \\
\text { DELICIOUS }\end{array}$ \\
\hline $\begin{array}{l}1 \\
8 .\end{array}$ & FDF & 70957 & 88 & 0 & 4696 & 1 & PÁG & 161414 & $18-24$ & 88 & 80 & - & - & $\begin{array}{c}\text { MENÉAME, } \\
\text { DELICIOUS, } \\
\text { TUENTI }\end{array}$ \\
\hline $\begin{array}{l}1 \\
9 . \\
\end{array}$ & LA SIETE & 26138 & 27 & 0 & 186 & 1 & PÁG & 12869 & $18-24$ & - & 11 & - & - & $\begin{array}{l}\text { MENÉAME, } \\
\text { DELICIOUS, } \\
\text { TUENTI, G+ }\end{array}$ \\
\hline $\begin{array}{l}2 \\
0 .\end{array}$ & BOING & 15280 & 173 & 0 & 7980 & 1 & PÁG & 79173 & $18-24$ & - & - & $7368^{*}$ & 1005458 & - \\
\hline $\begin{array}{l}2 \\
1 .\end{array}$ & DIVINITY & 136976 & 707 & 3 & $\begin{array}{c}1475 \\
9\end{array}$ & 1 & PÁG & 127257 & $25-34$ & 809 & 647 & $2164^{*}$ & - & $\begin{array}{c}\text { MENÉAME, } \\
\text { DELICIOUS, } \\
\text { TUENTI }\end{array}$ \\
\hline $\begin{array}{l}2 \\
2 .\end{array}$ & ENERGY & 23639 & 84 & 0 & 1638 & 1 & PÁG & 20786 & $25-34$ & 507 & 461 & - & - & $\begin{array}{c}\text { MENÉAME, } \\
\text { DELICIOUS, } \\
\text { TUENTI }\end{array}$ \\
\hline $\begin{array}{l}2 \\
3 . \\
\end{array}$ & NUEVE & 6275 & 72 & 0 & 38 & 1 & PÁG & 1310 & $25-34$ & - & - & - & - & 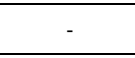 \\
\hline $\begin{array}{l}2 \\
4 . \\
\end{array}$ & $13 \mathrm{TV}$ & 19981 & 242 & 3 & 5445 & 1 & PÁG & 11283 & $35-44$ & 2 & 2 & $17 *$ & 1203412 & - \\
\hline $\begin{array}{l}2 \\
5 .\end{array}$ & $\begin{array}{l}\text { DSICOVERY } \\
\text { MAX }\end{array}$ & 34946 & 835 & 0 & 6780 & 1 & PÁG & 341335 & $25-34$ & - & 77 & $581^{*}$ & 1371941 & $\begin{array}{l}\text { FACEBOOK. } \\
\text { TWITTER }\end{array}$ \\
\hline $\begin{array}{l}2 \\
6 . \\
\end{array}$ & $\begin{array}{l}\text { INTERECON } \\
\text { OMÍA } \\
\end{array}$ & 94381 & 181 & 3 & $\begin{array}{c}2631 \\
5 \\
\end{array}$ & 1 & PÁG & 78267 & $35-44$ & 3058 & 1681 & $168^{*}$ & 538542 & DELICIOUS \\
\hline $\begin{array}{l}2 \\
7 . \\
\end{array}$ & $\begin{array}{c}\text { DISNEY } \\
\text { CHANNEL } \\
\end{array}$ & 4220 & 116 & 7 & 2161 & 1 & PÁG & 158198 & $18-24$ & 869 & 97 & - & 15603779 & - \\
\hline $\begin{array}{l}2 \\
8 .\end{array}$ & MTV & $\begin{array}{c}272556 \\
4\end{array}$ & 678 & 2 & 8903 & 1 & PÁG & 626984 & $18-24$ & - & - & 1220 & 186352 & PINTEREST \\
\hline $\begin{array}{l}2 \\
9 . \\
\end{array}$ & $\begin{array}{l}\text { PARAMOUN } \\
\text { T CHANNEL }\end{array}$ & 29118 & 228 & 0 & $\begin{array}{c}1068 \\
3 \\
\end{array}$ & 1 & PÁX & 17215 & $25-34$ & - & - & $661^{*}$ & 13141 & $\begin{array}{c}\text { FACEBOOK, } \\
\text { G+ } \\
\end{array}$ \\
\hline
\end{tabular}

Fuente: Elaboración propia a partir de las cuentas oficiales de los canales de televisión 
Tabla 2: Datos de las cuentas oficiales en las principales redes sociales correspondientes a las cadenas de televisión ecuatorianas

\begin{tabular}{|c|c|c|c|c|c|c|c|c|c|c|c|c|c|c|}
\hline & \multirow[b]{2}{*}{ Cadenas } & \multicolumn{5}{|c|}{ Twitter (Datos cuenta principal) } & \multicolumn{3}{|c|}{ Facebook } & \multicolumn{2}{|c|}{ Google +} & \multirow[b]{2}{*}{$\begin{array}{l}\text { Tuenti } \\
\\
\text { Segui } \\
\text { dores }\end{array}$} & \multirow{2}{*}{$\begin{array}{l}\text { Youtube } \\
\text { Reproduc } \\
\text { ciones }\end{array}$} & \multirow[b]{2}{*}{$\begin{array}{c}\text { Permite } \\
\text { compartir } \\
\text { contenidos } \\
\text { a través de } \\
\text { otras redes } \\
\text { como... }\end{array}$} \\
\hline & & $\begin{array}{l}\text { Segui } \\
\text { dores }\end{array}$ & $\begin{array}{l}\text { Sigui } \\
\text { endo }\end{array}$ & $\begin{array}{l}\text { Lis } \\
\text { tas }\end{array}$ & $\begin{array}{l}\text { Twe } \\
\text { ets }\end{array}$ & $\begin{array}{l}\text { Cue } \\
\text { ntas }\end{array}$ & $\begin{array}{l}\text { Página/ } \\
\text { perfil }\end{array}$ & $\begin{array}{l}\text { Segui } \\
\text { dores }\end{array}$ & $\begin{array}{c}\text { Edad } \\
+ \\
\text { frecu } \\
\text { ente }\end{array}$ & $\begin{array}{l}\text { Segui } \\
\text { dores }\end{array}$ & $\begin{array}{l}\text { Pers } \\
\text { onas } \\
\text { a las } \\
\text { que } \\
\text { tiene } \\
\mathrm{n} \text { en } \\
\text { Círc } \\
\text { ulos }\end{array}$ & & & \\
\hline 1 & $\begin{array}{c}\text { ECUAVIS } \\
\text { A }\end{array}$ & $\begin{array}{c}98472 \\
6\end{array}$ & 756 & 5 & $\begin{array}{c}961 \\
05\end{array}$ & 1 & PÁG & $\begin{array}{c}14372 \\
89\end{array}$ & $\begin{array}{l}18- \\
24\end{array}$ & 1314 & - & - & 3778190 & $\begin{array}{c}\text { TWITTER, } \\
\text { FACEBOO } \\
\mathrm{K}, \mathrm{G}^{+}\end{array}$ \\
\hline 2 & $\begin{array}{l}\text { TELEAMA } \\
\text { ZONAS }\end{array}$ & $\begin{array}{c}83361 \\
6\end{array}$ & 421 & 11 & $\begin{array}{c}841 \\
99\end{array}$ & 1 & PÁG & $\begin{array}{c}93217 \\
3\end{array}$ & $\begin{array}{l}18- \\
24\end{array}$ & 674 & 8 & - & 8717639 & $\begin{array}{c}\text { TWITTER, } \\
\text { FACEBOO } \\
\mathrm{K}, \mathrm{G}^{+}\end{array}$ \\
\hline 3 & TC TV & $\begin{array}{c}51564 \\
4\end{array}$ & 1002 & 5 & $\begin{array}{c}515 \\
15\end{array}$ & 1 & PÁG & $\begin{array}{c}10431 \\
59\end{array}$ & $\begin{array}{l}18- \\
24\end{array}$ & 498 & 47 & - & $\begin{array}{c}1030475 \\
6\end{array}$ & $\begin{array}{c}\text { TWITTER, } \\
\text { FACEBOO } \\
\mathrm{K}, \mathrm{G}^{+}\end{array}$ \\
\hline 4 & GAMA TV & $\begin{array}{c}22570 \\
9\end{array}$ & 3074 & 2 & $\begin{array}{c}383 \\
21\end{array}$ & 1 & PÁG & $\begin{array}{c}30115 \\
8\end{array}$ & $\begin{array}{l}18- \\
24\end{array}$ & 220 & 2 & - & 3677108 & $\begin{array}{c}\text { TWITTER, } \\
\text { FACEBOO } \\
\mathrm{K}, \mathrm{G}^{+}\end{array}$ \\
\hline 5 & RTS & $\begin{array}{c}32409 \\
6\end{array}$ & 3560 & 39 & $\begin{array}{c}103 \\
13\end{array}$ & 1 & PÁG & $\begin{array}{c}77983 \\
3\end{array}$ & $\begin{array}{l}18- \\
24\end{array}$ & - & - & - & 7143777 & - \\
\hline 6 & RTU & 90358 & 33515 & 7 & $\begin{array}{l}233 \\
880\end{array}$ & 1 & PÁG & 10596 & $\begin{array}{l}18- \\
24\end{array}$ & 263 & 178 & - & $\begin{array}{c}1946028 \\
5\end{array}$ & $\begin{array}{c}\text { FACEBOO } \\
\mathrm{K}\end{array}$ \\
\hline 7 & $\begin{array}{c}\text { TELERAM } \\
\text { A }\end{array}$ & 46611 & 533 & 1 & $\begin{array}{c}185 \\
03\end{array}$ & 1 & PÁG & 3573 & $\begin{array}{l}18- \\
34\end{array}$ & 82 & 2 & - & 507435 & - \\
\hline 8 & $\begin{array}{c}\text { ECUADOR } \\
\text { TV }\end{array}$ & $\begin{array}{c}21385 \\
4\end{array}$ & 1191 & 1 & $\begin{array}{c}114 \\
95\end{array}$ & 1 & PÁG & $\begin{array}{c}20693 \\
0\end{array}$ & $\begin{array}{l}18- \\
24\end{array}$ & 198 & - & - & - & $\begin{array}{c}\text { TWITTER, } \\
\text { FACEBOO } \\
\text { K... }\end{array}$ \\
\hline
\end{tabular}

Fuente: Elaboración propia a partir de las cuentas oficiales de los canales de televisión

\section{* TM: Tema en Facebook}

En segundo lugar estaría con 833.616 el canal Teleamazonas, seguido de TC TV con 525.644 y RTS con 324.096 seguidores. Los restantes canales analizados tienen menos de 200.000 seguidores. Con respecto a las personas que siguen estos medios de comunicación hay que resaltar RTU que, a pesar de no superar los 91.000 seguidores, se preocupa por buscar seguidores con los que mantener un feedback al seguir a 33.515 personas. En cuanto a listas, RTS supera al grupo español RTVE en 8 listas, quedando así con 39 el canal ecuatoriano.

Si hablamos de tweets, RTVE con 48.718 y RTU, que cuenta con 233.880 son los dos medios con mayor número de tweets. Así, observamos que la actividad de los canales españoles en comparación con los ecuatorianos es menor. Así son pocos los medios que superan los 10.000 tweets, cifra que consigue RTS ocupando la última posición del ránking de los canales en Ecuador. 
Con respecto a Facebook hay que señalar que ahora, además de perfil o página, hay que tener en cuenta los denominados temas. Estos modelos son páginas descriptivas de algún tema en concreto y son generadas automáticamente por Facebook basándose en los intereses de los usuarios de la plataforma Facebook, sin estar afiliados ni avalados por ningún ente asociado con el tema o empresa comunicativa. Con todo, son las páginas las que mayor número de seguidores presentan. Antena 3 con 809.539 seguidores, MTV con 626.984 y Telecinco con 517.774 encabezan la lista. La restantes cuentan con menos de 390 mil seguidores.

$\mathrm{Si}$ nos centramos en las cuentas propias de los canales televisivos de Ecuador, comprobamos que todos gestionan páginas. Ecuavisa lidera así el ránking de seguidores con 1.437.289 y TC TV se posiciona en segundo lugar con 1.043.159. En este ritmo Teleamazonas es seguido por un total de 932.173, RTS por 779.833 y Gama TV por 301.158. Si comparamos los resultados podemos concluir que los canales españoles tienen menor peso en esta plataforma y prueba de ello es que Antena 3, canal que lidera el número de seguidores del total analizado en España, es superada por los tres canales ecuatorianos que encabezan la lista de la muestra escogida para este país sudamericano.

En lo relativo a la franja de edad más frecuente en canales televisivos españoles podemos decir que es menor si la comparamos con estudios realizados sobre medios impresos españoles. Así, los intervalos que comprenden desde la mayoría de edad hasta los 34 años son los que mayor número de repeticiones presentan. Los canales ecuatorianos mantienen una tendencia con respecto a la franja de edad y, salvo algunas excepciones, esta se sitúa entre los 18-24 años.

Del total de canales seleccionados en España, sólo 12 gestionan cuenta en Google+, mientras casi el total de la muestra elegida en Ecuador -excepto RTS- apuesta por esta plataforma para la interacción y distribución de contenidos periodísticos. En red digital española Tuenti las televisiones ecuatorianas no figuran mientras en las españolas son 11 los canales que poseen cuentas oficiales identificadas mediante un asterisco- por lo que concluimos que esta red no convence a los medios de comunicación, principalmente por el perfil de usuario adolescente al que va dirigida. 
En ambas redes digitales (G+ y Tuenti) el grupo público RTVE es el que mayor número de seguidores presenta y en Google+ cuenta con 508.066 seguidores frente a los 1.314 de Ecuavisa. Estos datos muestran como lo importante no es que los medios de comunicación creen cuentas en redes sociales simplemente sino la interacción. Lo realmente importante es conseguir gestionar una comunidad de seguidores, que interactúen con otros lectores y que sepan que ahí pueden informase y compartir contenidos. Es decir, lo importante no es la cuenta sino la comunidad y su interacción. Esta idea es simple, pero no siempre la entienden las empresas.

Finalmente los datos de reproducciones en Youtube denotan una mayor atención por parte de los canales de televisión en comparación con estudios de prensa. Aquí es visible el carácter audiovisual de los canales de televisión al ya disponer de material propio, sin tener que abastecerse de otros medios o agencias para cubrir los contenidos de las plataformas digitales basadas en audio y vídeo.

Antena 3 con 682.547.012 reproducciones encabeza la lista de las televisiones en España, donde también destaca RTVE con 246.880.222 y La Sexta con 153.445.137 reproducciones. Si comparamos estos datos con el diario deportivo por excelencia en España, Marca, el cual contaba con 11.444 .900 reproducciones, observamos que la diferencia es notable e indicativa de la necesidad de contenidos audiovisuales que tienen los medios escritos. Además, en esta situación, al ser el deporte el tema principal de este medio de comunicación podría jugar con ventaja y ofrecer una información más completa y gráfica.

RTU con 19.460.285 reproducciones destaca junto a TC TV con 10.304.756 en la actividad de los canales ecuatorianos a través de Youtube. Así, la tendencia de los medios escritos españoles sirve para extrapolar a los medios audiovisuales en Ecuador que todavía saben sacar poco partido a la que sería la red que mejor se adapta para la distribución de contenido televisivo, por estar centrada únicamente material audiovisual y no literario.

Atendiendo a los datos obtenidos de los canales de televisión españoles, observamos que de los grupos de comunicación, solo RTVE gestiona cuentas en las cinco redes analizadas, junto a los medios Antena 3, La Sexta, Telecinco y 13TV. La mayoría de los 
canales de televisión solo gestionan dos o una única red social, que en la mayor parte de los casos se corresponde con la plataforma de mensajes cortos, Twitter.

Así, la media de cuentas que gestionan los principales canales de televisión españoles es de 2,7 cuentas, una cifra muy baja si la comparamos con los resultados de prensa española que se sitúa en las 3,2 cuentas o de las emisores de radio de España que supera la presencia en redes sociales de los medios ya citados al contar con un promedio de cuatro cuentas, cifra que también comparten los canales ecuatorianos analizados que no actúan en la plataforma Tuenti.

A pesar de todo lo analizado hay que tener en cuenta que la estrategia de gestión de RTVE destaca sobre las demás. Al tratarse de un grupo cuya financiación no está relacionada con la publicidad, puede desarrollar una política de emisión de contenidos más abierta que las das cadenas privadas, a través de Internet.

En paralelo a esto, se va asentando la estrategia general de publicidad en Youtube. A finales de 2013 esta lanzaba una campaña de aproximación a las principales marcas con el objetivo de incrementar los ingresos en Europa.

Hay que aclarar también que los canales de televisión tienen cuentas específicas para programas, series o informativos. Esta especialización de los contenidos, por temática o por programa, es algo positivo para el canal de televisión ya que así se conoce con mayor exactitud el público al que se dirige. Esto funciona también a la hora de hablar de las transmisiones en directo o diferido, donde el público interactúa con el medio y comenta lo que están viendo todos los interesados en el contenido a la misma hora.

\section{Conclusiones y propuestas de mejora}

- Las redes sociales que actualmente gestionan los principales canales de televisión españoles y ecuatorianos son Twitter y Facebook, mientras Tuenti no es considerado por las televisiones de Ecuador, que muestran mayor interés que las españolas por estar presentes en Youtube.

- El agregador Menéame es una de las plataformas para compartir contenidos más usadas por los canales de televisión españoles mientras en los de Ecuador se limitan a 
las redes en las que tienen cuentas sin buscar la presencia en agregadores de noticias.

- Las redes sociales funcionan como refuerzo de los canales televisivos pero los medios aún no alcanzan el nivel de conversación. Para concretar más esta cuestión habría que analizar por ejemplo si los canales usan etiquetas para hablar de determinadas emisiones como los programas de entretenimiento o las noticias de los informativos. El hashtag así como las listas en Twitter pueden ser un buen referente a la hora de saber si el medio sabe sacar partido a las nuevas herramientas. Después de este estudio observamos la situación de las listas y concluimos que los canales de Ecuador tienen un mayor dominio de esta herramienta. De todos modos, es necesario saber si el community manager o los periodistas intervienen de forma activa o simplemente se dedican a la exposición de contenidos.

- La actualización de los contenidos es mayor en los canales ecuatorianos que en los españoles y prueba de ello es la media de tweets.

\section{Referencias bibliográficas}

Aced, C. (2010): Perfiles profesionales 2.0. Madrid: UOC.

BBC (2012): "English Regions Socia Media Strategy", en:

http://downloads.bbc.co.uk/rmhttp/london/pdf/er social media st rategy 2012.pdf

Castells, M. (2001): La Galaxia Internet. Barcelona: Plaza y Janés.

Castells, M. (2009): Comunicación y poder. Madrid: Alianza Editorial.

Boyd, D. y Ellison, N. (2007): "Social Network Sites:

Definition, History, and Scholarship", en Journal of Computer-Mediated Communication, 13 (1), artículo 11. Recuperado el 20 de noviembre de 2013 de http://www.danah.org/papers/JCMCIntro.pdf

Boyd, D. y Ellison, N. (2013): "Sociality through Social Network Sites". En VV.AA., The Oxford Handbook of Internet Studies (Ed.: W. Dutton H.). Oxford: Oxford University Press.

Cabrera González, M. A. (Coord.) (2013): Evolución de los cibermedios. De la convergencia digital a la distribución multiplataforma. Madrid: Fragua. 
Ellison, N. B., Lampe, C. y Steinfield, C. (2009): "Social Network Sites and Society: Current Trends and Future Possibilities", en The Potential For Technology- Enabled Connections Enero- Febrero de 2009, Michigan. Recuperado el 25 marzo de 2014 de http://wwwpersonal.umich.edu/ enicole/EllisonLampeSteinfield2009.pdf Gillmor, D. (2005): Nós, os media. Lisboa: Presenta.

Lozano Aguiar, L. (2014): La gestión de la prensa española diaria de pago ante las redes sociales digitales. Trabajo de fin de Grado en Periodismo. Universidad de Santiago de Compostela. Santiago de Compostela.

Orihuela, J. L. (2012): 80 claves sobre el futuro del periodismo. Madrid: Anaya.

Salaverría, R. (2010): "Estructura de la convergencia". En VV.AA., Convergencia digital. Reconfiguración de los medios de comunicación en España (Coords., X. López García y X. Pereira Fariña): Santiago de Compostela: Servicio de Publicaciones e Intercambio Científico. 


\section{La gestión de las redes sociales en los servicios de radiodifusión públicos europeos}

Tania Fernández Lombao, Universidad de Santiago de Compostela (USC, España), t.lombao@gmail.com

Andrea Valencia Bermúdez, Universidad de Santiago de Compostela (USC, España), andrea.v.bermudez@gmail.com

\section{Resumen}

La transformación que viven los medios audiovisuales de forma generalizada, en parte como resultado de la llegada de la sociedad en red y la conectividad, influye decisivamente en los modelos hasta ahora vigentes. El presente trabajo analiza la gestión actual de las redes sociales en los servicios públicos de radiodifusión nacionales de Europa. En la primera parte del artículo se presenta una introducción al concepto de red de interacción social así como su incidencia en los medios de comunicación tradicionales. Partiendo de esa base, y entendiendo que atravesamos un proceso complejo y acelerado de transición digital, se realiza en la segunda parte un análisis cuantitativo y cualitativo de las redes sociales de cada una de las corporaciones públicas europeas, incidiendo no sólo en su presencia, impacto, e interacción con el usuario, sino también en las estrategias que cada uno de los grupos emplea sus redes sociales corporativas. Mientras algunas corporaciones como la BBC las utilizan como herramienta de búsqueda de una mayor complicidad, fidelización, y empoderamiento de sus audiencias, otros como RTVE las usan como simples difusores de contenidos.

Palabras clave: servicio público de radiodifusión, redes sociales, transformación, gestión. 


\section{Introducción}

— L panorama actual de la comunicación evidencia una necesaria los últimos años hemos asistido a un baile tecnológico al que se han tenido que unir tanto los medios tradicionales como los nativos digitales, lo que nos lleva a predecir un panorama de mudanza constante que cada vez contará con más elementos, campos y redes entrelazadas (López, 2005). Dentro de esos cambios se encuentran las redes sociales (referidas en su conjunto como social media), una semilla germinada tras la crisis de crecimiento de internet (Campos, 2008), que con el paso de los años se han diversificado (generalistas o temáticas) y convertido en instrumento principal de la narración transmedia.

Ahora los medios de comunicación tradicionales tienen como misión añadida el contar historias a través de múltiples soportes y plataformas, adaptándose así a las particularidades de cada uno. Es una preocupación que se muestra en el informe sobre medios sociales de la UER (2014), que subraya la necesidad de que los servicios de radiodifusión públicos lleven a cabo estrategias en las áreas de redes sociales, interactividad, y periodismo multiplataforma. Para hacer frente a estos desafíos, señala la institución, se puso en marcha la VISION2020, no solo para identificar cómo los medios públicos pueden continuar actuando como elementos imprescindibles para el mantenimiento de la democracia y los valores de una sociedad, sino también para fijar el futuro de estos servicios en lo que Castells (2001) denominó la sociedad red.

La metáfora de la que se sirve la UER para explicar la tendencia de este nuevo escenario digital (las capas de la cebolla) es idónea para visualizar el estado cambiante del nuevo mundo, donde las comunidades y grupos se reúnen en torno a valores, gustos, o intereses y los comparten e interactúan a través de medios sociales.

En este sentido, los servicios públicos de radiodifusión deberán hacer frente, en principio, a cuatro desafíos: el cambio hacia un contenido más personalizado y bajo demanda, la llegada de plataformas globales de reproducción, las presiones del público que 
exige un beneficio sobre lo que gasta, y la degradación del papel de estos servicios, que ven cómo desciende la confianza de las audiencias.

Lo que parece inevitable es la mudanza de audiencias hacia el nuevo escenario mediático digital. Un estudio reciente de la Pew Research Center (2013) pone de manifiesto el uso creciente de redes sociales como medio de comunicación: de entre 1.800 adultos encuestados en español e inglés, el $42 \%$ usa varias redes sociales, y Facebook se erige como la dominante. Otra investigación a cargo del Banco Mundial (2014), señala que cerca del 30\% de la población mundial usa redes sociales, 7.046 billones de usuarios. En 2017, de acuerdo a lo apuntado por eMarketer (2013), una de cada siete personas en el mundo usa redes sociales.

\section{Radiotelevisión pública y redes sociales}

Las radiotelevisiones públicas de la Unión Europea comenzaron sus emisiones de forma generalizada en las décadas de los cincuenta y sesenta del pasado siglo, llamadas a capitalizar los valores democráticos o, por el contrario, a dar voz a las premisas de regímenes totalitarios, como la RTVE en España (1956). Un pequeño grupo formado por siete corporaciones (la BBC de Reino Unido, dos nórdicas, las dos belgas, la austríaca y la croata) arrancaron emisiones años antes de la Segunda Guerra Mundial y sentaron las bases del servicio público de radiodifusión.

El desgaste económico, tecnológico y de gestión de las radiotelevisiones públicas ha derivado en que estos medios hayan dejado de abanderar en solitario la misión de servicio público para quedar inmersas en una crisis sobre su propia legitimidad, que no deja claro cuál será el modelo del futuro. En estas aguas, y desde el inicio del siglo XXI, Internet se ha convertido en el principal acceso al conocimiento, a la información y al entretenimiento y ha obligado a estos entes a tenerlas en cuenta como espacios de mediación, relación y negocio.

Tras las reticencias iniciales ante los social media y la incertidumbre sobre su futuro, los medios tradicionales han decidido hacer acto de presencia en lugares en los que sus contenidos tienen un público potencial de millones de usuarios.

La irrupción de las redes sociales y su masiva implantación desde hace poco más de cinco años como herramientas de intermediación e 
interactividad ha sido el germen de una nueva fase, la postmediática, que se caracteriza por una sociedad de servicios muy veloz en la que la atención aparece "más segmentada, personalizada, instantánea, diluida, convergente, transparente, flexible, liviana, conversacional, interconectada y abocada a la colaboración, participación y trivialización” (Campos Freire, 2008).

Las principales características de las redes sociales se centran en el concepto de comunidad, a través de la creación de conexiones de usuarios que interactúan, dialogan y aportan comunicación y conocimiento. Todo ello, gracias a una tecnología flexible y un ancho de banda necesario para el intercambio de información y estándares web de aplicación libre y una arquitectura que favorece la creación de aplicaciones complejas a un menor coste y de forma más rápida.

A la complejidad de las redes sociales hay que sumar la evolución del teléfono móvil que, "a través de nuevos terminales más atractivos ha transformado a los celulares de meros teléfonos para hablar en auténticas plataformas multimedia portátiles" (Vacas, 2010).

Alba Silva (2013) detecta que la capacidad de movilidad que permite y el hecho de poder estar siempre conectado ha sido un aspecto clave para el éxito de su socialización. El teléfono móvil es además el soporte por excelencia para la consulta de las redes sociales.

La movilidad es la característica intrínseca que más ha influido en los cambios sociales asumidos por los individuos. De hecho, Martínez y Aguado (2008) apuntan que esta particularidad "constituye un motor suficiente para apuntar hacia un papel aglutinador de las comunidades móviles en el proceso de convergencia que caracteriza al ecosistema informativo".

Estas novedades en el espectro tecnológico han influido significativamente en la gestión de la comunicación empresarial, en la relación con los grupos de interés e incluso en el periodismo. Los retos han traído consigo el afloramiento de nuevas exigencias por parte de los individuos, que cada día reclaman más instantaneidad y evolución sin que ello acarree pérdida de calidad.

\subsection{Los nuevos servicios de las radiotelevisiones públicas}

El actual contexto tecnológico ha conducido a las radiotelevisiones públicas de la Unión Europea a adaptarse y ampliar su oferta a las audiencias en un intento de mantener el nivel de competencia con el 
sector privado. Todo ello en un espacio poco favorable, en el que los medios públicos siguen marcados por la crisis económico-financiera iniciada en 2007 y por la convergencia digital.

A los canales tradicionales de televisión y radio, las corporaciones públicas han sumado nuevos servicios relacionados con Internet y telefonía móvil. De hecho, el total de las veintiocho corporaciones estatales públicas de la Unión Europea (excepto la griega NERIT, de reciente constitución tras el cierre de ERT, a raíz de los mandatos de la Troika) cuentan con sus propias aplicaciones móviles y plataformas de contenidos en Internet. Además, en su lucha por presentar la mejor calidad, han apostado por los canales en alta definición.

En esta tabla comprobamos cómo las corporaciones estatales públicas han ampliado su gama de servicios. En primer lugar, todas ellas, excepto NERIT y CyBC, han realizado experimentos con los canales de televisión de alta definición (HD). Sobresalen los casos de la RAI de Italia, la BBC de Reino Unido y la ZDF de Alemania, que ya suman en su cartera entre cinco y diez canales de estas características.

Tabla 1: Tipología de canales de las radiotelevisiones públicas

\begin{tabular}{|c|c|c|c|c|c|c|}
\hline CORPORACIÓN & CANALES TV & $\begin{array}{c}\text { EMISORAS } \\
\text { RADIO }\end{array}$ & $\begin{array}{l}\text { CANALES } \\
\text { INTERNET }\end{array}$ & $\begin{array}{c}\text { CANALES } \\
\text { HD }\end{array}$ & PLATAFORMAS & APPS \\
\hline ZDF - Alemania & 10 & & 8 & 5 & ZDF Mediathek & 3 \\
\hline ORF - Austria & 5 & 4 & 2 & 2 & TV Thek & 15 \\
\hline RTBF - Bélgica & 6 & 8 & 5 & 3 & RTBF Live Center & 1 \\
\hline VRT - Bélgica & 8 & 5 & 2 & 4 & deredactie.be & 14 \\
\hline BNT - Bulgaria & 4 & 3 & 2 & 1 & BNT World & 1 \\
\hline CyBC - Chipre & 3 & 4 & 2 & 0 & Piksat & 1 \\
\hline HRT - Croacia & 10 & 3 & 3 & 1 & HRT Player & 2 \\
\hline DR - Dinamarca & 9 & $4(+11$ en $D A B)$ & 8 & 2 & DR Live & 1 \\
\hline RTVS - Eslovaquia & 4 & $9(5 \mathrm{FM}+4$ DVB-T $)$ & 2 & 2 & OL Web Tv & 1 \\
\hline RTVSLO - Eslovenia & 5 & 8 & 3 & 2 & V-ZIVO & 1 \\
\hline RTVE - España & 7 & 6 & 4 & 2 & RTVE A la carta & 9 \\
\hline ERR - Estonia & 3 & 5 & 4 & 1 & ETV Otse & 1 \\
\hline YLE - Finlandia & 4 & 6 & 2 & 4 & YLE Arenan & 12 \\
\hline FT - Francia & 6 & _ & 20 & 2 & FranceTV Pluzz & 3 \\
\hline NERIT - Grecia & 2 & 3 & 1 & 0 & & 0 \\
\hline MTVA - Hungría & 4 & 4 & & 1 & hirado.hu & 3 \\
\hline RTÉ - Irlanda & 8 & 9 & & 4 & RTÉ player & 8 \\
\hline RAl - Italia & 15 & 11 & project (en & 10 & RAI.tv & 4 \\
\hline LTV - Letonia & 2 & 5 & curso) & 1 & LSM.LV & 3 \\
\hline LRT - Lituania & 2 & 3 & & $1 f_{+}$ & LRT.It & 5 \\
\hline PBS - Malta & 2 & 3 & & terrigoriales) & TVM Player & 1 \\
\hline NPO - Países Bajos & 3 & 7 & & terriburiales) & NPO-Player & 11 \\
\hline TVP - Polonia & 9 & & screen & territoriales) & $10 / 11 / 2014$ & 2 \\
\hline RTP - Portugal & 2 & 16 & & $78+$ & RTP Play & 1 \\
\hline BBC - Reino Unido & 31 & 18 & 1 & territoriales) & BBC iPlayer & 41 \\
\hline CT - República Checa & 7 & & & \begin{tabular}{|l|}
1 \\
\end{tabular} & HbbTV & 3 \\
\hline TVR - Rumanía & 6 & & & 1 & TVR+ & 2 \\
\hline SVT - Suecia & 8 & 5 & & 1 & svtplay.se & 1 \\
\hline
\end{tabular}

Fuente: Elaboración propia, 2014 
En cuanto a las plataformas de televisión y radio en Internet, también se comprueba que es un modelo totalmente asumido por las corporaciones de servicio público, en las que ofrecen sus contenidos en directo y continuo. De entre todas ellas, destaca la iPlayer de la BBC (en funcionamiento desde abril de 2008), que encara un ejemplo en el diseño, lanzamiento y gestión de productos y servicios digitales.

Desde el punto de vista de la telefonía móvil, las radiotelevisiones públicas están aplicando diferentes estrategias que las dividen en dos grupos: 1) las que ofrecen una única aplicación móvil a modo de plataforma en la que se presentan todos los servicios de radio y televisión, como la NPO holandesa, la YLE finlandesa y la ORF austríaca; 2) aquellas que proponen una aplicación por cada servicio, grupo en el que se encuadran la mayoría de entes públicos.

Las similitudes entre las aplicaciones móviles van desde la gratuidad del servicio hasta su disponibilidad para los sistemas operativos Android, iOS y Windows. Además, estas empresas públicas aprovechan las aplicaciones para profundizar en la interacción con las audiencias. Un ejemplo es la aplicación +rtve, de Radio Televisión Española, que permite compartir y comentar contenidos en directo.

A pesar de la adaptación a los nuevos modelos de comunicación de masas, las televisiones públicas, en general, continúan gozando de buenos índices de audiencia, aunque con una caída paulatina del share debido a la aparición exponencial de nuevos canales y la fragmentación y diversificación de las audiencias.

Según los datos de 2014 publicados por el Observatorio Europeo del Audiovisual, en un extremo se encuentran las televisiones ZDF, ORF VRT, DR, YLE, FT, RAI, PBS, NPO, TVP, BBC y SVT, que superan el 30 por ciento de share medio diario; mientras que en el otro se ubican BNT, CyBC, RTVS, RTVE, MTVA, LTV, LRT, RTP y TVR, con menos de un 20 por ciento de cuota de pantalla diaria.

Tal y como revela la tabla, independientemente del porcentaje medio de audiencia, ninguna corporación ha innovado en las relaciones vía móvil con la audiencia; solo la televisión polaca ofrece una aplicación inteligente a través de la que conectar con la audiencia.

\subsection{Redes sociales}

Las redes sociales se han convertido en parte de la estrategia informativa de los medios de comunicación en general $\mathrm{y}$, en 
consecuencia, de las radiotelevisiones públicas en Europa. A pesar de la escasa tradición de la ausencia de fórmulas empíricas sobre las mejores prácticas para alcanzar el éxito en los social media, parece que hay una tendencia por parte de las corporaciones a dejar en manos de la suerte los resultados de este modelo de comunicación.

Tabla 2: Audiencias televisiones públicas

\begin{tabular}{|c|c|c|c|}
\hline CORPORACIÓN & $\begin{array}{l}\text { SHARE MEDIO } \\
\text { DIARIO (\%) }\end{array}$ & ÓRGANO MEDIADOR & $\begin{array}{c}\text { APPS } \\
\text { INTELIGENTES }\end{array}$ \\
\hline ZDF - Alemania & 45,9 & Servicio del Espectador & $\mathbf{X}$ \\
\hline ORF - Austria & 39,4 & Consejo Público & $\mathrm{X}$ \\
\hline RTBF - Bélgica & 22,7 & Mediación & $\mathrm{x}$ \\
\hline VRT - Bélgica & 43,5 & $\mathrm{X}$ & $\mathrm{X}$ \\
\hline BNT - Bulgaria & 9,9 & $\mathbf{x}$ & $\mathbf{X}$ \\
\hline CyBC - Chipre & 19,5 & $\mathrm{x}$ & $\mathbf{X}$ \\
\hline HRT - Croacia & 27,4 & Comisionado para los usuarios & $\mathbf{x}$ \\
\hline DR - Dinamarca & 67,5 & Editor de los usuarios & $\mathrm{X}$ \\
\hline RTVS - Eslovaquia & 11,6 & $\mathrm{X}$ & $\mathrm{X}$ \\
\hline RTVSLO - Eslovenia & 28,5 & Defensor de la audiencia & $\mathbf{x}$ \\
\hline RTVE - España & 18,8 & Defensora del Espectador & $\mathbf{X}$ \\
\hline ERR - Estonia & 20,8 & Asesor de Ética & $\mathrm{X}$ \\
\hline YLE - Finlandia & 40,8 & $\mathrm{X}$ & $\mathrm{X}$ \\
\hline FT - Francia & 33,4 & Defensor de la Audiencia & $\mathbf{X}$ \\
\hline NERIT - Grecia & & $\mathrm{X}$ & $\mathbf{x}$ \\
\hline MTVA - Hungría & 14 & $\mathbf{x}$ & $\mathrm{X}$ \\
\hline RTÉ - Irlanda & 29.8 & Audience council & $\mathrm{X}$ \\
\hline RAI - Italia & 39.9 & $\mathbf{X}$ & $\mathbf{x}$ \\
\hline LTV - Letonia & 13.3 & $\mathrm{X}$ & $\mathrm{X}$ \\
\hline LRT - Lituania & 10.6 & $\mathbf{X}$ & $\mathbf{X}$ \\
\hline PBS - Malta & 36 & $\mathrm{X}$ & $\mathrm{X}$ \\
\hline NPO - Países Bajos & 34.6 & $\mathbf{X}$ & $\mathbf{X}$ \\
\hline TVP - Polonia & 34.2 & $\mathrm{X}$ & TVP Info \\
\hline RTP - Portugal & 18.8 & Conselho de opinão & $\mathrm{x}$ \\
\hline BBC - Reino Unido & 37.3 & BBC Trust Audience Councils & $\mathrm{X}$ \\
\hline CT - República Checa & 29.3 & $\mathrm{X}$ & $\mathbf{X}$ \\
\hline TVR - Rumanía & 6.2 & $\begin{array}{c}\text { Comisión de Ética y Arbitraje y } \\
\text { Defensor del pueblo }\end{array}$ & $\mathbf{x}$ \\
\hline SVT - Suecia & 36.5 & $\mathrm{X}$ & $\mathrm{X}$ \\
\hline
\end{tabular}

Fuente: Elaboración propia

Son aislados los casos de radiotelevisiones, del conjunto de las analizadas, que giren su actividad en torno a un código ético o unas normas editoriales con las que amparar las publicaciones -tanto en redacción como en contenido-, detallar los modelos de interactuación y sostener el flujo de información. 
Tabla 3: Regulación de los medios sociales en las radiotelevisiones públicas

\begin{tabular}{c|c|c|} 
CORPORACION & NORMAS EDITORIALES & CODIGOS ETICOS \\
\hline ZDF - Alemania & $\mathrm{X}$ & $\mathrm{X}$ \\
\hline ORF - Austria & Social Media Guidelines & $\mathrm{X}$ \\
\hline RTBF - Bélgica & $\mathrm{X}$ & $\mathrm{X}$ \\
\hline VRT - Bélgica & Decálogo sobre redes sociales & $\mathrm{X}$ \\
\hline BNT - Bulgaria & $\mathrm{X}$ & $\mathrm{X}$ \\
\hline CyBC - Chipre & $\mathrm{X}$ & $\mathrm{X}$ \\
\hline HRT - Croacia & $\mathrm{X}$ & $\mathrm{X}$ \\
\hline DR - Dinamarca & $\mathrm{X}$ & $\mathrm{X}$ \\
\hline RTVS - Eslovaquia & $\mathrm{X}$ & $\mathrm{X}$ \\
\hline RTVSLO - Eslovenia & $\mathrm{X}$ & $\mathrm{X}$ \\
\hline RTVE - España & $\mathrm{X}$ & $\mathrm{X}$ \\
\hline ERR - Estonia & $\mathrm{X}$ & $\mathrm{X}$ \\
\hline YLE - Finlandia & Pautas de Actividad de Redes & $\mathrm{X}$ \\
\hline Sociales & $\mathrm{X}$ & $\mathrm{X}$ \\
\hline FT - Francia & Guía de Buenas Prácticas en & $\mathrm{X}$ \\
\hline NERIT - Grecia & Redes Sociales & $\mathrm{X}$ \\
\hline MTVA - Hungría & $\mathrm{X}$ & $\mathrm{X}$ \\
\hline RTÉ - Irlanda & RTÉ Social Media Guidelines & $\mathrm{X}$ \\
\hline RAl - Italia & Editoriali nuovi media & $\mathrm{X}$ \\
\hline LTV - Letonia & $\mathrm{X}$ & $\mathrm{X}$ \\
\hline LRT - Lituania & $\mathrm{X}$ & $\mathrm{X}$ \\
\hline PBS - Malta & $\mathrm{X}$ & $\mathrm{X}$ \\
\hline NPO - Países Bajos & $\mathrm{X}$ & $\mathrm{X}$ \\
\hline TVP - Polonia & $\mathrm{X}$ & $\mathrm{X}$ \\
\hline RTP - Portugal & $\mathrm{X}$ & $\mathrm{X}$ \\
\hline BBC - Reino Unido & Social media guidance & $\mathrm{BBC}$ Use of Social Net \\
\hline CT - República Checa & Reglementări bloguri & $\mathrm{X}$ \\
\hline TVR - Rumania & & \\
\hline SVT - Suecia & & \\
\hline
\end{tabular}

Fuente: Elaboración propia, 2014

A pesar de carecer de normas editoriales con las que enfrentarse al uso de las redes sociales, todas las corporaciones de radiotelevisión pública estatal de la Unión Europea están presentes en ellas. En este estudio analizamos el uso que los entes hacen de Twitter, Facebook, Youtube, Google +, Delicious y Digg y Linkedin.

Todas las radiotelevisiones públicas apuestan por la presencia en Twitter y Facebook, por ser los canales que mejor se adaptan a la difusión de información de forma instantánea. Youtube se impone desde el punto de vista audiovisual, con cuentas de todas las corporaciones excepto cuatro. Google + y Linkedin, redes con un sentido más corporativo, tienen un seguimiento prácticamente total; 
mientras que en el extremo contrario se encuentran Digg y Delicious, totalmente excluidas del mapa de redes.

Tabla 4: Presencia de las radiotelevisiones públicas en redes sociales

\begin{tabular}{|c|c|c|c|c|c|c|c|}
\hline CORPORACIÓN & FACEBOOK & TWITTER & GOOGLE+ & DELICIOUS & DIGG & LINKEDIN & YOUTUBE \\
\hline ZDF - Alemania & 5 & 7 & 1 & $\mathrm{x}$ & $\mathrm{x}$ & 1 & 5 \\
\hline ORF - Austria & 1 & 1 & $\mathrm{X}$ & $\mathrm{x}$ & $\mathrm{x}$ & 1 & 1 \\
\hline RTBF - Bélgica & 1 & 1 & 1 & $\mathrm{x}$ & $\mathrm{x}$ & 1 & 1 \\
\hline VRT - Bélgica & 1 & 1 & $\mathrm{X}$ & $\mathrm{x}$ & $\mathrm{x}$ & $\mathrm{x}$ & 1 \\
\hline BNT - Bulgaria & 1 & 1 & 1 & $\mathrm{x}$ & $\mathrm{x}$ & 1 & 1 \\
\hline CyBC - Chipre & 1 & 1 & 1 & $\mathbf{x}$ & $\mathbf{x}$ & $\mathbf{x}$ & 1 \\
\hline HRT - Croacia & 1 & 1 & 1 & $\mathrm{X}$ & $\mathrm{X}$ & $\mathrm{X}$ & 1 \\
\hline DR - Dinamarca & 1 & 1 & 1 & $\mathrm{x}$ & $\mathrm{X}$ & 1 & 1 \\
\hline RTVS - Eslovaquia & 2 & 2 & $\mathrm{x}$ & $\mathrm{x}$ & $\mathrm{x}$ & 1 & 1 \\
\hline RTVSLO - Eslovenia & 2 & 7 & 1 & $\mathrm{x}$ & $\mathrm{X}$ & 1 & 1 \\
\hline RTVE - España & 1 & 9 & 1 & $\mathrm{x}$ & $\mathrm{x}$ & 1 & 1 \\
\hline ERR - Estonia & 2 & 2 & 1 & $\mathrm{x}$ & $\mathbf{x}$ & 1 & 1 \\
\hline YLE - Finlandia & 6 & 6 & $\mathrm{x}$ & $\mathrm{x}$ & $\mathbf{x}$ & 2 & 1 \\
\hline FT - Francia & 6 & 6 & 6 & $\mathrm{x}$ & $\mathbf{x}$ & 3 & 2 \\
\hline NERIT - Grecia & 1 & 1 & $\mathrm{x}$ & $\mathrm{x}$ & $\mathrm{x}$ & $\mathrm{x}$ & $\mathbf{x}$ \\
\hline MTVA - Hungría & 1 & 1 & $\mathrm{x}$ & $\mathrm{x}$ & $\mathrm{x}$ & 1 & $\mathrm{x}$ \\
\hline RTÉ - Irlanda & 17 & 27 & $\mathrm{x}$ & $\mathrm{x}$ & $\mathrm{x}$ & 3 & 7 \\
\hline RAI - Italia & 16 & 2 & 1 & $\mathrm{x}$ & $\mathrm{x}$ & 1 & 1 \\
\hline LTV - Letonia & 1 & 1 & $\mathrm{x}$ & $\mathrm{x}$ & $\mathrm{x}$ & $\mathrm{x}$ & $\mathrm{x}$ \\
\hline LRT - Lituania & 3 & 1 & 1 & $\mathrm{x}$ & $\mathrm{x}$ & 1 & 1 \\
\hline PBS - Malta & 1 & 1 & $\mathrm{x}$ & $\mathrm{x}$ & $\mathrm{x}$ & $\mathrm{x}$ & $\mathrm{x}$ \\
\hline NPO - Países Bajos & 4 & 1 & $\mathrm{x}$ & $\mathrm{x}$ & $\mathrm{x}$ & 1 & 4 \\
\hline TVP - Polonia & 1 & $\mathrm{X}$ & 1 & $\mathrm{x}$ & $\mathrm{x}$ & 2 & 3 \\
\hline RTP - Portugal & 4 & 10 & 1 & $\mathbf{x}$ & $\mathbf{x}$ & 1 & 8 \\
\hline BBC - Reino Unido & 51 & 123 & 15 & $\mathrm{x}$ & 1 & 3 & 40 \\
\hline CT - República Checa & 1 & 3 & 1 & $\mathrm{x}$ & $\mathrm{x}$ & 1 & 2 \\
\hline TVR - Rumanía & 1 & 1 & $\mathrm{x}$ & $\mathrm{x}$ & $\mathrm{x}$ & 1 & 10 \\
\hline SVT - Suecia & 13 & 4 & 1 & $\mathrm{x}$ & $\mathrm{x}$ & 1 & 2 \\
\hline
\end{tabular}

Fuente: Elaboración propia, 2014

A continuación perfilamos el comportamiento de las radiotelevisiones en Facebook, Twitter, Google+ y YouTube.

\subsubsection{Facebook}

Facebook es una red social que permite a los medios de comunicación combinar la publicación de noticias y difusión de la programación con la interactuación directa con los usuarios, que comentan y transmiten sus estados de ánimo. A pesar que resulta imposible hacer generalizaciones ya que solo una parte de la audiencia es activa en redes, sí que facilita conocer en tiempo real la opinión del público. 
Figura 5: Presencia en Facebook de las radiotelevisiones públicas

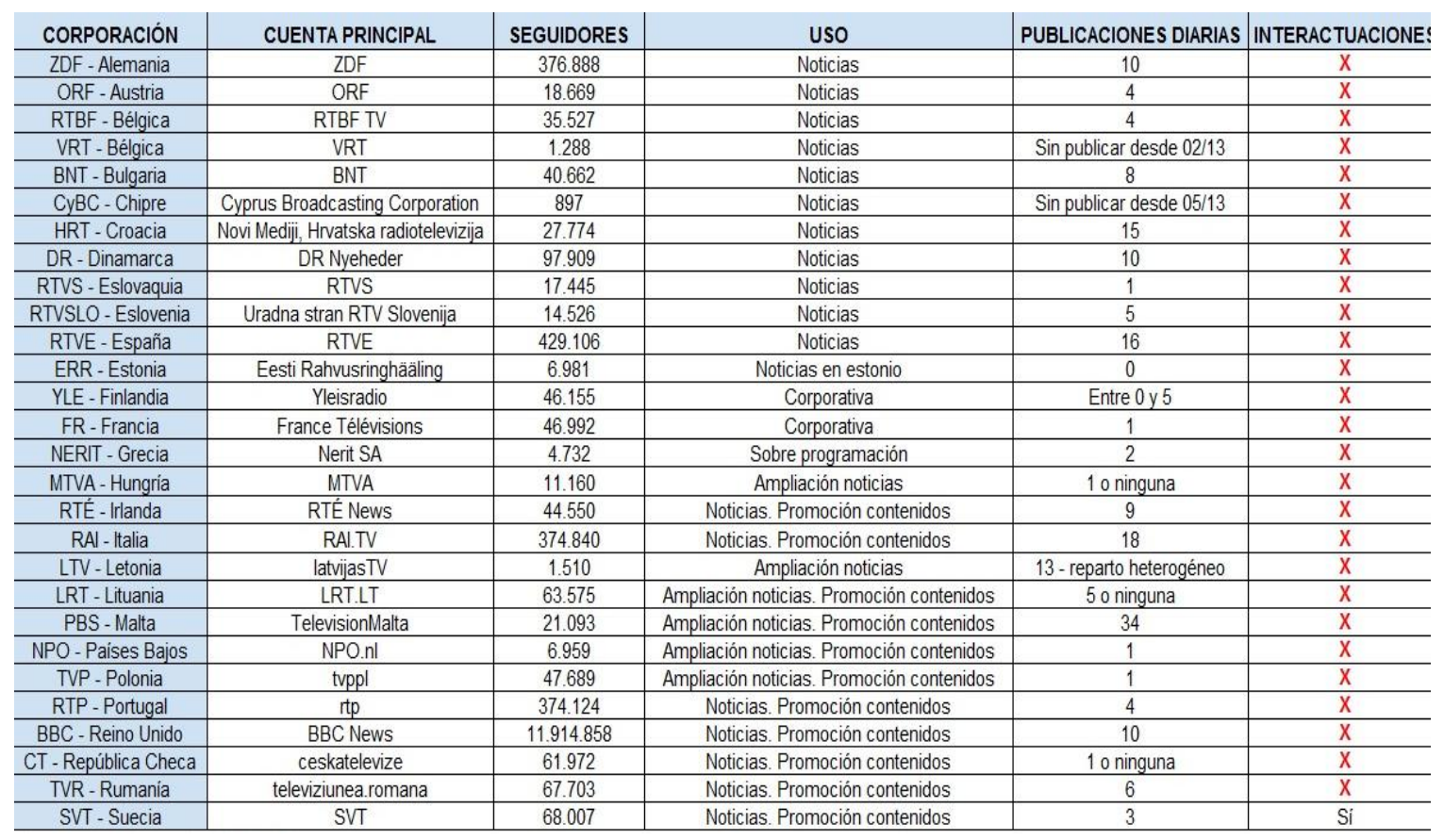

Fuente: Elaboración propia, 2014

De las 28 corporaciones públicas que se muestran en la tabla, todas disponen de una cuenta principal de Facebook, aunque dos de ellas (Chipre y Bélgica) no publican contenido desde hace un año. Otras, como es el caso de Estonia, República Checa o Finlandia no agregan contenido diariamente y usan su cuenta corporativa de forma esporádica.

Las diferencias entre el número de fans de las páginas de las corporaciones públicas europeas son, si no evidentes, notables. Si sumamos el número total de seguidores de cada país, la media asciende a un total de 507.985 fans, pero solo llega a esta cifra la BBC, con casi 12 millones de "Me gusta". Entre el resto se aprecian diferencias significativas: mientras Chipre no llega a los 1.000, Portugal, Italia y Alemania pasan los 370.000. Destacable es el caso de Grecia, que aunque cuenta con una televisión que acaba de nacer, sobrepasa los 4.700 fans.

En cuanto al contenido y el uso que cada uno de los radiodifusores otorga a sus páginas corporativas de esta red social, la mayoría emplea el portal para colgar noticias, ampliar y promocionar contenidos propios. Finlandia y Francia lo emplean simplemente para información de la corporación, de ahí las escasas publicaciones diarias 
de estos dos grupos. La TelevisionMalta es la cuenta que publica más contenido diario, con una media semanal de 34 post. El resto ronda la decena o veintena de publicaciones diarias; la RAI llega a 18, RTVE a 16, y Croacia a 15. Bélgica y Chipre no publican contenido desde principios y mediados de 2013, respectivamente.

Sobre interactuaciones, la única corporación que interactúa con los usuarios es la SVT de Suecia, que responde 1 o 2 veces diarias a los comentarios que publican los usuarios en las noticias.

El número de seguidores varía considerablemente de un país a otro. Destaca la Cyprus Broadcasting Corporation, con menos de 1.000 seguidores, a diferencia de la principal cuenta de la BBC, a la que se suman casi de fans de la página de BBC News. La media total de seguidores, si sumamos el número total de cada uno de los países, nos da un total de 381.734 fans, por lo que solo sobrepasarían ese número España y Alemania. El resto, dadas las diferencias entre el servicio de radiodifusión público británico y los demás países, se quedaría fuera de juego.

\subsubsection{Twitter}

Twitter es la red social que se encuentra bajo el concepto del microblogging, en la que los usuarios registrados pueden publicar comentarios, de forma breve y a modo de titulares. Su éxito reside precisamente en la fugacidad y rapidez con la que se publican los mensajes, características que la convierten en ideal para las empresas de comunicación para publicar informaciones de última hora.

Las 28 corporaciones analizadas disponen de cuentas corporativas, si bien algunas de ellas no la utilizan, como es el caso de VRT en Bélgica y PBS en Malta, que solo tiene una cuenta de temática deportiva, pero no una general de la corporación.

El número de seguidores varía de un país a otro. A pesar de que la media de los 28 se quedaría en 381.734 seguidores, de nuevo la BBC se diferencia notablemente del resto, con casi 8 millones de seguidores, y solo superan la media Alemania y España. En cuanto al resto, Grecia y Chipre no llegan al millar de seguidores, y Hungría no llega a los 100.

El uso y temática de sus cuentas es mayoritariamente de enlace a noticias o de noticias de última hora. Finlandia y Francia, como en Facebook, dedican esta página a verter información corporativa, y 
Alemania añade a este uso información sobre programación. Destacable es el caso de Rumanía, que en prácticamente todas sus publicaciones enlaza la información a videos de la corporación en su cuenta de YouTube.

Tabla 6: Presencia en Twitter de las radiotelevisiones públicas europeas

\begin{tabular}{|c|c|c|c|c|c|c|}
\hline CORPORACIÓN & CUENTA PRINCIPAL & SEGUIDORES & SIGUIENDO & Uso & PUBLICACIONES DIARIAS & INTERACTUACIONES \\
\hline ZDF -Alemania & ZDF & 503.000 & 220 & Corporación y programación & 24 & Retweets \\
\hline ORF-Austria & ORF & 7.041 & & Noticias & 6 & $\mathrm{X}$ \\
\hline RTBF-Bélgica & RTBFtv & 35.300 & 1.273 & Noticias & 8 & Retweets \\
\hline VRT - Bélgica & VRT & & & & & \\
\hline BNT - Bulgaria & BNT_1 & 5.915 & 107 & Noticias & 5 & $x$ \\
\hline CyBC-Chipre & cybc2012 & 874 & 47 & Noticias & Última publicación 08/14 & \\
\hline HRT - Croacia & novimedijïRT & 7.597 & 305 & Noticias & 3 & $\mathrm{X}$ \\
\hline DR - Dinamarca & DR Nyheder & 20.800 & 116 & Noticias & 30 & $x$ \\
\hline RTVS - Eslovaquia & RTVS & 2.545 & 29 & Noticias & Entre 0 y 2 & Retweets \\
\hline RTVSLO - Eslovenia & RTV_Slovenija & 23.000 & 1.546 & Noticias & 4 & Retweets \\
\hline RTVE - España & RTVE & 739.000 & 255 & Noticias & 30 & Retweets \\
\hline ERR - Estonia & err_ee & 4.352 & 40 & Noticias & 7 & $\mathrm{X}$ \\
\hline YLE - Finlandia & Yleisradio & 27.300 & 332 & Actividad corporativa & 5 & $x$ \\
\hline FR-Francia & francetele & 57.500 & 110 & Corporativa. Promoción. & 4 & $\mathrm{X}$ \\
\hline NERIT - Grecia & neritnetwork & 816 & 14 & Programación & 8 (entre 2 y 11 ) & $x$ \\
\hline MTVA-Hungria & hungarymatters & 67 & 5 & Noticias & 1 & $x$ \\
\hline RTÉ - Irlanda & the & 91.600 & 20.900 & Noticias. Programación & 23 & $X$ \\
\hline RAl - Italia & rai.tv & 274.000 & 247 & Noticias. Programación & 23 & Retweets \\
\hline LTV - Letonia & latvijasTV & 4.152 & 413 & Noticias. Programación & 4 & Retweets \\
\hline LRT - Lituania & LRT_LT & 3.994 & 78 & Noticias. Programación & 11 & $\mathrm{X}$ \\
\hline PBS - Malta & TelevisionMalta & 1.190 & 142 & Noticias. Programación & 31 & $\mathrm{X}$ \\
\hline NPO - Paises Bajos & PubliekeOmroep & 15.000 & 506 & Noticias & 8 & Retweets \\
\hline TVP - Polonia & (Solo cuenta tvppl sport) & & & & & \\
\hline RTP-Portugal & rtppt & 230.000 & 10.430 & Noticias. Redirección a RTP Noticias & 14 & $\mathrm{x}$ \\
\hline BBC - Reino Unido & BBCWorld & 7.800 .000 & 61 & Noticias. Programación & 40 & Retweets \\
\hline ;T-República Checa & CzechTV & 47.300 & 8 & Noticias. Promoción & 10 ninguna & $\mathrm{X}$ \\
\hline TVR - Rumania & TVR & 1.548 & 170 & Promoción + enlaces Youtube & 7 & $x$ \\
\hline SVT - Suecia & svt & 21.200 & 6.786 & Noticias. Programación & 4 & Comentarios + retweets \\
\hline
\end{tabular}

Fuente: Elaboración propia, 2014

Las interactuaciones se basan en su mayoría en retuits de cuentas de la corporación o ajenas, excepto Suecia, que también contesta a comentarios de los tuiteros. Las publicaciones medias diarias también varían de una corporación a otra. Mientras Reino Unido publica 40 de media y España 30, Croacia, Suecia o Francia no llegan a 5. Chipre no tiene actividad desde agosto de 2014, y Eslovaquia publica esporádicamente.

\subsubsection{You'Tube}

YouTube es una red social audiovisual que ofrece la posibilidad de crear canales propios en los colgar todo el contenido perteneciente a un único usuario. Se trata de una particularidad que favorece a los 
medios de comunicación en el sentido de poder crear una plataforma audiovisual propia hacia la cual derivar a su audiencia. Con respecto a la interacción, actúa como el resto de redes sociales, ya que permite recibir y enviar mensajes de forma rápida y en tiempo real.

Tabla 7: Presencia en YouTube de las radiotelevisiones públicas europeas

\begin{tabular}{|c|c|c|c|}
\hline CORPORACIÓN & CUENTA & REPRODUCCIONES & TIPOLOGIA \\
\hline ZDF - Alemania & $\begin{array}{l}\text { ZDF (Incluye Impressum, } \\
\text { Mediathek, zdf.de) }\end{array}$ & 5.826 .540 & Programación \\
\hline ORF - Austria & ORF & & Programación \\
\hline RTBF - Bélgica & RTBF & 6.338 .515 & Programación \\
\hline VRT - Bélgica & VRT & & Programación \\
\hline BNT - Bulgaria & BNT Bulgaria & 47.057 & Programación \\
\hline CyBC - Chipre & $\begin{array}{c}\text { Cyprus Broadcasting } \\
\text { Corporation }\end{array}$ & 164 & Programación \\
\hline HRT - Croacia & Hrvatska Radiotelevizija & 640.237 & Programación \\
\hline DR - Dinamarca & DR Nyheder & 371.696 & Programación \\
\hline RTVS - Eslovaquia & RTVSOfficial & 1.224 .165 & Programación \\
\hline RTVSLO - Eslovenia & RTV Slovenija & 200.358 & Programación \\
\hline RTVE - España & RTVE & 261.770 .491 & Programación \\
\hline ERR - Estonia & Eesti Rahvusringhääling & 19.835 .527 & Programación \\
\hline YLE - Finlandia & YLE & 7.635 .945 & Programación \\
\hline FT - Francia & France Télévisions & 18.417 .016 & Programación \\
\hline \multicolumn{4}{|l|}{ NERIT - Grecia } \\
\hline \multicolumn{4}{|l|}{ MTVA - Hungria } \\
\hline RTÉ - Irlanda & RTÉ & 107.403 .866 & Programación \\
\hline RAI - Italia & RAl & 6.944 .161 & Temática \\
\hline \multicolumn{4}{|l|}{ LTV - Letonia } \\
\hline LRT - Lituania & LRT & 29.733 .614 & Temática \\
\hline \multicolumn{4}{|l|}{ PBS - Malta } \\
\hline NPO - Paises Bajos & NPO - Tema & & Canal \\
\hline TVP - Polonia & itvp & 189.273 .087 & Programación \\
\hline RTP - Portugal & $\mathrm{rtp}$ & 286.973 .430 & Programación \\
\hline BBC - Reino Unido & BBC & 42.325 .323 & Programación \\
\hline CT - República Checa & Česka televize & 2.532 .200 & Programación \\
\hline TVR - Rumanía & TVR & 14.758 .458 & Programación \\
\hline SVT - Suecia & SVT & 21.677 .821 & Temática \\
\hline
\end{tabular}

Fuente: Elaboración propia

Todas las radiotelevisiones públicas estatales de la Unión Europea gestionan al menos una cuenta en Youtube, excepto las de Grecia, Hungría, Letonia y Malta. A pesar de que sí que tienen algún canal, esta red no ofrecía en el momento de la investigación los datos de reproducción de ORF, VRT y NPO. Entre todas las demás suman 736.956.584 reproducciones, con una media de 35,1 millones por radiotelevisión.

A la cabeza de flujo de datos se sitúan la BBC del Reino Unido, con más de 286 millones de reproducciones, y RTVE de España, con algo más de 261 millones. La TVP polaca y la RTÉ irlandesa ocupan el 
tercero y cuarto puesto de la lista, con 189 y 107 millones de visitas, respectivamente. Por otro lado, hay cuatro corporaciones que no alcanzan el medio millón de reproducciones: $\mathrm{CyBC}$ de Chipre, HRT de Croacia, DR de Dinamarca, RTVSLO de Eslovenia.

En cuanto a la temática de los canales, se impone el uso corporativo en la difusión de vídeos y contenidos que ya han sido emitidos a través de los canales tradicionales de televisión. No se dan casos de producción propia para Youtube. La mayor parte de los canales reproducen contenidos programáticos y en tres casos se reducen a una temática concreta -RAI, LRT y SVT-.

Holanda presenta un caso anecdótico puesto que cuenta con un canal que no es corporativo, sino que representa exclusivamente a una de las cadenas de televisión del grupo. Otros entes, como FT de Francia, han creado una cuenta por cada canal, pero respaldados por un canal corporativo general.

\subsubsection{Google+}

Google+ es la red social de Google que permite interactuar con individuales y empresas, crear comunidades y grupos, y clasificar al resto de usuarios en círculos de acuerdo a su afinidad y el tipo de relación que mantenga con cada uno de ellos. Esta red se parece a Twitter en que puedes visitar otro perfil sin la necesidad de seguirle, motivo principal de que sean tan distintos los datos de seguidores y visitantes en el caso de las radiotelevisiones analizadas.

Del total de las veintiocho corporaciones analizadas, veintiuna gestionan al menos una cuenta de Google + , con las que llegan en total a 6.245.324 seguidores. La media de usuarios que siguen a estas empresas es de 297.396, cifra totalmente desvirtuada, puesto que la BBC del Reino aglutina en solitario en su cuenta general 5.977.000 seguidores, y la ZDF de Alemania se sitúa en el segundo puesto del ranking, con tan solo 196.996. Esta tabla revela que la corporación británica ha situado a esta red social entre los puntales de su comunicación con la audiencia, mientras que para el resto de entes ocupa un tercero o cuarto puesto en nivel de importancia.

En cuanto a las visitas, vuelve a destacar la BBC, con 392 millones, seguida de nuevo por la ZDF alemana, con 32 millones de visitantes, y la TVP polaca, con 911.000. 
Tabla 8: Presencia en Google+ de las radiotelevisiones públicas europeas

\begin{tabular}{|c|c|c|c|}
\hline CORPORACIÓN & CUENTA & SEGUIDORES & VISITAS \\
\hline ZDF - Alemania & ZDF & 196.996 & 32.170 .241 \\
\hline \multicolumn{4}{|l|}{ ORF - Austria } \\
\hline RTBF - Bélgica & RTBF & 12 & 362.571 \\
\hline \multicolumn{4}{|l|}{ VRT - Bélgica } \\
\hline BNT - Bulgaria & BNT & 308 & 92.079 \\
\hline CyBC-Chipre & Cyprus Broadcasting Corporation & & \\
\hline HRT - Croacia & Hrvatska Radiotelevizija & 16 & 1844 \\
\hline DR - Dinamarca & DR Nyheder & 400 & 180.853 \\
\hline \multicolumn{4}{|l|}{ RTVS - Eslovaquia } \\
\hline RTVSLO - Eslovenia & RTV Slovenija & 54 & 3.910 \\
\hline RTVE - España & RTVE a la carta, TVE en directo, & 2.113 & 147.741 \\
\hline ERR - Estonia & Eesti Rahvusringhääling & 234 & 134.493 \\
\hline \multicolumn{4}{|l|}{ YLE - Finlandia } \\
\hline FT - Francia & France Télévisions & 27.181 & 799.999 \\
\hline \multicolumn{4}{|l|}{ NERIT - Grecia } \\
\hline MTVA - Hungría & Televizió Magyar & 4 & 2.962 \\
\hline RTÉ - Irlanda & RTE NewsNow & 871 & 1.918 \\
\hline RAI - Italia & Rai Tv & 370 & 12.155 \\
\hline \multicolumn{4}{|l|}{ LTV-Letonia } \\
\hline LRT - Lituania & $\begin{array}{l}\text { Lietuvos nacionalinis radijas ir } \\
\text { televizija }\end{array}$ & 290 & 197.077 \\
\hline \multicolumn{4}{|l|}{ PBS - Malta } \\
\hline NPO - Países Bajos & NPO Radio 2 & 74 & 121 \\
\hline TVP-Polonia & itvp & 1.588 & 911.036 \\
\hline RTP - Portugal & RTP & 4.074 & 2.025 .888 \\
\hline BBC - Reino Unido & BBC News & 5.977 .733 & 392.407 .174 \\
\hline CT - República Checa & Česka televize & 32.955 & \begin{tabular}{|c|} 
No tiene \\
publicaciones
\end{tabular} \\
\hline TVR - Rumanía & TVR (www.tvr_ro) & 384 & 116.802 \\
\hline SVT - Suecia & SVT & 37 & 51.666 \\
\hline
\end{tabular}

Fuente: Elaboración propia

La BBC se convierte, en consecuencia, en el paradigma del uso de Google+ por parte de los medios públicos. En su perfil publica noticias, generalmente desde el punto del vista del reportaje, y registra un importante flujo de interacción por parte de los visitantes, con mensajes sobre los contenidos. Alimenta la red con una media de cuatro publicaciones diarias, cifra muy inferior al número de post en Facebook y Twitter.

\section{Conclusiones}

Cuando se habla de televisión, sea pública o privada, debe atenderse a los cambios que han experimentado tanto el dispositivo como los contenidos. Si atendemos al origen de su concepción contemporánea, observamos que ha cambiado considerablemente desde que una joven 
BBC realizaba sus primeras emisiones públicas en 1927. La televisión ha caminado siempre de la mano de los tiempos que corrían y de las crecientes demandas de la audiencia, adaptándose y reestructurándose constantemente: de la tv en blanco y negro a color, de estándar a alta definición, y de ahí a tabletas de gran tamaño. Los usos y consumos de este medio también han sufrido grandes cambios: si bien continúan funcionando como instrumentos para ver la televisión, también se emplean para escuchar música, navegar por internet, etc. Los datos evidencian que vivimos en la edad de oro de la televisión: de los 28 países de la UE, se puede acceder a más de 9.000 canales de televisión, disponibles en múltiples plataformas.

El futuro, no obstante, es incierto, y el dilema sobre supervivencia de la televisión pública sigue encima de la mesa. La Unión Europea de Radiodifusión presentaba recientemente un informe sobre el futuro de la televisión en el que destacaba (2014):

1. Las televisiones atraviesan su "edad de oro", pero esto no garantiza que su futuro sea prometedor.

2. La tecnología y las expectativas del usuario cambian y los medios tienen que adaptarse en consecuencia, pero todavía no han hecho suficiente. El consumidor es el que manda, no los contenidos.

3. La sociedad, cada vez más fragmentada, pone en evidencia la necesidad del mantenimiento de los servicios públicos de radiodifusión en aras del mantenimiento de la democracia.

Sea como fuere, lo que parece evidente es que si el papel de las televisiones y las radios públicas es indispensable y justificable en el nuevo entorno mediático digital, entonces el reto principal será adaptar sus organizaciones e innovar, ya sea en estructuras, contenidos, o relaciones con las audiencias.

Al realizar esta investigación, se evidencia que los medios sociales están en el punto de mira de las corporaciones públicas europeas. Es un aspecto que preocupa a la UER y que hace visible a través de la VISION2020. Tal y como apunta Francisco Campos (2008):

"Las redes sociales, como plataformas de distribución de contenidos que son, generan su actividad y buena parte de su 
flujo de contenidos en base a la economía de la colaboración y contraprestación gratuita de los usuarios, sin apenas filtrado ni selección. Los medios tradicionales, por su parte, seleccionan, evalúan y construyen la pauta informativa en base a los criterios jerarquizados de la organización informativa profesional”.

En cuanto a las redes sociales generalistas de mayor uso (Facebook y Twitter), todas las televisiones disponen de al menos una cuenta, si bien una buena parte no la utilizan o lo hacen esporádicamente. El uso que se les da es mayoritariamente para noticias de sus plataformas tradicionales (televisión o radio), pero pocas corporaciones amplían contenidos o los presentan de acuerdo a la plataforma, siguiendo la narrativa transmedia que se citaba en la introducción. La interactividad, una de las herramientas fundamentales del nuevo escenario digital, está poco explotado en estas dos redes sociales. Solo la SVT de Suecia comenta y responde a los comentarios de sus seguidores.

Youtube y Google + se encuentran en el segundo escalón de uso por parte de los entes analizados. El uso que se les da es el de servir de espacio al que derivar los contenidos que son emitidos previamente en televisión, puesto que por el momento las corporaciones no se han arriesgado a producir contenidos específicos para estas redes. En cuanto a la red social de Google, recibe un trato residual por parte de buena parte de las corporaciones, que apenas dinamizan su muro para conseguir más seguidores y visitas. La principal excepción es la BBC que con solo cuatro publicaciones diarias, de alto interés mediático, alimenta un tráfico protagonizado por casi seis millones de usuarios. Por otra parte, prácticamente todas las corporaciones analizadas, excepto seis, manejan cuenta en Linkedin, aunque desde un punto de vista meramente informativo.

Los servicios públicos de radiodifusión tienen por delante un diamante en bruto, pero en sus manos está el pulirlo. Si bien ya han comenzado a dar pasos adelante en el nuevo camino digitalizado, parece que no son suficientes. Aunque cada grupo ha entrado en diferentes etapas del trayecto, se puede afirmar de forma generalizada que han de aprender a correr sin miedo, y viendo como oportunidad y no amenaza el nuevo suelo que pisan. Además, con la ayuda de instituciones y organismos públicos, han de saber todos ellos dónde 
está la meta y cuáles son los objetivos que persiguen, sin cojear y atentos a todos los desafíos que se les pongan por el camino. Solo así podrán continuar como referentes en su ámbito de actuación, y cumpliendo con la misión para la que fueron concebidos.

\section{Referencias bibliográficas}

Aguado, J.M. y Martínez, I. (2008): "La cuarta pantalla: industrias culturales y contenido móvil”. En VV.AA., Sociedad móvil: Tecnología, identidad y cultura (Coords., J. M. Aguado E I. J. Martínez). Madrid: Biblioteca Nueva.

Campos Freire, F. (2008): "Las redes sociales trastocan los modelos de los medios de comunicación tradicionales", en Revista Latina de Comunicación Social, 63. La Laguna, (Tenerife): Universidad de La Laguna, páginas 287 a 293; recuperado el 10 de noviembre de 2014 de:

http://www.revistalatinacs.org/_2008/23_34_Santiago/Francisco_Ca mpos.html.DOI: 10.4185/RLCS-63-2008-767-287-293.

Duggan, M. y Smitth, A., Pew Research Center (2014): Social Media Update 2013 (perteneciente al Journalism Project). Washington: EE.UU.

eMarketer (2013): Social Media Advertising: Seven Trends for 2014. Recuperado el 11 de noviembre de 2014, de: http://www.emarketer.com/Article/Year-of-Social/1010386

López, X. y Otero, M. (2005): Las herramientas tecnológicas de la nueva información periodística. A Coruña: Netbiblo.

Silva, A. (2013): Os cibermedios nos dipositivos móbiles. Análise estrutural, formal e interpretativa das características que definen o produto informativo no no novo soporte en catorce cabeceiras de referencia. Santiago: Universidade de Santiago de Compostela.

UER (2014): Media Online. Ginebra: Suiza. Recuperado el 9 de noviembre de 2014, de:

http://www3.ebu.ch/files/live/sites/ebu/files/Programming/Media $\% 20$ Online/MediaOnline_booklet_aug2014.pdf

UER (2013): VISION2020, An EBU Project. Connecting to a networked society. Ginebra: Suiza. Recuperado el 10 de noviembre de 2014, de:

http://www3.ebu.ch/files/live/sites/ebu/files/Knowledge/Pub lication\%20Library/EBU-Vision2020-Networked-Society_EN.pdf 
Vacas, F. (2010): "El poder de la movilidad. De medios de masas a medios personales", en Telos, Cuadernos de Comunicación e Innovación, 83. Madrid, páginas 72 a 83.

* Esta comunicación forma parte de una iniciativa de investigación desarrollada al amparo de la Red Internacional de Gestión de la Comunicación (XESCOM, R2014/026), promovida por el Grupo de Novos Medios de la Facultad de Ciencias de la Comunicación de la Universidad de Santiago de Compostela (USC), con el respaldo de la Consellería de Educación, Cultura e Ordenación Universitaria de la Xunta de Galicia (España) y de colaboración con el proyecto del profesor Francisco Campos Freire, apoyado por la Secretaría Nacional de Educación Superior, Ciencia, Tecnología e Innovación (SENESCYT) de Ecuador sobre "El uso, impacto y resultados de la gestión de las redes sociales en los medios, organizaciones e instituciones de comunicación de Ecuador así como en las redes científicas y la promoción de las buenas prácticas de calidad y RSC". 


\section{Uso de Facebook como forma de interacción con el público. El caso de los telediarios de Monterrey}

Claudia Alicia Lerma Noriega, Tecnológico de Monterrey (México), clerma@itesm.mx

Ilián Alejandra Cruz Zapata, Tecnológico de Monterrey (México), Ila.czapata@outlook.com

\section{Resumen}

Como señalaban en su momento Salaverría y García Avilés (2008), los medios de comunicación se han convertido en los principales impulsores de la circulación de conocimientos, además se puede decir también que el ciudadano de la civilización actual convive con ellos y los tiene como punto fundamental de referencia. La gente conversa de lo que hablan la televisión, la radio y la prensa, e ignora los acontecimientos sucedidos más allá de un entorno próximo, que no han merecido la calificación de noticiables. Extrapolando la idea, se puede pensar que lo que no sale en las redes sociales, no es importante y no da tema de conversación en muchos sectores sociales.

El crecimiento de las redes sociales es innegable en muchas partes del mundo, y en México no es la excepción, pues de los 59.3 millones de usuarios de internet, (que equivale a poco más del $50 \%$ de la población) $87 \%$ de esos accede a los sitios de interacción social (siendo el preponderante Facebook).

Es así que con la finalidad de echar un vistazo al panorama actual del ámbito periodístico en las redes sociales, se realizó esta investigación a partir de las páginas de Facebook de los telediarios de 
más audiencia en Monterrey: Multimedios Televisión y Las Noticias de Televisa Monterrey.

Para ello se realiza un análisis cualitativo de los mensajes publicados en las páginas oficiales de estos noticiarios. De este modo se puede identificar el tipo de contenidos que generan mayor interés por parte del usuario y el nivel de interactividad que se genera. Asimismo se percibe cuál es la utilidad que estos espacios informativos le están dando a la red social de mayor acceso en el mundo.

Palabras clave: interacción; periodismo; redes sociales; México; telediarios; ciberperiodismo.

\section{Introducción}

S IN duda, la presencia de las redes sociales se va incrementando $\checkmark$ entre la población cada vez más y van modelando una nueva forma de comunicación que permea a la diferentes estructuras sociales formándose una nueva cultura con hábitos que complementan los existentes. Algunos medios de comunicación, para no quedarse atrás asumen el reto e incorporan varias de las alternativas para entrar al juego de la interrelación con su audiencia o simplemente como una forma de mostrar contenidos. Quienes lo han hecho pueden evitar en cierta forma quedarse excluidos de los flujos comunicacionales actuales.

Sin embargo, existe una lentitud generalizada en México, por parte de los medios de comunicación, al adoptar las herramientas interactivas que dan las plataformas sociales. Los recursos que ofrecen para tener un mayor y mejor acercamiento con el público no son aprovechados en toda su capacidad.

Existen diversas razones por las cuales los medios deben estar conectados

Tejedor Calvo (2010) destaca:

1. Conectividad. Permite que las audiencias se sientan próximas al compartir tiempo, espacio, intereses e inquietudes en una misma comunidad.

2. Servicio. La diversidad de medios no ha hecho que los tradicionales sigan conservando el liderato como fuentes 
confiables de información pero ahora éstos tienen que dar servicios útiles a los usuarios además de producir y ofrecer noticias pues es una forma de tener presencia entre las nuevas generaciones.

3. Participación abierta y de calidad. Para los medios de comunicación puede ser un dilema el permanecer abiertos en internet y así actuar como canales ubicuos e imprescindibles para comunidades que se van formando en torno a ellos. Pero, señala Tejedor:

i. "construir una red social, en torno al medio, no significa cerrar sus puertas para atrapar a los usuarios; al contrario, la fidelidad está relacionada con el servicio que se logre proporcionar a las necesidades de la comunidad, ya que la gente quiere datos e información maleable, para mejorarla y adaptarla a sus necesidades." (2010)

4. Orientación y dinamización. La gran cantidad de información que circula en la red hace indispensable que el ciudadano localice, filtre y dé sentido a los datos. Es entonces que los medios van asumiendo el papel de filtro de acuerdo a determinados criterios sociales.

5. Gestión del conocimiento. Al tener una red social hay que dar contribuciones de calidad y hay que canalizarlas para que las comunidades creen fuertes lazos de reconocimiento.

La socialización que se crea también puede ir focalizada a los jóvenes con necesidad de información y comunicación. El medio, de esta forma entra en las redes sociales creando su identidad digital como marca para relacionarse en aquellos espacios donde convive su público objetivo (Lara: 2) creando contextos donde sus audiencias puedan interactuar con él y con otros usuarios, donde la gente sienta el espacio como suyo y como un lugar de pertenencia y de referencia personal y comunitaria.

Según Lasorsa y otros (cit. en Said, 70) los principales beneficios asociados a la participación son: la relación con la audiencia $(61,2 \%)$, contribuir al producto informativo (41,2\%), el negocio $(40 \%)$ y la contribución a la imagen del medio $(17,5 \%)$. Otros estudios asocian la adopción de patrones conversacionales mayoritariamente a razones prácticas o bien a proyección de marca y liderazgo. Otra de las 
ventajas de la adopción es que los espacios de intervención y participación comprenden todas las secciones y sectores de los medios.

A medida que los usuarios van adquiriendo nuevas habilidades o "practicando" otros espacios o surgen redes sociales, los grandes diarios, los que tienen tanto las posibilidades económicas de adaptarse a las circunstancias como la necesidad y responsabilidad de retener el capital que les ingresa por la publicidad (ambos factores del todo interdependientes), han ido incorporando dichas modificaciones de alguna u otra manera.

En este trabajo veremos si los los 2 telediarios regiomontanos que registran más audiencia televisiva, tienen presencia en Facebook. Esto nos permitirá tener un panorama general de cómo los 2 telediarios regiomontanos, de 2 cadenas distintas, utilizan las herramientas de participación social media, especialmente Facebook, para cumplir con sus actividades de presentación de información diaria.

Así también se pueden ver como objetivos específicos:

- la intensidad de la interactividad que se genera de acuerdo al tipo de notas que se manejan en las páginas de seguidores de los telediarios de la localidad de Monterrey, y

- el uso que se le da a la página de Facebook como forma de interactividad con los seguidores

\section{Panorama general}

La tecnología ahora brinda al ciudadano que está presente en un acontecimiento imprevisto (noticia) dar cuenta de ello, o también opinar y recoger ideas diversas referentes a lo que el propio medio informa. Esta participación puede ser catalogada de diferentes formas: periodismo ciudadano, periodismo participativo o denuncia ciudadana.

El periodismo ciudadano, también llamado en sus orígenes periodismo participativo, es aquel en que los lectores proporcionan noticias a los medios establecidos, pero también crean sus propios medios. Así nace el periodista/ciudadano, que complementa al periodista/profesional -y en algunos casos compite con él-. (de Fontcuberta, 2011).

En algunos estudios, se ha observado que la incorporación de espacios de periodismo ciudadano en portales de medios de prensa ha 
permitido darles mayor visibilidad a "aquellos problemas que se experimentan en las ciudades [...], dando cabida a temáticas de interés humano [...] problemas de la sociedad que no se recogen en las noticias que diariamente transmiten los medios: temas de servicios (sanidad, transporte, educación, justicia)..." (Larrondo Ureta y Tejedor Calvo, 2008: 180-181).

$\mathrm{Al}$ periodismo participativo se le define como "un acto de un ciudadano, o grupo de ciudadanos, desempeñando un rol activo en los procesos de recopilación, cobertura, análisis y difusión de noticias e información. El objeto de esa participación es proporcionar la información fidedigna, precisa, completa y relevante que requiere una democracia". (De Fontcuberta, 2011)

Los medios se han dado cuenta de que "la inmersión de usuarios en estas redes y el tiempo de permanencia en ellas siguen creciendo" (Lara, 2008), por lo que su intento de adaptación a estas nuevas rutinas de consumo de la información ha llegado, más que intentando traer a esas audiencias, llegando a donde ellas se encuentran.

Luis Pastor en su estudio La gestión periodística del público, realizado en 2009, propone una tipología de clasificación de los mensajes emitidos por los lectores de diarios en España a las editoriales de los mismos a través de cartas. Así pues, propone una tipología estructuralista vinculada a la teoría periodística, que a su vez atiende al recurso retórico utilizado, de esta manera las clasificó en tres:

- Las cartas de participación que pueden aportar información u opinión sobre cualquier realidad que importe a la comunidad a la que va dirigida.

- Las cartas de diálogo son cartas que responden a una carta anterior. Se trata de cartas que canalizan la opinión del lector respecto a otro lector.

- Las cartas de intervención son cartas que pueden aportar información, pero que, fundamentalmente, son cartas con una fuerte carga de opinión sobre el medio.

Analizar los temas permite comprender cuáles son los asuntos en los que los lectores sienten más necesidad de aportar ideas. Estor asuntos son, muy probablemente, los que más les interesan o, tal vez, son los asuntos en los que más cómodos se sienten al hablar. El análisis de los 
temas tratados no solo permite sincronizar las agendas informativas de diario y lector, sino que también supone una muestra evidente del perfil de los lectores.

Esta tipología propuesta por Pastor puede aplicarse a las aportaciones que algunos participantes de las redes sociales hacen en las páginas que los medios tienen en Facebook y es la que se usará en este trabajo.

Los temas podrían encuadrarse básicamente, según la lógica periodística, en las secciones: sociedad, política, economía, internacional y cultura, deportes (más las que resulten del análisis de datos como religión, ciencia, educación, meteorología) (Pastor, 2009). Todo esto ayuda a que la gente quede persuadida de que pasan cosas que le interesa saber o que se ve que le interesan efectivamente porque las está comentando. (Gomis, 1994 cit. en Pastor, 2009)

Y por ello las posibilidades de uso que le proponen los medios digitales a sus audiencias no son idénticas a las que se disponían en la prensa tradicional. Dentro de las actividades que el nuevo medio ha potenciado y que hoy las redes de afinidad en Internet reimpulsan, se destaca una que ya estaba presente en el diario de papel pero hoy adquiere otra sustancia y otro lugar: la crítica mediática (Braga, 2006) y el cambio en la producción de la información. (De Foncuberta, 2011).

Mark Deuze, subdividió las opciones interactivas en tres tipos: navigational interactivity, functional interactivity y adaptive interactivity (Deuze: 2001: s/n). La primera remite a las opciones de navegación de un sitio; la segunda, a herramientas como las que permiten el envío de e-mails a periodistas o discusiones moderadas; la tercera, a las posibilidades de personalización de la interfaz. Alejandro Rost (2003, 2006, 2008) distingue la interactividad selectiva que se da entre el usuario y los contenidos, de la interactividad comunicativa que se establece entre individuos (Rost, 2003: s/n); ambas con implicaciones muy diferentes:

"Con la primera, el lector interactivo es principalmente un receptor, con la segunda, es también emisor. Con una, el lector actúa en un proceso de recepción individual, con la otra el lector produce contenidos que adquieren una relevancia pública." (Ibíd.: 66)

Rost define a la interactividad como "una capacidad gradual y variable que tiene un medio de comunicación de darle un mayor poder a sus usuarios / lectores en la construcción de la actualidad ofreciéndoles 
tanto posibilidades de selección de contenidos como de expresión y comunicación" (Rost, 2003: 15).

Si partimos del hecho que el periodismo tiene como funciones tradicionales: la de informar (reflejar la realidad); la de formar (interpretarla) y la de entretener (ocupar el ocio) (de Foncuberta, 2011); en la actualidad hay que agregar una cuarta función: la tematización, que es el mecanismo de formación de la opinión pública en el seno de la sociedad posindustrial a través del temario de los medios de comunicación. Denominamos temario al conjunto de contenidos informativos y noticiosos existentes en un medio. (de Foncuberta, 2011). Es así que en las redes sociales también se siguen temarios que responden a los temas del momento presentados en los propios medios, o que estos recogen de los intereses de los usuarios de la red.

\section{Metodología}

Esta investigación consiste en un análisis cuantitativo, exploratorio y descriptivo de los mensajes noticiosos publicados por los Noticieros "Telediario" de Multimedios Televisión y "Las Noticias Televisa Monterrey" de Televisa Monterrey, en sus páginas oficiales de Facebook. Se hace uso del análisis de contenido a través de la observación estructurada.

Se considera exploratoria, ya que, como lo definen Hernández, Fernández \& Baptista (2006), "los estudios exploratorios se efectúan, normalmente, cuando el objetivo a examinar es un tema o problema de investigación poco estudiado o que no ha sido abordado antes". También se considera descriptiva puesto que se busca especificar las características relevantes del fenómeno que se ha sometido a análisis. "En un estudio descriptivo se seleccionan una serie de cuestiones y se evalúa cada una de ellas independiente, para así -valga la redundanciadescribir lo que se investiga", Hernández, et al, (2006).

Así mismo, el corpus del estudio está conformado por las publicaciones realizadas por los noticieros "Telediario" de Multimedios Televisión, y "Las Noticias Televisa Monterrey" de Televisa Monterrey, en su página oficial de Facebook, "Telediario Nocturno", durante una semana compuesta aleatoriamente, tomando en cuenta días de lunes a viernes correspondientes a octubre de 2013 por cada uno de los noticieros, resultando así un conjunto de 10 días. 
La elección de los noticieros se realizó bajo los criterios de popularidad de las páginas en Facebook de los tres canales de señal abierta que presentan noticias en Monterrey, Azteca Noreste, Multimedios Televisión y Televisa Monterrey. El criterio para evaluar la popularidad se determinó por el número de "Me gusta" y por el número de personas que se encuentran hablando de la página, según las estadísticas de Facebook. Cabe mencionar que las páginas engloban las emisiones matutinas, vespertinas y nocturnas de los noticiarios.

Hasta el mes de abril de 2014, las estadísticas de las páginas se encontraban de la siguiente manera: Azteca Noreste con la página "Info7": 81896 "Me gusta" y 4584 personas hablando de la página; Multimedios Televisión con su página "Telediario Nocturno": 237576 "Me gusta" y 7766 personas hablando de la página; y Televisa Monterrey con la página "Las Noticias Televisa Monterrey": 346691 "Me gusta" y 18337 personas hablando de la página.

Así, en primera instancia se contemplaron las páginas (1) "Las Noticias Televisa Monterrey" y (2) "Telediario Nocturno" y se descartó (3) "Info7" ya que es el medio con menor cantidad de seguidores, con una diferencia de más de 250 mil usuarios entre la página posicionada en el primer lugar y este.

Partiendo de lo anterior, se estableció un muestreo al azar, a través de la herramienta Randomizer, que es un sitio web para generar números aleatorios. "El programa utiliza un generador de números aleatorios JavaScript para producir conjuntos personalizados de números aleatorios" (Urvaniak \& Plous, 2013). Se le asignó un número consecutivo a cada bloque de días de la semana en un mes, para realizar la selección con números simples y así obtener los días a recolectar.

Por ejemplo, el mes de octubre de 2013 tuvo cuatro lunes, se les asignó un número del 1 al 4, quedando de la siguiente manera: lunes 7, número 1; lunes 14, número 2; lunes 21, número 3 y lunes $28,4$. Posteriormente se ingresaron los número a la herramienta antes mencionada y se arrojó el número seleccionado, en este caso, el número 1, correspondiente al lunes 7 de octubre de 2013.

El procedimiento anterior se realizó con cada uno de los días de la semana (lunes, martes, miércoles, jueves y viernes) y resultaron seleccionados los siguientes días: lunes 7, martes 15, miércoles 30, jueves 31 , viernes 4 , en los que se recolectaron capturas de pantalla de 
las notas compartidas en Facebook por "Las Noticias Televisa Monterrey" y "Telediario Nocturno".

Resultando un total de dos semanas compuestas por cinco días cada una, se analizó un promedio general de 80 publicaciones diarias en cada una de las páginas. En resumen, el análisis comprende un total de 805 publicaciones realizadas en 5 días tomados al azar en las páginas de Facebook "Las Noticias Televisa Monterrey" y "Telediario Nocturno". Se toma como objeto de estudio todos los contenidos publicados o diseñados por el medio, o por su audiencia En la ficha de análisis, se retoma el Modelo para el análisis del contenido de cibermedios propuesto por José Manuel Noguera Vivo (2010), disponible en el Anexo 1, y que se adapta para la observación sistemática que se realiza en este estudio pues la ficha de Noguera analiza la página en Facebook del medio en su conjunto y en el caso particular del estudio, se analizan las publicaciones realizadas por el medio. De tal manera que se estructuran cuatro bloques de análisis que proporcionan diferentes tipos de información sobre la actividad que el medio está desarrollando en Facebook: Contenidos, Conexión, Participación y Dinamización. Así pues, se recogen los siguientes datos de cada una de las publicaciones realizadas en cada una de las páginas de Facebook seleccionadas. Además, se aprovechan los citados parámetros para estructurar bloques de análisis que proporcionan diferentes tipos de información sobre la actividad que el cibermedio está desarrollando en Facebook.

\section{DATOS DE IDENTIFICACIÓN:}

1.1 Unidad de análisis $\mathrm{n}^{\circ}$

1.2 Nombre del medio

1.3 Fecha

2. CONTENIDOS:

2.1 Tema de la nota

2.2 Género de la nota

2.3 Multimedia en la nota: video, imagen, animaciones.

3. CONEXIÓN:

3.1 Hipertextualidad (URLs internas)

3.2 Transversalidad (URLs externas)

3.3 Uso de Hastags

4. PARTICIPACIÓN 
4.1 Número de comentarios en cada publicación

4.2 Número de "Me Gusta" en cada publicación

4.3 Número de "compartir" en cada publicación

5. DINAMIZACIÓN

5.1 Respuestas por parte del medio a la audiencia (Raimondo Anselmino, 2012)

5.2 Actividades anunciadas

\section{Resultados}

Se puede establecer que la participación de los usuarios se refleja de la siguiente manera:

Tabla 1: Páginas y número de noticias del mes de octubre

\begin{tabular}{|l|l|}
\hline Página & Octubre \\
\hline $\begin{array}{l}\text { Telediario Multimedios } \\
\text { Televisión }\end{array}$ & 363 \\
\hline $\begin{array}{l}\text { Las Noticias Televisa } \\
\text { Monterrey }\end{array}$ & 440 \\
\hline
\end{tabular}

Fuente: Elaboración propia

1. Las noticias que más comentarios generaron se encuentran dentro de las notas locales y de deportes, además de los gráficos con actividades anunciadas como son las preguntas del día. En la tabla aparecen las 10 notas con mayor número de "Me gusta", donde Las Noticias Televisa Monterrey aparece con mayor cantidad de notas dentro del listado, y Telediario Multimedios Televisión solo aparece una ve en el conteo principal, aunque con una interacción mayor por parte de su público en una sola publicación.

Tabla 2: Noticias de cada página de acuerdo a la categoría periodística

\begin{tabular}{|l|c|c|c|}
\hline \multicolumn{1}{|c|}{ Página } & No. De comentarios & Sección/Categoría & Detalle de sección \\
\hline $\begin{array}{l}\text { Las Noticias } \\
\text { Televisa } \\
\text { Monterrey }\end{array}$ & 174 & Local & \\
\cline { 2 - 4 } & 151 & Actividades anunciadas & Pregunta del día \\
\cline { 2 - 4 } & 146 & Deportes & Fútbol \\
\cline { 2 - 4 } & 135 & Deportes & Fúbol \\
\cline { 2 - 4 } & 131 & Deportes & Fútbol \\
\cline { 2 - 4 } & 130 & Actividades anunciadas & Pregunta del día \\
\hline
\end{tabular}




\begin{tabular}{|l|c|c|c|}
\hline \multirow{2}{*}{} & 118 & Local & \\
\cline { 2 - 4 } & 112 & Nacional & \\
\cline { 2 - 4 } & 104 & Política & \\
\hline $\begin{array}{l}\text { Telediario } \\
\begin{array}{l}\text { Multimedios } \\
\text { Televisión }\end{array}\end{array}$ & 233 & Local & \\
\hline
\end{tabular}

Fuente: Elaboración propia

En el caso de las noticias locales, las notas con mayor número de comentarios fueron:

En Telediario Multimedios Televisión: "Deja a su bebé de meses en guardería. Se lo regresan muerto", con un total de 233 comentarios

Imagen1: Noticia con mayor número de comentarios en Fan Page del Telediario

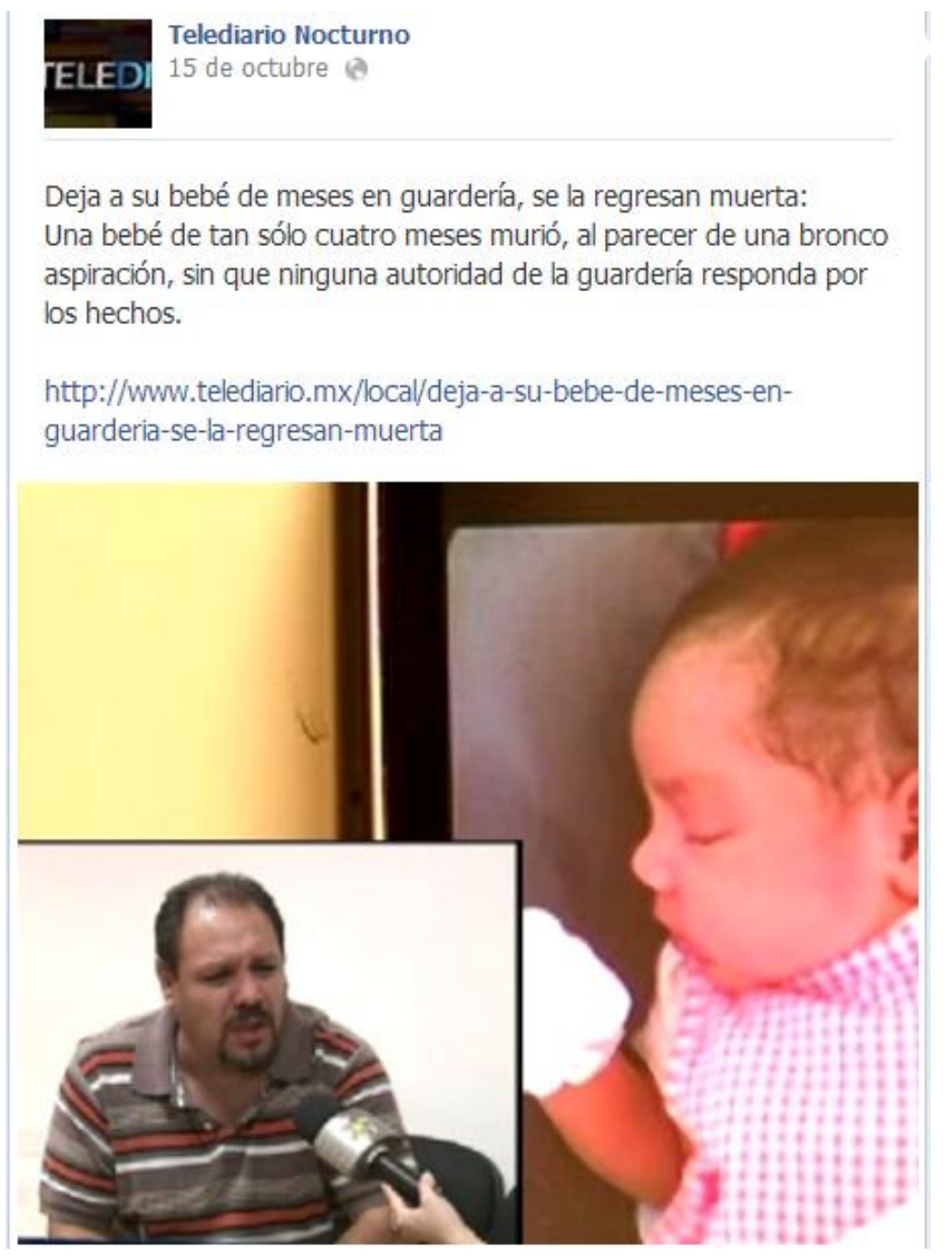

Fuente: Elaboración propia a partir de captura de pantalla 
El tipo de comentarios que se generaron iban entre condolencias a la familia en duelo, crítica a las autoridades para que investiguen el caso a profundidad, comentarios de indignación por lo ocurrido, e incluso críticas hacia la familia.

Imagen 2: Selección de comentarios de la Fan Page de Telediario

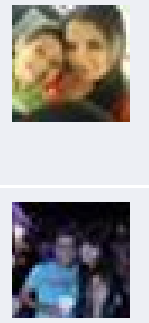

Liliana Moreno Pronta resignacion a los papas :(:) que en paz descanse y un angelito mas en el cielo que nos esta cuidando 15 de octubre a la(s) 9:14 - Me gusta ' a 3

Omar Alejandro Leal López ¿Porque no hacen una investigacion a la guarderia y checan las camaras de video? En la actualidad todas las guarderias cuentan con este servicio. No permitan que esto pase por alto. NO SE DEJEN. La guarderia tiene que hacerse cargo de TODO, hasta que se demuestre lo contrario. Porque a lo que toda la gente ve es que los de la guarderia tuvieron la culpa. En las guarderias es muy dificil que te acepten a una bebè que tiene una enfermedad, por lo mismo. Este no es el caso, ya que estaba sana desde antes. Saludos

15 de octubre a la(s) 9:14 ' Me gusta ' 16

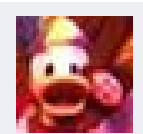

Olga Zamora Que triste, deseo pronta resignación a la mamá y abuelos

15 de octubre a la(s) 9:19 a través de celular · Me gusta

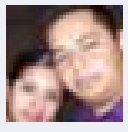

Zareth Delgado Garcia (:)

15 de octubre a la(s) 9:20 - Me gusta

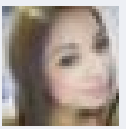

Karina Fraga de Cruz No hay como una madre para cuidar a sus propios hijos.

15 de octubre a la(s) 9:22 ' Me gusta ' $\alpha^{2} 11$

Victoria Hernández (-3) que tristeza y dolor ha de sentir la madre, tener que salir a trabajar para darle una mejor calidad de vida a este angelito, enviarla a una guarderia para que la cuiden y que no tengan las debidas precauciones.

15 de octubre a la(s) 9:16 ' Me gusta ' 6 
Diana de Garza No juzgen, que es la necesidad de trabajar, son cosas que solo Dios sabe porque pasan.. Bendiciones a los papas, no hay palabras que describan un dolor tan grande :):

15 de octubre a la(s) 9:26 ' Me gusta ' 14

鼠

Marisol Briones De Morua dios mio que tristeza me dolio el corazon al leer este tipo de noticias

consuelo a su mama. pronta resignacion y

15 de octubre a la(s) 9:29 - Me gusta ' $\propto 2$

this

Ana Maria Gzz La misma historia año tras año... los responsables seran los encargados de legislar estos negocios y los responsables de ejecutar las revisiones que marca la legislacion.... Carcel para la dueña del lugar, carcel para los inspectores, carcel para los responsables de la secretaria de salud de esta area... castigo ejemplar para estos homicidas

15 de octubre a la(s) 9:29 $\cdot$ Me gusta

Fuente: Elaboración propia a partir de captura de pantalla

En Las Noticias Televisa Monterrey: "Vendedores de Facebook invaden las calles del centro", con un total de 174 comentarios.

Imagen 3: Noticia con mayor número de comentarios en Fan Page de Las Noticias Televisa Mty

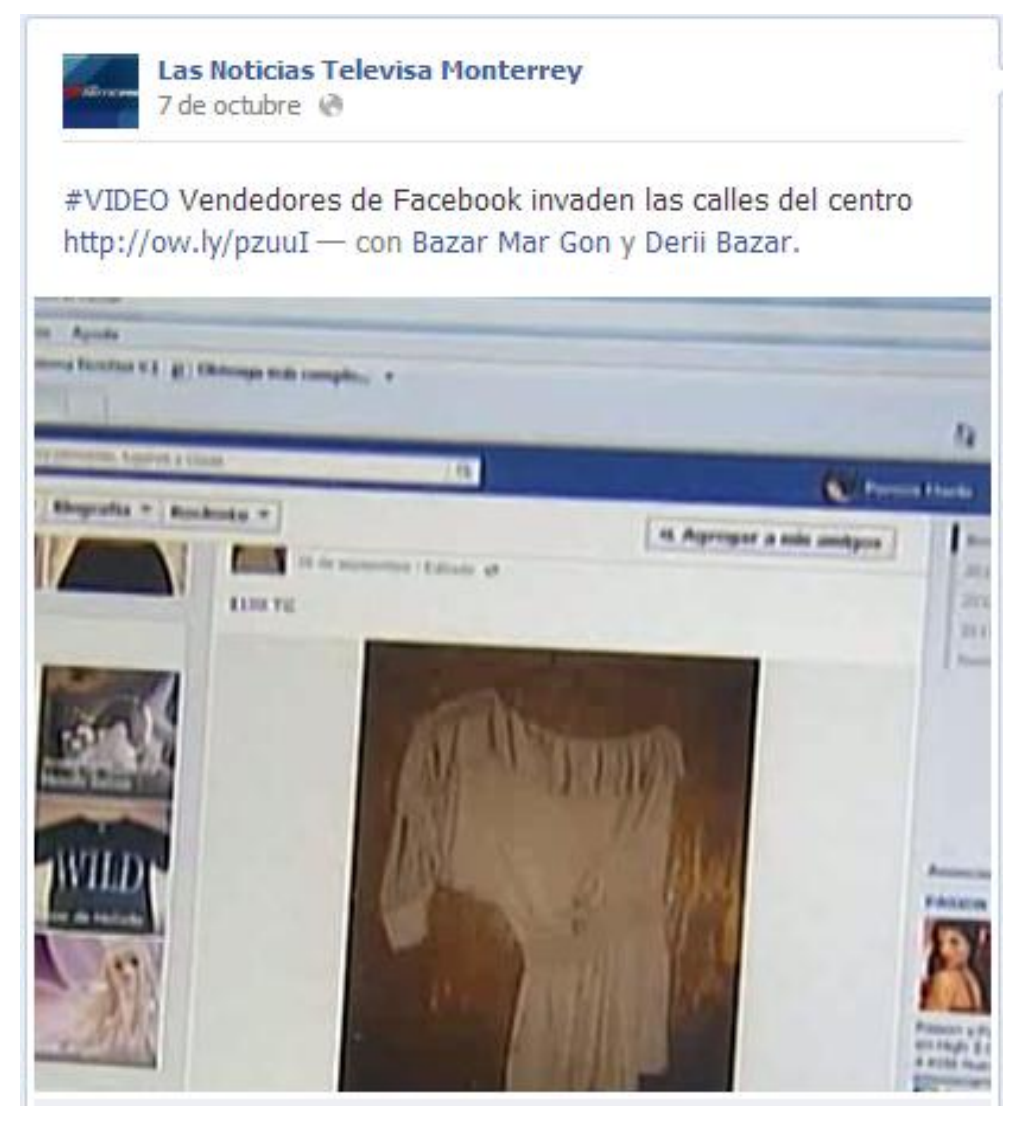

Fuente: Elaboración propia a partir de captura de pantalla 
En este caso, en los comentarios se genera un debate entre los usuarios del medio, ya que algunos se muestran a favor del comercio informal y otros los critican.

Imagen 4: Selección de comentarios de la Fan Page de Telediario

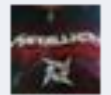

Rocio Del Roble Vazquez Y luego keeee!!!!! Cada kien hace su

"luchita" para salir adelante !! Pinches noticias PENDEJAS KE

SAKAS, INFO7 y Televisa no valen madre!! .

7 de octubre a la(s) 13:24 " Editado " Me gusta " \$3 36

Antonio Quistiano Navarro Jajaja

7 de octubre a la(s) 13:23 - Me gusta

Juany de Urbano Eeemmm no entendi jajajaja

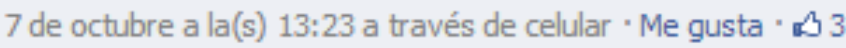

Q Mayela Diaz como no entender ???

7 de octubre a la(s) 13:23 - Me gusta

Martin Varela Yo igual no entender nad

7 de octubre a la(s) 13:24 - Me gusta

Oz Baterista y a los vendedores de pornografia de juarez y

colon?? ellos hacen mas daño vendiendo ese tipo de porqueria, obstruyendo la banqueta, ademas de que distribuyen otro tipo de 'mercancia' reto a LAS NOTICIAS que vengan y pongan en evidencia a estos delincuentes

7 de octubre a la(s) 13:25 - Me gusta * 355

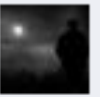

Alvaro Hdz Barrera pobrecitos....sakan el pretexto dq "comercio informal es delito" $x q$ no les pagan impuestos al recibir el pago $x$ algun producto.....q pena dan de veras.....muchos no pueden poner negocio propio y ni modo hay q sakar pa la papa d donde sea 7 de octubre a la(s) 13:25 - Me gusta * 17

Luiz Puente M No qerran decir vendedores de las calles del centro invaden facebook???????????????????????????

7 de octubre a la(s) 13:25 - Me gusta * 32

Alma Ortca de Lemus Muchas de las Chicas de los Bazares q se dedican a esto, son amas de casas o chicas q necesitan un ingreso de alguna manera, (-) felicidades chic@s, Por la creatividad y las ganas de salir adelante con su changarrito (ok)

7 de octubre a la(s) 13:25 * Me gusta ' 354

8. Dalia Leija enserio que a los de las "Noticias" hasta lo que no comen les hace daño ii

7 de octubre a la(s) 13:25 * Me gusta * 310

Gaby Ga Y que??? Ya van a sacar la nueva REFORMA

FACEBOOOKERA, jaja

7 de octubre a la(s) 13:26 a través de celular " Me gusta " $₫ 30$

Fuente: Elaboración propia a partir de captura de pantalla 
Los comentarios que se generaron en la sección de deportes, surgen posteriores a los partidos de fútbol de los dos equipos locales, Tigres y Monterrey, ya que surge controversia entre los aficionados de ambos equipos.

Imagen 5: Selección de comentarios deportivos de la Fan Page de Las Noticias Mty

Israel Aguirre Haber los Rayados ya dieron una disculpa por lo del Clasico $101 \ldots$.

Ahora, que la directiva Rayado exija que los Libres y Nacos...o como se llamen, den una disculpa cuando empiezan con sus cantos cuando salió Jonathan Orozco a calentar en Clasico No. 100....

Que exijan a esos del CENICERO, que den disculpas cuando empiezan con su POROPOPO PORPOPO el que no salte es Rayado Maricón........haber ahí nadie dice nada......sOn bien mamitas....

YA VIERON QUIENES SON LOS PECHOS FRIOS.....LAS MAMITAS DEL ESTADO..... hay si se burlaron de nosotros, si ganaron, porque se burlan de nosotros..... No es burla entiendan, ya es la costumbreeeeeeeeee......

4 de octubre a la(s) 13:32 - Me gusta ' 38

Adán López Ivan nosotros fuimos felices con cada golesito, lo mejor de un clásico es calentar los animos en la tribuna. Si ya son muy delicados y no aguantan es otro pex. 4 de octubre a la(s) 13:32 - Me gusta * 31

Jose Miguel Aguilar Pobre equipo les falta aficion, jajaja 6 mil al tec hahaha no mms

4 de octubre a la(s) 13:32 - Me gusta

Diana De la Fuente No descansaron las lloronas hasta que les pidieron disculpas jajaja iccontentos??? Pero cómo quiera perdieron por pen.....ales jajaja 4 de octubre a la(s) 13:33 a través de celular - Me gusta " 34

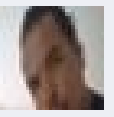

Mitlas Hernandez Lastima de jugadores y se disen profecionales sie do que en su himno hay una estrofa que dise "teniendo un bran respeto alos rivales" pero en fin asi son los rayados 4 de octubre a la(s) 13:33 - Me gusta " $₫ 1$

Alma Elizalde Pa q se disculpa q no sea joto y lo de la esposa de zava pues ni q fuera secreto o mentira jajaja 4 de octubre a la(s) 13:33 a través de celular - Me gusta " 31

Fuente: Elaboración propia a partir de captura de pantalla 
Por último, en el caso de las notas de Actividades anunciadas, que son publicaciones hechas con el propósito de interactuar directamente con el público, se obtiene una respuesta activa por parte de los usuarios. En este caso se trata de la pregunta del día por parte de Las Noticias Televisa Monterrey.

Imagen 6: Pregunta interactiva en la Fan Page de Las Noticias Mty

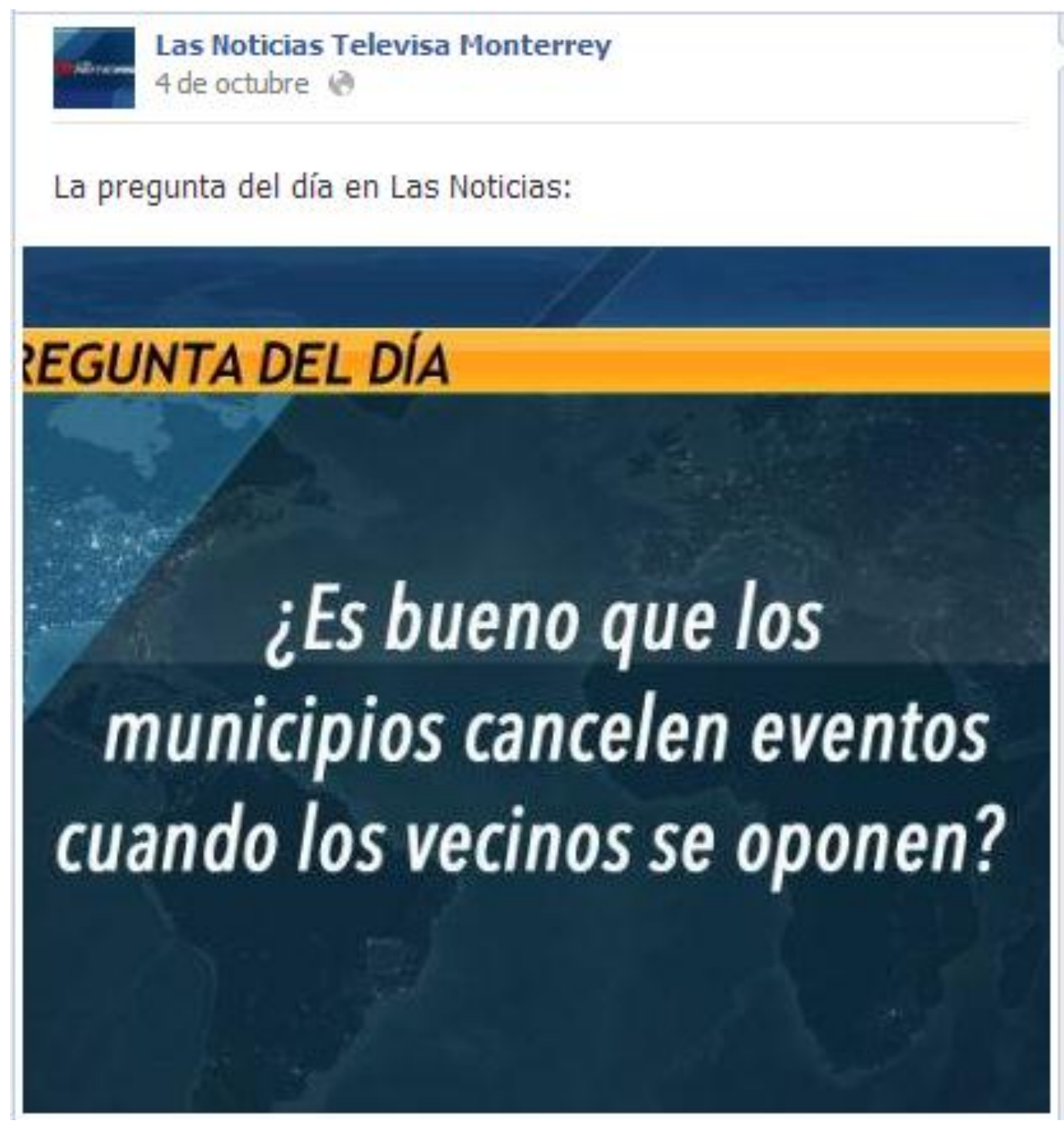

Fuente: Elaboración propia a partir de captura de pantalla

Los comentarios realizados en este tipo de publicaciones están enfocados en responder a la pregunta, sin embargo también se encuentran comentarios críticos en donde los usuarios ahondan un poco más y critican al gobierno. 
Imagen 7: Respuesta a la pregunta interactiva en la Fan Page de Las Noticias Mty

Josue Isai Orta Depende de que tipo sea...

4 de octubre a la(s) 19:15 - Me gusta

Clau Cabrera depende del evento

4 de octubre a la(s) 19:18 " Editado - Me gusta

Sergio Roberto Aburrido Claro la seguridad tranquilidad de los habitantes es primero.

4 de octubre a la(s) 19:16 a través de celular - Me gusta

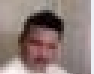

Carlos Canizales Loa San pedro. Es un municipio conservador y muy respetable, la desicion de sus habitantes.

4 de octubre a la(s) 19:16 * Me gusta ' $\$ 1$

Blanca Bravo No es bueno por que muchos lo hacen nada más

para molestar y no está bien !!,

4 de octubre a la(s) 19:17 a través de celular ' Me gusta ' " 31

Oscar Sanchez les deven de haser un salon para ese tipo de eventos en una sona donde $n$ molesten alos vecinos

4 de octubre a la(s) 19:17 ' Editado " Me gusta

的

Juan Reyes Pues todo depende de que tipo sea...porque no creo que si es para benefecio de TODOS, se quieran oponer.

4 de octubre a la(s) 19:17 · Me gusta

Brj Jrn depndiendo q eventes

4 de octubre a la(s) 19:17 $\cdot$ Me gusta

\section{Jesus Guardado Depende}

4 de octubre a la(s) 19:18 a través de celular - Me gusta

Griselda Sauceda claro que es válido. el respeto al derecho ajeno es la paz, no hay que olvidarlo

4 de octubre a la(s) 19:18 - Me gusta

Álvaro C. González A los vecinos nunca de los nuncas les darás gusto, pero hazles un evento donde les daras premios despensas y cosas gratis y estaran todos y hasta invitarán a sus familiares de otras colonias.

4 de octubre a la(s) 19:19 a través de celular ' Me gusta ' @ 1

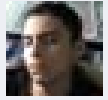

Ricardo Rodríguez Yo opino que esta mal. Porque da ha entender que el gobierno dejar muchos vacios al otorgat ese tipo de permisos. Ya que considero que es un punto ha ver eso de quienes salen afectados con dichos eventos.

4 de octubre a la(s) 19:19 a través de celular - Me gusta

Gilberto Martinez sres, depende de $q$ evento $y$ si se complica $x$ algunos vecinos q se opongan hacer encuestas y la mayoria manda.

4 de octubre a la(s) 19:19 $\cdot$ Me gusta

Fuente: Elaboración propia a partir de captura de pantalla 
2. Las noticias que más "Likes" o "Me gusta" generaron son de Las Noticias Televisa Monterrey y del tipo internacional y cultural, como se muestran en la siguiente tabla:

Tabla 3: Noticias con más "likes" en cada Fan Page

\begin{tabular}{|c|c|c|c|c|}
\hline Página & $\begin{array}{l}\text { No. de } \\
\text { me } \\
\text { gusta }\end{array}$ & Titular & Sección & País \\
\hline \multirow{6}{*}{$\begin{array}{l}\text { Las Noticias } \\
\text { Televisa } \\
\text { Monterrey }\end{array}$} & 958 & $\begin{array}{l}\text { Esquiva pequeño de } 6 \\
\text { años seguridad y abraza } \\
\text { al Papa }\end{array}$ & Internacional & Vaticano \\
\hline & 830 & $\begin{array}{l}\text { Se une Ruta } 2 \text { a campaña } \\
\text { contra cáncer de mama }\end{array}$ & Cultura & \\
\hline & 673 & $\begin{array}{l}\text { Duermen niños chinos } \\
20 \text { minutos durante } \\
\text { clases }\end{array}$ & Internacional & China \\
\hline & 488 & $\begin{array}{l}\text { Celebran a San } \\
\text { Francisco de Asis }\end{array}$ & Cultura & \\
\hline & 434 & $\begin{array}{l}\text { Burla pequeño de } 6 \text { años } \\
15 \text { y abraza al Papa } \\
\text { Francisco }\end{array}$ & Cultura & Vaticano \\
\hline & 347 & $\begin{array}{l}\text { Aseguran que aparece } \\
\text { figura de Jesús, tras paso } \\
\text { de lluvias }\end{array}$ & Cultura & \\
\hline \multirow{3}{*}{$\begin{array}{l}\text { Telediario } \\
\text { Multimedios } \\
\text { Televisión }\end{array}$} & 733 & $\begin{array}{l}\text { Deja a su bebé de meses } \\
\text { en guardería. Se lo } \\
\text { regresan muerto }\end{array}$ & Local & \\
\hline & 381 & $\begin{array}{l}\text { Descubren animal } \\
\text { marino de casi } 6 \text { metros } \\
\text { en California }\end{array}$ & Internacional & $\begin{array}{l}\text { Estados } \\
\text { Unidos }\end{array}$ \\
\hline & 397 & $\begin{array}{l}\text { Celebran a San } \\
\text { Francisco de Asis en } \\
\text { Real de Catorce }\end{array}$ & Cultura & \\
\hline
\end{tabular}

Fuente: Elaboración propia

Llama la atención que las noticias internacionales que destacan son aquellas relacionadas con el Vaticano, ya que la segunda categoría que salta a la vista es la de cultura.

3. El día de la semana que más movimiento presenta es el miércoles: 
Tabla 4: Noticias generadas cada día de la semana

\begin{tabular}{|c|c|c|c|}
\hline Día & $\begin{array}{l}\text { Número de } \\
\text { notas }\end{array}$ & $\begin{array}{l}\text { Número de } \\
\text { Me gusta }\end{array}$ & $\begin{array}{l}\text { Númer de } \\
\text { Comentarios }\end{array}$ \\
\hline Lunes & 158 & 5901 & 1080 \\
\hline Martes & 167 & 4155 & 1101 \\
\hline Miércoles & 179 & 6650 & 1341 \\
\hline Jueves & 170 & 3212 & 903 \\
\hline Viernes & 131 & 6300 & 1409 \\
\hline Total & 805 & 26218 & 5834 \\
\hline
\end{tabular}

Fuente: Elaboración propia

4. Características generales:

Uso de multimedia en las publicaciones

Tabla 5: Tipo de Multimedia utilizados en las Fan Pages

\begin{tabular}{|r|c|}
\hline Multimedia & No. De notas \\
\hline Fotografía & 470 \\
\hline Enlaces & 730 \\
\hline Hastags & 156 \\
\hline
\end{tabular}

Fuente: Elaboración propia

Uso de hashtags para indicar el contenido de multimedia en las notas.

Se utilizan mucho la transversalidad, ya que los medios incluyen enlaces hacia otros sitios web donde pueden visualizar las notas completas.

En actividades anunciadas, se presentan preguntas del día por parte de los noticieros, además de secciones como "sabías que" o concursos para regalar boletos de cine, entradas a partidos de futbol.

Los usuarios no participan con videos ni con fotografías, solamente con texto en los comentarios.

\section{Hallazgos y conclusiones}

Saber cómo se da la presencia de los medios en las redes sociales es importante para diseñar estrategias que sean eficaces con las nuevas 
formas de difundir el trabajo periodístico y dar un valor añadido (de interactividad, de integración y de promoción) a lo expuesto en forma tradicional.

En las diferentes redes sociales se pueden generar valor que redundaría en una mejor experiencia para el usuario porque daría facilidad de acceso a las noticias (ya que una gran parte de tiempo lo pasan conectados s una red social) en cualquier momento. Además se pueden personalizar contenidos al abrir espacios definidos $y$ especializados en las redes sociales de acuerdo a las características y gustos del público y las ventajas que ofrecen los espacios.

Además se puede hacer una actualización de información, en muchos de los casos porque se pueden tomar los datos de los sitios web de los propios medios y así se adelantan a la competencia.

Otro elemento es la confianza que ya se ha ganado el medio tradicional y que aunada a la confianza que muchos usuarios le confieren a la red (IAB señala que el 49\% de los usuarios de internet confía más en la red sobre un 23\% que quienes en la TV, $14 \%$ en la radio y los periódicos o un $8 \%$ en las revistas) (2014).

Se debe entonces tomar en cuenta que los medios tradicionales tienen la obligación de diseñar estrategias globales de actuación en estas redes, más allá de por simple "moda", para integrarlo en sus rutinas redaccionales con múltiples objetivos: captación de fuentes, retroalimentación de la Última Hora publicada, creación de espacios de autoría múltiple, rastreo y seguimiento de conversaciones, establecer puntos de contacto con la audiencia, etc. (Noguera, 179)

Aunque hay que tener cuidado en que los contenidos que se publiquen sean de calidad y que ofrezcan algún valor más allá de volcado del medio tradicional. Pueden provocar la acción del lector, generar ganancias económicas, seguidores al programa o lectores, en resumen, hay mucho por ganar y también mucho por perder si se van descuidando a los nuevos públicos y las rutinas diarias del nuevo receptor de noticias en este mundo informativo convergente.

La composición de las publicaciones trata de cautivar al usuario para que cliquee el link del sitio oficial del noticiario, en donde puede leer la información completa, así que ambos medios hacen uso de imágenes relacionadas con las notas para llamar la atención del usuario. 


\section{Referencias bibliográficas}

ComScore Media Metrix (2013): Futuro Digital Latinoamérica 2013 y Tendencias de Medición. comScore, Inc.

De Foncuberta, M. (2011): La noticia. Pistas para entender el mundo. Barcelona, España: Paidós.

Díaz-Campo, J., y Segado-Boj, F. (2013): “La radio en Facebook: análisis de los perfiles de las principales emisoras y programas radiofónicos en España”, en Icono 14 , 11 (2), páginas 209 a 228.

García González, M. (2004): Periodistas, ciudadanos del mundo. Fundamentos del periodismo. Madrid: Fragua.

Gomis, L. (1994): "Persuadir la gent de que passen coses interessants”, en Periodíatica (7), páginas 59 a 64.

Hernández Sampieri, R.; Fernández Collado, C. y Baptista Lucio, M. (2010): Metodología de la investigación. México, D.F.: McGRAWHILL.

Iab México (2014): Estudio de Consumo de Medios entre internautas mexicanos 2014. (M. B. IAB México, Productor) Recuperado el 20 de Agosto de 2014, de Ventas Televisa:

http://ventas.televisa.com/estudios/\#!/estudio-de-consumo-demedios-2

Lara, T. (Julio-Septiembre de 2008): La nueva esfera pública. Los medios de comunicación como redes sociales. Obtenido de Telos:

http://telos.fundaciontelefonica.com/telos/cuadernoimprimible.asp @,idarticulo $=9 \& \mathrm{rev}=76 . \mathrm{htm}$

Martínez Albertos, J. (1978): La noticia y la comunicación de públicos. Madrid.

Noguera Vivo, J. M. (2010): "Redes sociales como paradigma periodístico. Medios españoles en Facebook", en Revista Latina de Comunicación Social (65), páginas 176 a 186.

Pastor, L. (2009): La gestión periodística del público I. Teoría de las cartas al director. Barcelona: UOC.

Raimondo Anselmino, N. (2012): La prensa online y su público: un estudio de los espacios de intervención y participación del lector en Clarín y La Nación. Buenos Aires: Teseo.

Rodíguez-Martínez, R., Codina, L., y Pedraza-Jiménez, R. (enero-febrero de 2010): “Cibermedios y web 2.0: modelo de análisis y 
resultados de aplicación", en El profesional de la información, páginas 35 a 44.

Salaverría, R., y García Avilés, J. A. (2008): “Convergencia tecnológica en los medios de comunicación: reto para el periodismo", en Tripodos (23).

Said Hung, E. S. (2013): "La gestión de los social media en los medios informativos iberoamericanos", en Comunicación y Sociedad, 26 (1), páginas 67 a 92.

Tejedor Calvo, S. (2010): "Los cibermedios iberoamericanos en la web 2.0. Transformaciones y tendencias de los medios online de América Latina, España y Portugal en el contexto de la web social", en Mediaciones Sociales. Revista de Ciencias Sociales y de la Comunicación, , 7, páginas 57 a 87.

Urbaniak, G. C. y Plous, S. (2013 de septiembre de 2013): En Research Randomizer, Version 4.0. Obtenido de http://www.randomizer.org/

World Internet Project. (2013): Estudio de hábitos y percepciones de los mexicanos sobre Internet y diversas tecnologías asociadas". Tecnológico de Monterrey, Campus Estado de México, Departamento de Comunicación y Arte Digital, Escuela de Ciencias Sociales y Humanidades, Estado de México. 


\section{Un programa transmedia de sketches de humor revoluciona la TV y las redes sociales en Ecuador}

Carlos Ortiz, Universidad Técnica Particular de Loja (UTPL, Ecuador),ccortiz@utpl.edu.ec

Miguel Granda, Universidad Técnica Particular de Loja (UTPL, Ecuador),megranda2@utpl.edu.ec

Abel Suing, Universidad Técnica Particular de Loja (UTPL, Ecuador), arsuing@utpl.edu.ec

\section{Resumen}

Un grupo de jóvenes cineastas ecuatorianos, a través de un proyecto novedoso y creativo se convierten en menos de tres años en todo un éxito en las diferentes redes sociales para su posterior migración a la televisión tradicional.

Su debut lo realizan en noviembre de 2011 teniendo como plataforma un canal de YouTube, aquí lanzan su primer sketch de humor que rápidamente se vuelve viral en Facebook y Twitter, poco a poco fue creciendo y experimentando con lenguajes transmedia a través de YouTube, convirtiéndose en canal de vídeo en esa red social audiovisual, posteriormente dan el salto a la pantalla de televisión tradicional el 14 de septiembre de 2013, donde también logra altos índices de audiencias y viraliza contactos millonarios tanto en la televisión tradicional como en las redes sociales.

En este caso se puede observar como los nuevos medios sociales digitales potencian un proyecto spin-off que luego da vida a un 
programa de éxito de la TV tradicional, conservando toda su genuina y original potencia transmedia. Esté artículo analiza el caso del programa "Enchufe'Tv", creado y desarrollado por la productora Touché Films, desde sus inicios en Internet hasta su actual emisión en el canal un comercial de televisión abierta de Ecuador.

Palabras clave: transmedia, humor, televisión, internet, redes sociales.

\section{Introducción}

— L número y relevancia de las investigaciones sobre las redes el análisis de redes sociales, aún es pequeño pero crece exponencialmente, en la presente investigación nos enfocaremos en como las redes sociales pueden ser plataformas para impulsar productos audiovisuales como es el caso de Enchufe'Tv.

"Las redes son estructuras de relaciones sociales que unen elementos o agentes de la sociedad (personas y/o organizaciones) a través de vínculos o lazos que se pueden representar, respectivamente, mediante líneas y nodos" (Campos, 2013: 14)

Las relaciones y la interactividad que generan las redes sociales es el objetivo de muchas organizaciones que han visto en ellas una plataforma para expandir y promocionar su producto. Es lo que Castells (2009) define: una sociedad red es aquella cuya estructura social está compuesta de redes activadas por tecnologías digitales de la comunicación y la información basadas en la microelectrónica. El crecimiento de usuarios de la red de redes podría explicarse por la globalización pero también por el "incremento de una clase media que en Ecuador entre los años 2003 y 2012 creció un 35\%" (OBITEL, 2014) y dispone de recursos para adquirir los nuevos dispositivos, que incluyen acceso a Internet.

La relación de las Redes Sociales con los medios de comunicación cada vez va en aumento, tanto prensa como radio y televisión se han unido a las redes sociales al fin de estar a la par con sus seguidores. 
"Las redes sociales se configuran con un nuevo sistema de entretenimiento y también de información, que toma elementos, recursos y características de los medios tradicionales pero que incorpora tanto un nivel de interacción como un modelo de negocio más magro. Su evolución apunta más hacia el medio audiovisual y virtual que a las características de la prensa escrita. Como nuevo medio, su aplicación y proyección es la Web 2.0 y el llamado software social” (Campos, 2013: 67).

El propósito de esta investigación es conocer el nacimiento, desarrollo y posicionamiento de un proyecto audiovisual creado exclusivamente para la Web y su posterior migración a la televisión tradicional. El caso de estudio es la serie humorística Enchufe'Tv, producida íntegramente en Ecuador, que se emite a través de un canal de YouTube y cuenta con millones de seguidores tanto en dicha red social como en Facebook.

Los objetivos de la investigación son: analizar el proceso de posicionamiento y migración de un programa creado para la WEB a la televisión tradicional; conocer las tácticas utilizadas para viralizar los videos; determinar el éxito que tiene una serie creada para la WEB al ser transmitida en televisión tradicional; y analizar el crecimiento de seguidores y fans en las red social YouTube.

Las preguntas de investigación que se plantean son: 1.- ¿Cambia la narrativa de un producto audiovisual creado para la web, para ser transmitido en la TV tradicional? 2.- ¿Qué estilo de lenguaje y estilo debe tener un producto audiovisual para que sea exitoso a nivel internacional? 3.- ¿Cuáles son las claves para tener un modelo exitoso a nivel de la web? 4.- ¿Qué tan rentable es iniciar un proyecto audiovisual en la plataforma Youtube? 5.- ¿Se puede pasar directamente de la web a la pantalla grande o necesariamente tienen que pasar por la pantalla chica?

Las hipótesis que nos planteamos son: 1.- Los medios tradicionales no apoyan nuevas propuestas audiovisuales, sin estar seguros de su rentabilidad económica. 2.- Los productos audiovisuales exitosos creados y producidos para la WEB pueden migrar a la TV tradicional y obtener el mismo éxito. 3.- El estilo y narrativa audiovisual cambian de acuerdo a la plataforma a utilizarse. 4.- El mejor género audiovisual para conquistar un medio web es la comedia. 
5.- La utilización de un lenguaje coloquial ecuatoriano puede ser bien visto y entendible a nivel internacional.

Para la investigación se realizó un análisis cuantitativo y cualitativo, del canal en YouTube de EnchufeTv, desde el 13 de noviembre de 2011 fecha en que se realizó el lanzamiento del primer sketch "El peor casting", hasta el 25 de agosto de 2014 en que se cierra esta investigación. Los datos fueron levantados entre el 25 de agosto y 1 de septiembre de 2014.

\section{Inicios de Enchufetv}

Enchufe'Tv es un proyecto de la productora ecuatoriana Touché Films, ${ }^{32}$ que utiliza un canal de Youtube llamado Enchufe'Tr como plataforma de la serie de "sketches cómicos donde diversas situaciones y personajes cotidianos son vistos con una irreverencia única". (Touché Films, 2014).

En el año 2011, un grupo de amigos formados en el Instituto Superior Tecnológico de Cine y Actuación- (Incine) en Ecuador, "se reunieron y empezaron a quejarse y criticar el audiovisual ecuatoriano, nos quejamos tanto que llegamos a la conclusión de que debíamos hacer algo para ser criticados también” (Boscán, 2012).

Luego de llamar a las puertas de algunos canales de la televisión ecuatoriana, donde no tuvieron acogida, se dieron cuenta que es difícil abrirse paso con nuevas ideas en los medios tradicionales. Así lo menciona Campos (2013) "los medios de comunicación tienen una asignatura pendiente con las redes sociales: adaptarse para sobrevivir debe ser la máxima. La proliferación de medios sociales debe hacer reaccionar a las empresas periodísticas". Por esta razón ven en YouTube una plataforma con total libertad, sin filtros, ni censura para exponer su producción, demostrando que las redes sociales digitales pueden ser el sitio de inicio para grandes ideas.

\section{Lanzamiento del canal en You'Tube Enchufe'Tv}

El 13 de noviembre de 2011, lanzan su primer sketch en su propio canal de Youtube, titulado $<<$ El Peor Casting $>>$, que actualmente (24 de octubre de 2014) tiene 2.505.898 reproducciones; se trata de un video que busca generar expectativa de lo que será el canal de

\footnotetext{
${ }^{32}$ Productora ecuatoriana creadora de contenidos de entretenimiento para nuevos medios.
} 
comedia, donde participan actores que cada semana están presentes en diferentes situaciones, "vistas desde su humor negro, absurdo y satírico, han hecho esta serie web se ubique en el quinto canal de YouTube más grande de Latinoamérica."(Ávila, 2014).

Debido al éxito alcanzado por los sketches publicados, se empiezan a sumar a este proyecto personajes reconocidos a nivel nacional, el 16 de abril de 2012 Andrés Crespo actor ecuatoriano que participa en películas nacionales actúa en el sketch" "Las Amigas de Camilo con Blanquito" logrando nuevamente millones de visitas.

El 8 de noviembre del 2012 lanzan el sketch más visto en la historia de EnchufeTv "Compra Condones" con 18.880.938 reproducciones y 16.527 comentarios con la participación de unos de los actores más reconocidos de la serie Raúl Santana, quién interpreta el papel de Chichico, trata de una situación que atraviesan los adolescentes al intentar comprar preservativos por primera vez en una farmacia. En la web 2.0 producen contenidos (blogosfera), participan del valor (intercambio) y colaboran en el desarrollo de la tecnología. El proceso de comunicación genera, en definitiva, un flujo activo de participación.

\section{El primer año de Enchufe'Tv y el lanzamiento de nuevos segmentos}

Al cumplirse un año del canal Enchufe'Tv en YouTube, hacen el lanzamiento oficial de un nuevo segmento denominado: "microYAPA 34 ", que son videos cortos, aproximadamente de 40 segundos de duración, siguiendo los mismos lineamientos humorísticos de los sketch, pero cuentan con menos cantidad de reproducciones y se publican los miércoles.

También realizan un nuevo segmento denominado: Promo ${ }^{35}$ que es un avance de lo que se verá en el próximo sketch, y presentan el Making Off contando lo que ocurre tras cámaras durante el rodaje de los sketches.

\footnotetext{
${ }^{33}$ Ske'Tch: denominación propia de Touché Films refiriéndose a los sktechs lanzados los días domingos.

${ }^{34}$ Microyapa: Denominación propia de Touché Films refiriéndose a los sktechs de corta duración, aproximadamente 1 minuto lanzados los días miércoles.

${ }^{35}$ Promo: Avance del siguiente Ske'Tch
} 


\section{De la web a la televisión tradicional}

El 14 de septiembre de 2013 dan el salto de su formato digital a la televisión tradicional, incorporan el programa "EnchufeTV" en la cadena televisiva Ecuavisa ${ }^{36, " ~}$ "canal con mayor audiencia en el país" (Obitel, 2014: 240). El objetivo de este paso a la televisión, según Andrés Centeno productor de EnchufeTv, fue buscar nuevas audiencias.

"Teníamos alcance con lo digital. Lo que hicimos es abrazar a esta televisora (Ecuavisa), que tiene una presencia de cobertura del $97 \%$ en el país, y llegar a las audiencias que no nos habían visto. Esto generó el 'efecto de enchufe', muchos de los adolescentes que nos veían por redes empezaron a vernos en sus casas con sus padres, abuelos, con sus amigos y vecinos". (Ávila, 2014)

Para la transmisión del programa Enchufe'TV "Ecuavisa seleccionó los capítulos, tomando en cuenta las políticas del canal, la Ley Orgánica de Comunicación y la audiencia.”(Ávila, 2014).

$\mathrm{Al}$ inicio este programa fue transmitido para todo el país, sin embargo a la semana de su lanzamiento pesaron las diferencias regionales, Adoum 2000, en su libro Ecuador señas particulares, menciona "que el modo de hablar en la Sierra" ecuatoriana lleva, reconocible, la impronta del quichua, ${ }^{38},(\ldots)$ pero sobre todo la del modo de ser su poblador, no sé si, efectivamente, se puede hablar de un modo de ser serrano, frente a uno de ser costeño, porque mucho de lo que se difunde a través de los medios lo difunden como estereotipo". (Adoum, 2000). Estas razones pesaron para que el programa fuera retirado de la señal que se emite para la Costa, dejándolo únicamente para la Región Sierra. "Para la emisión del sábado 21 de septiembre de 2013 se dejó de emitir para la señal zona

\footnotetext{
${ }^{36}$ Ecuavisa: es una de las principales cadenas de televisión privadas, de cobertura nacional en Ecuador, (1967) Operado por Corporación Ecuatoriana de Televisión S.A. y Televisora Nacional Canal 8 C.A.

${ }^{37}$ Región interandina o comúnmente conocida como Sierra. Es una de las cuatro regiones naturales del Ecuador. El serrano tiene como peculiaridad en su comportamiento ser bastante amable y cordial en el trato, recatado, sereno y algo receloso.

${ }^{38}$ Costa litoral o mejor conocida como Costa, el costeño se caracteriza por ser descomplicado y alegre.
} 
Costa y centro sur (Ecuavisa, 2013), transmitiéndose únicamente para la región Sierra en el horario Prime Time (22h30).

Con este antecedente, la productora audiovisual Touché films abre un precedente histórico en los productos audiovisuales ecuatorianos, ya que ellos como nativos digitales con su producto estrella enchufe tv pudieron migrar del medio digital a un medio tradicional, debido a su éxito alcanzado en la web.

\section{Enchufe'Tv consigue rentabilidad económica a través de su propuesta}

El 13 de marzo del 2013 EnchufeTr pasó a ser Partners con YouTube $^{39}$, esto significa que trabaja de manera conjunta con las multinacionales digitales y divide las ganancias al insertar publicidad en cada uno de sus vídeos; Touché Films ganará un porcentaje de acuerdo al número de reproducciones de sus videos ${ }^{40}$. En julio de 2014 realizan un nuevo segmento denominado "sponsor" sktechs cómicos que sirven para promocionar bienes, productos o servicios, al igual que ser Partners de YouTube, esto genera ingresos económicos para la productora Touché Films, abriendo un nuevo mercado poco utilizado en Ecuador para la promoción y difusión de publicidad.

\section{Un programa con polémica}

Un evento importante que marca un giro importante para Enchufe TV, se da el 6 de julio de 2014 cuando publican el video "el chico del barril" que es una parodia y un tributo el Chavo del Ocho, a su estilo en la descripción del video claramente manifiestan "lo hicimos con cariño y si nos reclamas, responderemos: se nos chipoteó”. Debido a las duras críticas por parte de los autores de la serie original del Chavo del Ocho; el video solo puede ser visto mediante enlace y permanece oculto del buscador de YouTube, también generó críticas positivas y provocó en dos días tres millones de visitas y en una semana diez millones, más de doscientos mil 'me gusta', veinte mil 'no me gusta', con el 90\% de comentarios positivos. (Ávila, 2014).

\footnotetext{
39 https://www.youtube.com/watch?v $=$ FxzdnO-RZtc\&feature=youtu.be

${ }^{40}$ https://support.google.com/youtube/answer/72851?hl=es

${ }^{41}$ Denominación propia de Touché Films refiriéndose a los sktechs de promoción de bienes, productos o servicios.
} 


\section{Premios y reconocimientos}

Han logrado varios reconocimientos internacionales, en noviembre de 2013 en la primera entrega de los Youtube Music Award, ganan el primer lugar en la categoría "Golden Play" atribuido a los canales de Youtube con más de un millón de subscriptores. En septiembre de 2014 en los Streamy Awards se galardonó a EnchufeTv con el reconocimiento del "Show del Año" elegido por la audiencia, y fueron nominados como mejor "Show Internacional".

En noviembre de 2013, Enchufe.tv recibió el "Play de Oro" en Nueva York en la primera edición de los premios YouTube Music Awards, superó el millón de suscriptores, hasta finales de septiembre 2013 se posiciona en el top 50 de los canales más vistos en YouTube.

\section{EnchufeTv en redes sociales}

Además del éxito alcanzado en Youtube, logran posicionarse en otras redes sociales como: Facebook donde tienen 5.394 .023 seguidores, en Twitter 536.378, en Instagram 68.512 fans y en YouTube 7.284.618 seguidores.

También tienen su página web (www.enchufe.com) lo que hace ampliar su popularidad y aceptación no solo a nivel local, sino internacional en países como México, Colombia, Ecuador y Perú. En los dos primeros tienen más audiencia que en el propio país. El canal genera al mes entre 80 y 90 millones de visitas entre los 457 contenidos que tiene subidos en su canal desde noviembre del 2011 (Ávila, 2014).

\section{Metodología}

Análisis cuantitativo. EnchufeTv sube un skeTch semanalmente los domingos, para seleccionar la muestra se tomó un video trimestralmente desde el lanzamiento del primer sketch. Para está investigación únicamente se tomó en cuenta los videos de la categoría sketch, porque son los de mayor duración, mayor cantidad de visitas y de periodicidad semanal, dejando de lado los segmentos: microYAPA, Making Off y spOnsOr. Dando como resultado un total de 12 videos analizados. 
Tabla 1: Fecha y nombre de la muestra seleccionada para la investigación

\begin{tabular}{|l|l|}
\hline Fecha & \multicolumn{1}{c|}{ Nombre del skeTch } \\
\hline $13 / 11 / 2011$ & El peor casting \\
\hline $2 / 2 / 2012$ & $\begin{array}{l}\text { 2Tipos 1Ascensor: Un Barquito } \\
\text { Lleno De.. }\end{array}$ \\
\hline $6 / 5 / 2012$ & 2Tipos 1Ascensor: Reemplazo \\
\hline $6 / 8 / 2012$ & $\begin{array}{l}\text { Viendo Como Estudiante En } \\
\text { Supletorios }\end{array}$ \\
\hline $4 / 11 / 2012$ & Ya Supéralo \\
\hline $3 / 2 / 2013$ & Mundo Al Revés: Gringos y Latinos \\
\hline $5 / 5 / 2013$ & Las Cruzetas \\
\hline $4 / 8 / 2013$ & Si Enchufe Fuera... \\
\hline $3 / 11 / 2013$ & Viendo Como en Fiesta de Oficina \\
\hline $3 / 2 / 2014$ & Cachas Que Creciste \\
\hline $4 / 5 / 2014$ & Peaje Épico \\
\hline $3 / 8 / 2014$ & Te Ahuevas - ¡Qué Chuchas! \\
\hline
\end{tabular}

Fuente: Elaboración propia a partir del YouTube de EnchuféTv

Como herramientas cuantitativas se elaboró una ficha para levantamiento de información en la que constan los siguientes datos:

Tabla 2: Ficha de recolección de datos para YouTube

\begin{tabular}{|l|l|l|l|l|l|l|}
\hline Nurnbre & Fecha & $\begin{array}{l}\text { Número } \\
\text { de } \\
\text { visitas }\end{array}$ & $\begin{array}{l}\text { Me } \\
\text { Gusta }\end{array}$ & $\begin{array}{l}\text { Nu } \\
\text { me } \\
\text { Gusta }\end{array}$ & $\begin{array}{l}\text { Número de } \\
\text { Cumentarios }\end{array}$ & $\begin{array}{l}\text { Comcntario } \\
\text { con más me } \\
\text { gusta }\end{array}$ \\
\hline & & & & & & \\
\hline \multicolumn{5}{|c|}{ Captura de Pastalla } \\
\hline \multicolumn{5}{|c|}{ Estadisticals } \\
\hline Visualizaciones &
\end{tabular}

Fuente: Elaboración propia

Con esta ficha se podrá obtener datos cuantitativos que permitan determinar la evolución y posicionamiento de Enchufe'Tv en esta red social. La ficha contiene la siguiente información. 
Nombre: Nombre con el que se identifica el Sketch en la plataforma YouTube

Fecha: Fecha en la que se subió el video a la plataforma YouTube

Visitas: Es el número de reproducciones alcanzadas por el Sketch desde la fecha de su publicación hasta la fecha de recolección de datos.

Me Gusta: Número total de clics al icono de la mano con el pulgar hacia arriba (Me Gusta este Video) desde la fecha de su publicación hasta la fecha de recolección de datos. Es un indicador que refleja la aceptación del video. (Este valorativo solo pueden darlo quien posee un canal de YouTube o una Cuenta en Google)

No Me Gusta: Número total de clics dados en el icono de la mano con el pulgar hacia abajo (No Me Gusta este Video) desde la fecha de su publicación hasta la fecha de recolección de datos. Es un indicador que refleja la no aceptación del video (Este valorativo solo pueden darlo quien posee un canal de YouTube o una Cuenta en Google)

Comentarios: El número total de comentarios e interacciones que ha generado el video desde la fecha de su publicación hasta la fecha de recolección de datos (Este espacio de opinión solo pueden darlo quien posee un canal de YouTube o una Cuenta en Google)

Comentario con mayor cantidad de me gusta: Se tomó un Screenshot (Pantallazo) al comentario de opinión que genero mayor cantidad de aceptación del público mediante su número de me gustas (Este valorativo solo pueden darlo quien posee un canal de YouTube o una Cuenta en Google).

Captura de Pantalla: Se tomó un Screenshot (Pantallazo) de la parte detallada de la información del video, donde se aprecia: el nombre del video, nombre del canal el número de visitas, cantidad de comentarios, me gusta, no me gusta, numero de suscritores del canal, información del video, numero de comentarios, fecha de publicación del video.

Estadísticas: Se tomó un Screenshot (pantallazo) a las estadísticas acumuladas que da la propia plataforma de YouTube con variables como: visualizaciones, suscripciones, compartido. Cuya estadística dan datos son semestrales (Enero-Febrero) desde el año de la publicación del video. 


\section{Análisis de resultados}

Tabla 3: El peor casting. 13 de noviembre de 2011

\begin{tabular}{|c|c|c|c|c|c|c|}
\hline Nombre & Fecha & Visitas & $\begin{array}{l}\text { Me } \\
\text { Gusta }\end{array}$ & $\begin{array}{l}\text { No me } \\
\text { Gusta }\end{array}$ & $\begin{array}{l}\text { Número } \\
\text { de } \\
\text { Comentari } \\
\text { os }\end{array}$ & $\begin{array}{l}\text { Comentario con } \\
\text { más like }\end{array}$ \\
\hline $\begin{array}{l}\text { El peor } \\
\text { casting }\end{array}$ & $\begin{array}{l}13 / 11 / 20 \\
11\end{array}$ & 2.296 .676 & 11.134 & 918 & 1.671 & 闻 \\
\hline \multicolumn{7}{|c|}{ Captura de Pantalla } \\
\hline & 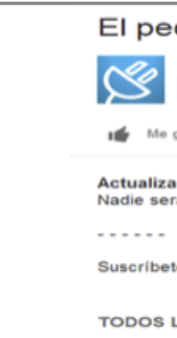 & 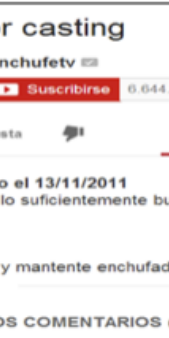 & thomection & compartit an & 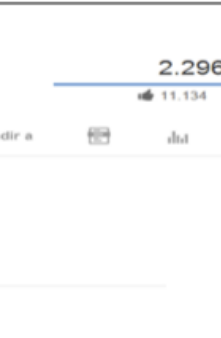 & $\frac{676}{10}$ \\
\hline \multicolumn{7}{|c|}{ Estadisticas } \\
\hline & & & & & & Acumulado Diarlo 0 \\
\hline \multirow{2}{*}{\multicolumn{2}{|c|}{$\begin{array}{l}\text { VISUALIZACIONES } \\
2.293 .341\end{array}$}} & 3.0000000 & & & & \\
\hline & & 20000000 & & & & \\
\hline & & & 3e 2012 & de 2012 & Jul de 2013 & ene. de 2014 \\
\hline
\end{tabular}

Fuente:

https://www.youtube.com/watch?v=TyiMl5doLwU\&list=UUoGDh1Xa 3kUCpok24JN5DKA (Recuperado el 25 de agosto de 2014)

Tal como se puede apreciar en la tabla, el primer video de Enchufe'Tv denominado "El peor casting" durante la semana que se analizó, mantenía 2.296.676 reproducciones, 11.134 "Me Gusta" una cifra alta en referencia a los 918 "No Me Gusta". El comentario que genero más "Me gusta" por parte de la audiencia fue el del usuario Guitarmusic43, que obtuvo 110 me gustas.

En cuanto a la curva estadística sobre visualizaciones, se puede notar que las reproducciones suben de forma acelerada. 
Tabla 4: Dos tipos un ascensor. 02 de febrero de 2012

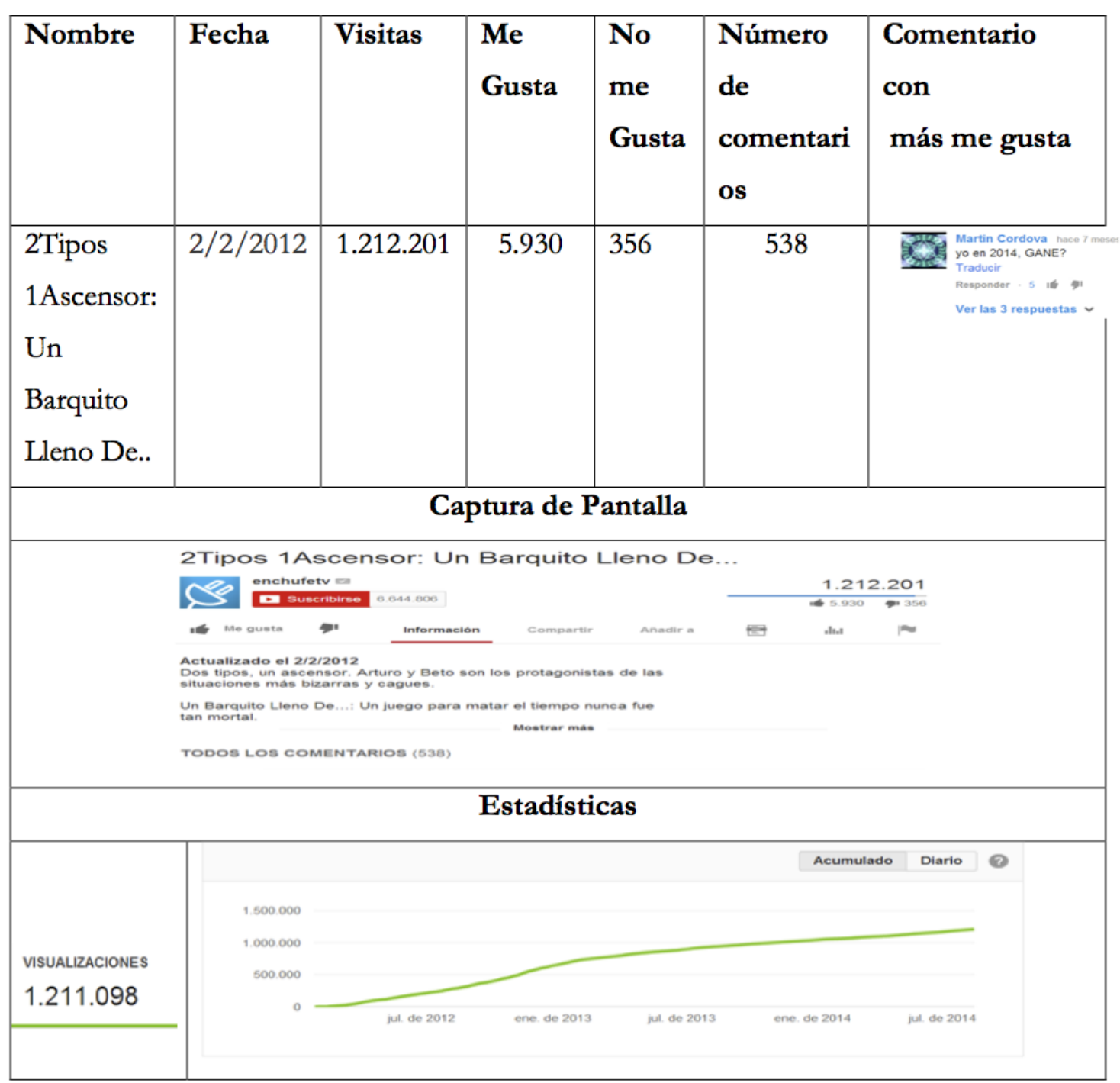

Fuente:

https://www.youtube.com/watch?v=YGHtiJVP0o\&list=UUoGDh1Xa3 kUCpok24JN5DKA (Recuperado el 25 de agosto de 2014)

El segundo video analizado se denomina "2Tipos 1Ascensor: Un Barquito Lleno De..." durante el periodo que se analizó, mantenía 1.212.201 reproducciones, 5.930 "Me Gusta" una cifra alta de aceptación si la comparamos con los 356 "No Me Gusta".

Este sketch, alcanza la mitad de reproducciones en relación al primer video, así mismo la cantidad de me gusta llega a la mitad. Se puede determinar que no todos los videos de EnchufeTr tienen la misma o similar cantidad de reproducciones. 
Tabla 5: 2 tipos 1 ascensor: reemplazo. 06 de mayo de 2012

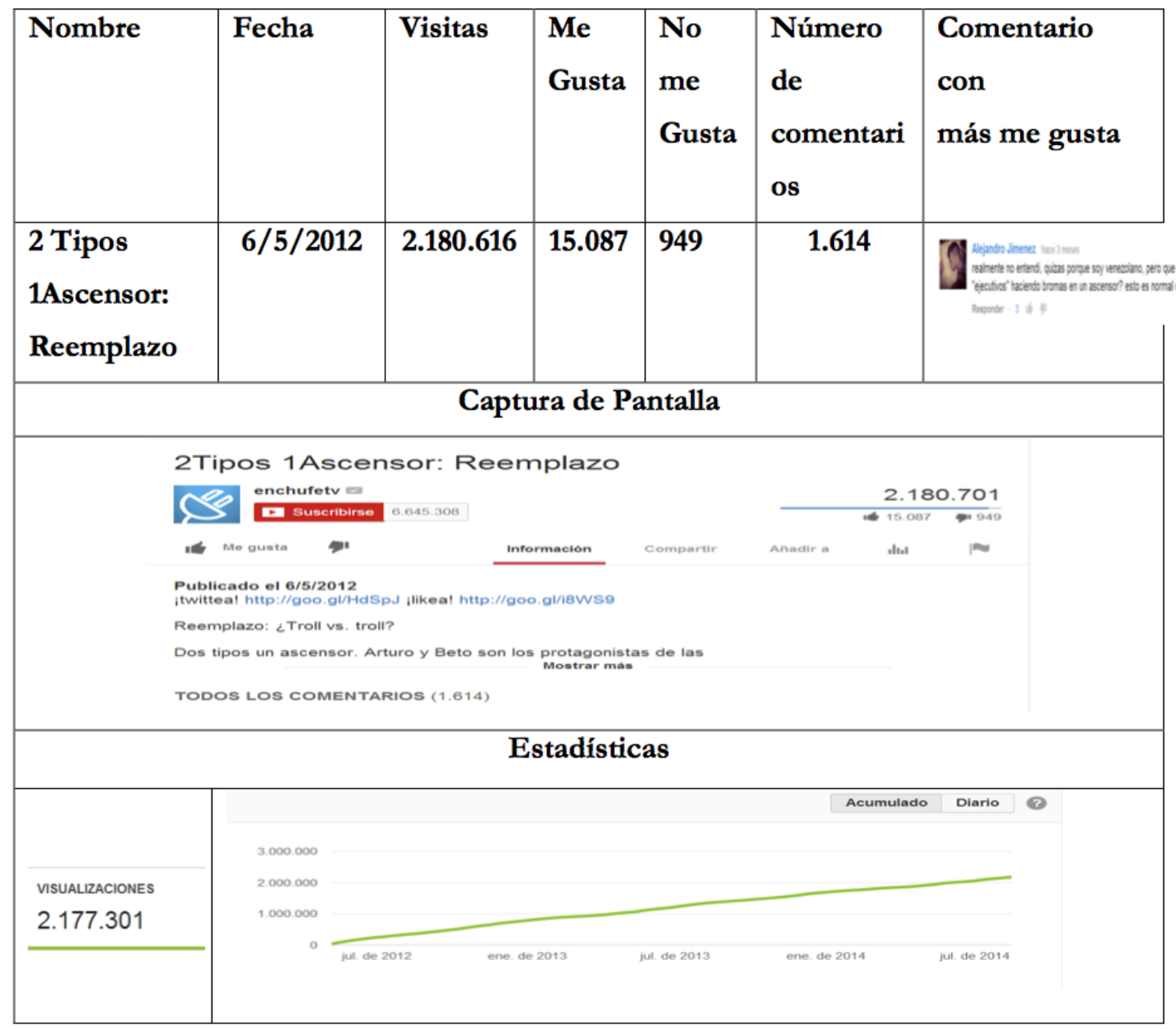

Fuente:

https://www.youtube.com/watch?v $=\mathrm{ft} 8 \mathrm{KbrFkm} 8 \mathrm{Q} \&$ list $=$ UUoGDh1Xa 3kUCpok24JN5DKA (Recuperado el 25 de agosto de 2014)

En este sketch, nuevamente se puede ver que sube a más de dos millones el número de reproducciones, triplica el número de "Me Gusta" (15.087), en relación al video anterior, sobrepasando al primer video, únicamente se pueden ver 949 "No Me Gusta". El comentario que genero más "Me Gusta" por parte de la audiencia fue el del usuario Alejandro Jiménez, que obtuvo 3 me gusta. 
Tabla 6: Viendo como estudiante en supletorio. 06 de agosto de 2012

\begin{tabular}{|c|c|c|c|c|c|c|}
\hline Nombre & Fecha & Visitas & $\begin{array}{l}\text { Me } \\
\text { Gusta }\end{array}$ & $\begin{array}{l}\text { No } \\
\text { me } \\
\text { Gusta }\end{array}$ & $\begin{array}{l}\text { Número de } \\
\text { comentario }\end{array}$ & $\begin{array}{l}\text { Comentario con } \\
\text { más me gusta }\end{array}$ \\
\hline $\begin{array}{l}\text { Viendo Como } \\
\text { estudiante en } \\
\text { Supletorios }\end{array}$ & $6 / 8 / 2012$ & 14.220 .590 & 101.230 & 1.491 & 1.491 & \\
\hline \multicolumn{7}{|c|}{ Captura de Pantalla } \\
\hline & 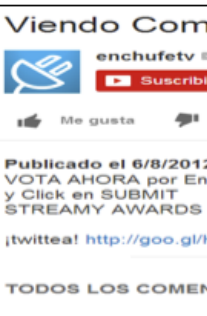 & 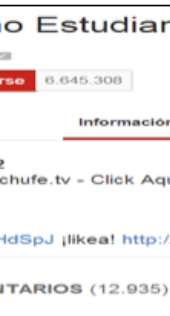 & 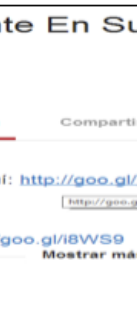 & Apletorios & 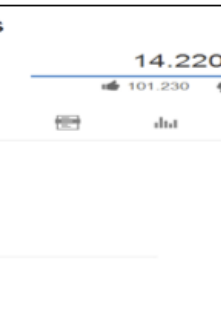 & $\frac{590}{12.191}$ \\
\hline \multicolumn{7}{|c|}{ Estadísticas } \\
\hline $\begin{array}{l}\text { VISUALIZACIONES } \\
14.214 .103\end{array}$ & $\begin{array}{c}15.000 .000 \\
10.000 .000 \\
5.000 .000 \\
0\end{array}$ & $\underbrace{2013}_{\substack{\text { ene de } \\
2013}}$ & $\begin{array}{l}\text { abr. de } \\
2013\end{array}$ & $\begin{array}{c}\text { oct de } \\
2013\end{array}$ & Acumulado & Diario 0 \\
\hline
\end{tabular}

Fuente:

https://www.youtube.com/watch?v=kC9YNz-h828 (Recuperado el 25 de agosto de 2014)

En cuanto a la curva estadística sobre visualizaciones, se puede notar que las reproducciones su tendencia en hacía arriba.

En el sketch "Viendo como estudiante en supletorios" que obtiene 14.220.590 reproducciones, siendo el video más visto de la presente investigación, en cuanto su calificación tenía 101.230 "Me Gusta" frente a los 1.491 "No me Gusta" siendo este el margen más grande de diferenciación. El comentario que genero más "Me Gusta" por parte de la audiencia fue el del usuario dueño del propio canal Enchufe'Tv, que obtuvo 147 me gusta escrito y anexado al vídeo mediante Google +. 
Tabla 7: Ya supéralo. 04 de noviembre de 2012

\begin{tabular}{|c|c|c|c|c|c|c|}
\hline Nombre & Fecha & Visitas & \begin{tabular}{l|} 
Me \\
Gusta
\end{tabular} & $\begin{array}{l}\text { No } \\
\text { me } \\
\text { Gusta }\end{array}$ & $\begin{array}{l}\text { Comentario } \\
\text { s }\end{array}$ & $\begin{array}{l}\text { Mejor } \\
\text { Comentario }\end{array}$ \\
\hline $\begin{array}{l}\text { Ya } \\
\text { Supéralo }\end{array}$ & $\begin{array}{c}4 / 11 / 201 \\
2\end{array}$ & 7.050 .754 & $\begin{array}{c}58.27 \\
4\end{array}$ & 1.095 & 5.578 & 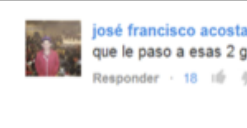 \\
\hline \multicolumn{7}{|c|}{ Captura de Pantalla } \\
\hline & \multicolumn{2}{|c|}{ 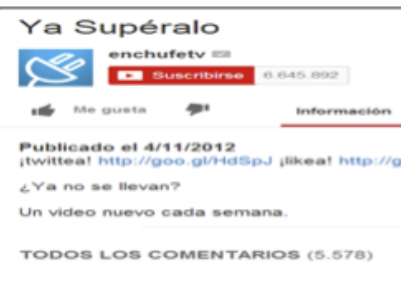 } & - & anaerer. & $\Rightarrow$ & \\
\hline \multicolumn{7}{|c|}{$\begin{array}{ll}\text { Estadísticas } \\
\end{array}$} \\
\hline $\begin{array}{l}\text { VISUALZZACIONES } \\
7.048 .735\end{array}$ & $\begin{array}{l}20000000 \\
20000000 \\
30000000\end{array}$ & & & & Acumulado Dia & \\
\hline
\end{tabular}

Fuente:

https://www.youtube.com/watch?v=gKVwYoNYp2g (Recuperado el 26 de agosto de 2014)

Tal como se puede apreciar en la ficha, el video "Ya Supéralo", mantenía 7.050.754 reproducciones, 58.274 "Me Gusta” y 1.095 "No Me Gusta" manteniendo la supremacía de aceptación en los videos investigados. El comentario que genero más "Me Gusta" por parte de la audiencia fue el del usuario José Francisco Acosta, que obtuvo 18 me gusta. 
Tabla 8: Mundo Al Revés: Gringos y Latinos. 02 de febrero de 2013

\begin{tabular}{|c|c|c|c|c|c|c|}
\hline Nombre & Fecha & Visitas & $\begin{array}{l}\text { Me } \\
\text { Gusta }\end{array}$ & $\begin{array}{l}\text { No } \\
\text { me } \\
\text { Gusta }\end{array}$ & $\begin{array}{l}\text { Número de } \\
\text { Comentario } \\
\text { s }\end{array}$ & $\begin{array}{l}\text { Comentario } \\
\text { con más me } \\
\text { gusta }\end{array}$ \\
\hline $\begin{array}{c}\text { Mundo Al } \\
\text { Revés: Gringos } \\
\text { y Latinos }\end{array}$ & $\begin{array}{c}3 / 2 / 20 \\
13\end{array}$ & 5.067 .663 & 49.549 & 1.719 & 1.719 & 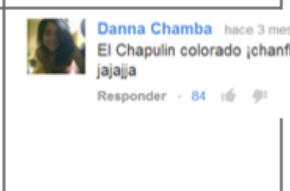 \\
\hline \multicolumn{7}{|c|}{ Captura de Pantalla } \\
\hline \multicolumn{7}{|c|}{ 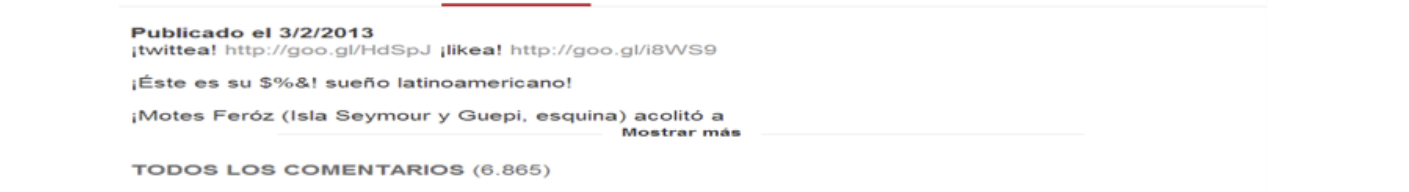 } \\
\hline \multicolumn{7}{|c|}{ Estadisticas } \\
\hline $\begin{array}{l}\text { VISUALIZACIONES } \\
5.063 .732\end{array}$ & $\begin{array}{r}6.000 .000 \\
4.000 .000 \\
2.000 .000 \\
0\end{array}$ & abr. de 2013 & & oct de 2013 & ene. de 2014 & Icumulado Diario 0 \\
\hline
\end{tabular}

Fuente:

https://www.youtube.com/watch?v=n2ISkJZC6DI (Recuperado el 26 de agosto de 2014)

El sketch "Mundo al revés: gringos y latinos" en el tiempo que duró la investigación, mantenía 5.067.663 reproducciones, 49.549 "Me Gusta" una cifra bastante alta en referencia a los 1.719 "No Me Gusta". El comentario con mayor cantidad de "Me Gusta" fue del usuario Diana Chamba, que obtuvo 84 me gusta. Se puede notar que todos los videos generan millones de espectadores, sin embargo no todos comentan o indican que les gusta, sino que en su gran mayoría únicamente los observan y pasan. 
Tabla 9: Las crucetas. 05 de mayo de 2013

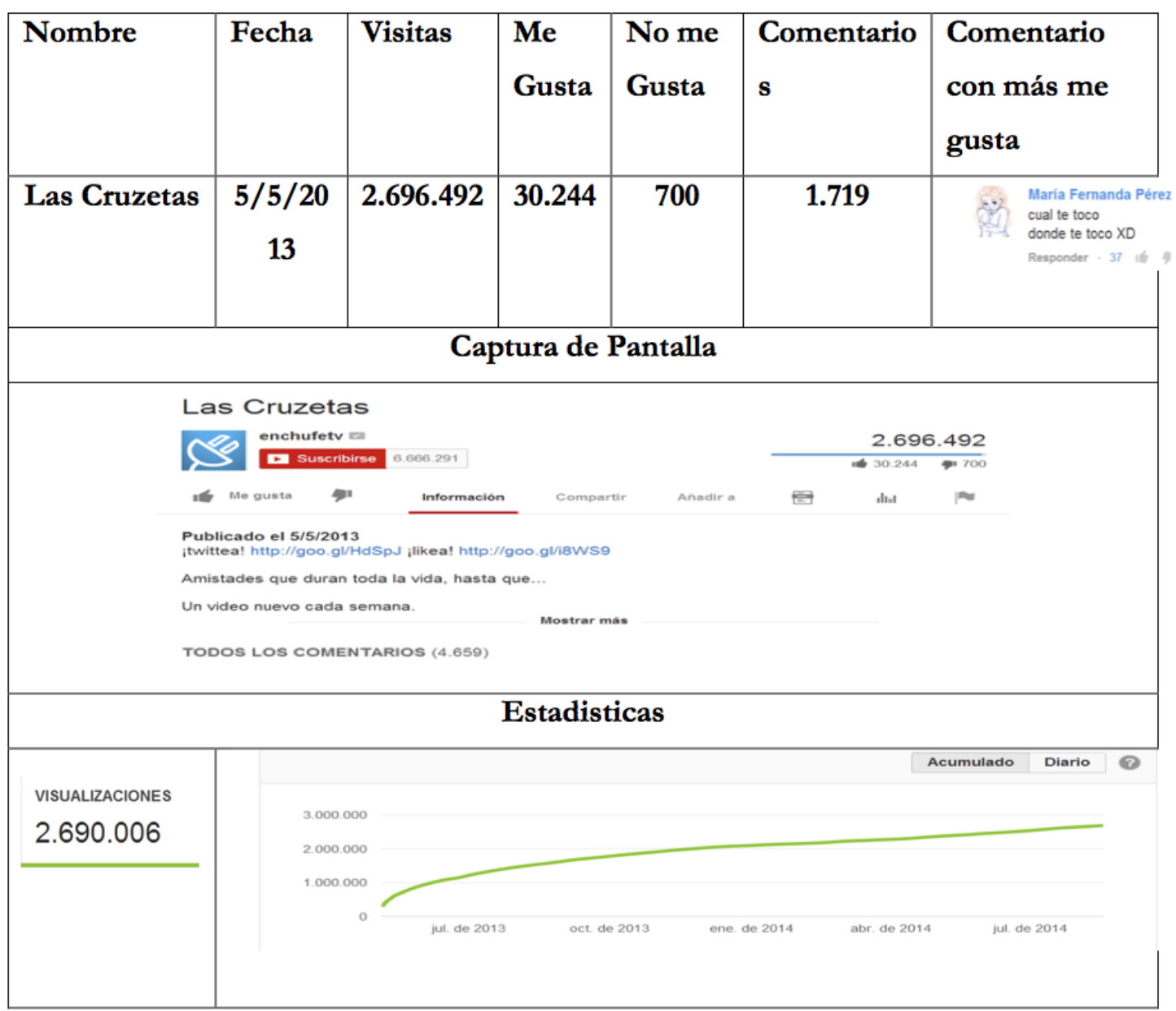

Fuente:

https://www.youtube.com/watch?v $=$ vKUh42s7qUs\&list=UUoGDh1Xa 3kUCpok24JN5DKA (Recuperado el 27 de agosto de 2014)

El sketch "Las Cruzetas" tiene 2.696.492 reproducciones, 30.244 "Me Gusta" y 700 "No Me Gusta" siendo amplias las diferencias en las cifras en cuanto a la valoración del video.

Con 2.690.006 la curva estadística sobre visualizaciones, se puede notar que las reproducciones suben con forme la línea de tiempo en este caso trimestral. 
Tabla 10: Si enchufe fuera... 04 de agosto de 2013

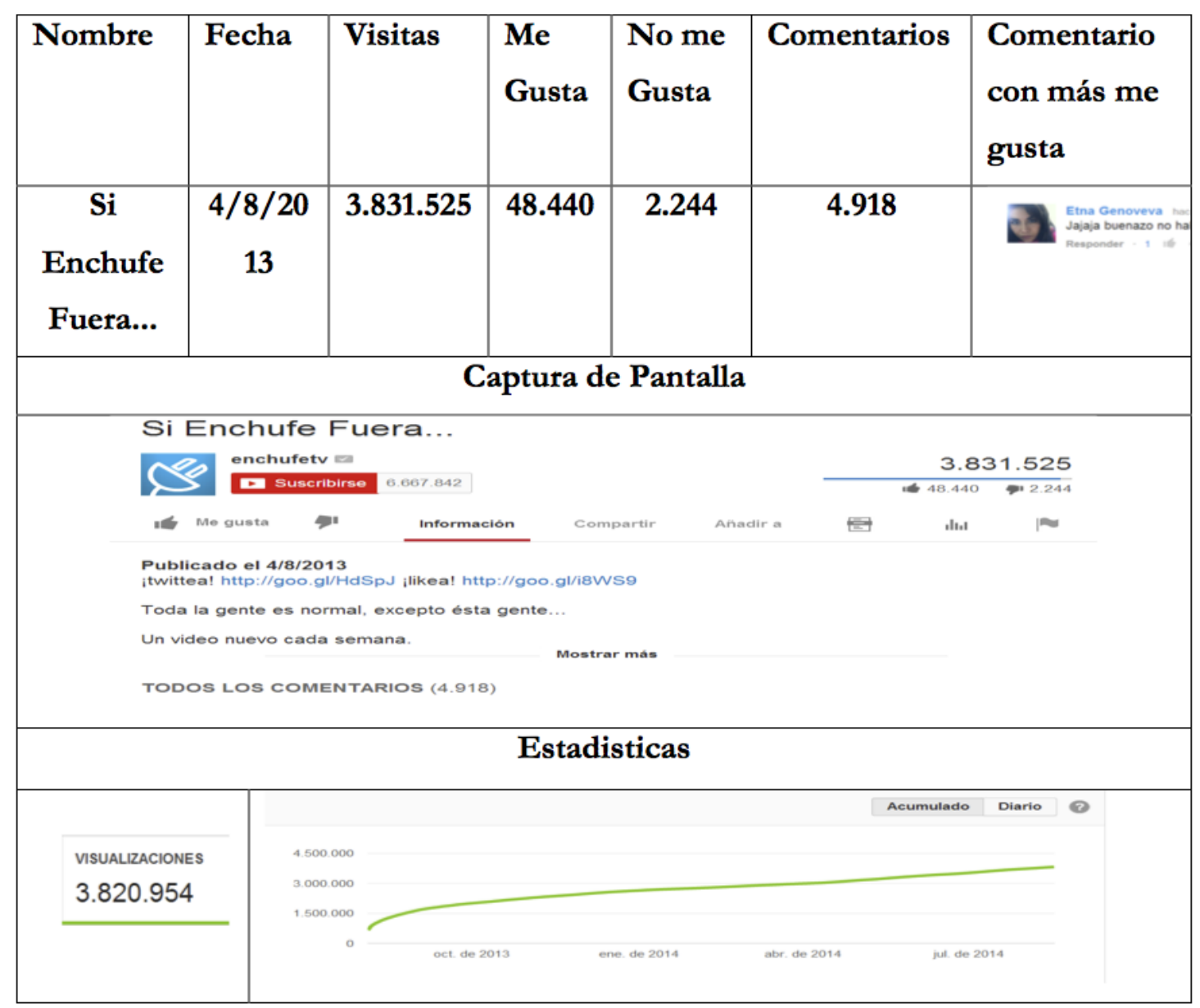

Fuente:

https://www.youtube.com/watch?v=Zlzxm6c9wo\&list=UUoGDh1Xa3 kUCpok24JN5DKA (Recuperado el 28 de agosto de 2014)

El sketch "Si Enchufe Fuera..." tiene 3.831 .525 reproducciones, 48.440 "Me Gusta" una cifra bastante elevada si lo comparamos con los 4.918 "No Me Gusta". El comentario que genero más "Me Gusta" por parte de los usuarios fue el del Etna Genoveva, que obtuvo únicamente 1 me gusta. 
Tabla 11: Viendo como fiesta de oficina. 03 de noviembre de 2013

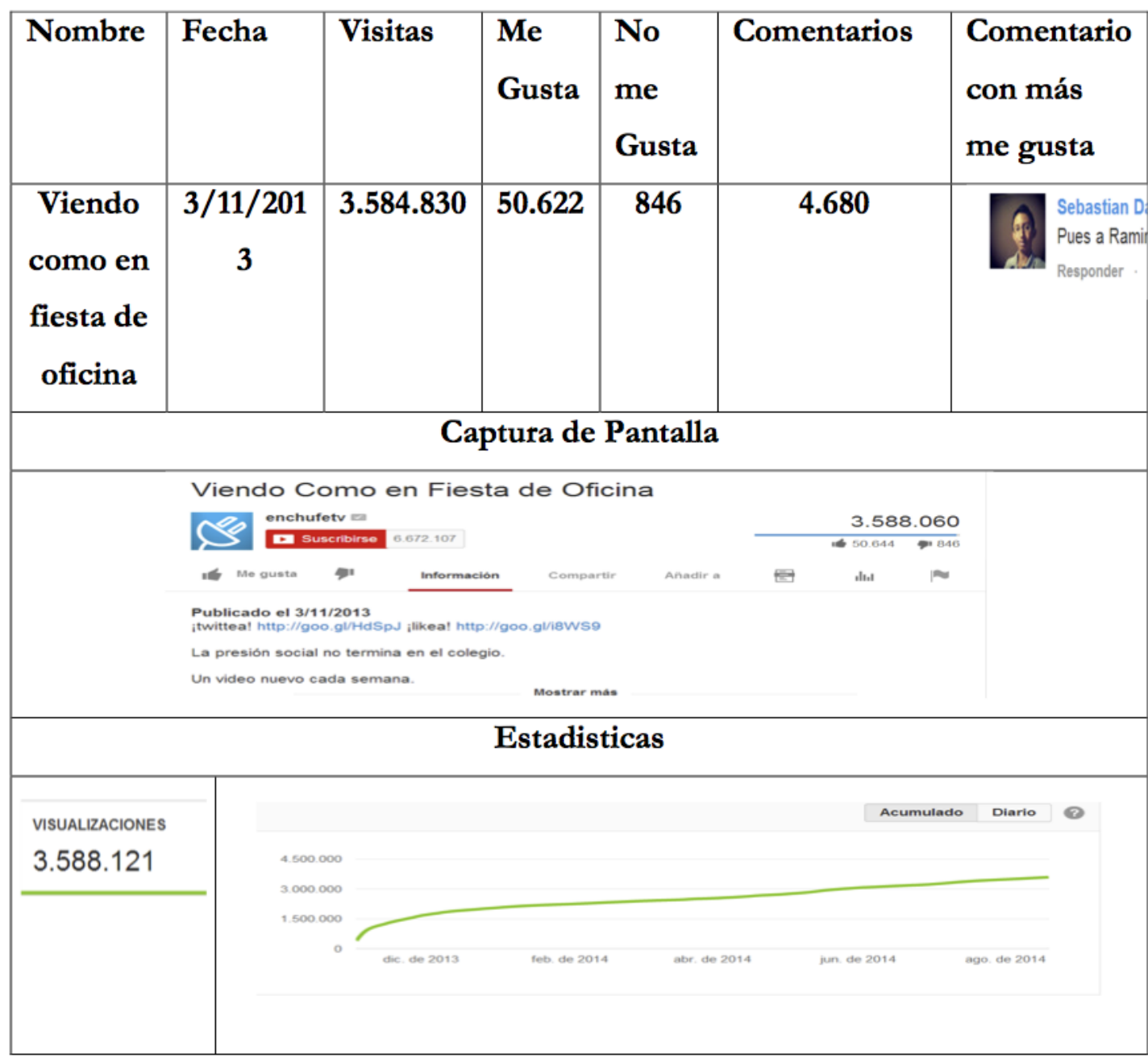

Fuente:

https://www.youtube.com/watch?v $=$ Yr uj0OtG3E (Recuperado el 28 de agosto de 2014)

Tal como se puede apreciar en la ficha el sketch "Viendo como en fiesta de oficina" durante la semana de investigación se pudo recolectar los siguientes datos: 3.584 .830 reproducciones, 50.622 "Me Gusta" una cifra distante de los 846 "No me Gusta”. De los 4.860 comentarios, el que generó más "Me Gusta" por la audiencia fue el de Sebastián Daza, que obtuvo 12 me gusta. 
Tabla 12: Cacha que creciste. 03 de febrero de 2014

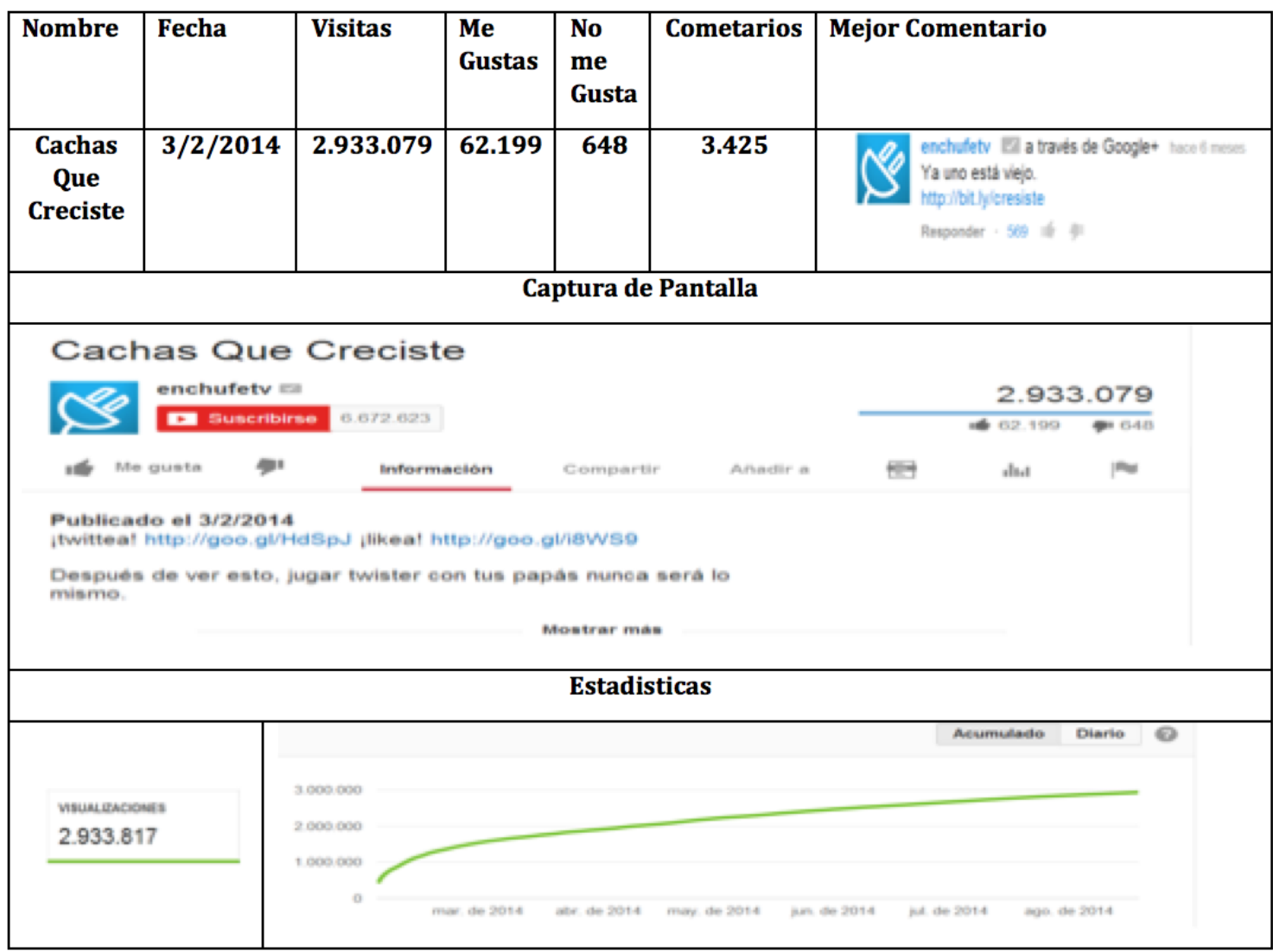

Fuente

https://www.youtube.com/watch?v=7OreJav7FgQ (Recuperado el 26 de agosto de 2014)

Tal como se puede apreciar en la ficha, el vídeo "Cacha que creciste" durante la semana que se analizó, mantenía 2.933.079 reproducciones, 62.199 "Me gusta" y 648 "No me gusta". El sktech generó 3.425 de comentarios, el comentario del usuario José Francisco Acosta obtuvo mas aceptación, que obtuvo 18 me gusta. 
Tabla 13: Peaje Épico. 04 de mayo de 2014

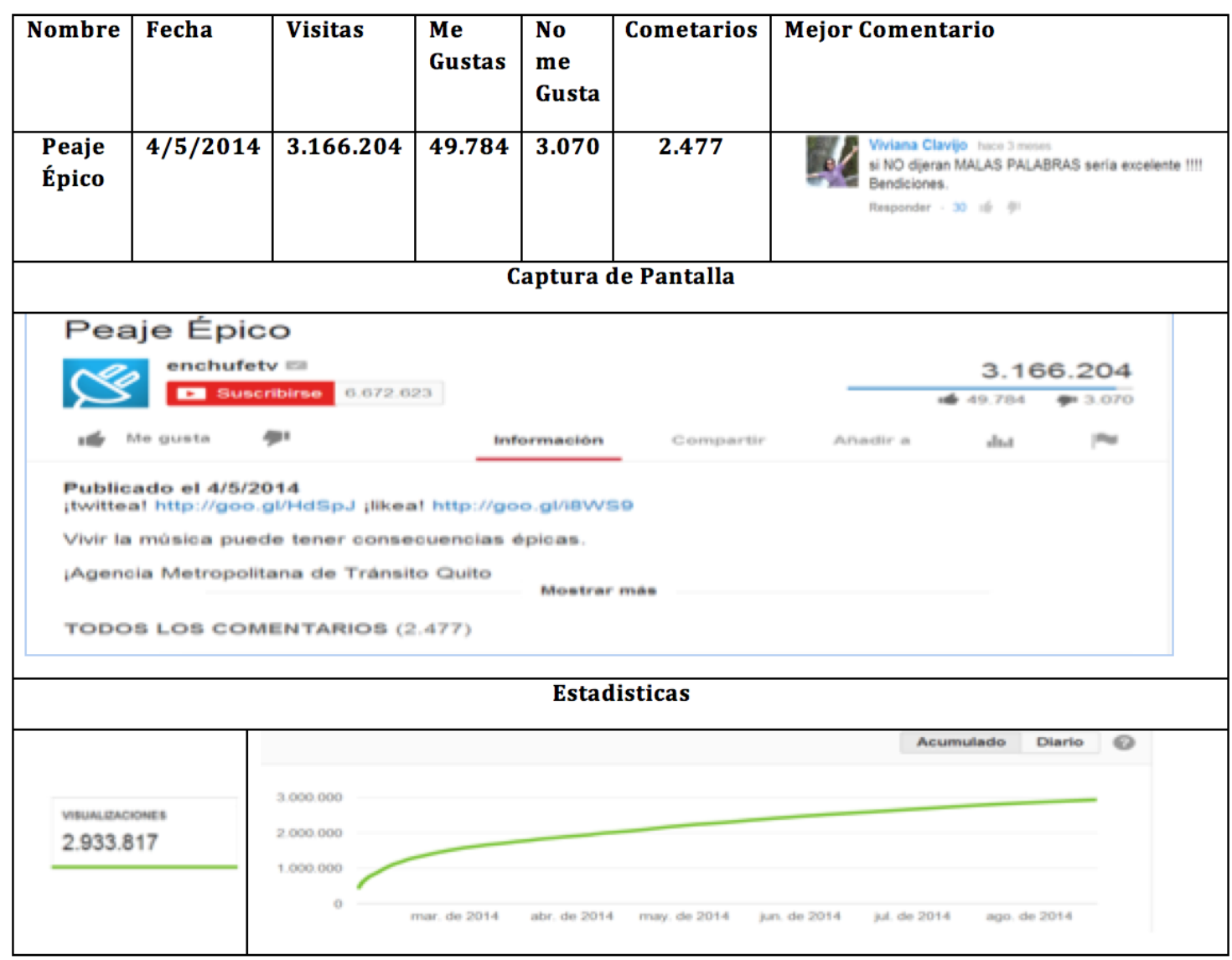

Fuente

https://www.youtube.com/watch?v=iLgJ4qwQwV8 (Recuperado el 26 de agosto de 2014)

En presente ficha del sketch "Peaje épico" durante la semana de investigación se obtuvo los siguientes datos: 3.166 .204 reproducciones, 49.784 "Me gusta" una cifra distante de los 3.070 "No me gusta". De los 2.477 comentarios, el comentario que genero más "Me gusta" por parte de la audiencia fue el de Viviana Clavijo, que obtuvo 30 me gusta. 
Tabla 14: Te ahuevas. 03 de agosto de 2014

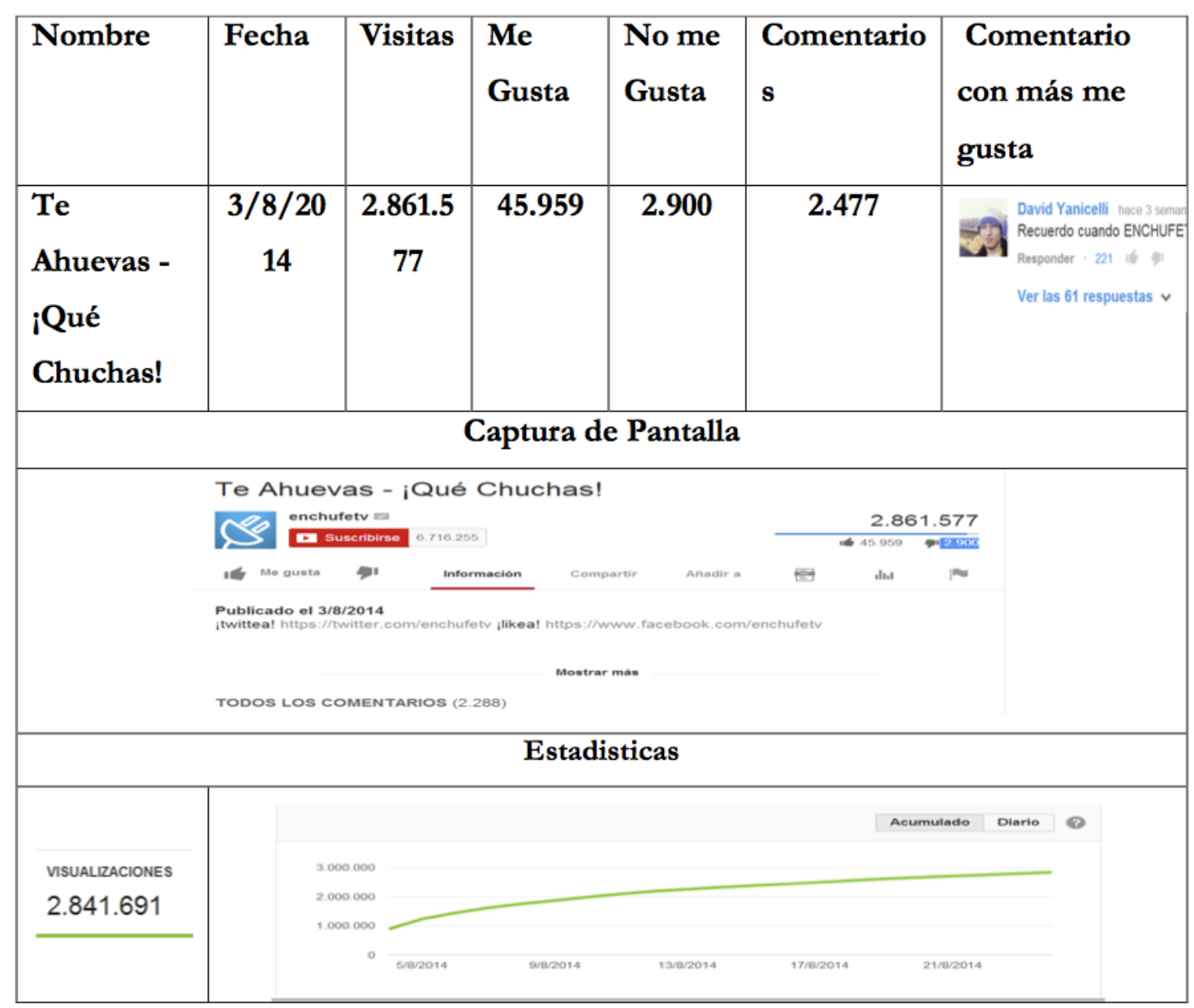

Fuente:

https://www.youtube.com/watch?v=ZNH3AiNaSSE\&list=UUoGDh1Xa3kU

Cpok24J (Recuperado el 28 de agosto de 2014)

En la última ficha de la investigación se analiza el video "Te ahuevas ¡Qué chuchas!" mantenía 3.166.204 reproducciones, 49.784 "Me gusta" y 3.070 "No me gusta" lo que confirmó la aceptación de todos los videos analizados, mantuvieron una amplia cantidad de "Me gusta" marcando una amplia diferencia sobre los "No me gusta". El comentario que genero más "Me gusta" por parte de la audiencia fue el de Viviana Clavijo, que obtuvo 30 me gusta.

En cuanto a la curva estadística sobre visualizaciones, se puede notar que las reproducciones tienden a subir conforme avanza la línea de tiempo. 


\section{Conclusiones}

Desde la fecha de la publicación de su primer sketch 13 de noviembre del 2011, Touché Films ha sido muy responsable con su producto web EnchufeTv. Publicando sus vídeos en tiempo fijo establecido que son los domingos, no fallando en ninguna entrega durante el tiempo que se realizó la presente investigación a pesar de que en un principio no recibían ningún tipo de incentivo económico.

Entre las técnicas de viralización que maneja Touché Films en su producto web EnchuféTv, lo que se pudo evidenciar en el presente estudio es la publicación periódica en un tiempo fijo. Esto lo hacen los domingos en horarios de la noche, día conocido como de ocio a nivel mundial. Otra de sus técnicas es de mantener un solo canal al momento de publicar sus vídeos, y crear expectativa anunciando el contenido del próximo sketch, y anunciar la publicación de su video a través las diferentes redes sociales donde tienen gran cantidad de seguidores.

En la red social YouTube también se produjo un incremento en el número de visualizaciones, tal y como reflejan las estadísticas, con un crecimiento acelerado desde la publicación de cada video.

Entre sus técnicas de promover y aumentar su número de seguidores en las redes sociales de Twitter y Facebook, está la colocar una invitación a que también formen parte de las redes sociales del propio programa, con sus respectivos enlaces de las cuentas. Esto es algo que se observa en la descripción de la mayoría de los videos analizados en la presente investigación.

Finalmente, otra de las cuestiones a destacar en la presente investigación fue la de los comentarios, donde observamos la nula interacción entre la cuenta oficial en YouTube de Enchufe'Tv y los comentarios emitidos por las personas sobre cada uno de los videos analizados.

\section{Referencias bibliográficas}

Adoum, J. E. (2000): Ecuador; señas particulares: Aproximación al patriotismo. Ecuador: Eskeletra.

Ávila, A. (2014): “Atrapados en el efecto EnchufeTV”, en La Revista el Universo, Ecuador, recuperado el 05 de noviembre de 2014, 
de: http://www.larevista.ec/actualidad/show/atrapados-en-el-efectoenchufetv.

Castells M. (2009): Comunicación y poder. Madrid: Alianza Editorial Charvolin.

Campos-Freire, F. (2013): "El futuro de la TV europea es híbrido, convergente y cada vez menos público", en Revista Latina de Comunicación Social, 68. La Laguna (Tenerife): Universidad de La Laguna, páginas 089 a 118, recuperado el 05 de noviembre de 2014, de: http://www.revistalatinacs.org/ 068/paper \970 Santiago/04 Campos.html

Campos-Freire, F. (2013): "Introducción a la investigación y gestión de las redes sociales digitales," en Revista Latina de Comunicación Social, 50. La Laguna. (Tenerife): Universidad de La Laguna, páginas 07 a 053, recuperado el 05 de noviembre de 2014, de:

http://www.revistalatinacs.org/068/cuadernos/cac50.pdf

Campos-Freire, F. (2013): "Epílogo, La gestión de los medios tradicionales en las Redes Sociales Digitales", en Revista Latina de Comunicación Social, 51. La Laguna. (Tenerife): Universidad de La Laguna, páginas 333 a 366, recuperado el 06 de noviembre de 2014, de: http://www.revistalatinacs.org/068/cuadernos/cac51.pdf

Campos-Freire, F. (2008): "Las redes sociales trastocan los modelos de los medios de comunicación tradicionales", en Revista Latina de Comunicación Social, 51. La Laguna. (Tenerife): Universidad de La Laguna, páginas 053 a 078 , recuperado el 05 de noviembre de 2014, de http://www.revistalatinacs.org/068/cuadernos/cac50.pdf

Noguera-Vivo, J. (2010): "Redes sociales como paradigma periodístico. Medios españoles en Facebook", en Revista Latina de Comunicación Social, 65. La Laguna (Tenerife): Universidad de La Laguna, páginas 176 a 186, recuperado el 05 de noviembre de 2014 de http://www.revistalatinacs.org/10/art/891 UCAM/13 JM Noguera. html DOI: $10.4185 / R L C S-65-2010-891-176-186$

Orozco, Gómez, G. y Vassallo, M. (2014): OBITEL 2014: Estrategia de producción transmedia en la ficción televisiva. Porto Alegre: Meridional Ltda. 


\section{Campaña "Un Diego para la torre": La estrategia comunicacional de Radio Ahijuna como experiencia de crowdfunding ${ }^{42}$}

Martín Iglesias (UNLP/UNQ - Argentina), meiglesias@gmail.com Carlos Leavi (UNLP - Argentina), carlosleavi@gmail.com Juan Pedro Legarreta (UBA - Argentina), jplegarreta@gmail.com

\section{Resumen}

El presente trabajo pretende sistematizar la campaña solidaria "Un Diego para la torre", como una estrategia comunicacional que resolvió la vuelta al aire de la emisora comunitaria Radio Ahijúna del sur del área metropolitana de Buenos Aires, Argentina, de abril a diciembre de 2012. Se procedió a la caracterización del ámbito en que se inscribe esta experiencia dentro del campo geográfico y temático, entendiendo que se trata de prácticas de comunicación popular en un entorno urbano y se inscribe dentro del movimiento de emisoras comunitarias de nuestro país. Las características y alcances de la campaña también

\footnotetext{
${ }^{42}$ La ponencia se inscribe en la línea de otros trabajos preliminares que tuvieron entre sus objetivos sistematizar la campaña, como la ponencia "Campaña 'Un Diego para la Torre': una estrategia comunicacional para devolver el aire a Radio Ahijuna (\#UnDiegoParaLa'Torre)", de Martín Iglesias, Juan Pedro Legarreta y Luciana Mignoli, presentada en el I Coloquio de Comunicación para la Transformación Social de la Escuela de Ciencias de la Información de la Universidad Nacional de Córdoba (Argentina) en el año 2012.
} 
nos permiten pensarla como instancias de "microfinanciación colectiva y masiva", es decir, como un modo del denominado "crowdfunding". Se relata un breve anecdotario sobre sucesos destacados en el devenir de la campaña. Más adelante, se presentan las principales nociones y la matriz de planificación integrada de la estrategia (Massoni), que servirán de guía para la descripción y análisis propuesto. Por último, además de los resultados de la campaña, se presentan algunas cuestiones e interrogantes a tener en cuenta, de cara a futuros trabajos.

Palabras clave: estrategia, comunicación popular, radios comunitarias, redes sociales, solidaridad y microfinanciación colectiva.

\section{Introducción}

— $\mathrm{L}$ presente trabajo tiene como finalidad sistematizar una estrategia comunicacional en el marco de la pérdida de la planta de transmisión de la emisora Radio Ahijuna, de la ciudad de Quilmes, durante el tornado que azotó a la zona del área metropolitana de Buenos Aires la noche del 4 de abril de 2012. En este sentido, la estrategia tuvo una doble finalidad: la difusión del problema a resolver y la recaudación financiera colectiva/masiva que permitió el logro del objetivo y la posibilidad de visibilizar las prácticas de una experiencia de comunicación popular en un ámbito urbano densamente poblado.

Para una emisora de radio no tener la torre y sus antenas es equivalente a pensar un "tachero", el conductor de un taxi, sin su vehículo: le falta su herramienta elemental de trabajo ${ }^{43}$. El tono de comunicación de la estrategia buscó recuperar esta idea de lo que ocurre en la calle, muy ligado a lo cotidiano y lo popular, con un lenguaje coloquial, amigable y de fácil empatia. Es así que puso su mayor énfasis en apelar a la solidaridad del público en la campaña

${ }^{43}$ La comparación fue explicitada por Martín Castro, socio fundador cooperativo, y responsable ejecutivo de los destinos de la emisora en ocasión de ser entrevistado en el programa radial "La Vuelta", conducido por María

O`Donnell en AM 590 Continental de la Ciudad Autónoma de Buenos Aires. 
solidaria masiva que tuvo como slogan principal: "Un Diego para la torre". Desde la consigna se invitó a oyentes, colaboradores y a la población en general, a realizar un mínimo aporte monetario de diez pesos argentinos (el aquel momento era el equivalente a 1 euro) a cambio de un bono contribución autoadhesivo y numerado ${ }^{44}$ La cooperativa que gestiona la emisora definió en un primer momento recaudar cincuenta mil pesos por esta modalidad, equivalentes a cinco mil bonos o "Diegos", suma que se aproximaba a los costos estipulados de inversión inicial ${ }^{45}$. Lo que urbanamente en el Río de la Plata se entiende por un "Diego": los diez pesos, se presentó como una necesidad de resolver el problema planteado de forma sencilla, apelando al lenguaje urbano, coloquial y con un claro tono humorístico.

\subsection{Ahijúna, la radio comunitaria del sur del Gran Buenos Aires}

Radio Ahijuna FM 94.7 es una iniciativa de la Cooperativa de trabajo "La Usina de Ideas" LTDA, organización que integran personas del campo de la comunicación, el arte, la educación y la cultura. El área de cobertura geográfica incluye a un millón y medio de personas de la zona sur del Gran Buenos Aires ${ }^{46}$. La emisora transmite las 24 horas, los 365 días del año desde la Biblioteca Pública y Complejo Cultural Mariano Moreno de Bernal.

En 2014, Ahijuna cumplió 10 años. Desde sus inicios, presentó una propuesta comunicacional marcada por una fuerte presencia de producción periodística propia, el cuidado estético de producciones de pequeño formato y una variada selección musical que enlaza el equilibrio entre estilos, ritmos y épocas. La emisora realiza acciones

\footnotetext{
${ }^{44}$ Se sugiere ver la imagen del bono en alta definición. Disponible en: https://dl.dropboxusercontent.com/u/9854085/BONO\%20ALTA.png (Última revisión: 30 de octubre de 2014).

${ }^{45}$ Posteriormente, debido a que todo el sistema irradiante quedó inutilizable, el equipo de gestión de la emisora recalculó los costos para la instalación de la planta transmisora cercanos a los setenta mil pesos argentinos

(aproximadamente 7000 euros). Sin embargo, no modificó el número de bonos a canjear por el público y conservando el objetivo de conseguir la venta de cinco mil, tal como estaba definido inicialmente.

${ }^{46}$ Ver el mapa de ubicación y área de influencia en el sitio de la emisora.

Disponible en: www.radioahijuna.com.ar (Última revisión 30 de octubre de 2014).
} 
junto a organizaciones e instituciones con las que comparte perspectivas metodológicas y objetivos similares, planificando actividades conjuntas y aprovechando a la radio como medio abierto a las necesidades de comunicación de la comunidad ${ }^{47}$. En esta línea se inscribe la relación con la universidad pública local. El vínculo con la Universidad Nacional de Quilmes se materializó en 2008 con la firma de un convenio de cooperación mutua, siendo el único acuerdo institucional entre una universidad pública y una emisora comunitaria. De esta manera, Radio Ahijúna FM 94.7 es centro de prácticas de estudiantes de la carrera de comunicación.

Además, en 10 años de trayectoria, Ahijuna ha sido declarada de interés cultural por la Secretaría de Cultura de la Presidencia de la Nación y el Concejo Deliberante de Quilmes, fue galardonada con el Premio Caduceo 2010 en reconocimiento a su labor comunitaria en el gran Buenos Aires, integra el Nodo Sudeste del Programa Polos Audiovisuales de la TV Digital Abierta (TDA) y es Punto de Cultura en la provincia de Buenos Aires, propuesta que vincula proyectos culturales de organizaciones sociales con el Instituto Cultural de la Provincia de Buenos Aires y el Ministerio de Cultura de Nación para fortalecer espacios de cultura comunitaria.

\section{Anecdotario: una primera idea en contexto de crisis o cuando "la crisis se transforma en oportunidad"}

El miércoles 4 de abril de 2012 un temporal azotó el área metropolitana de Buenos Aires, afectando gravemente a gran parte de los partidos del oeste y del sur del conurbano bonaerense. Los fenómenos, que fueron clasificados por el Servicio Meteorológico Nacional como tornados ${ }^{48}$, produjeron víctimas fatales, centenares de evacuados, caída de árboles y postes de electricidad, cuantiosas pérdidas materiales y el cese de servicios públicos durante semanas en

\footnotetext{
${ }^{47}$ En esta línea se inscribe su participación en redes de emisoras comunitarias con alcance nacional y regional: el Foro Argentino de Radios Comunitarias (FARCO), la Asociación Mundial de Radios Comunitarias en su capítulo argentino (AMARC Argentina) y la Asociación Latinoamericana de Educación Radiofónica (ALER).

${ }^{48}$ Según informe del Servicio Meteorológico Nacional. El informe completo puede leerse en:

http://www.smn.gov.ar/htms/INFORME TORMENTA 04 04 2012.pdf
} (Última revisión: 30 de octubre de 2014). 
algunos barrios de los partidos de Quilmes, Florencio Varela y Berazategui.

El temporal produjo la caída de la torre de transmisión que Radio Ahijuna FM 94.7 poseía en la ciudad de Quilmes. Los fuertes vientos produjeron daños en el mástil, antenas y cable de emisión, provocando la pérdida del servicio de emisión por aire y demandando la búsqueda de una nueva locación para instalar la planta transmisora.

En ese marco, el equipo de Radio Ahijúna se movilizó y diseñó una estrategia comunicacional. En primer lugar, se elaboró un comunicado para difundir lo sucedido por todos los medios posibles, desde prensa hasta la utilización de las redes sociales y los correos electrónicos. A su vez, se decidió brindar un servicio de emergencia a través de la señal vía streaming (internet) hasta recuperar el aire. La cooperativa se abocó al diseño e implementación de la campaña solidaria que se tituló "Un diego para la torre", tras el siguiente diálogo:

-Tenemos que sacar un bono contribución además de las gestiones que se puedan hacer... - dijo el actor A.

-¿Y qué le pedimos al público? -interroga el actor B

- Y... un Diego... Un Diego para la torre -sentenció el actor C.

Se planificó finalmente la impresión de 5 mil bonos numerados para ser canjeados a 10 pesos por unidad y obtener la suma de 50 mil pesos necesarios para cubrir casi la totalidad de la inversión en la nueva planta transmisora.

Como valor agregado a la idea se sumó la colaboración y cesión de su imagen del ex futbolista y actual comentarista deportivo Diego "Gambetita" Latorre, de trayectoria en Boca Junios y Racing Club, entre otros clubes, profundizando aún más el tono humorístico de la campaña a partir del anclaje visual del juego de palabras "Un Diego para La-torre". El logro de síntesis en la comunicación permitió apelar al humor, lo popular y masivo, apoyada en un modismo rioplatense y el lenguaje propio de la calle, del cotidiano urbano. 


\section{Nociones y metodología}

Entendemos junto a Sandra Massoni que

"Comunicar es hacer común (público) aquello que es privado. Cuando diseñamos una estrategia de comunicación lo hacemos con un objetivo, con una finalidad, porque hay un proyecto que nos motiva a hacer este movimiento. Hay una decisión de la organización en algunos de sus niveles que implica imprimir una cierta dirección en esta conversación, que estamos tratando de encausar como una transformación cognitiva. Para iniciarla resulta operativo traducir el tema acerca del cual queremos conversar en un análisis de aquello que está obstaculizando hoy la transformación. Es decir, traducir el tema a problema" (Massoni, 2007: 7)."

En este sentido que el concepto de estrategia de comunicación cobra dimensión en tanto se transforma en "dispositivo de conversación" que interpela y como "escenario para convocar a la acción de los actores relacionados con la solución del problema" (Massoni, 2007: 7). En el caso abordado, estos actores a los que hace referencia Massoni fueron en un principio la audiencia de la emisora, la comunidad de referencia y el público cercano al proyecto colectivo de Radio Ahijúna; pero luego -dado el salto en la escala de la comunicación- también se transformaron en actores relacionados el público que se enteró la situación, que no conocía el proyecto pero que se solidarizó con la causa.

En el caso que presentamos, la misma intervención produjo la modificación y transformación de las políticas de comunicación de una organización con fuerte identidad autónoma. Es importante resaltarlo ya que atiende a aspectos relativos a la gestión independiente de la resolución de problemas desde y para el proyecto en sí. Es decir, esto implicó un salto en la operatoria de trabajo del colectivo, que venía de una lógica basada en la gestión y la solución autónoma sin dar participación a los interlocutores de ese proceso. Esta vez, el conflicto inesperado que generó la caída de la torre de transmisión tras el tornado de abril obligó a saltar la barrera de esta lógica de trabajo para dar paso a la explicitación del problema y apelar a la interlocución de múltiples públicos para su solución. 
A los fines de realizar una delimitación necesaria referida a la atención principal que ha tenido la estrategia analizada, podemos establecer que la misma responde a un recorte sobre plataformas digitales y medios de comunicación masiva: identificando actores específicos, considerando sus intereses y necesidades y consumos actuales (Massoni, 2007: 10). Del mismo modo, podemos definir que las acciones fueron llevadas adelante a través de metodologías difusionistas. En términos de Uranga, podemos clasificarla como "de uso de medios y canales alternativos: generando medios propios, buscando acceder a otros nuevos propiciando la penetración de mensajes en el sistema de medios" (Uranga, 2011: 6). Se trata de una estrategia, además, al nivel de líneas de acción por tratarse de procesos planificados a corto plazo.

Aunque desde nuestras perspectivas conceptuales no estaba pensada la experiencia como parte de las iniciativas enmarcadas como crowdfunding, el encuentro y los diálogos con el Dr. Francisco Campos Freire, de la Facultad de Ciencias de Comunicación de la Universidad de Santiago de Compostela (España) en el último Congreso de la Asociación Latinoamericana de Investigadores en Comunicación (ALAIC), nos habilitó y nos permitió establecer estas relaciones. Los modos, características y alcances de la campaña "Un Diego para la torre" de Radio Ahijuna, despliegan prácticas típicas del crowdfunding, al promover la resolución de una problemática puntual: levantar la torre de transmisión de una emisora comunitaria de gestión cooperativa en el sur del gran Buenos Aires, a través de la "microfinanciación colectiva y masiva". Precisamente si consideramos una conceptualización general sobre el particular,

"el término Crowdfounding hace referencia al concepto de 'Financiación en masa': una modalidad de cooperación colectiva, llevada a cabo por personas que organizan una red para conseguir dinero u otros recursos, generalmente a través de Internet, para financiar con ello esfuerzos e iniciativas bien para iniciativas propias, de terceros u organizaciones". (VVAA, 2012: 4)

La campaña de Radio Ahijuna se trata de una 'financiación en masa' con un objetivo claro, preciso y concreto: levantar la torre de la 
emisora. Para ello apeló, en tono coloquial y en clave de humor popular, a la "cooperación colectiva" de poner $\$ 10$ (1 euro). Se desarrolló a partir de la reconocida imagen pública de un jugador de fútbol, quién comenzó con esa cadena solidaria, que se extendió prioritariamente a través de las "redes sociales" y teniendo a internet como soporte de desarrollo principal. Estas características principales son las que permitieron durante el desarrollo de la campaña, que otros personajes famosos de la cultura y la música se sumarán con su apoyo, además de los noticieros del principal canal de televisión abierta de Argentina (Canal 11 - Telefe ${ }^{49}$ que difundieron y promocionaron también la mencionada iniciativa de microfinanciamiento colectivo y solidario.

\section{Matriz de análisis}

Siguiendo la propuesta de Massoni, realizaremos una descripción y análisis de la estrategia comunicacional a partir de una matriz de planificación integrada. De esta forma intentaremos dar cuenta de aquellas variables y dimensiones que han intervenido en las acciones de comunicación: sensibilización, producción y distribución de información, participación y comunicación social. En términos generales, lo que se hizo fue poner todas las herramientas y plataformas ya existentes en la emisora al servicio de la campaña.

\subsection{Descripción}

Como veníamos relatando, "Un Diego para la torre" utilizó como primer soporte la existencia de un bono contribución para ser canjeado por su equivalente en pesos. La particularidad de la campaña se destaca en el protagonismo que cobró el público: la enunciación que apela a la solidaridad individual y colectiva, invita también a retratarse y mostrarse a otros con el bono contribución. Este condimento tuvo un fuerte impacto en la multiplicación de las voluntades que permiten acercar el objetivo planteado: devolver a Radio Ahijuna al éter.

La campaña contó con la solidaridad del público en general y de distintos medios de comunicación nacionales, incluso canales de

\footnotetext{
${ }^{49}$ Ver la sección "Ahijuna en otros medios" en el sitio institucional de la emisora. Disponible en: http://radioahijuna.com.ar/?q=ahijunaenlosmedios (Última revisión: 30 de octubre de 2014).
} 
televisión por aire y programas de radio con alta concentración de audiencias. La difusión mediática, sumada a la sinergia en la utilización de los plataformas con los que cuenta la organización (con especial protagonismo las redes sociales facebook ${ }^{50}$ y twitter ${ }^{51}$ ) como base fundamental de la campaña, fue esencial para lograr que se conozca la situación que atravesaba la emisora. Con fuerte implicación en las redes sociales, se comenzaron a utilizar dos herramientas para optimizar la cuenta de twitter: hootsuite (que permite programar twitts) y socialbro. Esta última ofrece herramientas para saber cuál es la mejor hora para publicar los mensajes en la audiencia seguidora de la emisora y aporta sistemas de búsqueda personalizadas, datos de influencia de seguidores y seguidos y cuáles son los usuarios de la comunidad que están en línea para interactuar, entre otras. Asimismo, para la optimización del uso de la fan page de Radio Ahijúna se prestó especial atención a la información que ofrece las estadísticas de Facebook, lo que permite orientar las estrategias de acuerdo al nivel de alcance, difusión, usuarios que interactúan y personas que hablan de cada publicación. La actualización sistemática y la apelación directa a otros usuarios (etiquetas en facebook y menciones en twitter) amplificó la difusión, generó tráfico en cada red social y aumentó la cantidad de fans y seguidores.

Toda la campaña fue atravesada por "excusas" comunicacionales que permitieron ir generando periódicamente algún pico de audiencia para sostener la progresión paulatina de ambas redes, "excusas" siempre ligadas al nombre de la campaña "Un diego para la torre" (Por ejemplo, en la semana del Día del Periodista -7 de junio-, fecha en la que se cumplieron dos meses del tornado y la caída de la torre. En ese marco, se inició una movida para sensibilizar a colegas y colectivos cercanos a los vínculos colectivos y personales para que difundan la situación que atravesaba este proyecto de comunicación comunitaria. Otras excusas fueron "100 días callados", "X famoso se puso con un Diego" y el anuncio de móvil en vivo con el canal de televisión por

\footnotetext{
${ }^{50}$ Perfil de Radio Ahijuna en la plataforma Facebook. Disponible en: http://www.facebook.com/radioahijuna (Última revisión 30 de octubre de 2014).

${ }^{51}$ Perfil de Radio Ahijuna en la plataforma Twitter. Disponible en: https://twitter.com/radioahijuna (Última revisión 30 de octubre de 2014).
} 
aire Telefé -de alcance nacional-, entre otras). Las repercusiones abarcan anécdotas de todo tipo: desde la colaboración de argentinos que radican en el exterior (por ejemplo, Estados Unidos, Israel y Costa Rica) que se enteraron por la televisión por satélite, hasta la realización de descuentos en negocios de barrio en la compra de lámparas de luz por haber visto la campaña en un canal de noticias. Además, se sucedieron múltiples llamadas telefónicas ofreciendo torres para montar la futura antena de Radio Ahijúna.

\subsection{Objetivo}

Comunicar el problema de la destrucción de la planta transmisora de Radio Ahijuna durante el tornado y apelar a la solidaridad del público con el aporte de diez pesos.

\subsection{Público meta}

La audiencia de la emisora, la comunidad de referencia y el público cercano al proyecto comunicacional (primer momento) y público en general (segundo momento).

\subsection{Propósito}

Recaudar los fondos necesarios para la reconstrucción de la planta transmisora de Radio Ahijúna.

\subsection{Actividades}

\section{- Producción de mensajes y actualización de plataformas digitales}

Estos procesos implicaron una primera definición de la producción de mensajes y la disponibilidad en múltiples plataformas ditales: web $^{52}$ y redes sociales y canal YouTube ${ }^{53}$ de la emisora. Todos estos perfiles, destinados a la comunicación de la emisora con su público, se pusieron al servicio de la campaña unificando los distintos elementos primarios definidos.

\footnotetext{
${ }^{52}$ Sitio web de Radio Ahijuna. Disponible en: http://www.radioahijuna.com.ar (Última revisión: 30 de octubre de 2014).

${ }^{53}$ Canal audiovisual de Radio Ahijuna en la plataforma Youtube. Disponible en: http://www.youtube.com/user/ahijunatv (Última revisión: 30 de octubre de 2014).
} 
- Canje de bonos: puntos de venta fijos y móviles

Distintas organizaciones sociales, centros culturales, radios comunitarias e incluso comercios se solidarizaron con la causa, consolidándose como puntos de venta: lugares en los cuales podían adquirirse los bonos contribución. A estos puntos de venta fijos se sumaron amigos y colaboradores de la emisora, desplegando una red de venta de bonos en distintas localidades del Gran Buenos Aires.

- Redes sociales: estas personas "se pusieron con un Diego" (imágenes en Facebook y el aporte individual hecho causa colectiva) y \#UnDiegoParaLaTorre La idea de registrar y difundir a través de la página de Facebook de la emisora la imagen de cada persona que hace su aporte en esta campaña tuvo varios objetivos. Por un lado, ser transparentes con el aporte de fondos, dando a conocer quiénes colaboraron. Por otro, lograr una sinergia con el/la contribuyente, que luego era etiquetado y, de esa forma, se iba tejiendo una red que lo transformaba en un difusor/a de la campaña en su propia página personal.

Las imágenes fueron de lo más variadas, pudiéndose observar personas de distintas edades y grupos sociales en contextos bien disímiles. Sin embargo, al agruparse en el álbum "Se pusieron con un diego para la torre ${ }^{, 54}$ esa colección de fotografías también materializó cada aporte individual como parte de una causa colectiva.

En otro plano y con mayor flujo de mensajes, la plataforma Twitter ofició de permanente instalación de la problemática dentro de la audiencia. En los más de 8 meses que duró la campaña se incrementó en un $80 \%$ el número de seguidores así como las interacciones con los usuarios. Los mensajes de comunicación del problema y aquellos que motivaron la colaboración fueron unificados bajo el hashtag \#UnDiegoParaLaTorre.

\section{- Radio en vivo}

El programa Franqueo Simple (clásico quilmeño conducido por el multifacético Pedro Costa) cumplió el $1^{\circ}$ de junio 150 emisiones. Para celebrar y, a su vez, apoyar la campaña "Un diego para la torre",

\footnotetext{
${ }^{54}$ Álbum "Se pusieron con Un Diego para la torre" sobre la plataforma Facebook. Disponible en:

https://www.facebook.com/media/set/?set=a.10150794736867691.396571.509 79997690\&type=3. (Última revisión: 30 de octubre de 2014).
} 
realizó una transmisión en vivo (vía internet) desde el anfiteatro del Complejo Cultural Mariano Moreno, donde Ahijuna tiene sus estudios de transmisión. El programa, que siempre toma como eje la correspondencia y juega con todas las variables de lo escrito, eligió como tema "torres, antenas, mangrullos, faros. Lugares desde la altura desde donde se ve, se observa, se dice...". En el evento se vendieron bonos, remeras y mates, contando con una importante participación del público.

\section{- Relaciones públicas: famosos que apoyan la iniciativa}

Se logró el apoyo de la campaña, a través del retrato fotográfico y/o video con el bono de distintas personalidades que no sólo ayudaron a difundir la campaña sino que le dieron sustento a la propuesta comunicacional. Se destaca el aporte del historiador y escritor Osvaldo Bayer, el periodista Norberto "Ruso" Verea, el humorista Diego Capusotto y la banda Bersuit Vergarabat, entre tantos otros.

\section{- Gestión de reconocimientos}

Se realizaron gestiones institucionales mediantes las cuales la emisora y su campaña obtuvo el reconocimiento de la Universidad de Buenos Aires y de la Cámara de Diputados de la Provincia de Buenos Aires, así como también la declaración de interés cultural del Concejo Deliberante del Municipio de Quilmes.

\section{- Difusión en medios masivos de comunicación}

Canales de aire, gráfica y radio (Telefé Noticias / Visión 7 - TV Pública / Diario Tiempo Argentino, Diario Popular, Diagonales (LP) Mú, periódicos locales y electrónicos / AM 750, Cooperativa, Continental, Del Plata y emisoras locales, entre otros medios.)

\section{- 10 de diciembre de 2012: \#V uelveRadioAbijuna}

El 10 de diciembre, 8 meses después de la caída de su torre de transmisión, la emisora comunitaria celebró su inminente vuelta al éter con una radio abierta en el auditorio de la Biblioteca Pública y Complejo Cultural Mariano Moreno, donde tiene sus estudios centrales. La jornada contó con invitados especiales (referentes del campo de la comunicación e integrantes de organizaciones sociales de la región con quienes se desarrollan acciones estratégicas) y música en 
vivo $^{55}$. La jornada se realizó en el marco del Día Internacional de los Derechos Humanos, fecha emblemática que celebra el derecho de las personas a expresarse con libertad e igualdad. A su vez, el 10 de diciembre era el primer día de la plena vigencia de la Ley de Servicios de Comunicación Audiovisual, luego de vencerse los plazos de una medida judicial cautelar del principal grupo económico-mediático del país, que lo eximía de adecuarse a la ley de medios de la democracia.

\section{- Publicación de los resultados de la campaña solidaria}

En el evento del 10 de diciembre también se proyectaron los resultados finales de la campaña. Esta decisión le dio transparencia al proceso de recolección de fondos para la vuelta al aire. El aporte de más de 2.500 personas se tradujo en una suma total de 54.350 pesos argentinos. Este dinero permitió que Ahijuna reinstale su planta transmisora. A la par, se compartieron los resultados por los canales de comunicación de la emisora (facebook, twitter y página web) y hasta el presente pueden consultarse a través de internet ${ }^{56}$.

\section{- Publicación de los avances de obra}

Otra acción complementaria que permitió cerrar el proceso iniciado en abril con el lanzamiento de la campaña fue la publicación de fotografías en la "fanpage" de Facebook que mostraban los avances en las obras de montaje de torre y tecnología.

\subsection{Recursos}

Para el desarrollo de todas estas actividades se desarrollaron recursos de comunicación (diseño, animación multimedia, locuciones, fotografía y video), la capacitación en actualización de redes para el equipo de campaña y herramientas de análisis sobre las estadísticas en plataformas de redes sociales. Intervino además la comunicación y motivación de los colaboradores de difusión a través de coordenadas puntuales para la publicación de contenidos simultáneos. En estos

${ }^{55}$ Álbum “\#10D: Vuelve Radio Ahijuna” sobre la plataforma Facebook.

Disponible en:

https://www.facebook.com/media/set/?set=a.10151145739202691.440473.509

79997690\&type $=3$. (Última revisión: 30 de octubre de 2014).

${ }^{56} \mathrm{http}: / /$ www.youblisher.com/p/509946-Campana-solidaria-

UnDiegoParaLa'Torre-de-Radio-Ahijuna (Última revisión: 30 de octubre de 2014). 
procesos se realizó un control y seguimiento de las acciones planificadas.

\subsection{Productos}

Además, la campaña incluyó el desarrollo de productos:

\subsubsection{Comunicados}

El primero, anunciando la situación. El segundo, explicando el canje de bonos. El tercero, detallando los lugares de canje. El cuarto, a tres meses del tornado, comunicando el estado de situación de la campaña (¿Tenemos media torre? ¿O nos falta media torre?). El quinto, a días de cumplirse los 8 años de la emisora. El sexto y el séptimo, haciendo mención a la cantidad de bonos que precisaba la emisora para volver a transmitir.

\subsubsection{Bono autoadhesivo, spots audiovisuales y piezas de radio}

Todos los productos presentaron la misma estética, con la imagen de Diego Latorre, la voz de Norberto "Ruso" Verea y la cortina musical del grupo uruguayo "Cuatro pesos de propina".

Se realizó un spot audiovisual y otro radial para el lanzamiento de la campaña. Una vez cumplido el objetivo, se realizó un nuevo video resaltando la vuelta al aire de Ahijuna gracias a la solidaridad del público en el marco del Día Internacional de los Derechos Humanos.

A partir de diciembre de 2012, y durante varios meses, se renovó la estética sonora de la radio con piezas institucionales que hacían mención a la vuelta al aire de Radio Ahijuna, utilizando para ello la voz oficial de la campaña de Norberto Verea.

\subsubsection{Remeras y mates}

Se diseñaron remeras con el estampado "Yo me puse un diego para la torre", leyenda que va en consonancia con la campaña ya que también recuperaba un tono de la comunicación muy ligado a lo cotidiano y popular y, a su vez, exaltaba el compromiso individual para una causa colectiva. También se elaboraron remeras con la frase "Vuelve Radio Ahijuna" con motivo del fin de la campaña solidaria. Los mates, por su parte, llevan el logo y el nombre de la radio. Las remeras fueron estampadas en un taller serigráfico que cedió sus honorarios. Varios integrantes de la emisora participaron en ese proceso de producción 
(desde el diseño de la imagen hasta el estampado en sí mismo). En tanto, los mates también fueron elaborados por un artesano que cedió parte de sus honorarios.

\section{Palabras finales: la vuelta al aire, el valor de la solidaridad colectiva, el papel de las redes sociales y los nuevos desafíos}

Históricamente, las organizaciones sociales (entre las que se encuentran las emisoras populares) muestran ciertas dificultades tanto en la planificación como en el registro de sus actividades. De esta manera, se pierde su vínculo estrecho con las prácticas sociales, con el hacer diario y con las estrategias políticas y territoriales que se tejen en el desarrollo de sus acciones.

Este trabajo representa la oportunidad de sistematizar elementos generales de una intervención en comunicación elaborada en plena crisis con resultados exitosos. Además, este proceso de sistematización es la expresión de un trabajo en equipo que tiene como fin reflexionar sobre nuestras prácticas: las que atañen a la gestión integral de Radio Ahijuna FM 94.7.

Realizamos este registro crítico de la experiencia a partir de nuestra condición de profesionales formados en ámbitos académicos que, a su vez, protagonizan procesos de comunicación comunitaria y popular. Lo hacemos reconociendo las limitaciones que nos plantea la propia práctica, pero con la certeza de recibir aportes de las instancias de presentación e intercambio que nos permitan repensar y revisar nuestra propia praxis. Es un modesto aporte para vincularnos con otros proyectos y que puedan capitalizar fortalezas y debilidades de una campaña de comunicación que nace en una crisis (paradójicamente, por causas climáticas y no políticas o sociales).

En lo que respecta a la gestión de la emisora, la campaña inauguró cambios en el trabajo cotidiano de la cooperativa. Por eso hablamos de parto, no sólo porque la vuelta al aire tardó más de 8 meses, sino fundamentalmente porque implicó nuevas formas de pensar (y hacer) nuestras prácticas. La crisis nos llevó a un proceso de cambio en el organigrama formal del colectivo de trabajo: el desarrollo de nuevos roles y el reordenamiento de las tareas colectivas en función de la campaña y de la futura vuelta al aire.

Los indicadores de la estrategia dan cuenta del cumplimiento del objetivo. Difundimos el problema, recaudamos el dinero necesario 
para volver al aire y visibilizamos las prácticas de una experiencia de comunicación popular que se propuso desde sus comienzos (y lo sigue haciendo) ser una alternativa en el mapa de medios local concentrado en manos privadas.

El éxito de la campaña se debe, en gran parte, a la planificación integrada y sus continuos ajustes para lograr la vuelta al aire. La planificación, como parte vital de la gestión integral de una emisora popular, es estratégica porque potencia los objetivos (dimensión político-comunicacional), el perfil y su programación (dimensión comunicacional), la administración de los recursos económicos (dimensión económica) y los modos de organizarse (dimensión organizacional) en relación con la coyuntura (Lamas y Villamayor, 1998: 20).

Radio Ahijuna nació hace 10 años. Pensamos y parimos este proyecto en plena crisis política, social y económica, a contramano de la ley de radiodifusión de la dictadura (y sus miedos). Desde nuestros comienzos luchamos por una ley de medios de la democracia junto a organizaciones sociales, radios y medios populares, sindicatos y universidades. La lucha tuvo sus frutos: la Ley de Servicios de Comunicación Audiovisual (26.522), que reconoce a la radiodifusión comunitaria en tanto puede lograr que los habitantes de una ciudad pongan en marcha sus propios medios de comunicación. Esto se traduce en la propiedad y el sostén económico del medio, así como también en el aporte de temas y problemas específicos de una comunidad.

Un tornado nos llevó a cambiar nuestras prácticas sin perder de vista nuestros objetivos político-comunicacionales. "Somos andando" (del pedagogo brasileño Paulo Freire) era una de las frases que nos guiaban en 2004, cuando lanzamos Ahijuna. 10 años después nos sigue guiando para ser parte de las luchas por la profundización de la democracia y las comunicaciones.

\section{Referencias bibliográficas}

Iglesias, M. y Leavi, C. (2013): "Las radios sin fines de lucro: comunicación desde la ciudadanía. Estrategias, posicionamientos y tensiones frente al mercado y regulación del Estado", en Revista Oficios Terrestres, N²9. La Plata: Facultad de Periodismo y Comunicación Social de la Universidad Nacional de La Plata; recuperado el 30 de 
octubre de 2014. Disponible en:

http://sedici.unlp.edu.ar/handle/10915/33600

Lamas, E. y Villamayor, C. (1998): Gestión de la radio comunitaria y ciudadana. Quito: Fundación FES-AMARC ALC. Recuperado el 30 de octubre de 2014. Disponible en: http://www.vivalaradio.org/gestionradios-comunitarias/PDFs/GES organizacion 05manual-gestion.pdf

Massoni, S. (2007): Modelo de Comunicación Estratégica (Tres movimientos y siete pasos para comunicar estratégicamente). Rosario (Argentina): Homo Sapiens Ediciones.

Uranga, W. (2011): Para pensar las estrategias en la planificación de la comunicación. Buenos Aires: Mimeo.

VV.AA. (2012): "Experiencias de Crowdfunding en el Estado español y Cataluña: principales características, retos y obstáculos. Inspiración y recomendaciones para un instrumento más sólido de financiación transversal colectiva, pública y privada de la cultura”. Barcelona: Informe de X.net con asesoramiento jurídico de Silvia Caparrós; recuperado el 30 de octubre de 2014. Disponible en: http://2012.fcforum.net/experiencias-crowdfunding-caracteristicasretos-obstaculos/ 


\section{La comunicación científica a través de las redes sociales digitales}

Gabriela Coronel Salas, Universidad Técnica Particular de Loja (UTPL, Ecuador), glcoronel@utpl.edu.ec

Francisco Campos Freire, Universidad de Santiago de Compostela (USC, España),francisco.campos@usc.es

\section{Resumen}

La comunicación científica, como otras formas generalistas o temáticas de transmisión y difusión de la información, está experimentando también la transición de las modalidades presenciales y analógicas a las manifestaciones virtuales y digitales. Las redes sociales digitales son una significativa representación del cambio experimentado en las formas de comunicación, relación, interacción y sociabilidad provocado por la revolución de Internet y las tecnologías de la información. Esta comunicación estudia esas emergentes formas de difusión del conocimiento, las tecnologías de uso de la llamada ciencia 2.0 y 3.0, los nuevos sistemas de investigación, colaboración y reputación on line así como las posibilidades de aprovechamiento de las redes generalistas masivas para la difusión de experiencias y descubrimientos científicos. Se toman como referencia dos investigaciones realizadas con aplicación de metodologías cuantitativas y cualitativas para el análisis del uso de las redes sociales digitales y para la observación participante y no participante de dos experiencias de difusión en línea de la investigación: una excavación arqueológica en Galicia (España) y la promoción de los congresos "Convergencia de pantallas, diversidad de visiones" de la Red Iberoamericana de Narrativas Audiovisuales y de investigadores de la 
comunicación de Ecuador (SEICOM), del 1 al 4 de octubre de 2014 en Loja, a cargo del Departamento de Ciencias de la Comunicación de la UTPL.

Palabras clave: comunicación científica, redes sociales digitales, redes científicas, ciencia 2.0 y 3.0 y reputación on line.

\section{Introducción}

— L propósito de esta comunicación es presentar la utilidad y posibilidades que ofrecen las nuevas redes sociales digitales, tanto las generalistas como las temáticas de agregación de investigadores, para la comunicación y la divulgación científica. Este propósito está directamente relacionado con la especialización de los grupos de investigación a los que pertenecen los académicos que suscriben esta comunicación, vinculados a las Universidades Técnica Particular de Loja en Ecuador y Santiago de Compostela, en España. Dichos profesores desarrollan proyectos de investigación simultáneos en línea y aprovechan también el potencial de las redes digitales para llevarlos a cabo.

La génesis de la comunicación que aquí se presenta surgió del proceso de puesta en marcha en la Universidad Técnica Particular de Loja (UTPL), por un miembro (el Dr. Campos Freire) del Grupo de Investigación de Novos Medios de la Facultad de Ciencias de la Comunicación de la Universidad de Santiago de Compostela (USC), del Proyecto Prometeo que le fue aprobado por la Secretaría de Educación Superior, Ciencia, Tecnología e Innovación (SENESCYT) para el estudio del "Uso, impacto y resultados de la gestión de las redes sociales en los medios, organizaciones e instituciones de comunicación de Ecuador así como en las redes científicas y la promoción de las buenas prácticas de calidad y Responsabilidad Social Corporativa".

Las experiencias investigadoras que aquí se muestran son el resultado del uso de las redes sociales digitales en verano de 2012 para divulgar en tiempo real una campaña de arqueología pública de recuperación de una fortaleza histórica y un yacimiento arqueológico en un lugar de la costa de Galicia, en el noroeste de España, a cargo de miembros del Grupo de Investigación de Novos Medios de la USC, y 
el lanzamiento de los congresos sobre "Convergencia de Pantallas, Diversidad de Visiones" de la Red Iberoamericana de Narrativas Audiovisuales y de investigadores de la comunicación de Ecuador (SEICOM), del 1 al 4 de octubre de 2014 en Loja, coordinado por el Departamento de Ciencias de la Comunicación de la UTPL.

Son dos eventos y acciones diferentes, pero deliberadamente así elegidos para comprobar en distintos contextos o temáticas el potencial de posibilidades de las redes digitales, cuando éstas son adecuadamente planificadas y gestionadas.

\section{Comunicación en vivo de recuperación arqueológica}

La Torre dos Mouros es una imponente fortificación ubicada en la parroquia de Lira (Carnota), a 315 metros de altura sobre las aguas del océano atlántico, en la conocida como Costa de la Muerte (por su peligrosa navegabilidad y abundante saldo de trágicos naufragios desde el siglo XVI), en la provincia española de Coruña y la región noroeste de Galicia. La recuperación arqueológica fue iniciada al alertar los vecinos de la zona de su existencia, ya que era desconocida y estaba descatalogada. La intervención fue desarrollada con participación de voluntarios, bajo dirección arqueológica especializada, apoyo tecnológico de especialistas en gestión del patrimonio y divulgación científica a cargo de docentes e investigadores del Grupo de Novos Medios de la Universidad de Santiago. El profesor de Comunicación y gestor cultural, Manuel Gago, dirigió el experimento de divulgación científica, contando también con la colaboración del investigador Carlos Toural y otros colaboradores del Grupo de Novos Medios de la USC, que está dirigido por el catedrático de Periodismo Xosé López García. La síntesis del relato que se reproduce en esta comunicación recoge la versión narrativa textual del proyecto comunicacional de difusión de la recuperación arqueológica de Lira, divulgada en publicaciones científicas por los profesores Xosé López García, Manuel Gago Mariño y Carlos Toural Bran, de la Universidad de Santiago de Compostela.

\section{Promoción del congreso de narrativas audiovisuales}

Durante el 1, 2 y 3 de octubre de 2014 se desarrolló el II Congreso Internacional de la Red Iberoamericana de Narrativas Audiovisuales INAV- y el II Congreso Nacional de Investigadores de la 
Comunicación -SEICOM-: "CONVERGENCIA DE PANTALLAS, DIVERSIDAD DE VISIONES" 57 , promovido por el Departamento de Ciencias de la Comunicación de la UTPL y cuyo objetivo fue propiciar un espacio para el encuentro, debate y exposición de ideas, las mismas que ayudarán a fortalecer el desarrollo del pensamiento de la narración audiovisual. En este caso el objetivo es observar la promoción del congreso audiovisual de carácter internacional desde un ámbito específico y una estrategia netamente informativa para la divulgación del evento que se celebraba en Loja.

\section{Metodologías empleadas}

El experimento de cobertura informativa de la recuperación arqueológica de Galicia (España) se basó en la creación de dos métodos de trabajo: uno vinculado a la producción de contenido y otro relativo al análisis de sus métricas. El proyecto contó con su propio equipo periodístico 'incrustado' en las tareas arqueológicas, dirigido por el profesor de Comunicación, Manuel Gago, de la Universidad de Santiago de Compostela. La comunicación se desarrolló de forma específica para los diferentes soportes digitales empleados: Web, Facebook, Twitter, Flickr y YouTube ${ }^{58}$, adaptando el mensaje a cada uno de los soportes, y fue realizada en su mayor parte desde el yacimiento arqueológico.

La difusión en tiempo real se produjo durante el mes de julio de 2012, aunque antes y después se realizó también un aporte de contenidos regular a las sedes digitales, vinculado primero a los preparativos del trabajo de campo y posteriormente al análisis de resultados y otras actividades adicionales del proyecto. La colaboración entre arqueólogos y periodistas, de forma continua, fue determinante para la producción de contenido y para la interacción con el público.

"En el ámbito de la producción de contenido -según explican Manuel Gago y Carlos Toural (2014) - la estructura del trabajo diario de campo nos permitió secuenciar la narración y enfatizar dos ciclos de tramas: las de largo recorrido (toda la campaña arqueológica o más

\footnotetext{
${ }^{57}$ Web: http://congresoinav2014.utpl.edu.ec/

${ }^{58}$ Web: Torredosmouros.net; Flickr: flickr.com/torredosmouros; Twitter: @ torredosmouros; Facebook: facebook.com/torredosmouros; YouTube: youtube.com/torredosmouros
} 
allá), combinadas con tramas específicas de cada episodio (estructuramos cada fin de semana de intervención como un episodio). Mientras que las grandes tramas responden a las grandes preguntas del yacimiento arqueológico (¿cuál es su funcionalidad y cronología?) y otorgan unidad a toda la narrativa, las tramas específicas enfatizaron desafíos concretos de los sondeos (cronología comparada de muros, relación entre estructuras, aparición de artefactos o estructuras) que se combinaban historias centradas en el ámbito humano (historias de voluntarios, impresiones emocionales del equipo científico). Todas estas tramas eran narradas, en pequeñas piezas multimedia, a través de los diferentes soportes del sitio".

"Desde el punto de vista narrativo -agregan ambos investigadores del Grupo de Novos Medios de la USC- observamos que se producían interesantes paralelismos entre las estructuras de los guiones audiovisuales de ficción -aplicados en formatos televisivos británicos como el Time Team para la narrativa científica- y el desarrollo del método científico durante la intervención en campo. Si bien la estructura narrativa no podía ser concebida de acuerdo con la división aristotélica tradicional del relato (planteamiento, nudo y desenlace), si era posible hacer crecer la narración de forma horizontal a través de tramas y plot points (puntos de giro de la narración) (Field, 2003), que encontraban equivalencias sugerentes en los instrumentos del método científico (indicios, evidencias, conjeturas, verificación o refutación de hipótesis)".

Los responsables del proyecto explican que clasificaron los contenidos de Facebook, Twitter, Web y Youtube, de acuerdo con un sistema de codificación doble: por tramas y por tipos de objetos multimedia. Las imágenes depositadas en Flickr ofrecieron un corpus de interacciones mucho más reducido y de diversidad muy limitada y no fueron consideradas en el análisis. A estos datos de contenido les añadieron los valores relativos a su consumo por parte de la audiencia.

Por la disparidad de métricas y la incompatibilidad entre ellas, plantearon los análisis específicos por plataformas (Facebook, Twitter, Youtube, web) y realizaron únicamente comparaciones desde un aspecto indicativo e ilustrativo. Desde un punto de vista demográfico y sociológico, tanto Facebook como Youtube ofrecen datos relevantes en términos de género, edad y ubicación; estos datos se basan en los dos primeros casos en las declaraciones de los usuarios en 
sus cuentas de Facebook y de Google. "Existe, por lo tanto, un margen de error indeterminado, pero consideramos que no afecta de forma global al conjunto de datos", agregan los investigadores de la USC.

Con respecto a la metodología empleada para la observación de la difusión e interacción sobre el congreso de narrativas audiovisuales de Loja, el análisis de contenido se ha convertido en la técnica empleada, como ocurre con bastante frecuencia en los estudios sobre comunicación social, entre otros ámbitos de conocimiento: "Ha llegado a ser un método científico capaz de ofrecer inferencias a partir de datos esencialmente verbales, simbólicos o comunicativos. Más allá de su continuo compromiso con cuestiones psicológicas, sociológicas y políticas sustanciales, en los últimos ochenta años ha aumentado de forma exponencial el interés por el uso de esta técnica y se ha procurado establecer criterios adecuados de validez" (Krippendorff, 1990: 27). Método con atributos que permiten contemplar aquellos parámetros de contenido característicos en las redes sociales digitales.

A través de una ficha de recolección, se estableció una semana compuesta, tomando como inicio del análisis, los post (21 de agosto al 10 de septiembre de 2014) del evento. Por consiguiente, el resultado final fueron 21 publicaciones analizadas entre Facebook y Twitter. La Web del evento es netamente informativa, no existen elementos de interacción, en tal sentido podemos decir que gestiona información de manera plana.

\section{La comunicación científica}

El sociólogo Daniel Bell manifiesta que el ser humano ha experimentado cuatro etapas comunicativas: el lenguaje, la escritura, la imprenta y las telecomunicaciones (Bell, 1993: 35). Esta última marca significativamente el desarrollo de la sociedad de la información a través de la comunicación en red. McLuhan afirmaba que "las sociedades siempre han sido moldeadas por la naturaleza del medio con el que se comunican los hombres, más que por el contenido de dicha comunicación" (1969: 8).

Los periodistas españoles, especializados en divulgación científica, Eugenia Angulo e Ignacio Fernández Bayo (2009: 5), sostienen que el nacimiento de la comunicación científica se extiende hasta los albores de la civilización. El propio Calvo Hernando en su 
obra Periodismo Científico y Divulgación de la Ciencia se remonta hasta el historiador griego Jenofonte (siglo IV a.C.) y el filósofo romano Lucrecio (siglo I a.C.) para saltar luego a Paracelso (siglo XVI) y, por fin, a Fontenelle (siglo XVIII), que ya hacía lo que hoy podríamos denominar divulgación o periodismo científico tanto a través de un medio periódico, Le Mercure Galant, como a través de libros.

Malén Ruiz de Elvira (2009: 4) coincide que el "objetivo de la comunicación científica no es promocionar la ciencia como tal, como actividad a alabar sin más, sino permitir al público formarse una opinión informada sobre temas que le están afectando diariamente de forma directa o indirecta. Como consecuencia, sin embargo, también se está actuando a través de la comunicación científica sobre la imagen que la sociedad de cada país tiene de la ciencia y de los científicos. Asimismo, se trata de informar al público de avances en el conocimiento que le interesan aunque no tengan un efecto directo en su vida cotidiana."

Se torna importante acotar que una adecuada y bien llevada información cientifica tanto en medios de masas como en la Red, mejora los procesos de análisis y percepción que la sociedad posee ante la ciencia, la tecnología y los científicos. Aquí, la cultura cientifica entra en juego.

A decir del investigador Oscar Montañés (2011: 102), "la cultura científica es una modalidad de cultura en la que los tres tipos de información mencionados se refieren a rasgos culturales -representaciones, conocimientos, creencias, prácticas, normas, pautas de comportamiento, reglas, sistemas de preferencias, valores, criterios de valoración, etc.- cuyos contenidos están relacionados con la ciencia. Pero no se restringe únicamente a aquellos de estos rasgos que forman parte de la cultura profesional de los científicos y que resultan necesarios para que el grueso de la comunidad científica realice su trabajo (según las convenciones establecidas o según las reglas del juego que se ha dado a sí misma), sino que también incluye aquellos que, teniendo que ver con la actividad y el conocimiento cientificos, constituyen la cultura de cualquier individuo o grupo de individuos, $y$, junto a los primeros, conforman la imagen pública de la ciencia y la relación que los individuos y la sociedad establecen con ella. Es en este sentido en el que trasladando al terreno de la ciencia la distinción introducida por Miguel Ángel Quintanilla en el ámbito de la 
tecnología, entre cultura técnica incorporada y cultura técnica no incorporada diferenciamos dos niveles de cultura científica: intrínseca o interna, y extrínseca o externa." (Quintanilla 1998: 55 y 2011; Montañés, 2005: 309).

\section{Las redes generalistas y la ciencia}

El constante movimiento de la ciencia, a la par de la sed de conocimiento del hombre, la hace compleja y particular a la vez. Uno de sus fines es llegar a la verdad y de la necesidad del saber qué existe más allá de lo que aparenta ser normal. Para esto, la ciencia empleará elementos característicos no comunes en otras prácticas o áreas de trabajo.

El desarrollo del conocimiento científico parte desde la visión de la ciencia como una institución social, que incorpora métodos de trabajo que se orienten a solventar la producción de investigación, a fin de mantener una constante actividad en el desenvolvimiento de los modos de construcción del pensamiento, llegando incluso a influir en nuestras las creencias y actitudes. En tal sentido, la formación de un científico está directamente relacionada con su labor docente en el ámbito universitario. La transferencia del conocimiento hacia los alumnos enriquecerá el campo científico desde el punto de vista teórico pasando por la formación práctica y de valores esenciales en el oficio del saber.

Para efectivizar el descubrimiento de nuevo conocimiento, los científicos junto con los investigadores, docentes, becarios, deberán contar con entornos y artefactos básicos para su producción, entre ellos: laboratorios, bibliotecas, salas de trabajo, oficinas; acceso a documentación y bibliografía actualizada de forma física y digital. La gestión de recursos (económicos, físicos, humanos, etc.) por parte del grupo (investigador principal) es neural para cumplir con el fin propuesto (objetivos, hipótesis, preguntas de investigación, metodología, resultados, difusión).

La ciencia se caracteriza por ser metódica, si bien los descubrimientos pueden producirse por el azar, la instauración de leyes, métodos y/o disciplinas cumplirá con un proceso de sistematización de la información, que se verá reflejada en la valoración de sus resultados que serán difundidos a través de los canales propios de la ciencia: publicaciones científicas, siendo uno de 
los principales referentes de calidad ante la comunidad científica mundial. Aquí cabe una pregunta ¿La ciencia podría llegar a tener el alcance de difusión que sólo lo proporciona un medio masivo de comunicación?

En respuesta a la pregunta planteada, la duda no sólo se manifiesta por los mass media, aquí la WWW y sus aplicaciones juegan un rol en la difusión científica. La Web se torna importante para los sectores dedicados a la investigación tecnológica, buscando la posibilidad de darle un giro en cuanto al uso, la técnica y el acceso. Es por ello, que la Web 2.0 está concebida para el uso de cualquier persona. Los blogs, las wikis, las redes sociales ${ }^{59}$ y demás herramientas impulsan la participación y colaboración de los usuarios, por el simple hecho de compartir su vida a través de textos, fotografías, videos, e incluso sus sitios web favoritos. En si, se trata de la revolución de los negocios en la industria informática, causada por el paso de Internet como una plataforma, y un intento de entender las reglas para el éxito en la nueva plataforma. Lo importante era crear aplicaciones que aprovechen los efectos (positivos) de la red, para así alcanzar al mayor número de personas.

\section{Las redes sociales científicas}

Las redes sociales digitales pueden ser directas e indirectas. Las primeras son aquellas (de carácter generalista) en las que existe una colaboración entre los grupos de personas que comparten algunos intereses comunes y que interactúan en igualdad de condiciones a través de perfiles (con determinados grados de privacidad) mediante los cuales gestionan su información personal y la relación con los otros usuarios. Las redes indirectas (foros y comunidades virtuales), precursoras de las directas, son las que suelen disponer de un perfil identitario reconocible por el resto de la comunidad, con una persona o grupo (moderador) que controla y dirige la información o las discusiones en torno a temas concretos.

Las redes directas pueden ser horizontales o generalistas (Facebook, Hi5, MySpace) y verticales o especializadas por temática (profesional, identidad cultural, aficiones, viajes y otras temáticas),

\footnotetext{
${ }^{59}$ Comunidades virtuales que se relacionadas entre si y mantener constante comunicación entre personas afines a ciertos temas de interés. Encontramos Facebok, Hi5, Myspace, Twitter, Second Life.
} 
actividad (microblogging, juegos, geolocalización o georeferenciación, marcadores sociales y compartir objetos), por contenido (fotos, vídeos, documentos, presentaciones, noticias, lectura o ciencia) o por especialización (investigación, ciencia, economía). También se pueden clasificar por las características de sus relaciones: dirigidas (no bidireccionales) y no dirigidas (relaciones recíprocas e interactividad); explícitas (declaración de relación) e implícitas (deducidas del comportamiento).

Las nuevas redes científicas -que son directas, verticales y especializadas- son más amplias, recíprocas e interactivas que las indirectas y se pueden clasificar también según su temática, actividad y contenido a través del que se genera la participación, colaboración y difusión abierta de las investigaciones y el conocimiento. Su capital social es mucho más amplio por el potencial proyectivo de su vínculo externo, tal como prueba el paradigma de Gronowetter (1974).

Las redes digitales, como medios sociales que son, abren la posibilidad a la colaboración ampliada, que puede ser científica, especializada o incluso de carácter ciudadano, como destaca Flichy (2010) cuando pone a colaborar al científico con el "amateur", el "pro-am" (profesional-amateur), experto autodidacta, ciudadano-actor, creador y copartícipe. .

La teoría de la ciencia ciudadana, que Florian Charvolin (2007) y Flichy (2010) entroncan con la tradición sociológica de Schultz y Garfinkel, quiere liberar la investigación de las almenas exclusivas de las Universidades y los laboratorios cerrados para trasladar su espíritu y debate a las calles físicas y virtuales, es decir, también a las nuevas redes y medios sociales.

Las redes sociales digitales científicas son (1) ecosistemas de servicios de software, repositorios y plataformas de comunicación abiertas en red que permiten a los investigadores (2) crear un perfil académico y profesional dentro de un sistema específico de divulgación e intercambio de conocimiento; (3) establecer una lista de usuarios relacionados dentro de una o varias especializaciones científicas para compartir contactos, networking, proyectos, documentos, apuntes, colaboraciones e investigaciones; (4) poder acceder, consultar en línea y/o descargar referencias y producciones científicas disponibles; (5) aplicar herramientas de metadatos e inteligencia semántica; (6) gestionar el valor cuantitativo y cualitativo 
(capital social científico) de las citas, índices de impacto e información sobre el seguimiento de las publicaciones de los investigadores y, por agregación derivada, (7) establecer ranking de posición de las instituciones universitarias a las que pertenecen (Boy y Ellison, $2007 \mathrm{y}$ 2013; Stenger, 2009; Campos, 2013).

De las redes especializadas de intercambio de datos y comunidades virtuales cerradas (grupos afines con identidades, afiliaciones e intereses comunes) de los años 90 se ha pasado, en la primera década del siglo XXI, a los sitios de redes digitales abiertos, que son más que el establecimiento de networking (contactos) y de comunicación mediada por ordenador porque articulan relaciones sociales virtuales (Web 2.0) sobre un sistema que reconoce e interconecta perfiles (públicos o semipúblicos), amistades, comentarios, enlaces y contenidos de todo tipo.

El procesamiento de metadatos y establecimiento de conexiones en red permite al sistema y a los motores de búsqueda del mismo incrementar las posibilidades propias de esas redes. Estas nuevas redes y medios sociales en línea permiten articular ecosistemas de colaboración con capacidades, competencias y formas de pensamiento más ambiciosas (Tapscott, 2007: 401). La efervescencia científica, innovadora y empresarial que se ha desarrollado en los dos últimos años alrededor del concepto Big Data (grandes datos, en inglés) anticipa el salto tecnológico y social que se está produciendo desde la gestión de la comunicación (Web 2.0) al aprovechamiento de la información semántica (Web 3.0, interpretación de metadatos) mediante herramientas y aplicaciones de inteligencia artificial.

Actualmente ya hay más de medio centenar de redes sociales de investigadores pero las más populares y de mayor penetración, por orden de creación, son Mendeley.com (2007), Researchgate.net y Academia.edu (2008), que suman cerca de 20 millones de investigadores agregados así como otros tantos documentos y millones de visitas cada mes. Algunas de ellas, como es el caso de Researchgate y Academia, ensayan algoritmos de impacto y popularidad para establecer índices de reputación de los investigadores así como ranking de posición de las Universidades a las que pertenecen los respectivos académicos. 


\section{Resultados de dos experiencias}

Los datos analizados de la experiencia de difusión sobre la recuperación arqueológica de Torre de Mouros corresponden al intervalo temporal 1 de junio de 2012 hasta 31 de septiembre de 2012, y permiten observar la evolución del proyecto en sus diferentes fases: concepción y limpieza inicial, desarrollo de los trabajos arqueológicos y la producción cultural derivada posterior.

Los profesores Manuel Gago, Carlos Toural y Xosé López García relatan los resultados de su investigación señalando que "el crecimiento de la audiencia en web y en redes sociales está directamente vinculado a la producción y distribución de contenido en las sedes digitales. Es decir, es la actividad de campo y a la retransmisión en tiempo real de la divulgación, especialmente durante el mes de julio la que es capaz de captar mejores cifras de audiencia. Sin embargo, se producen interesantes y notables diferencias entre los comportamientos de la audiencia en la web y en el perfil de Facebook".

Los citados profesores agregan que "el crecimiento de fans en las plataformas sociales fue muy disimilar, evidenciando, a nuestro juicio, que existe una topografía de la distribución del uso de redes sociales, que tiene que ver con perfiles de público y segmentos sociales. De esta forma, pudimos observar cómo mientras Facebook se convertía en una plataforma de amplio seguimiento en muy poco tiempo (más de 600 seguidores en dos meses para un perfil tan específico en lengua gallega es un buen dato), Twitter apenas alcanzó los 150 seguidores durante los momentos más intensos de la campaña".

Señalan también que hasta el 15 de julio Facebook y Twitter compartían flujos informativos relativamente similares, combinando la información en profundidad que se remitía a la web, con los avisos de servicios y la narrativa en tiempo real de la excavación. A partir del 15 de julio, al observar el impacto más limitado en Twitter de la difusión, decidimos eliminar del flujo continuo la narrativa en tiempo real, en su estructura de tramas. El crecimiento de Twitter ha sido sostenido pero lento desde entonces.

"Desde nuestro punto de vista -aducen Gago, Toural y Lópezla diferencia de impacto entre Facebook y Twitter tiene que ver con 
un uso social considerablemente distinto entre las dos redes en el ámbito gallego. Mientras que Facebook se ha capitalizado en un ámbito social más diverso y amplio, posiblemente Twitter continúa siendo un soporte especialmente usado por early adopters, siguiendo la conceptualización de Rogers (1962)".

El experimento comunicacional de los profesores de la Universidad de Santiago reveló también patrones de comportamiento de las audiencias con respecto al seguimiento de la cobertura de la recuperación arqueológica, ligados tanto o más al ámbito de entretenimiento que al de carácter informativo, consumos discontinuos, variaciones según la viralidad de la difusión y tramas diversas, especialmente las de acción social e interés general.

Con respecto al Congreso de Narrativas Audiovisuales de octubre de 2014, en Loja-Ecuador, al tratarse de un evento en el cual se tratan tópicos de índole audiovisual y digital, la estrategia de promoción se torna débil. Se inicia la difusión el 21 de agosto, un mes y medio antes del congreso y se torna netamente informativa, comentando fechas, lugar del evento y conferencias. A continuación se evidencia la tabla de interacción del uso de Twitter (twitter.com/congresoINAV) y Facebook (facebook.com/congre soinav)

Gráfico 1: Interacción Twitter @congresoINAV

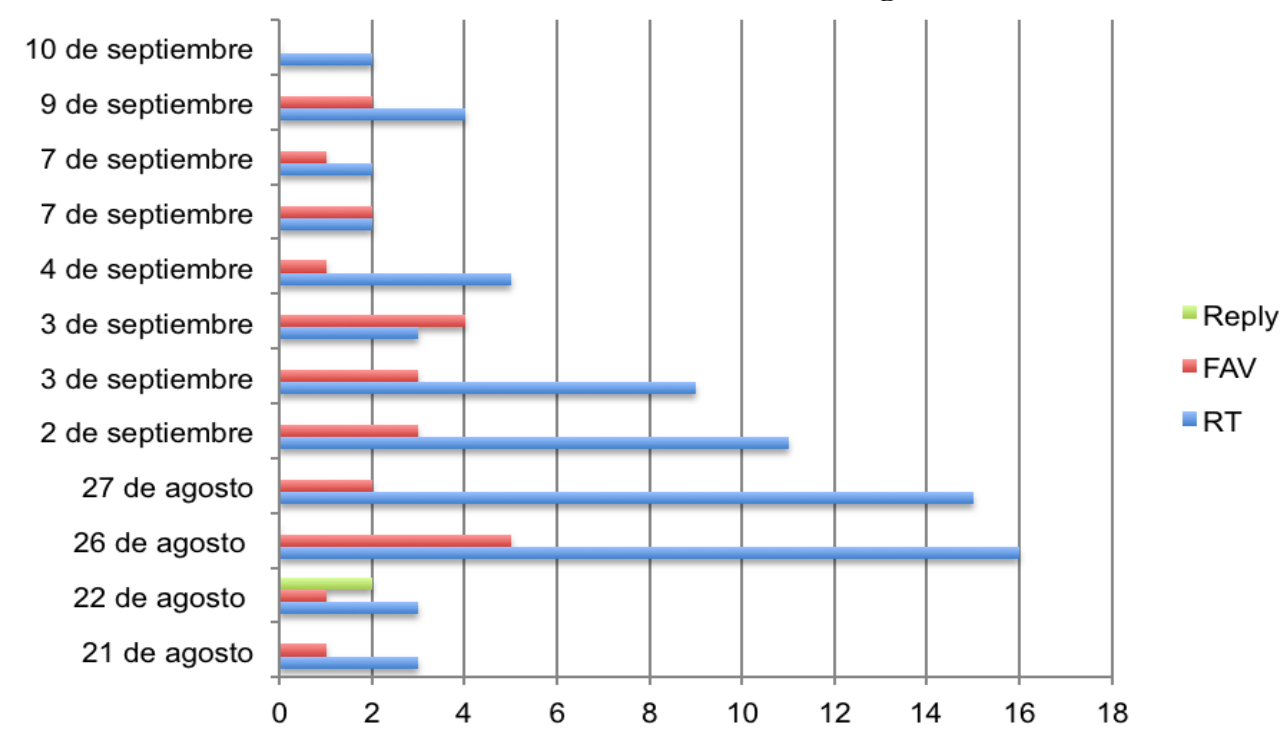

Fuente: Elaboración propia

Al ser una cuenta creada exclusivamente para el congreso, en Twitter registra 17 seguidores y sigue a 8. Su interacción llega a 108 
(RT, FV) En cambio en Facebook unas cien personas gustan de la página. En tal sentido, el alcance que posee la red social Facebook supera notablemente al microblogging Twitter.

Gráfico 2: Interacción Facebook.com/congresoinav

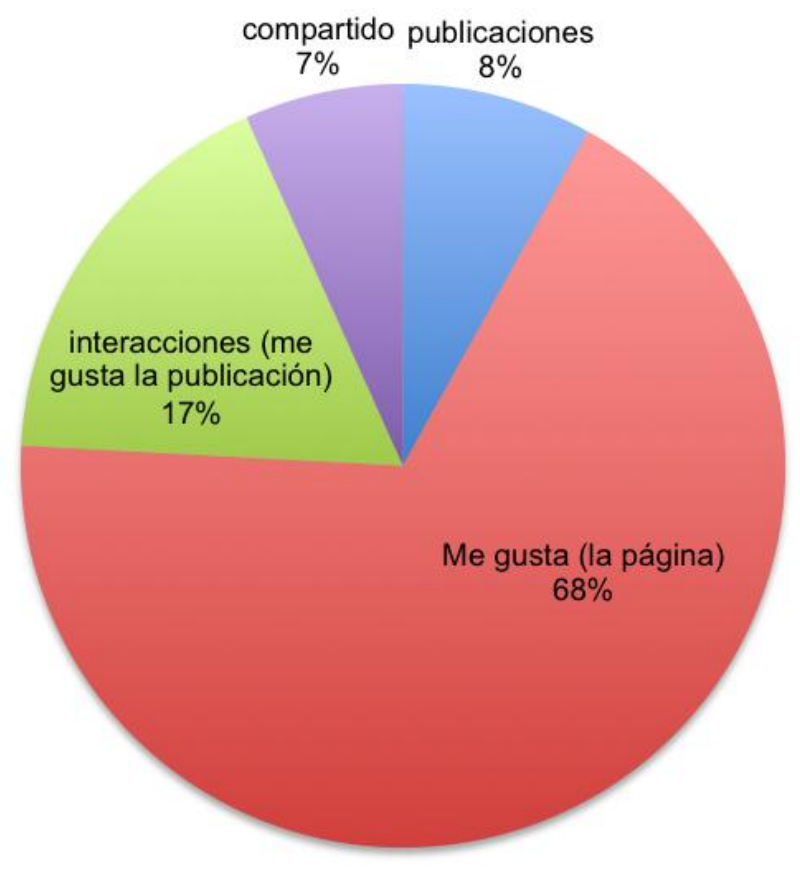

Fuente: Elaboración propia.

\section{Conclusiones}

El contraste de resultados sobre ambas experiencias de comunicación científica revela que el uso de los medios y redes sociales es de gran utilidad para la difusión de la ciencia, especialmente cuando existen estrategias, objetivos y planificación adecuada a los fines propuestos. Las experiencias revelan también la importancia de la colaboración interdisciplinar entre los científicos de determinadas áreas -en el caso español entre los arqueólogos y los comunicadores- para hacer llegar a la sociedad, mediante los nuevos medios sociales, los resultados de las acciones de la ciencia. La ciencia actual tiene que incorporar a sus estrategias de gestión y difusión no sólo los medios tradicionales de comunicación sino también los nuevos medios y redes sociales digitales. 


\section{Referencias bibliográficas}

Angulo, E. y Fernández Bayo, I. (1 de Enero de 2009): Innova. Recuperado el 5 de Agosto de 2014, de innova.uned.es:

https://www.innova.uned.es/webpages/agentesculturacientfica/mod ulo5/tema4/tema4.pdf

Balagué, Crhistine, Fayon, David (2012): Facebook, Twitter et les réseaux sociaux dans une stratégie d'entrepresse. París: Pearson.

Bardon, Audrey (2011): “Top 20 des réseaux sociaux scientifiques", en: http://www.knowtex.com/blog/le-top-20-desreseaux-sociaux-scientifiques/

Barnes, John (1954): "Class and comittees in a Norwegian Island parish”, en Human Relations, 7, páginas 39 a 58.

Bell, D. (1993): Las telecomunicaciones y el cambio social. Barcelona.

Foray, D. (2002): "Una introducción a la economía y a la sociedad del saber", en International Social Science Journal, no 171, páginas 7 a 28.

Benghozi, P. J. (2006): “Communaute virtuelle: structuration sociale ou outil de gestion?”, en Entreprises et Histoires, núm. 43, páginas 67 a 81.

Benghozi, P. J. (2011): "Économie numérique et industries de contenu: un nouveau paradigme pour les résaux", en Hermès, 59. París: CNRS.

Bouquillion, P. y Matthews, J. T. (2010): Le Web collaborative: Mutations des industries de la culture et de la communication. Grenoble: PUG.

Bourdieu, P. (1986): “The Forms of Capital”. En VV.AA., Handbook o Theory and Research for the Sociology of Education (Ed., J. G. Richards), páginas 241 a 258. Nueva York: Greenwood Press..

Boyd, D. M. y Ellison, N. B. (2007): "Social Network Sites: Definition, History, and Scholarship", en Journal of Computer-Mediated Communicaton, vol. 13,1, páginas 210 a 230.

Burt, R. S. (1992): Structural Holes: The Social Structure of Competition. Cambridge, MA: Harvard University Press.

Butts, C. T. y Cross, B. R. (2009): "Change and External Events in Computer-Mediated Citation Networks: English Language Weblogs and the 2004 US Electoral Cycle", en Journal of Social Structure (JOSS), vol. 10, 3. http://www.cmu.edu/joss/content/ 
Campos Freire, F., ed. (2013): Investigación y gestión de las redes sociales digitales. Tenerife: Cuadernos Artesanos de Comunicación (CAC, 50) de la Revista Latina de Comunicación Social. http://www.revistalatinacs.org/068/cuadernos/cac50.pdf

Casilli, A. A. (2010): Les liaisons numériques. Vers une nouvelle sociabilité? París: Seuil.

Castells, M. (2009): Comunicación y poder. Madrid: Alianza Editorial.

Charvolin, F., Micoud, A. y Nyhart, L., dir. (2007): Des sciencies citoyennes? La Tour d'Aigues, Éditions de 1' Aube.

Coleman, J. S. (1990): "Social Capital in the Creation of Human Capital", en American Journal of Sociology, 94, páginas 95 a 120.

Degenne, Alain (2011): "Retour à l'analyse des réseaux sociaux (entretien)", en Hermès, 59, páginas 39 a 40. París: CNRS.

Ellison, N. B. (2011): "Réseaux Sociaux, numérique et capital social (entretien)". Realizada por Thomas Stenger y Alexandre Coutant, en Hermès, 59, páginas 21 a 24.

Ellison, N. B., Steinfield, C. y Lampe, C. (2011): "Connection strategies: Social capital implications of Facebook-enabled communication practices", en New Mediadosociety, vol. 13, 6, Sage Pub.

Ellison, N. y Boyd, D. (2013): "Sociality through Social Network Sites." En The Oxford Handbook of Internet Studies (ed. William H. Dutton). Oxford: Oxford University Press.

Fayon, D. (2010): Web 2.0 et au-delà : Nouveaux internautes : du surfeur à l'acteur. París: Economica.

Field, S. (2003): The Definitive Guide to Screenwriting. Londres: Randomnivel de $\mathrm{p}$ House.

Flichy, Patrice (2010) : Le sacre de l'amateur. Sociologie des passions ordinaires à l'ère numérique. París: Seuil.

Freeman, L. C. (2012): El desarrollo del análisis de redes sociales. Un estudio de sociología de la ciencia. Bloomington: Palibro.

Gago Mariño, M.; Toural Bran, C. y López García, X. (2014): "La encrucijada de la divulgación científica: tiempo real y portabilidad de conceptos", en www.academia.edu. Consultado el 5-5-2014.

Gago, M.; Fernández Malde, A.; Ayán, X. y Toural, C. (2013): "A Torre dos Mouros (Lira, Carnota)". En VV.AA., Arqueología pública en España (Ed., J. Almansa Sánchez). Madrid: Servicepoint, www.servicepoint.es 
García-Valdecasas Medina, J. I. (2011): “Una definición estructural del capital social”, en Redes, vol. 20, 6, Barcelona. http://revista-redes.rediris.es

González Macías, Ma Á. (2013): Pinterest. La red social visualy creativa. Barcelona: UOC.

Granovetter, M. S. (1974): Getting a Job: a study of contacts and careers. Cambridge: Harvard University Press.

Hallam, J. (2012): The Social Media Manifesto. Palgrave Macmillan.

Hermés (2011): Ces résaux numériques dits sociaux. París: CNRS.

Herrera Gómez, M., Barquero Cabrero, J. D. (2012): Redes sociales. De metáfora a paradigma. Barcelona: Furtvangen Editores.

Jenkins, H. (2009): Fans, blogueros y videojuegos: la cultura de la colaboración. Barcelona: Paidós.

Jenkins, H. (2010): Piratas de textos: fans, cultura participativa y televisión. Barcelona: Paidós.

Knight, M.; Cook, C. (2013): Social Media for Journalists. Principles and Practice. Londres: Sage.

Krippendorff, K. (1990): Metodología de análisis de contenido: teoría y práctica. (L. Wolfson, Trans.) Barcelona: Paidós.

Lazega, Emmanuel (1998): Réseaux sociaux et structures relationnelles. París: PUF.

Lèvy, P. (2004): La inteligencia colectiva. Por una organización del ciberespacio. Washington: Organización Panamericana de la Salud (ed. PDF).

Lin, N. (2001): Social Capital: a theory of social structure and action. Cambridge: University Press.

McLuhan, M., y Fiore, Q. (1969): El medio es el masaje. Buenos Aires: Paidos.

Mercklé, P. (2011): Sociologie des réseaux sociaux. París: La Découverte.

Molina, J. L. (2004): "La ciencia de las redes", en Apuntes de Ciencia y Tecnología”, número 11.

Montañés Perales, O. (2005): "La comunicación pública de la cultura científica; ampliando la noción de "confianza"'. En VV.AA., Actas del III Congreso sobre Comunicación Social de la Ciencia Sin Ciencia no bay Cultura (Coord., R. Núñez) páginas 307 a 310. A Coruña.

Montañes, O. (10 de Marzo de 2011): La cultura cientifica: un marco conceptual de referencia para la evaluación de la percepción pública de la ciencia,. 
FECYT. Recuperado el 3 de Febrero de 2014, de Icono.Fecyt:

http://icono.fecyt.es/informesypublicaciones/Documents/Publicacio

n PSC2010.pdf

Moreno, J. L. y Jennings, H. H. (1934): Who Shall Survive: A new approach to the problem of human. Washington: Nervous and Mental Disease Publishing C.

Morín, E. (1994): Introducción al pensamiento complejo. Barcelona: Gedisa.

Noguera Vivo, J. M.; Martínez Polo, J. y Grandío Pérez, M. M. (2011): Redes Sociales para estudiantes de Comunicación. Barcelona: UOC.

Noguera, J. M. (2012): Redes y Periodismo. Barcelona: UOC.

O'Reilly Media. (02 de Enero de 2004): O'Reilly Media. Recuperado el 2014 de Abril from O'Reilly Media: http:/ / oreilly.com/

Poncier, A. (2011): Les réseaux sociaux d'entreprise. París: Diateino.

Putnam, R. (1993): “The prosperous community: social capital and public life", en The American Prospect, 13.

Quintanilla Fisac, M.A. (1998): “Tecnología y cultura”, en Teorema, XVII (3), páginas 49 a 69.

Quintanilla Fisac, M. A.; Escobar, M.; Groves, T.; Montero Becerra, J.; Palacios Sánchez, R.; Montañés Perales, O. y Orellana McBride, A. (2011): Scientific and technological culture in ESO textbooks. La cultura cientifica y tecnológica en los libros de texto de la ESO. Salamanca: Instituto de Estudios de la Ciencia y la Tecnología. Universidad de Salamanca.

http://www.novatores.org/html/es/eprint/show.html?ePrintId=177

Requena Santos, F. (2003, 2012): ed. Análisis de redes sociales. Orígenes, teorias y aplicaciones. Madrid: CIS.

Requena Santos, F. (2011): Las redes de apoyo social. Madrid: Thomson Reuters.

Rheingold, H. (1993, 2000): The virtual community: Homesteading on the electronic frontier. Reading, MA: Addison-Wesley.

Rheingold, H. (2004): Multitudes inteligentes. Las redes sociales y las posibilidades de las tecnologías de cooperación. Barcelona: Gedisa.

Rissoan, R. (2011): Les réseaux sociaux. Facebook, Twitter, Linkedin, Viadeo. Comprendre et maîtriser ces nouveaux outils de communication. Paris: Editions ENI.

Ruiz de Elvira, M. (1 de Enero de 2009): Innova. Recuperado el 15 de Agosto de 2014, de Medios y técnicas de la comunicación de la 
ciencia y la tecnología:

https://www.innova.uned.es/webpages/agentesculturacientfica/mod ulo5/tema3/tema3.pdf

Ruiz de Elvira, M. (1 de Enero de 2009): Innova. Recuperado el 15 de Agosto de 2014, de Medios y técnicas de la comunicación de la ciencia y la tecnología:

https://www.innova.uned.es/webpages/agentesculturacientfica/mod ulo5/tema3/tema3.pdf

Sluzki, C. E. (1998): La red social: frontera de la práctica sistémica. Barcelona: Gedisa.

Stenger, T. (2009): "Social Network Sites (SNS): do they match? Definitions and methods for social sciences and marketing research", en XXIX Conferencia INSN $A$ en San Diego (EE.UU.). Accesible también en línea en:

http://www.academia.edu/2521387/Social Network Sites SNS do they match Definitions and methods for social sciences and mar keting research

Stenger, T. y Coutant, A. (2011): "Introduction. Ces réseaux numériques dits sociaux", en Hermès, 59, páginas 9 a 20.

Summit, W. 2. (10 de Julio de 2010): Web 2.0 Summit. Recuperado 15 de Enero de 2014 from Web 2.0 Summit:

http://www.web2summit.com/

Tapscott, D. y Williams, A. D. (2007): Wikinomics. La nueva economía de las multitudes inteligentes. Barcelona: Paidós.

Tello, N. y De la Peña, J. A. (2013): "Modelos matemáticos de la sociedad y aplicaciones. Crecimiento de las redes sociales", en Redes, vol 24, 1, Barcelona. http://revista-redes.rediris.es

Watts, D. J. (2006): Seis grados de separación. La ciencia de las redes en la era del acceso. Barcelona: Paidós.

Wolton, D. (2011): "Ces réseaux numériques dits sociaux", introducción a número sobre redes sociales digitales, coordinado por Thomas Stenger y Alexandre Coutant, en Hermès, número 59. París: CNRS. 


\section{La participación e interacción de los investigadores de comunicación de países iberoamericanos en las redes sociales digitales científicas}

María Isabel Punín, Universidad Técnica Particular de Loja (UTPL, Ecuador),mipunin@utpl.edu.ec

Sabela Direito Rebollal, Universidad de Santiago de Compostela (USC, España), sabeladireito@hotmail.com

Daniela Calva, Universidad Técnica Particular de Loja (UTPL, Ecuador), danicalva13@gmail.com

\section{Resumen}

Desde su irrupción en la segunda mitad del siglo XXI, las redes científicas se consagraron como plataformas que les permiten a los académicos divulgar y compartir públicamente sus proyectos e investigaciones dentro de un sistema específico de intercambio del conocimiento, acceder a otras producciones científicas e, incluso, gestionar y obtener información sobre el seguimiento e impacto de las mismas.

Sin embargo, a pesar de que el desarrollo de estas nuevas redes es rápido y continuo, la participación y contribución de los investigadores de comunicación de una muestra de universidades iberoamericanas sigue siendo todavía baja, mientras que la interacción que se produce entre ellos es aún más reducida. 
Palabras clave: redes sociales digitales científicas, análisis de redes sociales, interacción, participación e influencia.

\section{Introducción}

F $\mathrm{L}$ concepto de red social es un término que ha ido evolucionando a lo largo del tiempo y modificándose a medida que los avances tecnológicos y, sobre todo, la evolución del desarrollo de Internet, la web y los cibermedios (Campos, 2013b) hacían mella en el panorama social y comunicativo.

Así, aunque las primeras redes sociales surgen poco después del origen de internet, no se popularizan hasta mediados de la primera década del siglo XXI. Es a partir del año 2003 cuando se empiezan a desarrollar las conocidas como redes digitales -Facebook, en 2004; YouTube, en 2005 o Twitter, en 2006- "que van pasando de pequeñas comunidades en línea a estructuras de comunicación masivas, populares, generalistas o temáticas, de carácter global o más locales y reducidas" (Íbid: 22).

Poco a poco, estas herramientas se consolidan como espacios de la World Wide Web en los que los usuarios pueden publicar información sobre sí mismos y sus intereses, o interactuar con el resto de miembros registrados en ellas (Nafría, 2007).

De hecho, tal y como afirman las norteamericanas Danah Boyd y Nicole Ellison (2007), las social networks les permiten a los individuos construir un perfil público o semipúblico dentro de un sistema informático, articular una lista de utilizadores con los que compartir contenido, ver o explorar esa lista de conexiones y otras realizadas por distintos usuarios dentro del sistema.

Posteriormente, ambas investigadoras reformularon dicha definición, puntualizando que, en estas plataformas en red, los participantes (1) disponen de perfiles asociados a una identificación única, creados por una combinación de contenidos producidos por el utilizador, por amigos y datos sistémicos; (2) pueden exponer públicamente las relaciones susceptibles de ser visualizadas y consultadas por otros; y (3) acceder a los flujos de contenidos (combinaciones de textos, fotos, vídeos, datos y nuevos enlaces) generados por los utilizadores y sus contactos a través de los sitios de Internet (Ellison y Boyd, 2013). 
Tomando como referencia esta acepción, Thomas Stenger (2009) propone que las redes sociales son servicios basados en la web que permiten (1) construir un perfil público o semipúblico dentro de un sistema limitado; (2) establecer una lista de usuarios con los que compartir conexión; y (3) navegar a través de esa lista de enlaces y de las establecidas por otros utilizadores dentro del sistema, considerando que la naturaleza de estas conexiones puede variar de un sitio a otro.

Según Manuel Castells (2009: 45), las redes digitales son un "conjunto de nodos interconectados formando clusters", que pueden ser mayores o menores según su centralidad, con funciones y significados dependientes de la estructura y de su interacción con otros nodos. "La importancia del nodo depende de su capacidad para contribuir a lograr objetivos, defender valores o intereses programados" (Íbid.)".

Si recurrimos a la definición de Alain Degenne (2011), serían herramientas de mediación, relación e interacción entre personas y organizaciones a través de teléfono o Internet.

Pero Pierre-Jean Benghozzi (2011) va más allá en la consideración de las redes sociales, al señalar que son un laboratorio de diversas formas de organización, de nueva economía híbrida, de una arquitectura innovadora de relaciones y de modelos de negocio diferentes.

Del mismo modo, Rheingold (2004) apunta que estamos inmersos en el comienzo del desarrollo de un nuevo medio de organización social, cultural y político. Dicho de otro modo, estaríamos sumidos en lo que Castells (2009: 20) denomina "sociedad red", que es "aquélla cuya estructura social está compuesta de redes activadas por tecnologías digitales de la comunicación y la información basadas en la microelectrónica".

Posteriormente a la aparición de esas redes sociales digitales generalistas, surgen en el año 2007 las conocidas como redes científicas, entendidas como:

"ecosistemas de servicios de software, repositorios y plataformas de comunicación abiertas en red que permiten a los investigadores (1) crear un perfil académico y profesional dentro de un sistema de divulgación e intercambio de conocimiento; (2) establecer una lista de usuarios relacionados dentro de una $\mathrm{O}$ 
varias especializaciones científicas para compartir contactos, proyectos, documentos, apuntes, colaboraciones e investígaciones; (3) poder acceder, consultar en línea y/o descargar referencias y producciones científicas disponibles; (4) gestionar el valor cuantitativo y cualitativo (capital social científico) de colaboraciones, contactos, citas, índices de impacto e información sobre el seguimiento de las publicaciones propias y ajenas" (Campos, 2013b: 39).

En este sentido, la presente investigación centra su objeto de estudio en el uso de las redes científicas como plataformas de comunicación que permiten la colaboración y el intercambio de conocimientos entre los investigadores agregados a ellas.

Sobre una muestra de universidades del área iberoamericana, se analiza la penetración de las redes científicas entre los docentes de las facultades de Ecuador, Portugal, Brasil y Galicia (España), para comprobar cuál es el uso que los académicos de los departamentos de Ciencias de la Comunicación hacen de estas herramientas.

La hipótesis que se plantea es que, a pesar del desarrollo continuo que están experimentando estas nuevas plataformas, la participación y contribución de los profesores de comunicación de la región iberoamericana sigue siendo todavía baja, al igual que la interacción que se produce entre ellos, que es aún más reducida y, fundamentalmente, de carácter endogámico.

\section{Metodología}

El objetivo definitorio de este estudio reside en proporcionar una panorámica general sobre el empleo que realizan los docentes de comunicación iberoamericanos de las redes sociales digitales académicas.

Para ello, se toman como muestra dos de las plataformas científicas más populares hasta el momento -Academia.edu y ResearchGate.nety la plantilla de profesores de las universidades de Ciencias de la Comunicación de Ecuador, Portugal, Brasil y Galicia (España). Concretamente, se han seleccionado la Universidad Técnica Particular de Loja (UTPL), Casa Grande (UCG) y San Francisco de Quito (USFQ), en Ecuador; Porto (UP), Minho (UM) y Beira Interior (UBI), en Portugal; Sao Paulo (USP), Federal de Santa Catarina (UDSC) y 
Federal de Bahia (UFBA), en Brasil; Santiago de Compostela (USC), Vigo (UVigo) y A Coruña (UDC), en Galicia (España).

Una vez definido el objeto de análisis, constatamos la presencia de investigadores del área de comunicación en las redes científicas para, posteriormente, establecer una comparación con el nivel de penetración en las redes de corte generalista -Facebook y Twitter-.

Además de la agregación de los académicos a las plataformas científicas, estudiamos también la actividad que registran en ellas, tomando como ejemplo ilustrativo el número de papers publicados en Academia.edu.

Asimismo, con el fin de obtener referencias sobre la circulación del conocimiento a nivel nacional e internacional, observamos el grado de interacción que se produce entre los docentes de Ecuador, Portugal, Brasil y Galicia con respecto a los académicos del resto del mundo. En este caso, nos servimos de los datos extraídos del seguimiento de las métricas de ResearchGate, debido a su mayor operatividad y utilidad.

Finalmente, a través del RG Score de cada investigador y de su índice $\mathrm{H}$ de Google, determinamos la visibilidad y reputación que adquiere la investigación en las universidades que forman parte de la muestra seleccionada.

\section{Las principales redes sociales digitales}

Aunque con un origen posterior al de las redes sociales generalistas, las plataformas científicas de intercambio del conocimiento están aumentando, desenvolviéndose y consolidándose de forma rápida y constante entre los miembros de la comunidad investigadora.

De hecho, es tal su avance, que éstas quebraron ya el monopolio que hasta el momento ostentaban las grandes revistas y grupos editoriales multinacionales -Thompson, Elsevier o Sage- en lo que respecta al control de la producción científica. Amenazadas por esta nueva herramienta de intercambio de saberes, algunas de las casas editoriales más importantes optaron por hacerse con el control de las redes científicas con un mayor desarrollo o, incluso, por crear las suyas propias.

Así, frente a la lentitud en la revisión y en la publicación de los artículos en las revistas, plataformas como Mendeley.com (2007), Academia.edu (2008) o ResearchGate.net (2008) permiten la 
divulgación abierta e instantánea de las investigaciones y, además, favorecen la colaboración e interacción entre los miembros agregados a ellas.

En este sentido, Mendeley, una de las más antiguas, aunque con un crecimiento y seguimiento menor, ofrece la posibilidad de organizar y compartir trabajos de investigación, establecer contacto con otros académicos de la misma disciplina, crear grupos temáticos, realizar colaboraciones en línea... La propia misión de la red así lo hace constar, en tanto se presenta como una plataforma que "ayuda a gestionar y compartir los datos de investigación del modo que el usuario elija" (http://www.mendeley.com).

Academia.edu, muy popular entre los docentes del área de Ciencias Sociales, permite compartir papers y supervisar, en todo momento, cuál es el impacto que eses artículos están causando en la comunidad investigadora. Mediante la creación de un perfil personal, el académico no sólo puede hacer públicos sus trabajos, sino también seguir a otros investigadores y consultar tanto sus papers como el ranking de visitas mensuales de las publicaciones propias y ajenas.

Con más de 15,5 millones de afiliados, cuatro millones de documentos y 1,3 millones de líneas de investigación (datos recuperados en noviembre de 2014), Academia.edu se postula como una de las plataformas más populares, encaminada a conseguir la misión de acelerar la investigación en el mundo, (http:// www.academia.edu).

En este mismo sentido pivota también el objetivo de ResearchGate, otra de las plataformas científicas más utilizadas -en este caso, entre los docentes de la rama de medicina y biologíadefinida por "conectar a los investigadores, haciéndoles más fácil compartir y acceder al conocimiento y a la experiencia científica" (www.researchgate.net). De hecho, en ResearchGate, se pueden publicar artículos, acceder a otros elaborados por los académicos seguidos, obtener estadísticas sobre el número de visitas, descargas y citas, conectar y colaborar con otros colegas de la misma área de interés...

Sin embargo, el rasgo diferenciador de esta red social es que incorpora una herramienta para realizar preguntas abiertas en línea, de modo similar al de una conversación a través de chat, con el propósito de que la comunidad pueda aportar instantáneamente sus 
conocimientos acerca del tema sobre el que se está investigando. Tal es así, que la propia plataforma científica se define en su sitio web como una red en la que los académicos "encuentran lo que necesitan para avanzar en su investigación" (www.researchgate.net).

Además, ResearchGate cuenta también con un indicador de reputación de los investigadores (RG Score), conformado por el índice de impacto de sus publicaciones y de la popularidad que tanto sus papers como su perfil adquieren en la propia red.

A pesar de ello, y aunque el número de personas agregadas a ResearchGate en 2014 superaba los cinco millones, esta cifra dista considerablemente de los más de quince con los que cuenta Academia.edu.

\section{La penetración y uso de las redes científicas en el área iberoamericana}

Prácticamente desde el nacimiento de las redes sociales digitales, éstas se postularon como nuevas plataformas para la difusión y relación entre los miembros de la comunidad investigadora. Sin embargo, tal y como afirma Campos (2013a: 119), "hay que pasar también a concebirlas como método y herramienta de trabajo para el desarrollo de la sociedad del conocimiento".

Así, si bien las redes sociales en línea ofrecen la posibilidad de articular ecosistemas de colaboración (Tapscott y Williams, 2007), puestos "al servicio de la investigación, la ciencia y el conocimiento son prometedores e interesantes sistemas de gestión de la comunicación necesarios para ampliar las fronteras geográficas y democráticas de nuestra cultura contemporánea" (Campos, 2013a: 106).

Pero, por el momento, únicamente podemos otorgarles ese calificativo de sistemas interesantes y prometedores, pues aunque la participación en las redes científicas por los académicos está registrando un crecimiento rápido y constante, lo cierto es que la agregación de investigadores de comunicación de las universidades de Ecuador y de las áreas de proximidad a la lusofonía todavía es baja.

En términos generales, entre los docentes de las universidades de Ecuador, Portugal, Brasil y Galicia, predomina la afiliación a Academia.edu frente a ResearchGate.net, confirmando el hecho de 
que, en el área de Ciencias Sociales, Academia es más popular que una de sus competidoras directas -ResearchGate-.

Tabla 1: Académicos de comunicación en las redes científicas

\begin{tabular}{|c|c|c|c|}
\hline Universidad & $\begin{array}{c}\mathrm{N}^{\circ} \text { de profesores de } \\
\text { comunicación en planta }\end{array}$ & $\begin{array}{c}\mathbf{N}^{\circ} \text { de profesores en } \\
\text { Academia }\end{array}$ & $\begin{array}{c}\mathrm{N}^{\circ} \text { de profesores en } \\
\text { ResearchGate }\end{array}$ \\
\hline \multicolumn{4}{|l|}{ Ecuador } \\
\hline Técnica Particular de Loja & 57 & 15 & 16 \\
\hline Casa Grande & 10 & 3 & 0 \\
\hline San Francisco de Quito & 22 & 4 & 3 \\
\hline \multicolumn{4}{|l|}{ Portugal } \\
\hline Minho & 30 & 15 & 14 \\
\hline Beira Interior & 41 & 15 & 9 \\
\hline Porto & 25 & 9 & 7 \\
\hline \multicolumn{4}{|l|}{ Brasil } \\
\hline Sao Paulo & 28 & 11 & 3 \\
\hline Sta. Catarina de Florianópolisis & 25 & 8 & 2 \\
\hline Bahia & 33 & 16 & 5 \\
\hline \multicolumn{4}{|l|}{ Galicia (España) } \\
\hline Santiago & 57 & 19 & 14 \\
\hline Vigo & 79 & 27 & 12 \\
\hline A Coruña & 41 & 16 & 13 \\
\hline
\end{tabular}

Fuente: Elaboración propia a partir de la consulta de los investigadores afiliados a las redes científicas. Datos de octubre de 2014

De hecho, el número de profesores lusófonos registrados en Academia oscilan entre el 30 y el $40 \%$ del total en plantilla, a excepción de la Universidad de Minho, que contabiliza un 50\% de docentes agregados, y de la Universidad Federal da Bahia, con un 48,8\%. En Ecuador, el porcentaje se reduce al 30\% en el caso de la Universidad Casa Grande, al 26,3\% de la Universidad Técnica Particular de Loja y al 18,1\% en la Universidad San Francisco de Quito.

Sin embargo, estas cifras decrecen a porcentajes que fluctúan entre el 20 y el 30\% si analizamos la presencia en ResearchGate de universidades como Beira Interior (21,9\%), Porto (28\%) y Santiago $(24,5 \%)$, y descienden hasta niveles iguales o inferiores al $15 \%$ en el caso de Sao Paulo (10\%), Santa Catarina (8\%), Bahia (15\%) y Vigo $(15 \%)$. Estas cifras únicamente son superadas por la Universidad de A Coruña (31\%) y la de Minho (46,6\%). En Ecuador, es destacable el caso de la Universidad Casa Grande, en la que ninguno de sus docentes está registrado en ResearchGate.

Comparando estos datos de afiliación a redes científicas con respecto al número de docentes e investigadores que están presentes en las de carácter generalista -Facebook y Twitter-, constatamos una 
tendencia mayor al uso de este tipo de medios vinculados con factores de sociabilidad.

A grandes rasgos, el número de académicos afiliados tanto a Facebook como a Twitter es superior al registro de docentes que emplean Academia.edu y ResearchGate.net, salvo en la Universidad de Porto, que cuenta con un 24 y 16\% de usuarios en Facebook y Twitter, respectivamente, frente al 36 y $18 \%$ de Academia y ResearchGate.

Tabla 2: Académicos de comunicación en las redes generalistas

\begin{tabular}{|l|c|c|c|}
\hline \multicolumn{1}{|c|}{ Universidad } & $\begin{array}{c}\mathbf{N}^{\mathbf{0}} \text { de profesores de } \\
\text { comunicación en planta }\end{array}$ & $\mathbf{N}^{\mathbf{o}}$ de profesores en Facebook & $\mathbf{N}^{\mathbf{o}}$ de profesores en Twitter \\
\hline Ecuador & & & \\
\hline Técnica Particular de Loja & 57 & 31 & 22 \\
\hline Casa Grande & 10 & 10 & 9 \\
\hline San Francisco de Quito & 22 & 6 & 4 \\
\hline Portugal & & & 5 \\
\hline Porto & 25 & 11 & \\
\hline Brasil & & & 18 \\
\hline Sao Paulo & 28 & 33 & \\
\hline Galicia (España) & & & \\
\hline Santiago & 57 & & \\
\hline
\end{tabular}

Fuente: Elaboración propia a partir de la consulta de los investigadores afiliados a las redes generalistas. Datos de octubre de 2014

Si analizamos el grado de empleo de las redes científicas, observamos que la adhesión y utilización por parte de los investigadores del área de comunicación de las universidades de Ecuador es muy reducida, tal y como queda reflejado tanto en la cifra de docentes agregados como en la actividad que éstos desarrollan.

De hecho, el uso de Academia.edu por parte de los profesores ecuatorianos en cuanto al número de papers subidos a la red social demuestra el bajo empleo de esta plataforma como herramienta para la divulgación de trabajos científicos originales. En la Universidad Técnica Particular de Loja, un 46,6\% de los miembros registrados en Academia no tiene ningún artículo publicado en su perfil. Sin embargo, este dato es todavía más acuciante en lo referente a la Universidad Casa Grande, con un 66,6\% de docentes que no han hecho público ningún paper en dicha red científica, o la Universidad San Francisco de Quito, donde esta cifra asciende al 75\%.

En la muestra de universidades escogidas para analizar la penetración de las redes científicas en Portugal, observamos una 
mayor actividad que en el caso de los miembros de las universidades ecuatorianas. No obstante, se registran diferencias notables entre aquéllos que hacen un escaso uso de la red social y otros que la emplean de manera más proactiva. Así, mientras un $60 \%$ de los docentes de la Universidad de Minho, un 33,3\% de los de Beira Interior y un $22,2 \%$ de los de Porto no tienen ningún artículo científico agregado a su perfil, un $33,3 \%$, un $46,6 \%$ y un $44,4 \%$, respectivamente, registran más de diez papers en su muro, la mayor parte de ellos con un número de visitas elevado o muy elevado. De los docentes incluidos en esa cifra, un $11 \%$ de los pertenecientes a la Universidad de Minho y Porto, y un 20\% de los de Beira Interior tiene más de 30 papers publicados.

De modo similar se podría definir la actividad de los profesores de Brasil en Academia.edu, puesto que también se observan contrastes entre unos y otros investigadores en cuanto al número de trabajos científicos publicados. Así, un 45,4\% de los docentes de la Universidad de Sao Paulo, un $25 \%$ de los de Santa Catarina y un $56,25 \%$ de los de Bahia no disponen de ningún paper publicado en su perfil, mientras que el $27,2 \%$, el $25 \%$ y el $18,75 \%$ cuentan con más de diez artículos accesibles en Academia.edu. Es destacable el caso de André Luiz Martins Lemos, que registra en su muro 84 artículos de investigación y 3.468 visitas.

Con respecto a la muestra de investigadores españoles analizados, los porcentajes son similares a los anteriores, haciendo de nuevo patente el desequilibrio existente en el uso de dicha red científica. En este caso, la cifra de docentes que no tienen ningún paper publicado en Academia representa el $57,8 \%$ de los académicos de la Universidad de Santiago, el 29,6\% de los de Vigo y el 43,7\% de los de A Coruña. Entre aquéllos que cuentan con más de diez publicaciones, los datos ascienden al 21\% de los investigadores de la USC, al 40,7\% de la UVigo y al 25\% de la UDC. De ellos, un 10,5\%, un 7,4\% y un $6,2 \%$, respectivamente, disponen de más de 30 artículos científicos en sus perfiles.

En general, se aprecia que tanto la expansión como el uso de las redes científicas por los investigadores de comunicación de Ecuador y del área lusófona no es ni una penetración muy numerosa ni una participación excesivamente activa en cuanto a número de publicaciones. 


\section{La interacción en las redes digitales científicas}

Las redes sociales digitales científicas son una importante plataforma de divulgación del saber que alimentan, en cierto sentido, los llamados "nuevos colegios invisibles" de la ciencia (Solla, 1961), redes más informales y menos institucionalizadas de intercambio de conocimientos entre científicos (Crane, 1972) aplicable a la red mundial de comunicaciones entre investigadores (Wagner, 2009). De hecho, tal y como afirman Campos, Rivera y Rodríguez (2014: 574), "las redes digitales forman parte de la esencia de los colegios visibles e invisibles porque son un medio de comunicación y un sistema de articulación de relaciones e interacciones entre científicos".

Sin embargo, a pesar de ser herramientas susceptibles de favorecer la colaboración entre los investigadores, los académicos del área de comunicación de las universidades de Ecuador, Portugal, Brasil y Galicia (España) todavía no aprovechan las posibilidades de interacción con otros colegas a nivel internacional.

Analizando el número de seguidores en ResearchGate de los investigadores ecuatorianos, observamos una tendencia de carácter eminentemente endogámico, puesto que en la mayoría de los casos, prácticamente la totalidad de los followers pertenecen a la misma universidad que la de aquél docente al que siguen. Las nacionalidades de los académicos restantes son Ecuador, España y Reino Unido, principalmente. Si tenemos en cuenta las visitas a los perfiles, observamos una preponderancia de consultas de científicos estadounidenses y chinos.

En el caso de Portugal, y de manera semejante a lo que ocurre en Ecuador, la mayoría de los seguidores pertenecen a la misma universidad o al mismo país. No obstante, la procedencia del resto de followers se divide, fundamentalmente, entre españoles, brasileños y alemanes. Con respecto a las visitas de los perfiles, éstas se derivan de investigadores de Estados Unidos y China, a los que se suman los de Portugal, Francia y Alemania.

Los docentes de las universidades de Brasil registran una actividad más bien baja en torno al uso de ResearchGate, pero en ella se refleja también la tendencia endogámica en lo que respecta a los seguidores. Sin embargo, en este caso, cuatro de los diez académicos presentes en esta red científica cuentan con más followers de otras universidades que de la suya propia. Con respecto a las nacionalidades, 
nuevamente predominan los seguidores del propio país (Brasil), junto con los de Portugal, España y Estados Unidos. Las visitas a los perfiles se reparten entre estadounidenses y chinos.

Los datos extraídos para las universidades gallegas reflejan que, en la de Santiago de Compostela, del total de investigadores registrados en ResearchGate, el 71,4\% tienen a más de la mitad de sus colegas como seguidores de sus publicaciones. En la Universidad de Vigo, este porcentaje se reduce al $50 \%$ y en la de A Coruña, se incrementa al 76,9\%. Las nacionalidades de los followers restantes se dividen entre España, principalmente, Ecuador, Brasil, Portugal, México y Estados Unidos. Este último país, unido a China y Francia, representa la procedencia de los científicos que, en la última semana, han consultado el perfil de los docentes de las universidades analizadas.

Por lo tanto, se observa que la tendencia endogámica es preponderante en todas las facultades de la muestra, puesto que la mayor parte de los seguidores pertenecen a la misma universidad o país que los investigadores a los que siguen. Esto hace evidente la necesidad de que las relaciones se incrementen y se ensanchen a nivel internacional, puesto que únicamente de este modo se podrá contribuir a ampliar eses nuevos colegios invisibles de la ciencia.

\section{El impacto de los investigadores en ResearchGate y Google Académico}

Junto con la expansión, uso, interacción y participación de los investigadores en las redes sociales digitales científicas, otro de los datos relevantes a tener en cuenta es el índice RG Score de los docentes, en tanto es el que permite elaborar el ranking de impacto general de las universidades en su conjunto.

En este sentido, lo que hace ResearchGate es emplear tanto la popularidad de las publicaciones de los académicos como el número de consultas y descargas de las mismas, para gestionar su RG Score individual y extraer, de la suma de todos ellos, el posicionamiento de sus respectivos departamentos y facultades.

Frente al índice $\mathrm{H}$ de Google, que mide el impacto y la productividad, el de ResearchGate registra el impacto y la popularidad, entendida en función de las producciones e interacciones de cada académico con respecto a los restantes miembros de la comunidad 
investigadora. Sin embargo, a pesar de no ser herramientas que midan exactamente lo mismo, existe una correlación entre ambos indicadores, aunque esta correspondencia no es automática, sino que depende directamente de la gestión particular que realice cada uno de ellos.

De la observación efectuada para este estudio, extraemos los datos mostrados a continuación.

Tabla 3: Impacto de los académicos de Ecuador en ResearchGate y Google Académico

\begin{tabular}{|l|c|c|c|}
\hline \multicolumn{1}{|c|}{ Universidad } & RG Score & Citas en Google Académico & Índice $\mathbf{H}$ \\
\hline UTPL & & & \\
\hline Patricio Barrazueta & - & 0 & 0 \\
\hline Isidro Marín & - & 0 & 2 \\
\hline Catalina Mier & - & 7 & 0 \\
\hline María Isabel Punín Larrea & 1.16 & 0 & 0 \\
\hline Rosario Puertas Hidalgo & - & 2 & 1 \\
\hline Diana Rivera & 1.34 & 2 & 0 \\
\hline Jenny Yaguache & 1.16 & 0 & 1 \\
\hline Kruzkaya Ordóñez & - & 3 & - \\
\hline Hernán Yaguana & - & - & 2 \\
\hline Universidad Casa Grande & - & & 2 \\
\hline San Francisco de Quito & & 109 & 2 \\
\hline Armando Salazar & - & 12 & 30 \\
\hline Romina Carrasco & - & - &
\end{tabular}

Fuente: Elaboración propia a partir de la consulta de los perfiles de los investigadores ecuatorianos en ResearchGate y Google Académico. Datos de noviembre de 2014

La docente ecuatoriana con un RG Score más elevado (1.34) es Diana Rivera, aunque no posee ni un mayor número de citas ni un índice $\mathrm{H}$ más alto. De hecho, es Armando Salazar el investigador más citado en Google Académico (109) y uno de los que cuenta con un índice H superior (2), junto con Isidro Marín, María Isabel Punín, Romina Carrasco y Lucía Lemos.

En Portugal, Rosa Cabecinhas es la investigadora con el RG Score más alto (15.41), el mayor número de citas en Google Scholar (1.524) y el índice H más elevado (16). 
Tabla 4: Impacto de los académicos de Portugal en ResearchGate y Google Académico

\begin{tabular}{|c|c|c|c|}
\hline Universidad & RG Score & Citas en Google Académico & Índice $\mathrm{H}$ \\
\hline \multicolumn{4}{|l|}{ Minho } \\
\hline Alberto Sá & - & 205 & 8 \\
\hline Elsa Costa e Silva & - & 24 & 3 \\
\hline Helena Sousa & 4.28 & 338 & 11 \\
\hline Luís António Santos & - & 49 & 5 \\
\hline Nelson Zagalo & 6.68 & 186 & 7 \\
\hline Rosa Cabecinhas & 15.41 & 1524 & 16 \\
\hline Sara Pereira & 1.21 & - & - \\
\hline \multicolumn{4}{|l|}{ Beira Interior } \\
\hline Joao Manuel Messias Canavilhas & 5.07 & 593 & 12 \\
\hline José Ricardo Pinto Carvalheiro & 1.74 & 36 & 3 \\
\hline Joao Carlos Ferreira Correia & 14.60 & 618 & 11 \\
\hline Herlander Elias & 1.16 & - & - \\
\hline Gisela Marques Pereira Gonçalves & 5.34 & 45 & 4 \\
\hline \multicolumn{4}{|l|}{ Porto } \\
\hline Ana Isabel Crispim Mendes Reis & - & 4 & 1 \\
\hline António Fernando Vasconcelos Cunha Castro Coelho & 5.59 & 208 & 7 \\
\hline Fernando António Dias Zamith Silva & - & 114 & 6 \\
\hline
\end{tabular}

Fuente: Elaboración propia a partir de la consulta de los perfiles de los investigadores portugueses en ResearchGate y Google Académico. Datos de noviembre de 2014

Tabla 5: Impacto de los académicos de Brasil en ResearchGate y Google Académico

\begin{tabular}{|l|c|c|c|}
\hline \multicolumn{1}{|c|}{ Universidad } & RG Score & Citas en Google Académico & Índice H \\
\hline Sao Paulo & & & \\
\hline Rosana de Lima Soares & 11.95 & 116 & 5 \\
\hline Thiago Mio Salla & - & 9 & 2 \\
\hline Vítor Souza Lima Blotta & - & 9 & 2 \\
\hline Sta. Catarina de Florianópolisis & & & \\
\hline Rogério Christofoletti & - & 258 & 7 \\
\hline Tattiana Teixeira & - & 84 & 5 \\
\hline Bahia & & & 27 \\
\hline André Luiz Martins Lemos & 2.60 & 3708 & 2 \\
\hline José Roberto Severino & - & 33 & 5 \\
\hline Leonor Graciela Natansohn & 1.28 & 51 & \\
\hline
\end{tabular}

Fuente: Elaboración propia a partir de la consulta de los perfiles de los investigadores brasileños en ResearchGate y Google Académico. Datos de noviembre de 2014

En las universidades de Brasil, el mayor RG Score pertenece a Rosana de Lima Soares. Sin embargo, el investigador más citado es André 
Luiz Martins Lemos (3.708 citas), que cuenta también con un índice H muy superior al de sus colegas (27).

Tabla 6: Impacto de los académicos de Galicia (España) en ResearchGate y Google Académico

\begin{tabular}{|c|c|c|c|}
\hline Universidad & RG Score & Citas en Google Académico & Índice $\mathrm{H}$ \\
\hline \multicolumn{4}{|l|}{ Santiago de Compostela } \\
\hline Bastos Boubeta, Miguel Anxo & 2.23 & - & - \\
\hline Campos Freire, Francisco Manuel & 3.30 & 155 & 4 \\
\hline Fernández Leiceaga, Xoaquín María & - & 90 & 5 \\
\hline Gago Mariño, Manuel & 1.01 & - & - \\
\hline García Díaz, Rubén & - & 1 & 1 \\
\hline López García, Xosé & 3.04 & 407 & 11 \\
\hline Pereira Fariña, José & 1.88 & 67 & 5 \\
\hline Pérez Pereiro, Marta & - & 0 & 0 \\
\hline Redondo Neira, Fernando & 0.01 & - & - \\
\hline Toural Bran, Carlos & - & 3 & 1 \\
\hline Túñez López, José Miguel & 4.06 & 283 & 10 \\
\hline \multicolumn{4}{|l|}{ Vigo } \\
\hline Dafonte Gómez, Alberto & - & - & - \\
\hline Doval Avendaño, $\mathrm{M}^{a}$ Montserrat & 1.74 & 22 & 3 \\
\hline Durán Vázquez, Xosé Francisco & 1.70 & 10 & 2 \\
\hline García González, Aurora & - & 36 & 4 \\
\hline García Soidán, Pilar Hortensia & 16.12 & - & - \\
\hline Pérez Cota, Manuel & 13.75 & - & - \\
\hline Román Portas, Mercedes & 1.16 & 39 & 4 \\
\hline Valderrama Santomé, Mónica & - & 8 & 2 \\
\hline Vidal-Puga, Juan J. & 18.21 & 335 & 11 \\
\hline \multicolumn{4}{|l|}{ A Coruña } \\
\hline Arrojo Baliña, $\mathrm{M}^{a}$ José & 2.23 & 34 & 3 \\
\hline Barneche Naya, Viviana & 4.00 & - & - \\
\hline Carballal Mato, Adrián & 8.68 & 28 & 4 \\
\hline Castro Pena, $\mathrm{M}^{\mathrm{a}} \mathrm{Luz}$ & 1.16 & - & - \\
\hline Hernández Ibáñez, Luís A. & 6.65 & 161 & 7 \\
\hline Juanatey Boga, Óscar & 2.05 & - & - \\
\hline Martínez Fernández, Valentín Alejandro & 2.03 & - & - \\
\hline Osorio Iglesias, Olga & - & 12 & 1 \\
\hline Pérez Ordóñez, Juan Luis & 16.60 & - & - \\
\hline Piñeiro Otero, $M^{a}$ Teresa & 1.16 & - & - \\
\hline Quintas Froufe, Natalia & 2.06 & 18 & 3 \\
\hline Taibo Pena, Fco. Javier & 5.37 & 59 & 5 \\
\hline Videla Rodríguez, José Juan & - & 21 & 2 \\
\hline
\end{tabular}

Fuente: Elaboración propia a partir de la consulta de los perfiles de los investigadores gallegos en ResearchGate y Google Académico. Datos de noviembre de 2014

Los resultados obtenidos para las universidades de Galicia (España) muestran, en primer lugar, un mayor registro de docentes que cuentan 
con su RG Score visible, así como de aquéllos que son citados en Google Scholar.

El académico que tiene un RG Score más elevado es Juan Vidal Puga (18.21) que, junto con Xosé López García, computa el número de citas y el índice $\mathrm{H}$ más elevado (407 y 335, respectivamente, y un $\mathrm{H}$ Index de 11 en ambos casos).

\section{Conclusiones}

Las redes sociales digitales son una nueva plataforma científica emergente que, si bien se están desarrollando y consolidando rápidamente como instrumento que mejora el intercambio y la difusión del conocimiento -estimulando la participación, colaboración e interacción entre los investigadores-, lo cierto es que, por el momento, todavía no han alcanzado su madurez científica. Aunque tanto las políticas públicas como las tecnologías propician esas sinergias, "la cultura cerrada de las organizaciones, los déficit de alfabetización digital, la inexperiencia y las carencias de cooperación entre los distintos grupos frenan aún la articulación de proyectos de investigación de matriz abierta" (Campos, 2013a: 106).

En este sentido, son significativos los resultados obtenidos a raíz del presente estudio, en tanto constatan la baja penetración de las redes digitales científicas entre los investigadores de Ciencias de la Comunicación pertenecientes a la comunidad iberoamericana y, en concreto, a los docentes de Ecuador, Portugal, Brasil y Galicia (España).

Asimismo, la gestión de los perfiles personales de aquellos académicos que están presentes en dichas redes es ineficiente y más bien pasiva, puesto que un gran número de investigadores cuentan con un perfil incompleto en lo tocante a información, o vacío en cuanto a contenido (artículos, libros, ponencias...).

Con respecto al seguimiento, se constata que, en la mayoría de los casos, apenas existe interacción con otros docentes más allá de los de la misma universidad o país. De este modo, la interrelación que se produce entre los académicos de las facultades es predominantemente endogámica.

Tan bajo como el nivel de interacción, participación, colaboración y uso de las redes sociales científicas, lo es también el índice RG Score de los profesores, lo que repercute, directamente, en 
los indicadores de impacto de las universidades y en su posicionamiento a nivel nacional e internacional.

Por lo tanto, a pesar de que las tecnologías de la comunicación y las redes digitales favorecen un vínculo capaz de trascender y ampliar las barreras democráticas y geográficas de la cultura contemporánea contribuyendo así al desarrollo de la sociedad del conocimiento-, dichas relaciones son, de momento, prácticamente inexistentes.

\section{Referencias bibliográficas}

Benghozzi, P. J (2011): “Économie numérique et industries de contenu: un nouveau paradigme pour les résaux", en Hermès, 59. París: CNRS.

Boyd, D. M y Ellison, N. B (2007): "Social Network Sites: Definition, History and Scholarsiph", en Journal of Computer-Mediates Communication, 13. Pensilvania (Estados Unidos): The Pennsylvania State University, páginas 210 a 230; recuperado el 29 de octubre de 2014, de http://onlinelibrary.wiley.com/doi/10.1111/j.1083$\underline{6101.2007 .00393 . x / \text { full }}$

DOI 10.1111/j.1083-6101.2007.00393.x

Campos-Freire, F. (2013a): "Nuevas redes en la configuración de proyectos de investigación científica”, páginas 105 a 114. En Ledo Andión, M. (2013), Cine, diversidad y redes. Pequeñas cinematografías, políticas de la diversidad y nuevos modos de consumo cultural. Buenos Aires-Santiago de Compostela: IUNA-USC.

Campos-Freire, F. (2013b): "Introducción a la investigación y gestión de las redes sociales digitales". En Cuadernos artesanos de Comunicación, 50. La Laguna (Tenerife): Latina, páginas 07 a 53; recuperado el 31 de octubre de 2014, de http://issuu.com/revistalatinadecomunicacion/docs/cac50

DOI: $10.4185 / C A C 50$

Campos-Freire, F., Rivera Rogel, D. y Rodríguez, C (2014): “La presencia e impacto de las universidades de los países andinos en las redes sociales digitales", en Revista Latina de Comunicación Social, 69. La Laguna (Tenerife): Universidad de La Laguna, páginas 571 a 592; recuperado el 29 de octubre de 2014, de http://www.revistalatinacs.org/069/paper/1025 USC/28es.html

DOI: 10.4185/RLCS-2014-1025

Castells, M. (2009): Comunicación y poder. Madrid: Alianza editorial. 
Crane, D. (1972): Invisible Colleges: Diffusion of Knowledge in Scientific Communities. Chicago: University of Chicago Press.

Degenne, A. (2011): "Retour à l'analyse des réseaux sociaux (entretien)", en Hermès, 59, páginas 39 a 40. París: CNRS.

Ellison, N. B y Boyd, D. M. (2013): "Sociability through Social Network Sites", páginas 151 a 172. En Dutton, W. H. (Ed.), The Oxford Handbook of Internet Studies. Oxford: Oxford University Press.

Nafría, I. (2007): Web 2.0. El usuario, el nuevo rey de Internet. Barcelona: Gestión 2000.

Rheingold, H. (2004): Multitudes inteligentes. Las redes sociales y las posibilidades de las tecnologías de cooperación. Barcelona: Gedisa.

Solla Price, D. J. (1961): Science since Babylon. New Haven: Yale University Press.

Stenger, T. y Coutant, A. (2011): "Introduction. Ces réseaux numériques dits sociaux”. En Hermès, 55, páginas 09 a 20.

Tapscott, D. y Williams A. D. (2007): Wikinomics. La nueva economía de las multitudes inteligentes. Barcelona: Paidós.

Wagner, C. S (2009): The new invisible college: Science for development. Washington: Brookings Institution Press. 


\section{La intersección entre las empresas de contenidos, tecnología e Internet y el nuevo papel de Telefónica como TV Company}

José Vicente García Santamaría, Universidad Carlos III de Madrid (UC3M, España), josevicente.garcia@uc3m.es

María José Pérez-Serrano, Universidad Complutense de Madrid (UC3M, España), mariajoseperezserrano@pdi.ucm.es

\section{Resumen}

Desde los planteamientos teóricos de media economy o media economics se mantiene un vivo debate sobre si los productos de los grupos de comunicación difieren de aquellos que fabrican otras compañías que operan en sectores de actividad diferentes. Dentro de esta corriente, en estas páginas, afrontamos una propuesta analítica basada en dos principios fundamentales: la metodología descriptiva y el case analysis. El primero parte de una revisión bibliográfica sobre los procesos de crecimiento externo y el segundo aborda la constitución de Telefónica como TV Company. La conclusión a la que se llega es directa: el grupo español afianza su transformación de empresa de telecomunicación a compañía de contenidos, fundamentalmente televisivos.

Palabras clave: empresas de contenidos, Internet, Telefónica, TV Company, case analysis. 


\section{Introducción}

T A empresa de comunicación es una de las estructuras que mayores y más profundos cambios ha sufrido en las últimas décadas. A finales de la II Guerra Mundial se formaron los primeros grandes grupos informativos, pero es a partir de 1980 cuando este proceso ha adquirido una nueva dimensión, tanto por el tamaño de las compañías, como por su carácter internacional y multimedia. En este hecho inciden factores económicos y mercantiles que hacen, ya en el siglo XXI, que sean muy pocos los medios informativos de cierto relieve que siguen actuando de forma mercantilmente independiente. Se tiende a que los medios pertenezcan a una gran empresa de la comunicación, y, como derivación, a que se minimice el efecto de una de las metáforas que más ha prendido en el mundo contemporáneo. Los medios ya forman parte del Poder, del único, dando lugar a una estructura en la que entidades financieras, empresas de telecomunicaciones y otras ajenas al mundo de la comunicación forman un entramado económico y mediático (Pérez Serrano, 2010).

En pos de analizar estos cambios, desde hace más de una década, la Academia -y, más concretamente, los especialistas en lo que se denomina media economy o media economics ${ }^{60}$ - vienen manteniendo un vivo debate sobre si los productos de los grupos de comunicación difieren de aquellos que fabrican otras compañías que operan en sectores de actividad diferentes, puesto que adoptan un modelo de estrategia de diversificación. Según la doctrina estándar de media economy, sustentada en autores como Albarran (2010), Picard (1989), Croteau y Hoynes (2001), Croteau (2006) o Doyle (2008), la principal diferencia entre los productos de los media y aquellos provenientes de sectores ajenos incluso a las industrias culturales es que las compañías mediáticas ofrecen una oferta dual, es decir, proporcionan bienes complementarios de contenido y distribución de producto y, por lo tanto, funcionan en un mercado también dual. Pero no es la única singularidad ya que no conviene olvidar que los contenidos de los que

\footnotetext{
${ }^{60}$ La media economy, en definición de Albarran (2010: 3), "es el estudio de cómo las empresas mediáticas operan en diferentes niveles de actividad (global, nacional o local), conjuntamente con otras fuerzas (globalización, regulación, tecnología...), y mediante la utilización de teorías, conceptos y principios provenientes de perspectivas micro y macroeconómicas".
} 
se nutren estos media albergan algunas de las características de servicio público.

No obstante, existen autores como Stephan (2005) que sostienen que los productos elaborados por los media no son distintos a los de otros sectores. Es más, este autor indica que el contenido es el output creativo o intelectual de una empresa de comunicación. Desde una perspectiva diferente, Wolton (2004) señalaba que las industrias culturales no son mercancías como el resto, puesto que "administran visiones del mundo y que, por tanto, son inseparables de una reflexión sobre sus condiciones de acogida".

No podemos olvidar tampoco que un media es un conjunto homogéneo de soportes que dependen de un idéntico modo de comunicación, y cuyo objetivo es facilitar la comunicación a partir de una misma fuente con numerosos destinatarios. Mientras que un producto mediático puede definirse como el conjunto de mensajes y de comunicaciones que utilizan un determinado medio como soporte (Gabszewicz y Sonnac, 2006).

\section{Estado de la cuestión y propuesta analítica}

En el estudio de la media economy cobran una importancia decisiva los procesos de integración vertical y horizontal que se producen entre diferentes medios y también entre grupos mediáticos. Como indica Campos Freire (2011), los estados europeos acceden a la globalización en la década de los ochenta del siglo pasado a través del modelo de sociedad de la información que trata de construir Europa como un espacio de convergencia económica y política superior.

En este modelo, sobresale el aumento de la talla de las grandes compañías al desarrollar procesos de integración vertical (aunque también de integración horizontal y conglomeral) al absorber a otras empresas de diferentes sectores de la comunicación. Esta búsqueda de un mayor tamaño obedece también a algunos de los más asentados principios, bajo los que se han perpetrado notables errores en el ámbito de los grupos de comunicación de los cuales somos testigos en la actualidad. Entre ellos, el grupo PRISA es un claro ejemplo de esta aseveración, puesto que, tras edificar en un par de décadas el mayor grupo español de comunicación, con una facturación superior a los dos mil millones de euros, y una notable presencia en toda la cadena de valor comunicativa, desde la prensa a la televisión de pago, ve 
como una serie de desafortunadas estrategias acaban por devolverle -a partir del año 2015- a la época de los años ochenta, donde controlaba un par de diarios, una cadena radiofónica y una editorial de prestigio, pero aún no disponía de negocios audiovisuales.

Habitualmente, la diversificación en mercados de productos relacionados se considera una estrategia acertada para conseguir adecuados niveles de eficiencia y generar beneficios derivados de unas buenas economías de escala ${ }^{61}$. Y, precisamente, es la generación de estas economías de escala, junto con las consabidas sinergias, lo que, en muchos casos, ha justificado la fusión entre grupos o compañías con diferentes culturas empresariales. Así, ha sucedido con la pretendida fusión entre los diarios $A b c$ y El Mundo, que aún siendo un rumor insistente a finales del año 2014 y comienzos de 2015, encontró en ese breve espacio de tiempo, abundantes justificaciones teóricas sobre las supuestas bondades de la creación de El Mundo de Abc.

Lo que ha ocurrido también es que la creación de grandes conglomerados mediáticos, con elevados niveles de concentración, puede llegar a poner en peligro (Prado, 2003) la viabilidad económica de estas megacompañías (caso por ejemplo de la francesa Vivendi), o llevar a su desaparición (ITV Digital), o, incluso, como subrayaba Bustamante (2005), pueden propiciar un cierto "economicismo" en la cultura europea y trasladar a los contenidos las consignas de concentración y poder de mercado que habían ido construyendo en el mundo de las telecomunicaciones y de la informática, en olvido de la tradición antimonopolista y de servicio público.

Con estos ejes, afrontamos una propuesta analítica basada en dos principios fundamentales: la metodología descriptiva y el case analysis. El primero parte -como se ha podido ver- de una breve, en extensión, pero profunda en contenido, revisión bibliográfica sobre los procesos de crecimiento externo y el enfoque y planteamiento teórico sobre ellos, y el segundo pretende abordar la constitución de la española Telefónica como TV Company.

\section{Discusión y análisis de caso}

Al afrontar la exégesis de un tema como el que nos ocupa, no solamente se debe establecer una base teórica y conceptual que facilite

${ }^{61}$ Desde una perspectiva tradicional, las economías de escala provienen del uso común de imputs compartidos en varias líneas de productos. 
el conocimiento de los cauces del discurrir interpretativo, sino que su amplitud y complejidad aconsejan contemplar algunas circunstancias y casos que contribuyan a tener una visión más precisa de estos procesos de integración (Pérez Serrano, 2010).

\subsection{Los procesos de integración de redes y contenidos}

Desde la fallida fusión entre AOL y Time Warner en 2009 tras de casi nueve años de actividad conjunta, los procesos de integración de empresas de redes y contenidos sufrieron un parón de varios años. Después del fracasado intento de los propietarios de Skype y Kaza con Joost (García Santamaría, 2011), llamada a liderar la televisión por Internet en el mundo, la absorción de NBC Universal por Comcast, completada definitivamente en el año 2013, marcó un nuevo rumbo para las empresas de cable y los operadoras de telefonía, más aún cuando, hasta entonces, el mercado no parecía maduro ${ }^{62}$ para desarrollar proyectos de estas características.

No obstante, la batalla por los contenidos es mucho más antigua, y no proviene de la controvertida creación del que es ahora el primer conglomerado mediático mundial (por facturación) ${ }^{63}$. En los años cincuenta del siglo pasado, las majors de Hollywood impusieron su boicot a la televisión al considerar a las cadenas televisivas competencia desleal (Litman, 1998). Más tarde, justo en los años setenta, los grandes estudios proveerían de contenidos a las cadenas televisivas tras la nueva regulación desarrollada por la Federal Communication Commission (FCC). Y, posteriormente, los broadcasters se integrarían con las grandes majors una vez que la Telecommunications Act de 1994 relajase las regulaciones de las autoridades competenciales norteamericanas, puesto que hasta

\footnotetext{
${ }^{62}$ Aunque fue la fusión de Warner con Time Inc., cerrada en el año 1989, y que dio origen al grupo Time Warner Entertainment, la mayor corporación del mundo del entretenimiento en aquellos años, fue sin duda la señal de partida de una serie de operaciones que consolidarían a los grandes grupos a escala global (Buquet, 2005).

${ }^{63}$ Los medios de comunicación norteamericanos definieron esta operación como una Comcastrophe, criticando severamente la decisión adoptada por las autoridades regulatorias norteamericanas (FCC).
} 
entonces estas cadenas televisivas veían limitada la producción de contenidos ${ }^{64}$.

A partir de aquí, los grandes grupos de comunicación, integrados verticalmente siguen deseando controlar producción y distribución de contenidos $^{65}$. Así, por ejemplo, Disney dispone de sus estudios de cine y televisión que aseguran una distribución masiva de sus programas al público infantil y juvenil, pero también al adulto, con una estrategia clara de promoción cruzada, y Paramount, Fox y Time Warner y Vivendi Universal (hasta que abandona NBC Universal) refuerzan su apuesta por la creación de contenidos al tiempo que consiguen fidelizar a la producción independiente con contratos a largo plazo.

Las cuestiones más importantes que surgen a partir de ese momento no son otras que cómo puede un gran grupo mediático, una empresa de Internet o simplemente un videoclub online (como Netflix) asegurarse el abastecimiento de programas, o cómo estos grandes grupos pueden asegurar una correcta distribución de estos productos en todas las ventanas.

No todos poseen cadenas de cable, como el caso de Time Warner, pero también de Fox y de Comcast. Los sistemas de transmisión clásicos (satélite y cable) han dado paso también a la irrupción de nuevos media, nacidos de empresas de telecomunicaciones, que explotan estos contenidos en redes de gran capacidad como Internet y plataformas de telefonía móvil. Y son también los grandes players de Internet las que disponen de tesorería suficiente para efectuar adquisiciones de empresas de otros sectores de actividad, incluidas compañías de telecomunicaciones o grupos de comunicación. En total, y a finales del año 2014, los grandes de Internet (Apple, Microsoft, Google, Samsung, Cisco, Qualcomm, Amazon, Hewlett Packard, Facebook e Intel) disponían de un total de 518.294 millones de dólares (467.000 millones de euros) en tesorería, aparte de una capacidad de endeudamiento considerable. Este grupo estaba encabezado por Apple, que tenía 178.000 millones de dólares en caja al cierre del ejercicio 2014 y que sólo en el cuarto trimestre de 2014

\footnotetext{
${ }^{64}$ No obstante, aquellas majors que no se habían integrado verticalmente con una televisión quedaban al albur de una dura negociación con el oligopolio de los grandes estudios.

${ }^{65}$ Como señalaría el patrón de Viacom, Redstone, "si el contenido es el Rey, la distribución es la reina".
} 
ganó 18.000 millones de dólares (sin duda la mayor cifra conseguida en un solo trimestre por una compañía norteamericana), y Google, que poseía 64.395 millones de dólares en caja (Expansión, 7 de marzo de 2015: 10).

Pero no se trata sólo de procesos de crecimiento externo y de operaciones empresariales, sino también de la influencia de estos en los contenidos. Como sucede con sus competidoras en servicios de VoD (Video On Demand), empresas de telecomunicaciones y televisiones de pago se están reconvirtiendo en TV companies, y se está observando nítidamente como se desencadenará una feroz competición por la adquisición de derechos de retransmisión deportiva, pero también por el control de otros contenidos premium como las series y los films. Este es el caso de Telefónica (cuya marca comercial es Movistar desde el año 2010), tras la adquisición en el año 2014 de Canal+, y de DirecTV por AT\&T (además de la compra de Time Warner Cable por Comcast) o la variación en su estrategia para España de Vodafone.

\subsection{Telefónica y la lucha en España por los contenidos de pago}

El hecho de que algunos servicios de telefonía se estén convirtiendo en una especie de commodity y de que solamente la distribución de contenidos premium a través de plataformas de pago - por cable, satélite o Internet- tengan un gran poder de fidelización de la clientela, y que sean estos contenidos los que permitan rentabilizar realmente las redes de fibra óptica, instaladas por las compañías telefónicas, ha hecho que los mercados mundiales se hayan dinamizado y en el caso de España que el presidente de Telefónica anunciase en la presentación de resultados del ejercicio 2014, que la compañía apostaba por la fibra óptica y la televisión de pago. Y, precisamente, estos servicios pretendía extenderlos a Latinoamérica, conformando un amplio mercado de 600 millones de clientes potenciales.

Como resultado de este viraje estratégico, la compañía decidió en el año 2014 impulsar Movistar TV (antes Imagenio TV), su servicio de televisión de pago por Internet, y de esta forma, ofrecer una oferta audiovisual más competitiva a sus clientes de fibra óptica. La segunda parte, como ya se ha comentado, ha sido la adquisición del 56\% del capital de Canal+ que detentaba el grupo PRISA y, posteriormente, del $22 \%$ restante, propiedad de Mediaset. 
Este viraje ha llevado a una reordenación de los recursos de la compañía y a potenciar su división audiovisual. La historia reciente de Telefónica, al menos desde sus últimas salidas a Bolsa en los años 1987, 1995 y 1996, no se puede disociar de su presencia en medios de comunicación. Ha tenido presencia en Endemol, Vía Digital, Antena 3, Onda Cero y, también, en el sector de la prensa. Pero la relación de Telefónica con los medios podemos calificarla como una relación de "ida y vuelta". En el año 1995 se crea Admira, filial dedicada a la gestión de medios de comunicación tras aprobarse la Ley de Telecomunicaciones que liberalizaba el sector; entre los años 1998 y 2000 consolida y expande su grupo mediático con Antena 3 y Onda Cero, pero conflictos de toda índole y relevantes pérdidas originadas por la deficiente gestión del grupo mediático, llevaron que en el año 2003, Telefónica decidiese desprenderse de sus participaciones en grupos de comunicación.

Tabla 1: Participaciones en medios y empresas de Telefónica en el año 2003

\begin{tabular}{|c|c|c|c|c|c|}
\hline Telefónica & & & & & \\
\hline Antena 3 & Teleté & \multirow{3}{*}{ Endemol } & \multirow{3}{*}{$\begin{array}{l}\text { Torneos } \\
\text { competencias }\end{array}$} & \multirow{2}{*}{\multicolumn{2}{|c|}{$\begin{array}{l}\text { Telefónica } \\
\text { servicios } \\
\text { música }\end{array}$}} \\
\hline Onda Cero & $\begin{array}{l}\text { Radio } \\
\text { Continental }\end{array}$ & & & & \\
\hline Sogecable & Azul TV & & & & $\begin{array}{l}\text { Telefónica } \\
\text { servicios } \\
\text { audiovisual }\end{array}$ \\
\hline
\end{tabular}

Fuente: Elaboración propia

Endemol fue vendida a Telecinco ${ }^{66}$ y Antena 3 y Onda Cero fueron a parar finalmente a manos del grupo Planeta-DeAgostini, y en el año 2007, acudió contra todo pronóstico a la OPA de Sogecable para vender su participación del $17 \%{ }^{67}$. Creó entonces Imagenio, con una

${ }^{66}$ El 75\% del capital de Endemol que controlaba Telefónica fue vendido en el año 2007 por un importe de 2.640 millones de euros a Telecinco, John de Mol Y Goldman Sachs, que en el año 2012, entregarían el control a la sociedad Apollo a cambio de que se hiciese cargo de 2.100 millones de euros de deuda generada.

${ }^{67}$ Aunque en puridad, Telefónica siempre mantuvo un pie en la comunicación. Por ejemplo, detentando una participación en Canal+ puesto que PRISA no 
apuesta decidida por la distribución de contenidos en Internet, aunque bien podría calificarse a la plataforma como una operación de $\mathrm{I}+\mathrm{D}$, que permitía a la compañía seguir posicionada en el ámbito de la distribución de contenidos.

A partir de ahí, la reflexión que debe hacerse es si un conglomerado tiene, o no, por qué gestionar el desarrollo de contenidos y la producción y la distribución de sus productos dentro de la misma empresa, si estas actividades pueden ser desarrolladas por firmas independientes (de hecho, y como hemos señalado, muchas compañías independientes trabajan para las majors de Hollywood). Pero a Telefónica se le plantearon dos problemas inmediatos: para mantener la masa de abonados que había conseguido con Imagenio, que llegó a superar los setecientos mil, necesitaba poseer derechos de retransmisiones deportivas, muchos de ellos propiedad de Mediapro y arrendados a Canal+, y, en segundo lugar, debía adquirir series de relevancia y films.

En este sentido, los pasos dados son muy claros. Desde el año 2013 dispone de una productora propia, Telefónica Studios, que aglutina las producciones de cine español y de series con equipos propios $^{68}$. En el año 2014, adquirió el campeonato de Fórmula 1 y el reparto de los derechos del Mundial de Motociclismo con Mediaset, el tenedor de estos derechos desde que se hizo con ellos provenientes de TVE. Y, en 2015, se hace con los derechos de difusión del Barcelona C.F. y de otros equipos controlados por Canal+, y aspira a disputarle a Mediapro la supremacía en estos eventos.

Con ello, el objetivo comercial de Telefónica queda patente: ofrecer a todos los clientes de su oferta convergente su servicio básico de televisión, convirtiendo así esta oferta en su principal reclamo.

$\mathrm{Y}$ esto siendo consciente de que su red de fibra óptica llegará a siete millones de hogares; que sus intenciones eran superar la barrera de 1,5 millones de abonados, que podrán conseguir fácilmente tras la integración total de Digital+; que, desde esa cota, podrán alcanzar los

podía hacer frente, por problemas de tesorería, al desembolso de capital correspondiente a la venta del 17\% de Canal+.

${ }^{68}$ Una TV Company española debe invertir el 5\% de su facturación en la producción de films, y en Argentina la legislación es similar, por eso, su productora está radicada en un país que, además, tiene unos costes de producción más bajos. 
tres millones de abonados, que suponen una mínima masa crítica de abonados con los que rentabilizar la plataforma ${ }^{69}$, y que, en un primer momento, la oferta de Movistar TV se comercializa como un servicio aparte, si bien los clientes de fibra óptica disponen de una versión gratuita, que no dispone de fútbol y que tiene menos canales de cine.

\subsection{La pugna por los derechos de emisión y el futuro inmediato}

La consultora Deloitte (2014) indicaba que el año 2013 había sido un año clave en España, por cuanto los operadores de telefonía pusieron en marcha estrategias de crecimiento, combinando la captación de clientes, la inversión en red y los programas de eficiencia.

Gráfico 1: Principales magnitudes económicas de Telefónica en el año 2014 (cifras en millones de $€$ )

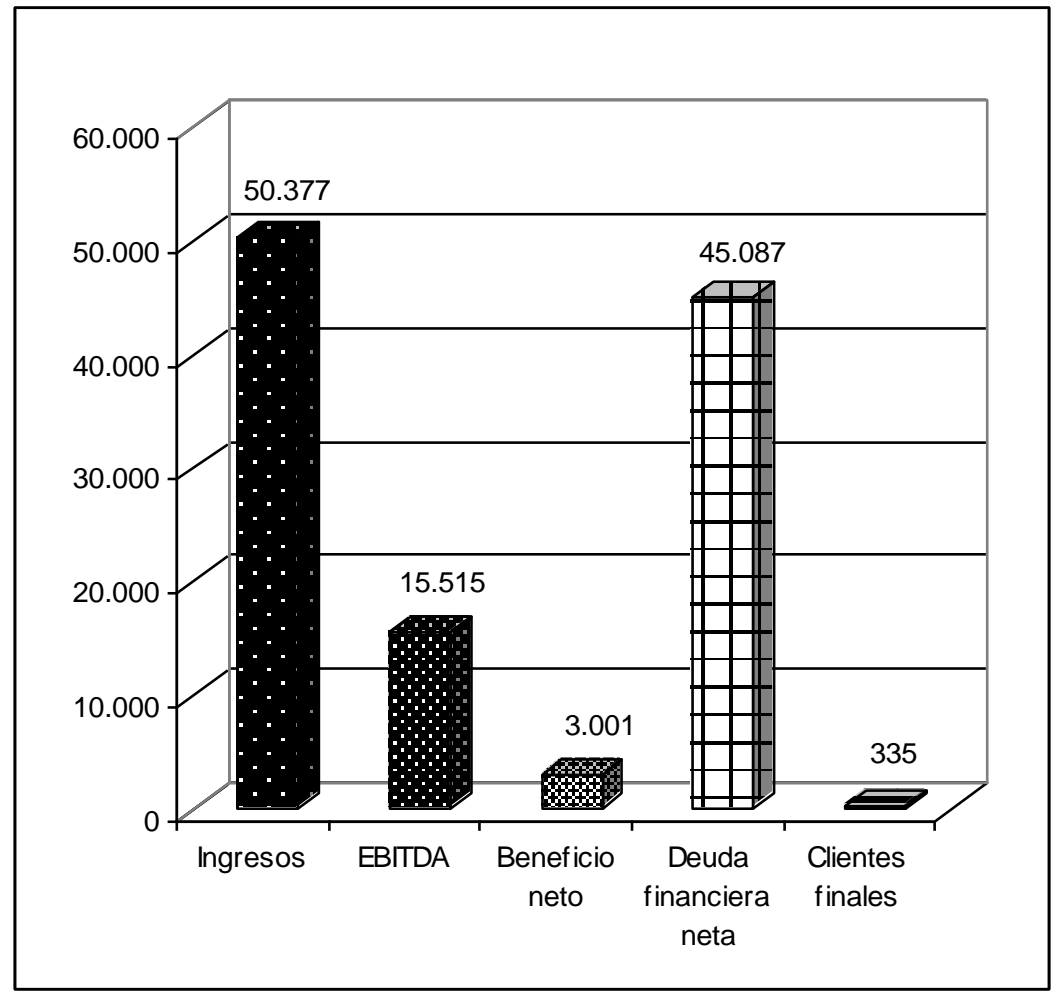

Fuente: Elaboración propia

Entre las estrategias para la captación y fidelización de clientes, destacan la puesta en marcha de ofertas convergentes en las que el mayor valor añadido son los servicios de televisión de pago. Siguiendo este planteamiento, desde el mes de octubre del año 2012, la compañía

${ }^{69} \mathrm{El}$ número máximo de clientes de TV IP con la antigua marca Imagenio se alcanzó en el cuarto trimestre del año 2011, en que llegó a 833 usuarios. 
objeto de estudio apostó por una oferta múltiple que englobaba voz, datos y televisión mediante redes fijas y móviles, bajo la marca de un nuevo producto denominado "Fusión", basado en el servicio de televisión Movistar TV (anteriormente Imagenio) ${ }^{70}$.

El 25 de febrero de 2015, Telefónica presentó resultados anuales y su presidente, César Alierta, subrayó -en uno de los puntos fundamentales de su discurso- que la compañía aspira a convertirse en el mayor grupo de la televisión de pago en español, con un mercado potencial de 600 millones de clientes en España y Latinoamérica. Idea que ya estaba marcada en la progresión seguida en el año 2014. En ese ejercicio, Telefónica fue el grupo mundial que más vio crecer sus abonados, un 41,2\%, hasta alcanzar un total de cinco millones.

Además, Alierta indicó que el mercado de la televisión de pago está dominado por tres grupos estadounidenses y otro británico, y la única alternativa capaz de competir con ellos en el mundo de los contenidos en español es Telefónica (Expansión, 26 de febrero de 2015: 3). Lo que significa que la compañía seguirá apostando por la compra de derechos de retransmisión deportiva y la creación de contenidos.

Sin embargo, y pese a la desaparición de un serio competidor como Digital+ y la retirada de Mediaset España de los servicios de televisión de pago al desprenderse del $22 \%$ de la participación que tenía en la operadora del grupo PRISA, la competencia por los servicios de VoD y la pugna por los derechos de retransmisión deportiva no ha hecho más que comenzar. Los competidores provendrán no sólo de otras compañías de telecomunicaciones erradicadas en España (Vodafone, Orange y Jazztel); de penetraciones futuras de empresas de Internet (Google, Apple, Samsung, etc.); de los propios grupos de comunicación españoles que cambien su

\footnotetext{
${ }^{70}$ Movistar TV ofrece sus servicios sólo en algunos países de Latinoamérica en las que está presente la compañía, primero con Vivo en Brasil y su oferta de TV de pago, además de Colombia, Chile, Perú y Venezuela con unos contenidos en los que el cine y la ficción televisiva (canales de HBO y Moviecity), además del contenido para adultos y, por supuesto, de las retransmisiones deportivas (programación de ESPN y Fox Sports) conforman el grueso de su oferta. Además, Telefónica opera con la marca O2 en Reino Unido y Alemania sin oferta televisiva, aunque a finales de 2014 anunció que no tenía un gran interés en mantener estas filiales si no podían transformarse también en una $T V$ Company.
} 
orientación hacia servicios de pago (Atresmedia, Mediaset); de grupos de comunicación extranjeros interesados en el mercado español y sus competiciones deportivas (Fox Sports, ESPN), o empresas de VoD, como Netflix.

\section{Conclusiones}

Como señala el Informe Deloitte (2014), existen cincuenta millones de hogares en todo el mundo que tienen contratados dos o más servicios de televisión de pago, y un 10\% de esos hogares, alrededor de cinco millones, podrían disponer incluso de tres o más proveedores. Pese a ello, las características del mercado español de VoD son muy singulares, ya que se puede calificar de muy estrecho, por la piratería existente.

$\mathrm{Si}$, como ya se ha apuntado, Netflix es un gigante estadounidense de la TV on line y dispone de 57 millones de clientes de televisión de pago, presentes en unos cincuenta países de todo el mundo y aparecerá en España a finales del año 2015 para lanzar su servicio de video en streaming, podemos concluir que, en un breve plazo de tiempo, este particular mercado en nuestro país se disputará entre Canal+, Movistar TV, Wuaki.tv y Netflix, aparte de otros operadores que pudieran estar interesados. Lo que significa, claramente, que, al estar en ese cuarteto, Telefónica consolida su estrategia como TV Company, es decir, afianza su transformación de empresa de telecomunicación a compañía de contenidos, fundamentalmente televisivos.

\section{Referencias bibliográficas}

Albarran, A. (2010): The Media Economy. London: Routledge.

Buquet Corleto, G. (2005): El poder de Hollywood. Madrid: Fundación Autor.

Bustamante, E. (2005): “Prólogo". En VV.AA., Elpoder de Hollywood (Coord., G. Buquet Corleto). Madrid: Fundación Autor, páginas 13 a 19.

Campos Freire, F. (2011): "La complejidad de la gobernanza de la comunicación en Europa". En VV.AA., Comunicación y gobernanza en Europa (Coord., F. Campos Freire). Madrid: Editorial Universitas.

Croteau, D. (2006): The Business of Media. Corporate Media and the Public Interest. Thousand Oaks (California): Pine Forge Press. 
Croteau, D. y Hoynes, W. (2001): The business of media: Corporate media and the public interest. Thousand Oaks, California: Sage.

Deloitte (2014): "Predicciones para Tecnología, Medios y Telecomunicaciones", en http://www.2.deloitte.com [Consulta: 2015/03/03].

Doyle G. (2008): Understanding Media Economics. Sage: New York, $2^{\mathrm{a}}$ edic.

Gabszewicz, J. y Sonnac, N. (2006): L'industrie des médias. Paris: La Découverte.

García Santamaría, J.V. (2011): “Joost”. En Álvarez Monzoncillo, J.M, La televisión etiquetada: nuevas audiencias, nuevos negocios. Madrid: Ariel/Fundación Telefónica, páginas 217 a 225.

Litman, B. R. (1998): The Motion Picture Mega Industry. Michigan State University, Needham Heights: Allyn and Bacon.

Pérez Serrano, M.J. (2010): La concentración de medios en España. Análisis de casos relevantes en radio prensa y televisión. Madrid: Servicio de Publicaciones UCM.

Picard, R.G. (1989): Media Economics: Concepts and Issues. Thousand Oakes, California: Sage.

Prado y Picó, E. (2003): “Tendencias internacionales". En López Vidales, N. y Peñafiel Saiz, C., La evolución del sector audiovisual: modos de producción cambiantes y nuevas tecnologías. Madrid: Fragua/Universidad Francisco de Vitoria.

Stephan, M. (2005): "Diversification Strategy of Global Media Conglomerates: a Comment" en Journal of Media Economics, 18 (2), páginas 85 a 103.

Wolton, D. (2004): La otra mundialización. Los desafíos de la cohabitación cultural global. Barcelona: Gedisa. 


\title{
La influencia de las redes sociales en las versiones móviles de los medios digitales
}

\author{
Nancy Graciela Ulloa Erazo, Pontificia Universidad Católica del \\ Ecuador-Sede Ibarra (PUCESI, Ecuador), nulloa@pucesi.edu.ec \\ Alba Silva Rodríguez, Pontificia Universidad Católica del Ecuador- \\ Sede Ibarra (PUCESI, Ecuador), alsilva@pucesi.edu.ec
}

\section{Resumen}

La presente investigación plantea la evaluación de la participación en las webs móviles de los cibermedios de referencia, con matriz impresa, más leídos de Ecuador. En concreto se analizan los sitios de El Comercio, El Telégrafo, El Universo y Abc, 20 Minutos, La Vanguardia, El Confidencial, Público, El Periódico, The Huffington Post, Libertad Digital y La $V$ oz de Galicia en lo que tiene que ver con el caso de España. Se ofrece una comparativa entre la situación en la que se encuentran diferentes cibermedios de contextos diversos para contrarrestar opiniones y comprobar si los principales medios de comunicación están incentivando la participación a través de sus sitios móviles.

Los resultados de este análisis nos indican que los cibermedios no están aprovechando las características que les ofrecen las plataformas de distribución vía móvil a la hora de establecer una conversación con sus audiencias. Además, no se explota ninguna de las funcionalidades específicas de las que disponen los dispositivos móviles como la geolocalización, personalización, participación o interactividad. 
Palabras clave: redes sociales, comunicación móvil, medios digitales, ciberperiodismo.

\section{Introducción}

- L riobambeño Rivera (Rivera, 2012), publicó en un estudio de 1991, cuando la compañía Ecuanet facilitó su primer acceso con el nodo establecido por la Corporación Interinstitucional de Comunicación Electrónica (Intercom), que forma parte de la red mundial del Institute for Global Communications/Alliance for Progressive Communications (IGC/APC), y provee este servicio a organizaciones no gubernamentales y de desarrollo.

Las primeras instituciones con acceso a Internet fueron: Acción Ecológica, Agencia Latinoamericana de Información Alai, Centro Andino De Acción Popular CAAP, Consejo Nacional de Universidades y Escuelas Politécnicas CONUEP, ahora SENESCYT, Facultad Latinoamericana de Ciencias Sociales Sede Ecuador FLACSO, y la Universidad Andina Simón Bolívar.

En 1992, se da un segundo nodo. Ecuanet fue establecido por la Corporación Ecuatoriana de Información, una entidad sin fines de lucro auspiciada por el Banco del Pacífico, la Escuela Superior Politécnica del Litoral (ESPOL) y la Universidad Católica Santiago de Guayaquil. Esta red estuvo conectada en forma directa al National Science Foundation Network (NSFNET), un programa norteamericano que promovió la investigación y la educación. A través de esto se ejecutó un convenio donde las instituciones educativas y de investigación quedaron exoneradas del pago mensual por la membresía. Esta conectividad usó el sistema de comunicación del Banco del Pacífico, con el que Ecuanet empezó a manejar dominios y las primeras redes de Internet.

El especialista en nuevas tecnologías, Eduardo Béjar (como se cita en Rivera, 2012) dijo que:

"El problema en ese tiempo era el costo del Internet, ya que un enlace de 64kbps vía radio en 98-99 tuvo el coste de $\$ 700$ mensuales; no había suficiente cobertura en las redes de cobre, evidentemente redes de fibras no existían y las opciones eran por 
vía telefónica mediante Dial-up o vía radio mediante antena inalámbrica." (p.8)

En cuanto al uso que se daba al internet, Bejar señaló:

"En el caso de las personas era un uso de investigación y esparcimiento, para las empresas lo primordial era el correo electrónico, porque lo que buscaban era comunicarse y era más económico que usar el fax o hacer una llamada. El internet se expandió ya que, aparte de la investigación las personas usaban los sistemas de comunicaciones de textos, videos, etcétera, lo que conocemos como mensajería instantánea." (Rivera, 2012: 8-9)

En esa época, hubo varias instituciones nacionales que con el dominio de Ecuanet crearon sus propias páginas, estas fueron: Ecuanet (http://www.ecnet.ec/), Universidad San Francisco de Quito (http:// usfa.edu.ec), Diario Hoy (http://www.ecnet.ec/hoy/hoy.htm), y el Instituto Nacional de Estadísticas y Censos de Ecuador - INEC (http: //www.ecnet.ec/inec/inechome.htm).

El 14 de agosto de 2009, nace el Ministerio de Telecomunicaciones y Sociedad de la Información (MINTEL) como una instancia destinada a llevar a Ecuador por el camino de la sociedad digitalizada, mediante la ejecución de políticas públicas en el campo de la Tecnología de la Información y Comunicación (MINTEL, 2014).

El ministro de Telecomunicaciones y de la Sociedad de la Información, Jaime Guerrero (como se cita en Rivera, 2012) expresó que: "En Ecuador se puso en marcha el primer plan de inclusión digital denominado 'Estrategia Ecuador Digital 2.0'. Se aspira a que el $50 \%$ de la población tenga acceso a banda ancha en cuatro años y que llegue al 70\% para 2016”. (Rivera, 2013: 10).

Rivera (2012) también describe que en 1994, se empieza a registrar un cambio en cuanto a información noticiosa. Algunos medios de comunicación tradicionales, principalmente los periódicos, comienzan a publicar habitualmente contenidos en internet, creando sus propias páginas web. El primer intento de cibermedio fue el boletín informativo del diario Hoy que circuló en 1995 y contenía un resumen diario de noticias. Este se constituyó en el único nexo para miles de ecuatorianos en el exterior (Rivera, 2012). El Subdirector de información de diario Hoy, Diego Araujo (como se cita en Rivera, 
2012) menciona que: "este diario es el primer medio de Sudamérica que tuvo el periódico en línea”. (Rivera, 2012: 14). Después, la empresa Servidatos, parte del grupo Hoy, creó un sitio web y ofreció una versión gráfica de la primera página del diario, incluso información adicional de un suplemento llamado La Epopeya del Cenepa. En ese tiempo, en el Ecuador, estar en internet constituía un gran logro. Para 1999, El Comercio contó con una edición digital más parecida a la de papel. Continuó siendo plana pero mejor organizada. En el 2000, incorporó un menú de navegación y banners, tuvo el servicio de titulares al e-mail; y para 2001, concluyó una sección de instantaneidad llamada "Lo último" y una sección especial de la versión digital para migrantes; apareciendo una opción para ver archivos en forma manual y secciones propias de entretenimiento (Rivera, 2012).

Esta evolución se estancó hasta el 2005, año en que incorporó audios y multimedia, como un primer intento de convergencia con radio Quito.

Se menciona que en la versión digital de los medios impresos, la información no es editada para formato web. Se afirma que existen casos excepcionales donde se hace esto, pero, por regla, lo que sale en el impreso se publica textualmente en el medio digital (Rivera, 2012).

Diario El Universo está en internet desde 1997. Históricamente, según la página web Alexa.com, es uno de los medios más visitados. Inició con una página diseñada en tablas HTML, gráficos fijos de baja calidad y en la cabecera integró un menú lateral con enlaces a sus secciones. En la página principal presentó solo una noticia sin foto, un editorial en la derecha y el menú en la izquierda, no tuvo opciones de contactos ni datos del medio.

En 1998, diario La Hora aparece en la web. Presentó un sitio con tablas HTML, buena distribución de secciones en la portada, fotos de baja calidad y un fondo con el logotipo del medio; permitió una navegación simple hacia sus contenidos. Los diarios Expreso y Extra nacieron en el 2007 con sus respectivos dominios de internet (Rivera, 2012).

Datos: El desarrollo de las telecomunicaciones en Ecuador avanza a pasos de gigante. Cada vez son más los usuarios que recurren al servicio de la telefonía móvil de acuerdo a sus necesidades y al ritmo de vida que llevan. Más de 16 millones de personas están abonadas a la 
telefonía móvil en Ecuador. El 48\% de los usuarios utilizan sus aplicaciones para navegar por páginas en Internet y redes sociales (Consultora Advance).

El teléfono móvil no ha sido objeto de estudio de las Ciencias Sociales hasta bien entrado el siglo XIX. Con la evolución del dispositivo ha emergido una corriente preocupada por la investigación de sus efectos sociales que ha comenzado, como bien apunta Geser, cara mediados de la década de 1990 (Geser, 2004). Los principales estudiosos que abarcaron este campo coinciden en apuntar que los usos de la telefonía móvil traen consecuencias muy diversas para la sociedad que afectan a aspectos tan dispares como su estructuración, los métodos de comunicación y la mutación de valores tradicionales como el espacio y el tiempo, lo público y lo privado, la identidad, la seguridad o la soledad, entre otros.

Los trazos que caracterizan a la sociedad moderna vienen marcados por los cambios en los procesos de comunicación. Asistimos a una comunidad interconectada cuya singularidad fundamental viene determinada por la movilidad. Las pequeñas pantalla en general y los teléfonos móviles en particular constituyen un artífice dentro del nuevo ecosistema de medios. En un contexto dominado por la movilidad aparecen cambios que atingen al espacio de consumo de la información y surgen nuevos contornos que surgieren repensar estrategias a partir de las cuales poder readaptarse con facilidad.

Estos modernos escenarios demandan contenidos breves, sencillos, claros y concisos, capaces de ser visualizados en un espacio muy breve de tiempo. La lógica del always on, del siempre conectado, altera los tradicionales ámbitos en los que se empleaban las tecnologías y surgen nuevos contextos de consumo. Entre estos, destacan los viajes, los medios de transporte, la calle, los bares y establecimientos o el lugar de trabajo y estudios.

Los teléfonos móviles fomentan, a su vez, las relaciones sociales. Dominick (2006: 65) ya resaltaba en su momento el potente poder de las tecnologías móviles para crear la unión social. Afirmaba así que "El telégrafo, al dominar la electricidad, fue una muestra de la tecnología que después se utilizaría en la radio; también fue el primer medio que usó la comunicación digital (puntos y guiones). El teléfono, con su 
estrecha red de cables y conmutadores, introdujo el mismo concepto esencial de internet: la humanidad unida por completo".

Por todo lo que venimos de comentar se deduce que los medios de comunicación no deberían dejar de lado el escenario de la comunicación móvil que en la actualidad está en pleno apogeo. Ramón Salaverría considera que "hay que apostar por una presencia óptima en todo tipo de dispositivos móviles, sobre todo teléfonos y tabletas. En la próxima década, Internet se va asociar mucho más naturalmente con los dispositivos móviles, sobre todo aquellas actividades relacionadas con la intercomunicación personal y el acceso a la información actualizada. Los medios digitales deberán estar preparados para satisfacer las demandas de un nuevo público que ya no esperará conectarse a su PC para acceder a las noticias" (Salaverría, 2010).

El periodismo vive un proceso de cambios e innovaciones que repercuten directamente en los contenidos, en los profesionales y en los propios usuarios. Aunque la esencia, las propiedades y la ética de la profesión periodística se mantengan inmutables, bien es cierto que el nuevo escenario, dominado por la información ubicua y los dispositivos multiplataforma, requiere una conversión de la naturaleza de la información. Juan Varela identifica nuevas particularidades en los contenidos: más abundantes, baratos, amigables, sociales, personales e interactivos (Varela, 2011: 3). Sánchez y Aguado opinan que la llegada del teléfono móvil provoca una transformación en el concepto original de periodismo desde el punto de vista de la estructuración, con el surgimiento de nuevas modalidades expresivas, aunque destacan que la manera de producir información sigue siendo la misma (Sánchez y Aguado, 2010: 6). Una característica que define a la nueva era de la movilidad, en relación con el consumo informativo, tiene que ver con los cambios que se producen en lo que se refiere al acceso de los usuarios a la información. Los contenidos pull se están imponiendo a los push, es decir, ahora son los contenidos los que llegan al usuario. El autor portugués Fidalgo asegura que los teléfonos son además "la tierra prometida del periodismo de proximidad" (Fidalgo, 2009: 122).

La cuarta pantalla, como así la han denominado muchos estudiosos (Cebrián y Flores Vivar, 2011: 18 y Aguado y Martínez, 2008) tiene para muchos autores una serie de características intrínsecas que le permiten adaptarse al nuevo entorno así como poder cumplir con las necesidades que demanda la sociedad. Señala Antonio Miguel 
Fumero que se trata de un dispositivo que refleja a la perfección la "hipermultifuncionalidad instrumental" y la complejidad del nuevo escenario tecnosocial que dibujan algunos pensadores (Fumero, 2010: 1-7).

Ahonen considera al móvil como el séptimo medio de comunicación de masas que cuenta, al igual que había sucedido en la década anterior con la introducción de Internet, con la peculiaridad de condensar en un único soporte todo aquello que sus antecesores no habían podido hacer. El teléfono tiene la capacidad de incorporar imágenes, vídeos, audios, música o mensajes. Sus cualidades técnicas lo convierten en un dispositivo que pone en peligro al resto de medios hasta llegar a atribuirle una "inherente amenaza" con respecto a los tradicionales canales de comunicación (Ahonen, 2008).

El comienzo del siglo XXI marcó un punto de inflexión en lo que se refiere a las relaciones entre la telefonía móvil y la comunicación y el periodismo. Dice Goggin que fue a partir del 2001 cuando el dispositivo se conforma como un verdadero medio de comunicación (Goggin, 2004). En este sentido tuvo gran importancia la evolución de los sistemas tecnológicos, sobre todo gracias a la aparición del GSM que abrió paso al Internet móvil tal y como constata Rojo Villada (Villada, 2008: 162). Fue precisamente la presencia de la red de redes en la telefonía móvil la "causa principal por la que el periodismo tiene la obligación de extender sus acciones más allá del formato en papel y del monitor" (Cebrián y Flores Vivar, 2011: 208).

Los dispositivos móviles empiezan a ser considerados como plataformas comunicativas con funciones realmente útiles para la transmisión de información. Entre sus ventajas y la explicación para su éxito destacan la usabilidad, la ubicuidad y la persuasividad (Aguado y Martínez, 2008: 3). El valor de poder consultar información desde cualquier punto, esa idea de conectividad permanente, constituye un factor crucial para distinguirlo de los medios de comunicación anteriores superando las limitaciones de tiempo y espacio que estos imponían (Soletic, 2008: 2).

\section{La situación en América Latina}

En América Latina la aparición de los sitios periodísticos, así como de otros servicios asociados, es un fenómeno reciente. En 2007, un 
estudio aplicado a los cibermedios de 18 naciones de la región reflejaba que existía un $57 \%$ de las webs que generaban contenidos móviles, casi la mitad por medio de SMS y un 32\% para PDA (El Tiempo, 2007). La aceleración en el uso de Internet móvil en Latinoamérica está planteando nuevos retos a múltiples sectores y empresas. Tal y como cita el Plan Nacional para el Buen Vivir 20132017 el segmento de mayor crecimiento en el país ha sido sin duda el de servicios móviles.

El escenario periodístico actual necesita adaptarse a los nuevos cambios tecnológicos y este proyecto se enmarca en dicho contexto con el fin de lograr una serie de contribuciones, tanto a nivel macro como micro.

La estrategia SoLoMo (Social, Local y Móvil) ha sido una de las principales características que ha definido la comunicación móvil desde sus comienzos. Los dispositivos móviles surgen como una de las tecnologías que conectan más directamente con los usuarios. Son los aparatos personales y privados del momento y su uso está tan masificado en la sociedad actual que han llegado a desbancar la posición que ostentaban los ordenadores personales. Su constante evolución técnica ha hecho que se convirtieran en un soporte con grandes posibilidades en el sector de la comunicación y, por consiguiente, en un excelente medio para difundir información.

Según sus diferentes usos, los dispositivos móviles tienen cierta relación con los ordenadores conectados a la red. Tal y como señala Christian Espinosa (Espinosa, 2011) "la naturaleza multi-modal de la comunicación móvil engloba, entonces, voz, texto, imágenes, vídeo pero un millón más de combinaciones". Entre los servicios y las herramientas que estos dispositivos multifunción incorporan están los medios sociales.

De acuerdo con las características de la comunicación actual, con la interactividad como base de cualquier estrategia, el trabajo periodístico precisa avanzar en la construcción de discursos en los que la conversación y la interacción marquen la estructura del relato y los ritmos de las diferentes fases. El papel activo de los usuarios exige discursos alejados del modelo lineal, con ventanas abiertas a la intervención de los usuarios en el momento en que lo estimen oportuno. La creación de formatos periodísticos innovadores, en especial de modelos que apliquen la preceptiva básica de la 
información rigurosa e imiten las dinámicas comunicativas actuales de raíz conversacional-, contribuirá a la creación de nuevos caminos para el periodismo en un escenario comunicativo donde los modelos lineales ocupan espacios minoritarios y los modelos circulares, participativos y bidireccionales predominan en las preferencias de los usuarios.

Los dispositivos móviles disponen de unas características específicas, diferentes a las de cualquier medio precedente, que conviene destacar. Christian Espinosa (2011) las describe de la siguiente manera:

1. Geolocalización. Posicionar la información para dejarla registrada en mapas. Sacarle jugo al GPS

2. Contexto. Apoyarse en apps que den referencias de quien reportan contenido en las redes sociales ubicados alrededor de nuestra propia cobertura

3. Compartir. Tener sincronizados los reportes para que automáticamente lleguen y se redifundan en las principales redes sociales

4. Integración. Planificación con la mesa de redacción de la puesta en escena de la cobertura móvil en la página principal del sitio; embeber los reportes con diferentes tipos de widgets para que la audiencia pueda recuperar la información o la lleve al sitio

5. Distribución. Valerse de toda la fuerza del medio para promover en sus diferentes soportes la cobertura: prensa, radio, TV, email, SMS, aplicación móvil, RSS.

6. Hacer seguimiento. Contar con un monitoreo móvil continuo de la audiencia y retroalimentación de la cobertura de otros medios gracias al lector móvil de noticias RSS.

\section{Metodología}

Este trabajo presenta una panorámica general de las tendencias detectadas en el ámbito de la participación de las versiones móviles de los principales cibermedios estudiados. El objetivo fundamental de esta investigación es analizar las vías de participación de los usuarios en los principales cibermedios de comunicación online de ámbito ecuatoriano y español. Seleccionamos, a partir de datos de ComsCore, 
(ver gráfico 1) once de los doce medios más leídos en España. Incorporamos cibermedios que tienen matriz impresa en su gran mayoría a excepción de Libertad digital, EL Confidencial y The Huffington Post. En la muestra también se contempla el estudio de las estrategias de participación que llevan a cabo diarios de información general con distribución gratuita como es el caso de 20 Minutos. La razón de tener que excluir uno de ellos (La información) se debe a que es el único cibermedio que no dispone de app para dispositivos móviles. La selección de medios españoles se complementa con El Telégrafo, El Universo, El Diario y La Hora, cuatro de los escasos medios que disponen de versiones para dispositivos móviles y que gozan de una gran popularidad en el ámbito ecuatoriano.

Gráfico 1: Ranking de medios más leídos en España según Comscore (febrero 2014)

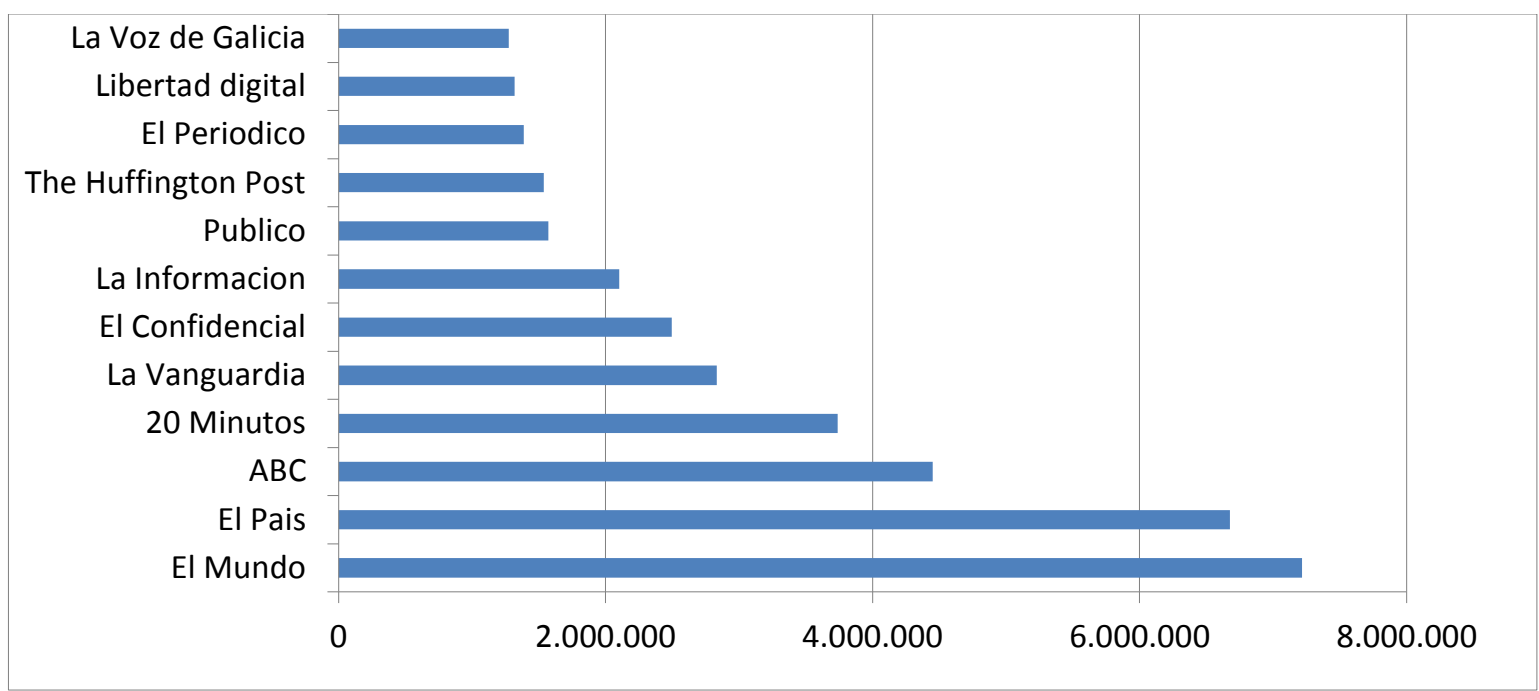

Fuente: Elaboración propia a partir de datos de Comscore.

Centramos este análisis en una de las modalidades de participación en función del tipo de interactividad que ofrece en su clasificación Suau Martínez (Suau, 2011: 178): la interactividad participativa, centrada fundamentalmente en la observación de los medios sociales en las nuevas plataformas de distribución móvil.

\section{Análisis}

\subsection{Análisis del consumo de medios en Ecuador}

Para analizar el nivel de consumo es preciso caracterizar el perfil del 
consumidor ecuatoriano de medios, de acuerdo al presente detalle:

- El 87,1\% de los hogares ecuatorianos tiene un televisor.

- Cada hogar tiene en promedio 1,54 televisores.25

- El 39,4\% de los hogares tiene una radio-grabadora y el 48,2\% un equipo de sonido, lo que da un total de $87,6 \%$ con dispositivo para captar radiodifusión

- El 47,6\% tiene DVD, VCD o VHS.

- El $17,9 \%$ de hogares tiene una computadora y el 2,5\% servicio de Internet.

- Cerca del 10\% de los ecuatorianos navega frecuentemente en Internet y tiene una cuenta de email.

- Ecuador es uno de los 6 países con más bajo nivel de lectura entre los estudiantes de América Latina y con menor lectura de libros: lee 1 cada año, según la Cámara Ecuatoriana del Libro.

- Cada día se editan en el país más de 900.000 ejemplares de diarios de alcance local, regional y nacional, lo que suma una audiencia de lectura de más de 4’500.00031 de personas, lo que representa el 41,28\% de la población de 10 años en adelante. (INEC, 2006: 13)

Tabla 1: Modalidad de versión móvil de los medios ecuatorianos

\begin{tabular}{|l|c|l|}
\hline & Sitio móvil & App Móvil \\
\hline El Comercio & $\mathrm{X}$ & $\begin{array}{l}\text { X iPad } \\
\text { iPhone } \\
\text { Blackberry }\end{array}$ \\
\hline El Universo & $\mathrm{X}$ & $\begin{array}{l}\text { XiPad } \\
\text { Android } \\
\text { Apple } \\
\text { Blackberry }\end{array}$ \\
\hline Telégrafo & - & - \\
\hline La Hora & $\mathrm{X}$ & - \\
\hline
\end{tabular}

Fuente: Elaboración propia

Las redes sociales se han convertido en poco tiempo en herramientas cotidianas para la mayoría de internautas de todo el mundo. 
Imagen 1: Web y app móvil de La Hora

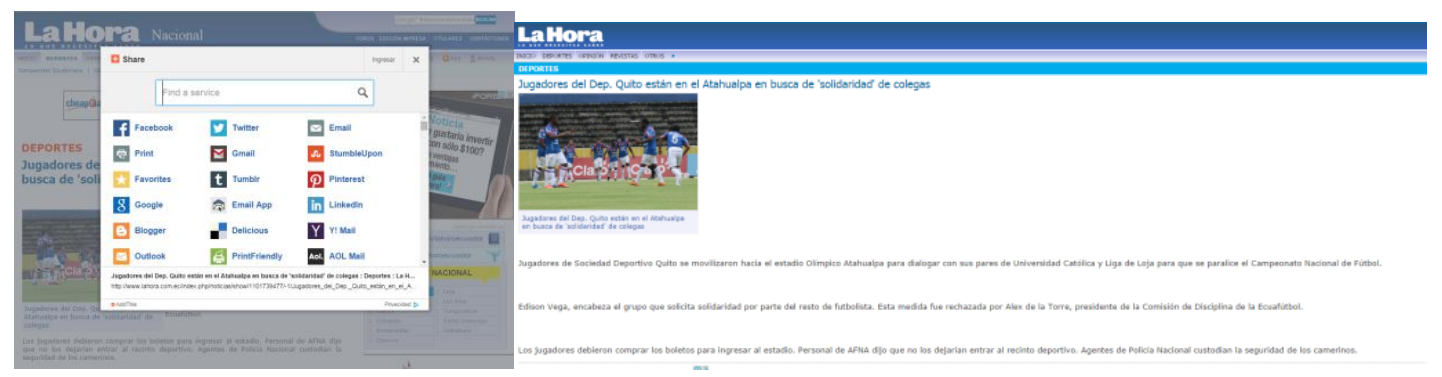

Fuente. Elaboración propia a partir de captura de pantalla

Tabla 2: Presencia del medio en plataformas de la Web 2.0

\begin{tabular}{|l|l|l|l|l|l|l|l|l|}
\hline & $\begin{array}{l}\text { EL } \\
\text { UNIVERSO } \\
\text { WEB }\end{array}$ & $\begin{array}{l}\text { EL } \\
\text { UNIVERSO } \\
\text { MÓVIL }\end{array}$ & $\begin{array}{l}\text { EL } \\
\text { COMERCIO } \\
\text { WEB }\end{array}$ & $\begin{array}{l}\text { EL } \\
\text { COMERCIO } \\
\text { MÓVIL }\end{array}$ & TELÉGRAFO & TELÉGRAFO & $\begin{array}{l}\text { La } \\
\text { HORA } \\
\text { WEB }\end{array}$ & $\begin{array}{l}\text { LA } \\
\text { HORA } \\
\text { MÓVIL }\end{array}$ \\
\hline Facebook & $\mathrm{X}$ & - & $\mathrm{X}$ & - & - & - & $\mathrm{X}$ & - \\
\hline Twitter & $\mathrm{X}$ & - & $\mathrm{X}$ & $\mathrm{X}$ & $\mathrm{X}$ & - & $\mathrm{X}$ & - \\
\hline $\begin{array}{l}\text { Google } \\
\text { Plus }\end{array}$ & $\mathrm{X}$ & - & $\mathrm{X}$ & - & $\mathrm{X}$ & - & $\mathrm{X}$ & - \\
\hline $\begin{array}{l}\text { RR.SS } \\
\text { propias }\end{array}$ & - & - & - & - & - & - & - & - \\
\hline Linkedin & $\mathrm{X}$ & - & $\mathrm{X}$ & - & - & & \\
\hline Flickr & - & - & - & - & - & & $\mathrm{X}$ & - \\
\hline Pinterest & $\mathrm{X}$ & - & $\mathrm{X}$ & - & - & & - & - \\
\hline
\end{tabular}

Fuente: Elaboración propia

La migración, nacimiento y evolución de lo que hoy se conoce como ciberdiarios, cibermedios o medios electrónicos surge a finales de los años noventa, a raíz de la llamada convergencia digital, en la cual los diarios latinoamericanos se volcaron hacia la gran red de redes. El crecimiento de los medios digitales en Ecuador está aumentando por el acceso a las nuevas tecnologías, bajos costos de conexión a la red de redes y por ciudadanos que necesitan estar informados y comunicados no solo en el territorio nacional sino también en otras esferas geográficas. 
Imagen 2: La presencia de las redes sociales en la web de El Universo

Viemes, 17 de octubre, 2014

\section{La Universidad de Guayaquil estará intervenida por un año más}

Hasta octubre del 2015 la Comisión Interventora y Fortalecimiento Institucional para la Universidad de Guayaquil permanecerá en esta institución.

Esto luego de que el Consejo de Educación Superior (CES) en su trigésima octava sesión ordinaria del miércoles pasado en la Universidad de Ambato aprobara el informe de labores de la Comisión y ratificara por segundo y último año este proceso de intervención. Este es el plazo que de acuerdo con el artículo 48 literal f del Reglamento de Creación, Intervención y Suspensión de Universidad tienen los integrantes de la Comisión para cumplir con su plan de excelencia.

El 23 de octubre del 2013 el CES inició con la intervención de esta institución superior de manera integral. El incumplimiento de la gratuidad, y el depósito de rubros de estudiantes a cuentas particulares fueron algunos de los motivos para que se diera el proceso.

En este año la Comisión ha impulsado proyectos como la construcción de la Plaza de Recreación y Bienestar Est de la contratación de los profe

Sin embargo, estudiantes cues hay un cambio notable en pro en varias facultades, tanto en

A finales de este mes está $\mathrm{p}$ comunidad universitaria.
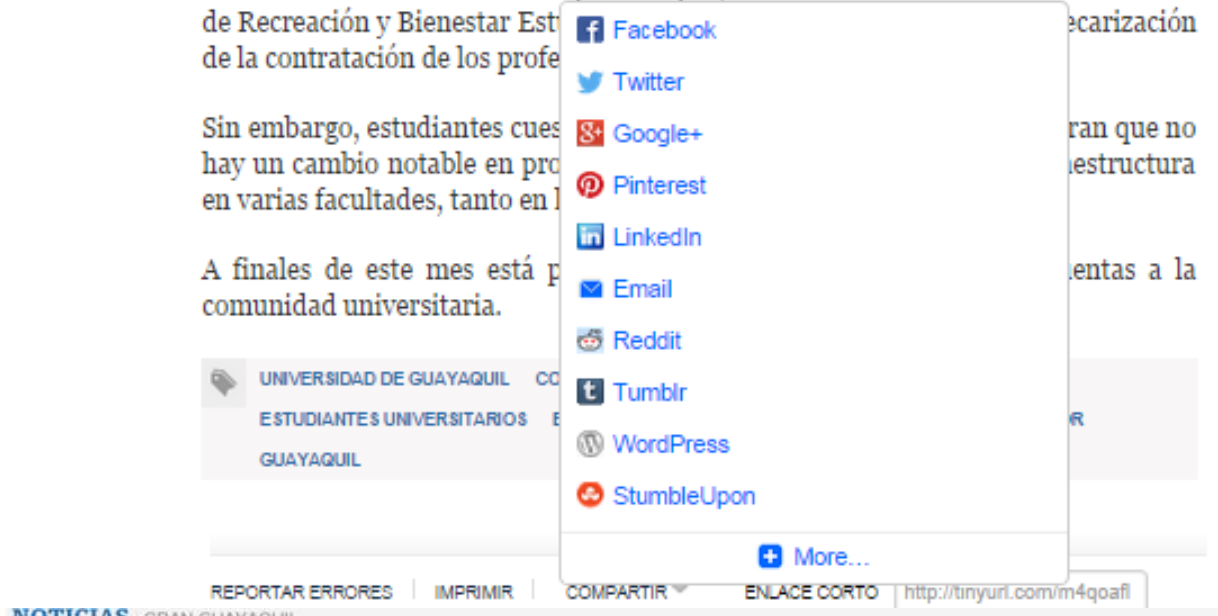

NOTICIAS GRAN GUAYAQUII.

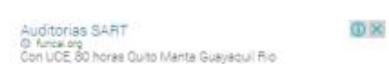

La Universidad de Guayaquil estará intervenida por un año más

16 de octubre, 2014

Hasta octubre del 2015 ta Comisión Interventora y Fortalecimiento Institucional para ta Universidad de Guayaquil permanecerà en esta institución

Esto luego de que el Consejo de Educación Superior (CES) en su trigesima octava sesión ordinaria del miercoles pasado en la Universidad de Ambato aprobara el informe de labores de la Comisiòn y ratifcara por segundo y ütimo año este proceso de intervenciòn. Este es el plazzo que de acuerdo con el articulo 48 inferal f del Reglamento de Creación. Intervención y Suspensión de Universidac tienen los integrantes de la comisión para cumplir con su plan de excelencia.

El 23 de octubre del 2013 el CES inició con la intervención de esta institución superior de manera integral. El incumplimiento de la gratuidad, y el depósito de rubros de estudiantes a cuentas particulares fueron algunos de los motvos para que se diera el proceso.

En este año la Comisión ha impulsado proyectos como la construcción de la Plaza de Recreación y Bienestar Estudiantil además de la eliminación de la precarización de la contrataciôn de los protesores

Sin embargo, estudiantes cuestionan las acciones de esta, ya que consideran que no hay un cambio notable en procesos internos. Ademàs de la falta de infraestructura en varias facukades, tanto en las fachadas como en los baños

A finales de este mes está previsto que se realice la rendición de cuentas a la comunidad universitania. 
Fuente: Capturas de pantalla de la web y la web móvil de El Universo Imagen 3: La presencia de las redes sociales en la web y la web móvil de El Comercio

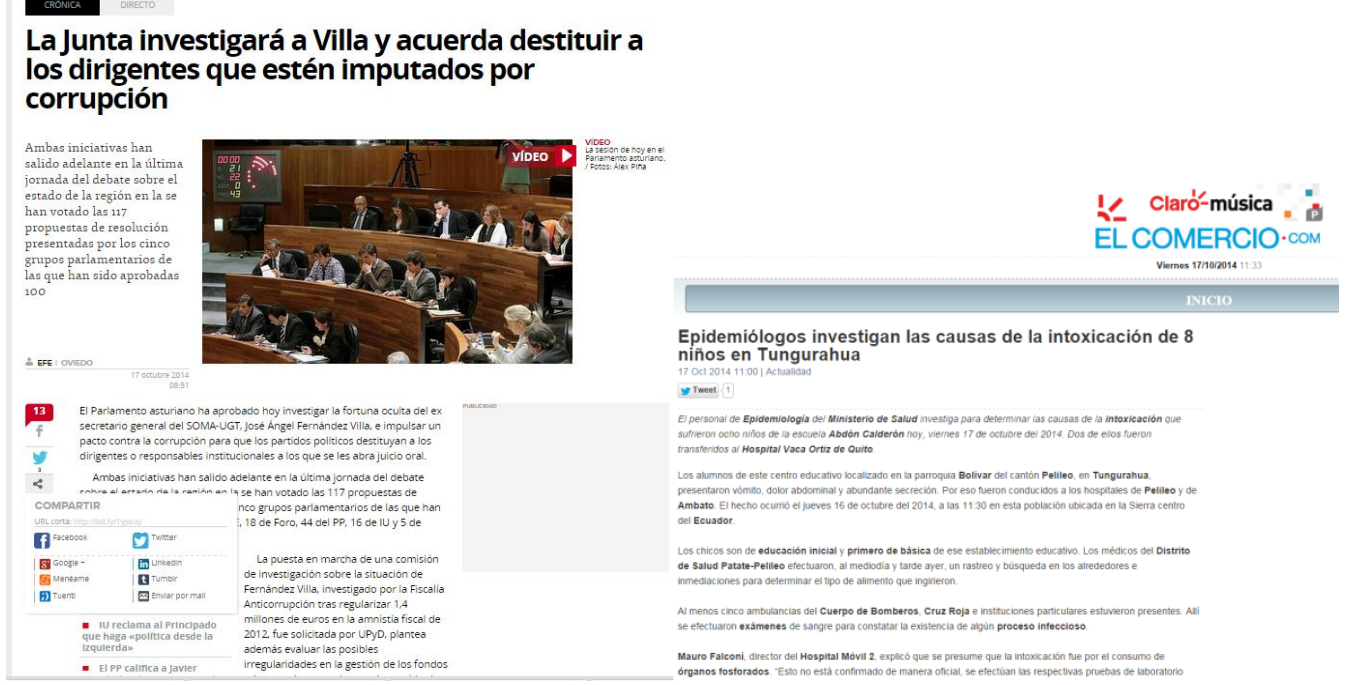

Fuente: Capturas de pantalla de la web y la web móvil de El Comercio

Tabla 3: Estadísticas y monitoreo de visitas de periódicos matriciales

\begin{tabular}{|c|c|c|c|c|c|c|}
\hline \multicolumn{7}{|c|}{$\begin{array}{l}\text { PERIÓDICOS MATRICIALES (Imbabura y Carchi) } \\
\text { Estadísticas y monitoreo de visitas: sitios web y redes sociales ( } 30 \text { de abril 2014) }\end{array}$} \\
\hline $\mathbf{N}^{\circ}$ & Medios & Sitio web & $\begin{array}{l}\text { Ciudad y } \\
\text { año de } \\
\text { creación }\end{array}$ & $\begin{array}{r}\text { Fan page/ } \\
\text { Facebook }\end{array}$ & $\begin{array}{l}\text { Seguidores/ } \\
\text { Twitter }\end{array}$ & $\begin{array}{l}\text { Otras } \\
\text { redes } \\
\text { sociales }\end{array}$ \\
\hline 1 & Diario La Hora & http://www.lahora.com.ec/ & Quito 1998 & 72.700 & 118.000 & $\begin{array}{l}\text { Sttorify, } \\
\text { Pinterest, } \\
\text { Google } \\
\text { plus. }\end{array}$ \\
\hline 2 & Diario El Norte & http://www.elnorte.ec/ & Ibarra 2003 & 8.850 & 3.223 & $\begin{array}{l}\text { YouTube } \\
\text {, RSS. }\end{array}$ \\
\hline 3 & Diario La Nación & http://www.diariolanacion.com.ec/ & Tulcán 2013 & 270 & 23 & YouTube \\
\hline 4 & $\begin{array}{l}\text { Interdiario } L a \\
\text { Prensa. }\end{array}$ & No disponible & Tulcán 2014 & $\begin{array}{l}\text { Posee una } \\
\text { cuenta con } \\
259 \text { amigos }\end{array}$ & No disponible & \\
\hline
\end{tabular}

Fuente: Elaboración propia

\subsection{Interactividad Participativa: Redes sociales y comentarios}

Para estudiar la sección de participación comenzamos por estudiar cual era la presencia de las redes sociales en el soporte móvil. Observamos que del conjunto de cibermedios analizados tan solo dos (El Periódico de Catalunya y La Vanguardia) no contemplan ninguna vía de interacción a través de las redes sociales. Un elevado porcentaje de los diarios digitales, un 40\%, se decantan por escoger dos vías de medios sociales a través de los cuales los usuarios puedan compartir 
contenidos. Se trata de Facebook y Twitter. Tan solo dos de ellos (El País y La Voz de Galicia) incorporan la app de mensajería instántanea Whats $A p p$ en sus apps móviles como otra de las opciones principales a través de la cual poder interactuar con los contenidos publicados por el medio. Google Plus tan solo está presente en el diario El País, The Huffington Post y en el nativo Libertad Digital.

La tendencia que se observa nos indica que las posibilidades de participación a través de los medios sociales se reducen notablemente en las apps móviles, algo que contrasta con el hecho de que sea el dispositivo móvil uno de los principales medios que propician la interacción. Es el soporte móvil además la vía de acceso preferida por los usuarios para consultar sus redes sociales, por encima de otros dispositivos como los ordenadores. De hecho, el uso de los smartphones para esta finalidad ha crecido un $25 \%$ en el último año (Iab, 2014: 11).

Tabla 4: Presencia de las redes sociales en las apps móviles de los diarios digitales más leídos en España

\begin{tabular}{|c|c|c|c|c|c|c|}
\hline & \multicolumn{5}{|c|}{ REDES SOCIALES } & AGREGADORES \\
\hline & Facebook & Twitter & $\begin{array}{l}\text { Google } \\
\text { Plus }\end{array}$ & WhatsApp & Linkedin & (Menéame) \\
\hline E1 Mundo & $\mathrm{x}$ & & 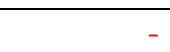 & - & - & - \\
\hline E1 País & $\mathrm{x}$ & & $\mathrm{X}$ & $\mathrm{X}$ & $\mathrm{X}$ & $\mathrm{X}$ \\
\hline Abc & $\mathrm{x}$ & & - & - & - & - \\
\hline 20 minutos & $\mathrm{x}$ & & - & - & - & - \\
\hline La Vanguardia & & & - & - & - & - \\
\hline E1 Confidencial & $\mathrm{x}$ & & - & - & - & - \\
\hline Público & $\mathrm{x}$ & & - & - & - & $\mathrm{X}$ \\
\hline E1 Periódico & - & - & - & - & - & - \\
\hline $\begin{array}{l}\text { The Huffington } \\
\text { Post }\end{array}$ & $\mathrm{x}$ & & $\mathrm{x}$ & $\mathrm{x}$ & - & - \\
\hline Libertad Digital & $\mathrm{x}$ & & $\mathrm{x}$ & & - & - \\
\hline La Voz de Galicia & $\mathrm{x}$ & & & $\mathrm{x}$ & - & - \\
\hline
\end{tabular}

Fuente: Elaboración propia

\section{Conclusiones}

Este breve análisis exploratorio nos permite extraer una serie de conclusiones:

- Los cibermedios más leídos de Ecuador disponen de aplicación para dispositivos móviles y le prestan atención a las redes sociales, Twitter principalmente. 
- Todos los cibermedios más leídos de España tienen una app móvil.

- La participación a través de las redes sociales en los diarios de Ecuador y España se centran en la web tradicional.

- Se observan diferencias notables entre la variedad de posibilidades de interacción a través de redes sociales que permiten las apps móviles de los cibermedios españoles en relación con las apps de los cibermedios ecuatorianos

- Aunque no ha sido objeto de estudio de este análisis, se observa que -a nivel de participación- queda todavía un largo camino por recorrer en los dos ámbitos analizados. Tanto los cibermedios referenciados de Ecuador como de España no hacen uso de las herramientas propiamente específicas de los dispositivos móviles, como son la geolocalización o la personalización de contenidos.

\section{Referencias bibliográficas}

Aguado, J. M., E Martínez, I. (2008): “La cuarta pantalla: industrias culturales y contenido móvil”. En VV.AA., Sociedad móvil: Tecnología, identidad y cultura (Coords., J. M. Aguado e I. J. Matínez). Madrid: Biblioteca Nueva.

Ahonen, T. (2008): Mobile as 7th of the Mass Media: Cellphone, cameraphone, iPhone, smartphone. Londres: FuturetexT.

Cebrián, M. y Flores, J. (2011): Periodismo en la telefonia móvil. Madrid: Fragua

Dominick, J. (2006): La Dinámica de la Comunicación Masiva. México: McGraw Hill Interamericana.

Espinosa, C. (2011): “Cobertura móvil de noticias. Deberes del periodismo en la era de los teléfonos inteligentes". En VV.AA., Periodismo Digital: Convergencia, redes y móviles. $4^{\circ}$ Foro Internacional de Periodismo Digital Rosario 2011 (Eds., F. Irigay, D. Ceballos y M. Manna), páginas 135 a 155. Rosario: Laborde Libros Editor.

Fidalgo, A. (2009): "O celular de Heidegger - comunicaçao ubíqua e distância existencial”, en Revista Matrizes. URL: http://www.matrizes.usp.br/index.php/matrizes/article/view/121/1 $\underline{97 .}$ 
Geser, H. (2004): “Towards a Sociological Theory of the Mobile Phone", en Revista Sociology in Switzerland: Sociology of the Mobile Phone. Online Publications. Zuerich. URL:

http://socio.ch/mobile/t geser1.pdf.

Goggin, G. (2004): "Mobile text", M/C, en A Journal of Media and Culture, 7. http://www.media-culture.org.au/0401/03-goggin.html

Salaverría, R. (2010): “¿Ciberperiodismo sin periodistas? Diez ideas para la regeneración de los profesionales de los medios digitales". En VV.AA., El cambio mediático (Coord., F. Campos Freire), páginas 236 a 249). Zamora: Comunicación Social.Sánchez, E. y Aguado, J. M. (2010): Dispositivos móviles y convergencia digital en los grupos de comunicación españoles: la perspectiva de los profesionales. II Congreso Internacional AE-IC "Comunicación y Desarrollo en la Era Digital”. Málaga, 3-5 febrero de 2010. URL: http://www.aeic2010malaga.org/upload/ok/95.pdf

Soletic, A. (2008): “Telefonía móvil: nuevos territorios virtuales en la sociedad de redes." En Universidad Nacional del Litoral (Ingreso 2008). URL:

http://aulavirtual.unl.edu.ar/2010/pdf/telefonia movil.pdf

Varela, J. (2011): "Periodismo mutante", en Telos.

* Este artículo forma parte del proyecto "Estudio sobre el periodismo a través de móviles en Latinoamérica y creación de una red de investigación iberoamericana y de los países nórdicos de Europa especializada en el análisis de la comunicación móvil" realizado en la Universidad Pontificia Católica del Ecuador (Sede Ibarra). 
- Todos los trabajos de este libro han sido sometidos a un proceso doble ciego de revisión previa por pares. 